\title{
Towards a market-based climate regime in China?
}

Citation for published version (APA):

Chen, H. (2015). Towards a market-based climate regime in China? A legal perspective on the design and implementation of greenhouse gas emissions trading. [Doctoral Thesis, Maastricht University]. Uitgeverij BOXPress. https://doi.org/10.26481/dis.20151021hc

Document status and date:

Published: 01/01/2015

DOI:

10.26481/dis.20151021hc

Document Version:

Publisher's PDF, also known as Version of record

\section{Please check the document version of this publication:}

- A submitted manuscript is the version of the article upon submission and before peer-review. There can be important differences between the submitted version and the official published version of record.

People interested in the research are advised to contact the author for the final version of the publication, or visit the DOI to the publisher's website.

- The final author version and the galley proof are versions of the publication after peer review.

- The final published version features the final layout of the paper including the volume, issue and page numbers.

Link to publication

\footnotetext{
General rights rights.

- You may freely distribute the URL identifying the publication in the public portal. please follow below link for the End User Agreement:

www.umlib.nl/taverne-license

Take down policy

If you believe that this document breaches copyright please contact us at:

repository@maastrichtuniversity.nl

providing details and we will investigate your claim.
}

Copyright and moral rights for the publications made accessible in the public portal are retained by the authors and/or other copyright owners and it is a condition of accessing publications that users recognise and abide by the legal requirements associated with these

- Users may download and print one copy of any publication from the public portal for the purpose of private study or research.

- You may not further distribute the material or use it for any profit-making activity or commercial gain

If the publication is distributed under the terms of Article $25 \mathrm{fa}$ of the Dutch Copyright Act, indicated by the "Taverne" license above, 


\title{
Towards A Market-Based Climate Regime in China?
}

\begin{abstract}
A legal perspective on the design and implementation of greenhouse gas emissions trading
\end{abstract}

Huizhen Chen 
Cover design: $\quad$ Proefschriftmaken.nl || Uitgeverij BOXPress

Printed \& Lay Out by: Proefschriftmaken.nl || Uitgeverij BOXPress 


\title{
Towards A Market-Based Climate Regime in China?
}

\section{A legal perspective on the design and implementation of greenhouse gas emissions trading}

\author{
DISSERTATION \\ to obtain the degree of Doctor \\ at Maastricht University, \\ on the authority of the Rector Magnificus, \\ Prof. dr. L.L.G Soete \\ in accordance with the decision of the Board of Deans, \\ to be defended in public \\ on Wednesday 21 October 2015, at 12.00 hours
}

by 


\section{Supervisor:}

Prof. dr. M. G. W. M. Peeters

\section{Co-Supervisor:}

Prof. dr. Zhiping Li, Sun Yat-sen University, the People's Republic of China

\section{Assessment Committee:}

Prof. dr. M.G. Faure (Chairman)

Prof. dr. C.W. Backes

Prof. dr. Tianbao Qin, Wuhan University, the People's Republic of China

Prof. dr. J.M. Verschuuren, Tilburg University 


\section{ACKNOWLEDGEMENT}

It is an exciting moment, arriving at this last station of my doctoral research journey in Maastricht University, where I have devoted myself to a complicated but fascinating topic for four years. At the moment of finalizing my $\mathrm{PhD}$ dissertation, I can't help being grateful to all the people who have supported and helped me along this long but meaningful journey towards a $\mathrm{PhD}$ in Maastricht.

This dissertation is the outcome of $\mathrm{PhD}$ research at Maastricht University, in cooperation with Sun Yat-sen University in China, with the support of the China Scholarship Council (CSC). As a joint $\mathrm{PhD}$ program, this research has been carried out in Maastricht and China during the last four years. I deeply appreciate the Faculty of Law of Maastricht University and CSC, which provided the opportunity for me to conduct $\mathrm{PhD}$ research in Maastricht. In particular, my deep gratitude goes to my supervisors, Professor Marjan Peeters and Professor Li Zhiping. Ever since I started this doctoral research, Marjan has guided me with her profound knowledge, insightful inspiration and full support, helping me to find the way and move forward gradually in my research on the ETS. Even when I conducted the research in China, she travelled a long way to discuss my dissertation with me, giving me insightful comments, which I deeply appreciated. I also extend a special thanks to Professor Li, my co-supervisor in Sun Yat-sen University. She lead me to the research field of environmental law and helped me a lot with my research, career and life. I am wholeheartedly indebted for her unconditional support since the beginning of my $\mathrm{PhD}$ research. Both of their profound understanding of and sincere commitment to environmental law scholarship has enlightened me greatly during the past four years and will encourage me to continue in the future.

I am deeply grateful to the members of the assessment committee: Professor Michael Faure, Professor Chris Backes, Professor Jonathan Verschuuren, and Professor Qin Tianbao. I really appreciate the time and patience they have spent reading my thesis, in particular the inspiring comments and suggestions they have provided for the improvement of my thesis. Special gratitude goes to Michael who provided inspiring guidance and generous help for my research under the umbrellas of METRO and Ius Commune training courses during my stay in Maastricht. I extend additional thanks to Professor Qin Tianbao for his valuable comments and encouragement. Moreover, I also want to express my thanks to the other experts who agreed to sit in the supervisory committee and participate in my defense.

This thesis could not have been accomplished without the support and help of my colleagues and friends in and around the Faculty of Law in Maastricht. My sincere gratitude goes to Licette Poll who helped me to deal with lots of documents and procedures when I was not in Maastricht. Additional thanks are due to the helpful METRO team, Yleen Simonis, Chantal Kuypers, Elke Hundhausen, Marina Jodogne, and Marjo Mullers. During my stay in Maastricht, lots of friends have accompanied me and brought me memorable pleasures. Special thanks go to Professor Liu Junping, Liu Jing, Yue Taotao, Liao Wenqing, Gao Yang, Wang Jie, He Tianxiang, Chen 
Xiahong, Zhao Jinjin, Lv Tian, Kevine Kindji, Emma Dermawati, Viorelia Gasca, Mehdi Piri Damagh, Natascha, Rogier, Xun Xiao, Xin Wen and Chen Bo. Additional thanks also go to Yue Taotao, Gao Yuan, Liu Ancui, and Sandra Nóbrega, who have helped me a lot with my research after I came back to China.

I am sincerely grateful to the colleagues and experts outside the Faculty of Law for their willingness to share their knowledge and ideas with me through interviews and discussions, which were important for my research. Particular thanks go to Stefan Weishaar, Edwin Woerdman, Paul van der Lee, Joris Pinkster, Chris Dekkers, Johannes Enzmann, Benjamin Görlach, Michael Mehlings, Matthias Duwe, Anatole Boute, Vicky Pollard, Jin Guoliang, and other Chinese officers and experts working on the Chinese ETS pilot projects.

I would also like to thank all the teachers and colleagues in China for their help with my research in Sun Yat-sen University. Special thanks go to Professor Cheng Xinhe, who is my supervisor in knowledge and in life since I participated in the master program. Additional thanks go to Professor Huang Yao, Professor Liu Guozhen, Professor Wang Hongyi, Professor Yang Xiaoqiang, Professor Zeng Donghong, Professor Zhou Xianzhi, Professor Gu Dejin, and Professor Wang Huanhuan, Dr. Liang Lingfeng, Dr. Wu Xiaohui, Professor Zhang Yongzhong, Professor Zhang Shuangmei, Professor Deng Minzhen, Dr. Zeng Xiaoyun, Dr. Deng Xiaomei, Dr. Qiu Xin, Professor Peng Benli, Dr. Chen Lin, Dr. Wei Xu, Dr. Cheng Lingxiang, Dr. Ye Yuanbo, Dong Xiaojia, and Xiao Mingxin.

Last but not least, my deepest gratitude and appreciation goes to my beloved family for their unconditional love, considerate understanding and full support. Despite the difficulties during the long journey since I started this research, it is their love and support that encouraged me to keep moving and to accomplish this thesis finally! 


\section{TABLE OF CONTENTS}

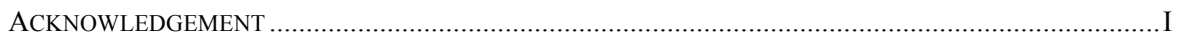

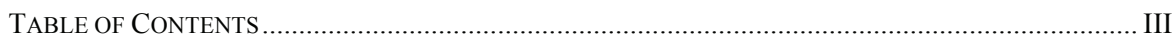

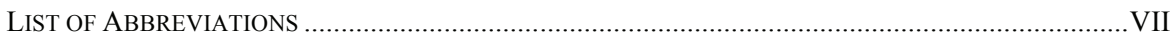

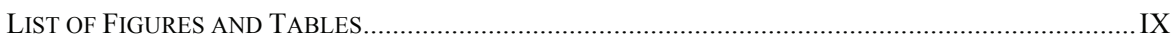

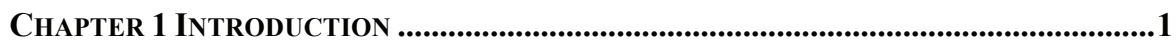

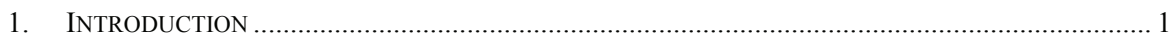

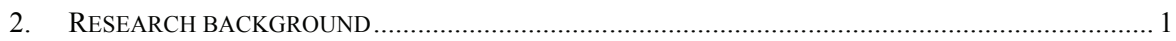

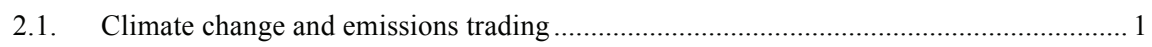

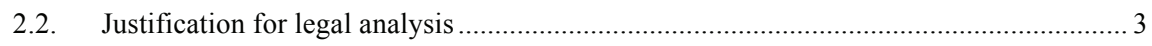

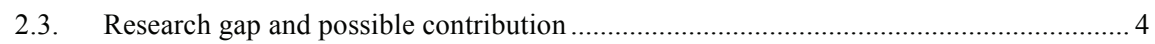

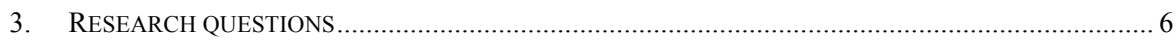

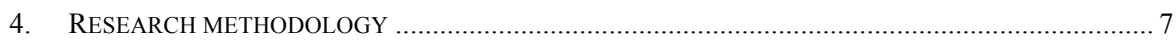

4.1. Reasons for a comparative analysis ........................................................................... 7

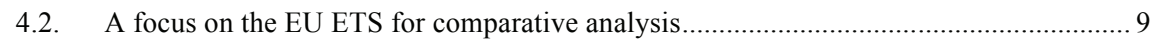

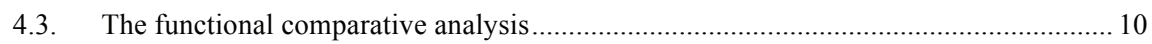

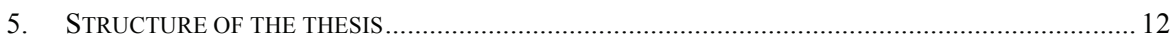

ChaPter 2 TheORETICAL LEgal FraMeWORK FOR EXAMining THE ETS ...........15

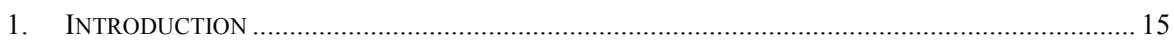

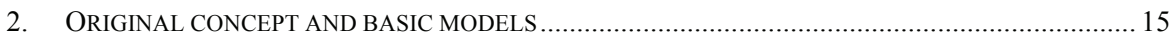

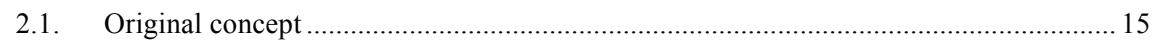

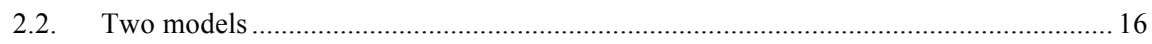

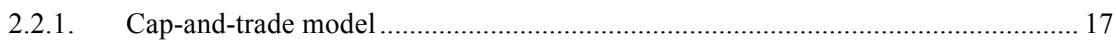

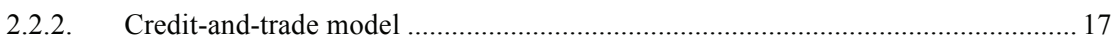

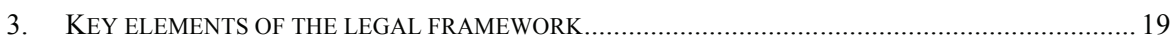

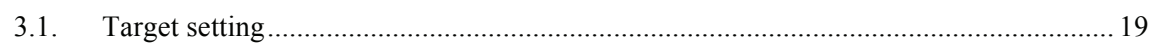

3.1.1. Emissions reduction target and target setting.................................................... 19

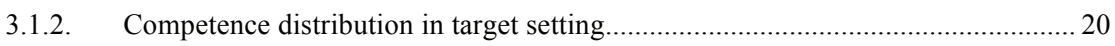

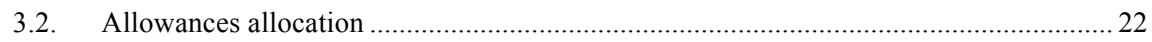

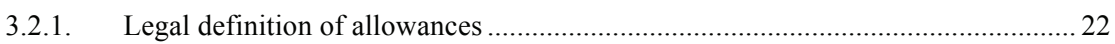

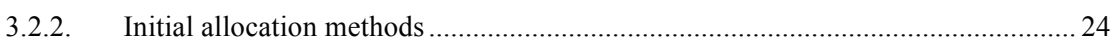

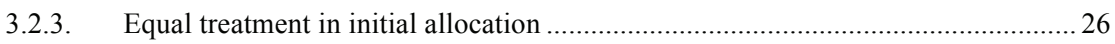

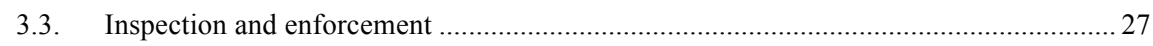

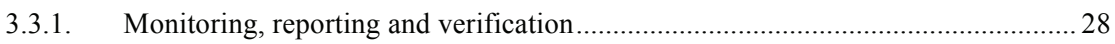

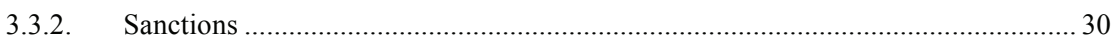

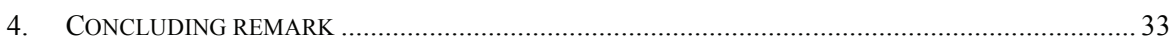

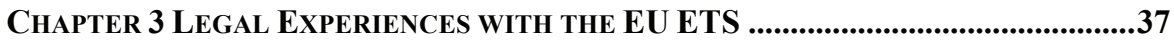

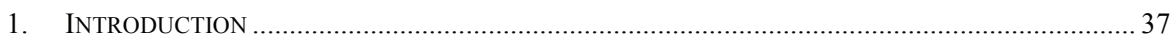

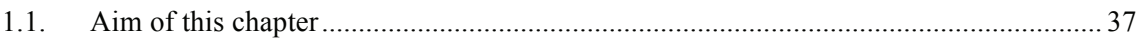




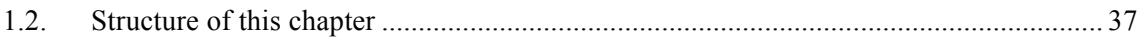

2. GENERAL INTRODUCTION TO THE EU ETS: AN ELEMENT OF EU ENVIRONMENTAL LAW .........38

2.1. EU environmental law: regulatory structure and basic principles ................................... 38

2.1.1. The regulatory structure of EU Environmental law ................................................ 38

2.1.2. General principles in EU Environmental law .................................................... 41

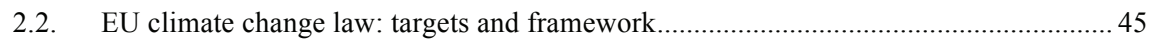

2.2.1. The targets of EU climate change law: joint and individual ................................. 45

2.2.2. Regulatory framework for EU climate change law............................................... 48

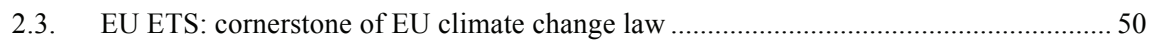

2.3.1. Emergence and preparation: adoption of Directive 2003/87/EC ........................... 50

2.3.2. The first period (2005-2007): learning by doing .................................................... 51

2.3.3. The second period (2008-2012): developing and improving ................................. 51

2.3.4. The third period (2013-2020): changing radically and moving forward ................ 52

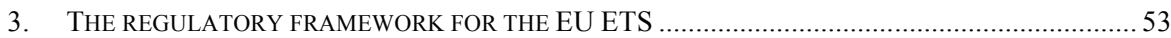

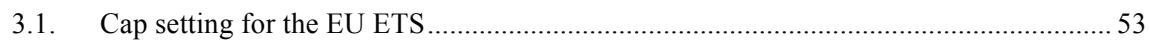

3.1.1. The original design before the establishment of the EU ETS ................................. 54

3.1.2. Model one: decentralised approach from 2005 to 2012 ........................................ 54

3.1.3. Model two: harmonised approach from 2013 onwards......................................... 59

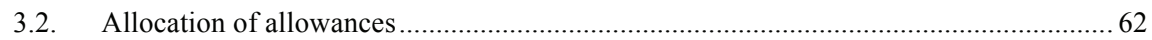

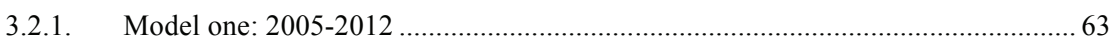

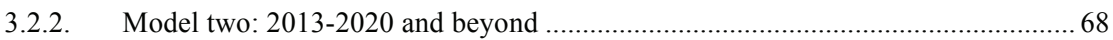

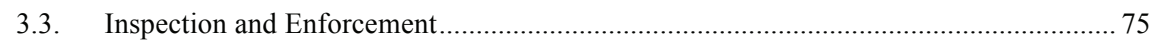

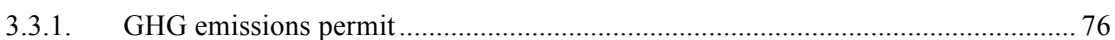

3.3.2. Monitoring, reporting and verification ............................................................ 78

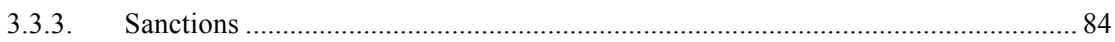

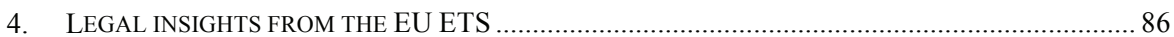

4.1. Cap setting: competence distribution between the EU and Member States.....................86 86

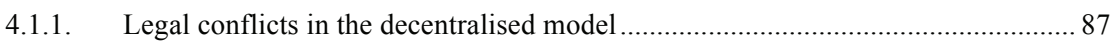

4.1.2. Potential problems under the centralised model ................................................. 92

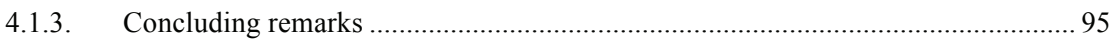

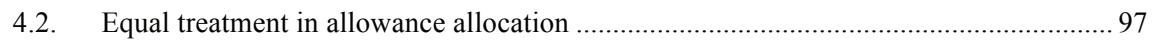

4.2.1. Equal treatment and competence distribution ....................................................... 98

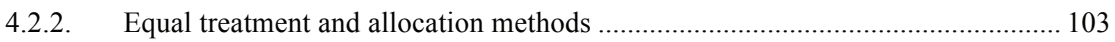

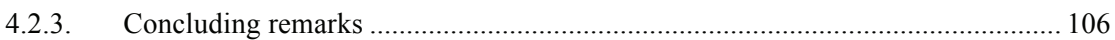

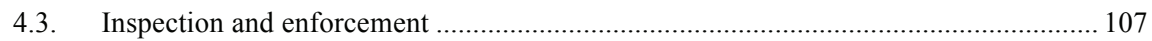

4.3.1. Harmonising approach of enforcement ............................................................ 107

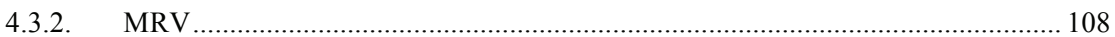

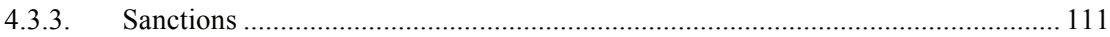

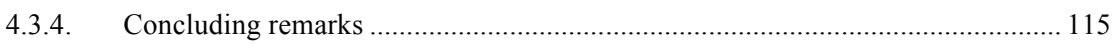

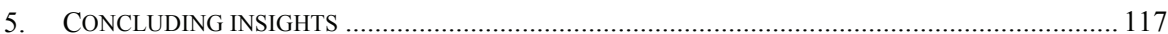

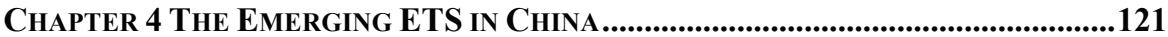

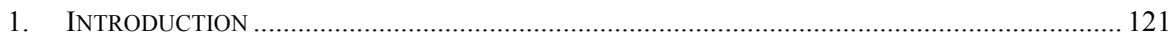

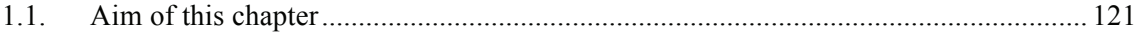




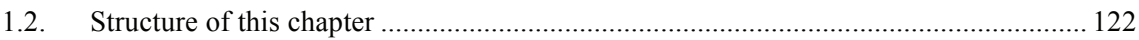

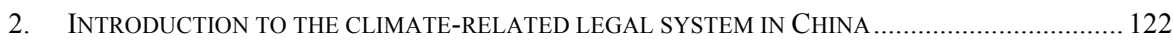

2.1. Governmental framework for addressing climate change: existing policies and

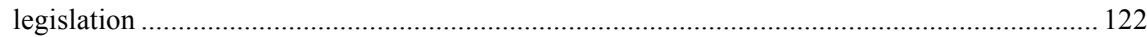

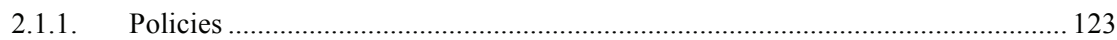

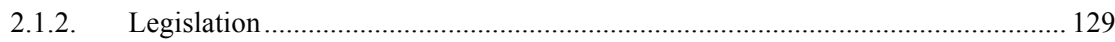

2.2. The governance structure of Chinese climate law and policy ..................................... 131

2.2.1. Legislative competence distribution and legislation structure ............................. 132

2.2.2. Administrative structure for climate policy making .............................................. 136

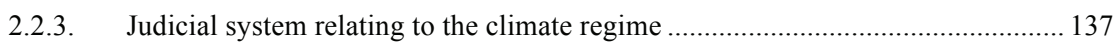

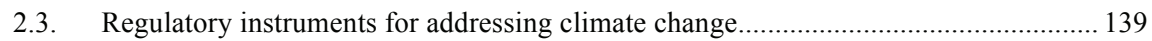

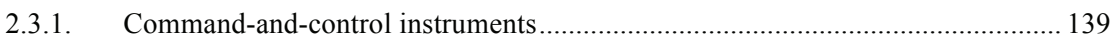

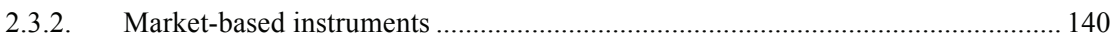

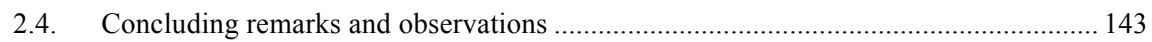

2.4.1. The roles of and relationship between legislation and policy .............................. 143

2.4.2. Multi-level governance structure: the Chinese context......................................... 144

2.4.3. Potential leading role of market-based instrument................................................ 145

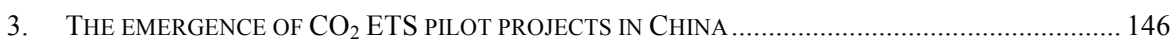

3.1. Overview of the development concerning the pilot projects........................................ 146

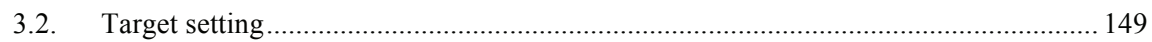

3.2.1. China's carbon emissions reduction target..................................................... 149

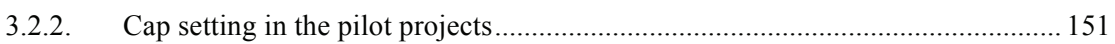

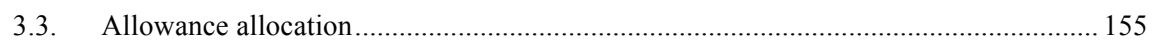

3.3.1. Free allocation based on various allocation criteria …….................................. 156

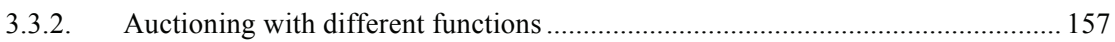

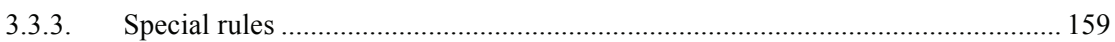

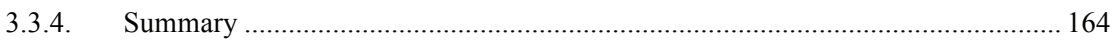

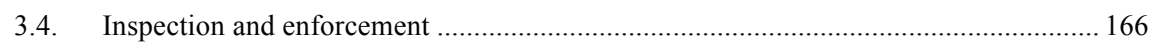

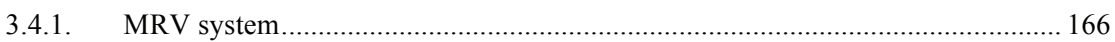

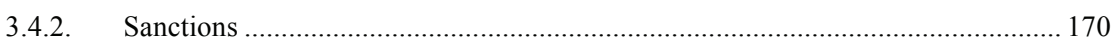

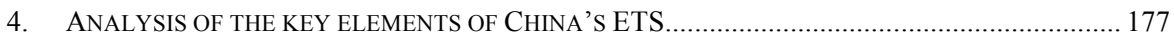

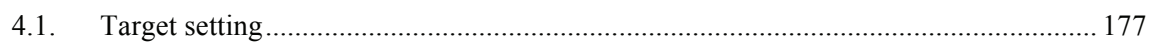

4.1.1. Legal effect of the carbon emissions reduction targets ....................................... 177

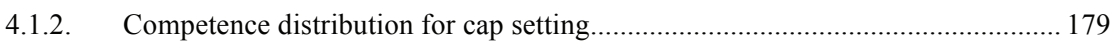

4.1.3. Dynamic and relative features stemming from the cap setting ............................. 182

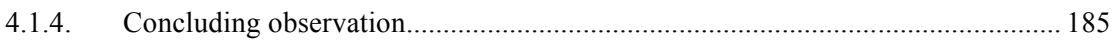

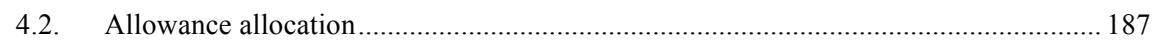

4.2.1. Competence distribution for allowance allocation ............................................ 187

4.2.2. Allowance allocation in the dynamic economy ................................................. 190

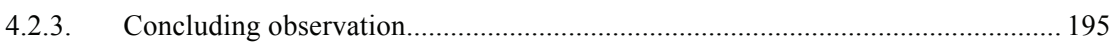

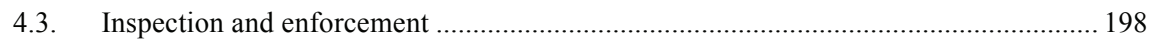

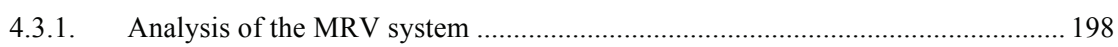

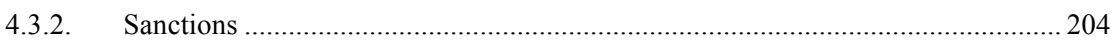

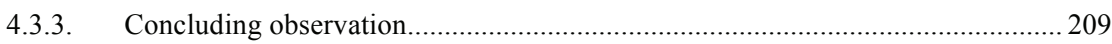


5. THE POTENTIAL FOR A NATIONAL ETS IN CHINA ........................................................... 211

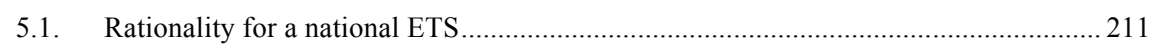

5.1.1. Requirement for sufficient legislative competence.......................................... 212

5.1.2. Concerns on the fragmentation and inconsistency of the local carbon markets ... 213

5.1.3. Risk of local protectionism driven by the GDP-oriented evaluation system ........ 214

5.2. Further consideration on the possible design of the national ETS ............................ 216

5.2.1. Consideration on competence distribution for target setting .............................. 216

5.2.2. Challenges relating to the allocation of allowances ......................................... 219

5.2.3. Evolving progress towards a harmonised enforcement system .......................... 221

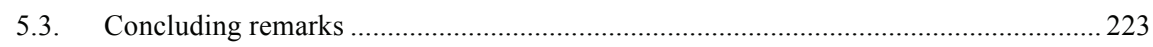

6. COMPARATIVE ANALYSIS BETWEEN THE EU ETS AND THE CHINESE ETS ......................... 224

6.1. Comparison of the design features: similarities and differences............................... 224

6.1.1. General characteristics of the legal framework for the ETS ............................... 224

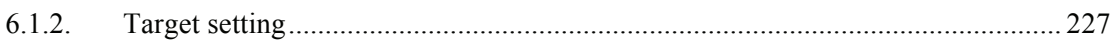

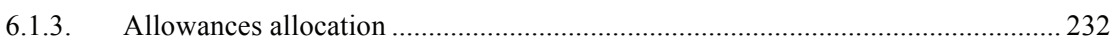

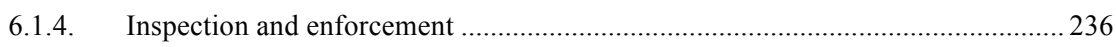

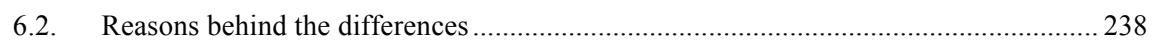

6.2.1. Legal tradition and legal system..................................................................... 239

6.2.2. Governance structure and competence distribution .......................................... 242

6.2.3. Economic system and economic governance ................................................ 246

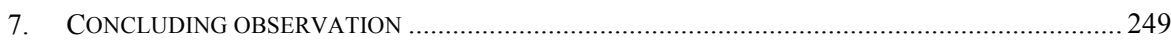

Chapter 5 CONCluSiON AND RECOMMENDATIONS...........................................251

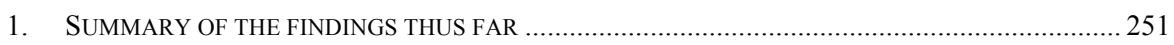

2. THE NEED FOR A LEGAL FRAMEWORK FOR THE CHINESE ETS ............................................253

2.1. The significance of a legal framework regulating governmental action ...................... 253

2.2. The choice between policy and legislation .......................................................... 254

3. THE POTENTIAL IMPROVEMENT OF THE THREE SELECTED ELEMENTS ....................................256

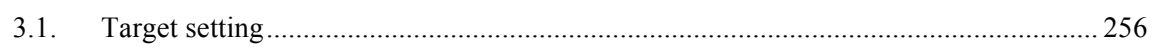

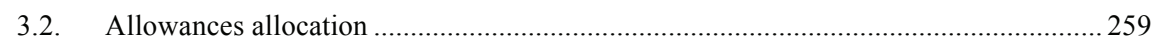

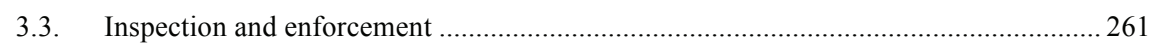

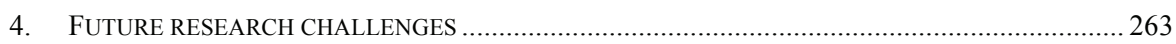

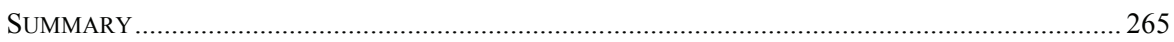

RELEVANT TREATIES, LEGISLATION, POLICY DOCUMENTS AND CASE LAW IN THE EU ................. 267

RELEVANT LEGISLATION, POLICIES AND GOVERNMENTAL DOCUMENTS IN CHINA ...................... 274

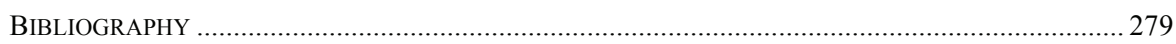

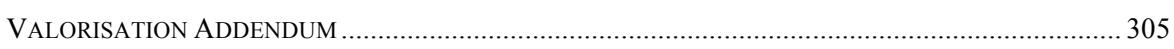

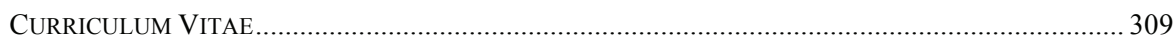




\section{LIST OF ABBREVIATIONS}

\begin{tabular}{|c|c|}
\hline AVR & Accreditation and Verification Regulation \\
\hline CBDR & Common But Differentiated Responsibility \\
\hline $\mathrm{CCS}$ & Carbon Capture and Storage \\
\hline $\mathrm{CDM}$ & Clean Development Mechanism \\
\hline CFI & Court of First Instance \\
\hline CJEU & Court of Justice of the EU \\
\hline $\mathrm{CNY}$ & China Yuan \\
\hline $\mathrm{CO}_{2}$ & Carbon Dioxide \\
\hline $\mathrm{CPC}$ & Communist Party of China \\
\hline DRC & Development and Reform Commission (China) \\
\hline $\mathrm{EC}$ & European Community \\
\hline $\mathrm{ECCP}$ & European Climate Change Programme \\
\hline ECJ & European Court of Justice \\
\hline ET & Emissions Trading \\
\hline ESD & Effort Sharing Decision \\
\hline ETS & Emissions Trading Scheme \\
\hline EU & European Union \\
\hline EUA & European Union Allowance \\
\hline EU ETS & European Union Emissions Trading Scheme \\
\hline EUR & Euro \\
\hline GDP & Gross Domestic Product \\
\hline GHG & Greenhouse Gas \\
\hline IEA & International Energy Agency \\
\hline IPCC & Intergovernmental Panel on Climate Change \\
\hline JI & Joint Implementation \\
\hline LULUCF & Land Use, Land-use Change and Forestry \\
\hline MEP & Ministry of Environmental Protection (China) \\
\hline MRV & Monitoring, Reporting and Verification \\
\hline MRR & Monitoring and Reporting Regulation \\
\hline Mt & Million tonnes \\
\hline NAP & National Allocation Plan \\
\hline NDRC & National Development and Reform Commission (China) \\
\hline NGO & Non-governmental Organisation \\
\hline NIMs & National Implementation Measures \\
\hline NPC & National People's Congress (China) \\
\hline NPCSC & National People's Congress's Standing Committee (China) \\
\hline OECD & Organisation for Economic Co-operation and Development \\
\hline OJ & Official Journal (of the European Union) \\
\hline PSR & Performance Standard Rate \\
\hline SEPA & State Environmental Protection Agency (China) \\
\hline SOE & State-Owned Enterprise \\
\hline
\end{tabular}


$\mathrm{SO}_{2}$

TEU

TFEU

UNFCCC

UK

US

USD
Sulfur Dioxide

The Treaty on European Union

The Treaty on the Functioning of the European Union

United Nations Framework Convention on Climate Change

The United Kingdom

The United States

United States Dollar 


\section{LiST OF FIGURES AND TABLES}

Figure 1 State organs at the central level in China.....

Figure 2 Timeline concerning the establishment of the pilot projects ............................... 147

Figure $3 \mathrm{MRV}$ process in the Shanghai pilot project ................................................. 167

Table 1 Climate related binding targets in the Five-Year Planning ................................... 126

Table 2 Carbon intensity of some regions and countries ................................................ 127

Table 3 Legislative competence distribution and ranking of the legislation in China......... 135

Table 4 Status of some pilot projects (by the end of April 2014) .................................... 147

Table 5 Carbon Intensity Reduction Target during the $12^{\text {th }}$ Five-Year Period (2011-2015) 150

Table 6 Summary of cap setting among the pilot projects .............................................. 154

Table 7 Major allocation methods applied in the pilot projects ........................................... 165

Table 8 Basic penalties for major noncompliance among the pilot projects ..................... 176

Table 9 Specific legislation and policy adopted in the pilot projects

(by the end of June 2014)..... 


\section{CHAPTER 1 \\ INTRODUCTION}

\section{Introduction}

As a market-based instrument, the emissions trading scheme (ETS), in which specific emissions rights can be traded on the market, has been applied in the field of the mitigation of climate change in order to reduce greenhouse gas (GHG) emissions cost effectively. Nowadays, the People's Republic of China [hereafter referred to as China in this thesis] ${ }^{1}$ is trying to establish its own GHG ETS. This thesis is going to explore the question of how China can improve the regulatory design and implementation of the GHG ETS, which will be discussed from a legal perspective. The aim of this chapter is to introduce the research background, main research questions, research methodology, and the structure of this thesis.

This chapter is divided into four interrelated sections. First, background information on this research will be presented in section 2. Section 3 will pose and explain the main research questions of this thesis. The research methodology to be applied in this thesis will be discussed in section 4 . The last section will introduce the structure of this thesis.

\section{Research background}

\subsection{Climate change and emissions trading}

Climate change is becoming a global challenge for sustainable development. According to the report of the Intergovernmental Panel on Climate Change (IPCC), there is increasing agreement among scientists that the rising GHG concentrated in the atmosphere has had and will continue to have a substantial impact on the natural and social systems, requiring the sustained reduction of GHG emissions. ${ }^{2}$ During the international legal development in recent decades, there is more and more attention for GHG emissions reduction and, connected to that, emissions trading. For instance, according to the Kyoto Protocol to the United Nations Framework Convention on Climate Change (UNFCCC) [hereafter referred to as the Kyoto Protocol], the industrialised countries listed in Annex I of the UNFCCC should have reduced their overall emissions of specific GHG by at least 5\% below 1990 levels in the commitment period 2008 to $2012^{3}$ in order to achieve the objective set out in the UNFCCC. Moreover, the ETS was even adopted as part of the Kyoto Protocol in three specific forms including the Clean Development Mechanism

\footnotetext{
${ }^{1}$ In this thesis, it will be limited to the mainland of China, not including Taiwan, Hong Kong and Macao. 2 IPCC (2014), p.4-8.

3 Article 3, Kyoto Protocol to the United Nations Framework Convention on Climate Change, the United Nations, 1998. The Kyoto Protocol was adopted on 11 December 1997 and entered into force on 16 February 2005 .
} 
$(\mathrm{CDM})^{1}$, Joint Implementation $(\mathrm{JI})^{2}$ and Emissions Trading among states $(\mathrm{ET})^{3}$. These flexible mechanisms are intended to help the Annex I countries of the UNFCCC achieve their binding targets in a cost-effective way.

In an attempt to achieve the GHG emissions reduction targets, the ETS, considered as an important policy option, has been gradually applied at the regional, national and sub-national levels in different forms. In particular, some Annex I parties with emission reduction obligations under the Kyoto Protocol, such as the European Union (EU) and its Member States, have chosen to establish the ETS in their legal systems in order to comply with the emission reduction targets. Remarkably, there is an emerging practice that some countries without a binding international GHG emission reduction obligation have also started to develop an ETS. For instance, as the first market-based regulatory programme in the United States (US) to reduce GHG emissions, the Regional Greenhouse Gas Initiative (RGGI) has resulted in cooperation by nine states aiming to cap and reduce carbon dioxide $\left(\mathrm{CO}_{2}\right)$ emissions from the power sectors by $10 \%$ by $2018 .{ }^{4}$

Based on the principle of Common But Differentiated Responsibility (CBDR), China as a developing country has not adopted a GHG emissions reduction target under the Kyoto Protocol. However, reducing GHG emissions in order to address climate change requires the joint efforts of the international community, including China. In this respect, the establishment of its own GHG ETS has been put on the agenda of the Chinese government, aiming to reduce the GHG emissions and to promote the development of a low-carbon economy. On 25 November 2009, the State Council of the People's Republic of China [hereafter referred to as State Council] firstly pledged to reduce its $\mathrm{CO}_{2}$ emissions per unit of Gross Domestic Product (GDP), which is also called carbon intensity, by $40 \%$ to $45 \%$ of 2005 levels by $2020^{5}$. Moreover, the reduction of carbon intensity was set as the binding target in the Guidelines of the Twelfth Five-year Planning on National Economic and Social Development (2011-2015) [hereafter referred to as the $12^{\text {th }}$ Five Year Planning], which was passed by the National People's Congress of the People's Republic of China [hereafter referred to as the National People's Congress (NPC)] on 14 March 2011. To be specific, in the period from 2011 to 2015, China intends to reduce its $\mathrm{CO}_{2}$ emissions by $17 \%$ per unit of GDP compared to that of $2010 .^{6}$

In order to reach these national targets, a mix of instruments including the traditional command-and-control instruments and the market-based instruments has been taken into consideration in China. On the one hand, the national carbon intensity reduction target has been divided and distributed among provinces in line with their economic and environmental performance. Meanwhile, the fulfilment of the reduction target relies heavily on the performance assessment system of the leading cadres (ling dao gan bu) ${ }^{7}$, in which the outcome of target

1 Article 12, Kyoto Protocol.

2 Article 6, Kyoto Protocol.

3 Article 17, Kyoto Protocol.

${ }^{4}$ More information is available at the website of the RGGI, available at: http://www.rggi.org/.

${ }^{5} \mathrm{Liu}, \mathrm{H}$, et al, China announced a clear and quantified goal of GHG reduction for the first time, 26 November 2009, available at: http://news.xinhuanet.com/politics/2009-11/26/content_12545939.htm. last accessed 29 June 2013 (in Chinese).

${ }^{6}$ Chapter 3, $12^{\text {th }}$ Five Year Planning (2011-2015).

${ }^{7}$ In China, the cadre usually means the official holding the positions of managers and leaders in the ruling party, state organs, state-owned enterprises, and other public institutions and organisations. 
fulfilment will have a significant impact on the promotion or demotion of the leading cadres. ${ }^{1}$ On the other hand, the carbon emissions trading scheme ${ }^{2}$ has been considered by the national policy makers to be an important instrument for reducing GHG emissions and helping China transition into a low-carbon economy. According to the $12^{\text {th }}$ Five-Year Planning (2011-2015), which mentions it explicitly but shortly, the carbon emissions trading market was to be established gradually. ${ }^{3}$ The stage was set by a notice issued by the National Development and Reform Commission (NDRC) on 29 October 2011, approving seven provinces and municipalities - Guangdong, Hubei, Beijing, Tianjin, Shanghai, Chongqing, and Shenzhen to start pilot projects of $\mathrm{CO}_{2} \mathrm{ETS}^{4}$. Moreover, it was expected by the NDRC that these pilot projects would be started in 2013 and would then be expanded across the country in $2015 .^{5}$

With regard to these pilot projects of carbon emissions trading, they have been selected to reflect different levels of local economic development, aiming to test and to explore different models of ETS at the local level, before the establishment of a possible national ETS. By the end of 2013, pilot projects had been officially started in Shenzhen, Shanghai, Beijing, Guangdong, and Tianjin, while the rest of the pilot projects were started in 2014. Following the experimental approach, the pilot projects are being designed and implemented independently by those seven local governments, resulting in a variety of unique design features in each pilot project. However, several important similar design features shared by different pilot projects can still be identified to a large degree, suggesting some possible options as well as challenges facing the national scheme and which are worthy of an in-depth critical analysis and further improvement.

Particular attention should also be paid to the fact that these pilot projects seem to be established based on the so-called 'cap-and-trade' model, in which the government sets up the cap, equal to the overall amount of allowances ${ }^{6}$ to be issued and allocated to the emitters, who are obliged to surrender the allowances to cover the emissions in a specific period. In the course of designing the pilot projects, however, a variety of challenges facing the Chinese government are emerging in terms of the target setting, allowance allocation, market oversight, inspection, and enforcement and these challenges require careful consideration and construction in accordance with the special Chinese circumstances.

\subsection{Justification for legal analysis}

The possibilities for designing and implementing an ETS have been explored from various academic perspectives. Abundant economic and political scientific literature addressing the design options and implementation process has contributed to the development of emissions

\footnotetext{
${ }^{1}$ See Yu, G. \& Elsworth, R. (2012), further discussion will be provided in chapter 4.

2 In China, the GHG ETS is generally referred to as the carbon emissions trading or $\mathrm{CO}_{2}$ ETS, since it mainly covers the $\mathrm{CO}_{2}$ right now and other GHG is usually calculated by the $\mathrm{CO}_{2}$ equivalent.

${ }^{3}$ Section 1 of chapter 21, the Twelfth Five-Year Planning.

${ }^{4}$ NDRC, The Notice on Initiating Pilot Programs of Emissions Trading, 29 October 2011, (in Chinese).

${ }^{5}$ Shi, D.D. China will start a pilot project for carbon emissions trading, Dong Fang Daily, 18 July 2011, available at: http://www.dfdaily.com/html/113/2011/7/18/632294.shtml, last accessed 12 May 2013 (in Chinese).

${ }^{6}$ When referring to the specific amount of emissions to be allowed and traded, different scholars have employed various terms in different fields. This thesis will opt for the term 'allowance', which will be defined and explained in the theoretical legal framework in chapter 2 of this thesis.
} 
trading. ${ }^{1}$ To a certain degree, the literature has discussed emissions trading in an instrumental way by reviewing the effectiveness and efficiency of the design options, on the one hand, and thereby analysing how the legislators make up the relevant decisions, on the other hand. ${ }^{2}$

The ETS is an economic instrument, the original idea and theory of which can be traced back to Dales in $1968^{3}$. Economic analytical approaches, such as the ex ante study and ex post analysis, have been frequently employed to evaluate an ETS. A report assessing different ETSs was delivered by the Organisation for Economic Co-operation and Development (OECD) in 2004 ${ }^{4}$. Despite the fact that there are a number of criteria by which an environmental policy instrument can and should be assessed, for example in relation to its environmental effectiveness, economic efficiency and administration $\operatorname{costs}^{5}$, it is not difficult to find that the basic logic behind most of the economic literature is the cost-benefit-profit apparatus. However, as it emphasises mainly cost-effectiveness and economic efficiency, the economic analysis is not enough for a comprehensive solution to the pollution problems which are social problems per se.

On the contrary, it must be pointed out that it is the law that transforms the theory of the ETS into something that can exist in practice. Given that the emissions trading market is created artificially by the government, all the key elements of the ETS, including setting the cap, allocating the allowances, monitoring the emissions, trading the allowances, and punishing non-compliance, must be determined and implemented through the legal system. Without the law, the ETS cannot be employed by the government to reduce GHG emissions effectively, while providing legal certainty to emitters regarding their obligations and trading possibilities. In this sense, and in line with the rule of law, it is the legal system that establishes and underpins the operation of an ETS. Hence, what are considered to be the important legal aspects of the design and application of ETS will be a crucial part to be explored in the legal analysis of this thesis.

\subsection{Research gap and possible contribution}

A rich body of legal literature has laid a foundation for the understanding of the ETS from a legal perspective, although the number of publications is still relatively small compared to the economic field. However, as argued by Bogojević, emissions trading has enjoyed a 'honeymoon' period in legal scholarship, since the legal complexity embedded in emissions trading has been oversimplified or overlooked in some literature, creating the perception that the ETS is a straightforward and unproblematic instrument. ${ }^{6}$ Nevertheless, it is noticeable that some important legal literature has shed light on the specific complexity of the problems embedded in the choice, design and implementation of emissions trading. For instance, Winter has provided critical thoughts on the choice of an emissions trading instrument ${ }^{7}$; the books edited by Delbeke et al in $2006^{8}$ and by Faure and Peeters in $2008^{1}$ have provided fruitful discussions on different

\footnotetext{
${ }^{1}$ For instance, a list of economic literature concerning emissions trading can be found on the website of Tietenberg: http://www.colby.edu/personal/t/thtieten/tradable_permits.htm.

2 Peeters, M. (2008), p. 21.

${ }^{3}$ Dales, J. H. (1968), republished in 2002.

${ }^{4}$ OECD (2004)

${ }^{5}$ OECD (1997).

${ }^{6}$ Bogojević, S. (2009), p.446

7 Winter, G. (2010).

${ }^{8}$ Delbeke, J. et al (2006).
} 
aspects of the European Union Emissions Trading Scheme (EU ETS), such as the allocation of allowances and ex post adjustment; Van Zeben's article about the case law of the EU ETS has emphasised the relationship between legal certainty and legal clarity ${ }^{2}$; Peeters provides an in-depth discussion on an important court decision regarding the principle of equal treatment and the step-by-step approach for extending the scope of the EU ETS ${ }^{3}$; Epiney offers a critical observation on the inspection and enforcement of the EU ETS ${ }^{4}$.

In addition to the legal literature mentioned above, the list is far from being complete. It forms a good basis for this research, but a research gap still exists. For instance, although the literature discussing the National Allocation Plan (NAP) in the EU ETS dealt with the cap-setting issue to a certain extent, as stated by Bogojević, the attention paid to this important issue is still limited yet in the legal literature. ${ }^{5}$ Meanwhile, the legal complexity and implementation regarding the inspection and enforcement of the ETS has also been overlooked to a certain degree in the legal literature. ${ }^{6}$ Furthermore, the design features of and implementation challenges facing the carbon emissions trading pilot projects being established in China right now are mainly described and discussed from an economic or political perspective. ${ }^{7}$ Most of the existing legal literature concerning Chinese emissions trading is still limited to the discussion on the sulfur dioxide $\left(\mathrm{SO}_{2}\right)$ ETS $^{8}$ or it focuses on one aspect of the GHG ETS such as the legislative approach, ${ }^{9}$ the choice of allowance allocation method ${ }^{10}$, the Monitoring, Reporting and Verification (MRV) system ${ }^{11}$, and market oversight ${ }^{12}$ in China. The practice of Chinese carbon emissions trading, which can provide us with a lot of vivid and valuable material on and insight into the choice, design and implementation of the ETS, still deserves further analysis from a legal perspective.

In order to narrow the research gap mentioned above, this thesis aims to provide a more in-depth legal discussion on and insight into the design of and thereby the potential improvements of the Chinese GHG ETS. This will be based on an analysis of the Chinese pilot projects ${ }^{13}$, while taking account of the legal experiences, in terms of regulatory design and case law, with the EU ETS (see section 4 below for the comparative methodology). In this respect, other colleagues have made active contributions. For instance, the thesis completed by Dr. Chen Ping considered the linkage between the EU ETS and Chinese $\mathrm{ETS}^{14}$, providing a possible development direction for the Chinese ETS. However, before exploring the linkage issues, the specific design and

\footnotetext{
1 Faure, M. \& Peeters, M. (eds.) (2008) .

2 van Zeben, J. A. W. (2009b).

3 Peeters, M. (2011a).

${ }^{4}$ Epiney, A. (2012).

5 Bogojević, S. (2013), p.153.

${ }^{6}$ See for relevant literature Peeters, M. (2006a), p.177; see also Verschuuren, J. \& Fleurke, F. (2014), p.8.

7 See for instance, Wang, Y. G. \& Ge, X.A. et al(2011), Chen, B. (2014).

${ }^{8}$ See for instance Chang, Y.C. \& Wang, N. (2010); See also Wang, J.N., Yang, J.T., et al. (2004); Lin, F \& Buhi, J. (2009).

${ }^{9}$ See Qin, T. B. \& Fu, L. (2012).

${ }_{10}$ Such as Qi, S.Z \& Wang, B. B.(2013); Ding, D. \& Feng, J. R.(2013).

${ }^{11}$ For instance, Cao, M. D. \& Cui, J. X. (2012).

12 See Li, Z. P.(2012).

${ }^{13}$ Since the regulatory framework for the Chinese GHG ETS established at the local and national levels is still in the middle of development right now, the analysis of this thesis mainly addresses the development of the pilot projects until the end of August 2014 (when the first compliance cycle of most pilot projects was finished), and the further developments until November 2014 is incorporated to the extent possible, after which no substantive research has been done.

${ }^{14}$ See Chen, P. (2014).
} 
implementation of the Chinese ETS has to be considered and analysed in depth in accordance with the current Chinese legal and political systems, in order to provide insights that help to gain a mutual understanding of each other's system, which is essential for exploring how to improve the regulatory design and implementation of the Chinese ETS.

\section{Research questions}

While China has established several pilot projects for building experience with carbon emissions trading, thereby following the use of emissions trading by the EU, it still faces the challenge of how to design and implement this market-based instrument within its own legal system, particularly also in view of its aim to establish a national ETS. The central aim of this thesis is to provide an in-depth insight into potential improvements that help to result in a well-functioning ETS in China that would ensure the reduction of GHG emissions, based on a comparative legal analysis with the EU. To realise this aim, the central research question is: How can China, seen from the perspective of its specific legal system, and considering the legal experiences with the EU ETS, improve the regulatory design and implementation of its own ETS? This research does not mean to be so ambitious as to discuss and to provide a comprehensive legal framework, covering all the legal aspects relating to the ETS in China. Instead, given the limited time and the fact that the legal framework for the ETS is formed by certain basic elements, three key aspects of the legal framework have been selected for an in-depth analysis and comparison (see chapter 2 section 3 of this thesis for a discussion on this).

In order to answer the main research question mentioned above, the following four sub-questions will be explored:

1. How can key elements of the legal framework for an ETS, which are setting an environmental target, the allocation of allowances, and inspection and enforcement, be understood from a theoretical perspective? (Chapter 2)

2. What legal experience exists with these key elements in the EU in terms of their regulatory design and relevant case law? (Chapter 3)

3. How is the ETS being established in China and to what extent does the current regulatory design and implementation of the ETS in China show similarities and differences with the EU ETS? (Chapter 4)

4. How can China, particularly seen from the perspective of its aim to strengthen the rule of law and its aim to establish a national ETS, improve the regulatory design and implementation of its own ETS, in particular regarding the selected key elements? (Chapter 5)

In search of the answers to the research questions mentioned above, the author has already published several papers, in English or Chinese, analysing the legal problems concerning target 
setting ${ }^{1}$, allowances allocation ${ }^{2}$, inspection and enforcement ${ }^{3}$ of the Chinese pilot projects, which have also been modified and incorporated into this thesis.

\section{Research methodology}

This section of the chapter will introduce the methodology applied to address the main research questions, which will focus on the comparative methodology.

\subsection{Reasons for a comparative analysis}

From the perspective of the rule of law, it is the legal framework that underpins the establishment and proper functioning of emissions trading, and the ETSs in different countries will be established with various features, aiming to adapt the design and implementation of the ETS to that country's legal and political system. It is noticeable that the evolution of the ETS has witnessed legal borrowing on two dimensions, not only the horizontal dimension between countries but also the vertical dimension, in particular between the Kyoto Protocol and domestic law. In the field of comparative law, the classic concept of legal borrowing or legal transplantation is usually defined as 'the moving of a rule or system of law from one country to another" ${ }^{4}$. In other words, this kind of legal borrowing, the intended copying and adaptation of a substantial part of statute or specific doctrines of law ${ }^{5}$, is usually conducted between countries at the horizontal level. According to Wiener, this kind of legal borrowing can be considered as traditional horizontal legal borrowing ${ }^{6}$. However, the past few decades has witnessed a debate over the feasibility and functioning of such traditional horizontal legal borrowing. The opponents of horizontal legal borrowing or transplantation, such as Kahn-Freund and Legrand, have questioned and criticised this approach. Because of the national diversity in culture, geography, and other factors, the objective and effects of a certain rule will change in a new context, implying the difficulty and failure of the legal transplantation. ${ }^{7}$ In this respect, some western scholars have even announced the 'impossibility of legal transplant ${ }^{8}$. Meanwhile, the Chinese scholar Zhu Suli has also realised that the 'native resources' or 'local knowledge' in China would result in the futility and failure of legal transplants. ${ }^{9}$ On the contrary, the supporters, represented by Alan Watson, have argued that this kind of trans-national borrowing is the most important source driving legal evolution ${ }^{10}$.

In addition to the classic approach of legal borrowing between different countries at the horizontal level mentioned above, another branch of comparative law known as vertical or trans-echelon legal borrowing ${ }^{11}$ should not be ignored. As argued by Wiener, there is a

${ }^{1}$ Chen, H. Z.(2013).

2 Cheng, X. H.\& Chen, H. Z. (2014); Chen, H. Z. (2014a).

${ }^{3}$ Chen, H. Z.(2014b)

${ }^{4}$ Watson, A. (1993), p.5.

5 Ibid.

${ }^{6}$ Wiener, J. B. (2001), p.1297.

${ }^{7}$ Kahn-Freund, O. (1974); see also Legrand, P. (1997).

${ }^{8}$ Legrand, P. (1997).

${ }^{9}$ Zhu, S. L. (1996), p.17.

${ }^{10}$ Watson, A. (1993), p.95.

11 Wiener, J. B. (2001), p.1295-1371. 
possibility of vertical legal borrowing upwards from national law into international law or downwards from international law into national law ${ }^{1}$. In other words, there is substantial interaction between international law and national law: national law can affect international law on the one hand, while international law may influence subsequent national law on the other hand, even when there is no concrete obligation for state parties under international law. Moreover, this kind of vertical legal borrowing, as well as the interaction mentioned above, can be exemplified by the evolution of the concept with regard to emissions trading. In this respect, the legal concept of ETS, first used in the Clean Air Act of the US based on the theory put forward by Dales, has been 'uploaded' to the international level in the form of the Kyoto Protocol, with its particular design features in line with the structure of international law. ${ }^{2}$ Later, the concept of ETS was then accepted and applied in the EU under the influence of the Kyoto Protocol, with its own design characteristics and in accordance with its special EU legal system. In other words, the concept and design of the ETS, as demonstrated by the existing practice, has to be adapted with the introduction of new characteristics bringing the ETS in line with the new circumstances of the country in which it is 'translated'. This is relevant for both directions of legal borrowing at the vertical dimension, including 'uploading' the national instrument to the international treaties and 'downloading' the concept from the international treaties to the national legal system.

Furthermore, in the field of climate change, the emergence of the concept of global environmental law has also implied a potential of convergence or hybridisation among different legal systems dealing with the same problems, such as the reduction of GHG emissions. ${ }^{3}$ Based on the pathways including legal borrowing (at the horizontal and vertical dimension), convergence, integration, and harmonisation, global environmental law has emerged out of a diverse set of legal systems and cultures ${ }^{4}$. Convergence means that different legal systems facing similar external pressures and internal demands develop to establish similar systems, and the similarity of those systems is therefore unintended ${ }^{5}$. Concerning integration and harmonisation, the former connects national legal systems together and the latter brings their standards and requirements into conformity with an international system or with each other, while both of them are designed to seek coordination and cooperation in pursuit of a common goal ${ }^{6}$. In other words, shared characteristics of environmental problems may result in similar features regarding the design and effect of the legal solution. ${ }^{7}$ In addition, Wiener has advocated a new comparative path, an interwoven network of hybridisation approaches, entailing the exchange of regulatory ideas, legal concepts and learning about performance from each other, which thereby will blur the boundaries of different legal systems and overlap the diversity of specific rules or policies. ${ }^{8}$ In this respect, the exchange of regulatory ideas and learning about performance has made some contributions to the diffusion of the ETS from the US acid rain programme to the EU ETS. ${ }^{9}$ Particularly since the design features of various legal frameworks for ETSs have certain

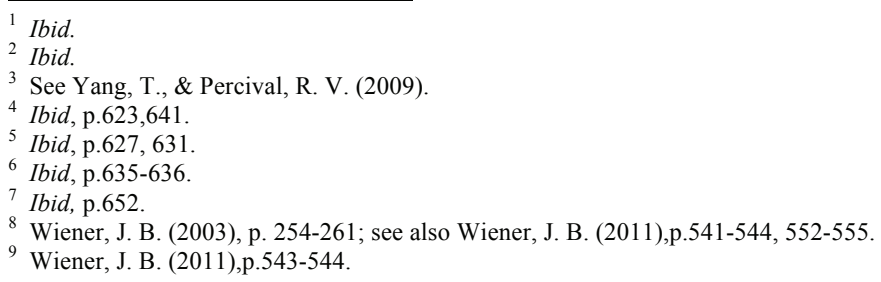


similarities and differences, a comparison of the legal frameworks can be carried out in order to explore the possibility for learning from each other.

Moreover, China has a tradition of looking at some legal concepts or approaches from other jurisdictions, which will then be "translated" for use in the Chinese context. In this respect, horizontal legal borrowing has been widely employed in the legal reform in China at the academic and practical level, especially since the beginning of the policy of reform and opening-up in 1978. ${ }^{1}$ In particular, the idea and the theory of ETS remains relatively new and complicated for China, which has been relying on traditional command-and-control instruments in environmental protection for a long time. ${ }^{2}$ Although China has experienced the market-based emissions trading approach through the $\mathrm{CDM}$ and $\mathrm{SO}_{2} \mathrm{ETS}$, the $\mathrm{CDM}$ is very different from the domestic ETS and the $\mathrm{SO}_{2}$ ETS has not provided as many successful lessons as was expected ${ }^{3}$. In light of the complexity embedded in this market-based instrument, it is necessary for China to gain more insights into the existing ETS from abroad, in an attempt to understand how the ETS can be applied and to gather more useful ideas to deal with the potential legal problems of the ETS in the specific context of China.

In view of the fact that carbon emissions trading in China is still in the pilot project phase, this thesis compares the design and implementation of the EU ETS with the Chinese ETS pilots, detecting and explaining the similarities and differences. The primary goal of this comparative analysis is to provide a recommendation for the potential improvement of the Chinese ETS in line with its special legal and economic circumstances, taking account of the legal experiences with the EU ETS. Instead of just copying the existing legislation adopted in other jurisdictions, it is necessary to 'translate' the experiences in the existing schemes, in particular the EU ETS, in order for those experiences to provide insights that would be relevant for the Chinese ETS, considering its particular political and legal system.

\subsection{A focus on the EU ETS for comparative analysis}

In order to address the challenges concerning climate change, more and more countries have established or are establishing a GHG ETS. With regard to the existing ETSs, however, special attention will be paid to the EU ETS in this thesis, the largest domestic system operating since 2005. Different from the project-based ETS provided by the Kyoto Protocol, which is also called credit-and-trade, the EU ETS is a mandated GHG ETS based on a cap-and-trade model. In addition to Directive 2003/87/EC, based on which the EU ETS is established, there are some other related directives, regulations and decisions comprising the EU ETS legal framework, which is relatively comprehensive but has become complicated. Moreover, the EU ETS Directive has been amended three times from 2004 to $2009^{4}$, in order to deal with the problems

\footnotetext{
${ }^{1}$ See Xin, C. Y.(2007); Pan, H.D.(1990); Zhu, J.W.(2006).

2 See for instance, Lin, J. (2012); Price, L., et al. (2011).

3 They will also be discussed later in section 2 of chapter 4 in this thesis.

${ }^{4}$ See Directive 2004/101/EC; Directive 2008/101/EC; Directive 2009/29/EC. In this thesis, an unofficial consolidated version of the EU ETS Directive containing all the amendments made by these Directives mentioned above will be used when referring to the specific articles of the EU ETS Directive, which is generally referred to as the EU ETS Directive. But when referring to the provisions of Directive 2003/87/EC that have been deleted or amended by the subsequent directives, this thesis will still refer to Directive 2003/87/EC in order to be as precise as possible.
} 
emerging from practice and to improve the EU ETS. Confronted with the depressed price of European Union Allowances (EUAs) in the carbon market due to the growing surplus of allowances, the European Commission (hereafter referred to as the Commission) proposed to amend the auctioning rules aiming to stabilize the price and allowances market ${ }^{1}$, which was finally approved by the European Parliament and the Council of the EU (hereafter referred to as the Council) with some restricted conditions, for the purpose of legal certainty and market predictability ${ }^{2}$. In addition to the proposal of 'back-loading' some of the auctioning allowances, according to the Commission, other necessary structural measures may also be considered to address the challenges facing the EU ETS. ${ }^{3}$ In particular, a market stability reserve for the next trading period from 2021 was proposed by the Commission, which would allow the adjustment of the supply of allowances to be auctioned in line with pre-defined rules. ${ }^{4}$

While the EU ETS is at a crossroads, confronted with emerging challenges, China is endeavouring to establish its own GHG ETS currently by means of experimenting pilot projects. Moreover, there is an indication that some of the basic design features concerning the Chinese ETS seem to be quite similar to those in the EU ETS, such as the cap-and-trade model and the MRV system. In addition, both the Chinese ETS and the EU ETS seem to be designed and implemented within a multi-level governance structure involving at least two levels of governments - Member States and the Commission in the EU and local and central governments in China, implying that some design features and implementation challenges relating to the legal framework for the ETS may be shared by China and the EU. ${ }^{5}$ In this sense, problems encountered by the EU in relation to the functioning of the EU ETS in practice may provide some meaningful insights for China, from a legal perspective, in establishing and implementing an ETS.

\subsection{The functional comparative analysis}

In spite of the variety of differences regarding economic development and the legal systems of the EU and China, there are still some common elements that may be shared in terms of the principles and rules for designing and implementing an ETS. In this sense, China can learn lessons from the EU by translating the lessons from the EU experience to the specific Chinese legal circumstances. To realise this aim, this research will try to explore to what extent and how China can derive useful insights from the EU ETS in view of the development and design of the ETS. Especially taking into account the great difference between the two regulatory frameworks for the EU ETS and the Chinese ETS, the functional method of comparative analysis may serve as a useful bridge connecting the EU ETS and the Chinese ETS in this thesis, facilitating a mutual understanding of both systems.

\footnotetext{
${ }^{1}$ See $\operatorname{COM}(2012) 416$.

2 Article 1, Decision No 1359/2013/EU.

3 See COM(2012)652 final.

${ }_{5}^{4}$ See $\operatorname{COM}(2014)$ 20/1.

5 The great difference between the EU on the one hand and China on the other hand will be explained in this thesis as well, particularly in section 6 of chapter 4 .
} 
The functional method, first proposed by Ernst Rabel, which argued that the function of an institution had to lie at the heart of the comparative analysis ${ }^{1}$, has become an important method of comparative law. According to Zweigert and Kötz, 'the basic methodological principle of all comparative law is that of functionality'2. In the eyes of a number of comparative lawyers, the functional method focuses not on the rules but on the problems and effects, serving as a 'yardstick for comparison', the so-called 'tertium compararationis', which can make different institutions comparable as long as they have equivalent functions in various legal systems. ${ }^{3}$ In other words, in the view of the functionalists, the legal source for comparison should not be limited to the formal legislation; on the contrary, the policy provisions and specific policy instruments should also be taken into consideration seriously, as long as they have an influence on the institutions to be compared. ${ }^{4}$

Nevertheless, the controversy and criticism over the functional method continues. Sometimes, it has been criticised as a 'methodological mishmash' and 'a theory hardly exits', ${ }^{5}$ one reason for which may be that the founders of the comparative method were more pragmatically than methodologically interested. ${ }^{6}$ Such criticism and reasoning, however, implies that, at a pragmatic level, the functional method is indeed helpful for understanding and making sense of the similarities and differences among different legal systems, fulfilling the expected goals of comparative analysis. ${ }^{7}$

Especially in light of the special characteristics of the Chinese legal system, in which the policy still has a substantial impact on the development of the ETS, the functional method thus would provide a feasible approach to making the seemingly incomparable features of the EU and China comparable. In this respect, the functional method can be employed for the comparative analysis of the similarities and differences between the EU ETS and the Chinese ETS, in view of the great differences in terms of their economic development and legal systems. Hence this thesis will focus on the specific comparative analysis between the EU ETS and the Chinese ETS by means of the functional method, aiming to search for useful legal insights to inspire potential improvement regarding the regulatory design and implementation of an ETS in China.

Furthermore, particular attention must be paid to the special Chinese circumstances in the course of the functional comparative analysis between the EU ETS and the Chinese ETS, ensuring that any relevant legal experiences with the EU ETS would be adapted to the Chinese context. Admittedly, there is no universal solution and the particular legal system will always required the 'best' approach for its own specific context. ${ }^{8}$ In other words, because of the divergent circumstances, borrowing or the direct transplantation of the EU ETS would be unlikely to take root very easily in China; moreover, the best approach recommended for China is likely to be

\footnotetext{
${ }^{1}$ Ernst Rabel (1924). Aufgabe und Notwendigkeit der Rechtsvergleichung, 13 Rheinische Zeitschrift für Zivilund Prozeßrecht 279-301, p.282, quoted in Michaels, R. (2006), p.362

2 Zweigert, K., \& Kötz, H. (1998), p.34.

3 see for instance, Michaels, R. (2006), p.342.

${ }^{4}$ Gao, H. J. (2009).

${ }^{5}$ Michaels, R. (2006), p.340, see also Frankenberg, G. (1985), p.416.

${ }^{6}$ Michaels, R. (2006), p.362.

7 Gordley, J,(2012), p.107.

${ }^{8}$ Orts, E. W. (2003), p.547-548.
} 
different from that for the EU. ${ }^{1}$ In particular, the possible legal borrowing, the transfer of the normative dimension of the law, will be inevitably linked to adaptation in terms of the legal culture and political tradition, requiring the legal borrowing or transplant to be contextualized. ${ }^{2}$ Therefore, to the extent possible, the functional comparative analysis of this thesis will try to facilitate the "translation" of valuable legal experiences from the EU ETS into the Chinese ETS in a contextualized approach, based on a better mutual understanding of the contexts in which both systems are designed and implemented.

\section{Structure of the thesis}

In order to answer the research questions, this research will be mainly structured with chapters focusing on the theoretical legal framework for examining emissions trading, the legal experiences with the EU ETS in terms of regulatory design and case law, and the development of and challenges facing the Chinese ETS respectively; moreover, each chapter will be organised in line with the three key elements determined in the theoretical legal framework.

After this introductory chapter which explains the research questions and the methodology to be used, Chapter 2 explores the theoretical framework for examining the ETS from a legal perspective. In order to understand the original concept of and basic models for emissions trading, relevant economic literature will be reviewed in this respect. A theoretical analytical framework for the ETS will be established subsequently, which will lead to the determination of three key elements of the ETS from the legal perspective. To be specific, three key elements have been selected: (1) the determination of an emissions reduction target; (2) the definition and distribution of allowances; (3) inspection and enforcement. Moreover, potential legal problems in terms of the three key elements will be analysed, respectively, aiming to provide a theoretical understanding of the legal framework underpinning the proper functioning of the ETS.

Next the legal framework for the EU ETS will be examined and observed in depth in Chapter 3, a main part of this thesis, in an attempt to explore key insights into regulatory design of the EU ETS and related case law. In order to understand the legal system in which the EU ETS is introduced and implemented, a general introduction to European environmental law and climate law, such as the regulatory approaches and the legal principles, will be presented. Moreover, emphasis will be placed on the design and implementation of the EU ETS from a legal perspective, in terms of the three key elements determined in the theoretical framework, mainly on the basis of the legislation and case law. Furthermore, the three key elements of the EU ETS will be analysed from a legal point of view, in pursuit of some important legal insights into the design and implementation of an ETS, which can be used for other countries such as China to a certain extent.

Chapter 4 will concentrate on the discussion on the Chinese ETS, forming another main body of this thesis. It will begin with an introduction to the Chinese legal system relating to emissions trading, based on which we can understand the legal conditions for the establishment of the ETS

\footnotetext{
${ }^{1}$ Ibid, p.546-548.

${ }^{2}$ Chen, L. (2012), p.192-193.
} 
and the gap to be closed in terms of the legislation and enforcement in China. Moreover, a detailed description and analysis of the design features of the pilot projects will be undertaken in order to identify the latest and fundamental challenges facing the establishment of the legal framework for emissions trading in China. Since Chinese carbon emissions trading is still in the middle of its evolution, it is not easy to provide a full picture of the status quo in China or to predict the outcome of such an evolution. However, it is still important to sketch the main characteristics of the existing pilot projects, to point out the problems so far and to provide insights into the possible direction of future developments at the national level. Furthermore, an in-depth comparison of the EU and Chinese legal system concerning the three key elements of the ETS, focusing on the differences and similarities between the EU ETS and the Chinese ETS, as well as the reasons behind the differences, will be provided in section 6 of chapter 5 .

The last chapter will provide the final conclusion of the thesis. The main findings of this thesis will be summarised first. Taking account of the legal experiences with the EU ETS, this chapter will put forward recommendations for China regarding the establishment of the legal framework for the Chinese ETS as well as potential improvements of its regulatory design and implementation. Last but not least, the future research challenges will be proposed. 


\section{CHAPTER 2}

\section{THEORETICAL LEGAL FRAMEWORK FOR EXAMINING THE ETS}

\section{Introduction}

This chapter aims to explore how key elements of the legal framework for an ETS, which are setting an environmental target, the allocation of allowances, and inspection and enforcement, can be understood from a theoretical perspective (sub-question 1). Concerning the specific design and implementation of emissions trading, different options and models are provided for policy makers. Given emissions trading is an economic instrument first introduced by economists, the original concept and design features of emissions trading can be traced back to numerous economic publications, including the classic book written by Dales, in which emissions trading was introduced and designed for the first time. Fruitful discussions have focused on the cost-effectiveness and economic efficiency of the ETS. However, sufficient attention must be paid to the legal framework which underpins the proper functioning of emissions trading. This chapter will focus on the theoretical framework for and key elements of emissions trading for undertaking a legal analysis. This chapter will firstly introduce the economic foundation of emissions trading by reviewing relevant economic literature, in order to understand the original concept and basic designs of emissions trading. Secondly, the discussion will concentrate on the legal framework and its three key elements, which are target setting, allowances allocation, inspection and enforcement. The chapter ends with concluding observations.

\section{Original concept and basic models}

\subsection{Original concept}

In order to control pollution effectively, two main approaches had been proposed by the late 1950s. The former is the command-and-control instrument, controlling pollution through a series of legal regulations inter alia administrative standards adopted by governments, in which the government plays a leading role. The latter is the market-based instrument, trying to fulfil the environmental goal based on the market by putting a price on pollution and letting the market participants make the decision. ${ }^{1}$ For example, Pigou argued that levying a per-unit tax on the pollution was an appropriate remedy to deal with an externality. ${ }^{2}$ Apart from taxation, the ETS is another important market-based instrument, the original idea and concept of which can be traced back to the economic theory.

${ }_{1}^{1}$ OECD (1989); see also Stavins, R. N. (1989).

2 Pigou, A. C. (1932). 
In 1960, Coase put forward a new approach focusing on property rights, arguing that the right to do something causing harm (such as pollution) was also a factor of production. ${ }^{1}$ As the consequence and cost of exercising a right is always the loss that is suffered elsewhere, these externalities could be turned into property rights that could be explicit and tradable in the market. ${ }^{2}$ Based on the property right approach proposed by Coase, Dales pointed out its applicability in pollution control and proposed a new policy instrument namely 'markets in pollution rights's.

In his classic book, Dales set up two equations about pollution costs, stating that the waste disposal cost was the sum of pollution prevention costs and pollution costs, which included expenditures to avoid pollution damage and the welfare damage of pollution. ${ }^{4}$ As pollution is a social problem, how to allocate the costs in order to minimize the social cost of waste disposal should be an important objective ${ }^{5}$. Three possible approaches can be applied to implement the pollution control policy, including regulation, subsidisation and pollution charges. ${ }^{6}$ Moreover, Dales argued that the across-the-board pollution-charges were efficient because the burden of pollution control was shared in the right way and every polluter would adjust to the charges in order to minimize his costs, therefore the social cost would be minimized correspondingly. ${ }^{7}$ However, it had its own awkwardness, such as the trial-and-error procedure to find out the right level of the charge ${ }^{8}$. Though Dales noted that regulation and subsidisation had created a sort of property right called a 'fixed tenure' or 'certified tenure', they were inefficient because they were not transferable. ${ }^{9}$ In order to solve this problem, Dales suggested a market in pollution rights should be set up. Once the market was in full operation, individual holders would buy and sell pollution rights on their own initiative, and the price of tradable rights would be determined by the market mechanism. ${ }^{10}$ Therefore, it is transferability that allows the market to distribute the control responsibility ultimately to those who can fulfil the previously established reduction targets at the lowest costs. ${ }^{11}$

\subsection{Two models}

Based on the fundamental concept and design features proposed by Dales, different options of emissions trading, as for example the cap-and-trade model and credit-and-trade model, can be applied. Moreover, the design features of these two emissions trading models are closely connected with the types of emissions reduction targets set for them.

${ }^{1}$ Coase, R. ( 1960), particularly p.22-23.

2 Ibid.

${ }^{3}$ Dales, J. H. (1968).

${ }^{4}$ Ibid, p.12-15.

5 Ibid, p.104.

${ }^{6}$ Ibid, p.81-83.

${ }^{7}$ Ibid, p.92.

${ }^{8}$ Ibid, p.93.

9 Ibid, p.106.

${ }_{10}$ Ibid, p.93-94.

11 Tietenberg, T. H. (2006), p.4. 


\subsubsection{Cap-and-trade model}

The first well-known emissions trading model is the cap-and-trade model, which is usually chosen by policy makers at the starting point of applying an ETS. To some extent, the most important design features of the cap-and-trade model concentrate on the absolute emissions reduction target and the ex ante allocation of allowances for a specific trading period. In the cap-and-trade model, the absolute emissions reduction target is determined in the form of a cap, which means the total emissions to be emitted would be limited to and defined by a certain amount. Once the cap is set for the specific period, the maximum amount of emissions could not be exceeded or be eroded by new entrants ${ }^{1}$. Then the allowances representing a certain amount of emissions would be distributed among the emitters ${ }^{2}$ covered by the scheme before the trading period begins.

It is widely argued that the cap-and-trade model can provide more certainty for an environmental outcome. $^{3}$ Moreover, it is also argued that it is simple to administer once the initial allocation of allowances is completed. ${ }^{4}$ After receiving the allowances through specific allocation methods, the emitters can make their own decisions whether to reduce the emissions or to buy extra allowances based on the market price in order to cover their excess emissions. Given that the cap determines the total amount of emissions to be allowed while the market determines where the necessary reduction will take place, the cap-and-trade model is quite attractive to both the policy makers and environmental groups. ${ }^{5}$ Furthermore, it has played a dominant role in the practice of emissions trading, such as the EU ETS, and literature has been exploring its effective design and implementation.

\subsubsection{Credit-and-trade model}

In contrast to the cap-and-trade model, the credit-and-trade model is another emissions trading model but without an absolute cap, which is also known as 'baseline and trade', 'benchmark and trade' or 'performance standard rate system' (PSR). In this model, the emissions reduction target is usually set up in the form of a relative target by establishing a performance standard, allowing specific amount of emissions emitted per unit of production (or per unit of fuel). ${ }^{6}$ Furthermore, the tradable rights — credits - in this model are not issued by specific methods ex ante. On the contrary, the credits are issued through an ex post approach. When an industry demonstrates that it produces less emission than indicated by this relative target, such over-performance in relation to the baseline can give rise to credits, which can be traded by industries later. However, if the

\footnotetext{
I Ibid, p19.

2 With regard to the source or entities covered by the ETS, different terms have been applied in various schemes. In the EU ETS, the term 'installation' and 'operator' have been used, while the Chinese pilot projects have employed different terms to refer to the emitters covered by the ETS, such as the 'emissions controlled unit' in Shenzhen, 'emissions controlled enterprise' in Guangdong, and 'emitting enterprise' in Beijing. There are some differences in the scope of the entities covered by the various projects, which deserve careful analysis, but this thesis will generally refer to them as the 'emitters'. However, the term 'installation' will still be used in the part relating to the EU ETS, in order to be precise and consistent with the EU ETS Directive.

3 Tietenberg, T., \& Johnstone, N. (2004), p.13. See also Vis, P. (2006), p.50.

${ }^{4}$ Vis, P. (2006), p.49-50.

${ }^{5}$ Lefevere, J. (2005), p.116.

${ }^{6}$ Peeters, M., Weishaar, S., \& de Cendra de Larragán, J. (2007), p.191, see also Peeters, M. (2008), p.21-22.
} 
participating emitter's emissions exceed the relative target, it is obliged to cover the extra emissions with credits bought from the market. ${ }^{1}$ In some cases, trading is not allowed until the end of a given period when the emitter's actual performance has been verified and compared to the pre-determined standard, which thus can provide some certainty in terms of compliance. ${ }^{2}$

When comparing these two emissions trading models, the most important difference can be found in terms of emissions reduction targets. In other words, they can be differentiated by whether a certain amount of allowed emissions would be set for the emitters covered by the scheme. In general, the absolute cap set in the cap-and-trade model is supposed to limit the emissions, providing environmental certainty while capping the economic growth to a certain extent at the same time. Since the economy and emissions is uncertain in the future, even though it can be predicted with various methods, the certain amount of GHG emissions set with an ex ante approach in the cap-and-trade model may become an obstacle for economic growth. On the contrary, the credit-and-trade model, without additional constraints built into the system, will allow aggregate emissions to rise. ${ }^{3}$ In other words, the relative target stipulated in the credit-and-trade model can allow economic growth with relative emissions reduction at the same time. Therefore, the credit-and-trade model is also an attractive alternative option for emitters and developing countries favouring green economic growth.

Moreover, the credit-and-trade model can avoid the complicated ex ante allowances allocation embedded in the cap-and-trade model, such as free allocation and auctioning. ${ }^{4}$ However, the determination of the baseline or relative target for specific sector per se and the administrative procedure by which the credits are created may be not less complex and controversial than those ex ante allowances allocations. ${ }^{5}$ It requires at least two parameters in the course of establishing and monitoring the relative target, one is emissions and the other is output. ${ }^{6}$ In terms of determining the specific baseline, a lot of technical factors have to be considered. Meanwhile, given the uncertainty of the environmental outcome, the environmental effectiveness of the credit-and-trade model is subject to more controversy than the cap-and-trade model ${ }^{7}$.

There is no doubt that more difference can be found between these two emissions trading models in terms of the specific design of the legal framework. It is important for the policy makers to consider both options of the emissions trading model seriously at the starting point of the establishment of the ETS. The following sections will focus on the specific design features of the legal framework for the ETS. This means that more emphasis will be placed on the cap-and-trade model, considering the EU and the Chinese pilot projects have chosen this design option.

\footnotetext{
${ }^{1}$ Peeters, M., Weishaar, S., \& de Cendra de Larragán, J. (2007), p.195.

${ }^{2}$ Vis, P. (2006), p.51.

3 Tietenberg, T. H. (2006), p. 19.

${ }^{4}$ Peeters, M., Weishaar, S., \& de Cendra de Larragán, J. (2007), p.193.

5 Tietenberg, T., \& Johnstone, N. (2004), p.24.

${ }^{6}$ Vis, P. (2006), p.52.

7 Tietenberg, T., \& Johnstone, N. (2004), p.24.
} 


\section{Key elements of the legal framework}

It is well accepted that a mandatory emissions trading $\operatorname{market}^{1}$ is not a natural market but one artificially created and constructed by legislation and governmental actions. ${ }^{2}$ Numerous core decisions must be adopted by regulators in terms of the design and implementation of emissions trading. It is the legal framework that establishes and underpins the proper functioning of emissions trading market. This legal framework contains a variety of elements, for example the level of environmental protection to be ensured, the choice between cap-and-trade and credit-and-trade, the identification and distribution of the allowances, and the establishment of a reliable monitoring scheme together with an effective enforcement mechanism. ${ }^{3}$ In this chapter, emphasis will be placed on the legal aspects of three key elements establishing an ETS, namely (1) target setting, (2) allowances allocation, and (3) inspection and enforcement. In particular, EU law will be mainly taken as a starting point for determining the key elements in order to develop an analytical framework for discussing the EU ETS in chapter 3, after which chapter 4 will undertake a comparative approach thereby acknowledging the differences in Chinese law.

\subsection{Target setting}

\subsubsection{Emissions reduction target and target setting}

Policy makers can set a GHG emissions reduction target to achieve and to ensure climate protection, which could also imply or bring consequences for the legal position of private actors. There was once an oversimplified belief that the main purpose of an ETS was just to reduce the costs, while its environmental effect was purely determined by the emissions limit or standard outside the system ${ }^{4}$. Nevertheless, Tietenberg has reminded us that the environmental effect was one endogenous effect of emissions trading ${ }^{5}$. From the environmental perspective, the core of the ETS is about setting an environmental goal and ensuring that it is achieved. ${ }^{6}$ In this sense, the emissions reduction targets set for the climate policy and the ETS should reflect the ecological necessity and its feasibility to be reliably achieved cost-effectively.

While the trading provides for the flexibility to reduce emissions cost-effectively, the environmental goal and emissions reduction target set for emissions trading cannot be fulfilled automatically by trading. On the contrary, the environmental benefits from the emissions trading depend critically on the stringency of the emissions reduction target and the way to set the target. $^{7}$ As discussed above, two types of emissions reduction targets employed in the emissions trading models may have different impacts on the environmental outcome. Regulators can make different choices concerning the type of emissions reduction target. Meanwhile, the determination of specific targets is a complicated process requiring multidisciplinary

\footnotetext{
1 The voluntary emissions trading will be left untouched in this thesis.

2 Bothe, M. (2001), p. 121.

3 Peeters, M. (2008), p.20.

4 Tietenberg, T. H. (2006), p.61.

5 Ibid.

${ }^{6}$ Vis, P. (2006), p. 41-42.

${ }^{7}$ Driesen, D. M. (2010), p.1.
} 
consideration, including scientific knowledge, socio-economic understanding, and value judgments. ${ }^{1}$ However, critics have pointed out that the GHG emissions reduction targets, which in essence seem to be political choices made by governments, cannot always ensure the environmental goal. ${ }^{2}$ Moreover, who should be responsible and competent to make up this decision in pursuit of the environmental goal remains a critical element of the legal framework for the ETS.

\subsubsection{Competence distribution in target setting}

With regard to the ETS designed and implemented in a multilevel governance system, which involves multiple actors and different levels of governments, the competence distribution concerning target setting can be explored on two dimensions: one is horizontal and the other is vertical.

\section{Horizontal dimension}

From the horizontal perspective, the theory of competence distribution can be traced back to Montesquieu's argument on the virtues of the separation and division of powers. ${ }^{3}$ In general, the competence of setting the emissions reduction target for emissions trading is distributed to the legislators or conferred on the governments. Meanwhile, the courts can play a specific role in the course of target setting according to different legal systems. In theory, a judicial remedy should be available for stakeholders to seek legal arguments to contest the justification and intensity of the emissions reduction targets, though the courts probably will give considerable discretion to the legislators and governments in determining the target. ${ }^{4}$ Nevertheless, the decisions made by the courts can have some influence on the design and implementation of emissions trading to a certain extent.

Moreover, it is also important to take account of the consideration of different stakeholders in terms of target setting. In the course of deciding the emissions reduction target, the value of democratic debate and public participation is not less important than the prominent economic gains. The discussion about democratic accountability in emissions trading can be traced back to Ackerman and Stewart's article 'Reforming Environmental Law: the Democratic Case for Market Incentives', in which they argued the positive role that emissions trading would play in view of democratic accountability. ${ }^{5}$ To be specific, they argued that the application of market incentives would not only improve economic and administrative efficiency, but it would also improve the quality of democratic debate about environmental values by facilitating the public to address basic but complex technical issues relating to the regulatory system. ${ }^{6}$ Since the emissions reduction target will influence the legal position of private actors inter alia the emitters which are obliged to reduce a certain amount of emissions under the emissions reduction target, it is also (next to the public and environmental non-governmental organisations (NGO)

${ }^{1}$ Frame, D. J. (2011), p.141.

2 See Winter, G. (2010), p.16; See also Peeters, M. (2013), p.134-135.

3 Charles de Secondat, Baron de Montesquieu (1748).

${ }_{5}^{4}$ Peeters, M. (2013), p. 140.

5 Ackerman, B. A., \& Stewart, R. B. (1987).

${ }^{6}$ Ibid, p.171. 
necessary to allow the private actors to participate in decision making concerning the target setting.

\section{Vertical dimension}

In this chapter, special emphasis will be placed on the vertical dimension of competence distribution between different levels of authorities within multilevel governance systems. In this respect, the economic theory of federalism has been developed and applied in the domain of law and economics in legal academy, in which centralisation and decentralisation models concerning competence distribution have been discussed. ${ }^{1}$

In general, decentralisation is supported because it is usually believed that lower authorities seem to know more about their industries and to be in a better position to oversee the industries. ${ }^{2}$ Moreover, legislators of the decentralisation approach can compete with each other in the market of laws in order to win the vote. ${ }^{3}$ However, one can also raise concerns that lower authorities have strong incentives to reduce the environmental protection standard aiming to attract more investment, which is also called the 'race-to-bottom' ${ }^{4}$. Relying on the 'race-to-bottom' hypothesis, centralisation in environmental regulation is favoured by economists, especially in the cases of transboundary environmental pollution and the risk of regulatory capture. ${ }^{5}$

While using economic theory to try to provide substantial criteria for determining how specific competences should be distributed between different levels of authorities, one must realise the fact that the optimal solution does not exist in practice. In contrast, it is an inevitable challenge to cope with the tension or conflicts among higher and lower authorities in terms of target setting, aiming to strike a balance between them in accordance with specific legal orders. Although the emissions reduction target is to a large degree a political compromise of political negotiation, authorities have to comply with it once it has binding effect.

When setting the GHG emissions reduction target, we have to recognise the fact that GHG emissions is strongly connected to the economic development but they do not have local effect, which is quite different from other environmental pollution. Given the special characteristics of GHG emissions, it is not difficult to imagine the dilemma that local regulators may confront in setting the emissions reduction target. Lower authorities, which are not directly bound to the overall emissions reduction target, may have a strong incentive to set a relatively loose target favouring their own industries if they have such competence in the decentralisation model. The possibility of racing to the 'bottom' of the emissions reduction targets may endanger the integrity of the environment. Moreover, the inconsistence of the emissions reduction targets set by different lower authorities may also cause a distortion of competition in the emissions trading

\footnotetext{
${ }^{1}$ See for instance Van den Bergh, R. (2000), p. 80-95, discussing the competence distribution in competition policy; see also the Faure, M. G., \& Johnston, J. S. (2009) comparing the environmental federalism in the EU and the US; see also van Zeben, J. A. W. (2012) discussing the competence allocation at the international level, EU level and Member State level.

${ }^{2}$ Van den Bergh, R. (2000), p. 80-95, see also de Cendra de Larragán, J. (2008), p.59.

3 Tiebout, C. M. (1956).

${ }^{4}$ See for instance Baumol, W. J., \& Oates, W. E. (1988); Oates, W.E. (2002).

${ }^{5}$ Van den Bergh, R. (2000), p. 80-95.
} 
market. Therefore, it is necessary to control the target setting by lower authorities in the decentralised model in the legal framework. Considering higher authorities may focus on the overall environmental protection and prefer a stringent target for various reasons, potential tension and legal conflicts between higher authorities and lower authorities in terms of target setting also need to be dealt with carefully within the legal framework according to the specific legal system.

\subsection{Allowances allocation}

\subsubsection{Legal definition of allowances}

The cap-and-trade model is based on allowances defined in concrete terms of certain tonnes of emissions. ${ }^{1}$ As far as the specific amount of emissions to be allowed and traded is concerned, different scholars have employed various terms in different fields, including allowances, tradable rights, public rights, and permits. For instance, the economists usually prefer the terms of 'permit' and 'tradable right'. However, both the Clean Air Act of the US and the EU ETS Directive have chosen the term 'allowance' for the definition of a certain amount of GHG emissions to be allowed, issued and traded. Therefore, this thesis will also opt for the term 'allowance' for the definition. In a cap-and-trade model, an allowance provides a one-time entitlement to emit a specific amount. ${ }^{2}$ In contrast to the allowance, the tradable right under the credit-and-trade model is denominated in the form of a credit, which represents an amount of emissions emitted per unit of production (or per unit of fuel). ${ }^{3}$

While the tradable rights may be defined as credits or allowances in different emissions trading models, it is the legal nature of the tradable right that plays a substantial role in the legal framework. Concerning the legal nature of the tradable rights, they have been argued by economists consistently to be secure property rights, with the aims to protect and promote the investment in the resources. ${ }^{4}$ As Dales has argued, legal definitions of property rights stood at the centre of the solution to social problems. ${ }^{5}$ Nevertheless, the property right approach has been questioned and criticised by environmentalists from the perspective of ethics, arguing that the environment belongs to the people and should not be treated as a private property right. ${ }^{6}$ In addition, it is also argued that an ETS cannot be justified without an ethical basis. ${ }^{7}$ Therefore, a compromise to solve this conflict has been put forward in practice as for example most of the US ETSs try to give the allowance holders adequate legal certainty, while the allowances per se don't constitute property rights. ${ }^{8}$ Meanwhile, some scholars characterized the allowances as

\footnotetext{
1 Tietenberg, T. H. (2006), p.7.

2 Ibid, p. 18.

3 Ibid, p.17-18.

4 Tietenberg, T. H. (2006), p.193.

5 Dales, J. H. (1968), p.75.

${ }^{6}$ Ibid. See also Winter, G. (2010), p.1.

${ }^{7}$ Swift, B. (2005), p.72.

${ }^{8}$ See for instance Section 403(7) under Title IV of the Clean Air Act of the USA, which states: 'An allowance allocated under this subchapter is a limited authorization to emit sulfur dioxide in accordance with the provisions of this subchapter. Such allowance does not constitute a property right.....'; see also Tietenberg, T. H. (2006), p.193.
} 
'mixed, hybrid or regulatory property rights', which contain not only public law rights but also private property rights. ${ }^{1}$

There is no doubt that the climate should not be traded as a commodity. ${ }^{2}$ But the possession of allowances confers a public law right on operators to emit a certain amount of GHG, which can be considered as a type of tradable administrative authorisation. ${ }^{3}$ The allowances may not be treated as private property rights but instead a public law right with economic value. Given that the allowance is a kind of public law right, the holder of the allowances should be protected by the principle of legal certainty, which generally requires the law to be clear, stable and comprehensive. ${ }^{4}$ Moreover, the protection of allowances can rely on the principles of acquired rights, non-retroactivity and legitimate expectations, which are the corollaries of the legal certainty principle. ${ }^{5}$ As the reliance on the legal order must be respected $^{6}$, a favourable legislation creating an acquired right cannot be revoked ${ }^{7}$. However, it does not mean that the legislation cannot be amended at all. If there is a need for amendment, a delicate balance must be struck between the individual interest (certainty) and the public interest (legality). ${ }^{8}$

However, one can raise the question of whether the government can intervene with the allocation of allowances from the legal certainty perspective. Since the ex post adjustment adopted by governmental decisions within an ETS may change the legal circumstances under which the market participants, such as the allowances holders, may operate. ${ }^{9}$ If governments want to intervene with the initial allocation of allowances, for example withdrawing some allowances, the competence of the government in the legal framework has to be addressed. In other words, it is also closely connected to the question about the role of governments in a market-based instrument. According to Dales' initial design, the government can play an active role like a broker in the ETS. ${ }^{10}$ But it remains a crucial question for the legislator to determine the specific role of the government in an attempt to strike a balance between the legal protection of allowance holders under the legal certainty principle, on the one hand, and other specific policy goals of the ETS, on the other hand. ${ }^{11}$ To a certain degree, the legislator may deal with this question in choosing the emissions trading model with the ex post adjustment of allocated allowances or ex post allocations of allowances, such as that in the credit-and-trade model. ${ }^{12}$ Further discussions will be presented based on the experience and problems of the EU ETS and Chinese ETS in the following chapters.

\footnotetext{
${ }^{1}$ See for instance Rose, C.M. (1999); Yandle, B. (1999); see also Woerdman, E., Arcuri, A. and Clò, S.,(2007), p.9. 


\subsubsection{Initial allocation methods}

How to allocate the allowances is one of the most important and controversial issues in emissions trading. Exactly as Tietenberg has argued, in theory the initial allocation should not have much influence on cost-effectiveness, but it matters a great deal in practice, and it has a substantial impact on the fairness and cost-effectiveness of the ETS. ${ }^{1}$ Since the credits in credit-and-trade model are usually generated by comparing the actual performance of emitters with the baseline set in advance, this section will only focus on the initial allocation of allowances in cap-and-trade model.

From the theoretical point of view, there are several kinds of possible allocation methods, such as random access, first come first serve, administrative allocation based on eligibility criteria, and auctioning. ${ }^{2}$ Free allocation based on administrative rules and auctioning have been widely applied in practice.

\section{Free allocation}

When the allowances are subject to free allocation, the allocation rules are commonly based upon the output of a certain product or emissions according to specific administrative rules. If the free allocation is based on the specific output of a certain product in a given time period, the amount of allowances allocated to specific emitters can be updated as the output level changes. To some extent, this allocation method can provide a certain flexibility to accommodate the dynamic economic development. However, it was also criticised as neither efficient nor cost-effective, because it provided an implicit subsidy to output. ${ }^{3}$ In contrast, another approach is based upon emissions. In particular, the free allocation of allowances based on the historical emissions in a given year, typically only for the existing emitters, is often called grandfathering.

Grandfathering is generally preferred by the incumbents as they do not have to pay extra costs for the allocation but will receive valuable allowances. ${ }^{4}$ Thus it has been chosen quite often by policy makers at the starting point of establishing an ETS aiming to gain enough political acceptability and support. However, with regard to the application of grandfathering, a lot of questions have also been raised. Since grandfathering is based on the historic emissions, it is a static approach, keeping the status quo of certain emissions level, which may put the early actors that have already achieved significant emissions reduction in the past in a disadvantaged position. ${ }^{5}$ It may even create a negative incentive to emitters to increase emissions in order to get more allowances ${ }^{6}$, which is not compatible with the environmental objectives of the ETS. Moreover, it has been criticised for its inconsistency with the polluter pays principle, which requires the polluter to bear the costs of addressing pollution. ${ }^{7}$ Moreover, the free allowances

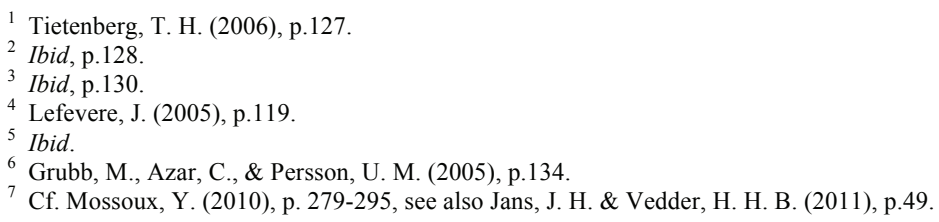


can be considered as a capital gift, leading to incompatibility with the polluter pays principle from the perspective of equity. ${ }^{1}$

In this respect, the equal treatment issues may be more serious in the cases when other emitters or the new entrants will be allocated allowances through other methods rather than grandfathering. Even for the sectors receiving free allowances, an allocation method, namely benchmarking, may be applied to set more objective criteria for free allocation to different types of emitters covered. ${ }^{2}$ But the design and implementation of the benchmarking is even more complicated, similarly complicated as the baseline selection in the credit-and-trade model.

\section{Auctioning}

While free allocation based on administrative rules is the predominant choice of existing programmes, auctioning is preferred by economists as it is supposed to be most efficient. ${ }^{3}$ In an auction, potential buyers compete with each other to ensure that the allowances go to the users who value them most. Thus it is argued that auctioning can be designed in such a way as to ensure allocative efficiency. ${ }^{4}$ In other words, the auctioning will be operated mainly based on the market price, eliminating the need to establish historical baselines and facilitating to ease political contention which occurs in grandfathering. ${ }^{5}$ Given all the emitters have to buy the allowance, auctioning is also considered to be compatible with the polluter pays principle. Moreover, considerable revenue will be raised through auctioning, which can be recycled, for instance, to promote technology innovation and renewable energy investment. ${ }^{6}$

With regard to the difference between auctioning and grandfathering, Tietenberg has shed light on the implicit ethical logic that lies behind their baseline specifications. ${ }^{7}$ According to Tietenberg, the implied baseline control responsibility in auctioning is for all emitters to eliminate all emissions. ${ }^{8}$ When they fall short of that baseline they must pay for the difference. On the contrary, it is assumed in grandfathering that existing emitters are entitled to emit specific levels as determined by the initial allocation. Only when the actual emission is over that level, they have to pay by buying additional allowances. ${ }^{9}$ Meanwhile, the incumbents can even earn money by reducing the emissions below that baseline and selling the surplus allowances.

From a legal point of view, the incumbents and new entrants covered by the emissions trading seem to be treated more equally in the course of auctioning than grandfathering. Both of them have to buy the allowances through auctioning and they will be subjected to the same auctioning rules. But it is a challenge for legislators to design objective, simple and transparent auctioning rules, such as choosing suitable auction formats, timing, market structure and transparency. ${ }^{10}$

\footnotetext{
${ }^{1}$ See Woerdman, E., Arcuri, A. \& Clò, S.,(2007).

2 Lefevere, J. (2005), p.119.

3 Tietenberg, T. H. (2006), p.128.

${ }^{4}$ Weishaar, S. (2009), p.61.

${ }^{5}$ ELI (1997), p.67; see also Zhang, Z. X. (1999), p.14.

${ }^{6}$ Bausch, C., \& Cavalieri, S. (2007), p.137.

7 Tietenberg, T. H. (2006), p.131.

8 Ibid.

9 Ibid.

${ }^{10}$ See further discussion in Weishaar, S. (2009), p. 203-210. This thesis is not going to explore this aspect in
} 


\subsubsection{Equal treatment in initial allocation}

Given GHG emissions do not have local effect and the environmental effectiveness of the ETS is determined by the stringency of the emissions reduction target, it does not matter who will 'use' the allowances eventually from an environmental point of view. ${ }^{1}$ It has also been argued that the allocation method is not important for the operation of emissions trading per se, because the initial allocation only determines the allocation of economic value of the allowances, while the market redistributes them through trading in order to fulfil the cost-effective objective. ${ }^{2}$ However, the initial allocation has been one of the most controversial issues concerning emissions trading. Literature has been exploring effective and efficient allocation methods from an economic perspective, but special attention will be paid to equal treatment issues concerning the allowance allocation in this section.

In emissions trading, in particular the cap-and-trade model, the legal position of emitters covered by the scheme would be affected directly by the choice and design of the allocation methods. As discussed above, the tradable rights, inter alia the allowances in the cap-and-trade model, are public law rights with economic value. The allocation of allowances, distributing burden and benefit among emitters to a large extent, will have distribution consequences on relevant sectors and emitters. ${ }^{3}$ Given that the total amount of allowances is fixed by an absolute cap, emitters demanding allowances to comply with the rules will be placed in the same allowances market artificially created by the regulators. It is the initial allocation choices made by the regulators that determine how the emitters will receive allowances through specific allocation methods.

According to the principle of equal treatment, comparable situations must not be treated differently and different situations must not be treated in the same way, only if such treatment is objectively justified. ${ }^{4}$ In terms of emissions trading, the principle of equal treatment is relevant for the regulators in designing and implementing the allocation rules. It requires that identical emitters should operate under a uniform legislative regime. ${ }^{5}$ However, a hybrid approach combining allocation methods - allocating part of the allowances free of charge and auctioning the remaining part regularly - is usually the dominant choice applied to accommodate different situations in practice. ${ }^{6}$ Emitters of different sectors or even the same sectors, such as incumbents and new entrants, may be treated differently in the allocation process. Differential treatment is not prohibited as long as the objective justification can be proved. Hence the application of the equal treatment principle entails an evaluation of the differential treatment in terms of the factual and legislative context, the objective of the legislation, the interests involved, and other factors, in order to strike a balance between conflicting interests involved in the ETS. ${ }^{7}$

\footnotetext{
depth because of the limited scope of this research.

${ }^{1}$ Ibid, p.36.

${ }^{2}$ Lefevere, J. (2005), p.118.

${ }^{3}$ Kurkowski, S. J. (2005), p.727.

${ }^{4}$ As explained above in the beginning of section 3 in this chapter, this section takes EU law as a starting point for discussing the equal treatment principle. See Article 18, TFEU; see also Jans, J. H. \& Vedder, H. H. B. (2011), p.21.

${ }^{5}$ See de Cendra de Larragán, J. (2010a), p.162; see also Article 18, TFEU.

${ }^{6}$ Lefevere, J. (2005), p.120.

${ }^{7}$ de Cendra de Larragán, J. (2010a), p.163, see also Tridimas,T. (2006), p.472.
} 
In addition, attention should also be paid to the variety of competition relationships that may involved in the ETS, as for example relationships between incumbents and new entrants, between different trading sectors, between trading sectors and non-trading sectors, and between international competitive emitters located in different countries. ${ }^{1}$ In the course of allocating allowances, important questions will be raised before the regulators: how to treat the emitters equally in order to ensure a level playing field in the emissions trading market, on the one hand, and to maintain the advantages or at least to prevent the disadvantage of its own industries in the international market, on the other hand.

Furthermore, it is also argued that the principle of equal treatment has evolved from a market unifier to a fundamental right. ${ }^{2}$ If the individual emitters are treated differently without an objective justification, they should have the right to access to the justice system and to challenge the differential allocation decisions. However, the notion of objective justification is so abstract that more specific requirements or criteria are needed. When the court wants to apply this principle to test the legality of the allocation rules, there should be at least criteria for comparing undertakings and deciding whether the differential treatment is objectively justified. ${ }^{3}$

\subsection{Inspection and enforcement}

Apart from target setting and allowances allocation, inspection and enforcement make up another cornerstone of the legal framework to ensure the compliance and ultimately the environmental goal. Since the compliance with the emissions trading rules is a precondition for the effective operation of an emissions trading market ${ }^{4}$, various stakeholders share a common interest in achieving a high level of compliance with the ETS $^{5}$. From the perspective of the regulators and environmental NGOs, the environmental target cannot be achieved without compliance by emitters covered by the ETS. For the emitters, high level of compliance is crucial for the establishment of the level playing field, which can ensure that all the competitors comply with the same rules; otherwise they will be detected and punished. ${ }^{6}$ Considering that the allowance is a kind of public law right, the possession of this right has no 'natural benefit' but only has value by complying with the law. ${ }^{7}$ Therefore, the high level of compliance which can affect the actual value of allowances is also important for other market participants selling and buying the allowances. In this sense, only with high levels of compliance by the emitters will the ETS achieve the goal of reducing GHG emissions efficiently, effectively and equitably. ${ }^{8}$

However, the compliance challenge for the ETS is not smaller than that of the command-and-control instrument. From an economic point of view, the emitters - as the rational economic man - generally make decisions on compliance or non-compliance by

\footnotetext{
${ }^{1}$ See Weishaar, S. (2009), p.167-171, see also Weishaar, S. (2008a), p.165-171.

2 More, G. (1999), p.517-773.

3 Jans, J.H., de Lange, R., Prechal, S., Widdershoven, R. J. G. M., (2007), p.62.

${ }^{4}$ Peeters, M. (2006b), p. 169.

5 Kruger, J., \& Egenhofer, C. (2006), p.8-9.

${ }^{6}$ Ibid, p.8.

${ }^{7}$ See Ibid, p.9.

${ }^{8}$ Ibid, p.2.
} 
weighing the cost and benefit of each choice in order to minimise their own costs. ${ }^{1}$ Since the emitters' decision making regarding their environmental performance in a market-based instrument are mainly price-driven, the most attractive feature of an ETS however may become the financial attraction leading to illegal behaviour and thus a threat to the level of compliance. ${ }^{2}$ Therefore, the compliance level of the emitters needs to be ensured and strengthened by a comprehensive and stringent enforcement package.

The effectiveness of inspection and enforcement in emissions trading relies on a variety of requirements, such as an accurate measurement of actual emissions, registries tracking the allowances, sanctions for non-compliance, public access to a data system of emissions and allowances. Given that the emitters may have the motivation and convenience to conduct illegal activities concerning the emissions data in order to maximise their profit, inter alia in cases in which the price of allowances is very high, special attention will be paid to the emissions data collection and sanctions for non-compliance in this section.

\subsubsection{Monitoring, reporting and verification}

\section{Choice of monitoring methods}

The data on actual emissions is crucial for the proper functioning of the ETS. With respect to the cap-and-trade model, the actual emissions data of the emitters needs to be collected with a reliable method in order to decide the corresponding amount of allowances to be surrendered by emitters. In view of the economic value concerning the allowance, the quantity of real emissions will have a significant impact on whether the emitters can make money from selling the surplus allowances or pay extra bills for buying allowances to cover the excess emissions. ${ }^{3}$ For the credit-and-trade model, the actual emissions data can also determine whether and how many credits can be generated. Therefore, the monitoring and determination of real emissions of each emitter covered by the ETS is essential for compliance. ${ }^{4}$

However, most ETSs will face a common challenge of collecting accurate emissions data. In theory, there are two basic approaches that can be employed to gather the emissions data of emitters; one is direct measurement and the other is estimation using emissions factors. ${ }^{5}$ With regard to the direct measurement, Continuous Emissions Monitoring System (CEMS) can be considered to be a prominent application. Usually it is conducted by electromechanical instruments installed in the chimney through which emissions pass, therefore the emissions information can be sampled, analysed, measured, and recorded automatically and continuously. ${ }^{6}$ Compared to a direct measurement with high accuracy, a less accurate but relatively cheap and quick way by estimating emissions with emissions factors is often used as an alternative. ${ }^{7}$ However, estimations should be supplemented by on-site inspections in order to ensure the

1 Tietenberg, T. H. (2006), p171.

2 Peeters, M. (2006a), p.179.

${ }^{3}$ Peeters, M. (2011c), p.414.

4 Peterson, S. (2004), p.189-206.

5 McAllister, L. K. (2010a), p.1203-1208.

${ }^{6}$ Reitze, A. W. Jr. \& Schell, S. D. (1999), See also McAllister, L. K. (2010a), p.1203.

${ }^{7}$ McAllister, L. K. (2010a), p.1205. 
truthfulness and accuracy of the data. ${ }^{1}$ In general, the higher the accuracy requirement is, the more emissions monitoring will cost. This may give rise to some legal conflicts between regulators preferring accurate data, on the one hand, and emitters favouring less costly methods, on the other hand. Therefore, it is important for the policy makers to strike a delicate balance between the accuracy and cost-effectiveness when choosing the monitoring methods. ${ }^{2}$

\section{Option of self-monitoring, self-reporting and verification}

Furthermore, it is also crucial to determine how to distribute the responsibility of monitoring emissions between regulators and emitters in the legal framework. In order to ensure that violations are discovered and punished, adequate resources need to be available for the necessary enforcement work, inter alia the emissions data collection. ${ }^{3}$ But if the number of emitters covered by the scheme is very large, the intensity of emissions monitoring may be much higher than other environmental regulation. In this sense, it would be difficult for the government to conduct the monitoring activities and to collect the emissions data on its own. In addition, some regulators may also be confronting a growing problem of regulatory failure as governmental agencies lack adequate resources and expertise to monitor and detect non-compliance. ${ }^{4}$ In order to improve the effectiveness of the governmental regulation and enforcement, public-private governance has been applied as an alternative option.

In contrast to the traditional governance, where government acts as the main regulator in a centralised approach ${ }^{5}$, the public-private governance can be defined as a wide range of arrangements through which public and private actors cooperate with each other. ${ }^{6}$ In terms of the ETS, the emissions data can also be monitored and reported by the emitters themselves. Compared to other enforcement regulation in which the emissions data is collected and inspected by the government directly, self-monitoring and self-reporting would shift lots of the burden from the government to the regulated industries in monitoring the emissions. ${ }^{7}$ Therefore the government can focus on the compliance assistance measures or penalties dealing with the non-compliance. ${ }^{8}$

In this context, a balance must be found between allocating responsibility to the operators and fulfilling the governmental task to ensure the achievement of the environmental goal. ${ }^{9}$ Once the approach of self-monitoring and self-reporting is chosen by regulators, there will be a subsequent challenge for the regulators to ensure and to promote the reliance and truthfulness of the emissions data generated by self-monitoring and self-reporting mechanisms. Therefore, the emissions data collected by emitters should be subjected to verification, which can be conducted

\footnotetext{
1 Tietenberg, T. H. (2006), p177-178.

2 Peeters, M. (2011c), p.414.

3 McAllister, L. K. (2010b), p.28.

${ }^{4}$ McAllister, L. K. (2011), p.1.

${ }^{5}$ See ibid, p.13.

${ }^{6}$ Ibid, p.12-13.

${ }^{7}$ Mulkey, M. E. (2004), p.2, 5.

${ }^{8}$ McAllister, L. K. (2010a), p.1208.

9 Peeters, M. (2006a), p. 193.
} 
by governmental/regulatory bodies or private third-party organisations. ${ }^{1}$ However, the governmental verification may still have to face similar problems of the lack of resources and expertise. Thus two solutions to these problems have been proposed: one is introducing third-party verification and the other is imposing criminal sanctions for false reporting which will be explored later. ${ }^{2}$ In the former solution, the independent third-party verifiers provide professional opinions and deliver a finding to the regulators regarding whether the emitters have reported accurate data and thus have complied with the scheme. ${ }^{3}$ In this sense, the third-party verifier may play a significant role as 'gatekeeper' in the enforcement. ${ }^{4}$

Therefore, the special role of third-party verifiers is crucial. As a result of the application of third-party verification, the direct costs of inspection and compliance assessment would be shifted from the government to the regulated industries, which is compatible with the polluter pays principle. ${ }^{5}$ However, the third-party verifiers are usually contracted with and paid by the emitters on the one hand, and they have an important influence on determining whether the emitters have complied with the monitoring and reporting rules on the other hand. One can raise considerable concerns on the independence, professionalism, competence, and accountability of the third-party verifiers. Therefore, 'the verifier of the verifier ${ }^{6}$ is required, which would be the government. Furthermore, the regulation of the third-party verification through accreditation and supervision of the verification process is crucial for the legal framework for enforcement. In addition, the relationship among the emitter, verifier and regulator needs to be well determined and further clarified in the specific legal framework.

\subsubsection{Sanctions}

In addition to the requirement for MRV, a rigorous sanction regime is the last element safeguarding a well-functioning ETS. In general, emitters covered by the ETS should not emit extra GHG unless they are covered by the allowances. If the emissions data is collected by a mechanism of self-monitoring, self-reporting and third-party verification, the emitters and verifiers must meet relevant requirements stipulated in the legislation. A variety of non-compliance of the participants may emerge during the operation of the ETS. In pursuit of the compliance with and confidence in the ETS, it is necessary to set up effective sanctions regime.

Aiming to achieve a high level of environmental protection, the functions of sanctions or penalties in the environmental law can be differentiated at least in three categories: deterrence, restoration of harm caused in the past and prevention of future harm. ${ }^{7}$ Moreover, the sanctions imposed on the offenders should be effective, dissuasive and proportionate. ${ }^{8}$ In terms of determining the sanctions in the ETS, considerable attention needs to be paid to the ETS's special nature of market-based instrument as well as its ultimate environmental goal. Therefore,

\footnotetext{
1 Rohleder, J. (2006), p.26.

2 Tietenberg, T. H. (2006), p.182.

3 See McAllister, L. K. (2011), p.5-6.

${ }^{4}$ Kraakman, R. H. (1986), cite in McAllister, L. K. (2011), p.12.

${ }^{5}$ See Gunningham, N. A. (1997), p.566; see also Wagner, W. E. (2003), p.1668-1669; McAllister, L. K. (2011), p.27.

${ }^{6}$ McAllister, L. K. (2010a), p.1229.

${ }^{7}$ Faure, M. (2010), p. 259-260, p.268.

${ }^{8}$ Ibid, p.259.
} 
not only the economic efficiency but also the environmental effectiveness should be taken into account in designing and applying the sanctions. In this section, three major penalties will be discussed.

\section{Financial penalty}

As a market-based instrument, the ETS not only provides an economic incentive to reduce emissions in a cost-effective way but it also serves as a financial incentive for emitters to behave illegally. ${ }^{1}$ The profitability of the allowances may induce an incentive for noncompliance, which is particularly a risk in the absence of an effective enforcement system. ${ }^{2}$ In order to reduce and to remove the incentive for non-compliance, financial penalties imposed on the offenders with non-compliance inter alia excess emissions is widely considered to be a necessary and effective approach for enforcing emissions trading.

Based on the possible cost-benefit analysis approach adopted by the emitters in making up the decisions concerning compliance, economists propose that regulators can raise the expected costs of non-compliance by paying attention to two main elements that determine that cost: the likelihood that violations will be detected and sanctions imposed, as well as the level of the sanctions. ${ }^{3}$ For instance, economists argued that the expected non-compliance cost could be set to be equal to the expected damage caused by non-compliance. ${ }^{4}$ In order to achieve a higher level of compliance, it is further argued that the regulators should ensure the expected cost of non-compliance such as the fine per unit of excess emissions is higher than the allowance's price. $^{5}$ In other words, the potential offender will face a high non-compliance cost ensured by the sanctions, in which the financial benefit accruing from the non-compliance will be deprived. ${ }^{6}$ From an economic perspective, the two conditions mentioned above not only stimulate the emitter to submit truthful emissions reports, but also guarantee that each emitter will hold enough allowances to cover their emissions. ${ }^{7}$

The economic consideration is indeed important for effective enforcement, however, a more problematic issue from the legal perspective is how to determine and implement the financial penalties so that they are in conformity with legal principles such as, for the EU, the principle of proportionality. In theory, the amount of financial penalties imposed on offenders holding insufficient allowances can be determined in the form of a specific fixed amount or by a connection with the dynamic prices of allowances. While the fixed financial penalties seem to be easier to implement, it is argued that the direct connection with the prevailing market price of allowances seems to be more proportionate. ${ }^{8}$ Especially in the face of price fluctuation, the direct connection with the market price rather than the fixed fines can stabilise and ensure the

${ }^{1}$ Peeters, M. (2006a), p.179; see also Epiney, A. (2012), p. 27.

2 See OECD (2004), p. 25

3 Tietenberg, T. H. (2006), p.173.

${ }^{4}$ See Becker, G. S. (1968); See also Faure, M. (2010), p.260.

5 Stranlund, J.K., Chaves, C.A. \& Field, B.C, (2002), p.346.

${ }^{6}$ Peeters, M. (2011c), p.413.

${ }^{7}$ Tietenberg, T. H. (2006), p.175.

${ }^{8}$ Stranlund, J. K., Chavez, C. A., \& Field, B. C. (2002), p.343-361, see also Peeters, M. (2011c), p.421. 
compliance incentive. ${ }^{1}$ However, both approaches may face the same challenge to determine the effective and proportionate level of the financial penalty in order to ensure the deterrence against all the potential violations. In addition, one can also raise the question of whether such financial penalties will be implemented automatically or be subjected to the authorities' discretion on a case-by-case basis. According to the requirement of proportionality, attention should be paid to the relationship between the type and intensity of the penalty on the one hand and the type of non-compliance on the other hand. ${ }^{2}$ In other words, it will be better to take account of all the relevant circumstances of the violation before imposing the financial penalties from the proportionate perspective.

\section{Compensation for excess emissions}

Since the economic instrument like the ETS is applied to achieve the environmental goal, it is important to ensure the environmental effectiveness of emissions trading through enforcement.. In addition to providing a proper incentive for emitters to reduce emissions at a lower cost, it is also necessary for emissions trading to prevent and to punish the excess emissions compared to the overall emissions target.

With regard to the cap-and-trade model, the emissions reduction target is determined by the cap, equal to the overall quantity of allowances. Thus the amount of emissions emitted by emitters cannot exceed the quantity of allowances held by them. Otherwise, the excess emissions not covered by allowances should be detected and restored afterwards by compensating those excess emissions with an equal amount of allowances. ${ }^{3}$ Although the environmental target of the credit-and-trade model may be set by the so-called baseline or performance standard, the emitters should also be obliged to cover the extra emissions exceeding the relative standard with emissions credits. $^{4}$ Otherwise, the penalties of surrendering an equal amount of credits afterwards should also be applied. Only with this sanction compensating for excess emissions can the overall environmental goal of emissions trading be achieved and maintained.

\section{Criminal penalties}

In general, financial penalties and compensation for excess emissions can make the emitters comply with the basic rules of emissions trading to a certain degree. However, financial penalties may be ineffective if they exceeds the financial capacity of the offenders and thus additional penalties would be necessary. ${ }^{5}$ Given that a variety of potential non-compliance exists in the emissions trading, other options of sanctions should also be taken into consideration in the enforcement mechanism. Especially aiming to ensure the reliance of emissions data monitored and reported by individual emitters, it is proposed to designate responsible persons for emissions

\footnotetext{
${ }^{1}$ Stranlund, J. K., Chavez, C. A., \& Field, B. C. (2002), p.354.

2 Faure, M. (2010), p.264.

${ }^{3}$ Peeters, M. (2011c), p.413.

4 Peeters, M., Weishaar, S., \& de Cendra de Larragán, J. (2007), p.191.

${ }^{5}$ See Becker Gary, S. (1968); Shavell, S. (1985). referred to by Peeters, M. (2011c), p.421. According to an evaluation report of the EU ETS, in Germany several cases of insolvent operators have been the case, see Verschuuren, J. \& Fleurke, F. (2014), p. 33.
} 
monitoring and reporting in order to enhance accountability. ${ }^{1}$ The possibility to impose criminal sanctions for false reporting and other illegal conduct is also suggested. ${ }^{2}$

However, it is generally believed that when optimal dissuasion can be achieved equally through either fines or criminal sanctions, fines are preferred as they are less expensive to administer. ${ }^{3}$ Moreover, imprisonment seems to be limited to cases of fraud or serious environmental harm in the practice. ${ }^{4}$ In addition, whether noncompliance in emissions trading is serious enough to impose criminal penalties, in particular the personal criminal liability of people responsible for the performance of business entities still deserves careful consideration before the legislators provide this option.

\section{Concluding remark}

The ETS is a market-based instrument which was first introduced in economic literature, but it is the effective legal framework that establishes and underpins the well-functioning emissions trading market. Considering that two basic models of emissions trading can be applied to achieve a specific environmental goal, legislators should pay enough attention to their differences and make up the decisions carefully based on its own circumstances. Otherwise the legislators may have to bear the enormous risk of being 'locked' into the model chosen in the beginning. ${ }^{5}$ However, from a legal perspective, some crucial problems must be solved in both emissions trading models, such as how to set up a proper emissions reduction target (absolute or relative) for the ETS, how to define and allocate the tradable rights, and how to ensure compliance. This chapter has explored how key elements of the legal framework for emissions trading, in particular the cap-and-trade model, can be understood from a theoretical perspective. Its main insights are provided below.

Firstly, target setting is the first key element of the legal framework, which will determine the environmental goal that emissions trading is applied to achieve. Since the types of emissions reduction targets are closely connected with the emissions trading models, the legislators should make the choice based on its own circumstances in order to strike a delicate balance between the environmental goal and economic development. Moreover, it is crucial for the legal framework to distribute the competence concerning target setting within a multi-level governance system. In general, the competence distribution can be explored at the horizontal as well as vertical dimensions. In view of the special role of government in emissions trading and the emissions reduction target's influence on economic development, special attention has been paid to the competence distribution between different governmental levels within a multi-level governance structure. Numerous arguments for centralisation or decentralisation in terms of competence distribution in environmental regulation can be found in the literature. In general, the competence should be distributed based on its own legal systems. Considering GHG emissions

\footnotetext{
${ }^{1}$ Choi, I. (2005), p.945.

2 Tietenberg, T. H. (2006), p.182.

3 See Faure, M. (2010), p.266; see also Polinsky, A.M. \& Shavell, S., (1979).

${ }^{4}$ Faure, M. (2010), p.266.

${ }^{5}$ Peeters, M., Weishaar, S., \& de Cendra de Larragán, J. (2007), p.195.
} 
do not have local effects, lower authorities may have a strong motivation to set lax emissions reduction targets favouring their local industries. If lower authorities are distributed with competence to determine the emission reduction target aiming to take account of the local circumstances and to ensure the flexibility, it will be necessary for higher authorities to control the target setting at the local level in the legal framework.

Secondly, how to define and allocate the tradable rights is a crucial but controversial element of the legal framework for emissions trading. The allowances in the cap-and-trade model can be distributed through free allocation based on administrative rules and auctioning. Although auctioning is considered to be more equal and efficient, free allocation, inter alia grandfathering, is usually preferred by the industries and is adopted by legislators in order to establish the ETS in the beginning. Meanwhile, a combination of different allocation methods may be a more feasible choice to accommodate different circumstances. Emitters covered by the same scheme will thus be treated differently in the course of allowances allocation. The question of whether any differentiated treatment in the allocation is objectively justified should be examined carefully in the legal framework. Although allowances can be denominated differently in the emissions trading projects, the legal nature of the allowances can be considered as public law rights. Thus the legal certainty issues concerning their allocation should be considered, in particular in the case of governmental intervention or adjustment.

Thirdly, inspection and enforcement is the last cornerstone underpinning the proper operation of the ETS. Compliance with the emissions trading rules by participants is important for the integrity of the environment and emissions trading market. In order to ensure a high level of compliance, the real emissions data must be collected and appropriate sanctions for non-compliance must be applied. Aiming to ensure the reliance and accuracy of the emissions data, not only the technology but also the cost should be taken into consideration in choosing monitoring methods. Moreover, legislators can also consider the option of self-monitoring, self-reporting and third-party verification based on the idea of public-private governance. Special attention should also be paid to the role of the verifier in the legal framework. One can raise the question of to what extent verifiers can ensure the compliance of operators in terms of monitoring and reporting the real emissions data. The verification should be regulated by accreditation and supervision of the verification procedure. In addition to the requirement of MRV, effective and proportionate sanctions play a crucial role in punishing the non-compliance and deterring potential violations. In this respect, both the environmental goal and economic character of the ETS should be borne in mind. It is necessary to remove the economic incentive for non-compliance with financial penalties, on the one hand, and to oblige the violators to compensate for the excess emissions uncovered by sufficient allowances in an attempt to ensure the environmental integrity, on the other hand. Moreover, other optional sanctions, such as imprisonment, may be applied in some special cases to achieve the goal of high environmental protection. But the application of criminal penalties should be considered very carefully in line with the specific legal system.

These three key elements discussed above cannot cover all the important legal aspects of emissions trading but without them the ETS cannot be established and function properly. This 
chapter has explored some crucial challenges concerning the three key elements in an attempt to establish an analytical framework ensuring the environmental effectiveness, allocation equity and stringent but just enforcement of emissions trading. The theoretical design concerning each element of the legal framework is debatable per se, let alone the big challenge of specific design and implementation in practice adapted to the specific legal system. These legal challenges and possible solutions will be analysed in the following chapters. 


\section{Chapter 3}

\section{LEGAL EXPERIENCES WITH THE EU ETS}

\section{Introduction}

\subsection{Aim of this chapter}

This chapter aims to provide an in-depth legal examination of the EU ETS in terms of its regulatory design and case law (thereby answering sub-question 2). Ever since the establishment of the EU ETS in 2003, the EU carbon market has grown rapidly and has become the largest domestic GHG emissions trading market in the world. However, the EU ETS should not be imitated automatically by other countries, such as China, in view of the numerous differences between the EU and China in terms of the economic, legal and political systems. Nevertheless, serving as an attractive option and reference model, the EU ETS should be examined in depth, in order to enhance the understanding of core legal aspects and different design options of this complicated instrument used in practice.

The EU ETS is a key element of EU climate law and policy. The EU ETS has been designed and implemented in line with the EU legal system, in particular EU environmental law. In this respect, a general introduction to the regulatory structure and general principles of EU environmental law related to the EU ETS will be helpful to build a general understanding of the role and function of the EU ETS in a broader context. In addition, the emphasis of this chapter goes to the examination of the specific design features and the implementation of the EU ETS. In line with the three key elements determined in the analytical framework established in chapter 2 , this chapter discusses target setting, allowances allocation, inspection, and enforcement. Based on an in-depth description of the EU ETS in terms of these key elements, a critical observation follows, focusing on the analysis of significant legal problems emerging from the implementation of the EU ETS. Moreover, this chapter will also try to gain some legal insights from the EU ETS based on the critical analysis and thus will explore alternative design options of other ETS which have yet to be designed in other legal systems.

\subsection{Structure of this chapter}

In this chapter, the emphasis will be placed on the design and implementation of the EU ETS, which will comprise another four sections. Section 2 will provide a general introduction to the legal framework for the EU ETS in the context of EU environmental law, including the regulatory structure, basic principles and main instruments related to the EU ETS. Section 3 will shed light on the three key components of the EU ETS in terms of legislation and its application. Section 4 will observe and discuss the legal problems concerning the design and implementation 
of the EU ETS regarding those three key elements. Based on these description and observation, a conclusion will follow in section 5 .

\section{General introduction to the EU ETS: an element of EU environmental law}

\subsection{EU environmental law: regulatory structure and basic principles}

Climate change policy in the EU is mainly addressed within the framework of environmental law. In order to reduce the GHG emissions cost-effectively, the EU ETS has been established on the basis of the EU environmental competence. In order to understand this complicated instrument, it is necessary to sketch some general but fundamental aspects of EU environmental law, in particular the regulatory structure and basic principles.

\subsubsection{The regulatory structure of EU Environmental law}

\section{Competence distribution between the EU and Member States}

In general, the regulatory structure within the EU comprises two levels: the EU and the Member States. According to the Treaty on European Union (TEU), the limits of the EU competences are governed by the principle of conferral, stipulating that the competences not conferred on the EU remain with the Member States ${ }^{1}$. Moreover, the Treaty of Lisbon makes further clarification on the competence distribution between the EU and Member States, which are classified into three types of competences, namely exclusive competences ${ }^{2}$, shared competences ${ }^{3}$ and supporting competences $^{4}$. Despite the fact that the boundary problems between these three categories of competences may still exist, ${ }^{5}$ clarification concerning the competence distribution between the $\mathrm{EU}$ and the Member States is vital for the proper functioning of the EU.

According to Article 4 of the Treaty on the Functioning of the European Union (TFEU), the governance in relation to the environment belongs to the domain of shared competence between the EU and the Member States, resulting in a multi-level regulatory structure for EU environmental law. ${ }^{6}$ To be specific, according to Article 2(2) TFEU:

When the Treaties confer on the Union a competence shared with the Member States in a specific area, the Union and the Member States may legislate and adopt legally binding acts in

\footnotetext{
1 Article 4-5, TEU.

2 Article 3, TFEU.

3 Article 4, TFEU.

4 Article 6, TFEU.

${ }^{5}$ Craig, P. \& De Búrca, G. (2011), p.84.

${ }^{6}$ Article 4, TFEU; see also Carlarne, C. P. (2010), p.147-150.
} 
that area. The Member States shall exercise their competence to the extent that the Union has not exercised its competence. The Member States shall again exercise their competence to the extent that the Union has decided to cease exercising its competence. ${ }^{1}$

\section{The EU institutions involved in the EU environmental governance}

With regard to environmental governance at the EU level, generally speaking, there are several important institutions that play substantive roles, including the European Parliament, the Council, the Commission, and the Court of Justice of the EU (the CJEU). Moreover, each institution shall not act exceeding the limits of its powers conferred by the Treaties and they shall cooperate with each other, aiming to ensure the EU policies and actions are effective and consistent. ${ }^{2}$

Firstly, according to the EU Treaties, the Council, the principal legislative and decision-making institution, shall act by a qualified majority voting (QMV) in the decision making procedure, in line with the different definition of 'qualified majority' provided for various transitional periods. ${ }^{3}$ It is noticeable that qualified majority voting has been applied as a general rule to replace unanimous voting in some domains. However, unanimity is still required for decisions on matters such as specific environmental issues as stipulated in Article 192(2) TFEU. ${ }^{4}$

Secondly, in terms of environmental law, the Council shares the legislative competence with the European Parliament. ${ }^{5}$ To be specific, according to Article 192 (1) TFEU, the standard procedure for environmental lawmaking is defined as the ordinary legislative procedure:

The European Parliament and the Council, acting in accordance with the ordinary legislative procedure and after consulting the Economic and Social Committee and the Committee of the Regions, shall decide what action is to be taken by the Union in order to achieve the objectives referred to in Article 191. ${ }^{6}$

As a result, the European Parliament, which is directly elected, has the power to influence the adoption and content of an environmental measure. ${ }^{7}$

Thirdly, the Commission plays a significant role as the 'driving force ${ }^{8}$ of EU policies. Meanwhile, it is noticeable that the Commission enjoys an exclusive right to propose secondary legislation. In this sense, the EU legislative act may only to be adopted based on a Commission proposal, unless otherwise specified by the Treaties. ${ }^{9}$ Moreover, the Commission also serves as the 'guardian of the Union law' ${ }^{10}$, overseeing and ensuring the application and implementation of EU legislation (primary or secondary) by Member States, under the control of the CJEU. ${ }^{11}$ In the

\footnotetext{
${ }^{1}$ Article 2(2), TFEU.

2 Article 13, TEU.

3 See Article 16, TEU; Article 238, TFEU. To be specific, the Protocol (no 36) on transitional provisions of the TFEU have stipulated the transitional provisions relating to the definition of the qualified majority which shall be applicable until 31 October 2014 and from 1 November 2014 to 31 March 2017, at Article 3.

${ }^{4}$ Borchardt, K.D. (2010), p.61.

5 Article 14 and 16, TEU.

${ }^{6}$ Article $192(1)$, TFEU.

7 Article 14, TEU; see also Jans, J. H. \& Vedder, H. H. B. (2011), p.59.

8 Borchardt, K.D. (2010), p.64.

9 Article 17(2), TEU.

${ }_{10}$ Borchardt, K.D. (2010), p.64.

11 Article 17(1), TEU.
} 
case of any violation of EU law, the Commission may institute infringement proceedings and, if necessary, refer the issue to the CJEU. ${ }^{1}$

Fourthly, the CJEU shall ensure that the law is observed when the Treaties are interpreted and applied, by means of the judicial work carried out at the three levels including the Court of Justice, the General Court and specialised courts. ${ }^{2}$ In particular, the Court of Justice, as the top instance of the EU legal order, plays an important part in clarifying the interpretation of the EU law, assessing the validity of the acts adopted by the EU institutions and the implementation measures by Member States or EU institutions. ${ }^{3}$ In the domain of environmental law, the Court of Justice established the foundations for its case law on the direct effect of the EU environmental law in 1963 by ruling that European law can confer rights on the individuals, which are capable of being enforced before the national courts. ${ }^{4}$

\section{The EU legislative instruments concerning environmental governance}

In order to regulate environmental issues, these EU institutions function through a multi-level legal system. ${ }^{5}$ According to Article 288 TFEU, the EU institutions, in particular the European Parliament and the Council shall adopt legislative instruments including regulations, directives, decisions, recommendations, and opinions to exercise the competences of the EU. ${ }^{6}$ With regard to the establishment of the EU environmental legal framework, specific attention should be paid to several important legislative instruments that can be used at the EU level.

Firstly, European environmental law can be adopted in the form of a regulation, which shall have binding effect in its entirety and can be applied directly across all Member States. ${ }^{7}$ In other words, a regulation adopted at the EU level that comes into force in line with Article 297 TFEU can be applied by the courts of each Member State without any further action by the Member States. $^{8}$

The second important legislative instrument is the directive, which is binding regarding the objective to be achieved upon each Member State to which it is addressed, but it leaves some degree of flexibility to the national authorities in choosing the form and methods for its implementation aiming to achieve the final result prescribed in the directive. ${ }^{9}$ In this sense, directives adopted by the European institutions need to be transposed into national legislation by the Member States, resulting in a two-stage legislative process. ${ }^{10}$ Different from the regulation, the directive is not directly applicable in all the Member States automatically, requiring each Member State to incorporate the directive into their national legal systems. ${ }^{11}$ In this respect, the

\footnotetext{
1 Article 258, TFEU.

2 Article 19, TEU.

3 Article 19, TEU, Article 258, 259, 263, 265, 267 of TFEU.

${ }^{4}$ See Jans, J. H. \& Vedder, H. H. B. (2011), p. 183-184.

5 Carlarne, C. P.(2010), p.150-152.

${ }^{6}$ Article 288, TFEU.

7 Article 288, TFEU.

${ }^{8}$ Fairhurst, J. (2010), p.63.

${ }^{9}$ Article 288, TFEU.

${ }_{10}$ Borchardt, K.D. (2010), p.90.

${ }^{11}$ Fairhurst, J. (2010), p.64.
} 
directive generally does not intend to confer rights or impose obligations on the individual, although provisions may be qualified as having direct effect allowing citizens and industries to rely on those provisions before the court. Instead of moving towards the unification of EU law, the directive, however, aims to facilitate the harmonisation of EU law by removing conflicts between the national laws and European regulations. ${ }^{1}$ In this sense, the directive has been considered as the most important legislative instrument at the EU level, since the directive may make a contribution to the reconciliation of the dual objectives of ensuring the necessary uniformity of EU law on the one hand and respecting the diversity of the national circumstances of each Member State on the other hand. ${ }^{2}$

The third legislative instrument is the decision, of which the effect is specific in its content and binding in its entirety only against the parties, including the individuals and companies, to whom it is addressed. ${ }^{3}$ Especially in the case of the implementation of EU law by the institutions themselves, the decision can be employed to require the individual or Member State to perform or to refrain from an action, or it can confer rights or influence the right and obligations of the individual or Member State. ${ }^{4}$

It is noticeable that all the legislative instruments mentioned above are legally binding and thus legally enforceable. ${ }^{5}$ In addition, some additional tools with no binding force, such as recommendations, opinions and guidelines have often been applied by the institutions to achieve the goals in the domain of environmental governance. ${ }^{6}$

\subsubsection{General principles in EU Environmental law}

In view of achieving the objectives of EU environmental law mentioned in Article 191(1) $\mathrm{TFEU}^{7}$, legal principles play a certain role. As an important source of law, legal principles fulfil three functions: (1) they guide the legislator in the law-making process; (2) they guide the interpretation of legislation by courts; and (3) they serve to test the legality of legislation and administrative decisions. ${ }^{8}$ In the domain of environmental protection, the three fundamental principles stipulated in Article $5 \mathrm{TEU}$, governing the definition and exercise of the competences of the $\mathrm{EU}^{9}$, together with the principle of equal treatment, have significant impact on the design and implementation of the European environmental law. ${ }^{10}$ In addition, Article 191(2) TFEU has set out some specific principles on which EU environmental policy should be based. ${ }^{11}$ However,

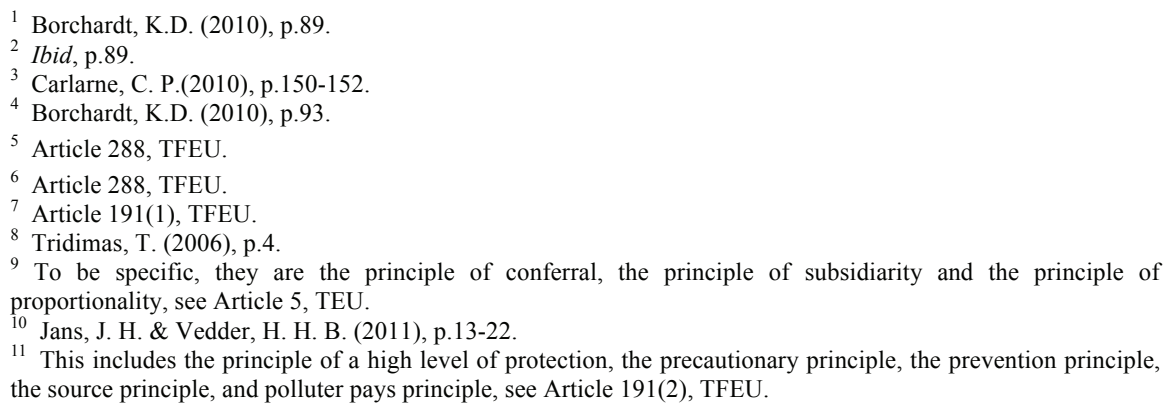


the legal principles are so abstract that they have to be translated into concrete obligations in secondary EU environmental legislation for the Member States. ${ }^{1}$

Especially in the case of the legal framework for the EU ETS, which is established mainly at the EU level, there is a need to understand, interpret and implement the relevant legislation in light of these general principles relating to EU environmental law. In this section, emphasis will be placed on some fundamental principles of EU law related to environmental protection as well as some specific principles of EU environmental law, mainly containing the subsidiarity principle, the principle of proportionality, the principle of equal treatment and the polluter pays principle.

\section{The principle of subsidiarity}

Aiming to determine the level of action in regard to the competence shared between the EU and Member States, the principle of subsidiarity is stated in Article 5(3) of TEU as follows:

Under the principle of subsidiarity, in areas which do not fall within its exclusive competence, the Union shall act only if and in so far as the objectives of the proposed action cannot be sufficiently achieved by the Member States, either at central level or at regional and local level, but can rather, by reason of the scale or effects of the proposed action, be better achieved at Union level. ${ }^{2}$

In other words, this principle contains both a negative criterion (not sufficiently achieved by the Member States) and a positive one (better achieved by the Union) by which to judge European acts and both criteria must be met for the measure to be justified. ${ }^{3}$

As a dynamic concept, subsidiarity should be applied in line with the objectives prescribed in the Treaty. ${ }^{4}$ With the aim to monitor the principle of subsidiarity, the Protocol on the application of the principles of subsidiarity and proportionality, first introduced by the Treaty of Amsterdam and strengthened by the Treaty of Lisbon, has laid down three guidelines to examine the justification of action at the European level, ${ }^{5}$ which results in several implications for European environmental law. Firstly, it is justified for the EU to take actions for transnational environmental problems that cannot be regulated by Member States satisfactorily. ${ }^{6}$ Secondly, attention should also be paid to the questions of whether the action taken by Member States alone without the European action would be contrary to the requirements of the treaties. ${ }^{7}$ Thirdly, another important element is whether action at the EU level would produce clear and better benefits compared to action at the national level. ${ }^{8}$

With regard to the EU ETS, the principle of subsidiarity is also reflected under consideration point 19 of the preamble of Directive 2004/101/EC, stating:

\footnotetext{
1 Jans, J. H. \& Vedder, H. H. B. (2011), p.41.

2 Article 5(3), TEU.

3 Jans, J. H. \& Vedder, H. H. B. (2011), p.14.

4 The Treaty of Amsterdam, Protocol on the application of the principles of subsidiarity and proportionality, p.105-106.

5 Ibid.

${ }^{6}$ Ibid, p.106. See also Lee, M.(2005), p.10; see also Jans, J. H. \& Vedder, H. H. B. (2011), p.15.

${ }^{7}$ The Treaty of Amsterdam, Protocol on the application of the principles of subsidiarity and proportionality, p 106 .

Ibid.
} 
Since the objective of the proposed action, namely the establishment of a link between the Kyoto project-based mechanisms and the Community scheme, cannot be sufficiently achieved by the Member States acting individually, and can therefore by reason of the scale and effects of this action be better achieved at Community level, the Community may adopt measures, in accordance with the principle of subsidiarity as set out in Article 5 of the Treaty. ${ }^{1}$

Although the principle of subsidiarity has provided some legal basis for designing and implementing the GHG ETS at the EU level, it has also resulted in some controversy about the extent of harmonisation. One may still raise the question of which precise level of harmonisation would ensure that the main objectives of an ETS are achieved while leaving as much freedom as possible to Member States to pursue their own regulatory choices ${ }^{2}$, which will be discussed in section 4 of this chapter.

\section{The principle of proportionality}

Based on the principle of proportionality laid down in Article 5 TEU, 'the content and form of Union action shall not exceed what is necessary to achieve the objectives of the Treaties'. ${ }^{3}$ In other words, the action of the EU should be kept to the minimum and be proportionate to the objective proposed to be achieved. ${ }^{4}$ Closely connected to the principle of subsidiarity discussed above, the criteria for the application of the principle of proportionality is also provided in the Protocol on the application of the principles of subsidiarity and proportionality mentioned above.

To be specific, with regard to the form of the European action, it shall be kept as simple as possible, consistent with the objective fulfilment of the measures and the need for effective enforcement. ${ }^{5}$ In an equal situation, the application of directives should be preferred above the use of regulations, and framework directives should be preferred to detailed measures. ${ }^{6}$ In terms of the nature and extent of the European action, the EU legislature should choose the necessary measures leaving freedom for Member States to the extent possible, respecting the national legal system. $^{7}$ In order to fulfil the objectives of the European measures, Member States should also be provided with alternative methods, in view of the need for proper enforcement. ${ }^{8}$

With regard to EU environmental law, compliance with the principle of proportionality can be demonstrated by the use of the directives for action, except for a few cases that indeed require the application of a regulation for a uniform regime. ${ }^{9}$ There is also an indication about the willingness of the Court to review the European environmental measures in the light of the principle of proportionality in the case law, but the Court will in general respect the 'wide discretion' available to the European institutions and will only question the legality of the EU

${ }^{1}$ Point 19 of the Preamble of Directive 2004/101/EC.

2 de Cendra de Larragán, J. (2008), p.58.

3 Article 5(4), TEU.

4 Jans, J. H. \& Vedder, H. H. B. (2011), p.17.

5 The Treaty of Amsterdam, Protocol on the application of the principles of subsidiarity and proportionality, p.106.

${ }^{6}$ Ibid.

${ }^{7}$ Ibid.

8 Ibid.

9 Jans, J. H. \& Vedder, H. H. B. (2011), p.18. 
measures that are 'manifestly inappropriate'. ${ }^{1}$ Next to this, the principle of proportionality needs to be respected by Member States when implementing a directive such as the EU ETS Directive. Regarding the enforcement of the EU ETS by a Member State, there is a remarkable difference between the opinion of Advocate General and the judgment of the Court of Justice concerning the Billerud Karlsborg AB and Billerud Skärblacka $A B$ v Naturvårdsverket case ${ }^{2}$, which will be discussed in section 4.3 of this chapter.

\section{The principle of equal treatment}

This principle, one of the fundamental general principles of EU law, is set out in Article 18 TFEU, stating that 'any discrimination on grounds of nationality shall be prohibited' in the scope of the application of the Treaties. ${ }^{3}$ According to this principle, comparable situations should not be treated differently and different situations should not be treated in the same way, unless such treatment is objectively justified. ${ }^{4}$ Moreover, this principle has become a powerful tool for the Commission to ensure a "level playing field" . However, the notion of objective justification is so abstract that more requirements or criteria are needed in practice. When the court wants to apply this principle to test the legality of the legislation at both the EU and national level, the criteria for comparing undertakings and deciding whether a differential treatment is objectively justified will be required ${ }^{6}$, which depends on the specific objectives and circumstances of the legislation. ${ }^{7}$

In the domain of the EU ETS, this principle has also played an important role particularly in the Arcelor case $^{8}$, which dealt with the limited scope of the EU ETS in accordance with the step-by-step approach, covering the steel industry but not the entire chemical and aluminium industries. According to the conclusion of the court, a difference in treatment is justified if it is based on an objective and reasonable criterion, that is, if the difference relates to a legally permitted aim sought by the legislation and it is proportionate to the aim pursued by the treatment. ${ }^{9}$ In other words, the GHG emitters in a comparable situation should be treated equally; moreover, differential treatment must be based on a valid and objective justification.

\section{The polluter pays principle}

This principle is one of the foundations of European environmental policy. According to a Communication from the Commission to the Council in 1975, this principle is defined as: 'natural or legal persons governed by public or private law who are responsible for pollution must pay the costs of such measures as are necessary to eliminate that pollution or to reduce it' ${ }^{10}$ In this sense, this principle is a matter of distributive justice ${ }^{11}$, which has relevance for the

1 Ibid, p. 19 .

2 Case C-203/12, Billerud Karlsborg AB and Billerud Skärblacka AB v. Naturvårdsverket.

3 Article 18, TFEU.

4 Jans, J. H. \& Vedder, H. H. B. (2011), p. 21.

5 de Cendra de Larragán, J. (2008), p.66.

${ }^{6} \mathrm{Ibid}, \mathrm{p} .62$.

${ }^{7}$ Ibid.

${ }^{8}$ Case T-16/04, Arcelor SA v. Parliament and Council [2010] ECR II-00211.

9 Ibid, at para. 168 .

${ }^{10}$ See the Communication from the Commission to the Council regarding cost allocation and action by public authorities on environmental matters, OJ 1975 L 194/1.

${ }^{11}$ de Cendra de Larragán, J. \& Peeters, M. (2010), p.202.; see also Calabresi, G., \& Melamed, A. D. (1972). 
design and implementation of an economic instrument, such as the allowances allocation of the ETS. Although the Communication mentioned above is not as such binding, the definition of this principle still plays a role as a guideline, requiring the EU to ensure the application of the polluter pays principle by adopting specific measures such as establishing environmental charges and creating an environmental liability system. ${ }^{1}$ Concerning the definition of the principle itself and the measures it has caused to be created, there are two aims behind them. On the one hand, the principle tries to ensure that the social costs generated by pollution are internalised by polluters, thereby adapting production to the socially optimal levels; on the other hand, it should also ensure that such internalisation is incurred by all firms within a market, in order to avoid distortions of competition stemming from different environmental regulations. ${ }^{2}$

However, these aims of the polluter pays principle are problematic issues per se, not only from an economic perspective but also from a legal perspective. From an economic perspective, the socially optimal level is generally set by the government, whose choice of a specific level will inevitably be rather arbitrary. ${ }^{3}$ From the regulatory perspective, the principle is at the core of the EU guidelines on state aid for environmental protection, which refer explicitly to tradable right schemes ${ }^{4}$, such as the EU ETS. It has been argued that grandfathering systems are liable to constitute state aid while PSR systems should not. ${ }^{5}$

In summary, the legal principles discussed above have different impacts on the shaping of European environmental law, including the design and implementation of the EU ETS. In line with the principle of subsidiarity and proportionality, two closely interconnected general principles of the EU law, the legal framework for the EU ETS is established mainly at the EU level by means of a directive. Moreover, the principles of equal treatment and polluter pays, two principles of European environmental law, influence the specific design of the key elements of the EU ETS, such as the choice of the allocation methods and the specific distribution decisions relating to the EU ETS.

\subsection{EU climate change law: targets and framework}

\subsubsection{The targets of EU climate change law: joint and individual}

The EU has been devoted to international efforts to tackle climate change and tried to set an example through robust policy making at home. The targets of EU climate change law consist of joint and individual targets of Member States. To be specific, there are two ways through which the EU has played an important role to reduce GHG emissions. One way is adherence to binding

\footnotetext{
1 Jans, J. H. \& Vedder, H. H. B. (2011), p.50.

2 See Jans, J. H. \& Vedder, H. H. B. (2011), p.50; See also de Cendra de Larragán, J. (2008), p.60.

${ }^{3}$ Risbey, S.J. (2006), p.527-536.

${ }^{4}$ Community guidelines on state aid for environmental protection, OJ C 82/1, 1.4.2008.

5 See Weishaar, S. (2008a), p.175. For instance, in a court case regarding the Dutch NOx ETS, the CFI ruled that the PSR system did not constitute state aid based on selectivity, see Case T-233/04 The Netherlands $v$. Commission [2008] ECR II-591, at para.84-100. The Commission brought an appeal against the judgment delivered by the CFI, the Court upheld the Commission, ruling that Member States should demonstrate the justification for the differential treatment between undertakings and the distinguishing criterion used in the NOx ETS is not sufficiently excluded from the classification of selective measures for state aid. See Case C-279/08 P Commission $v$ the Netherlands [2011] ECR I-7671, at para.74-49.
} 
international commitments, particularly commitments set in the Kyoto Protocol within the UNFCCC, while the other is the unilateral target within the EU legal order, which consists of a set of secondary legislation. In this respect, targets for the EU as a whole have been established together with targets for Member States individually.

\section{EU GHG emissions reduction targets at the international level}

At the international level, the EU has been a driving force in the international negotiations that led to the UNFCCC in 1992 and the Kyoto Protocol in 1997. As a whole, the European Community (EC, the predecessor of the EU), consisting of 15 Member States in 1997, thus also called the EU-15, committed to reducing GHG emissions to 8\% below 1990 levels collectively in the period 2008-2012. ${ }^{1}$ According to Article 4.6 of the Kyoto Protocol ${ }^{2}$, which was drafted to fit the specific situation of the $\mathrm{EC}^{3}$, the $\mathrm{EC}$ as a whole had to meet the target mentioned above jointly with its Member States. ${ }^{4}$ Thus, a so-called EU bubble was created, with a binding target for the EC and its Member States.

The EU-15 countries rearranged the Kyoto commitment of the EC through the burden sharing agreement, in which the $8 \%$ reduction target was redistributed based on the expectations of economic growth, the industrial structure and energy mix of each country. ${ }^{5}$ Hence those 15 Member States each had an individual target. Nevertheless, all these individual commitments were covered by the EC $8 \%$ commitment and amounted to a joint effort. ${ }^{6}$ Moreover, based on Article 10 TEC and Article 4 of the Kyoto Protocol, a collective responsibility on the part of Member States was established in order to ensure compliance with the EC's target. ${ }^{7}$ Member States were not only responsible for their individual targets, but they were also required to attempt to ensure the fulfilment of the EC target collectively. ${ }^{8}$ In the event of a failure to fulfil the collective target, each Member State was responsible for its own target and the EC was jointly responsible for not only the Member State's target but also for its own overall target. ${ }^{9}$ In other words, as long as the EC 8\% reduction target would be achieved, the EU bubble could provide flexibility for the compliance by the Member States, in which over-compliance and under-compliance of the Member States could be compensated. However, the flexibility allowed by the EU bubble could result in a risk whereby Member States could play the system in favour of their national interest, such as free-riding ${ }^{10}$.

\footnotetext{
1 Annex B, Kyoto Protocol.

2 To be specific, 'If Parties acting jointly do so in the framework of, and together with, a regional economic integration organization which is itself a Party to this Protocol, each member State of that regional economic integration organization individually, and together with the regional economic integration organization acting in accordance with Article 24, shall, in the event of failure to achieve the total combined level of emission reductions, be responsible for its level of emissions as notified in accordance with this Article.' See Article 4.6, Kyoto Protocol.

3 Depledge, J., (2000), p.135.

${ }^{4}$ De Cendra de Larragán, J. (2010b), p.234.

${ }^{5}$ Recital 12, Council Decision 2002/358/EC.

${ }^{6}$ See Council Decision 2002/358/EC.

7 Recital 10 of the Council Decision 2002/358/EC.

${ }^{8}$ See recital 10 of the Council Decision 2002/358/EC; see also de Cendra de Larragán, J. (2010b), p.332-339.

${ }^{9}$ See Article 4.6 of the Kyoto Protocol, recital 10 of the Council Decision 2002/358/EC; see also de Cendra de Larragán, J.(2010b) , p.258.

10 Jacquemont, F. (2005), p.372.
} 
According to the annual report of the GHG inventory of the EU provided by the European Environment Agency, the EU-15 emissions in 2012, without Land Use, Land-use Change and Forestry (LULUCF), stood at 15\% (643 million tonnes $\mathrm{CO}_{2}$ equivalents) below the 1990 level, demonstrating its over-achievement beyond the Kyoto target during 2008-2012 period. ${ }^{1}$

As the international negotiations on the second commitment period of the Kyoto Protocol is still on the discussion table, legally binding targets for GHG emissions reduction at the international level after 2012 have not entered into force yet. On 8 December 2012 an amendment to the Kyoto Protocol was adopted in Doha. ${ }^{2}$ According to the Doha amendment to the Kyoto Protocol, the EU pledged to reduce GHG emissions by $20 \%$ by 2020 compared to 1990 levels, and the EU reiterated its conditional offer to move towards a $30 \%$ reduction provided other countries make a comparable contribution. ${ }^{3}$ Moreover, this unilateral target pledged in the second commitment period under the Kyoto Protocol is also supposed to be achieved by the EU and its Member State jointly according to Article 4 of the Kyoto Protocol.

\section{GHG emissions reduction targets at the EU level}

In the mean, the EU has also made some unilateral commitments for GHG emissions reductions.

\section{$20 \%$ target by 2020}

In order to transform the EU into an energy-efficient and low carbon economy, in 2007 the EU Heads of State and Governments made a unilateral commitment and established a range of demanding climate and energy targets to be achieved by 2020, known as the '20-20-20' targets ${ }^{4}$. In pursuit of the reduction target of GHG emissions by $20 \%$ below 1990 levels by 2020 , the EU has established a specific reduction target of $14 \%$ compared to 2005 throughout the period of 2005 to 2020 , which has been delivered through a dual approach made up as to $21 \%$ by the EU ETS and $10 \%$ by the non-ETS sectors. ${ }^{5}$

\section{Moving towards a $30 \%$ target?}

In addition to the present ' $20-20-20$ ' target, the EU has been considering the option to increase its emissions reduction target up to $30 \%$ by $2020^{6}$, demonstrated by the conditional offer mentioned in the Doha amendment to the Kyoto Protocol ${ }^{7}$. Meanwhile, in the climate and energy policy framework for 2030, the Commission proposed that the EU should set itself a 40\% GHG emissions reduction target below 1990 levels by 2030. Moreover, the Roadmap for moving to a competitive low-carbon economy in 2050, a long-term policy plan, has suggested the EU should

\footnotetext{
${ }^{1}$ Annual European Union greenhouse gas inventory 1990-2012 and inventory report 2014 Submission to the UNFCCC Secretariat, Technical report No 09/2014, European Environment Agency, 27 May 2014, p.110.

${ }^{2}$ Doha amendment to the Kyoto Protocol, Doha, 8 December 2012, available at: https://treaties.un.org/doc /Treaties/2012/12/20121217\%2011-40\%20AM/CN.718.2012.pdf, last accessed 25 August 2014.

3 Article 1, Doha amendment to the Kyoto Protocol.

${ }^{4}$ To be specific, these targets contain: a reduction of GHG emissions in EU by at least $20 \%$ below 1990 levels; $20 \%$ of EU energy consumption from renewable resources; $20 \%$ reduction in primary energy use compared to projected levels, by energy efficiency improvement.

5 See COM (2008)30, p.6-7; see also Peeters, M. \& Stallworthy, M. (2012), p.17.

${ }^{6}$ See $\operatorname{COM}(2010) 265$ final.

${ }^{7}$ See Article 1, Doha amendment to the Kyoto Protocol; see also COM(2010) 265 final.
} 
reduce its GHG emissions by $80 \%$ below 1990 levels by 2050 and set up a cost-effective pathway to this goal - reductions in the order of $40 \%$ by 2030 and $60 \%$ by $2040 .{ }^{1}$

Although the challenge of reaching the $30 \%$ reduction target remains huge, the EU ETS Directive has provided corresponding provisions for the further commitment to reduction targets ${ }^{2}$. According to Article 28 of the EU ETS Directive, the Commission shall submit an assessment report within three months of the approval of an international agreement by the EU, which will lead to a mandatory cut of GHG emissions exceeding $20 \%$ compared to 1990 levels. ${ }^{3}$ Hence this would mean a stricter cap to the EU ETS. Based on the assessment report, the Commission shall submit a legislative proposal to the European Parliament and Council, possibly leading to an amendment to the EU ETS Directive. ${ }^{4}$

\subsubsection{Regulatory framework for $\mathbf{E} U$ climate change law}

\section{Mix of instruments}

In order to achieve the targets, the EU has gradually established a complicated framework of climate change policy and law. At the European level, EU governance in relation to climate change is carried out by two principal methods: the EU adopts some general policies and meanwhile the EU adopts a wide array of secondary legislation. ${ }^{5}$

The European Climate Change Programme (ECCP) has provided the foundation for the policy umbrella $^{6}$. The first ECCP was launched by the Commission in June 2000, with the goal to develop an EU strategy with all the necessary elements to implement the Kyoto Protocol. The first ECCP examined various instruments with a potential for reducing GHG emissions and the establishment of the EU ETS is one of the achievements. The second ECCP was launched in October 2005, exploring further cost-effective options for reducing GHG emissions.

In order to achieve the 20-20-20 targets, the Commission proposed a set of secondary legislation known as the 'climate and energy package', which was adopted by the European Council on 11 and 12 December $2008^{7}$, and was voted on by the European Parliament one week later. ${ }^{8}$ This package covers most of the important issues related to climate and energy, with, at the core, four pieces of complementary legislative documents. First of all, it focuses on the revision of the EU ETS Directive ${ }^{9}$, which is an important instrument for reducing GHG emissions cost-effectively. Secondly, the Effort Sharing Decision ${ }^{10}$ was adopted, regulating emissions from sectors not

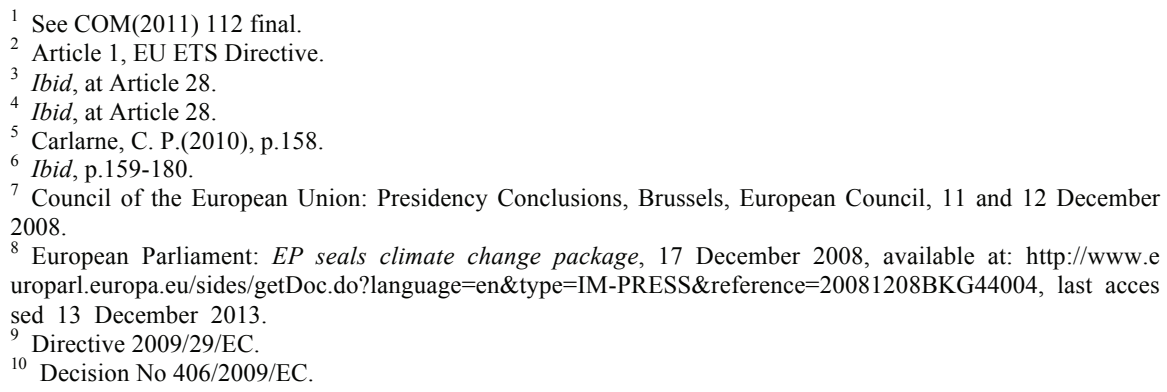

${ }^{10}$ Decision No 406/2009/EC. 
covered by the EU ETS. Thirdly, the binding national targets for renewable energy were set up, in order to increase the average renewable share across the EU to $20 \%$ by 2020 collectively $^{1}$. Fourthly, a legal framework for carbon capture and storage (CCS) was constructed ${ }^{2}$.

In addition, there is abundant secondary legislation and policies adopted by the EU to implement and achieve the specific targets, based on which a tremendous regulatory framework for addressing climate change is established gradually. There is an exhaustive list of legislation and measures relating to GHG emissions reductions, including but not limited to the EU ETS Directive $^{3}$, the Effort Sharing Decision ${ }^{4}$, the Industrial Emissions Directive ${ }^{5}$, the CCS Directive ${ }^{6}$, and the Renewable Energy Directive ${ }^{7}$. Reviewing the extensive legislation, it is not difficult to conclude that a mix of instruments has been applied by the EU in climate change law. In addition to the EU ETS mentioned above, a ban of specific substances, the promotion of energy saving and renewable energy, voluntary agreements, and other measures also contribute to the framework. ${ }^{8}$

Meanwhile, environmental protection including addressing climate change in the EU has been integrated into other EU policies to a certain degree in the domains of agriculture, transport and energy. ${ }^{9}$ This kind of integration has a clear external function that aims at integrating economic and social development with environmental protection ${ }^{10}$. In view of the vast and diverse legislative package that supports EU climate policy, however, it may give rise to the question as to whether the instrument mix may easily become an instrument mess or not ${ }^{11}$, implying that the problem of an unsystematic framework may also be created by the mix of instruments at the same time as a negative by-product.

\section{Two main approaches}

In line with the dual approach delivering the $20 \%$ reduction target, there are two main approaches playing an important role in reducing GHG emissions among the mix of instruments. One is the EU ETS, which operates in 31 countries $^{12}$ and covers GHG emissions including $\mathrm{CO}_{2}$, Nitrous oxide $\left(\mathrm{N}_{2} \mathrm{O}\right)$ and Perfluorocarbons (PFCs) from specific installations and sectors ${ }^{13}$. According to the Commission, the installations currently covered by the EU ETS account for almost half of the EU's $\mathrm{CO}_{2}$ emissions and approximately $45 \%$ of its total GHG emissions. ${ }^{14}$ Due to the amendment to the EU ETS Directive in 2009, a single EU-wide cap on emissions

\footnotetext{
${ }^{1}$ Directive 2009/28/EC.

2 Directive 2009/31/EC.

${ }^{3}$ Directive 2003/87/EC.

${ }^{4}$ Decision no 406/2009/EC.

5 Directive 2010/75/EU.

${ }^{6}$ Directive 2009/31/EC.

${ }^{7}$ Directive 2009/28/EC.

${ }^{8}$ Krämer, L. (2006), p.286-288.

9 See for discussion in Dhondt, N. (2003).

${ }_{10}$ Peeters, M. (2006c), p. 92-93.

11 Peeters, M. (2014); see also Sorrell, S., \& Sijm, J. (2013), p. 420-437.

1228 EU Member States plus Iceland, Liechtenstein and Norway.

13 Such as the $\mathrm{CO}_{2}$ from the power stations, combustion plants, oil refineries and iron and steel works, as well as factories making cement, glass, lime, bricks, ceramics, pulp, paper, and board.

${ }^{14}$ Information is available at the website of the Commission, available at: http://ec.europa.eu/clima/policie s/ets/index_en.htm, last accessed 28 August 2014.
} 
allowances will be applied from 2013, and the free allocation method will progressively be replaced by auctioning. In addition, some other substantive changes have occurred, which will be discussed in detail later.

The second approach is usually called the Effort Sharing Decision (ESD), which covers all the non-ETS sectors as a whole. In 2009, Decision No 406/2009/EC was adopted, establishing an annual binding GHG emission target for each Member State from 2013 to 2020. Moreover, the respective target for the Member States is determined based on their relative wealth (GDP/capita). As a result, each Member State will contribute to the joint effort, with national emission targets ranging from minus $20 \%$ for the richest Member States to plus $20 \%$ for poorer Member States in 2020 compared to 2005 levels. ${ }^{1}$ Meanwhile, flexibility is allowed for Member States in meeting their targets with the ESD. For example, part of the allocated emissions allowance can be transferred to other Member States under some conditions ${ }^{2}$, and overachievement of the Member States can be carried over to subsequent years within that period $^{3}$.

\subsection{EU ETS: cornerstone of EU climate change law}

According to the Commission, the EU ETS is a cornerstone of EU climate change law and policy ${ }^{4}$. As one of the main approaches to reducing GHG emissions effectively, the EU ETS has played a vital role in the climate change framework and has helped the EU achieve the 8\% commitment set out in the Kyoto Protocol. In this part, attention will be given to the development of the EU ETS per se, in order to gain a general understanding of this cornerstone by presenting its status quo and trajectory.

\subsubsection{Emergence and preparation: adoption of Directive 2003/87/EC}

Before the Kyoto Protocol was signed in 1997, hardly any real attention had been paid to the ETS at both the European level and the national level. ${ }^{5}$ The focus of climate protection in the EU was on taxes and other forms of public charge. ${ }^{6}$ The Commission proposed an EU-wide carbon energy tax in $1992^{7}$, but it was finally withdrawn in 1997. The failure of the EU-wide carbon energy taxation proposal is not only because of the lack of a unanimous approval according to EU law but also the strong opposition and inability of Member States to agree on issues of taxation or fiscal regulation concerning energy products. ${ }^{8}$

\footnotetext{
1 Ibid.

2 Articles 3.4 and 3.5, Decision No 406/2009/EC.

3 Ibid, Article 3.2 .

${ }^{4}$ The introduction on the website of the Commission, available at: http://ec.europa.eu/clima/policies/ets/ind ex en.htm, last accessed 10 November 2014.

5 See Peeters, M. (1992), p.117.

${ }^{6}$ Hansjürgens, B. (2005), p.6.

${ }^{7}$ See COM (92) 226 final.

${ }^{8}$ Massai, L. (2011), p.77.
} 
When the Kyoto Protocol was signed, the Commission finally embraced the idea of the ETS, as Psalmist puts it: 'the stone which the builders rejected had become the cornerstone.' In July 2003, Directive 2003/87/EC was adopted and came into effect on 13 October 2003. Moreover, Directive 2003/87/EC was amended in 2004 by the 'Linking Directive', allowing the use of a limited amount of emissions credits from the Kyoto Protocol's project mechanisms. ${ }^{2}$

In the development of the EU ETS, three trading periods are distinguished: the first period (January 2005 - December 2007), the second period (January 2008 - December 2012) and the third period (January 2013 onwards).

\subsubsection{The first period (2005-2007): learning by doing}

It is noticeable that the first trading period of the EU ETS has served as a learning-by-doing period. A lot of work and associated development of the technology and skills across the Member States as well as the European institutions were needed to ensure a well-functioning EU ETS before the first Kyoto commitment period is started. In this respect, the court, in the ruling on the Arcelor case, also recognised the rationality of the step-by-step approach adopted by the European legislature in the establishment of the EU ETS, in particular the gradual enlargement of its scope. ${ }^{3}$

During this learning-by-doing period, the design and implementation of the EU ETS has been governed mainly by Directive 2003/87/EC together with other provisions, such as the monitoring and reporting guidelines ${ }^{4}$. To a certain degree, the legal framework established for the EU ETS in the first period has succeeded in establishing the basic rules and necessary infrastructure for the cap setting, allowance allocation, allowance transaction, MRV system, and sanctions. For instance, based on Directive 2003/87/EC, each Member State was required to develop a NAP in order to determine the total amount of GHG emissions that can be emitted by all the ETS installations in their country as well as the specific number of allowances allocated to each individual installation ${ }^{5}$. However, legal conflicts regarding the NAP between the Commission and Member States occurred, which continued in the second period. A further analysis will be presented in section 4.1 of this chapter.

\subsubsection{The second period (2008-2012): developing and improving}

The second period of the EU ETS overlaps with the Kyoto commitment period. The EU together with the Member States has tried to make some improvements to the implementation of the EU ETS, in order to keep consistently moving towards the Kyoto goals.

\footnotetext{
${ }^{1}$ See Convery, F. J. (2009), p.393. Moreover, the EU institutions subsequently adopted a series of policies concerning the establishment of emissions trading, such as the Green Paper on EU ETS (March 2000), the first ECCP (June 2000) and other supporting documents.

${ }^{2}$ Directive 2004/101/EC.

3 Case T-16/04, Arcelor SA v. Parliament and Council [2010] ECR II-211, at para. 168.

${ }^{4}$ Commission Decision 2007/589/EC.

5 Article 9(1), Directive 2003/87/EC.
} 
The second trading period has witnessed several changes in the EU ETS, including the enlargement of the scope and coverage of the EU ETS. Meanwhile, compared to the first trading period, the percentage of allowances for free allocation decreased from $95 \%$ to $90 \%{ }^{1}$ and the fine for the excessive emissions was increased from 40 EUR to 100 EUR per tonne ${ }^{2}$. Another important development of the EU ETS is the inclusion of the aviation activities in 2012 by Directive 2008/101/EC. Despite the fact that this directive came into effect on the insistence of the EU, this step is so controversial that it has been opposed by many airline companies and countries outside the EU, which can be exemplified by the Air Transport Association of America and Others $v$ Secretary of State for Energy and Climate Change case, in which the court upheld the validity of Directive 2008/101/EC. ${ }^{3}$ Nevertheless, the Commission made a proposal to limit its application to flights into and out of Europe during 2012, which was subsequently approved by the European Parliament and the Council. ${ }^{4}$

\subsubsection{The third period (2013-2020): changing radically and moving forward}

From January 2013, Directive 2009/29/EC provided a radical change in the EU ETS, inter alia for stationary installations.

According to the EU ETS Directive, revised by Directive 2009/29/EC, a single EU-wide cap replaces the NAPs, meaning that, in this new system, conflicts on national caps can no longer happen. The cap will be decreased annually in a linear way by $1.74 \%$. Moreover, the grandfathering allocation method will gradually be replaced by auctioning, thus an Auctioning Regulation $^{5}$ was adopted in 2010. In addition, there are EU-wide harmonised allocation rules, including full auctioning to power sectors, and partially free allocation to industries based on EU-wide harmonised benchmarks ${ }^{6}$.

Meanwhile, remarkable changes concerning the legal framework for the EU ETS can be found in the harmonised approach employed in the MRV system, in which the guidelines for the monitoring and reporting of GHG adopted in 2007 (MRG 2007) ${ }^{7}$ were replaced by two respective regulations: the Monitoring and Reporting Regulation (MRR) ${ }^{8}$ and the Accreditation and Verification Regulation(AVR $)^{9}$. Moreover, the first case law concerning the enforcement of the EU ETS, the Billerud Karlsborg AB and Billerud Skärblacka AB v Naturvarrdsverket case, ${ }^{10}$ took place in this period and was decided by the CJEU on 17 October 2013. With regard to the questions of whether it is possible for the Member States to waive or reduce the fine for the

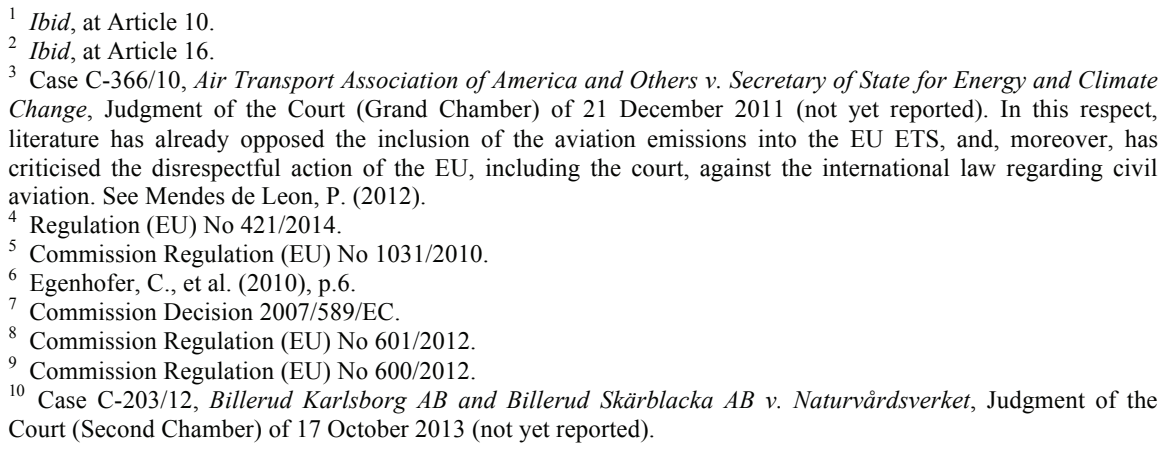


excessive emissions set up in the EU ETS Directive in light of the principle of proportionality, the Court chose a strict enforcement approach in the ruling that forbid the variation of the fine in the national implementation ${ }^{1}$, while the Advocate General preferred a different approach taking account of the proportionality ${ }^{2}$.

In addition, there is an ongoing discussion about the structural reform of the EU ETS in view of price management. In order to deal with the depressed EUA price mainly caused by the growing surplus of allowances, and partly caused by the economic crisis that has depressed emissions more than anticipated, the auctioning of 900 million allowances from the years 2013-2015 have been postponed until 2019-2020. ${ }^{3}$ Meanwhile, other options have been considered by the Commission. ${ }^{4}$ Particularly, a market stability reserve for the next trading period from 2021 has been proposed by the Commission. This mechanism would allow the adjustment of the supply of allowances to be auctioned in line with pre-defined rules. ${ }^{5}$

It is noticeable that the EU ETS has been designed and implemented with an experimental approach, in which the 'learning by doing' still lies at the heart of the EU ETS, even after the adoption of the major revision in $2009 .{ }^{6}$ Although at this moment it is hard to predict the future of the EU ETS, the review of the development of the EU ETS, at least, has implied a process of learning and improving in line with the changing practice. In the following sections, the design features and implementation concerning three key elements of the EU ETS, in particular related legal problems, will be described and discussed in depth, after which an analysis will follow in section 4.

\section{The regulatory framework for the EU ETS}

\subsection{Cap setting for the EU ETS}

Target setting is the first key element of the legal framework. Ever since its establishment, the specific reduction target of GHG emissions for the EU ETS is set in the form of a cap. In the EU ETS, the cap means the total amount of allowances to be issued, which is equal to the authorised quantity of emissions. With the amendment of the EU ETS Directive in 2009, the way to set a cap has been changed significantly, compared to the first and second trading periods. In this section, two models concerning cap setting as being used in the EU ETS will be explored. One can be defined as a decentralised approach for cap setting in the period from 2005 to 2012, in which the caps were set through the Member States' NAPs assessed by the Commission. The other is a centralised approach in the form of an EU-wide cap, which is applied from 2013 onwards.

\footnotetext{
${ }^{1}$ Ibid.

2 Case C-203/12, Opinion of Advocate General Mengozzi delivered on 16 May 2013 (not yet reported), at para. 43.

3 See Decision No 1359/2013/EU; see also Commission Regulation EU No 176/2014.

${ }^{4}$ See $\operatorname{COM}(2012) 652$ final.

5 See $\operatorname{COM}(2014) 20 / 1$.

${ }^{6}$ Peeters, M., \& Weishaar, S. (2009).
} 


\subsubsection{The original design before the establishment of the EU ETS}

Before the discussion on the two models, the argument as to how to distribute the competence of setting the cap for the EU ETS between the EU and Member States can be traced back to its initial legislative history. In the Green Paper on GHG emissions trading within the EU, which was presented by the Commission in 2000, the Commission argued for a mandatory cap-and-trade system with the cap determined at the EU level or a high degree of harmonisation. ${ }^{1}$

Based on the response of the following consultation with the stakeholders by the Green Paper, the Commission proposed the EU ETS Directive in 2001. Within the EU bubble of the Kyoto target, each Member State has its own national target stipulated in the EU burden-sharing agreement. Given the difference between Member States' obligations under the EU burden sharing agreement and between their progresses towards meeting those commitments, the Commission considered that a wide degree of discretion as regards total allowance allocation within a Member State should be left to Member States ${ }^{2}$. Compared to the Green Paper, the cap setting was proposed as a decentralised approach, in which the total amount of allowances would be essentially left up to the Member States. ${ }^{3}$ This proposed approach was criticised strongly by the European Parliament and the environmental NGOs, who preferred more certainty of environmental protection result of the EU ETS. ${ }^{4}$ However, in view of the limited time for the EU to establish and implement the EU ETS before the beginning of the first commitment period of the Kyoto Protocol, the European Parliament supported the proposal with some small amendments to the criteria that Member States had to consider when developing the NAPs (Annex III). ${ }^{5}$ As a political comprise, the EU ETS Directive with the decentralised approach on cap setting was adopted in 2003 .

\subsubsection{Model one: decentralised approach from 2005 to 2012}

\section{Setting the cap through the NAP}

During the first two trading periods (2005-2012), the cap setting for the EU ETS was a rather decentralised model, which placed some decisions at the EU level while leaving considerable discretion for the Member States. ${ }^{6}$ Although the 15 Member States of the EU-15 had individual targets from 2008 to 2012 set by the Burden Sharing Decision in line with the Kyoto target ${ }^{7}$, Directive 2003/87/EC itself did not set a cap of total emissions for the EU ETS ${ }^{8}$. In the first two trading periods, Member States have the authority and discretion to set up the national caps for their ETS sectors, the sum of which can constitute the overall effort of the EU ETS.

\footnotetext{
${ }^{1}$ See COM (2000) 87 final; see also Skjærseth, J. B. (2010), p.299.

2 Meadows, D. (2006), p.75.

3 See COM (2001) 581 final, p.11.

${ }^{4}$ De Sépibus, J. (2007), p.4.

${ }^{5}$ Lefevere, J. (2005), p. 103-128.

${ }^{6}$ van Zeben, J. A. W. (2009a), p.340.

${ }^{7}$ Council Decision 2002/358/EC.

${ }^{8}$ De Sépibus, J. (2007), p.3.
} 
In this decentralised approach, the cap of the EU ETS is set through the NAPs, the content and procedure of which are governed by Articles 9 to 11 of Directive 2003/87/EC in conjunction with Annex III. To be specific, the NAP addresses the national emissions target by two steps. First, it distributes the country's overall responsibility to reduce GHG emissions between the trading and non-trading sectors; second, it specifies how the allowances will be allocated among individual installations in the trading sector. ${ }^{1}$ Moreover, the NAP shall be based on objective and transparent criteria as well as those listed in Annex III to Directive 2003/87/EC, which can be seen as the connection between setting the cap and allocating the allowance within the cap. ${ }^{2}$ Explanations of the meaning of the individual criterion are given in the Commission's guidance ${ }^{3}$ and some criteria, such as criterion 1, 2, 3, 4 and 12 have addressed the questions of which conditions should be met in the course of setting a national cap by Member States. ${ }^{4}$

Concerning the procedure for developing the NAP, each Member State shall develop, publish and submit the NAP to the Commission. ${ }^{5}$ The NAP shall be published and notified to the Commission and other Member States in the due time set up in the EU ETS Directive ${ }^{6}$. The NAP shall be considered within a special Committee ${ }^{7}$, which is composed of representatives of Member States who give opinions on the content of the NAP and highlight issues for the Commission to consider in its assessment ${ }^{8}$. However, the decision on the NAP is to be taken by the Commission alone, without the involvement of this Committee, which is not the same as what the Committee generally does in approving decision by comitology. ${ }^{9}$ By assessing the NAP, the Commission may reject that plan, or any aspect thereof, based on its incompatibility with the criteria listed in Annex III or with Article $10^{10}$. If the Commission makes up the decision to reject a NAP wholly or partly, reasons shall be given by the Commission ${ }^{11}$. The Member State concerned shall propose amendments to the Commission and take a decision about the NAP until the Commission accepts the amendments. ${ }^{12}$

Meanwhile, the NAP determination should be evaluated in the light of the reduction target for that period. There was no legally binding target for the EU or its Member States in the first trading period, while the legal target for the EU under the Kyoto Protocol and the respective targets for Member States in the Burden Sharing Decision ${ }^{13}$ must be complied with from 2008 to 2012. Therefore, the two periods in the decentralised approach need to be examined separately.

\footnotetext{
${ }^{1}$ Kruger, J., Oates, W. E., \& Pizer, W. A. (2007), p.115-116.

2 Van Asselt, H. (2009), p.89.

3 See COM(2003)0830 final; see also COM (2005) 703 final.

${ }^{4}$ De Sépibus, J. (2007), p.5.

5 Meadows, D. (2006), p.79.

${ }^{6}$ Article 9(1), Directive 2003/87/EC.

7 Ibid, at Article 9(2).

${ }^{8}$ Zapfel, P. (2007), p. 23.

9 Meadows, D. (2006), p.80.

${ }^{10}$ Article 9(3), Directive 2003/87/EC.

${ }^{11}$ Ibid.

12 Ibid.

${ }^{13}$ Council Decision 2002/358/EC.
} 


\section{Period I: path to meet the Kyoto Protocol target}

In the first trading period of the EU ETS (2005-2007), most Member States decided on the national caps based on the business-as-usual projection of the $\mathrm{CO}_{2}$ emissions. ${ }^{1}$ The virtual cap of the EU ETS (meaning the sum of all national caps) in this period seemed quite lenient and hence was widely criticised as 'over-allocation', meaning that emissions are lower than the virtual EU cap. $^{2}$ The emissions data for the year 2005 showed that the virtual cap of the EU ETS was likely to exceed the emissions in Period I, although the Commission had rejected a lot of NAPs. ${ }^{3}$ According to the data published by the EU, in Period I there were 6,095,607,894 tonnes of $\mathrm{CO}_{2}$ emissions, while the total virtual cap of the EU ETS reached 6,455,778,519 tonnes of $\mathrm{CO}_{2}{ }^{4}$. In other words, the EU ETS had allocated about $5.6 \%$ more allowances than needed to cover emissions. ${ }^{5}$

The question of whether it really constitutes an over-allocation problem or not and the reasons for this phenomenon have been discussed a lot from the economic perspective. It is often argued that the reason for the apparent surplus of allowances is that the national authorities were too generous to their industries to avoid a competitive disadvantage ${ }^{6}$. However, there are also indications that the EU ETS actually makes a contribution to the emissions reductions and to low-carbon economy development. ${ }^{7}$ Taking account that the Kyoto commitment period (2008-2012) was not yet applicable during the first trading period of the EU ETS, Member States were not yet bound to an international emission reduction obligation ${ }^{8}$. Hence the 'over-allocation' cannot be considered as a problem constituting a breach of a legal obligation.

However, in the eye of the Commission, it was necessary when reviewing the NAPs to avoid the 'over-allocation' that would cause a price collapse of the EU ETS. ${ }^{9}$ The Commission's assessment of the NAPs mainly depended on projections of total GHG emissions that Member States have reported regularly. ${ }^{10}$ Nevertheless, the Commission required a reduction of the total cap for more than half of the NAPs in its rejecting decisions, which resulted in about 290 million fewer allowances than intended in those NAPs ${ }^{11}$. The reasons that the Commission justified its amendment of the NAPs mainly relied on criterion 1 and 2 in Annex III of Directive 2003/87/EC, arguing that the NAPs concerned is inconsistent with the path to achieve the Kyoto target and have an intended excessive allocation. ${ }^{12}$ In the 14 NAPs for which the Commission proposed a tightening, only regarding France, Poland and the United Kingdom (UK), a decision was adopted

\footnotetext{
${ }^{1}$ Ellerman, A. D., Buchner, B. K. \& Carraro, C. (2007), p.347.

2 McAllister, L. K. (2009), p.411.

3 Ellerman, A. D., \& Buchner, B. K. (2007), p.78.

${ }^{4}$ Press Release, European Union Emissions Trading System, Emissions Trading: 2007 Verified Emission s From EU ETS Businesses, IP/08/787 (May 23, 2008), available at: http://europa.eu/rapid/pressRelease sAction.do? reference=IP/08/787. Last accessed 2 August 2013.

5 McAllister, L. K. (2009), p.409.

${ }^{6}$ Kuik, O., \& Oosterhuis, F. (2008), p.217.

${ }^{7}$ Ibid, p.221.

${ }^{8}$ Peeters, M. (2008), p.16.

${ }^{9}$ Sépibus, J. D. (2007), p.10

10 Ibid.

11 Zapfel, P. (2007), p.25; see also De Sépibus, J. (2007), p.10.

${ }^{12}$ See the explanation of the Commission on its website, available at: http://ec.europa.eu/clima/policies/et s/pre2013/nap/index, see also the decisions on the NAPs in the first period, available at http://ec.europa. eu/clima/policies/ets/pre2013/nap/documentation_en.htm, last accessed 4 December 2014.
} 
by the Commission rejecting part of the intended total cap. ${ }^{1}$ The rest of the submitted plans were formally amended by Member States based on bilateral contact with the Commission. ${ }^{2}$

Nevertheless, the dispute between Member States and the Commission, which wanted to prevent such an 'over-allocation' problem by assessing and rejecting the NAPs of the first period, has been brought before the EU courts. The decisions about setting the national caps were left to the discretion of the Member States, to be reviewed by the Commission, which could be followed by a procedure at the Court of First Instance (CFI, now the General Court), to be followed by an appeal at the European Court of Justice (ECJ, now the CJEU). In this respect, some Member States, such as Germany and the UK have challenged the Commission's decisions on their NAPs before the court and they won their cases. ${ }^{3}$

\section{Period II: under the Kyoto Protocol target}

In the second period of the EU ETS (2008-2012), the EU and its Member States are obliged to achieve the Kyoto target as well as the burden sharing target for the EU-15. As a Member State's ETS emissions are counted as part of the target for total national emissions under the Kyoto Protocol, the cap setting of the EU ETS in the second period must be developed in line with the Kyoto target. However, the emissions reduction target under the Kyoto Protocol and the circumstances of the Member States are different. Moreover, the 12 new Member States are transition economies classified as Annex I countries under the Kyoto Protocol with significantly lower emissions than their levels in 1990, and as a result such so-called 'hot air" has been included in the EU targets ${ }^{5}$.

In this period, the Commission made some further efforts to tighten the cap set by Member States through the determination of the NAP in order to ensure the achievement of the targets under the Kyoto Protocol. For instance, the Commission published a second communication concerning the $\mathrm{NAP}^{6}$, distinguishing Member States into two groups: the first group had a gap to close to achieve their Kyoto targets and the second group had no problem concerning compliance. ${ }^{7}$ Moreover, the Commission recommended that the Member States of the first group seek for a balanced mix of lowering the national cap in period II.

Furthermore in a third guidance concerning the NAP, according to the Commission, it applied explicitly 'objective' projections based on 2005 verified emissions across the EU for all the $\mathrm{NAPs}^{8}$, which was supposed to cut $10 \%$ of Member State's proposal allocations and to leave the

\footnotetext{
${ }^{1}$ Zapfel, P. (2007), p.28.

2 De Sépibus, J. (2007), p.11.

${ }^{3}$ Case T-374/04, Germany v. Commission, action brought on 20 September 2004, OJ C 284, 20.11.2004, p. 25. Judgment of the Court of First Instance (Third Chamber, extended composition) of 7 November 2007, European Court reports 2007 Page II-04431; case T-143/05, UK v. Commission, action brought on 11 April 2005, OJ C 115, 14.05.2005, p. 39.

4 The term 'hot air' refers to the positive difference between the Kyoto target and the actual emissions of a country, further discussion about the potential consequence of hot air for the EU burden sharing can be seen in Michaelowa, A., \& Betz, R. (2001).

${ }^{5}$ de Cendra de Larragán, J. (2010b), p.237.

${ }^{6}$ See COM (2005) 703 final.

${ }^{7}$ De Sépibus, J. (2007), p.14.

${ }^{8}$ See COM (2006) 725; See also in Egenhofer, C., et al (2010), p.5.
} 
ETS sector short of $5 \%$ for the second period. ${ }^{1}$ In this respect, the formula applied by the Commission in assessing the NAPs of Member States, which is argued to impose thereby de facto an EU-wide cap for the EU ETS, seems to have made a contribution to the avoidance of the so-called 'over-allocation' in the second trading period. ${ }^{2}$ In addition, the Commission restated that the assessment of the NAP would focus on its consistency with the Member State's Kyoto target, in order to ensure sufficient scarcity in the ETS. ${ }^{3}$

In practice, the Commission rejected a lot of initial NAPs after the assessment. In the first batch of NAPs submitted by ten Member States, only the NAP of the UK was accepted while all the other NAPs were rejected by the Commission in its decisions of 29 November $2006 .{ }^{4}$ Moreover, the Commission 'cut' certain national caps significantly in its decisions. ${ }^{5}$ The Commission required these Member States to reduce the national caps in the forms of absolute terms and relative terms, such as the largest reduction in absolute emissions was asked of Germany, amounting to $6 \%$ of the intended cap, while the largest cut in relative terms was required of Latvia - almost $56 \%$ compared to the proposed cap. ${ }^{6}$ After finishing all the assessments, the Commission only accepted the proposed national caps without modification for Denmark, France, Slovenia, and the $\mathrm{UK}^{7}$ In total, the caps proposed by Member States for the second trading period amounted to 2,320 million allowances, which would have allocated almost 200 million allowances more than the total amount of ETS verified emissions in 2005 (2,122 million), while the final caps accepted by the Commission was 2,080 million allowances with a cut of 240 million. ${ }^{8}$ In other words, the total cap for the Period II of the EU ETS was set about $13 \%$ lower on an annual average basis than the cap of Period I and 6\% lower than comparable 2005 emissions. ${ }^{9}$

Furthermore, most of the Member States which were required to reduce their national caps substantially were the new Member States ${ }^{10}$, as their caps were considered to have exceeded the verified emissions of 2005 by the Commission. A lot of Member States from Eastern Europe have challenged the Commission's decisions in the ECJ, leading to numerous cases concerning the NAPs that will be discussed in section 4.1 of this chapter.

\footnotetext{
${ }^{1}$ Egenhofer, C., et al (2010), p.6.

2 Ibid.

3 See COM (2006) 725; see also Netherlands Environmental Assessment Agency (2008), p.39.

${ }^{4}$ The nine Member States concerned were Germany, Greece, Ireland, Latvia, Lithuania, Luxembourg, M alta, Slovakia, and Sweden. The decisions are available at http://ec.europa.eu/clima/policies/ets/pre2013/na p/documentation_en.htm, last accessed 8 December 2014 .

${ }^{5}$ De Sépibus, J. (2007), p.18.

${ }^{6}$ Convery, F. J. \& Redmond, L. (2007), p.94.

${ }^{7}$ Netherlands Environmental Assessment Agency (2008), p.39.

${ }^{8}$ Clò, S. (2011), p.82.

9 Ellerman, A. D. \& Joskow, P.L. (2008), p.32.

${ }^{10}$ See, for instance the cuts of the caps for the Czech Republic (14.8\%), Estonia (48.8\%), Hungary (12.4\%), and Poland $(26.7 \%)$.
} 


\subsubsection{Model two: harmonised approach from 2013 onwards}

\section{Shift from the decentralisation towards centralisation?}

According to the Commission, the decentralised approach in the first two trading periods of the EU ETS has allowed a large degree of flexibility for Member States to take account of specific national circumstances, but it also entailed some problems including complexity and lack of a level playing field and transparency. ${ }^{1}$ Firstly, the Commission argued that the cap setting rules in the first two trading periods created a 'prisoner's dilemma' where each individual Member State has an incentive to maximise its national cap, although they have recognised the collective interest to set stringent caps for emissions reduction in the EU. ${ }^{2}$ In other words, although the Commission had assessed the NAPs with the criteria in Annex III, from the standpoint of the Commission, the NAP system did not provide sufficient guarantees for the achievement of emissions reduction $\operatorname{targets}^{3}$. Secondly, the Commission also explained that this decentralised decision-making approach by Member States implied an incentive for Member States to favour their 'own' industries ${ }^{4}$. Due to the different levels of the stringency of the national caps, not only the ETS sectors and non-ETS sectors, but also the international competing industries located in different Member States, would be treated differently, resulting in the lack of level playing field within the EU ETS. Thirdly, the decentralised decision-making structure would have a negative impact on the market operation because of the lack of certainty and predictability. As the NAPs were decided by Member States and approved by the Commission respectively, it is a long-lasting and cumbersome process giving rise to prolonged uncertainty. ${ }^{5}$ As a result, the long-term investment related to the abatement and low-carbon economy would be restrained. Moreover, severe price volatility of the allowances would occur because of the uncertainty about the actual stringency of national caps. ${ }^{6}$ For instance, it was reported that the allowance price dropped largely since the German proposed NAP submitted to the Commission at the end of March 2004 was larger than expected. ${ }^{7}$

Furthermore, the Commission was frequently brought before the court by Member States who challenged its decisions concerning the NAPs and it lost almost all the cases in the first two periods. Based on the lessons from the first two periods of the EU ETS, a more centralised and harmonised approach for the cap setting was proposed by the Commission in the amendment to the EU ETS Directive in 2008. Meanwhile, in the legislative process of revising the EU ETS Directive, neither the determination nor the stringency of the EU-wide cap was seriously contested. It is explained that the decentralised model led to a 'sense of collective ownership' among Member States and industries who realised that a centralised model was necessary for the achievement of the more ambitious climate targets. ${ }^{8}$

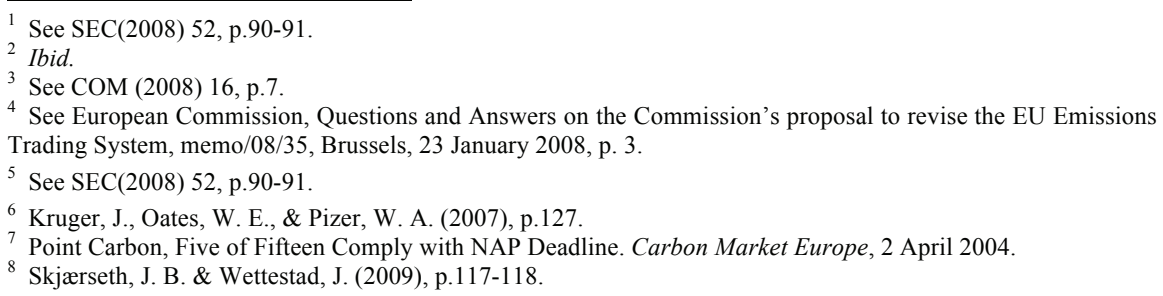


As a result, with the aims to solve the problems embedded in the decentralised decision-making approach, an EU-wide cap determined in a centralised approach based on Directive 2009/29/EC has been applied in the third trading period and beyond.

\section{Cap setting in the third period}

In contrast to the cap of the EU ETS in the first and second trading periods, which was composed by the individual caps as set out in the NAPs by Member States, the cap for the third trading period is now defined centrally by the EU. ${ }^{1}$ According to the EU ETS Directive revised by Directive 2009/29/EC, an EU-wide cap has been established annually to determine the total amount of allowances that can be issued for all the sectors covered by the EU ETS since the beginning of 2013. ${ }^{2}$ Meanwhile, Article 9 and 9 a of the EU ETS Directive has provided for the methods and requirements as to how to determine and adjust the EU-wide cap by the Commission for the EU ETS.

In pursuit of the achievement of the $21 \%$ emissions reduction target compared to 2005 for the ETS sectors by 2020, the EU-wide cap will be decreased by 1.74\% linearly each year from 2013 to 2020 and beyond. ${ }^{3}$ Firstly, the length of the third period is increased to eight years, which is geared towards meeting the EU emissions reduction targets by 2020 and is supposed to enhance the predictability and stability of the cap of the EU ETS. ${ }^{4}$ Secondly, the starting point for the cap setting should be calculated by the Commission based on the total quantities of allowances issued or to be issued by the Member States according to the Commission's decisions on their NAPs for the second period from 2008 to $2012 .^{5}$ The change of the NAPs will hence have an influence on the EU-wide cap. Thirdly, the EU-wide cap determined by the Commission shall decrease by a linear factor of $1.74 \%$ compared to the average annual cap of the second period. ${ }^{6}$ It is worth pointing out that the Commission shall review the linear factor and submit a proposal to the European Parliament and to the Council as from 2020 where appropriate, in order to adopt a decision by $2025 .^{7}$

In addition, based on the total amount of allowances issued or to be issued in the EU ETS for the second trading period, the Commission shall adopt a decision about the EU-wide cap for the EU ETS each year and it is also obliged to publish the cap for 2013 by 30 June $2010 .^{8}$ In practice, the Commission adopted Decision 2010/384/EU on 9 July 2010, which determined that the absolute EU-wide quantity of allowances to be issued under the EU ETS for 2013 amounted to $1,926,876,368 .{ }^{9}$ In contrast to the cap of the EU ETS in the first two periods, where the overall cap would not be known until all the NAPs were accepted by the Commission, this new EU-wide

\footnotetext{
${ }^{1}$ Enzmann, J. \& Marr, S. (2008), p.162.

2 Article 9, EU ETS Directive.

3 Ibid.

${ }^{4}$ Van Asselt, H. (2009), p.60.

5 Article 9, EU ETS Directive.

${ }^{6}$ Article 9, EU ETS Directive.

7 Article 9, EU ETS Directive.

${ }^{8}$ Article 9, EU ETS Directive.

9 Article 1, COMMISSION DECISION 2010/384/EU.
} 
cap approach is supposed to create a predictable price signal and to provide the necessary certainty for the market. ${ }^{1}$

Furthermore, in respect of the possibility of new inclusion or exclusion of installations during the second trading period and other changes from 2013 onwards, it is necessary for the Commission to adjust the EU-wide cap based on the additional information and publish it by 30 September $2010 .^{2}$ In practice, the Commission adopted a new decision on the EU-wide cap on 22 October 2010 and repealed Decision 2010/384/EU based on additional information available after its adoption. Moreover, the Commission made a modification of the EU-wide cap again after assessing the National Implementation Measures (NIMs) for free allocation submitted by Member States. Hence, the final EU-wide cap is changed into 2,084,301,856. ${ }^{3}$ In the event that new Member State joins the Union, as was the case with Croatia, the Commission needs to consider adjustments to the EU-wide cap for the EU ETS ${ }^{4}$.

\section{The centralisation of the cap setting}

The shift of the competence concerning cap setting from Member States to the Commission implies a centralisation of the cap setting in the third trading period of the EU ETS. However, the fulfilment of the EU-wide cap for the EU ETS set up by the Commission still requires action by Member States. ${ }^{5}$ Some tasks are still left to Member States, like the free allocation in line with the rules set up in the EU ETS Directive, but the discretion and flexibility of Member States in deciding national caps has been taken away. In other words, substantial power with regard to cap setting has been transferred from the Member States to the European level (represented mainly by the Commission). ${ }^{6}$

The trend of centralising the cap setting in the EU ETS Directive seems to be a vital step of the EU climate policy. However, one may raise the questions of whether it is justified to make the decision about cap setting at the EU level or not and to what extent this decision making should be centralised in the EU ETS. Since the competence to regulate environmental issues including addressing climate change is shared between the EU and Member States, hence EU action in regard to the cap setting for the EU ETS needs to be in conformity with the principle of subsidiarity and proportionality. ${ }^{7}$

Based on the discussion in section 2 of this chapter, as far as the justification of the EU action is concerned, the requirement concerning the negative criterion (not sufficiently achieved by the Member States) and positive criterion (better achieved by the EU) of the principle of subsidiarity codified in Article 5 TEU, has to be met by the EU legislative institution in order to acquire competence. $^{8}$ According to the reasons and explanations given by the Commission mentioned

\footnotetext{
${ }^{1}$ Enzmann, J. \& Marr, S. (2008), p.162.

2 See Article 9a(3), EU ETS Directive; see also Enzmann, J., \& Marr, S. (2008), p.163.

3 See Commission Decision 2010/634/EU.

${ }^{4}$ See Preamble (5), Commission Decision 2010/634/EU.

5 Netherlands Environmental Assessment Agency (2008), p.36-37.

${ }^{6}$ van Zeben, J. A. W. (2009a), p.341.

7 Article 3b, TEC.

${ }^{8}$ See Article 5(3), TEU; see also Jans, J. H. \& Vedder, H. H. B. (2011), p.14.
} 
above, the advantages of ensuring a stringent cap, providing certainty and predictability, and supporting fair competition would be gained from the EU-wide cap. However, the reasons provided by the Commission for centralising the cap setting in the EU ETS do not appear to be sufficiently convincing for the shift of the determination of the cap to the EU level. ${ }^{1}$ Meanwhile, one may also argue that the long-term national emissions reduction targets together with the long-term NAPs can also provide such certainty and predictability.

In addition, the legality of a European measure may sometimes be examined by the CJEU in the light of the proportionality test, which contains three basic elements. The first criterion is suitability, which requires that the measures must be appropriate for attaining the objectives; the second criterion is necessity, which determines whether the measure is necessary (legitimate) to reach the objective pursued; the third criterion is proportionality stricto sensu, which involves the balancing of interests. ${ }^{2}$ However, the court will usually respect the 'wide discretion' available to the European institutions and their political choices and complex assessments to be made. ${ }^{3}$ With regard to the EU-wide cap for the EU ETS, it may be quite hard to challenge this approach as 'manifestly inappropriate' before the court in the course of applying the proportionality test. But it is still worthwhile for the policy makers to reconsider which precise level of centralisation would ensure that the main objectives of the ETS are achieved.

However, under the existing centralisation of cap setting, Member States may still adopt more stringent protective measures, according to Article 193 TFEU. ${ }^{4}$ In the domain of climate law and policy, some Member States have established more ambitious climate targets than the EU and would like to adopt stricter controlling measures on their domestic industries, such as the UK which has set a GHG emissions reduction target of $80 \%$ by $2050 .{ }^{5}$ Moreover, there is an indication that the UK intends to reduce GHG emissions by the adoption of other instruments in addition to the EU ETS. For instance, the Energy Act of the UK set up the Emissions Performance Standard (EPS), imposing an annual $\mathrm{CO}_{2}$ emissions limit duty on the operators of the fossil-fuel plant, equivalent to $450 \mathrm{~g}$ of $\mathrm{CO}_{2}$ per kilowatt hour of electricity for a plant operating at base load until $2044 .^{6}$

\subsection{Allocation of allowances}

In addition to setting the cap for the EU ETS, the allocation of allowances constitutes another important aspect of the legal framework for the EU ETS. According to Article 3(a) of the EU ETS Directive, “'allowance' means an allowance to emit one tonne of carbon dioxide equivalent during a specified period". ${ }^{7}$ Despite the debate on the legal natures of the allowance ${ }^{8}$, the possession of an allowance confers a public law right on operators covered by the EU ETS to emit a certain

\footnotetext{
1 de Cendra de Larragán, J. (2008), p.76.

2 Groussot, X. (2006), p.146-152.

3 Jans, J. H. \& Vedder, H. H. B. (2011), p.19.

4 Article 193, TFEU.

${ }^{5}$ Scott, J. (2011), p.26.

${ }^{6}$ See Article57, chapter 8, part 2, Energy Act 2013 (c. 32), Parliament of the UK, 18.12.2013, p.56.

7 Article 3(a), the EU ETS Directive.

${ }^{8}$ See for instance the discussion presented in Mace, M. I. (2005); see also Manea, S. (2012).
} 
amount of GHG. ${ }^{1}$ How to allocate the allowances to the installations covered will have a substantial impact on the legal position of individual installations directly. ${ }^{2}$

In line with the two models concerning cap setting of the EU ETS, two models for the allocation method can also be distinguished in the development of the EU ETS. In the first two trading periods (2005-2012), free allocation by the Member States is the dominant allocation method. Contrary to model one, auctioning will gradually replace free allocation in the third trading period (2013-2020) and beyond. Moreover, the allocation to be executed by Member States, not only by auctioning but also with free allocation, is harmonised to a large extent in model two.

\subsubsection{Model one: $2005-2012$}

As discussed in the previous section, each Member State shall develop the national cap and allocate the allowances to the operators of each installation. ${ }^{3}$ Directive 2003/87/EC only stipulates some general rules about the allocation method. According to Article 10 of Directive 2003/87/EC, free allocation is the basic allocation method in the first two trading periods. To be specific, at least $95 \%$ and $90 \%$ of allowances respectively for the first and the second trading period had to be allocated free of charge by the Member States. ${ }^{4}$

Concerning the choice between the implementation of free allocation and auctioning, Member States have quite some discretion to suit their individual circumstances. Some general criteria have been set up in Annex III to Directive 2003/87/EC, explained by the Commission in some guidelines. Some criteria concerning the allocation established by Annex III are optional while some are obligatory. ${ }^{5}$ Member States had to develop the list of the installations, specifying the intended amount of allowances to be allocated to each installation. ${ }^{6}$ In doing this, Member States shall not discriminate between sectors or installations by unduly favouring certain undertakings or activities according to the requirement of the Treaty inter alia the state aid rules. $^{7}$

\subsubsection{Free allocation}

\section{Grandfathering as the general rule}

In model one, free allocation was the dominant allocation approach followed by Member States from 2005 to 2012. As indicated in chapter 2 of the theoretical framework for the ETS, free allocation can be implemented generally by grandfathering based on the historical emissions in a given year and by benchmarking based on specific performance standards of emissions during a

\footnotetext{
1 Meadows, D. (2006), p.83.

2 In this chapter, the analysis will focus on the stationary installation and the aviation sector will not be discussed.

3 Article 9,11, Directive 2003/87/EC.

4 Ibid, at Article 10

5 Vis, P.(2006), p.199.

${ }^{6}$ Criterion 10 , Annex III.

${ }^{7}$ Article 11(3), Criterion 5, Annex III, Directiv2003/87/EC.
} 
given year. ${ }^{1}$ In the implementation of the EU ETS before 2013, the majority of Member States chose to allocate the allowances free of charge mainly by grandfathering. Although it is often criticised for favouring the historically high-emitters and being inconsistent with the polluter pays principle, it seems to be a pragmatic way of getting the ETS started with the acceptance of the installations to the extent possible. ${ }^{2}$

With grandfathering, Member States choose a year as the baseline for the free allocation. However, the baselines of historical emissions used by Member States were not uniform ${ }^{3}$. In the first trading period, most Member States chose an annual average of a multi-year baseline stretching back three to five years. ${ }^{4}$ In the second trading period, most Member States updated the baseline based on periods extending to 2005 , when the installations' verified emissions data were available. ${ }^{5}$

Based on the historical emissions baseline, Member States allocated the allowances to the existing installations. Moreover, all Member States, except for Germany, adopted a two-step allocation approach, which breaks down the cap first into sectoral caps and then allocates at the installation level. ${ }^{6}$ In the course of specific allocations to installations, Annex III to Directive 2003/87/EC set up some requirements. For instance, the quantities of allowances to be allocated shall be consistent with the reduction potential of activities covered. ${ }^{7}$ However, the Member States are free to decide how to allocate the allowances to individual installations.

Contrary to the dominant role of grandfathering, benchmarking was not well accepted by Member States in the first two trading periods, especially taking into account of its data-intensive character requiring endless discussions on the establishment of an appropriate baseline and disclosure of emissions data. ${ }^{8}$ In practice, the most common use of benchmarking in the first trading period was the allocation to new entrants, where there was no historical emissions data available for the application of grandfathering. ${ }^{9}$ In the second period, several Member States ${ }^{10}$ have allocated the allowances to the power sectors based on benchmarks, most of which were specific fuel and/or technology average benchmarks instead of uniform benchmarks or best-available-technology. ${ }^{11}$

\section{Allocation for the new entrants}

Following the step-by-step approach in the establishment of the EU ETS, the scope of installation or the activities covered by the EU ETS is supposed to be enlarged gradually. As a result, there will be new entrants, not only new installations but also new extended capacity within existing installations ${ }^{12}$, qualified to participate in the ETS. In view of the fact that most incumbents receive the allowances free of charge before 2013, the treatment of new entrants

\footnotetext{
${ }^{1}$ See in the section 3.2 of chapter 2 .

2 Vis, P.(2006), p.192.

3 De Sépibus, J. (2007), p.27

${ }^{4}$ Ellerman, A. D., Buchner, B. K. \& Carraro, C. (2007), p.357.

${ }^{5}$ Betz, R., Rogge, K., \& Schleich, J. (2006), p.372.

${ }^{6}$ Zapfel, P. (2007), p.18.

7 Criterion 3, Annex III to Directive 2003/87/EC.

8 Vis, P.(2006), p.194.

9 Sépibus, J. D. (2007), p.26; see also in Buchner, B., Carraro,C. \& Ellerman, A. D.(2006), p.14.

${ }^{10}$ such as Belgium, Italy, Latvia, Spain, Sweden, and the UK.

11 De Sépibus, J. (2007), p.31-32.

12 Article 3(h), EU ETS Directive.
} 
during the allowance allocation should be considered seriously. In this respect, Article 11(3) of Directive 2003/87/EC has emphasised that Member States shall consider the need to provide new entrants with necessary access to allowances when deciding upon allocation. ${ }^{1}$ This rule is reiterated in Criterion 6 of Annex III, requiring the NAP to contain information on the method enabling new entrants to participate in the EU ETS. ${ }^{2}$ To be specific, three options have been provided by the Commission in the guidance communication, including requiring the new entrants to buy all allowances from the market, setting aside some allowances for periodic auctioning and reserving certain allowances for free allocation to the new entrants in the NAPs. ${ }^{3}$ New entrants defined in one trading period should be treated as other incumbents when the NAP for the subsequent period is notified. ${ }^{4}$

In the first trading period, all Member States chose to set aside a new entrant reserve for the free allocation to the new entrants. This is an exceptional feature of the EU ETS, compared to other already existing cap-and-trade systems at that time. ${ }^{5}$ In order to implement the new entrant reserve, Member States had to make subsequent decisions, for instance, on the amount of allowances to be set aside, and the specific allocation formulae. ${ }^{6}$ With regard to the specific allocation rules for the new entrants, benchmarking taking account of best practice or technology and expected production or new capacity has been adopted widely by Member States. Nevertheless, the characteristic of the benchmarks applied by Member States varied significantly from one country to another. ${ }^{7}$ Moreover, the difference of benchmarks had also resulted in considerable disputes on distortions to the internal market and the need for further harmonisation of the benchmark. ${ }^{8}$

In the second trading period, almost all Member States have also foreseen the establishment of new entrant reserves, except for the new entrants of Swedish non-CHP plants that have to buy allowances from the market. ${ }^{9}$ The size of the new entrants reserve varies largely, ranging from $2 \%$ of the total German allowances to approximately $45 \%$ of that in Latvia. ${ }^{10}$ When allocating the reserved allowances, most Member States based the allocation on best-available-technology. ${ }^{11}$

\section{Ex post adjustment}

Apart from the special rules for new entrants, the possibility of ex post adjustment has been considered and applied in the NAPs proposed by Member States, in particular Germany in the first two trading periods. However, the Commission had a different opinion on the application of ex post adjustment in the allocation of allowances and prohibited the intended ex post

\footnotetext{
1 Article 11(3), Directive 2003/87/EC.

2 Criterion 6, Annex III to Directive 2003/87/EC.

${ }^{3}$ COM (2003) 830.

${ }^{4}$ Meadows, D. (2006), p.81.

5 Ellerman, A. D., Buchner, B. K. \& Carraro, C. (2007), p.360.

${ }^{6}$ Zapfel, P. (2007), p.19.

7 Ellerman, A. D., Buchner, B. K. \& Carraro, C. (2007), p.361.

${ }^{8}$ See for instance Ellerman, A. D., \& Buchner, B. K. (2007), p.75; see also Ellerman, A. D.(2008), p.63-76.

${ }^{9}$ De Sépibus, J. (2007), p.32.

${ }^{10}$ Betz, R., Rogge, K., \& Schleich, J. (2006), p.376.

${ }^{11}$ De Sépibus, J. (2007), p.32.
} 
adjustments in 13 NAPs proposed by Member States in the first trading period ${ }^{1}$, which can be exemplified by the Germany $v$ Commission case ${ }^{2}$.

For instance, in the NAP proposed by Germany for the first trading period, Germany allowed different installations to choose free allocation methods based on historical emissions or projected emissions ${ }^{3}$. Meanwhile, the German NAP provided for ex-post adjustments of the quantities of allowances allocated in specific cases, such as the de facto closure of installations and a change of actual production volume of the existing installations. In particular for the existing installations, which began to operate in 2003 or 2004, the amount of emission allowances allocated to them would be adjusted in line with the actual production volume, leading to a reduction or increase of allowances when the actual production volume was less or more than the projected one declared for the purposes of the initial allocation. ${ }^{4}$

According to the Commission, initial allocation should be determined before the beginning of each trading period; ex post adjustments after the conclusion of the national allocation decision were not allowed except for the cases of new entrants and closure. ${ }^{5}$ Therefore, the Commission had rejected the 'ex post adjustment' mechanism in the German NAP based on its incompatibility with criteria 5 and 10 of Annex III to Directive 2003/87/EC, which was against the Directive and its objectives. ${ }^{6}$ Germany brought the Commission before the CFI, seeking a partial annulment of the Commission decision.

In the judgment by the court, the CFI adopted a four-part analysis with a literal, historical, contextual, and teleological interpretation, in order to determine whether such ex post adjustment mechanism was against the rational of the EU ETS Directive. ${ }^{7}$ Even though the Commission argued that the ex post adjustment would cause uncertainty, the CFI rejected the Commission's opinion, stating that the ex post adjustment is not against the objective of the EU ETS Directive and Member States still have the freedom to apply the ex post adjustment. ${ }^{8}$ In addition, the CFI also recognised the positive effects entailed by the ex post adjustment, creating disincentives on markets to stop producing unprofitable but undersupplied goods rather than selling allowances on the emissions trading market, which is compatible with the objectives of maintaining cost effectiveness and economic efficiency in accordance with the EU ETS Directive. ${ }^{9}$ As a result, the CFI annulled the Commission's decision, stating that the Commission's arguments were neither 'factually substantiated nor legally well founded"10. The Commission did not appeal and Germany won the case.

\footnotetext{
${ }^{1}$ Press Release of 20 June 2005, 'Emissions trading: Commission approves last allocation plan ending NAP marathon', [2005] IP/05/762.

${ }^{2}$ Case T-374/04, Germany v. Commission, action brought on 20 September 2004, OJ C 284, 20.11.2004, p. 25; [2007] ECR II-04431.

3 Case T-374/04, Germany v. Commission [2007] ECR II-04431, at para.151-164, para. 27-29.

4 Ibid, at para. 31.

5 See Decision of 16 January 2007 of European Commission regarding second NAP of Belgium.

${ }^{6}$ Commission's decision about the German allocation plan, C(2004) 2515/2 final, 07 July 2004, article 2, para. 4-7.

${ }^{7}$ Case T-374/04 Germany v. Commission [2007] ECR II-04431, para. 92-148, see also Van Aken, N., \& Paques, M. (2008), p.107-109.

${ }^{8}$ Case T-374/04 Germany v. Commission [2007] ECR II-04431, at para. 148, see also Van Aken, N., \& Paques,

M. (2008), p.109; see also Weishaar, S. (2008b), p. 129.

9 See Case T-374/04 Germany v. Commission [2007] ECR II-04431, at para. 137-139.

${ }^{10} \mathrm{Ibid}$, at para.151-164.
} 
In view of the strong opinion of the Commission to only allow ex post adjustments in case of closure and new entrants, however, Member States seemed to choose not to fight against the Commission and gave up the attempt to use the ex post adjustment in the allocation of allowances. ${ }^{1}$ For instance, the definite allocation rules for the first trading period in Germany, stipulated in the German law on the allowances allocation (Zuteilungsgestz 2007 and the Zuteilungsverordnung 2007), have been revised with a remarkable difference from that proposed in the draft NAP judged by the CFI. ${ }^{2}$ To be specific, the ex post adjustment would not lead to an increase of allowances in any case, but it only contains the possibility to reduce the issued allowances by withdrawing an allocation decision in six possible situations in the first trading period. ${ }^{3}$ Meanwhile, in the NAP for the second period proposed by Germany and the new Zuteilungsgesetz 2008-2012, several months before the judgment made by the CFI, almost all possibilities of ex post adjustments have been excluded. ${ }^{4}$ In addition, other Member States, such as Luxembourg, also decided to exclude ex post adjustments in its NAP for the second period. ${ }^{5}$ The reason for these changes may be complicated but it however suggests that the rejection of the NAP by the Commission appears to have achieved its aims as expected to a large extent. ${ }^{6}$

\subsubsection{Auctioning}

With regard to the allocation method of auctioning, periodic auctioning has been considered by the Commission as a technically preferable choice, since it would provide an equal and fair access to allowances for all operators in a transparent way. ${ }^{7}$ However, just a limited amount of allowances are allowed to be allocated by auctioning in the first two trading periods, as a compromise reached in the adoption of Directive 2003/87/EC. ${ }^{8}$

As a result, auctioning has not been applied widely in the first two trading periods. In the first trading period, only four Member States (Denmark, Ireland, Hungary, and Lithuania) set aside a modest amount of allowances for auctioning. ${ }^{9}$ In the second trading period, six Member States have auctioned part of their allowances but their intensities are very different. The average annual quantity of allowances to be auctioned ranged from 0.4 million to 40 million and the proportion of auctioning in the total allowances allocated ranged from $0.5 \%$ to $9 \% .{ }^{10}$ For instance, the average annual quantity of allowances auctioned by Germany is 40 million, taking about $9 \%$ of the total German allowance in the second trading period, almost the maximum of

\footnotetext{
${ }^{1}$ Backes, C., Deketelaere, K., Peeters, M., \& Schurmans, M. (2008), p.184-185.

2 See $i$ bid, p.188.

${ }^{3}$ Case T-374/04,Germany v. Commission [2007] ECR II-04431, at para.34-35; see also Backes, C., Deketelaere, K., Peeters, M., \& Schurmans, M. (2008), p.188-190.

${ }^{4}$ Backes, C., Deketelaere, K., Peeters, M., \& Schurmans, M. (2008), p. 192

5 European Environmental Agency(2008), p. 55-56.

${ }^{6}$ Backes, C., Deketelaere, K., Peeters, M., \& Schurmans, M. (2008), p.188.

7 See COM (2000) 87 final, p.18.

8 Meadows, D. (2006), p.75.

9 Schleich, J, Betz, R. \& Rogge. K. (2007), p.15.

${ }_{10}$ These Member States are Germany (40 million, 9\%), the UK (17 million, 7\%), the Netherlands $(3.2$ million, 3.7\%), Austria (0.4 million, $1.3 \%)$, Ireland (0.557 million, $0.5 \%)$, and Hungary (2.7 million, 2 $\%)$. Available at: http://ec.europa.eu/clima/policies/ets/pre2013/second/index_en.htm, last accessed 15 Febru ary 2015 .
} 
the proportion allowed in Directive 2003/87/EC. ${ }^{1}$ However, the auctioning scale of other Member States fell short of the maximum in the EU ETS Directive.

\subsubsection{Model two: 2013-2020 and beyond}

Compared to the previous two trading periods (2005-2007 and 2008-2012), the method of allocating emission allowances significantly changed from 2013 onwards. Together with the establishment of the EU-wide cap, a more harmonised allocation approach will be applied in the third trading period (2013-2020) and beyond according to Directive 2009/29/EU.

First of all, allowances will be distributed according to fully harmonised and EU-wide rules, meaning that the same rules will be applied across all EU Member States. In the legislative history of the EU ETS, the degree of 'subsidiarity' was sought by a majority of Member States, while a greater degree of harmonisation was advocated by the European Parliament and a smaller group of Member States led by France and Belgium. ${ }^{2}$ The final compromise on the allocation method was reached in Article 30(2) of Directive 2003/87/EC, requiring the Commission when reviewing the application of the EU ETS Directive to take account of the further harmonisation of the allocation method (including auctioning applied since 2013) and the practicality of creating EU-wide benchmark for allocation. ${ }^{3}$ Along with the centralisation of the cap setting in the revision of the EU ETS Directive with Directive 2009/29/EC, harmonised rules for auctioning and free allocation have also been laid down explicitly. In order to implement these harmonised rules, the Commission subsequently adopted the Auctioning Regulation ${ }^{4}$ and the decision on transitional EU-wide rules for harmonised free allocation on 27 April $2011^{5}$.

Secondly, the general allocation rules will shift towards auctioning gradually, together with free allocation for some special sectors with significant risk of carbon leakage. According to Directive 2009/29/EC, Member States shall auction all allowances which are not subject to free allocation according to Article 10a and 10c from 2013 onwards. ${ }^{6}$ In other words, although most of the allowances will still be allocated for free for installations other than power sectors, auctioning will be the rule rather than the exception gradually. Auctions will increasingly phase in as the default method of allocation, rising from $20 \%$ in 2013 to $70 \%$ in 2020 , while full auctioning is aimed for in $2027^{7}$.

There will be three categories of installations subject to different allocation methods in the third trading period. ${ }^{8}$ The first category is the power sector (including its new entrants) subject to full auctioning, in which no allowances will be allocated free of charge for electricity production, with some temporary options to derogate from the auctioning rule. ${ }^{9}$ The second category

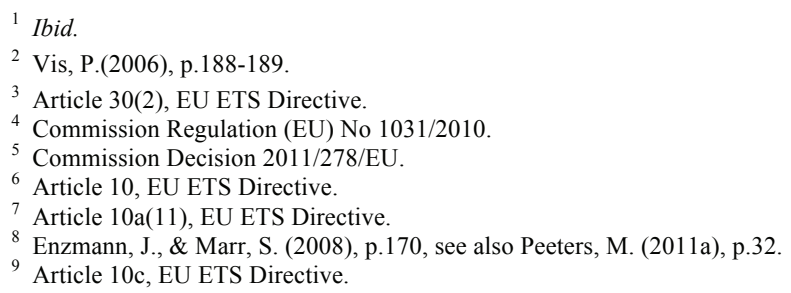


consists of installations in sectors or subsectors exposed to a significant risk of carbon leakage, which will receive all allowances through free allocation by Member States. ${ }^{1}$ The third category is the remainder of installations, which will get allowances by transitional and proportional free allocation with EU-wide ex ante benchmarks and buy some allowances by auctioning or in the secondary market. ${ }^{2}$

\subsubsection{Auctioning}

As auctioning will be the main rule for allowance allocation in the third trading period, attention needs to be paid to several important aspects of auctioning stipulated in Directive 2009/29/EC and the Auctioning Regulation.

Firstly, the estimated amount of allowances to be auctioned by Member States shall be determined by the Commission, but Member States are free to decide how to use the revenue from auctioning. ${ }^{3}$ Under the EU-wide cap of the EU ETS, the total quantity of allowances for auctioning is defined by the overall available allowances minus $5 \%$ of the EU-wide cap for the new entrants reserve and the amount for free allocation, which is likely to follow a two-stage approach. ${ }^{4}$ Concerning the total amount of allowances to be auctioned, the Commission will distribute them among the Member States: $88 \%$ will be distributed to Member States pursuant to the share of the verified emissions of 2005 or the average of first trading period; $10 \%$ will be allocated to certain Member States with the view of solidarity and growth within the EU; the remaining $2 \%$ is given to those Member States that were in 2005 at least $20 \%$ below their Kyoto protocol base year emissions, the so-called Kyoto bonus. ${ }^{5}$ Based on this distribution, Member States will be responsible for putting the allowances assigned to them into the EU-wide carbon market by auctions. The use of revenues generated from auctioning the allowances should be determined by Member States, including, for instance, stimulating the GHG emissions reduction and renewable energy development. Member States have the possibility to adopt specific rules on spending of the auction revenues in the implementation of the EU ETS. ${ }^{6}$ Member States shall inform the Commission in the reports submitted under Decision No 280/2004/EC how they spend the auction revenue. ${ }^{7}$

Secondly, objectives and design for auctioning have been set out in Directive 2009/29/EC and the Auctioning Regulation. To be specific, auctions shall be held in an open, transparent, harmonised, non-discriminatory, and predictable method. ${ }^{8}$ Access to auctions is a precondition for operators to buy allowances in the initial market. In the design of the auctioning, the auction platform shall provide for the means to access its auctions on a non-discriminatory basis. ${ }^{9}$ In particular for small and medium sized enterprises and small emitters covered by the EU ETS, auctions shall be

1 Article 10a(12), EU ETS Directive.

2 Article 10(1), EU ETS Directive.

3 Article 10, 10a, EU ETS Directive.

4 Article 10a, EU ETS Directive, see also Bausch, C., \& Cavalieri, S. (2007), p.166.

5 Article 10(2), EU ETS Directive, see also van Zeben, J. A. W. (2009a), p.352.

${ }^{6}$ The practice of the Netherlands demonstrates that no binding rule on the choice to spend the auction revenues was proposed by the government. For a further discussion see Peeters, M. (2011b), p. 130-131.

7 Article 10(3), EU ETS Directive.

${ }^{8}$ Article 10(4), EU ETS Directive.

${ }^{9}$ Article 16(1), Auctioning Regulation. 
designed to ensure full, fair and equitable access. ${ }^{1}$ In the Auctioning Regulation the legislator has opted for the sealed-bid uniform price auction ${ }^{2}$, requiring that all participants should have the same access to the information. ${ }^{3}$ Furthermore, the Auctioning Regulation also details the nature of the auctioning products, the auctioning calendar, the auctioning process, and the auction monitor.

Thirdly, the auctioning will be implemented at the EU level as well as the national level. In order to implement auctioning across the EU, a common platform to auction emission allowances on behalf of the Member States should be appointed jointly by Member States and the Commission ${ }^{4}$, which is expected to be a cost-efficient approach for Member States and bidders. Moreover, the Commission and the Member States have reached two joint procurement agreements, laying down the conditions under which the joint procurement procedures will be conducted. ${ }^{5}$ Apart from the common platform, Member States that do not want to join the joint action, such as Germany, Poland and the UK can opt out and appoint their own auction platforms. ${ }^{6}$

Fourthly, auctioning can also be employed in the event of excessive price fluctuation in line with Article 29a of the EU ETS Directive. When the allowance price exceeds three times the average market price of allowances during the two preceding years for more than six consecutive months, Member States may be allowed to bring forward the auctioning of certain amount of allowances up to $25 \%$ of the remaining allowances in the new entrants reserve, according to the procedure provided in Article 4 and 7 of Decision 1999/468/EC. ${ }^{7}$

In addition, the Commission shall monitor the functioning of the European carbon market including the implementation of the auctions. Within one month of the auction, Member States shall submit a report about the implementation of the auctioning rules, which shall also be published on the Commission's website. ${ }^{8}$ Moreover, each year, the Commission shall submit a related report to the European Parliament and to the Council, based on relevant information submitted by Member States. ${ }^{9}$

In practice, the first report on the functioning of the European carbon market was presented by the Commission in the end of 2012, earlier than required by Directive $2009 / 29 / \mathrm{EC}$. $^{10}$ In this report, the Commission proposed a review of the auction timetable determining the allowances supply in the third trading period and a delay of the auctions of certain amount of allowance

\footnotetext{
${ }^{1}$ Article 10(4), EU ETS Directive.

2 To be specific, bidders submit their bids via one given bidding window, without seeing bids submitted by other bidders, and each successful bidder will pay the same clearing price. See Article 5, Auctioning Regulation.

3 Article 10(4)(b), EU ETS Directive.

${ }^{4}$ Article 26, Auctioning Regulation.

5 More information can refer to the two agreements: Joint Procurement Agreement to procure common auction platforms (09/11/2011), Joint Procurement Agreement to procure an auction monitor (09/11/2011).

${ }^{6}$ See Article 30, Auctioning Regulation. Germany has appointed the EEX as its auction platform, which is also contracted by Poland to auction on its behalf, while the UK has appointed ICE Futures Europe (ICE) in London as its auction platform, more information can refer to the website of the Commission, available at: http://ec.europa.eu/clima/policies/ets/cap/auctioning/index_en.htm, last accessed August 2920 14.

${ }^{7}$ Article 29a, EU ETS Directive.

8 Article 10(4), EU ETS Directive.

9 Article 10(5), EU ETS Directive.

${ }^{10}$ See $\operatorname{COM}(2012) 652$ final.
} 
from 2013 to 2015, as a short-term measure to deal with the growing surplus of allowances. ${ }^{1}$ Moreover, this 'back-loading' of auctions is being implemented through an amendment to the Auctioning Regulation, by postponing the auctioning of 900 million allowances in the period from 2014 to 2016 until 2019-2020. ${ }^{2}$ Furthermore, as part of the structural reform of the EU ETS, a market stability reserve at the beginning of the next trading period in 2021, which may allow the government to adjust the supply of allowances to be auctioned, has also been proposed by the Commission. ${ }^{3}$

\subsubsection{Free allocation}

Although auctioning will be the default allocation method of allowances in the EU ETS from 2013, free allocation is still allowed on some conditions.

\section{Optional derogation of auctioning by grandfathering}

Although no free allowances will be allocated to electricity generators in the third period, there is an exclusion of certain industries from the auctioning principle. Article 10c of the EU ETS Directive provides the specific possibility of optional derogation for Eastern European Member States $^{4}$ to allocate free allowances to the electricity sectors in view of the modernisation of electricity generation; but this transitional free allocation will be restricted in terms of time, scope and quantity. In view of the serious legal conflicts between these Member States and the Commission regarding the cap setting in the first two trading periods, the application of Article $10 \mathrm{c}$ may be one of the important reasons for the acceptance of the centralisation of cap setting by these Member States.

Specific requirements and procedures for this transitional free allocation are set up by Directive 2009/29/EC. For instance, the total quantity of transitional free allocation shall decrease annually until zero by $2020 .^{5}$ Meanwhile, interestingly enough, the procedure for this optional derogation provision is similar to those procedures concerning the NAP in the first two trading periods. According to Article 10c of the EU ETS Directive, Member States that want to implement this optional derogation provision shall submit a national plan to the Commission. ${ }^{6}$ Similarly, the Commission is empowered to assess the application based on a series of elements stipulated in Article 10c (5) and the Commission may reject the application, or any aspect thereof, within six months after the receipt of the relevant information. ${ }^{7}$ The Commission has issued guidelines concerning the methodology for transitional free allocation of allowances to installations for electricity. ${ }^{8}$ Furthermore, an excessive allocation of free allowances can be seen as illegal state

\footnotetext{
${ }^{1}$ See $\operatorname{COM}(2012) 652$ final, p.6-7.

2 To be specific, in 2014 the auction volume will be reduced by 400 million allowances, in 2015 by 300 million, and in 2016 by 200 million. See Commission Regulation (EU) No 176/2014, p. 11-13.

${ }^{3}$ See $\operatorname{COM}(2014) 20 / 1$.

4 These ten eligible Member States are Bulgaria, Cyprus, Czech Republic, Estonia, Hungary, Latvia, Lithuania, Malta, Poland, and Romania.

5 Article 10c(2), EU ETS Directive.

${ }^{6}$ This national plan provides for investments in upgrading infrastructure and clean technologies, and diversification of energy mix and supply. See Article 10c(1), EU ETS Directive.

${ }^{7}$ Article 10c(6), EU ETS Directive

${ }^{8}$ See C (2011) 1983 final.
} 
aid. Some requirements regarding whether the optional derogation implementation can be considered compatible with the internal market have been set up in the specific guideline for state aid in the context of the EU ETS. ${ }^{1}$

Except for Latvia and Malta, eight of the eligible Member States had submitted the national plans to the Commission as required in Article 10c of the EU ETS Directive. Based on the guidance mentioned above ${ }^{2}$, the Commission has assessed the plans submitted by the eight Member States and has issued 'positive' decisions on the requests for a continued free allocation of allowances to their power sectors from 2013 to 2019 on 16 May $2012^{3}$.

However, in view of the similarity between this transitional free allocation and the former free allocation by the NAP before 2013 in terms of the submitting, assessing and rejecting the national plans, it is still possible to envisage the potential tension between the Commission and Member States concerned. For instance, Member States will also want to allocate more free allowances to their electricity sectors, but the Commission may still want to control it by rejecting the plans proposed by Member States. Based on the case law regarding the competence distribution in relation to the NAP, Member States could have taken the Commission to the courts ${ }^{4}$ and win again if the Commission exceeded its competence in assessing those national plans. It would be worth knowing whether the experience of the Commission losing cases regarding the NAPs has influenced its decision making on the plans for the transitional free allocation, although this may be hard to examine.

\section{Transitional free allocation by benchmarking}

Furthermore, free allowances will also be allocated to heating sectors and certain energy-intense industries in the case of carbon leakage in the third trading period. In general, free allocations will take the form of Community-wide ex ante benchmarks based upon the average of the top $10 \%$ most efficient installations in a sector or subsector during the period 2007-2008 ${ }^{5}$. In contrast to auctioning or grandfathering, this allocation method, applied from 2013 onwards, is based on administrative criteria determined by the Commission ${ }^{6}$, which will serve as benchmark in the EU ETS. If installations meet the ex ante benchmark, and are thus among the most efficient installations in the EU, they will receive a certain amount of free allowances to cover their emissions. The other installations that cannot meet the benchmark will also receive allowances for free, but the free allowances are not enough to cover their emission. As a result, these installations have to reduce their emissions or buy extra allowances from auctioning and the secondary market to cover the emissions. In addition, with regard to the new entrants (not including the power sectors) defined by the harmonised rules adopted by the Commission, $5 \%$ of

\footnotetext{
1 See C (2012) 3230 final, at para.40, p.12-13.

2 See C(2011) 1983 final

${ }^{3}$ The details of the decision can be found on the website of the Commission, available at: http:/ec.euro pa.eu/clima/policies/ets/cap/auctioning/documentation_en.htm, last accessed 29 August 2014.

${ }_{5}^{4}$ The time has elapsed, but no case emerged in practice.

5 Article 10a(2), EU ETS Directive.

${ }^{6}$ Commission Decision 2011/278/EU.
} 
the EU-wide cap for the third trading period shall be set aside for and allocated to these new entrants by benchmarking as well. ${ }^{1}$

Before the elaboration of the transitional free allocation, it is import to bear in mind that the reason for it mainly rests on the concern of carbon leakage. As far as the carbon leakage is concerned, it is an emissions increase outside a region due to the policy capping emissions in that region. ${ }^{2}$ Carbon leakage may occur in various forms, on which the debate can be traced back to the similar argument under the key terms 'pollution haven' and 'race to the bottom' in the globalisation since the $1990 \mathrm{~s}^{3}$. With regard to the EU ETS, the carbon leakage is mainly concentrated on the relocation of production and the associated $\mathrm{CO}_{2}$ emissions in the sectors, the production of which is energy-intensive and which are subjected to strong international competition. ${ }^{4}$ In view of the production cost increase due to the emissions trading, in particular when the allowances are not allocated for free, the industries concerned that cannot pass on the price of allowances in their products (otherwise their products will not be bought), hence may move from countries with stricter regulations to countries with looser or no carbon regulation. ${ }^{5}$ In this respect, the transitional free allocation has been adopted in the third trading period of the EU ETS in order to provide for compensation and thus minimise the regulatory impact that the EU ETS may produce on the international competitiveness of the vulnerable industries ${ }^{6}$.

In order to implement the transitional free allocation, the Commission has to define which sectors are exposed to carbon leakage, inter alia those exposed to significant risk of carbon leakage in advance. Based on the qualitative requirement ${ }^{7}$ and quantitative criteria ${ }^{8}$ set up in Directive 2009/29/EC, the Commission has adopted Decision 2010/2/EU determining the special list of the sectors exposed to a significant risk of carbon leakage. ${ }^{9}$ Moreover, this list should be determined every five years, while a sector satisfying the criteria can be added to the list each year by the Commission. ${ }^{10}$

With regard to the benchmark, it will be defined with along a product-based rather than an industry-based criterion. In order to maximise GHG emissions reduction and energy efficiency savings throughout the production process, the benchmark shall be calculated for products rather than inputs. ${ }^{11}$ The word 'calculated' used here seems to leave little discretion to the Member States as to implementation. ${ }^{12}$ In principle, the Commission should develop one benchmark for each product, as well as intermediate products that are traded between installations. ${ }^{13}$ The starting point for the benchmark shall be the average performance of the $10 \%$ most efficient

\footnotetext{
${ }^{1}$ Artice 10a(7), EU ETS Directive.

2 See Reinaud, J. (2008).

${ }^{3}$ Görlach, B. et al (2008), p.5.

${ }^{4}$ Ibid, p.4.

5 Ibid, p.10-11.

${ }^{6}$ van Asselt, H. \& Biermann, F.(2007), p.500; see also Spassov, Y. (2012), p.319.

7 Article 15-16, EU ETS Directive.

8 Article 17-18, EU ETS Directive.

${ }^{9}$ Commission Decision 2010/2/EU.

${ }^{10}$ Article 10a (13), EU ETS Directive.

${ }_{11}$ Article 10a (1), EU ETS Directive.

12 Peeters, M., \& Weishaar, S. (2009), p.97.

13 Preamble 4, Commission Decision 2011/278/EU.
} 
installations in the sector in the years 2007-2008 . Furthermore, the most efficient techniques, alternative production processes, and other related factors should also be taken into account by the Commission. ${ }^{2}$

Moreover, according to the Commission, setting a benchmark for a product is feasible and no differentiation was made on the basis of geography, technologies or fuels used, in order to avoid distortions and to enhance the harmonisation of transitional free allocation rules. ${ }^{3}$ Furthermore, the Commission has stressed that all relevant products will be classified as exposed to carbon leakage or not based on the list determined and updated by the Commission ${ }^{4}$; hence the products of the same kind could get an equal treatment in terms of carbon leakage. However, various kinds of products will be treated differently in line with the degree of the carbon leakage. The sectors determined as exposed to a significant risk of carbon leakage can receive free allowances at a level of $100 \%$ of the quantity determined by the benchmark ${ }^{5}$. Nonetheless, the other sectors can receive only $80 \%$ of the free allowance in 2013 , dropping to $30 \%$ in 2020 and reaching zero in $2027 .^{6}$ If a new international agreement on climate change is reached, leading to a mandatory reduction target, the benchmark should be reviewed to ensure that the free allocation will be justified $^{7}$.

Although the free allocation rules have been harmonised at the EU level to a large extent, Member States still have a role in allocating the allowances to each installation. Each Member State shall publish and submit a list of installations and the free allocation to each installation calculated, known as the NIMs, to the Commission by 30 September $2011 .^{8}$ If the NIMs are rejected by the Commission, Member State may not issue allowances to installations concerned free of charge. ${ }^{9}$ However in practice, few Member States met the deadline. The Commission has launched infringement proceedings against six Member States, including Belgium, Bulgaria, Germany, Greece, Spain, and Italy, over their late submission of allocation plans for the third trading period. ${ }^{10}$ Until 25 May 2012, 22 Member States have notified their NIMs to the Commission. On 5 September 2013, the Commission adopted a decision on the NIMs, concluding that most NIMs submitted by Member States, except for certain aspects of the NIMs submitted by the Czech Republic and Germany, are compatible with Directive 2003/87/EC and Decision 2011/278/EU. ${ }^{11}$ In particular, Germany wanted to allocate supplementary allowances to some EU ETS installations in view of the hardship situation under Paragraph 9(5) of the German Law on GHG emissions trading of 21 July 2011, which was refused by the Commission. ${ }^{12}$ Although the Commission is brought before the court again by the company

\footnotetext{
1 Article 10a (2), EU ETS Directive.

Article 10a (1), EU ETS Directive,

3 Preamble 5, Commission Decision 2011/278/EU.

${ }^{4}$ See Commission Decision 2011/278/EU, see also the website of the Commission, available at: http://ec. europa.eu/clima/policies/ets/cap/leakage/index_en.htm, last accessed 10 February 2015.

5 Article 10a (12), EU ETS Directive.

${ }^{6}$ Article 10a (11), EU ETS Directive.

${ }^{7}$ Article 10a (1), EU ETS Directive.

${ }^{8}$ Article 11(1), EU ETS Directive.

9 Article 11(3), EU ETS Directive.

${ }_{10}^{10}$ Infringement action begun over late ETS plans, ENDS Europe DAILY, Monday 7 May 2012.

11 Preamble 9-10, Commission Decision 2013/448/EU.

12 See Commission Decision 2013/448/EU.
} 
concerned, the General Court dismissed the case, emphasising the very limited discretion for Member States in the allocation process regarding the third trading period. ${ }^{1}$

As there is no other further revision of free allocation rules foreseen unless the new international agreement is approved, the free allocation approach will provide some legal certainty on the quantity of free allowances allocated to each installation for the whole trading period. ${ }^{2}$ Moreover, ex-post adjustment of free allocations by Member States is implicitly prohibited. ${ }^{3}$

Apart from the harmonised rules of transitional free allocation, financial measures based on the ex ante benchmarks can also be adopted by Member States to support the sectors exposed to a significant risk of carbon leakage. These measures should also be compatible with the state aid rules. ${ }^{4}$ In this sense, the large degree of harmonisation of the allocation is somehow flawed by potentially different financial supporting measures by Member States, which do not need to be fixed at the beginning of the trading period and hence may be changed in the period up to 2020 .

\subsection{Inspection and Enforcement}

Enforcement is a crucial element of the legal framework for the EU ETS to ensure a high level of compliance. In order to achieve the environmental goal of the EU ETS, enforcement can be referred to as a broad range of actions taken to ensure the participants complying with the scheme. ${ }^{5}$ According to the Commission, the complete, consistent, transparent, and accurate monitoring and reporting of GHG emissions are fundamental for the effective operation of the EU ETS. ${ }^{6}$ Operators of installations covered by the EU ETS have a series of obligations under an annual 'compliance cycle', which contains monitoring, reporting and verification of the emissions data.

Furthermore, as far as the enforcement of the EU ETS Directive is concerned, the level of compliance with the EU ETS also relies on the Member States' fulfilment of their obligation to implement the EU ETS Directive correctly. According to the EU ETS Directive, Member States are required to report to the Commission on the implementation of the system annually. ${ }^{7}$ In accordance with the EU legal system, the Commission is responsible for ensuring that all Member States implement the EU ETS Directive in a correct way and, if the Commission considers that Member States are failing to take all necessary measures to ensure the correct implementation of the EU ETS Directive, it can institute an infringement proceeding against the Member States concerned under Article 258 TFEU. ${ }^{8}$ For instance, with regard the non-communication of implementation measures for directives, a specialised procedure introduced for infringement proceedings allows the Commission to ask directly for an imposition

\footnotetext{
${ }^{1}$ Case T 614/13 Romonta v. Commission, Judgment of the General Court of 26 September 2014, OJ C 395, 10.11.2014, p. 47.

2 Peeters, M., \& Weishaar, S. (2009), p.97.

3 Enzmann, J., \& Marr, S. (2008), p.170.

${ }^{4}$ Article 10a(6), EU ETS Directive.

5 McAllister, L. K. (2010a), p.1197.

${ }_{7}^{6}$ Preamble 1, Commission Decision 2007/589/EC, OJ L 229, p.1.

7 Article 21, EU ETS Directive.

${ }^{8}$ Further discussion on this topic can refer to Eritja, M. C. (2006).
} 
of a lump sum or penalty payment in accordance with Article 260(3) TFEU. ${ }^{1}$ This thesis however will not focus on this legal issue but the specific legal framework of enforcement with regard to the installations. Moreover, in view of the impossibility to explore the national framework in all the Member States because of the limitation of time and limitations in relation to language ${ }^{2}$, the attention in this thesis will be paid to the legal framework for the enforcement package mainly established by the EU ETS Directive and relevant secondary legislation containing the GHG emissions permit, monitoring, reporting, and verification of the emissions and sanctions for the breaches.

Ever since the establishment of the EU ETS, the provisions of GHG emissions permit and sanctions have almost stayed the same. However, some changes concerning MRV rules have been witnessed by the revision of the EU ETS Directive with Directive 2009/29/EC and two specific regulations replacing the previous guidelines.

\subsubsection{GHG emissions permit}

Before the elaboration of the GHG emissions permit, one has to be aware of the difference between the permit discussed here and the allowances. As indicated in chapter 2, the term 'permit', referred to as the 'allowances' or 'tradable right', has been frequently used in the economic literature. Nevertheless, the legal definition provided in the EU ETS Directive has differentiated the allowance from GHG emissions permit. As discussed in section 3.2 of this chapter, the allowance, issued and allocated by Member States, is a tradable right that can be held by and transferred among the installations and other persons in the allowance market. In contrast, the GHG emissions permit is a legal document in which the specific GHG activities of the installation are described and in which the main obligations of the operations are included. ${ }^{3}$ The GHG emissions permit will be issued and changed in a separate procedure different from the allowances allocation and transaction. However, the obligation of the operator to surrender sufficient allowances to cover the verified actual emissions of its installations has constituted an important content of the GHG emissions permit. ${ }^{4}$

Aiming to ensure the compliance with the EU ETS, the GHG emissions permit is an important instrument of the legal framework for the EU ETS. According to the EU ETS Directive, no installation covered by the EU ETS can perform any activities listed in Annex I to the EU ETS Directive resulting in emissions of specific GHG from 1 January 2005, only if its operator holds a GHG emissions permit. ${ }^{5}$ In other words, holding a GHG emissions permit is the precondition for the stationary installation to emit specific GHG and to receive the allowance issued by the competent authority of Member States.

In view of the significant impact of the GHG emissions permit on the obligation and right of the operators at the first beginning when they participate in the EU ETS, specific attention needs to

\footnotetext{
${ }^{1}$ Article 260(3), TFEU; for further analysis see in Jans, Hans H. B. Vedder (2011), p.176.

2 But further discussion on the enforcement in Member States can refer to Verschuuren, J. \& Fleurke, F. (2014)

3 Peeters, M. (2006a), p. 173.

4 Article 6(2), EU ETS Directive.

5 Article 4, EU ETS Directive.
} 
be paid to its application procedure. All the stationary installations covered by the EU ETS are required to apply for the GHG emissions permits according to the requirement laid down in Article 5 and 6 of the EU ETS Directive. Before the issuance of the permit, the competent authority is required to assess whether the operators are able to meet the basic conditions for fulfilling the obligation of monitoring and reporting. ${ }^{1}$ Only if the competent authority is satisfied with the result that the operator is capable of monitoring and reporting emissions, it may issue the GHG emissions permit granting authorisation to emit $\mathrm{GHG}^{2}$

The GHG emissions permit issued by the competent authority contains not only the basic information about the operator and the emissions but also a monitoring plan, reporting requirements and an obligation to surrender allowances. ${ }^{3}$ Therefore, three important aspects with regard to compliance with the EU ETS - self-monitoring of emissions, reporting on the result of self-monitoring and verification of the emissions report — will be regulated by the GHG emissions permit, laying a foundation for the MRV system of the EU ETS. ${ }^{4}$

Meanwhile, the competent authority of Member States shall review and make appropriate amendments to the GHG emissions permit at least every five years ${ }^{5}$. In case of any intended changes to the nature or functioning of the installation or any extension or significant reduction of its capacity, according to the EU ETS Directive, the operator should inform the competent authority, who will update the permit where appropriate ${ }^{6}$. After the initial issuance of the permit, the change of the monitoring plan, such as the monitoring methodology, needs to be approved by the permitting authority and then to be included within the updated GHG emissions permit. ${ }^{7}$

In addition, attention also needs to be paid to the interplay between the EU ETS Directive and the Integrated Pollution Prevention and Control Directive (IPPC Directive) as well as its successor, the Industrial Emissions Directive (IE Directive) ${ }^{8}$, since many installations covered by the EU ETS also hold permits under the IE Directive. Aiming to ensure that the ETS is compatible with IE Directive, Member States shall adopt necessary measures to coordinate a GHG emissions permit regarding its condition, procedure and issuance with those permitting under IE Directive. ${ }^{9}$ Nonetheless, Member States are not obliged to integrate these procedures. ${ }^{10}$ However, the permit under IE Directive shall not include an emission limit value for direct emissions of certain GHG form an installation, if they are specified in Annex I to Directive 2003/87, unless it is necessary to prevent significant local pollution. ${ }^{11}$ With regard to this provision, questions have been raised in the literature, ${ }^{12}$ which will be further discussed in section 4 of this chapter.

\footnotetext{
1 Article 6(1), EU ETS Directive.

${ }^{2}$ Ibid.

3 Article 6(2), EU ETS Directive.

${ }^{4}$ Peeters, M. (2006a), p. 184.

5 Article 6(1), EU ETS Directive.

${ }^{6}$ Article 7, EU ETS Directive.

7 Article 6(2)c, EU ETS Directive; see also Article 15, Commission Regulation (EU) No 601/2012, p. 37.

${ }^{8}$ See Directive 2008/1/EC and Directive 2010/75/EU.

9 Article 8, EU ETS Directive.

${ }^{10}$ Meadows, D. (2006), p.72.

11 Article 26, EU ETS Directive; see also in Article 9(3) of Directive 2008/1/EC and then Article 9(1), Directive 2010/75.

${ }^{12}$ Further discussion can refer to the Squintani, L., Holwerda, M. \& de Graaf, K. (2012), p,79-86; See also
} 


\subsubsection{Monitoring, reporting and verification}

Monitoring, reporting and verifying the GHG emissions are the cornerstone of the inspection and enforcement of the EU ETS. The legal framework for monitoring, reporting and verifying the emissions of the industry installations has been established by the EU ETS Directive and subsequent legislation.

In Directive 2003/87/EC, principles for monitoring and reporting of emissions and criteria for verification of emissions have been set out in Annex IV and Annex V. Moreover, the Commission is obliged to adopt guidelines for monitoring and reporting ${ }^{1}$, through which the rules concerning monitoring and reporting have been harmonised gradually to a large degree. In line with these basic principles of the EU ETS Directive, the Commission has adopted guidelines for the monitoring and reporting of GHG emissions in $2004^{2}$ for the first trading period, and the guidelines were last revised in $2007^{3}$ for the second trading period. Member States shall ensure that emissions are monitored and reported in line with the guidelines. ${ }^{4}$ According to the Commission, these guidelines thus provide for the legally binding rules regulating the monitoring and reporting of GHG emissions within the EU ETS. ${ }^{5}$ Meanwhile, the rules of verification are also harmonised to some extent in the guidelines adopted in 2007.

In the third trading period, the MRV rules are further harmonised. According to Directive 2009/29/EC, the Commission is obliged to adopt regulations respectively for the monitoring and reporting of emissions, and for the verification and accreditation of verifiers based on the principles set up in the Annexes to the EU ETS Directive by 31 December 2011. ${ }^{6}$ In June 2012, two separate regulations, one specific to monitoring and reporting $(\mathrm{MRR})^{7}$ and the other to verification and accreditation $(\mathrm{AVR})^{8}$, were adopted, both of which are binding in its entirety and can be directly applied in all Member States. Except for the transitional application of the Decision $2007 / 589 / \mathrm{EC}$ for the emissions activity data occurring prior to 1 January $2013^{9}$, the monitoring, reporting and verification in the third trading period and onwards will be required to comply with these two new regulations in a more harmonised approach.

\footnotetext{
Epiney, A. (2012), p.22-27.

1 Article 14(1), Directive 2003/87/EC.

2 Commission Decision 2004/156/EC.

${ }^{3}$ Commission Decision 2007/589/EC.

${ }^{4}$ Article 14(2)(3), Directive 2003/87/EC

5 Answers to Frequently Asked Questions on Greenhouse Gas Emissions Monitoring and Reporting under the EU Emissions Trading System Pursuant Directive 2003/87/EC, September 2007, p.1.

${ }^{6}$ Article 14, 15, EU ETS Directive.

${ }^{7}$ Commission Regulation (EU) No 601/2012.

${ }^{8}$ Commission Regulation (EU) No 600/2012.

9 Article 76, Commission Regulation (EU) No 601/2012; see also Article 77, Commission Regulation (EU) No 600/2012.
} 


\subsubsection{Monitoring and reporting}

\section{Monitoring and Reporting Guidelines (MRG 2007)}

Before the beginning of the third trading period, the basic requirement concerning monitoring and reporting the GHG emissions were provided by the guidelines listed in Annex I of Decision 2007/589/EC ${ }^{1}$ (the so-called MRG 2007). ${ }^{2}$ In order to ensure the accuracy and verifiability, monitoring and reporting of GHG emissions should be based on several principles, such as completeness, consistency, and transparency. ${ }^{3}$ In view of the obvious tension between the accuracy of the emissions data and the cost of the feasible methodology applied, the Commission tried to strike a balance between accuracy and costs. ${ }^{4}$ In the guidelines on monitoring and reporting, the consideration of such a balance has been incorporated into the provisions as examples of the specific choice of monitoring methodology and the reporting requirement.

Firstly, the monitoring methodology to be applied by a specific installation is the core element of the monitoring plan. There are two main types of monitoring methodology allowed in the EU ETS, one is calculation and the other is measurement. ${ }^{5}$ If the operator proposes to use a measurement based methodology, it must be approved by the competent authority of Member State. ${ }^{6}$ In this respect, the monitoring and reporting of emissions for the EU ETS before 2013 has a heavy reliance on the estimation of emissions, with diverse levels of sophistication. ${ }^{7}$

Secondly, a so-called 'tier system' provided by the legal framework for monitoring and reporting allows some flexibility for installations as well as Member States. ${ }^{8}$ Based on the definition provided by the MRG 2007, the 'tier' is 'a specific element of a methodology for determining activity data, emission factors and oxidation or conversion factors'. 9 In other words, different tiers of methodology represent various levels of accuracy. The highest tier approach shall generally be applied by all operators. ${ }^{10}$ However, taking account of cost efficiency based on the huge difference between the size and types of operations of different installations, the tier system allows varying options to be chosen when installations are applying a specific methodology. ${ }^{11}$ Operators inter alia the small ones may apply for a next lower tier within a monitoring methodology only when the highest tier approach is technically infeasible or will cause unreasonably high costs. ${ }^{12}$ If the competent authority is satisfied with the application, the competent authority may waive this obligation and drop the installation's methodology to a lower tier. ${ }^{13}$ In other words, there is a differential treatment between the big and small

\footnotetext{
${ }^{1}$ Commission Decision 2007/589/EC.

2 The MRV system for the aircraft operators will not be discussed in this section.

3 Commission Decision 2007/589/EC, p. 10.

${ }^{4}$ Peeters, M. (2006b), p.174-175.

5 Annex IV to Directive 2003/87/EC.

${ }^{6}$ Commission Decision 2007/589/EC, p.11.

${ }^{7}$ Kruger, J., \& Egenhofer, C. (2006), p.6-7.

${ }^{8}$ Kruger, J., Oates, W. E., \& Pizer, W. A. (2007), p.124.

9 Commission Decision 2007/589/EC, p.7.

${ }^{10}$ Ibid, p.14.

${ }_{11}$ Hartridge, O. (2006), p. 240.

12 Commission Decision 2007/589/EC, p. 14.

13 Ibid.
} 
installations in order to strike a balance between accuracy and cost-efficiency. ${ }^{1}$ According to the Commission, the tier system forms the backbone of monitoring, which can not only provide flexibility to accommodate different sectors and technologies, but also may preserve a level playing field for operators across the EU. ${ }^{2}$

Thirdly, Member States shall ensure that each operator monitors and reports the emissions annually to the competent authority. ${ }^{3}$ Nevertheless, in order to minimise the reporting burden on industries, Member States shall coordinate GHG emissions reporting with existing reporting requirements through necessary measures. ${ }^{4}$ As complete certainty of the emissions data cannot be achieved in practice, the monitoring and reporting guidelines allows a certain degree of uncertainty as well as a misstatement for installations. The emissions report will be assessed and verified by the verifier in the next step. With regard to the quality of the reports, the guideline has introduced the term "materiality level' 5 and different categories of installation apply different materiality levels ${ }^{6}$. According to the MRG 2007, if the misstatement in the total emissions figure results in aggregate omissions, misrepresentations or errors in the total emissions figure being greater than $5 \%$, it can be considered as material misstatement by the verifier. ${ }^{7}$ However, it may give rise to a potential dispute about the reporting requirements in relation to uncertainty with respect to the calculation or measurement methodology and the reliability of measurement methods. ${ }^{8}$

\section{Change in the Monitoring and Reporting Regulation (MRR)}

In pursuit of a further harmonisation of the monitoring and reporting system of the EU ETS, the Regulation on monitoring and reporting (the so-called MRR) ${ }^{9}$ has been adopted to replace the MRG 2007. According to the Commission, the MRR has sent a strong signal for harmonisation. ${ }^{10}$ Based on the basic legal framework established by the EU ETS Directive, MRG 2007 and the previous guidelines, the MRR has made some further improvement and amendment in several aspects. Compared to the basic requirement set up in the MRG 2007, there is some important change in the MRR worthy of attention.

The central role of the monitoring plan for the whole MRV system has been further emphasised by the MRR. Important issues relating to the development and modification of the monitoring plan have been stipulated in chapter 2 of the MRR. ${ }^{11}$ For instance, the condition and procedure for the modification of the monitoring plan has been further clarified. In this respect, the MRR

\footnotetext{
${ }^{1}$ Hartridge, O. (2006), p.243.

2 Answers to Frequently Asked Questions on Greenhouse Gas Emissions Monitoring and Reporting under the EU Emissions Trading System Pursuant Directive 2003/87/EC, September 2007, p.6.

3 Article 14(3), EU ETS Directive.

4 Annex IV to Directive 2003/87/EC.

${ }^{5}$ It means the quantitative threshold or cut-off point to be used to determine the appropriate verification opinion on the emission data reported in the annual emissions report. See Commission Decision 2007/589/EC, p.9.

6 To be specific, installations of categories A and B will apply the materiality level amounting to $5 \%$ while the level for installations of category $\mathrm{C}$ is just $2 \%$. Ibid, p. 31 .

${ }^{7}$ Ibid, p.9, p.31.

${ }_{8}$ Peeters, M. (2006b), p.176.

9 Commission Regulation (EU) No 601/2012.

10 European Commission, The Monitoring and Reporting Regulation - General guidance for installations, MRR Guidance document No. 1, 16 July 2012, p.6.

${ }^{11}$ Commission Regulation (EU) No 601/2012, p. 35-39.
} 
provides a list of the 'significant changes' and exempts the non-significant changes from getting approval of the competent authority. ${ }^{1}$ Moreover, the MRR has also introduced new rules for the process of updating the monitoring plan, in particular requiring the operator to react to the recommendation of the verifier's finding in pursuit of the continuous improvement of the monitoring plan. ${ }^{2}$

In addition, the flexibility in the choice and application of the monitoring methodologies seems to be increased for the installations to a certain degree. Both the MRG 2007 and MRR allow the operators to choose the monitoring methodologies based on the monitoring approach, but the MRR allows a new approach called 'the fall-back approach' (Methodology not based on tiers) and the possibility to combine the allowed approaches, under the condition that the operator demonstrates that neither double counting nor data gaps in the emissions will occur. ${ }^{3}$ Moreover, the measurement-based approaches have been put on equal footing with calculation-based approach in the MRR. ${ }^{4}$

With regard to the 'tier system', the requirements for choosing the appropriate and required tier have been amended by the MRR. Especially for the application for a derogated tier by small operators, the competent authority must assess its justification based on the technical feasibility and unreasonable cost, the detailed definition and requirement of which has been provided by the MRR. ${ }^{5}$ In particular, the cost-benefit analysis has been employed in the detailed description of the 'unreasonable cost'.

In the case of missing data, there is specific obligation for the operator to inform the competent authority without undue delay and to propose adequate measures in order to improve the quality of data. ${ }^{7}$ Moreover, the competent authority shall make a conservative estimation of the emissions in the specific circumstances, including the operator's failure to submit the verified emissions report before the deadline, the noncompliance of the verified emissions report with the MRR, and the emissions report not being verified as required. ${ }^{8}$

\subsubsection{Verification}

The objective of verification is to ensure that emissions have been monitored as required and that the reported emissions data are correct. The emissions reports submitted by operators must be verified each year by 31 March in accordance with the criteria set out in Annex V to the EU ETS Directive and any detailed provisions adopted by the Commission. ${ }^{9}$ A verifier is a competent, independent, accredited verification body or person (legal or nature) responsible for carrying out and delivering a report on the verification activities. ${ }^{10}$ Verifier's strict task is to compare the

\footnotetext{
1 Ibid, at Article 15.

2 Ibid, at Article 9, 14(2).

3 Ibid, at Article 21, 22.

${ }^{4}$ European Commission, Guidance document No. 1 - The Monitoring and Reporting Regulation - General guidance for installations, 22 November 2012, p. 22.

5 Article 17-18, Commission Regulation (EU) No 601/2012.

${ }^{6} \mathrm{Ibid}$, at Article 18.

$7 \mathrm{Ibid}$, at Article 45.

${ }^{8}$ Ibid, at Article 70.

9 Article 15, EU ETS Directive.

${ }^{10}$ Commission Decision 2007/589/EC, p.10; see also Article 3, Commission Regulation (EU) No 600/2012..
} 
theory of the monitoring methodology laid out in the GHG emissions permit against the implementation in reality. ${ }^{1}$ The requirement of the verification process and accreditation are regulated by different approaches in the first two trading periods and the third trading period.

\section{General guidance in the MRG 2007}

In the first two trading periods, the verification process should be conducted based on the general principles set out in the Annex V to Directive 2003/87/EC and related guidelines. The Commission was not obliged to adopt guidelines about verification, but the monitoring and reporting guidelines, in particular the MRG 2007, have provided general guidance for verification in regard to the general principles and verification methodology including the execution of strategic analysis, risk analysis, the verification, the internal verification report, and the external verification report. ${ }^{2}$

Firstly, the operator shall submit the emissions report to the verifier, together with a copy of the approved monitoring plan, and other relevant information. ${ }^{3}$ Moreover, in order to assess and determine the reliability and accuracy of the monitoring system and reported data, the verifier shall be provided with access to all sites and information relating to the verification. ${ }^{4}$ Secondly, minimum competency requirements for the verifier are also necessary. The verifier shall be independent from the operator, carrying out the verification activities in an objective way. Moreover, the verifier should be professional, capable of understanding the related legislation and the generation of the information regarding the emission. ${ }^{5}$ At the end, the verification shall deliver a reasonable verification opinion on whether the emissions data and report are validated. Only if the operators show that the emissions can be determined with a high level of certainty based on the reliable and credible data and information, such as the emissions report is free from material misstatements, the reported emissions may be validated. ${ }^{6}$ Member States shall ensure that no operator can make further transfers of allowances until its emissions report has been verified as satisfactory. ${ }^{7}$

Although fundamental principles have been set up at the EU level, Member States still have some discretion to develop their own specific national verification rules. Similar flexibility also exists in relation to the approach to the accreditation of verifiers. Article 15 of Directive 2003/87/EC requires the annual emission reports to be verified, while leaving substantial room for Member States to decide whether the verification is done by their competent authorities or through private independent verifiers. ${ }^{8}$ Member State also has the competence to establish its own procedure for accreditation, and the national rules vary in practice. ${ }^{9}$ For instance, 24 Member States have established accrediting rules for independent verifiers; 20 Member States required a double check for some of the verified emissions reports in order to ensure the quality

\footnotetext{
${ }^{1}$ Hartridge, O. (2006), p.245.

2 Commission Decision 2007/589/EC, p.30-33.

3 Annex V sub 2, 4, 7 of Directive 2003/87/EC, see also Commission Decision 2007/589/EC, p.30-31.

${ }^{4}$ Ibid.

5 Annex V, sub 7 of Directive 2003/87/EC.

${ }^{6}$ Annex V, sub2,3 of Directive 2003/87/EC.

7 Article 15, EU ETS Directive.

8 Meadows, D. (2006), p.90; see also Peeters, M. (2006a), p.187.

9 Kruger,J., Oates, W. E. \& Pizer, W. A. (2007), p.124.
} 
of the verification process; governmental authorities in 7 Member States have the competence to adjust the verified emissions reports that are deemed unsatisfactory. ${ }^{1}$

\section{Accreditation and Verification Regulation (AVR)}

In the third trading period, the requirement for verification and accreditation has been harmonised to a larger degree by the new regulation on accreditation and verification (the so-called AVR). ${ }^{2}$ According to the Commission, it is necessary to establish a consistent and comparable level of accreditation and verification, to harmonise the internal market for accreditation and verification service, and to improve cost-effectiveness. ${ }^{3}$ In order to establish the overall framework for accreditation and verification, important issues, such as mutual recognition of verifiers, on-going supervision of verifiers and corrective measures, single verifier issues and independent technical review, and the content of the verification report, have been addressed by this specific regulation.

Particular emphasis of the AVR has been placed on the requirement for ensuring the reliability, impartiality and independence of the verification. In this respect, both the general obligations and pre-contractual obligations of the verifier have been stipulated in the regulation. ${ }^{4}$ It not only requires the verifier to plan and perform the verification with an attitude of professional skepticism, but it also requires that the verification is conducted 'in the public interest', while remaining independent of the operators and the competent authorities. ${ }^{5}$ Moreover, detailed requirements for objectivity, independence and impartiality have been provided for in the regulation.

For instance, aiming to ensure the independence of the verifier from the operator and the impartiality of the verification activities, relevant requirements on verifiers have been laid down in the harmonised standard listed in Annex II to the AVR. ${ }^{6}$ In particular, the potential situations concerning conflicts of interest in the relationship between the operator and verifiers have also been clarified to a certain extent. ${ }^{7}$ Furthermore, according to the AVR, if the verifier discovers that an operator is not complying with the MRR, the verifier is obliged to include the detected irregularity and noncompliance of the operator in the verification report. ${ }^{8}$

Meanwhile, an independent review of the draft verification report per se, including the subsequent amendment to report, will be required before the issuance of the final verification report, aiming to ensure that the verification process is complied with the requirement provided by the AVR. ${ }^{9}$ In other words, the independent review is a verification of the verifier, which is to be executed by the independent reviewer that is appointed by the verifier and is independent

\footnotetext{
${ }^{1}$ McAllister, L. K. (2010a), p 1228; see also European Environmental Agency (2009), p.54-55.

2 Commission Regulation (EU) No 600/2012.

3 Ibid, at Preamble (3).

${ }^{4} \mathrm{Ibid}$, at Article 7, 8.

$5 \mathrm{Ibid}$, at Article 7(2), (3).

${ }^{6} \mathrm{Ibid}$, at Article 42, Annex II.

${ }_{8}^{7}$ Ibid, at Article 42(4).

$8 \mathrm{Ibid}$, at Article 7(5), 27(3).

9 Ibid, at Article 25.
} 
from the verification team. ${ }^{1}$ In view of the important role played by the independent reviewer, its independence and competence has to be ensured. In this sense, the independent reviewer is required to meet the competence requirement for an EU ETS auditor as well as a verifier, but the reviewer should not have carried out any verification activities that are subject to his review. ${ }^{2}$

Furthermore, a general framework for accreditation has been provided in chapter four of the AVR, in order to ensure that verifiers have the competence to perform the verification activities. With regard to the establishment of the general framework for accreditation, Member States should establish their own national accreditation body in accordance to Regulation (EC) No $765 / 2008^{3}$, or have recourse to other Member State's one, in order to carry out accreditation activities and to supervise on the quality of verification. ${ }^{4}$ According to the AVR, the national accreditation body should not only be independent from the verifiers but also distinguished from the competent authority for the EU ETS and other national authorities. ${ }^{5}$ In this light, there will be two kinds of regulators involved in the governance in relation to the verification. One is the enforcing competent authority responsible for the EU ETS Directive and the other is the specific national accreditation body. They have different function and power, but both of them need to cooperate with each other within the legal framework. For instance, when the competent authority makes a complaint concerning the verifier, the national accreditation body shall take appropriate action and respond to the compliant in line with the AVR, within a reasonable time after the receipt of the compliant. ${ }^{6}$

In addition to the annual surveillance of each accredited verifier, the national accreditation body may adopt specific administrative measures as examples of suspending, withdrawing or reducing the accreditation of verifier, where the verifier does not meet the requirements of the AVR. ${ }^{7}$ For instance, if the verifier has intentionally provided false information, the national accreditation body shall withdraw the accreditation. ${ }^{8}$ In these cases, the verifiers concerned can appeal against these administrative measures based on the national procedures established by Member States. ${ }^{9}$

\subsubsection{Sanctions}

In the legal framework for the EU ETS, Member States are obliged to establish sanctions for infringements of the national measures adopted pursuant to the EU ETS Directive. ${ }^{10}$ Member States shall notify these provisions to the Commission without delay and take all measures necessary to implement them. ${ }^{11}$ The penalties determined and applied by Member States must be effective, proportionate and dissuasive ${ }^{12}$, which is a so-called catch-all provision to ensure that Member States' implementation measures and actual enforcement address all potential

${ }^{1}$ Ibid, at Article 36(3).

$2 \mathrm{Ibid}$, at Article 25(2), 37(2), 38.

3 Regulation (EC) No 765/2008.

4 Preamble (18)-(20), Commission Regulation (EU) No 600/2012.

$5 \mathrm{Ibid}$, at Article 56.

${ }^{6} \mathrm{Ibid}$, at Article 61.

${ }^{7} \mathrm{Ibid}$, at Article 53

${ }^{8} \mathrm{Ibid}$, at Article 53(3).

9 Ibid, at Article 53(4).

${ }_{10}$ Article 16(1), EU ETS Directive.

11 Ibid, at Article 16(1).

$12 \mathrm{Ibid}$, at Article 16(1). 
Member States' implementation measures and actual enforcement address all potential breaches of the EU ETS Directive ${ }^{1}$. Next to this, five specific sanctions have to be provided.

The first penalty for violators is called naming and shaming. If operators cannot meet the requirements to surrender sufficient allowances under the EU ETS Directive, Member States shall ensure the publication of the names of these operators. ${ }^{2}$ Although naming and shaming has been criticised as an unacceptable style of governance ${ }^{3}$, it can still be considered as a new enforcement approach at least in the field of European environmental legislation ${ }^{4}$.

The second penalty to be implemented by Member States is an automatic financial penalty. If any operator that fails to surrender sufficient allowances by 30 April of each year to cover its actual emissions of the preceding year, they should be imposed with an excess emissions penalty by Member States ${ }^{5}$. Concerning the specific amount of the financial penalty, a standard was set out in the EU ETS Directive, which was 40 EUR in the first trading period and then increased to 100 EUR from the second trading period. In other words, the operators should pay 100 EUR for each tonne of $\mathrm{CO}_{2}$ equivalent emitted for which they have not surrendered allowances ${ }^{6}$. The excess emissions penalty shall increase in line with the European index of consumer prices from 1 January 2013 onwards. $^{7}$

The third penalty is the compensation of excess allowances by surrendering a specific amount of allowances. From the perspective of the Commission, the financial penalty would not release the offender from the obligation to surrender allowances corresponding to the excess emissions, because this would undermine the pre-determined environmental outcome of the EU ETS. ${ }^{8}$ Therefore, the operator, who cannot surrender enough allowances to cover its emissions, must surrender an amount of allowances equal to those excess emissions in the following calendar year. $^{9}$

Fourthly, a prohibition on transferring allowances is also provided as one of the penalties in relation to the MRV. If the emission report submitted by the operators has not been verified as satisfactory by an independent verifier, no further transfers of allowances can be made by such an operator until a report is verified as satisfactory. ${ }^{10}$

Fifthly, the administrative measures including the suspension, withdrawal of the accreditation certificate and reduction of the scope of accreditation may be applied to the verifier too. To be specific, if the verifier has failed to meet the requirement of the AVR persistently and repeatedly, or has committed a serious breach of the requirement of the AVR or other specific terms and conditions of the national accreditation body, the scope of the accreditation should be restricted

\footnotetext{
1 Meadows, D. (2006), p.93.

2 Article 16(2), EU ETS Directive.

3 See Whitman, J.Q. (1998).

${ }^{4}$ Peeters, M. (2006b), p. 180.

5 Article 16(3), EU ETS Directive.

${ }^{6}$ Article 16(3), EU ETS Directive.

7 Article 16(4), EU ETS Directive.

${ }^{8}$ Meadows, D. (2006), p.93.

${ }^{9}$ Article 16(3), EU ETS Directive.

${ }^{10}$ Article 15, EU ETS Directive.
} 
and even the accreditation would be suspended. ${ }^{1}$ Moreover, the accreditation would be withdrawn by the national accreditation body, in the cases of the verifier has failed to remedy the grounds for the suspension of the accreditation certificate and has intentionally provided false information, or a member of the top management of the verifier has been found guilty of fraud. ${ }^{2}$

Among the five penalties mentioned above, the first three penalties are imposed on the excessive emissions, the basic non-compliance act in the implementation of the EU ETS. In particular the financial penalty and the compensation by re-surrendering the allowances are supposed to be a backbone ensuring the compliance of the operators with the EU ETS. In the first and the only case judged by the CJEU concerning the enforcement of the EU ETS for now, ${ }^{3}$ the Billerud Karlsborg $A B$ and Billerud Skärblacka AB v Naturvårdsverket case, the Billerud companies had not surrendered the allowances equal to their emissions for 2006 and a fine was imposed of more than 2 million EUR by the competent authority in Sweden. ${ }^{4}$ However, the Billerud companies argued that their alleged failure to surrender allowances on time was not intended, since they owned sufficient emission allowances in their holding accounts to cover their total emissions for 2006, but they failed at the first instance and appealed to the Swedish Supreme Court. ${ }^{5}$ In this context, the questions with regard to the concept of excess emissions and the possibility for the implementation by Member States to waive or reduce the fine for the excessive emissions in light of the principle of proportionality have been referred to the Court of Justice for preliminary ruling, which will be discussed in section 4.3 of this chapter.

\section{Legal insights from the EU ETS}

\subsection{Cap setting: competence distribution between the $\mathrm{EU}$ and}

\section{Member States}

As the Kyoto target has set an absolute cap on the overall emissions for the Annex I countries, this choice has influenced the choice of the EU in establishing the EU ETS. Although the choice of an absolute cap is a political choice, and hence there was no legal obligation for the EU to adopt the same approach, it has been welcomed by the policy maker of the EU at the first glance for the reasons of certainty and environmental effectiveness. ${ }^{6}$ However, the cap-and-trade model, which has been chosen by the EU ETS, has also been criticised in the sense that the economic logic has supplanted ecological logic. ${ }^{7}$

The cap setting for the EU ETS has witnessed a significant change by shifting the decision making competence concerning the cap from the national level to the EU level. This section will

\footnotetext{
1 Article 53(2), Commission Regulation (EU) No 600/2012.

2 Ibid, at Article 53(3).

3 There might have been quite some cases before the national courts, which will not be discussed because of the limited scope of this research.

${ }^{4}$ Case C-203/12 Billerud Karlsborg AB and Billerud Skärblacka AB v. Naturvårdsverket, Judgment of the Court (Second Chamber) of 17 October 2013 (not yet reported), at para.17-18.

${ }^{5}$ Ibid, at para. 19-20.

${ }^{6}$ See, $\operatorname{COM}(2000) 87$ final, p.8.

7 Winter, G. (2010), p.1.
} 
first analyse the legal problems concerning competence distribution between the Commission and Member States in different periods of the EU ETS, in particular the case law in the first two periods and the potential problems that emerge in the centralisation approach applied in the third period. Thereafter some useful concluding insights for the Chinese ETS will be provided to the extent possible.

\subsubsection{Legal conflicts in the decentralised model}

In the first two trading periods of the EU ETS, the cap setting is a decentralised model in which Member States make substantive decisions through the NAPs. Meanwhile, within three months of notification of a NAP by a Member State, the Commission may reject that plan. ${ }^{1}$ Moreover, Member States cannot take a decision about the total quantity of allowance to be allocated to the installations in its country unless the NAP or the following amendment is accepted by the Commission. ${ }^{2}$ This decentralised approach of cap setting had allowed a large degree of flexibility for Member States to take account of specific and national circumstances in the course of making decisions, but it also provided the Commission with powers to control the Member States.

For the first two periods, the competence distribution between the Commission and Member States regarding the NAP was not sufficiently clear. The tension between the Commission's right to reject and Member States' competence in elaborating the NAPs is one of the most important issues of the first two periods. ${ }^{3}$ Particularly Eastern European states reacted strongly against the decisions of the Commission on their NAPs for the period 2008-2012. The legal conflicts between the Commission and Member States have been demonstrated by the case law regarding the NAPs. With the cases brought before the EU courts, the competence distribution between the Commission and Member States was further clarified and reconfirmed by the courts.

\section{The case law regarding the NAP}

In the first trading period, particularly in the process of the determination of the NAP, more than half of the plans submitted by Member States have been rejected by the Commission. ${ }^{4}$ This has given rise to lots of case law challenging the Commission's decision on the NAP, such as the UK $v$ Commission case ${ }^{5}$, the Germany $v$ Commission case $^{6}$, the Romania $v$ Commission case ${ }^{7}$, and the Bulgaria $v$ Commission case $^{8}$. Moreover, the Commission's decisions in some cases, such as the UKv Commission and the Germany v Commission cases have been annulled by the court.

\footnotetext{
1 Article 9(3), Directive 2003/87/EC.

2 Ibid.

3 van Zeben, J. A. W. (2009a), p.340-356.

4 Zapfel, P. (2007), p.25; see also De Sépibus, J. (2007), p.10.

${ }^{5}$ Case T-143/05, UK v. Commission, action brought on 11 April 2005, OJ C 115, 14.05.2005, p. 39.

${ }^{6}$ Case T-374/04, Germany v. Commission, action brought on 20 September 2004, OJ C 284, 20.11.2004, p. 25; Case T-374/04 Germany v. Commission [2007] ECR II-4431.

${ }^{7}$ Case T-484 07, Romania v. Commission, this case was removed by the order of the General Court of 11 July 2012, OJ C 258, 25.8.2012, p. 27-27.

${ }^{8}$ Case T-500/07, this case was removed from register by the Order of the General Court of 7 June 2010.
} 
The case law concerning the NAP does not cease to exist in the second trading period. The Commission rejected a lot of initial NAPs after the assessment in practice, many Member States, in particular some new Member States that were required to reduce their national caps substantially, brought the Commission to court by challenging its decisions.

To be specific, in the Slovakia $v$ Commission case $^{1}$, Slovakia filed the legal complaint against the Commission alleging that the Commission violated the proportionality principle by ignoring the need to increase its electricity generation by burning fossil fuel due to the obligation to shut two power stations. ${ }^{2}$ In the Poland $v$ Commission case ${ }^{3}$, Poland sought an annulment of the Commission's decision on its NAP on the basis that the contested decision reducing its proposed cap by $26.7 \%$ was adopted after the expiry of the three-month period prescribed by Article $9(3)$ of Directive 2003/87/EC, and Poland also claimed that the Commission conducted an inconsistent application of its own preferred economic analysis method infringing the duty to state reasons. ${ }^{4}$ Meanwhile, the action brought by Poland was supported by eight other complaints of Polish companies. ${ }^{5}$ In the Czech Republic v Commission case, the Czech Republic claimed that the Commission had exceeded its authority and infringed Article 9(3) and 11(2) of Directive 2003/87/EC by applying its own method for fixing the national cap. ${ }^{6}$ In the Republic of Hungary $v$ Commission case, Hungary also complained that the Commission had determined its national cap alone in its decision. ${ }^{7}$ In the Estonia $v$ Commission case, Estonia argued the Commission had made manifest errors of assessment which infringed Article 9(3) and 11(2) of Directive 2003/87/EC mentioned above ${ }^{8}$. In the Latvia $v$ Commission case, Latvia alleged that the Commission's extensive explanation of the Article 9(3) had infringed upon its right to determine its domestic energy policy and had violated non-discrimination on nationality in that the Commission's methods put Member States with low emissions in a disadvantaged place. ${ }^{9}$ In the Lithuania $v$ Commission case, Lithuania argued that the Commission had exceeded its review power and determined the national cap based on its own methods. ${ }^{10}$ In the Romania $v$ Commission case, Romania also sought the annulment of the Commission's decision on its NAP

\footnotetext{
${ }^{1}$ Case T-32/07, Slovakia v. Commission, OJ C 69, 24.3.2007, p. 29-29, Action brought on 7 February 2007.

2 De Sépibus, J. (2007), p.20.

3 Case T-183/07, Poland v. Commission, OJ C 155, 07.07.2007, p. 41, action brought on 28 March 2007.

${ }^{4}$ See Case T-183/07, Poland v. Commission, [2009] ECR II-03395, at para. 27-30, para. 48-59; see also Ghaleigh, N. (2009), p.26.

${ }^{5}$ See Case T-193/07, Górażdze Cement v. Commission, OJ C 170 of 21.07.2007, p.36; Case T-195/07, Lafarge Cement v. Commission, OJ C 170 of 21.07.2007, p.37; Case T-196/07, Dyckerhoff Polska v. Commission, OJ C 170 of 21.07.2007, p.38; Case T-197/07, Grupa Ożarów v. Commission, OJ C 170 of 21.07.2007, p.38; Case T-198/07, Cementownia 'Warta' v. Commission, OJ C 170 of 21.07.2007, p.39; Case T-199/07, Cementownia 'Odra' v. Commission, OJ C 170 of 21.07.2007, p.39; Case T-203/07, Cemex Polska v. Commission, OJ C 170 of 21.07.2007, p.40; Case T-208/07, BOT Elektrownia Betchatów and Others v. Commission, OJ C 170 of 21.07.2007, p.41.

${ }^{6}$ Case T-194/07, Czech Republic v. Commission, OJ C 199, 25.8.2007, p. 38-39, action brought on 4 June 2007.

${ }^{7}$ Case T-221/07, Republic of Hungary v. Commission of the European Communities, OJ C 199, 25.8.2007, p. 41-41, action brought on 26 June 2007.

${ }^{8}$ Case T-263/07: Judgment of the Court of First Instance of 23 September 2009 - Estonia v. Commission, OJ C 267, 7.11.2009, p. 59-59.

9 Case T-369/07: Judgment of the General Court of 22 March 2011 - Republic of Latvia v. Commission, OJ C 139, 7.5.2011, p. 15-16; see also Ghaleigh, N. (2009), p.26.

${ }^{10}$ Case T-368/07: action brought on 26 September 2007 - Lithuania v. Commission, OJ C 283, 24.11.2007, p. 35-36. But the President of the Seventh Chamber has ordered that the case be removed from the register in Case T-368/07: Order of the General Court of 19 September 2011 - Lithuania v. Commission, OJ C 340, 19.11.2011, p. 32-32.
} 
on the basis that the Commission had determined the national cap for Romania with its own methods. ${ }^{1}$

Finally, Poland and Estonia ${ }^{2}$ won their case in September 2009 and Lithuania won its case in $2011^{3}$ on the grounds that the Commission had not followed proper procedures and exceeded its power when assessing the NAPs, ${ }^{4}$ meaning that the Commission failed in its attempt to make the Member States tighten their national caps. For instance, in the Poland $v$ Commission case, the CFI ruled on 23 September 2009 annulling the Commission's decision ${ }^{5}$. The Commission appealed this judgment before the ECJ, but the claim was dismissed by the court. ${ }^{6}$ The courts supported these Member States and annulled the Commission's decisions on the NAPs. However, in other cases, such as the Romania $v$ Commission case ${ }^{7}$, the Slovakia $v$ Commission case $^{8}$, the Czech Republic $v$ Commission case ${ }^{9}$ and the Hungary $v$ Commission case ${ }^{10}$ have been removed from the register by the court. ${ }^{11}$ In addition, some individual companies also contest the decisions on NAP made by the Commission before the courts, such as the EnBW Energie Baden-Württemberg AGv Commission case ${ }^{12}$, the Werke GmbH and Others v. Commission ${ }^{13}$, US Steel Košice v. Commission case ${ }^{14}$, the Elektro Belchatow and Others v. Commission case ${ }^{15}$, the Cemex UK Cement v. Commission case ${ }^{16}$. However, all these cases have been dismissed due to the lack of locus standi or lack of direct and individual concern, a precondition for instituting proceedings according to Article 263 TFEU. ${ }^{17}$

In the cases brought by Member States against the Commission mentioned above, Member States lodged their complaint with the CFI requiring the annulment of the Commission's decisions on the NAPs, inter alia those reducing their national caps. Moreover, the claims rest on similar essential grounds including a breach of basic procedural requirements and certain rules of

\footnotetext{
${ }^{1}$ Case T-484/07: action brought on 22 December 2007 - Romania v. Commission of the European Communities, OJ C 51, 23.2.2008, p. 57-57

2 Case T-263/07, Republic of Estonia v. Commission [2009] ECR II-03463. The Commission appealed in 2009 but the court dismissed the appeal; see the Case C-505/09 P: Judgment of the Court (Second Chamber) of 29 March 2012, OJ C 151, 26.5.2012, p. 2-3.

${ }^{3}$ Case T-369/07, [2011] ECR II-01039, the Commission appealed but the case was dismissed by the court, see Case C-267/11 P: Judgment of the Court (First Chamber) of 3 October 2013 - European Commission $v$. Republic of Latvia, Republic of Lithuania, Slovak Republic, United Kingdom of Great Britain and Northern Ireland, OJ C 344, 23.11.2013, p. 6-6.

${ }^{4}$ Cooper, R. (2010), p.56.

${ }^{5}$ Case T-183/07 Poland v. Commission [2009] ECR II-3395.

${ }^{6}$ Case C-504/09 P, European Commission v. Republic of Poland, Judgment of the Court (Second Chamber) of 29 March 2012 (not yet reported).

${ }^{7}$ Case T-484/07, Romania v. Commission, this case was removed by the order of the General Court of 11 July 2012, OJ C 258, 25.8.2012, p.27-27.

8 Case T-32/07, Slovakia v. Commission. It was removed by the Order of the Court of First Instance of 14 May 2008 - Slovak Republic v. Commission, OJ C 171, 5.7.2008, p. 49-49.

9 Case T-194/07, Czech Republic v. Commission. It was removed by the Order of the General Court of 26 April 2013 - Czech Republic v. Commission, OJ C 171, 15.6.2013, p. 40-40.

${ }^{10}$ Case T-221/07, Republic of Hungary v. Commission of the European Communities. It was removed by the Order of the General Court of 23 April 2013 - Hungary v. Commission, OJ C 171, 15.6.2013, p. 40-40.

${ }_{11}$ With regard to the reasons why the cases were removed by the court, there is not so much information about it. Maybe they are not of practical relevance anymore.

12 Case T-387/04, EnBW Energie Baden-Württemberg AG v. Commission [2007] ECR II-1195.

13 Case T-28/07, Werke GmbH and Others v. Commission [2007] ECR II-00098.

${ }^{14}$ Case T-27/07, US Steel Košice v. Commission, CFI 1 October 2007, [2007] ECR II-128.

${ }^{15}$ Case T-208/07, Elektro Belchatow and Others v. Commission [2008] ECR II-00225

16 Case T-13/07, Cemex UK Cement v. Commission, CFI 6 November 2007, [2007] ECR II-146.

${ }^{17}$ See van Zeben, J. A. W. (2009b), p.123-125.
} 
law; and an excess of the Commission's power regarding assessment. ${ }^{1}$ Especially in respect of the issue that the Commission exceeded its competence in the decentralised model, this section will try to explore the boundary of the Commission's competence concerning the NAP and the legal effect of its decisions, aiming to get a better insight into the legal conflicts between the Commission and Member States.

\section{The boundary of the Commission's competence}

The respective roles and competence of the Commission and Member States under Directive 2003/87/EC were first examined in the case UK v. Commission ${ }^{2}$ and were then further clarified in the following case law.

In the UK $v$ Commission case, the boundary of the Commission's competence to review the NAP under Directive 2003/87/EC was first interpreted and clarified by the court. The UK had submitted a 'provisional' NAP to the Commission, which included several 'ongoing activities' mainly connected to public consultation rounds. After submitting the NAP to the Commission, the UK wanted to update and amend its plan to bring it in line with the public consultation, but the Commission did not accept the amendment to the UK NAP. As a result, the UK challenged the Commission's decision and argued that the Commission had exceeded its power in reviewing the NAP. According to the judgment of the CFI, despite the fact that the Commission was empowered to review the NAP before Member State adopted the definite decision, the Commission could not restrict a Member State's right to propose an amendment. ${ }^{3}$ On the contrary, the CFI supported the right of the Member State to propose amendments to its NAP after its notification to the Commission until it adopted the definite decision about the national cap under Article 11(1) ${ }^{4}$, and the amendments of the NAP were not limited to those intended to address the incompatibilities raised by the Commission. ${ }^{5}$

In addition, with regard to the question of whether the Commission can reduce the national cap for the Member State in its decision, the court approved the national discretion. In this respect, Poland and Estonia appealed against the Commission's decisions determining a lower cap on the allowances in the allocation plans, the CFI accepted their claims and the ECJ also supported these Member States. In the judgment of the court for the Poland $v$ Commission case, the General Court ruled that, when exercising their competences, Member States and the Commission had a certain margin for manoeuvre. ${ }^{6}$ To be specific, only the Member States have the competence to compose their NAP first and then to make final decisions fixing the total quantity of allowances to be allocated. ${ }^{7}$ Therefore, the Commission's power is limited to a review of legality, which means that the Commission is entitled to assess first the conformity of

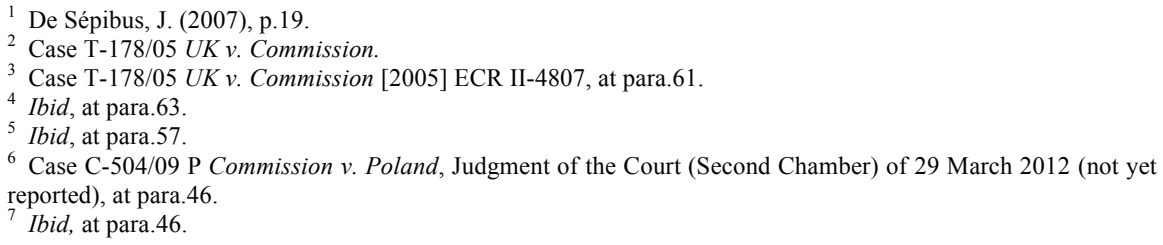


the NAPs with the criteria established in the EU ETS Directive and second to reject the plans that are incompatible with those criteria and provisions. ${ }^{1}$

The case law above showed that the Commission had less power than it wanted to have. In other words, according to the court, the Commission's competence was strictly limited to reviewing the NAPs and its amendments against Article 10 and the Annex III criteria. ${ }^{2}$ With regard to the criteria, based on which Member States develop the NAP and the Commission reviews or rejects the NAP, it is not free of challenge either. It is also argued that the objective and transparent criteria for setting the NAP is not limited to the criteria listed in Annex III to Directive 2003/87/EC. The word 'including' mentioned in Article 9(1) does not mean exclusive, as it is also stipulated in Article 9(3) that the Commission may reject a NAP if it is incompatible with the criteria listed in Annex III or with Article 10. ${ }^{3}$ However, if the Commission wants to reject the NAPs based on criteria other than Annex III, where such criteria are transparent and objective, the Commission should demonstrate how the NAP infringes the EU ETS Directive or EC law. ${ }^{4}$ Moreover, any rejection made by the Commission has to be based on the NAP's incompatibility with the criteria of Annex III or with Article 10 of Directive 2003/87/EC . According to the court, the Directive doesn't provide other ground for rejecting a NAP. ${ }^{6}$

In this respect, it is noticeable that the Commission has adopted several guidelines to help Member States compose their NAPs. ${ }^{7}$ However, one may raise the question as to their legal validity and effect on the NAP. According to the judgment of the court in the case Germany $v$ Commission, the guidance, which the Commission applied extensively to improve the transparency when it excised its administrative discretion and supervisory power, did not in principle have binding effect on third parties. ${ }^{8}$ In other words, the Commission's communications have no real lawful effect except for the Commission itself, which can be used by Member State to limit any unjustified breach of the declaration made by the Commission before. $^{9}$

\section{The legal effect of the Commission's decisions}

All cases brought by private actors against the Commission's decisions on the NAPs have been dismissed as inadmissible because of a lack of the direct and individual concern and thus the legal standing. In other words, the private parties did not have sufficient interest to lodge an appeal against the Commission's decision on the NAP, which was only addressed to the Member States rather than to the private parties. ${ }^{10}$

\footnotetext{
${ }^{1}$ Ibid.

2 Van Zeben, J. A. W. (2009b), p.121.

${ }^{3}$ Netherlands Environmental Assessment Agency (2008), p.88.

${ }^{4}$ Case T-374/04 Germany v. Commission [2007] ECR II-4431; see also Ghaleigh, N. (2009), p.17.

5 Article 9(3), Directive 2003/87/EC.

${ }^{6}$ Case T-178/05, UK v. Commission [2005] ECR II-4807, at para.54.

7 Such as COM (2003) 830 final, COM (2005) 703 final and COM (2006) 725, see also Van Aken, N., \& Paques, M. (2008), p.103.

${ }_{9}^{8}$ Case T-374/04 Germany v. Commission [2007] ECR II-4431, at para.110.

${ }^{9}$ Van Aken, N., \& Paques, M. (2008), p.104.

${ }^{10}$ Ibid, p.93.
} 
For instance, in the case EnBW Energie Baden-Württemberg v. Commission, the court ruled that the evaluation of the NAP by the Commission was not an 'authorisation' sensu stricto, because the Commission could only carry out its review of the NAP during the three months starting from the notification, otherwise the NAP would be automatically accepted. ${ }^{1}$ Moreover, the court stated that the NAP made by Member State was presumed to be legal valid ${ }^{2}$, and thus the purpose of the Commission's review procedure and decision was to provide for legal certainty for Member States. ${ }^{3}$

Therefore, in this case the final decision made by Member State itself would influence the legal position of the individual concerned, without the need for general authorisation by the Commission's decision. ${ }^{4}$ The only remedy for an applicant in these cases, where appropriate, may be to bring a legal claim before the national court instead of the EU courts. However, the number of the cases brought by companies against the Commission in the EU courts continued to increase in the first two trading periods, despite the clear jurisprudence of the courts. ${ }^{5}$

\subsubsection{Potential problems under the centralised model}

Due to the adoption of the EU-wide cap that leads to a centralised approach, the legal conflicts between the Commission and Member States in regard to the competence distribution in the determination of the NAP have ceased to exist in the third trading period. However, the centralised approach per se is not free from challenge. In particular, the uncertainty in terms of the implementation of the centralised approach for cap setting within a multi-level governance structure needs to be analysed in light of Article 193 TFEU. Moreover, specific attention should also be paid in this section to the potential waterbed effect that may take place under the EU-wide cap of the EU ETS.

\section{The possibility for stricter targets and measures adopted by Member States}

The shift of the decision-making power from the national level to the EU level gives rise to the question of what the consequences are for national policies and thus the other relevant GHG emitting sectors. ${ }^{6}$ One may wonder about the possibility for more ambitious national measures under the centralised approach for cap setting, since the decentralised model allowed Member States to set strict caps.

As indicated in section 3 of this chapter above, some Member States have tried to employ additional stringent measures on the ETS sectors in pursuit of a further cut in GHG emissions, which can be exemplified by the adoption of national emissions performance standard in the UK. In addition, the application of the emission limit value on other pollutants from the same installations may also make a contribution to the reduction or increase of the GHG emissions covered by the EU ETS in some circumstances. But the introduction of a new measure to control

${ }^{1}$ Ibid.

2 Case T-387/04, EnBW Energie Baden-Württemberg AG v. Commission [2007] ECR II-1195, at para. 115.

3 Ibid, at paras. 117-118; see also Kurkowski, S. J. (2005), p.123.

${ }_{5}^{4}$ Ghaleigh, N. (2009), p.19.

${ }^{5}$ Van Zeben, J. A. W. (2009b), p.126-127.

${ }^{6}$ Peeters, M. (2008), p.36. 
the emissions that are already regulated by existing measures may risk duplicating the burden on the affected operators. ${ }^{1}$ As far as the establishment of national emissions performance standards or, alternatively, the emissions limit value is concerned, the relationship between the EU ETS Directive and the IPPC Directive (then replaced by the IE Directive) is relevant.

As stipulated in Article 26 of the EU ETS Directive, the IPPC Directive was amended and the change was also reflected in its successor, the IE Directive, requiring that the GHG emissions permit for the installations covered by the EU ETS 'shall not include an emissions limit value for direct emissions of that gas unless it is necessary to ensure that no significant local pollution is caused $^{2}$. In this respect, both EU ETS Directive and IPPC Directive (then the IE Directive) can be considered to qualify as a rule of total harmonisation that does not permit derogation. ${ }^{3}$ One has to wonder whether there is still a possibility for Member States to impose stricter measures on the installations located in their countries. This option might become more relevant if the concerns about climate change increase, which might induce national authorities to consider more ambitious measures compared to the EU-wide cap. In this sense, attention needs to be paid to the legality of national measures that require operators to limit their GHG emissions from installations covered by the EU ETS Directive to a national standard. ${ }^{4}$

In order to answer the question as to whether Member States are allowed to employ more stringent measures, Article 193 TFEU has to be taken into account. According to Article 193 TFEU, 'the protective measures adopted pursuant to Article 192 shall not prevent any Member State from maintaining or introducing more stringent protective measures', which must be compatible with the Treaties and shall be notified to the Commission. ${ }^{5}$ In other words, Member States may introduce more stringent environmental protective measures pursuant to Article 193 TFEU. In accordance with Article 193 TFEU, recital 10 of the IE Directive also emphasises that 'this Directive does not prevent Member States from maintaining or introducing more stringent protective measures, for example greenhouse gas emission requirements'. ${ }^{6}$ In contrast to the ambiguous meaning of recital 10 mentioned above, however, relevant amendments put forward by the European Parliament during the negotiation on the IE Directive tried to provide a further clarification. $^{7}$ For instance, the amendment proposed aimed to clarify explicitly that stringent protective national measures could be adopted for 'installations that are covered by Annex I of Directive 2003/87/EC' ${ }^{8}$ Moreover, the proposed amendment even contains the phrase 'Member States may choose not to impose' replacing 'the permit shall not include' an emissions limit value for the EU ETS installations, attempting to clarify that Article 193 TFEU allows Member

\footnotetext{
${ }^{1}$ Olsen, B. E. (2006), p.162.

2 Article 26, EU ETS Directive; see also in Article 9(3) of Directive 2008/1/EC and then Article 9(1), Directive $2010 / 75$. The literature has also criticised that the provision of excluding the possibility of the establishment of an emission limit value under the permit is incompatible with the precautionary principle, supporting the combination of the overall cap, the ETS and the emissions limit values. See Epiney, A. (2012), p.23-27.

3 Jans, J. H. \& Vedder, H. H. B. (2011), p.104; see also the discussion in Peeters, M.(2011b), p.129-130.

${ }^{4}$ Further discussion can be referred to Squintani, L., Holwerda, M. \& de Graaf, K. (2012), p.71-86.

5 Article 193, TFEU.

${ }^{6}$ Recital 10, Directive 2010/75/EU.

${ }^{7}$ See Recommendation for Second Reading on the Council position at first reading for adopting a directive of the European Parliament and of the Council on industrial emissions (integrated pollution prevention and control) (recast), COD/2007/0286, No. A7-0145/2010, European Parliament, 6 May 2010.

${ }^{8} \mathrm{Ibid}$, at Amendment 4.
} 
States to apply more stringent requirements within the permit under the IE Directive. ${ }^{1}$ Nevertheless, the proposal of these amendments was not accepted by the Council finally, resulting in the current unclear recital 10 of the IE Directive.

In this sense, it remains very questionable whether the application of Article 193 TFEU may be restricted by the European measure like the EU ETS Directive ${ }^{2}$, on which opinions in the academic literature have differed to a large degree. Some scholars supported the idea that Member States can always take stricter measures in a harmonised approach under Article 192 TFEU, while the opposite view argued that the European legislature can decide to what extent Member States may adopt more severe measures than those set up in the Directive ${ }^{3}$. Both sides of the argument have valid reasons, but it is also argued that the answer to the question may depend on the interpretation of the CJEU of the secondary objectives of the EU ETS Directive, inter alia the goal of cost-effectiveness and economic efficiency in achieving the emissions reduction target. ${ }^{4}$

Hence, there exists regulatory uncertainty as to the question of whether Article 26 of the EU ETS Directive can and will limit the possibility for Member States to adopt strict measures in the harmonising approach in line with Article 193 TFEU, which means that operators are also not sure whether additional national measures might be imposed on them. In this sense, the case law is needed again in order to clarify the question of whether Member States may take more stringent measures in specific circumstances. In view of the potential influence of the IE Directive on the functioning of the ETS and vice versa, the integration of the EU ETS into the existing legal system is also of significance, requiring an elegant coordination between these instruments in the implementation.

\section{Waterbed effect under the EU-wide cap of the EU ETS}

The potential problem of the so-called 'waterbed effect' that may occur under the EU-wide cap should not be overlooked, since this may influence the willingness of Member States to adopt stricter measures for their EU ETS industries.

The cap is equal to the total amount of the allowances to be issued. When the installations have reduced emissions as required by additional measures adopted by Member States in accordance with Article 193 TFEU, these installations need fewer allowances. These spared allowances may be sold to other installations located in other Member States. Consequently, the price of the allowances in the EU carbon market may drop, leading to a decrease of the abatement cost for other Member States at the same time. As a result, it may be less attractive for one Member State to adopt more stringent measures, in view of the fact that its additional effort may be used by industries in other Member States. This phenomenon is called the 'waterbed effect', which means that applying pressure in one place causes a rise over the rest of the surface, because the

${ }^{1}$ Ibid, at Amendment 18.

2 See Jans, J. H. \& Vedder, H. H. B. (2011), p.118; See also Krämer. L. (2007), p.127.

3 See Jans, J. H. \& Vedder, H. H. B. (2011), p.118-119.

${ }^{4}$ Squintani, L., Holwerda, M. \& de Graaf, K. (2012), p.86-87. 
total volume is constant. ${ }^{1}$ In other words, extra reductions of the ETS sectors in one Member State can be nullified by less of a reduction in other Member States. ${ }^{2}$

Not much attention has been paid to the waterbed effect in the EU ETS where the problem will be obvious under the EU-wide cap of the EU ETS. With the revision of the EU ETS Directive in 2009, as indicated above, there will be no national caps for the trading sectors except for the EU-wide cap in the EU ETS from 2013 beyond. Once the EU-wide cap of the EU ETS is set up, the overall emissions allowed to be emitted by installations covered by the EU ETS will be determined by the total amount of allowances that is fixed ex ante. In light of the basic logic of the ETS, the extra reduction of emissions by one installation would be sold to other installations participating in the market, which will probably be changed into equal amount of emissions finally. As a result, if a Member State adopts additional measures for emissions reduction to be achieved by EU ETS installations in its country, this national effort will not make an effective contribution to the overall emissions reduction of the EU ETS. ${ }^{3}$ This effect may only be prevented if the extra emissions reduction caused by the additional measures adopted at the national level will be covered by the governmental withdrawal of such allowances. ${ }^{4}$ Yet, no suitable provisions have been established. In the course of designing the price management provisions in structural reform of the EU ETS, it could be considered to allow for the withdrawal of allowances if Member States adopt more stringent measures for their EU ETS industries.

Because of the establishment of an EU-wide cap, the incentive for national legislators to address the EU ETS sector is not only reduced, but also the intensity of national policies concerning the non-trading sectors covered by the ESD will be influenced. ${ }^{5}$ If there is less room or willingness to address the EU ETS sectors, further measures may be imposed on the ESD sectors.

In view of the problem due to the waterbed effect, in particular of the possible impact of the additional measures on the economic development or other social policies, one may raise the question as to the willingness and desire of the Member States to set up more stringent targets for and to apply additional measures to the domestic industries, aiming to gain a further cut of GHG emissions at the national level. In this respect, despite of the establishment of the EU-wide cap for the EU ETS, it remains a challenge for the EU to deal with this problem in order to provide sufficient incentives for Member States to adopt more stringent and additional measures or to facilitate Member States that really want to move on with more stringent national policies, like the UK, or prevent some negative incentives for Member States to do less, within the multi-level governance structure.

\subsubsection{Concluding remarks}

GHG emissions reduction target is a specific instrument ensuring the environmental goal of the climate policy. How to determine the specific emissions reduction target is the first key element

\footnotetext{
${ }^{1}$ Netherlands Environmental Assessment Agency (2008), p.38.

2 Ibid.

3 Sorrell, S., \& Sijm, J. (2013), p.426.

${ }^{4}$ Peeters, M. (2011b), p. 130.

5 Peeters, M. (2008), p.37.
} 
for the ETS. Since the EU ETS has been established based on the cap-and-trade model, how to distribute the competence of deciding the cap between the EU and Member States within the multi-level governance structure has been very crucial and sensitive.

Within the European multi-level governance structure, different levels of authorities may have a distinct priority and preference in the policy making and agenda, in particular in the process of cap setting for the ETS. In this respect, the higher authorities at the EU level (mainly represented by the Commission) may pay more attention to the stringency of the European climate goal, in particular the GHG emissions reduction target, as a whole to strengthen the EU's leading role played in the international community. Meanwhile, the Commission may also focus on the integrity of the internal market that may be influenced by the national caps, aiming to ensure a level playing field in the EU. Nevertheless, the authorities at the lower level, such as the Member States, may prefer the domestic economic development to the ambitious climate target, trying to set up a cap that may benefit its domestic industries to the extent possible. Due to the possible and remarkable difference in terms of the policy priority of different levels of authorities, it is easy to give rise to potential legal conflicts between the authorities in the course of cap setting.

With regard to the question as to how to distribute the competence to set up the cap in the legal framework for the ETS, the analysis of the two models employed in the EU ETS can provide us with some useful learning points. To be specific, in the course of setting up a cap for the ETS, the legal conflict between different levels of authorities involved in the cap setting may occur, which should be controlled and solved in a sufficiently clear way by the legal system, if possible, in advance.

In particular for the case of the decentralised model used in the first two trading periods, there is lesson to be drawn from it that the different interests of different levels of authorities call for a clear legislative framework to avoid potential legal conflicts. However, the legislative framework for competence distribution in the decentralised model was not sufficiently clear. Since there are different concerns, where Member States focus on national circumstances while the Commission focuses on the overall EU performance, the legal conflicts have occurred, demonstrated by the case law regarding the NAPs. As suggested by the case law, Member States wanted to allocate more allowances to the installations than the Commission wanted them to allocate, but the Commission acted in breach of the law when it tried to reduce the national caps.

In this respect, the case law shows that the court's decision was necessary to clarify the legislative framework in relation to competence distribution. Based on the judgment of the courts, the competence distribution between the EU and Member States had to be further clarified and confirmed in terms of the boundaries of the competences and the legal effect of the decisions. Despite the fact that the Commission has lost most of the cases brought before the court, mainly because it exceeded its competence, the Commission still has the power to reject an NAP, in order to influence the cap setting by Member States in the decentralised approach. However, the analysis has indicated that the methods and approaches that the Commission used in exercising its power were wrong, such as using its own data, methods and even reducing the national caps for Member States. 
In the case of a centralised model, however, the way to deal with the waterbed effect needs to be considered, if it is the wish to allow further movement toward national or local climate action. In the centralised approach in the third trading period, the EU has adopted the EU-wide cap to replace the NAP, which has, at the same time, presented the option to avoid the seeming over-allocation by Member States to a certain degree. Moreover, this approach has solved the legal conflicts of competence distribution between the Commission and Member States that occurred in the decentralised model by a new revised EU ETS Directive to a large extent. Although the centralised model has made a clear arrangement about the competence distribution on the cap setting through the EU-wide cap of the EU ETS, potential problems, in particular the waterbed effect may also have a substantial impact on the design and implementation of the EU ETS as well as national climate policies. Consequently, the competence distribution for adopting climate legislation still needs a delicate design and implementation. In particular when the centralised approach is adopted, the potential waterbed effect under the cap determined at the central level should be dealt with carefully. It will be very important for the legal framework for the ETS to provide sufficient positive incentives for lower authorities that want to move forward by adopting more stringent climate laws.

Despite the unique legal system established in the EU, the challenges facing the EU ETS in terms of the cap setting may also be encountered in third countries that may establish the ETS within a multi-level governance structure. In this respect, the main learning point from the EU ETS for other countries may be the importance of paying attention to potential legal conflicts between the different levels of authorities in terms of competence distribution and trying to figure out a possible solution based on the legal system of that country.

\subsection{Equal treatment in allowance allocation}

The allowance allocation is, to a large extent, a distributional choice and exercise. In the context of the EU ETS, there are various kinds of competitive relationships that might be affected by the allocation of allowances, including the relationship between trading sectors and non-trading sectors, between different trading sectors, between competing firms of the same Member State or different Member States. ${ }^{1}$ Furthermore, when allocating the allowances for free, regulators have to decide how to treat the incumbents and new comers, small and large installations, early actors and late actors, installations with different potentials and technologies to reduce, installations sensitive to international competition and those that are not. ${ }^{2}$ As far as the distributional issues relating to allowance allocation are concerned, the principle of equal treatment should be taken into account from the legal perspective. As indicated in section 2 of this chapter, the principle of equal treatment requires that comparable situations must not be treated differently and different situations must not be treated in the same way, unless that treatment is based on objective justification. $^{3}$

\footnotetext{
${ }^{1}$ Weishaar, S. (2008a), p.167-170.

2 de Cendra de Larragán, J. (2010a), p.360.

3 Jans, J. H. \& Vedder, H. H. B. (2011), p. 21.
} 
When discussing equal treatment and allowance allocation in the EU ETS, one has to be aware of the fact that there are at least two stages of the allowance allocation: first determining the scope of the EU ETS and then allocating the allowances to the installations covered by the EU ETS. Before the specific allocation among the ETS sectors is carried out, the scope of the EU ETS, determining which sector needs to participate in the scheme and to receive the allowances, has a significant impact on the equal treatment of the ETS sectors and non-ETS sectors. One may hence raise the question of whether the scope of the EU ETS is compatible with the principle of equal treatment, which can be exemplified by the Arcelor case. In the Arcelor case, the steel company argued that Directive 2003/87/EC violated the principle of equal treatment, since the Directive had a selective scope and hence failed to treat all polluters equally ${ }^{1}$. Although Arcelor lost the case, in the rulings the courts had emphasised again that, whatever approach is taken by the EU legislature, it must be on the basis of a valid and objective justification for treating polluters differently. ${ }^{2}$ In other words, the step-by-step approach in enlarging the scope is possible, but the ultimate goal is equal treatment of comparable sectors.

With regard to the ETS, the legal position of individual installations covered will be affected directly by the choice and design of the allocation methods. ${ }^{3}$ It is of significance to ensure compliance with the principle of equal treatment in the course of the design and implementation of allocation methods, in pursuit of the market integrity and a level playing field for the installations covered by the EU ETS. Aiming to deal with various competitive relationships, model one of the EU ETS applied free allocation by grandfathering within the decentralised approach, which was a political choice and a compromise in order to initiate the ETS. In order to solve the problems of market distortion and differentiated treatment that emerged in model one, model two applies auctioning as the main rule together with free allocation for some special cases, both of which are designed and implemented in a harmonised approach.

Based on the description of two models applied to the allocation of allowances in section 3 of this chapter, there is an indication that two important aspects of the design and implementation of allowance allocation may have a substantial impact on the extent to which equal treatment can be achieved. To be specific, the attention of this section focuses on the competence distribution between the EU and Member States with regard to the determination of allocation rules on the one hand and the specific choice and design concerning the allocation methods on the other hand.

\subsubsection{Equal treatment and competence distribution}

Within a multi-level governance structure, the level of decision making has an important impact on the design and implementation of the EU ETS, which has been demonstrated by the cap setting discussed in the above section. In particular for the allowances allocation, a significant distributional decision for the installations located in different Member States but covered by a

\footnotetext{
${ }^{1}$ See Peeters, M. (2011a), p.24; See also Case T-16/04 Arcelor SA v. Parliament and Council [2010] ECR II-211, at para. 161-164

2 See Peeters, M. (2011a), p.26; see also Case T-16/04 Arcelor SA v. Parliament and Council [2010] ECR II-211, at para. $167-168$

${ }^{3}$ See in section 3 of chapter 2 and section 2 of chapter 3 of this thesis.
} 
Community scheme is how to distribute the competence of deciding the allocation rules between the EU and Member States, and this is crucial to ensure a level playing field from the perspective of equal treatment. In view of the close connection between cap setting and allowance allocation, the two models of allowance allocation applied in the EU ETS can also be distinguished into a decentralised model for the first two trading periods and a harmonised model in the third trading period and beyond, which is quite similar to that of the cap setting.

\subsubsection{Decentralised approach in model one}

Model one (2005-2012) is a decentralised approach in which Member States have quite some competence in designing the domestic allocation rules and making the final decisions on allocation to each installation located in its territory. This decentralised competence distribution however has resulted in the differentiation of the allocation rules across Member States to a large extent, which can be exemplified by the description in section 3 of this chapter. For instance, the proportion of allowances that have been auctioned in the first two trading periods is very different among Member States. Meanwhile, Member States have also chosen different baselines of historical emissions for the grandfathering. In addition, the benchmarks employed by some Member States for specific sectors also vary to a large degree.

It is noticeable that the divergence among the national allocation rules determined and implemented by Member States may cause some distributional consequences, in particular differential treatment among similar installations, as they are subject to different national allocation rules and will receive various amounts of allowances. ${ }^{1}$ With regard to the significant diversity in the allocation methodologies among the Member States, some scholars have analysed the possible impact that may be induced by this decentralised approach. For instance, there is an indication that the diverse design of allocation rules, inter alia the different approach to the free allocation to the new entrants, may have varying impacts and may provide different incentives for investment across the Member States. ${ }^{2}$

Especially in view of the competition pressure from the internal market, the decentralised approach may put Member States in a kind of so-called 'prisoner's dilemma' with regard to cap setting as well as the allowances allocation, where Member States may exercise its discretion to favour its powerful industries at home. ${ }^{3}$ In this respect, the attempt by Member States to set up a generous national cap for their home industries covered by the EU ETS has been illustrated by the analysis of the cap setting in the above section. By analogy, Member States are also motivated to allocate the allowances to their ETS sectors as much as possible. If one Member State adopts preferential treatment for its favoured industry, it would give that industry a competitive advantage over similar industries in other Member State, at the cost of burdening other industries at home. ${ }^{4}$ In this respect, the competence of Member States in deciding the

\footnotetext{
${ }^{1}$ de Cendra de Larragán, J. (2010a), p.348.

2 Matthes, F. et al (2005), p.139; see also Ahman,M., Burtraw, D., Kruger, J. \& Zetterberg, L. (2006).

3 Kurkowski, S. J. (2005), p.702.

${ }^{4}$ Ibid, p.708-709.
} 
allowance allocation, together with the discretion in setting the national caps, has led to concerns on the equity of the initial allocation of allowances in the decentralised approach. ${ }^{1}$

With regard to the differential treatment of the installations due to the decentralised approach, it is of course not right to conclude that this kind of differential treatment is unequal treatment simply. In view of the disparity among the Member States, it seems be justified to allow Member States some flexibility in determining the allocation approach. ${ }^{2}$ Although installations in a comparable situation in principle should be treated equally, there may still be a valid reason to treat such installations differently. ${ }^{3}$ In other words, differential treatment among the national implementation rules is not discrimination on the condition that those rules conform to the objectives of the European regime and are applied in accordance with objective criteria ${ }^{4}$, which needs to be evaluated.

According to Directive 2003/87/EC, the differentiated allocation rules contained in the NAPs should be assessed by the Commission. In the first two trading periods, the variety in allocation methodologies, from the perspective of the Commission, has generated distortions of competition across Member States. ${ }^{5}$ As a result, the Commission has rejected some NAPs based on the equal treatment consideration. For instance, the Commission rejected the NAP submitted by Germany for the first trading period, stating that the intended ex post adjustments to the allocation of allowances to new entrants would unduly favour new entrants compared to others listed in the NAP without ex post adjustment and thus contravened criterion 5 in Annex III of Directive 2003/87/EC. ${ }^{6}$ Nevertheless, the Court did not support the Commission, ruling that Criterion 5, mentioned above, has resulted in the specific application of the principle of equal treatment in the implementation of the EU ETS at the national level, inter alia the allocation of allowances based on the NAP. ${ }^{7}$ To be specific, the NAP shall not unduly favour certain undertakings or activities by discriminating between companies or sectors. ${ }^{8}$ Based on the Court's ruling, a correct application of the principle of equal treatment to the allocation requires due consideration of whether the operators in question are in comparable situations. ${ }^{9}$ Moreover, the Court ruled that the Commission could not merely allege that there is unequal treatment concerning the application of an ex post adjustment, without the due consideration required above and thus a justification for its conclusion in the contested decision. ${ }^{10}$ In other words, the Commission had the competence to assess and reject the allocation rules in the NAP in accordance with the principle of equal treatment, in particular Criterion 5 mentioned above. However, it is suggested that the Commission has not exercised that power in a correct and appropriate way.

\footnotetext{
1 Ibid, p.702.

2 Ibid, p.709-710.

3 Peeters, M. (2011a), p.26.

${ }^{4}$ See Case C-292/97 Karlsson [2000] ECR I-2737, at para.53; Seel also de Cendra de Larragán, J. (2010a), p.164.

See $\operatorname{SEC}(2008)$ 52, p.92.

${ }^{6}$ See C(2004) 2515/2 final, at preamble 4, Article 1.

7 Case T-374/04 Germany v. Commission [2007] ECR II-4431, at para. 153.

${ }^{8}$ Criterion 5, Annex III of Directive 2003/87/EC.

${ }^{9}$ Case T-374/04 Germany v. Commission [2007] ECR II-4431, at para.154.

${ }^{10} \mathrm{Ibid}$, at para. 163.
} 
Since the discretion of the Member States in allowance allocation is respected in the decentralised approach, the Commission can only reject the national allocation rules based on the criteria set up in Annex III of Directive 2003/87/EC. However, the criteria in relation to the allocation method are quite vague. Even though the Commission has adopted some detailed guidelines concerning the allocation rules, they are not legally binding. In this sense, the potential unequal treatment relating to the allocation of allowances can also be dealt with by the state aid rules. Stemming from the allocation, and some special free allocation measures adopted by Member States in the NAPs, state aid would endanger the equal treatment of private actors and the fair competition of the internal market. Although state aid rules may not be effective in guiding Member States towards selecting the least distortive allocation measures ${ }^{1}$, the examination is necessary to a certain degree. However, in the first two trading periods, the Commission did not conduct a formal investigation into the state aid issues but just carried out a provisional evaluation when assessing the NAP. ${ }^{2}$ Some case law concerning the NAP has focused on the state aid issue, such as EnBW Energie Baden-Württemberg $v$ Commission, but it was dismissed by the Court because of lack of direct and individual concern of the applicant.

\subsubsection{Harmonised approach in model two}

The principle of equal treatment does not deny, in advance, the freedom of Member States to choose allocation rules which can be justified by the logic and objective of the EU ETS. ${ }^{3}$ However, the experience of the determination of the NAPs in the decentralised approach has suggested that Member States have the propensity to protect their favoured installations by allocating more allowances to them, which can result in potential unequal treatment and distortion to the internal market. Since the establishment of the internal market is crucial for the $\mathrm{EU}^{4}$, according to the Commission, a 'common approach' in order to protect the internal market is hence an important objective of the Commission. ${ }^{5}$ Meanwhile, total harmonisation of the allocation methodology has also been considered by the European Parliament to be 'imperative' in order to make better use of the ETS and to avoid distortions in the internal market. ${ }^{6}$ Especially based on the lessons learnt from the first two trading periods, the desire of the EU legislator to avoid distortion and to enhance equal treatment through harmonising the allocation rules has at the same time increased. In light of the potential problem of the decentralised approach that Member States would like to allocate more allowances to preferential installations through their own allocation rules, a harmonised approach about the allocation rules was introduced in the third trading period in line with the EU-wide cap.

Model two (2013-2020 and beyond) is a harmonised approach in which the allocation rules, not only the auctioning but also the free allocation, have been adopted at the EU level to a large extent. The allocation methodologies, which have been determined and set up in detail in Directive 2009/29/EC, have to be applied by all Member States across the EU.

\footnotetext{
1 Weishaar, S. (2008a), p.175.

2 De Sépibus, J. (2009), p.127.

3 de Cendra de Larragán, J. (2008), p.81.

4 Article 3, TEU.

5 Vis, P.(2006), p.189.

${ }^{6}$ Position of the European Parliament on the EU ETS amendment recital 8, see also de Cendra de Larragán, J. (2010a), p.350.
} 
Concerning auctioning, which will be phased in gradually as the default allocation rule, the Auctioning Regulation has been adopted and will be directly applicable to the Member States addressed. ${ }^{1}$ Auctioning will be implemented with a common platform, in which the participants will be treated equally. In other words, all the participants will purchase the allowances at the same price or a similar price based on the market mechanism. Even though some Member States, such as Germany, the UK and Poland, can choose to opt out of the common platform for the auctions by appointing their own auction platforms, the auctioning rules of the Auctioning Regulation should be followed by all the Member States. Following verification by the Commission that the platforms satisfy the rules of the Regulation and the objectives of the ETS Directive, the appointments of the national auction platform have been approved through amendments to the Auctioning Regulation. ${ }^{2}$ Moreover, each auction held by the auction platforms appointed by Member States is open to buyers from anywhere in the EU, ensuring full, fair and equal access to auctioning for all industries covered by the EU ETS. ${ }^{3}$

Furthermore, the transitional free allocation rules have also been harmonised to a large extent, which is a key move to enhance equal treatment among the installations across the EU. In contrast to the decentralised approach, the free allocation rules have been determined by the EU legislative institutions in the form of benchmarking. The benchmark for each product concerned has been defined in the Commission Decision 2011/278/EU, which is binding in its entirety on the Member States addressed. ${ }^{4}$ Once the benchmarks are determined, all operators producing the same or similar products will receive the free allowances according to the specific benchmark. The potential unequal treatment between competing players located in different Member States seems to be reduced greatly. Therefore, the principle of equal treatment is supposed be respected and implemented in such a harmonised approach, although it depends on the precise rule and legal claims are still possible.

From the perspective of competence distribution, a harmonised approach distributing more competence to the Commission regarding the determination of the allocation rules enables equal treatment of the installations. Based on the harmonised allocation rules, installations in comparable situations hence are generally to be treated in a similar way across Member States since 2013. Nevertheless, it should also be noticed that, even in the harmonised approach, some Member States still have a certain discretion and flexibility in implementing the allocation rules based on their own circumstances. The description in section 3 indicated that the implementation of the transitional free allocation, particularly the grandfathering to the electricity sectors in eight Member States, still relies on the national measures or plans submitted by Member States and assessed by the Commission. In light of the experience of the decentralised approach, in particular the potential legal conflict between the Commission and Member States in regard to the competence distribution, how to control the allocation of Member States in order to avoid the potential generous allocation and unequal treatment thus remains a crucial challenge of the EU ETS legal framework to ensure fair competition in the EU carbon market and the proper functioning of the EU ETS.

\footnotetext{
${ }^{1}$ Craig, P., \& De Búrca, G. (2011), p.190.

2 See Commission Regulation (EU) No 784/2012; Commission Regulation (EU) No 1042/2012.

3 See Article 10 (4), EU ETS Directive.

${ }^{4}$ Craig, P., \& De Búrca, G. (2011), p.191.
} 


\subsubsection{Equal treatment and allocation methods}

The distribution of competences in relation to allocation is important and determines the level at which decisions are made to ensure the equal treatment in the internal market, while the specific choice and design of the allocation rules may affect the legal position of individual installation directly. The EU ETS have applied free allocation and auctioning at the same time in both models, which can be considered as a mix of allocation methods. However, the specific role of each allocation method varies a lot in the two models, leading to a different impact on the equal treatment of the installations.

\subsubsection{Lessons from model one}

According to Directive 2003/87/EC, free allocation has played a dominant role in the first two trading periods. Meanwhile, most of the allowances were allocated based on grandfathering rather than benchmarking or auctioning. As advocated by economists, auctioning is compatible with the polluter pays principle fundamentally and it also raises revenue for governments which could be recycled, for example to ease the unequal distributional consequences. ${ }^{1}$ The main reason auctioning was so seldom chosen by Member States in the first trading periods seems to be the strong opposition by the operators of existing installations who were heavily involved in the process of allocation by lobbying. In face of the argument that the competitiveness of the affected home industry would be reduced inevitably by unilateral auctioning, most Member States chose to allocate all allowances for free under the tremendous political pressure from the industries. $^{2}$

However, the free allocation method applied in model one has also raised some discussions in view of equal treatment. Frequently, allowances allocated to the power sectors for free have been criticised as windfall profit, as power sectors can pass the costs on to the consumers while the allowances can be traded with the market value, but other sectors competing on the international market may not do so. ${ }^{3}$ In other words, the emitters competing in the emissions trading market have different trading possibilities due to whether or not they can pass costs on to consumers. Moreover, according to a Commission staff working document, free allocations have had significant redistribution effects, most prominently but not exclusively in the power generating sector, leading to undesirable and unjustified distributional effects. ${ }^{4}$

With regard to installations covered by the free allocation rules, unequal treatment problems could also emerge. Since the amount of allowances to be allocated to incumbents based on the historical emissions, grandfathering led to a fierce battle concerning the amount of allowances allocated between governments and sectors, between industries of different sectors and between industries within single sectors. ${ }^{5}$ The intensive lobbying conducted by installations influences the political decision making. Moreover, the installations often complained about the diversity

${ }^{1}$ Betz, R., \& Sato, M. (2006), p.356; See also Grubb, M. \& Neuhoff, K. (2006).

2 De Sépibus, J. (2007), p.25.

3 See Grubb, M., Neuhoff, K., (2006); See also Betz, R., \& Sato, M. (2006), p.353.

${ }^{4}$ See SEC(2008) 52, p.93.

${ }^{5}$ Schmitt-Rady, B. (2006), p.87. 
and complexity regarding the free allocation rules adopted and designed by Member States, arguing that the rules were unequal where operators had received very different amounts of allowances. $^{1}$

\subsubsection{Observation on model two}

In order to solve the problems of distortion and unjustified differentiated treatment in the first two trading periods, the allocation methods have been revised significantly in the third trading period.

As indicated above, the allocation rules have been harmonised to a large extent at the EU level in the model two (2013-2020 and beyond), and thus installations across the EU are supposed to be treated more equally through the mix of allocation methods, in which auctioning will be applied as the main allocation rule together with some exceptions for free allocation. With regard to the application of each allocation method for three different categories of installation, there seems to be some justification for each of them. The auctioning, compatible with the polluter pays principle, can be designed and implemented well in order to reflect and ensure the equal treatment. ${ }^{2}$ Although there will be an optional derogation of auctioning for the electricity generators in the eight East European Member States, the transitional grandfathering may still be justified by the further modernisation and transition to low-carbon track. Concerning the transitional free allocation to the carbon leakage sectors to different extent by benchmarking, it may also be accepted as a reasonable step for the international competiveness consideration in the context of the EU's unilateral action without an international agreement with a commitment for GHG emissions reduction. In this respect, the differential treatment in the allowance allocation to these three categories of installations seems to be reasonable and falls within the discretion of the EU legislator.

From the perspective of equal treatment, however, one may still raise the question of whether this differential treatment among the sectors covered by the EU ETS is objectively justified or not, where they have been separated into three categories subjected to different allocation methods. ${ }^{3}$ There is a debate about the question whether there is evidence substantiating the risk of carbon leakage. ${ }^{4}$ The sectors exposed to a significant risk of carbon leakage, determined by the regulators, can receive allowances for free, while others will have to buy all or part of the allowances from auctioning or in the market. This special approach for the carbon leakage sectors will lead to the internal EU legal question of whether this preferential treatment is objectively justified or not and to what extent a differential treatment will still be allowed.

In this respect, the determination of the list concerning the carbon leakage sectors as well as the definition of the specific benchmark is crucial decision. As indicated in section 3, the scope of sectors exposed to a significant risk of carbon leakage is determined in the decision adopted by

\footnotetext{
${ }^{1}$ De Cendra de Larragán, J. (2010a), p.361.

2 Woerdman, E., Arcuri, A., \& Clò, S. (2007), p.22.

3 Peeters, M. (2011a), p.32.

${ }^{4}$ In this respect, several reports have concluded that there is little evidence detected for the occurrence of carbon leakage as defined by the EU ETS Directive, see for instance, Ecorys (2013); see also de Bruyn,S., Nelissen, D. \& Koopman, M. (2013).
} 
the Commission. According to the Commission, Member States proposed a list of 164 sectors and sub-sectors at risk of carbon leakage, accounting for about a quarter of the total emissions covered by the EU ETS and more than three quarters of the total emissions from the manufacturing industry in the EU ETS. ${ }^{1}$ Based on the qualitative and quantitative assessment, the Commission determined the list of carbon leakage sectors in $2009 .{ }^{2}$ It is however criticised by some scholars, arguing that the carbon leakage sectors would have been reduced if the assessment had been based on more realistic and strict assumptions. ${ }^{3}$ Meanwhile, it is noticeable that the carbon leakage sector cannot be determined in a static way in view of the changing international playing field ${ }^{4}$, which can be demonstrated by the amendment to the list of the carbon leakage sectors by the Commission annually from 2011 to $2013^{5}$. In addition, the definition of the benchmarks, per se, is also very problematic, even though it is supposed to foster legal certainty and equal treatment once it is set up. ${ }^{6}$ Since the benchmarks are determined by the regulators in the form of administrative decisions, the sectors concerned may still complain that the benchmarks are too high or too low.

In the light of this differential treatment among the installations provided in model two, such as the determination of the carbon leakage sectors and the benchmarks, there is a need to examine the justification for the differentiated treatment in a judicial proceeding. ${ }^{7}$ In particular, if installations find themselves wrongly categorised, ending up in a disadvantageous position in the allowances allocation and competition, the case may be brought to the courts. ${ }^{8}$ For instance, in the Eurofer case the benchmark for hot metal has been argued to be too strict for free allocation, stating that the Commission's decision is in breach of Article 10a of the EU ETS Directive. However, this case has been dismissed by the General Court, concluding that the Commission's decision is a regulatory act which entails implementing measures and it is not necessary to analyse the question of whether the members of Eurofer are directly concerned by that decision. ${ }^{10}$ In view of the Article 263 TFEU, the industries cannot go to the EU courts in accordance with the EU legal system. However, this matter may be brought to the national courts.

Meanwhile, in view of the complication concerning the possible unjustified treatment relating to benchmarking, the court is also likely to give a large margin of appreciation to the legislator in dealing with the complex allowances allocation. ${ }^{11}$ The principle of equal treatment does not preclude the legislator from adopting general application or special treatment, but more new claims of unequal treatment may be caused by any attempt to tailor legislation to different

\footnotetext{
${ }^{1}$ Emissions trading: Member States approved a list of sectors deemed to be exposed to carbon leakage, European Commission - IP/09/1338, 18/09/200.

${ }^{2}$ See Commission Decision 2010/2/EU.

3 de Bruyn,S., Nelissen, D. \& Koopman, M. (2013), p.5.

${ }^{4}$ Peeters, M. (2011a), p.32.

5 See Commission Decision 2011/745/EU; Commission Decision 2012/498/EU; Commission Decision

2014/9/EU.

${ }^{6}$ Schmitt-Rady, B. (2006), p.92.

7 Peeters, M. (2011a), p.32.

${ }^{8}$ Peeters, M. (2011a), p.32.

9 Case T-381/11: Action brought on 21 July 2011 - Eurofer v. Commission, OJ C 269, 10.9.2011, p. 56-57.

${ }^{10}$ Case T-381/11, Eurofer v. Commission, Order of the General Court (Seventh Chamber) of 4 June 2012, at para.62.

${ }^{11}$ For a general discussion on the margin of appreciation doctrine, see for instance Brauch, J. (2005).
} 
situations that exceed specific limits. ${ }^{1}$ In this sense, it is possible for the legislator to employ differential treatment in the allowances allocation, like the approach applied in model two of the EU ETS, but the differential or preferential treatment should be examined whether it can be objectively justified in the design and implementation of the allocation rules.

\subsubsection{Concluding remarks}

Allowance allocation is the second key element of the legal framework for the EU ETS, which is also a distributional exercise affecting the legal position of each individual installation. Therefore, the allocation method needs to be fair, consistent, clear and feasible. ${ }^{2}$ Given there are a variety of competitive relationships between different market participants in the EU ETS, the principle of equal treatment should be respected and reflected through the design and implementation of the allocation rules. In other words, comparable situations should not be treated differently, and different situations should not be treated in the same way, unless such treatment is objectively justified. $^{3}$

With regard to the EU ETS, there are two different models of allocation. Model one covers the first two trading periods, in which the dominant allocation rule is free allocation based on historical emissions. Moreover, Member States have quite some discretion to design and implement the free allocation rules. In contrast to model one, model two is applied from 2013 with an obvious harmonising characteristic. In line with the EU-wide cap, the allocation rules on auctioning and transitional free allocation are harmonised at the EU level. Since auctioning will be gradually phased in as the dominant allocation method, free allocation can only be applied to the electricity generators in eight Member States and to the special sectors based on benchmarks determined by the Commission in advance. Therefore, the sectors covered by the EU ETS will be differentiated into three categories and are treated differently since 2013. When examining these two allocation models of the EU ETS from the perspective of the principle of equal treatment, two important aspects should be taken into account in order to summarise useful learning points.

Firstly, how to distribute competence concerning decision making in relation to allocation rules is important to ensure equal treatment in the context of a unified allowances market. When Member States are able to decide on the allocation rules, the diversity in allocation rules may become so great that it could cause distortions to the internal market. Member States usually have a propensity to allocate allowances to some preferred industries in their own countries as many as possible, which could constitute unequal treatment in relation to other competitors in a comparable situation. In order to avoid such potential distortion and unequal treatment, the EU has moved to a further harmonisation of the allocation rules that can be applied to all the participants.

Secondly, it is critical to base differential treatment on an objective justification in the design and implementation of allocation rule, in view of the mix of allocation methods applied in the EU

1 de Cendra de Larragán, J. (2010a), p.350.

2 Peeters, M. (2003), p.86.

3 see Fairhurst, J. (2010), p.80; see also Jans, J. H. \& Vedder, H. H. B. (2011), p.21. 
ETS. Especially in the third trading period, trading sectors are divided into three groups (excluding aviation ${ }^{1}$ ) and treated differently. Admittedly, there are many choices concerning the allocation methods in theory and most of them are very complicated. The legislators are not precluded from applying different allocation rules to the installations based on specific considerations, but the differential treatment should be based on an objective justification. Otherwise, the specific design and implementation of the allocation rules may lead to new claims of unequal treatment and the justification for the differential treatment would thus need to be examined.

\subsection{Inspection and enforcement}

Inspection and enforcement is the last cornerstone, together with the cap setting and allowances allocation, underpinning the proper functioning of the ETS. Compared to the abundant literature focusing on cap setting and allowance allocation, the design and implementation of the enforcement package for the EU ETS, in particular the imposition of penalties on the non-compliance, has received only limited attention in the literature, implying a gap that needs to be closed in the research on the EU ETS. For a better understanding of the legal problems relating to the enforcement package of the EU ETS, the national law enforcing the EU ETS is relevant. There is a need for this to be examined by EU lawyers with knowledge of national systems, including their languages. This section will focus on the enforcement package of the EU ETS at the EU level. More specially, two aspects will be discussed: the MRV system and sanctions. Before specifically addressing these two points, the harmonising approach of the enforcement package including these two points will be analysed first.

\subsubsection{Harmonising approach of enforcement}

In the EU ETS, enforcement, to a large degree, is a decentralised model, in which Member States have to ensure compliance by installations. Member States have the responsibility for all aspects of inspection and enforcement, including emissions verification, while the Commission supervises whether Member States execute the enforcement task correctly. The Commission is competent to start an infringement procedure against the Member State when the Member State fails to fulfil its responsibility. ${ }^{2}$ Indeed, this decentralised enforcement seems to be consistent with the European multi-level political system, where the EU layer of governance (Council of Ministers and the European Parliament on proposal of the Commission) agrees on the legal framework, leaving Member States a high degree of discretion in implementation in their respective jurisdictions. ${ }^{3}$

\footnotetext{
${ }^{1}$ Interestingly enough, there is also case law concerning aviation, discussing equal treatment for airlines in the form of fair and equal competition in providing international air transportation in line with the Open Skies Agreement, see Case C-366/10, Air Transport Association of America and Others v. Secretary of State for Energy and Climate Change, Judgment of the Court (Grand Chamber) of 21 December 2011 (not yet reported), at para.99.

2 Article 258, TFEU.

${ }^{3}$ Kruger, J., \& Egenhofer, C. (2006), p.5.
} 
However, in view of the decentralised competence distribution concerning the cap setting and allowances allocation in the first trading period, there is also a significant risk of inconsistency stemming from the decentralised approach of enforcement, which may affect the compliance level of the installations. As the competence of implementing and enforcing the EU ETS has mainly been distributed to Member States, Member States can choose a different enforcement strategy based on their own circumstances, which may be even motivated by protecting their own economy. A Member State may be reluctant to implement stringent inspection tasks and to apply necessary sanctions against the non-complying industries because of the possible lobbying and pressure by industry. ${ }^{1}$ There is thus a need to monitor Member States in the decentralised inspection and enforcement model. ${ }^{2}$

The enforcement package of the EU ETS also provides for harmonised MRV rules and harmonised penalties, in particular the automatic financial penalties and surrendering allowances covering excess emissions, which differentiates itself from most other EU environmental directives. ${ }^{3}$ The justification for this may rely on the market nature of the EU ETS and the particular significance of ensuring the equivalent sanctions for the noncompliance in the single market. ${ }^{4}$ Moreover, the ECJ, when settling the dispute on the legality of the Framework Decision on the protection of the environment through criminal law ${ }^{5}$, asserted that the EU has the power to require Member States to establish criminal penalties for the purpose of protecting the environment. ${ }^{6}$ So far, however, criminal penalties have not been explicitly established for the EU ETS and they remain at the discretion of Member States.

The harmonisation approach to enforcing the EU ETS is seen as a necessary step to ensure the compliance level to a certain degree. Nevertheless, this harmonising approach of enforcement is not free from challenge. For instance, one may raise the questions of whether and to what extent additional penalties and measures can be introduced by Member States if deemed necessary, and whether more stringent penalties may be applied by Member States. ${ }^{7}$ In addition, the fixed and automatic fine for excess emissions is also problematic from the legal perspective, which will be discussed in the following observation on the sanctions.

\subsubsection{MRV}

In addition to the further harmonisation of the MRV rules for the EU ETS through the adoption of two specific regulations replacing the previous guidelines, the description in section 3 of this chapter has demonstrated the significance of the GHG emissions permit as well as the complexity of the MRV rules.

\footnotetext{
Peeters, M. (2006a), p.183.

2 Ibid, p. 182.

3 Meadows, D. (2006), p.92.

${ }^{4}$ Ibid, p.92.

${ }^{5}$ Council Framework Decision on the protection of the environment through criminal law, 2003 OJ L 29/55.

${ }^{6}$ See in the Case C-176/03 Commission v. Council [2005] ECR I-07879; further discussion and different argument can refer to Faure, M. (2004).

7 See Jans, J. H. \& Vedder, H. H. B. (2011), p.118-121.
} 


\section{Potential legal problems relating to the implementation of the GHG emissions permit}

According to the description in section 3, the competent authority will assess whether the operator is cable of monitoring and reporting emissions and shall issue the permit if the competent authority is satisfied with the result of the assessment. ${ }^{1}$ But based on the abstract and ambiguous text of the EU ETS Directive, it is not clear how the assessment has to be implemented. In this respect, one may wonder what criteria have been used in practice by the competent authority in the course of assessing the application. If the competent authority is not satisfied with the outcome of the assessment, the application would be likely denied, resulting in the operators not being able to receive the permit to emit GHG and thus not being able to operate. In light of the serious consequences of the denial of the application, a sufficient justification demonstrating the inability of the operator to monitor and report emissions must be provided by the competent authority. ${ }^{2}$ The operator should be able to have access to the court to contest the denial of the permit. Available English literature has not yet discussed any legal dispute on this issue. One crucial point yet to be evaluated is whether the competent authority is too reluctant to apply a strict assessment and, consequently, is reluctant to deny the operators' application.

After the initial issuance of the permit, there is a need to amend the permit in accordance with the law in the case that the relevant condition for or contents of the permit change. For instance, a change to the monitoring plan, such as a change in the monitoring methodology used, needs to be approved by the permitting authority and then to be included within the updated GHG emissions permit. ${ }^{3}$ However, according to the EU ETS Directive, in the event of a change in the operator's identity, 'the competent authority shall update the permit to include the name and address of the new operator'. ${ }^{4}$ In this respect, when the operator is changed, such as an installation is transferred between companies, the procedure required by the Directive seems to require simply updating the content of the permit by the competent authority. One may however raise the question whether there is also a requirement for the competent authority to assess the capacity of the new operator in line with the procedure for the initial application and to approve the changes. It is not specified clearly in the EU ETS Directive. But if there is no such procedure, this is rather strange compared to the initial application procedure in which the capacity of the applicant has to be assessed.

\section{Possible complicated relationship in the MRV process}

Within the legal framework for the enforcement of the EU ETS, the verifier has been conferred with special competence and power. The verifier has the task to determine whether emissions have been monitored and reported in line with the validated methodology approved in the GHG emissions permit. ${ }^{5}$ The quality of the emissions data monitored and reported by the operators in the EU ETS hence has to be ensured by such a third-party verifier, accredited by the national accreditation body. However, it is not clear who is going to employ the verifier. As indicated in

\footnotetext{
1 Article 6(1), EU ETS Directive.

2 Peeters, M. (2006a), p.185.

3 Article 6(2)c, EU ETS Directive; see also Article 15, Commission Regulation (EU) No 601/2012, p. 37.

${ }^{4}$ Article 7, EU ETS Directive.

5 Kruger, J., \& Egenhofer, C. (2006), p.7.
} 
section 3.3 of this chapter, both the EU ETS Directive and the AVR leave it to Member States to decide who is to be employed as the verifier for the verification of the emissions reports and who is going to hire the verifiers. In other words, as implied in chapter 2, there could be two types of verifier, one is the private third-party verifier and the other may be the governmental verifier. For instance, the authorised verifiers announced by the competent authority in Germany not only include the environmental auditor approved by German competent Approval Body (DAU) and the equivalent verifiers accredited by other EU Member States, but they also include the ETS experts appointed publicly by the Chamber of Commerce. ${ }^{1}$ Moreover, it is not explicitly prohibited that a private third-party verifier can be hired by the government; this possibility also seems to remain. In this light, different choices may have various impacts on the national implementation of the MRV rules, giving rise to different potential tensions in the relationship among the operator, competent authority and verifier.

Whatever choice is made by Member States, several actors such as the operator, verifier, competent authority, national accreditation body, independent reviewer, will be involved in the process of verification. Especially in light of the special role of the third-party verifier in the MRV system, the rights and obligations of the relevant actors need to be well defined in the legal framework in order to ensure the independence, reliability and competence of the verifier and the impartiality of the verification process. In this respect, some relationships among them and the relevant challenges facing them need to be dealt with carefully.

If the private third-party verifier is contracted by the operator, which is supposed to be the basic choice, an emphasis may have to be placed on the possible tension in the relationship between the operator and verifier and thus the potential risk it may cause to the inspection and enforcement of the EU ETS.

Firstly, the description above has demonstrated the attempt of the AVR to ensure the independence of the verifier, the core element of their relationship. In this respect, the relationship between the operator and verifier is established based on but not limited to the contract concluded by them voluntarily. Based on the contract, the verifier provides a professional service to the operator in the form of rendering the qualified verification report and is paid by the operator. In addition, as mentioned in section 3.3 of this chapter, the general rights and obligations of the verifier and operator during the verification process as well as the pre-contractual stage have been prescribed in the AVR. ${ }^{2}$ However, one may raise the question whether in practice the verifier will really carry out the verification in an independent manner as the operator may try to influence the verifier in order to ensure a satisfactory outcome in the verification report. For instance, the operator may be motivated to try to 'lower' their emissions determined in the verification report by influencing or even bribing the verifier, when the penalties for the excessive emissions is strict and the market price of the allowance is high for them. Whether this conflict may be avoided by the AVR requiring the verifier to include the irregularity and noncompliance of the operator detected in the verification report remains to be seen.

${ }^{1}$ See Handke, A. (2012).

2 Article 7-8, Commission Regulation (EU) No 600/2012. 
Secondly, when there is damage caused by the verification, the potential damage liability concerning the verification activities also deserves attention. In the process of verification, a verifier may fail to perform his duties or commit a breach of the rules, although the operator has presented the emissions report and provided the necessary information according to the legislation. If inadequate performance of the verifier results in serious consequences, for example a breach of the obligation of surrendering a required amount of allowances, the legal status of the operator may have to come into question. As the operator will be prohibited from transferring allowances and possible economic damage would take place, it is possible for the operator to include this possible situation and solution in the service contract and claim financial compensation for the damage. ${ }^{1}$ Of course, the specific solution to the legal conflict will depend on the specific arrangement of the national law in that Member State.

However, the situation may be even more complicated if the private third-party verifier is contracted by the government or even the verifier is accredited as governmental verifier according to the national law. Especially in case of the damage caused by the verifier to the operator mentioned above, it may give rise to the questions of whether the government will also be held liable for the damage and must compensate the operator. Since there are no clear rules addressing this problem in the EU ETS Directive or the AVR, it needs to be dealt with carefully according to national law. For instance, a judgment of Federal Court of Germany ruled that the verifier acts as an official of the state; in the case of wrongful verification causing damage to the operator, the state is liable for any errors appearing in the verification process according to the principle of public liability. ${ }^{2}$ This practical example from one Member State shows that there is a need to define the right and obligation of the verifier and the government clearly in the legal framework.

\subsubsection{Sanctions}

\section{The establishment of the sanction: extra sanctions for other non-compliance?}

The EU ETS Directive has established quite a comprehensive sanction package with the prescription of specific sanctions, but there is not much available information about the application of the sanctions. The enforcement package of the EU ETS is not perfect at the beginning and problems may occur in practice, which will call for a necessary improvement of the EU ETS Directive.

According to the EU ETS Directive and MRR, for instance, the operator is obliged to monitor and report its emissions and to submit the emissions report verified by the third-party verifier. In this process, it is possible for the situation of a lack of (part of) emissions data to take place, in which there is no or wrong emissions data available, leading to the impossibility of determining the correct amount of allowances to be surrendered by that operator. ${ }^{3}$ The reasons behind the missing emissions data may be diverse, but the consequence of this situation seems to be quite problematic. According to Article 15 of the EU ETS Directive, the prohibition of transferring

1 Peeters, M. (2006a), p.189.

2 Decision BGH (Federal Court of Germany), 15.09.2011, reference number BGH III ZR 240/10.

${ }^{3}$ Peeters, M. (2006b), p. 183. 
allowances is imposed on the operator whose emissions report has not been verified as satisfied. In the case of an insufficient emissions report, however, the specific amount of allowances to be surrendered by the operator cannot be determined. In other words, it is problematic to punish the operator for any possible excess emissions. In this regard, the potential problem mentioned above seems to be addressed to a large extent by the MRR, by providing for the specific obligation for the operator in the case of missing data and requiring the competent authority to make a conservative estimation of the emissions in the specific circumstances. ${ }^{1}$ If the estimation determined by the competent authority is conservative enough to ensure that the estimation of emissions is equal or even higher than the actual emissions of the installation, this mechanism can be seen as a kind of punishment for the operator.

In other words, the sanction mechanism at the EU level has been gradually expanded, implying that the enforcement package of the EU ETS has been improved gradually with the law. But it may also remain very questionable as to how to define the criteria of 'conservative' mentioned in the MRR and how to estimate the emissions in the implementation. Moreover, there are still no additional penalties provided for this kind of non-compliance which occur in this process of MRV by the EU ETS Directive or the MRR. Meanwhile, in view of the experimental approach, it still needs to be observed how the regulatory framework and its gradual improvement affect the market behaviour of the participants in the MRV process.

One may raise the question whether the existing penalties stipulated in the EU ETS Directive are sufficient enough for the enforcement of the EU ETS. In particular, taking account of the significance of the MRV system in the EU ETS, there is a need to establish sanctions for other types of non-compliance in addition to the excess emissions. In this respect, the AVR has made some effort, which can be demonstrated by the requirement for the national accreditation body of the Member States to impose specific administrative measures on the non-compliance of the verifiers. In view of the fact that the existing provisions of the EU ETS Directive and the regulations still lack the rules concerning the sanctions for other types of potential non-compliance, such as the misconduct of the operators during the MRV process, there is a need for Member States to develop specific enforcement competence and adopt additional enforcement provisions for these situations that have not been addressed at the EU level.

\section{The implementation of the sanctions}

The implementation of the sanctions, particularly the financial penalty for excess emissions, is not free from challenge either. As stipulated in the EU ETS Directive, the fine for excess emissions is nondiscretionary and automatic, leaving little room for Member States. ${ }^{2}$ The uniform regime for penalties established in Article 16 of the EU ETS Directive may seem to be important for the proper functioning of the EU ETS, but the harmonisation may ignore the diverse legal systems of the Member States. ${ }^{3}$ Moreover, it remains questionable whether the specific circumstances should be taken into account in order to ensure that the fine is imposed in a proportionate way, which can be exemplified by the Billerud Karlsborg $A B \quad v$.

${ }^{1}$ Article 45 and 70, MRR.

2 Kruger, J., \& Egenhofer, C. (2006), p.7.

${ }^{3}$ Olsen, B. E. (2006), p.164-165. 
Naturvårdsverket case. ${ }^{1}$ It is noticeable that, regarding this question, there is a remarkable difference between the judgment of the CJEU and the opinion of the Advocate General.

In this case, the Advocate General suggests that the cause and circumstances of the excess emissions need to be taken into consideration. From the perspective of the Advocate General, although the operator failed in surrendering the allowances as required, no additional pollution was caused if the operator holds sufficient allowances. ${ }^{2}$ There hence may be two infringements with a distinct nature and scope in regard to the excess emissions, which should be treated differently instead of being punished by the same penalties prescribed in the EU ETS Directive. ${ }^{3}$ In this respect, the situation of the Billerud company holding sufficient allowances should not be subjected to the automatic fine prescribed in Article 16 (3) and (4) of the EU ETS Directive, but it needs to be dealt with by Member States in line with Article 16(1) of the EU ETS Directive, which enables other sanctions other than the automatic fine. ${ }^{4}$

On the contrary, the Court has emphasised that the concept of excess emissions should be based on the strict interpretation of Article 16(3) and (4) of the EU ETS Directive. According to the Court, in the absence of obvious force majeure, an external cause with inevitable and unavoidable impacts leading to the objective impossibility for the fulfilment of the obligation, the operator who has not surrendered the allowances by 30 April of the current year, to cover the emissions for the preceding year, should be punished because of excess emissions, even though they hold a sufficient number of allowances at that time. ${ }^{5}$ In this respect, other circumstances are not allowed to be taken into consideration in deciding whether an operator is liable for the excess emissions, leaving little room for Member State in the course of implementation.

But, as argued by the Advocate General above, the operator holding sufficient allowances does not cause additional pollution and should not be punished by the same penalties as an operator without sufficient allowances would incur. In this light, a careful case-by-case consideration of whether the penalty must be imposed could be considered as a better approach than automatic sanctioning. ${ }^{6}$ In particular for the operator that acted in good faith and simply forgot to surrender the allowances on time, it may seem to be unfair not to allow that operator a chance to recognise and correct their mistakes. In this respect, despite the strict approach adopted by the Court in the interpretation of the excess emissions, the Court also admits that Member States are still free to introduce necessary mechanisms like warnings, reminders and advance surrender to allow and to facilitate the operator holding allowances to comply with the scheme, in order to avoid a similar situation such as in this case. ${ }^{7}$

${ }_{1}^{1}$ C-203/12, Billerud Karlsborg AB v. Naturvårdsverket.

2 Case C-203/12, Opinion of Mr Advocate General Mengozzi delivered on 16 May 2013 (not yet reported), at para. 31 .

3 Ibid, at para. 27,43 .

4 Ibid, at para.42-43.

${ }^{5}$ Case C-203/12, Billerud Karlsborg AB and Billerud Skärblacka AB v. Naturvairdsverket, Judgment of the Court (Second Chamber) of 17 October 2013 (not yet reported), para. 31-32.

${ }^{6}$ Peeters, M. (2006b), p. 182.

${ }^{7}$ Case C-203/12, Billerud Karlsborg AB and Billerud Skärblacka AB v. Naturvairdsverket, Judgment of the Court (Second Chamber) of 17 October 2013 (not yet reported), para.41. 
Next to this, the case also gives rise to the questions of whether the fixed amount of the fine per se is appropriate and proportionate to punish the operator with excess emissions. The Court in the case mentioned above chose to respect the broad discretion of the EU legislature in assessing and designing the complex system of the EU ETS, translating a political orientation into a legislative choice with the aims to deal with the climate change. ${ }^{1}$ In other words, the Court's assessment cannot be substituted for that of the EU legislature, which can only be criticised if it appears manifestly incorrect based on the information available to it when that legislation is adopted. ${ }^{2}$ As prescribed in the EU ETS Directive, the fine for excess emissions has been set at a fixed amount, increasing from 40 EUR in the first trading period to 100 EUR since the second period. But concerning the level of the fixed fine established in the EU ETS, one may still raise the question as to which level the financial penalties will meet the requirement of effective, proportionate and dissuasive. In light of the relatively low market price of the EUAs, around 6 EUR in recent years ${ }^{3}$, the existing fine seems extremely high to cover only the administrative burden at the side of the operator. In view of the experimental approach, in the future the EU legislature needs to consider uncertain effects of its action in pursuit of the gradual improvement of the scheme. ${ }^{4}$

One may wonder whether, contrary to the facts of the case above, Member States can establish and apply stricter financial penalties compared to the fixed fine established in the EU ETS Directive. This might become relevant in case the market price increases significantly, for instance, as a result of price management measures. The Court has refused the possibility of varying the fine at the national level, emphasising a stringent and consistent enforcement approach throughout the EU, in particular taking account of the harmonisation of the EU ETS. ${ }^{5}$ In the eyes of the Court, the penalty for excess emissions established in the EU ETS is compatible with the principle of proportionality, since it is impossible for a national court to change the amount of the fine. ${ }^{6}$ To be specific, the fixed and automatic fine, rather than a transitional lowering of the amount of the fine, is considered as a necessary mechanism by the EU legislature to prevent some operators from circumventing or manipulating the EU ETS. ${ }^{7}$

However, the reasons provided by the Court in the judgment, without further analysis and explanation, appear to give hardly any further guidance. In particular, taking account of Article 193 TFEU, there is already a debate over the questions of whether the application of Article 193 TFEU will be limited by the provision concerning the fixed fine established in the EU ETS. ${ }^{8}$ If a measure based on Article 192 TFEU prohibits Member States from adopting certain protective measures implicitly or explicitly, a Member State cannot justify the adoption of such a measure on the basis of Article 193 TFEU.' In other words, a Member State cannot rely on a 'more

\footnotetext{
1 Ibid, at para.36.

2 Ibid, at para.35-37.

${ }^{3}$ More information can refer to the website of Intercontinental Exchange, available at: https://www.theice. com/products/197/data.

${ }^{4}$ Case C-203/12. Billerud Karlsborg AB and Billerud Skärblacka AB v. Naturvairdsverket, Judgment of the Court (Second Chamber) of 17 October 2013 (not yet reported), para.36.

5 Ibid, at para.39.

6 Ibid, at para.38.

7 Ibid, at para.39.

8 See the discussion in Jans, J. H. \& Vedder, H. H. B. (2011), p.118-119.

9 Ibid, p.119.
} 
stringent measures' clause in a directive if this is incompatible with the explicit content of the directive itself. ${ }^{1}$ In this respect, the possibility for Member States to adopt stricter financial penalties remains quite problematic.

\subsubsection{Concluding remarks}

In order to ensure a high degree of compliance by installations, the EU ETS has adopted a comprehensive enforcement package containing the GHG emissions permit, rules on MRV and a range of sanctions. As a special inspection tool, the application and approval of a specific monitoring plan contained in the GHG emissions permit can facilitate the operator to choose and implement the optimal monitoring methodology at the installation level. Moreover, the guidelines and the regulations on the MRV have set up the basic rules and obligations for operators, verifiers and relevant competent authorities in the course of collecting emissions data. In order to punish noncompliance in an effective, proportionate and dissuasive way, a wide range of specific sanctions including reputation derogation, automatic financial penalties and other penalties have also been stipulated in the enforcement package.

Firstly, the harmonising approach of the enforcement measures, a remarkable characteristic of the enforcement package in the EU ETS, has a significant impact on the integrity of the market and the environment. In the legal framework for the EU ETS, Member States are responsible for implementation and enforcement in line with the decentralised political and legal structure of the EU. However, the potential inconsistency concerning the enforcement strategies and stringency can also cause concerns with regard to the level playing field and the outcome of the whole scheme. At the initial stage of the EU ETS, a common approach of monitoring, reporting and verification of emissions has been considered and has appeared in the form of the general principles and criteria set up in the Annex of the EU ETS Directive. In the first two trading periods, legally binding guidelines adopted by the Commission have harmonised the monitoring and reporting rules to a larger degree and the verification to a lesser degree. In the third trading period, two new regulations, one on monitoring and reporting and one on accreditation and verification have been adopted as a bigger step moving towards harmonisation. Moreover, non-compliance, inter alia excess emissions, will be punished by the uniform penalties prescribed in the EU ETS Directive. However, the harmonisation of the legal framework for the enforcement package does not necessarily mean the equal application in the practice of the Member States, which needs to be considered carefully in the specific circumstances in line with the legal system.

Secondly, the choice of self-monitoring, self-reporting and third-party verification is important for collecting GHG emissions data effectively, but some potential and complicated problems embodied in the design and implementation of the MRV rules need to be taken into consideration. With regard to the GHG emissions permit, the procedure concerning its application and grant needs to be clarified in the legislation. Moreover, the integration of the GHG emissions permit into the existing instrument also needs to be conducted in an adequate way, in order to avoid a congestion of instruments. In addition to the GHG emissions permit,

1 Ibid, p.121. 
many questions may also be raised as to the complicated relationship among the parties involved in the MRV process. In particular, taking account of the special role and significance of the verifier, the rights and obligations of the verifier should be well defined and implemented in the enforcement package. However, there may be different relationships among the operators, verifiers and relevant authorities, since the verifier may be accredited as one of the two types of verifiers and may be contracted by the operator or the government. When the private third-party verifier is contracted by the operator, particular attention needs to be paid to legal mechanisms that can ensure the independence of the verifier from the operator. But if the verifier is accredited as a governmental verifier or contracted by the government, it will be important to make a clear distinction between these verifiers and the relevant competent authorities. Moreover, the clear provisions concerning these complicated relationships under different circumstances, which are missing in the EU ETS Directive and regulations, still needs to be prescribed by Member States in their national legislation.

Thirdly, the design and implementation of the sanctions for non-compliance should be effective and proportionate in line with the legal system. Although the EU ETS Directive has established several important penalties for the basic types of non-compliance emerging from the ETS, the emphasis has been mainly placed on the penalties on excess emissions. But, as discussed above, other types of non-compliance, such as the lack of emissions data, may also take place in the course of the MRV process, which should also be punished in the implementation of the EU ETS. In addition to the existing penalties established for the basic types of non-compliance, the extra penalties against the breach of other rules, inter alia the MRV rules, needs to be considered for the design of an effective enforcement package. Meanwhile, the implementation of the existing sanctions, in particular the fine for the excess emissions has also given rise to the questions of whether and how the penalties are applied by Member States under the uniform regimes in light of the principle of proportionality. In this respect, the Court in the judgment of the Billerud Karlsborg $A B$ v. Naturvardsverket case has emphasised that the penalties for excess emissions prescribed in the EU ETS Directive must be interpreted and implemented strictly, leaving little room for the discretional implementation by Member States. In other words, the application of the specific amount of financial penalties is not allowed to be varied at the national level. This uniform regime of the automatic penalties may be one of the keys to the proper functioning of and high level of compliance with the EU ETS, but it seems to be problematic without taking account of the specific circumstances in light of the principle of proportionality. In this respect, the elegant approach suggested by the Advocate General of differentiating the cause and circumstance of non-compliance, and thus the corresponding penalties, may deserve attention. There is at least not a common opinion as to how to deal with this matter. Moreover, it still remains questionable whether a stricter financial penalty can be adopted by Member States in line with Article 193 TFEU. In view of the precedence of the Treaties over secondary legislation, as well as the legislative goal of the EU ETS Directive, it would be reasonable for Member States to apply stricter measures to strengthen the enforcement of the EU ETS in line with the principle of proportionality. 


\section{Concluding insights}

The legal framework for the EU ETS has been established by the EU ETS Directive and relevant regulations and decisions in line with the EU legal system. The review of the development concerning the EU ETS has indicated that two basic models can be differentiated. Particularly the design of the cap setting and allocation method differs to a great extent after the reform in 2009 , while the basic design of the enforcement system has evolved in a comparatively stable way through all the three trading periods.

Although the EU ETS per se is a kind of an experiment in the middle of evolution, the EU ETS has been considered as a significant model by other countries that want to establish their own ETS, like China. It is clearly recognised that the design and implementation of the EU ETS features many European characteristics, inter alia the complicated relationship between the Commission and Member States in the multi-level governance structure. Due to the unique political and legal system in the EU, it is impossible for other countries to copy the model of the EU ETS, which will be further discussed in the comparative analysis of the following chapter. However, the examination of the EU ETS in terms of its regulatory design and case law in this chapter (which concerns sub-question 2 of this thesis) has provided various insights into the design features and implementation challenges regarding the three key elements of the ETS in the EU context. This will be presented below.

\section{Experimental approach}

It is noticeable that the establishment and implementation of the EU ETS has followed an experimental approach. In view of the experimental approach, the description and analysis of the three key elements have implied that the legal framework for the EU ETS established in the beginning was not sufficiently clear, leading to quite a lot of legal problems in the implementation, which have been demonstrated by the case law concerning the EU ETS, such as the cases concerning the NAPs, the scope of the EU ETS and the enforcement. Based on the analysis of the legal problems that emerged in practice, inter alia in the case law, lessons have been drawn from this and the legal framework for the EU ETS has hence been improved gradually. In this respect, the experimental approach with gradual improvement can be exemplified by the shift of competence distribution model in cap setting, the gradual expanded scope and sanctions of the EU ETS.

Furthermore, the 'learning by doing' has not come to the end yet ${ }^{1}$, which can be demonstrated by the ongoing discussion on the structural reform in addition to the amendment of the EU ETS Directive in 2009. Nevertheless, such an experiment concerning the EU ETS is conducted through the law, with changes to the relevant legislation in line with the EU legal system. Moreover, following the experimental approach, the assessment of the legal framework from the legal, political and economic perspectives needs to be carried out for and before the gradual improvement.

${ }^{1}$ See Peeters, M., \& Weishaar, S. (2009), p.88. 


\section{Cap setting}

The EU has applied an absolute target for GHG emissions reduction, which is similar to the emissions reduction targets set in the Kyoto Protocol. In order to achieve the target committed by the EU-15 as a whole under the Kyoto Protocol, an 8\% reduction below 1990 levels collectively in the period 2008-2012, this target has been redistributed among those 15 Member States by the Burden Sharing Decision. ${ }^{1}$ In addition, the EU has set up unilateral targets, reducing GHG emissions by $20 \%$ compared to 1990 levels by 2020, which has been delivered to the sectors covered by the EU ETS and ESD instruments to different extents.

As an important instrument to reduce GHG emissions, the EU ETS has been established based on the cap-and-trade model. With regard to the cap setting, the first key element of the legal framework, the emphasis of this chapter was placed on the competence distribution between the Commission and Member States. As indicated by the description above, two models concerning the cap setting for the EU ETS were witnessed.

Under the decentralised model, the national caps have been determined through the NAPs that are proposed by Member States and assessed by the Commission in the first and second trading periods. In this respect, Member States have had quite broad competence in cap setting, while the Commission had the power to reject the NAP. There is an indication that some Member States have tried to establish a generous national cap for its own industries during the first two trading periods. In order to control the national caps set up by Member States, the Commission has rejected and reduced lots of NAPs, leading to legal conflicts between the Commission and Member States, which can be demonstrated by the case law concerning the NAPs. The Commission has lost most of the cases because the Commission exercised its power in a wrong way.

Based on the lessons from the decentralised model, an EU-wide cap has been established for the EU ETS for the period 2013-2020, replacing the national caps set up in the decentralised model. This shift of competence in regard to cap setting from Member States to the EU level has prevented and reduced the potential legal conflicts to a large extent. However, the potential waterbed effect embedded in the EU ETS, in particular in the centralisation of cap setting, may create some negative incentives for Member States not to set up more stringent emission reduction targets or to adopt additional protective measures. In this regard, there is still a need to strike an elegant balance between the Commission and Member States in the legal framework for the EU ETS, in order to provide sufficient positive incentives for lower authorities to do more or, otherwise, to prevent negative incentives for them to do less based on the EU legal system.

In light of the legal experiences with the EU ETS with regard to cap setting, the potential legal conflict between different levels of authorities involved in the cap setting may take place in different forms within various models, which should be controlled and solved carefully by the legal systems. However, one has to notice that an optimal model of competence distribution does

\footnotetext{
${ }^{1}$ Recital 12, Council Decision 2002/358/EC.
} 
not exist. On the contrary, the competence distribution for cap setting needs to be designed and fine-turned in line with the specific legal system and circumstances.

\section{Allowance allocation}

Closely connected with the cap setting, the allocation of allowances has been designed in line with the two models in the EU ETS. In the first two trading periods, the allowances are allocated in a decentralised model, in which Member States have quite some competence in choosing and implementing the specific allocation method. Meanwhile, the free allocation, inter alia grandfathering, has played a dominant role, but the specific allocation varies among the Member States. In contrast to the decentralised model, the allocation of allowances will be implemented in the second model with a harmonised approach, in which the allocation methods have been determined at the EU level. As the default allocation method in the third trading period, auctioning will be implemented in accordance with the EU ETS Directive and the Auctioning Regulation. However, free allocation will still be applied in some special circumstances for some electricity generators in eight Eastern European Member States and benchmarking for the carbon leakage sectors. Based on the harmonised free allocation rules determined in the EU ETS Directive, Member States still have some flexibility in implementation, which can be exemplified by the application of national plans for allocating free allowances to the electricity generators in line with Article 10c of the EU ETS Directive. Moreover, it is noticeable that the ETS sectors have been grouped into three categories and subjected to different allocation methods in the allowances allocation. Hence, a mix of allocation methods will be applied.

In view of the substantive impact of the allocation of allowances on the legal position of each individual installation, two aspects of the allocation of allowances, competence distribution and the allocation method, have been examined from the perspective of equal treatment. On the one hand, how to distribute competences concerning decision making in relation to allocation rules has a considerable impact on equal treatment in the context of a unified allowances market. Especially in light of the experience of the decentralised approach in cap setting, Member States may tend to allocate more allowances to their own industries by implementing diverse allocation methods, leading to the differential treatment of the installations based in various territories. In this respect, the centralised approach applied in the third trading period, through the harmonisation of the allocation methods, is expected to ensure the equal treatment of the installations to a better degree. On the other hand, the differential treatment of the installations due to the design and implementation of the mixed allocation methods established at the EU level in the second model needs to be objectively justified. Both models of allowance allocation have applied the mixed allocation methods, each of which has its own pros and cons from different perspectives. In designing the specific method for the allocation of allowances, the legislator can make up some specific choices based on particular circumstances, but the objective justification for any kind of differential treatment should be considered carefully, at least in the context of EU law. 


\section{Inspection and enforcement}

As a relatively stable element of the legal framework for the EU ETS, the enforcement package of the EU ETS has largely relied on the detailed MRV system and the stringent sanctions system. Similar to the first two key elements, cap setting and allowances allocation, a harmonising approach has also been applied to the inspection and enforcement, which can be demonstrated by the adoption of two specific regulations replacing the guidelines concerning the MRV rules.

With regard to the MRV system for the EU ETS, the GHG emissions permit has been employed as an important inspection tool, laying the foundation for the collection of emissions data correctly to a large extent. However, the implementation of the GHG emissions permit still faces some potential problems. In the domains of the self-monitoring, self-reporting and verification of the emissions data, not only the general rights and obligations concerning the operator and verifiers, but also the accreditation of and surveillance over the verifier, have been prescribed in the specific guidelines and then the regulations. Moreover, specific attention has been paid to the complicated relationship among the various actors involved in the MRV process. Especially in light of the significance of the verification and the possibility that the verifier may engage in the verification of the emissions data based on different legal arrangement, the relationships among the verifier, operator and relevant authorities have seemed to be rather complex. In particular, when the private third party verifier is contracted by the operator, how to ensure the independence of the verifier may lie at the heart of the MRV system. But in case the verifier is closely connected to the government through accreditation or contract, then attention may need to be paid to not only the effective supervision of the verifier by means of a clear distinction between different governmental departments, but also the arrangement regarding the right and obligation of the verifier and government in the legal framework.

As far as the sanctions system is concerned, one may wonder whether they are established and implemented in an effective and proportional way. The description in section 3 sketched the existing penalties for the basic types of non-compliance within the EU ETS. However, the analysis pointed out the need for Member States to establish additional penalties for other types of non-compliance in addition to those for excess emissions, in particular the breach of the MRV rules. Furthermore, much emphasis has been placed on the questions of whether and how the excess emissions should be punished by the financial penalties in line with the principle of proportionality, based on the analysis of the case law concerning enforcement in the EU ETS with a great difference between the Court's judgment and the opinion of the Advocate General. Although the Court emphasises that Article 16 of the EU ETS Directive concerning the penalties imposed on the excess emissions should be interpreted and implemented strictly, the specific circumstances as argued by the Advocate General stipulated that another, more proportional approach could have been taken. Moreover, the automatic and fixed fine gives rise to the questions of whether the level of the fine per se is effective and whether Member States are still allowed to take more stringent measures in accordance with Article 193 TFEU, particularly in the case of a further increase of the price of the allowance. The questions are still worth further discussion and should be taken into consideration by the legislator in the future. 


\section{CHAPTER 4 \\ The EMerging ETS IN CHINA}

\section{Introduction}

\subsection{Aim of this chapter}

This chapter, which focuses on the GHG ETS in China, aims to provide a specific understanding and analysis of the design and implementation of the ETS in the Chinese context. Firstly, this chapter examines how the ETS is being established in China (sections 2-5). After this, the similarities and differences between the Chinese ETS and the EU ETS regarding the current regulatory design and implementation will be determined and explained in section 6 .

Firstly, this chapter will shed light on Chinese policy and law concerning climate change in which the ETS will be crafted and implemented. In China, the national $\mathrm{CO}_{2}$ emissions reduction target has been stipulated in national policies and legislation and will be implemented by series of legislation and governmental policies, forming the governmental framework for addressing climate change. It is necessary to understand the governance structure for dealing with climate change, in particular the decision-making structure, in order to get a better understanding of how an ETS is being established within the existing Chinese legal system.

Secondly, this chapter identifies and analyses problems that have emerged or may arise in the pilot projects under the particular Chinese circumstances, in view of the legal insights gained in the EU ETS. In accordance with the three key elements determined in the theoretical framework and analysed in the EU ETS, the description and analysis of the pilot projects in this chapter will concentrate on the following issues:

-Target setting

In view of the significance of China's carbon intensity reduction target, the type of and legal effect of such an emissions reduction target per se needs to be first analysed. In addition, specific attention will be paid to the competence distribution in terms of target setting for emissions trading, in which the co-existence of centralisation and decentralisation as well as potential tension in the central-local nexus will be identified and analysed in the special Chinese context.

-Allowance allocation

In addition to the mix of allocation methods, many special design features regarding allowances allocation are emerging among the pilot projects. In order to get an insight into how and why these rules are designed, particular attention will be paid in this chapter to the competence distribution for and special rules of allowance allocation, which aims to address the dynamic economic development, carbon leakage concerns and equal treatment issues.

-Inspection and Enforcement 
There is an indication that the pilot projects adopt an approach of self-monitoring, self-reporting and third-party verification in relation to emissions data. In the context that fraud, collusion and corruption often take place in China, relevant legislation and policies concerning the requirement about the MRV as well as the sanctions for noncompliance have to be considered and analysed within the Chinese context.

Thirdly, this chapter will address the potential for and consideration of a Chinese national ETS, given the fact that the pilot projects are established in an experimental approach towards a national scheme. After this, a comparative analysis between the EU ETS and Chinese emissions trading in terms of the three key elements determined in the theoretical framework will be conducted, exploring to what extent the current regulatory design and implementation of the ETS in China shows similarities and differences with the EU ETS.

\subsection{Structure of this chapter}

In the following section of this chapter, first a brief introduction to the legal system relating to emissions trading in China will be provided. Section 3 will provide a description of the pilot projects in terms of the three key elements determined in the theoretical framework, shedding light on the existing regulatory framework for and design options of the pilot projects. Moreover, special emphasis in section 4 will be placed on the analysis of the problems that emerge and may arise in those three key elements from the legal perspective. Section 5 aims to explore the rationality for a national ETS and then make a preliminary observation on its possible design. Furthermore, the comparative analysis of those three key elements between the EU ETS and China's ETS is going to be conducted in section 6. The last section is the concluding observation.

\section{Introduction to the climate-related legal system in China}

The ETS is, to a certain degree, a new 'imported good' for China. The regulatory framework of Chinese environmental law, inter alia climate law, including relevant policies and legislations, governance structure and regulatory instruments will be outlined in this section, in pursuit of a general understanding of the legal system in which the Chinese ETS will be designed and implemented.

\subsection{Governmental framework for addressing climate change: existing policies and legislation}

In view of the serious damage that may be caused by climate change as well as the relationship between climate change and GHG emissions supported by the IPCC reports, China is trying to strengthen its domestic efforts to reduce and to control GHG emissions through policy and 
legislative approaches. Based on the re-conception of climate change, the last two decades since the ratification of the UNFCCC has witnessed not only the shift of China's attitude to climate change, from a stander-by to a stakeholder, but also the evolution of Chinese climate change policy and law. ${ }^{1}$

In pursuit of GHG emissions reduction, a series of targets, policies, legislation, and measures at the national and local levels have been adopted by China since the establishment of the National Coordination Committee on Climate Change in 1998, opening the stage of Chinese climate policies and laws. Especially in view of the significant role of policies played in Chinese economic and social development, legislation is not enough for the mitigation of climate change. According to the observation of Cai Shouqiu, in the special Chinese context the governmental framework for climate change can be composed of legislation (containing laws, regulations, rules), policy (of the ruling party and government), administrative orders (including administrative decisions, notices and work plans), disciplinary documents, moral norms, and agreements. ${ }^{2}$ Moreover, it is also not difficult to identify a mix of instruments applied in Chinese policies and laws on climate change, leading to the integration of administrative tools, market mechanisms and voluntary actions (like Corporate Social Responsibility). ${ }^{3}$ In this section, the existing policies and legislation concerning climate change in China will be introduced and examined briefly in order to present the developmental trajectories and status quo of the Chinese governmental framework for climate change.

\subsubsection{Policies}

In order to achieve certain goals in a specific period, a series of policies have been adopted and implemented by the state and ruling party in China. The definition of policy in China may be rather broad, including the policies adopted by the party in power and the policy documents issued by governments at all levels outside the range of formal legislation ${ }^{4}$. Furthermore, a substantial part of the legislation is usually formulated on the basis of national policy, which is adopted in line with the policies of the party in power. ${ }^{5}$ In other words, certain policies with great influence and stability can be transformed into legislation by means of the legalisation of policies. ${ }^{6}$ Moreover, at least two main functions can be identified in policy in the Chinese context: providing direction for legislation by setting up targets and principles on the one hand and specifying the implementing rules backing up or supplementing the implementation of the legislation on the other hand.

In the last two decades, China has become quite proactive in addressing climate change by adopting a series of multi-level policies, which can be categorised into three groups based on their scope of impact and characteristics. The first category of general policy mainly consists of those policies providing general direction and guidance, the second category of basic policy

${ }^{1}$ Qin, T. B. (2009), p.2; see also Zang, D. S. (2009), p.572.

2 Cai, S. Q. (2012), p.15.

3 Ibid, p.13.

${ }^{4}$ The formal legislation will be further discussed in section 2.2 .1 of this chapter.

5 Shen, Z. L. (2009), p. 270.

${ }^{6}$ See Chen, T. (2001). 
usually establishes objectives and composes development plans, and the third category of specific policy focuses on the specific implementing guidelines and measures, including incentives and noncompliance penalties. ${ }^{1}$ Moreover, the first two categories are usually formulated by the central government and its relevant departments, while the third category is determined mainly at the local levels, including the provincial, municipal, and county governments. ${ }^{2}$ In this respect, climate policies made by local governments have more explicit and practical functions but also may differ greatly, depending on the awareness, willingness and strategies of the respective local authorities. ${ }^{3}$ A review of literature on climate change policies in China still suggests that the coherence of the national policy making aiming to reduce $\mathrm{CO}_{2}$ emissions has been improved, but the local policies are still fragmented. ${ }^{4}$ Therefore, this section will only focus on the most important policies at the national level, while relevant policies relating to the pilot projects at the local level will be discussed in the following sections when necessary.

\section{Five-Year Plan/Planning}

Policies measures addressing climate change in China are designed within the domestic policy framework, which largely relies on plan/planning. ${ }^{5}$ In particular, the most important general policies relating to climate change have been mainly provided in the National Five-Year Plan/Planning for Economic and Social Development (hereafter referred to as National Five-Year Plan/Planning) ${ }^{6}$, supplemented and implemented by other national policies such as China's National White Paper on Climate Change ${ }^{7}$, the Comprehensive Work Plan for Energy Conservation and Emission Reduction ${ }^{8}$, the Work Plan for Greenhouse Gas Emissions Control ${ }^{9}$.

With regard to the Chinese five-year plan system, known as 'three levels and three types of planning and management system', it usually contains three hierarchy layers of planning based on Chinese administrative levels, namely national planning, provincial planning and

\footnotetext{
${ }^{1}$ See Yao, R., Li, B., \& Steemers, K. (2005); see also Rommeney, D. (2008).

2 See Yao, R., Li, B., \& Steemers, K. (2005).

3 See Rommeney, D. (2008).

${ }^{4}$ See Marks, D. (2010), p. 971-986; Fang, Y., \& Zeng, Y. (2007).

${ }_{6}^{5}$ Balme, R. (2011), p.47.

6 There is debate over the legal status of the National Five-Year Planning, which will be further explained in section 4 of this chapter. But, in this thesis, the National Five-Year Planning is argued to be more likely the national policy providing for the goal and direction of the Chinese climate policy and law; hence it is elaborated on in the category of policy in this section.

${ }^{7}$ China has promulgated annul national white papers about policies and actions for addressing climate change since 2007. The white paper issued in 2007 by the NDRC became a programmatic document, setting the main framework for climate change policy. Following the white paper, an annual report summarises the policies and actions, the results and targets in addressing climate change.

${ }^{8}$ For instance, eleven categories containing up to forty-eight specific measures have been adopted in the Comprehensive Work Plan for Energy Conservation and Emission Reduction in the $12^{\text {th }}$ Five-Year Planning Period, refining the energy saving target and emissions reduction targets for several main pollutants set in the $12^{\text {th }}$ Five-Year Planning and reaffirming that the government would launch pilot projects of carbon emissions trading as well as voluntary emissions reduction scheme. See the Notice on Printing and Distributing the Comprehensive Work Plan for Energy Conservation and Emission Reduction in the 12th Five-Year Planning Period, State Council, 31 August 2011 (in Chinese).

${ }^{9}$ It has adopted nine categories of twenty-eight specific measures to reach the $17 \%$ carbon intensity reduction target, including the general direction and main steps concerning the establishment of carbon emissions trading market. See The Notice on Issuing the Work Plan for Greenhouse Gas Emissions Control during the $12^{\mathrm{th}}$ Five-Year Planning Period, State Council,1 December 2011, (in Chinese).
} 
municipal/county planning; it can also be divided into overall planning, special planning and regional planning. ${ }^{1}$ Ever since the foundation of the Peoples' Republic of China in 1949, the National Five-Year Plan, as a key strategy document setting the development priorities and basic governmental objectives of the country in the five-year period covered, has been applied by the Chinese central government in pursuit of specific development goals. Proposed by the Central Committee of the Communist Party of China (CPC), drafted by the State Council and passed by the NPC every five years, the National Five-Year Plan is the most important plan and strategy for all the key issues, including addressing climate change.

However, just as its name implies, the National Five-Year Plan traditionally had a strong focus on the development of the national economy. It was not until the beginning of the 1980s that environmental issues and targets entered the National Five-Year Plan. With the increasing public awareness of the importance regarding environmental protection and environmental justice, environmental issues were first mentioned in the $6^{\text {th }}$ Five-Year Plan (1980-1985), one year after the Environmental Protection Law (Trial) came into force. ${ }^{2}$ Meanwhile, a growing attention to energy issues, mainly focusing on energy conservation projects, has also shown up in the National Five-Year Plans since the $6^{\text {th }}$ Five-Year Plan. ${ }^{3}$

Nevertheless, two important changes occurred in the $11^{\text {th }}$ Five-Year Planning (2006-2010) in 2006. On the one hand, the Chinese government changed the name of the $11^{\text {th }}$ Five-Year programme from 'plan' (ji hua) to 'planning' (gui hua) in Chinese. The change in the wording has sparked extensive debate on the impact and reasons behind such a modification in the language. At least one conclusion that the five-year programme is now depicted more as a guiding roadmap compared to the traditional plans in an old 'planned economy' style can be deduced from this change in language. ${ }^{4}$ Moreover, this shift towards a systemic outlook reveals the trend that the central government is trying to explore innovative approaches, such as market-based instruments, to deal with various emerging challenges in practice. ${ }^{5}$ On the other hand, an energy intensity reduction target, reducing energy consumption per unit of GDP by around $20 \%$ below 2005 level by 2010 , was set as the binding target for the first time. ${ }^{6}$ To be specific, two categories of targets were established in the planning, in order to clarify the responsibility for the implementation of the planning between governments and market players. The first category, namely the predictive indicators, will be mainly achieved by the autonomous acts of the market players. ${ }^{7}$ Nevertheless, the second category, the so-called binding targets, is the government's commitment to the people and the main binding targets will be allocated to and implemented practically by the related ministries and the provincial governments. ${ }^{8}$

${ }^{1}$ Zhang, H. (2012), p.10264-10265.

${ }^{2}$ Yu, G. \& Elsworth, R. (2012), p.9.

3 See Yao, R., Li, B., \& Steemers, K. (2005).

${ }^{4} \mathrm{Yu}, \mathrm{G}$. \& Elsworth, R. (2012), p.8.

${ }^{5} \mathrm{Lu}$, Y., The Significance from Five-Year Plan to Five-Year Planning, available at: http://news.xinhuanet. com/politics/2005-10/10/content_3602338.htm, 10 October 2005, last accessed 12 October 2013 (in Chine se).

${ }^{6}$ Chapter $3,11^{\text {th }}$ Five-Year Planning (2006-2010).

${ }^{7}$ Chapter $1,11^{\text {th }}$ Five-Year Planning.

${ }^{8}$ Ibid. 
The trend of combating climate change in the $11^{\text {th }}$ Five-Year Planning (2006-2010) was further strengthened in the $12^{\text {th }}$ Five-Year Planning (2011-2015), in which more attention has been paid to energy saving, low-carbon economy development, environmental protection, and issues closely related to climate change. An unprecedented high number of environmentally focused targets (10 targets out of 28 targets) are set as the so-called binding targets in the $12^{\text {th }}$ Five-Year Planning. In addition to the energy efficiency target ${ }^{1}$, China has addressed climate change by means of adopting the carbon intensity reduction target, targeting the specific reduction of $\mathrm{CO}_{2}$ emissions per unit of GDP directly. Moreover, shifting the energy intensity reduction target to a carbon intensity reduction target has witnessed an important strategic transformation in China's energy policy, where both energy efficiency and emissions reductions should be considered as the binding targets in the energy strategic plan ${ }^{2}$.

Table 1 climate related binding targets in the Five-Year Planning 3

\begin{tabular}{|l|l|l|l|}
\hline \multicolumn{1}{|c|}{ Targets } & $\begin{array}{l}11^{\text {th }} \text { FYP Targets set } \\
(2006-2010) \\
\left(\text { compared to } 10^{\text {th }}\right. \\
\text { FYP) }\end{array}$ & $\begin{array}{l}11^{\text {th }} \text { FYP } \\
\text { Targets } \\
\text { achieved end } \\
2011\end{array}$ & $\begin{array}{l}12^{\text {th }} \text { FYP Targets } \\
\text { set (2011-2015) } \\
\text { (compared to 11 } \\
\text { FYP) }\end{array}$ \\
\hline Energy Intensity decreased by (\%) & 20 & 19.1 & 16 \\
\hline Carbon Intensity decreased by (\%) & N/A & N/A & 17 \\
\hline $\begin{array}{l}\text { Non-fossil Fuel in Primary Energy } \\
\text { Consumption (\%) }\end{array}$ & N/A & 8.3 & 11.4 \\
\hline Forest Coverage rate (\%) & 20 & 20.36 & 21.7 \\
\hline $\begin{array}{l}\text { Forest Stock increased by (million } \\
\text { cubic metre) }\end{array}$ & N/A & 137 & 143 \\
\hline
\end{tabular}

According to the definition in the IPCC report, the amount of $\mathrm{CO}_{2}$ emissions per unit of GDP is defined as "carbon intensity", which can be calculated based on the GDP and total amount of $\mathrm{CO}_{2}$ emissions. However, the data of total amount of $\mathrm{CO}_{2}$ emissions of China in 2010 is still not available at the time of writing, at least not published by the Chinese government. According to a report published by International Energy Agency (IEA), the total amount of $\mathrm{CO}_{2}$ emissions of the whole world in 2010 reached to 30326 Million tonnes (Mt) of $\mathrm{CO}_{2}$, in which China took up a share of $24.5 \%{ }^{5}$ In other words, the total amount of $\mathrm{CO}_{2}$ emissions of China in 2010 amounted to $7311 \mathrm{Mt}$ of $\mathrm{CO}_{2}$, and the carbon intensity is hence $1.80 \mathrm{~kg} \mathrm{CO} / 2005$ United States Dollar (USD), shown in the following table given by IEA in that report ${ }^{6}$. Therefore, in line with the $17 \%$ carbon intensity reduction target set up in the $12^{\text {th }}$ Five-Year Planning (2011-2015), the carbon intensity in 2015 is supposed to be $1.494 \mathrm{~kg} \mathrm{CO}_{2} / 2005$ USD. However, it is rather strange

\footnotetext{
${ }^{1}$ In China, the energy efficiency target is set up in the form of energy intensity target, meaning the amount of energy used in per unit of GDP.

2 See Lin, B. Q., The qualitative change of China's energy saving and emissions reduction policies: from energy intensity to carbon intensity. China Daily, 5 December 2009 (in Chinese).

${ }^{3}$ Chapter 3, $12^{\text {th }}$ Five-Year Planning (2011-2015).

${ }^{4}$ IPCC (2007), p.811.

5 It is calculated using the IEA's energy balances and the Revised 1996 IPCC Guidelines, $\mathrm{CO}_{2}$ emissions are from fuel combustion only, see IEA (2012), p.45.

${ }^{6}$ In this report, the GDP is calculated in 2005 USD rather than Chinese Yuan (CNY), see Ibid, p.48-49.
} 
that neither the $12^{\text {th }}$ Five-Year Planning (2011-2015) itself nor any other Chinese policies have provided similar data and explained this.

Table 2 Carbon intensity of some regions and countries

\begin{tabular}{|l|l|l|l|}
\hline Region/Country/Economy & $\begin{array}{l}\text { GDP } \\
\text { (billion 2005 USD) }\end{array}$ & $\begin{array}{l}\mathrm{CO}_{2} \text { emissions } \\
\left(\mathrm{Mt} \text { of } \mathrm{CO}_{2}\right)\end{array}$ & $\begin{array}{l}\mathrm{CO}_{2} / \mathrm{GDP} \\
\left(\mathrm{kg} \mathrm{CO}_{2} / 2005 \text { USD }\right)\end{array}$ \\
\hline World & 50942 & 30326 & 0.60 \\
\hline OECD & 37494 & 12440 & 0.33 \\
\hline $\begin{array}{l}\text { Non-OECD Europe and } \\
\text { Eurasia }\end{array}$ & 1533 & 2606 & 1.70 \\
\hline China & 4053 & 7311 & 1.80 \\
\hline
\end{tabular}

(Source: International Energy Agency, Key World Energy Statistics 2012)

\section{Target-based accountability system}

The fulfilment of the $\mathrm{CO}_{2}$ emissions reduction targets relies on the governmental framework with different policy instruments. The part on environmental protection and green development in the $12^{\text {th }}$ Five-Year Planning starts with a specific chapter responding to climate change actively, focusing on the role of technological innovation, capacity building, institutional and policy improvement. ${ }^{1}$ In order to reduce energy intensity and carbon intensity significantly and to control GHG emissions effectively, a variety of means, such as adjustments to industrial structures and energy structure, conserving energy and enhancing energy efficiency will be employed as well. ${ }^{2}$ In addition, sound statistical and accounting systems for GHG emissions will also be put on the agenda. ${ }^{3}$ Notably, the carbon emissions trading instrument is going to be established gradually and pilot cities for low carbon development will be promoted. ${ }^{4}$

However, the implementation of Chinese climate policy still relies heavily on the accountability system, holding the leading cadres of local governments responsible for the fulfilment of the carbon intensity reduction target and other binding targets. In pursuit of the achievement of the carbon intensity reduction target set up in the $12^{\text {th }}$ Five-Year Planning (2011-2015), the national carbon intensity reduction target, similar to other binding targets, has been allocated from the central government to the local governments through a top-down approach. ${ }^{5}$ Moreover, the results of the performance evaluation concerning the fulfilment of the binding targets set up in the $12^{\text {th }}$ Five-Year Planning will be deemed to be an important basis for the election, promotion, punishment, and awards for the leading cadres. ${ }^{6}$ Similar to the existing accountability system applied in the domains of the economic development and social management, the leading cadres may be punished by the disciplinary sanctions including warning, demotion, demerit recording,

\footnotetext{
${ }^{1}$ Chapter $21,12^{\text {th }}$ Five-Year Planning.

2 Ibid.

3 Ibid.

${ }^{4}$ Ibid.

${ }^{5}$ It will be described and analysed in depth in section 3 and 4 of this chapter.

${ }^{6}$ Section 3, Chapter 61, $12^{\text {th }}$ Five-Year Planning (2011-2015). This is also discussed in the section concerning the legal nature of the $12^{\text {th }}$ Five-Year Planning in section 4.1 of this chapter later.
} 
or even dismissal once any failure of a specific target achievement is detected. ${ }^{1}$ In this sense, the literature has argued that in China the policy, in particular the Five-Year Planning, is as important as law or even more important since the existing legislation tends to be rather general without specific goals and implementation measures ${ }^{2}$, while the Five-Year Planning binds the local governments through the integration of the target achievement into the cadre system. ${ }^{3}$

Moreover, this target-based accountability system has been reiterated by a variety of governmental documents. For instance, according to the Work Plan for GHG Emissions Control during the $12^{\text {th }}$ Five-Year Plan Period, the provincial governments are responsible for controlling the GHG emissions under their respective administration; the fulfilment of the allocated carbon intensity reduction target will be closely linked with the promotion of the major leaders of the local governments, who will be punished or rewarded because of the failure or success in achieving the targets. ${ }^{4}$ By analogy, according to the Action Plan for energy saving, emissions reduction and low-carbon development in 2014-2015, the leading cadres failing in accomplishing the annual targets shall not be appraised as excellent and promoted within one year after the publication of the evaluation result to the public. ${ }^{5}$

In particular, the NDRC has formulated specific performance assessment measures regarding the implementation and completion of the distributed carbon intensity reduction targets at the provincial levels. ${ }^{6}$ Following the evaluation steps, including self-assessment by provincial governments, preliminary examination and on-site check by the NDRC together with relevant departments, ${ }^{7}$ the fulfilment of the carbon intensity reduction target (50 points), task and measures (24 points), basic work and capacity building ( 26 points) and other performance ( 6 points) will be assessed based on the centesimal system, in accordance with a detailed index and grading rule. ${ }^{8}$ In particular, it will be graded as a disqualification once there is a failure in the fulfilment of the carbon intensity reduction target, even though the final score exceeds 60 points. ${ }^{9}$ The province's innovative exploration in terms of GHG ETS, total emissions control and emission reporting may be awarded with two bonus points respectively, which can only be considered in the final assessment but not calculated into the final score. Based on the assessment result, the provincial government graded excellent will be praised by circulating a notice of commendation and getting priority in the arrangement of relevant projects. The provincial governments failing in the assessment will be required to produce a written report

\footnotetext{
1 This is usually called the 'One-vote veto' policy (yi piao fou jue zhi) in China, since these targets have the 'veto power', the failure to achieve which can trump other accomplishments. Further discussion can for instance refer to Deng, K. Z. (2011).

${ }^{2}$ See Alford, W. P., \& Shen, Y. (1997), p134-135; Mol, A. P., \& Carter, N. T. (2006), p.157.

${ }^{3}$ Lin, J. (2012), p.11.

4 Article 26, The Notice on Issuing the Work Plan for Greenhouse Gas Emissions Control during the $12^{\text {th }}$ Five-Year Plan Period, State Council, 1 December 2011, (in Chinese).

5 The Notice of the State Council on Printing and Distributing the Action Plan for energy saving, emissions reduction and low-carbon development in 2014-2015, General Office of State Council, 15 May 2014, (in Chinese).

6 The Notice of the State Council on Printing and Distributing the Performance Assessment Measures Regarding the Carbon Intensity Reduction Target Responsibility, NDRC, 6 August 2014 (in Chinese).

${ }^{7}$ Ibid, at Article 7.

8 Ibid.

${ }^{9}$ Ibid, at Article 5.
} 
with corrective actions within a limited time to the State Council, making a copy to the NDRC, within one month after the release of the assessment result. ${ }^{1}$

\subsubsection{Legislation}

In parallel to the general policies addressing climate change, a series of legislation relating to climate change have been adopted or amended in the recent decades.

\section{Existing laws, administrative regulations and governmental rules}

With the first Environmental Protection Law coming into force in 1989, the Chinese environmental law regime has been growing steadily over the past 30 years. According to the White Paper on China's Efforts and Achievements in Promoting the Rule of Law in 2008, China has enacted 9 laws concerning environmental protection and 17 laws with regard to resource conservation and protection. ${ }^{2}$ At the time of the adoption of Environmental Protection Law (1989), $\mathrm{CO}_{2}$ emissions were not considered to affect air quality or contribute to global warming in the early days, thus it was not regulated directly by the traditional environmental law. Even when the Environmental Protection Law was revised in 2014, the GHG emissions seem to remain outside the range of the pollutants regulated by it, leading to the difficulty to apply the revised law directly to the GHG emissions activities so far. However, the basic principles and institutions provided for in the Environmental Protection Law have laid the foundation for the regulatory framework for addressing climate change to a certain degree. For instance, according to the amendment of the Environmental Protection Law in 2014, the target-based responsibility system and performance assessment system for environmental protection will be implemented in 2015, requiring the government to incorporate the completion of environmental protection targets, as an important basis for the assessment of the competent departments and persons in charge thereof at the same level as well as the lower levels. ${ }^{3}$ Moreover, the governments shall prepare annual reports on the environmental conditions and the completion of the environmental protection objectives for the people's congress or its standing committee at the same level. ${ }^{4}$ This amendment suggests the linkage between the legal system and the political accountability mechanism mentioned in the $12^{\text {th }}$ Five-Year Planning, but the exact design and detailed implementation of this new regime is not yet further explained.

Several important laws relating to climate change have also been adopted and amended, such as the Energy Conservation Law (1997, revised 2007), the Renewable Energy Law (2005, revised 2009, 2010), the Law on Prevention and Control of Air Pollution (1987, revised 1995, 2000), and the Cleaner Production Promotion Law (2002), forming the primary legal framework for mitigating climate change. Despite the fact that the Chinese climate law regime is still in its infancy ${ }^{5}$, some climate-specific laws and regulations have made the effort to address climate

1 Ibid, at Article 9, 10.

${ }^{2}$ China's Efforts and Achievements in Promoting the Rule of Law (2008), Information Office of the State Council, February 2008, Beijing.

3 Article 26, Environmental Protection Law of China.

${ }^{4} \mathrm{Ibid}$, at Article 27.

${ }^{5}$ Zhang, H. (2012), p.10267. 
change through a variety of instruments. It has been argued by scholars that an 'energy turn' from 'environment' occurred in 2003, after which climate change was conceptualised as an energy policy issue and was addressed in the energy strategy. ${ }^{1}$ Given the strong connection between $\mathrm{CO}_{2}$ emissions and energy structure and efficiency, the achievement of the climate targets still largely relies on the existing legal framework for energy saving and emissions reduction, in which the Energy Conservation Law, the Renewable Energy Law and series of administrative regulations and governmental rules have played significant roles.

For instance, aiming at enhancing energy conservation management and improving energy efficiency, the Energy Conservation Law was first enacted in 1997 and was amended extensively in 2007. A series of instruments have been applied in this law, constituting the core of the legal framework for energy conservation and emissions reduction. A specific chapter focusing on the administration of energy conservation is established right after the general provisions, including a sound system of standards for energy conservation ${ }^{2}$, an energy conservation assessment and examination system for fixed-asset investment projects $^{3}$, an energy efficiency labelling system ${ }^{4}$, and a sound energy statistics system ${ }^{5}$. Great emphasis on governmental management and performance showed in the provisions has indicated that strong governmental control and supervision is still playing the leading role in achieving the energy conservation and emissions reduction targets. ${ }^{6}$

Furthermore, the use of the cadre system was explicitly referred to in the amendment of Energy Conservation Law, linking planning and laws for the first time in the way that is not found in earlier legislation. ${ }^{7}$ According to Article 6 of the Energy Conservation Law, the State will implement a system of accountability for energy conservation targets and a system for performance evaluation whereby the fulfilment of energy conservation targets will be included as part of the evaluation of the local governments as well as the officers leading the governments. ${ }^{8}$ In addition, up to nineteen articles, relating to legal liabilities for noncompliance in terms of energy saving, have been set up. The key to strengthening the liability system, as a scholar argued, relies on the legal liability for the administration when a violation is detected ${ }^{9}$, where they will be subjected to administrative sanctions and criminal liabilities in accordance with the Energy Conservation Law. ${ }^{10}$ The sanctions for the private violators are also argued to be much higher than they were before amendment. ${ }^{11}$

In addition to the major laws mentioned above, a variety of administrative regulations and governmental rules have been adopted by the governments aiming to achieve the energy saving

\footnotetext{
${ }^{1}$ Zang, D. S. (2009), p.562.

2 Articles 13, 14 Energy Conservation Law of China.

3 Article 15 Energy Conservation Law of China.

${ }^{4}$ Articles 18, 19, 20 Energy Conservation Law of China.

5 Article 21 Energy Conservation Law of China.

${ }^{6}$ Zhang, H. (2012), p.10269.

${ }^{7}$ Lin, J. (2012), p.12.

${ }^{8}$ Article 6, Energy Conservation Law of China.

9 Zhang, Z. T. (2007), p.121.

${ }^{10}$ Article 68,86, Energy Conservation Law of China.

${ }^{11}$ Zhang, H. (2012), p.10269.
} 
and emissions reduction targets, most of which have played a certain part in the Chinese governmental framework for addressing climate change. In spite of the fact that many of those laws and regulations do not stipulate reductions of GHG emissions directly, their provisions have been adjusted to a different degree and their implementation and enforcement has, as a matter of fact, made an actual contribution to the reduction of GHG emissions in China. ${ }^{1}$ Meanwhile, the Interim Measures for the Administration of Voluntary Greenhouse Gas Emission Reduction Trading $^{2}$, ensuring the voluntary emission reduction trading activities are carried out in an orderly manner, is important to accumulate experience for the progressive establishment of a cap-and-trade carbon emission trading market.

\section{Climate law being drafted}

However, legislation focusing mainly on energy issues is not enough for addressing climate change issues, requiring China take a further step 'from energy to climate' ${ }^{3}$. A comprehensive legislation on climate change has been put on the agenda at the top legislature, indicating a further step to be taken by China towards a well-designed legal framework for addressing climate change. On 27 August 2009, the Resolution on Actively Addressing Climate Change was adopted by the National People's Congress's Standing Committee (NPCSC), emphasising the basic Chinese principles and measures in dealing with climate change. ${ }^{4}$ Even though this resolution seems to be a declaration rather than legislation, it will take the lead and guide the lawmaking concerning climate change in the future. ${ }^{5}$ Following this resolution, the Climate Change Law has been included in the legislation plan of the NPC since 2011, the draft of which is supposed to be submitted by the NDRC. On 18 March 2012, a draft proposed by a research team of the Chinese Academy of Social Sciences was submitted to the NDRC and was open to the public for advice ${ }^{.6}$, but the legislative process appears to be rather slow, with little progress by the time of writing. As a specific mitigation measure addressing climate change, the establishment of ETS has also been proposed in this draft. ${ }^{7}$

\subsection{The governance structure of Chinese climate law and policy}

In contrast with the doctrine of separation of power favoured in most western countries, a unique centralised power system with four levels has been developed in China, including the central, provincial, prefecture, and county levels. ${ }^{8}$ Moreover, the people's congress and its standing committee, the governments and the judicial system with the people's court and procuratorate play specific roles and interact at each level. In this sense, the governance structure of Chinese

\footnotetext{
${ }^{1}$ Qin, T. B. (2009), p.2.

2 The Interim Measures for the Administration of Voluntary Greenhouse Gas Emission Reduction Trading, NDRC, 13 June 2013 (in Chinese).

3 Balme, R. (2011), p.45.

${ }^{4}$ Resolutions of Standing Committee of the National People's Congress on Actively Addressing Climate Change, adopted by Standing Committee of the National People's Congress, 27 August 2009 (in Chinese).

${ }^{5}$ Zhang, Z. T. (2010a), p.39.

${ }^{6}$ The draft (in Chinese) is available at: http://www.china.com.cn/news/txt/2012-03/18/content_24923504.ht m.

${ }^{7}$ See for instance Article 38-40 of the proposed draft.

8 Du, Q. (2009), p.419.
} 
climate law and policy will be introduced briefly in terms of the legislation structure, administration and judicial system.

\subsubsection{Legislative competence distribution and legislation structure}

\subsubsection{Legislative competence distribution}

The legislative competence in China has been distributed to the central and local authorities in line with the unique Chinese circumstances. According to the Constitution, the division of functions and competences between the central and local authorities is guided by the general principle of 'giving full scope to the initiative and enthusiasm of the local authorities under the unified leadership of the central authorities'. 'In this provision, the special characteristic of centralisation (by saying 'under the unified leadership of the central authorities') with a certain degree of decentralisation (by emphasising 'giving full scope to the initiative and enthusiasm of the local authorities') is not difficult to identify. To be specific, in the Legislation Law the legislative competence, one of the most important state powers, has been distributed to the central authorities, on the one hand, and allocated to the local authorities, on the other hand, but it is under control of the central authority.

In China, the state organs are mainly composed of the NPC, the State Council, Central Military Commission, Supreme People's Court and Supreme People's Procuratorate (shown in the chart below). The principal legislative competence enacting national laws and administrative regulations is distributed to the NPC and the State Council, which take the leading positions in the whole legislative structure.

Figure 1 State organs at the central level in China

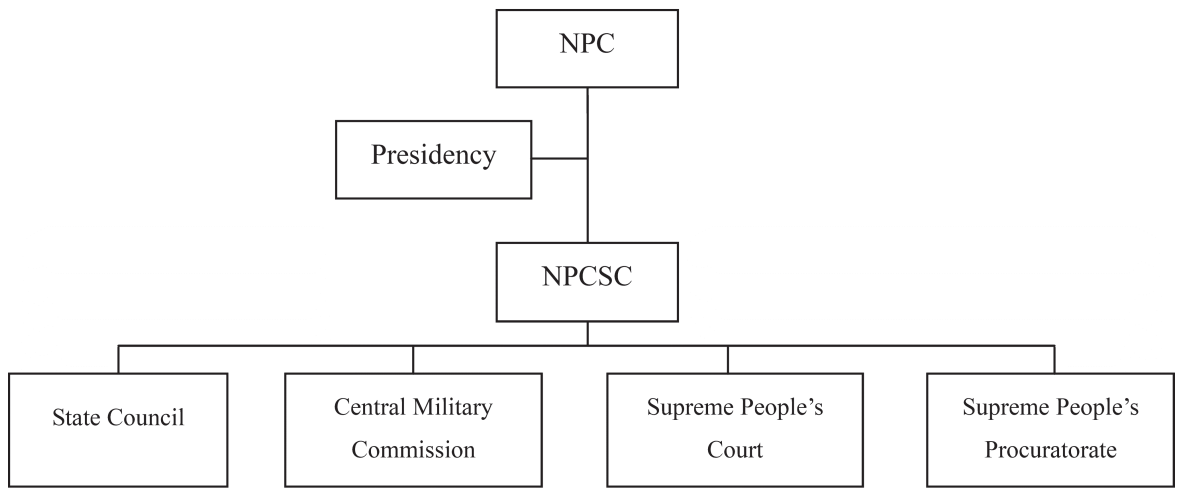

\section{National People's Congress and its Standing Committee: enacting laws}

According to China's constitutional structure, the National People's Congress (NPC) is the highest organ of national power and authority ${ }^{2}$. As the highest legislature, the NPC and its

\footnotetext{
1 Article 3, Constitution of China.

2 Article 57, Constitution of China. In other words, all other national constitutional organs, including the State Council, the President, the Central Military Commission, the Supreme People's Court, and the Supreme People's Procuratorate are established under and accountable to the NPC. See Article 3, 58, Constitution of China.
} 
Standing Committee (NPCSC) are delegated the authority to enact all kinds of national laws, in order to exercise the legislative power of the State ${ }^{1}$. Based on the Legislation Law, specific affairs provided for in Article 8 of the Legislation Law must be governed by laws, enacted exclusively by the NPC and its Standing Committee. ${ }^{2}$ Moreover, the Constitution and the basic laws governing, such as, criminal offences and civil affairs should only be enacted and amended by the NPC. ${ }^{3}$

\section{State Council: adopting administrative regulation}

The State Council, namely the Central People's Government, is the highest organ of the state administration to execute state power. ${ }^{4}$ Under the current Constitution, the State Council is responsible for implementing the principles and policies of the $\mathrm{CPC}$ as well as the laws adopted by the NPC. ${ }^{5}$ In order to implement the laws and to exercise the administrative functions and powers as stipulated in the Constitution, administrative regulations can be formulated by the State Council according to the Constitution and laws. ${ }^{6}$

\section{Provincial congress and its standing committee: adopting local regulation}

Given the imbalanced development among different regions of China, certain legislative competence has been allocated to the local authorities at the provincial level ${ }^{7}$ in the Constitution and the Legislation Law. To be specific, the provincial people's congresses or their standing committees may enact local regulations, provided that such regulations do not contradict the Constitution, the laws and administrative regulations, and approve local regulations formulated by the people's congresses or their standing committees of the comparatively larger cities. ${ }^{8}$ In addition, the provincial authorities as well as the comparatively larger cities may first adopt local regulations on the affairs which has not yet been regulated by any laws or administrative regulations adopted at the national level, in light of the specific local conditions and actual needs. ${ }^{9}$ Furthermore, the people's congresses or their standing committees of the provinces and cities where special economic zones are located, like Shenzhen, are allocated even more competence to make appropriate modifications regarding some provisions of laws, administrative regulations or local regulations within its own jurisdiction. ${ }^{10}$

\footnotetext{
${ }^{1}$ Article 58, Constitution of China.

2 Article 8, Legislation Law of China.

3 Article 62(1)(3), Constitution of China.

${ }^{4} \mathrm{Ibid}$, at Article 85.

5 Ibid, at Article 89.

${ }^{6}$ Article 56, Legislation Law of China.

7 The administrative division of China contains three basic levels: province, county, and town. At the provincial level, the country is divided into provinces, autonomous regions and municipalities directly under the central government. See Article 30, Constitution of China.

${ }^{8}$ Article 100, Constitution of China; see also Article 63, Legislation Law of China. According to the Legislation Law, the term of 'comparatively larger city' used in the legislation Law refers to a city where a provincial or autonomous regional people's government is located or where a special economic zone is located, or a city approved as such by the State Council. For instance, Shenzhen is one of the comparatively larger cities.

9 Article 64, legislation law of China. Again, these affairs should not fall in the range of the affairs provided for in Article 8 of the Legislation Law, which should only be governed by laws enacted by the NPC and its Standing Committee.

${ }^{10}$ Article 81, legislation law of China.
} 


\section{Ministries and provincial governments: formulating rules}

The ministries and commissions of the State Council, like the NDRC, may adopt rules within the limits of their power, in accordance with the laws and administrative regulation. ${ }^{1}$ Meanwhile, the provincial governments and governments of the comparatively larger cities, such as the two provinces and five cities establishing the pilot projects, may enact rules in accordance with laws, administrative regulations and their respective local regulations. ${ }^{2}$ Within the Chinese legal system, no legislative competence is distributed to lower levels of governments and its departments than those mentioned above, which can only adopt other normative documents.

\subsubsection{Legal sources of the Chinese legal system}

In spite of the long history of China, the legal system of the People's Republic of China is still very young in the process of establishment and improvement. Over the last six decades, especially after the introduction of the reform and opening-up policy in 1978, China has enacted numerous pieces of legislation based on the legislative competence distribution structure, in order to build up a socialist legal system with Chinese characteristics based on a specific understanding of the rule of law. In the first governmental white paper on China's Efforts and Achievements in Promoting the Rule of Law, China officially declared that a modern Chinese legal system, mainly comprised of seven branches and three levels of legislation, had been established. $^{3}$ In addition to the Constitution, three levels of legislation are officially designated as the formal sources of Chinese law: (1) laws; (2) administrative regulations; and (3) local regulations, autonomous regulations and separate regulations. ${ }^{4}$ In addition, rules can be adopted by the ministries under the State Council, provincial governments and local government of certain large cities.

According to the Constitution and the Legislation Law in China, all the legislation promulgated by different competent authorities should be implemented in accordance with its legal ranks (shown in the following table), in order to ensure the uniformity and consistency of the legal system. To be specific, the Constitution has the supreme legal force and no legislation may contravene the Constitution. ${ }^{5}$ Under the Constitution, the legal rank of laws is higher than that of the administrative regulations, local regulations and rules, while the authority of administrative regulations is higher than that of local regulations and rules. ${ }^{6}$ The legal effect of the local regulations is higher than that of the rules formulated by local governments at and below the corresponding level ${ }^{7}$. Moreover, the effect of the rules adopted by ministries of the State Council is equal to that of the rules of local governments, the application of which shall be limited to their respective competence. ${ }^{8}$ However, if the provisions of local regulations are inconsistent

\footnotetext{
${ }^{1}$ Other organs endowed with administrative functions directly under the State Council also have this legislative competence. See ibid, at Article 71.

${ }^{2}$ Ibid, at Article 73.

${ }^{3}$ China's Efforts and Achievements in Promoting Rule of Law (2008), Info. Office of the State Council Feb. 28, 2008 (in Chinese).

${ }^{4}$ Annual Report on China's Legal Development Under Rule of Law (2010), China legal society, June 2011, Beijing. (in Chinese).

5 Article 78, Legislation Law of China.

${ }^{6} \mathrm{Ibid}$, at Article 79.

$7 \mathrm{Ibid}$, at Article 80.

${ }^{8} \mathrm{Ibid}$, at Article 82.
} 
with those in the rules of ministries, it is a complicated problem which should be submitted to the State Council for a decision or even the NPCSC for a ruling, and it is difficult to decide which provisions shall prevail. ${ }^{1}$

Table 3 Legislative competence distribution and ranking of the legislation in China

\begin{tabular}{|c|c|c|c|}
\hline \multicolumn{2}{|r|}{ Authorities } & Legislation & Ranking \\
\hline \multirow{5}{*}{$\begin{array}{l}\text { National } \\
\text { level }\end{array}$} & \multirow[t]{2}{*}{ NPC } & Constitutions & 1 \\
\hline & & Basic laws & 2 \\
\hline & NPCSC & Laws (except basic laws) & 2 \\
\hline & State Council & Administrative regulations & 3 \\
\hline & Ministries of State Council & Rules of ministries & 5 \\
\hline \multirow[t]{3}{*}{ Local level } & $\begin{array}{l}\text { Provincial People Congress (including } \\
\text { some comparatively larger cities) }\end{array}$ & Local regulations & 4 \\
\hline & $\begin{array}{l}\text { People's congresses of the ethnic } \\
\text { autonomous areas }\end{array}$ & $\begin{array}{l}\text { Autonomous regulations and Separate } \\
\text { regulations }\end{array}$ & 4 \\
\hline & Provincial governments & Rules of local government & 5 \\
\hline \multicolumn{4}{|c|}{ Other normative documents and policies } \\
\hline
\end{tabular}

In addition to the formal legal sources mentioned above, numerous 'other normative documents' (qi ta gui fan xing wen jian) and policies adopted by the governments and its departments at all levels play important roles in China. In particular, governments often adopt 'other normative documents' within its competence in the form of administrative decisions, orders, measures, and other documents, in order to apply the legislation and implement the policies within its own jurisdiction. According to the existing Chinese legal system, the 'other normative document' is not considered as a formal legal source ${ }^{2}$. However, it is noticeable that 'other normative documents' and policies adopted by governments sometimes have an even stronger practical influence than formal legislation, given the special role and mode of operation of government in China, which will be illustrated by the practice of the pilot projects.

\subsubsection{Co-existence of centralisation and decentralisation}

The Chinese legislative system features a mix of characteristics of centralisation and decentralisation, exemplified by the system of recording and examination for legislation, in which multi-levels of legislation exist in a unified legal system while the lower legislators are supervised and controlled by the higher authorities layer by layer. The legislative competence distributed to certain levels of the local people's congresses and local government has exemplified the decentralisation characteristic to a certain degree, in line with the principle of 'giving full scope to the initiative and enthusiasm of the local authorities' . However, all these regulations and rules are subjected to a system of recording and examination stipulated in the Constitution and the Legislation Law, aiming to ensure the Constitution and laws are respected

\footnotetext{
1 Ibid, at Article 86 (2).

2 There is an ongoing debate on the question of whether the other normative document adopted by government should be included into the formal legal source in China. Further discussion can be refer to, for instance, Zhan, Z.L. (1992); Wu, P. (2006); Jin, Z. N. (2010); Wang, Q.T. (2011).
} 
and complied with. In line with their legal ranks, the legislation enacted by the competent authorities should be filed with the legislators at higher levels for their records. Furthermore, all the legislation except for the Constitution shall be altered or annulled by competent legislators at higher levels under specific circumstance as provided in Article 87 of Legislation Law, such as transcending the limit of power, contravening the legislation of upper levels and violating the legal procedures. ${ }^{1}$

Another feature of the Chinese legal system is the bottom-up experimental approach applied for the reform and innovation of the legal systems. According to the Legislation Law, the State Council or the provincial people's congress can firstly enact administrative regulations or local regulations respectively, preparing for the adoption of future laws or administrative regulation when the conditions are ripe. ${ }^{2}$ Especially when there is no specific legislation available governing the emerging affairs, the experimental approach taking place by policies or other normative documents rather than legislation, in pursuit of the establishment of a new legal system, has been applied frequently in China. The experimental approach at the local level leading to the policy and law formulation and reformation in a wider range of geographic coverage, even at the national level gradually, is not new to the Chinese political system, based on which a variety of successful cases and also failures are worth attention. ${ }^{3}$ In this respect, a good example will be provided by the policies and legislation on climate change, inter alia the emissions trading pilot projects, to be explored in following sections of this chapter.

\subsubsection{Administrative structure for climate policy making}

The main structure of the Chinese environmental governance system is generally established on a so-called 'two committees, one bureau' model, in which the 'two committees' refer to the environment and resource committee of the people's congress and the environmental protection committee of each government, while the 'one bureau' refers to the environmental protection bureau at each level. ${ }^{4}$ Nevertheless, the administrative structure for addressing climate change appears to be a little different, engaging a variety of institutions at the central to local levels from environmental protection agencies to sector regulators. ${ }^{5}$

According to the Annual Report on Chinese Climate Policies in 2013, China has established a basic administrative system with mechanisms for inter-departmental coordination, in which the National Leading Group for Addressing Climate Change plays a leading role. ${ }^{6}$ This high-level National Leading Group, headed by the Premier of State Council, was established by the State Council in June 2007. The National Leading Group is responsible for developing and coordinating key national strategies, guidelines and measures addressing climate change. The Office of the National Leading Group is established within the NDRC, which is virtually the national competent authority playing leading role in coordinating climate change policies and

\footnotetext{
1 Article 87, Legislation Law of China.

2 Ibid, at Article 9 and 64.

${ }^{3}$ Chung, J. H. (2011), p.58.

${ }_{5}^{4}$ Chang, Y. C. \& Wang, N. (2010), p.3358.

5 Ibid, p.3363.

${ }^{6}$ China's Policies and Actions for Addressing Climate Change (2013), NDRC, 5 November 2013, p.5-7.
} 
actions adopted by various ministries. The NDRC is responsible for centralised administration and tasks are distributed between relevant departments and local governments as well. ${ }^{1}$

As a result, the NDRC, which is also the macro-economic regulatory organ responsible for designing national development strategy including the Five-Year Planning, has become the central actor in climate change policy making. ${ }^{2}$ As one of the most important parts of the State Council, the NDRC has a broad and significant competence and functions, including formulating and implementing strategies of national economic and social development, putting forward targets and policies for national economic development, guiding pilot projects of economic system restructuring and work in the experimental reform zones, promoting the strategy of sustainable development, undertaking the comprehensive coordination of energy saving and emissions reduction, organising the formulation of key strategies, plans and policies in addressing climate change, taking the lead with related ministries in attending international negotiations of climate change, and undertaking relevant work with regard to the fulfilment of the UNFCCC at national level. ${ }^{3}$

The establishment of the high-level leading group, especially the lead taken by the NDRC, has demonstrated that climate change issues have been given higher priority on China's political agenda than before. ${ }^{4}$ Meanwhile, given the broad and powerful competence of NDRC, the climate policy is expected to be better implemented and achieved in other economic, social and environmental policies adopted by the NDRC. In this sense, it can facilitate the external integration of climate policy in China. In particular, the NDRC is also in charge of the development of the GHG ETS, which are designed and implemented by seven local governments with the approval of the NDRC.

\subsubsection{Judicial system relating to the climate regime}

In the governance structure of Chinese climate law and policy, the judicial system is supposed to play its role in the enforcement of the legislation, dealing with possible disputes emerging in the design and implementation of the ETS. China's legal system has provided for a set of civil remedies based on tort law principles, which can be found in the Tort Law, the General Principles of Civil Law and the Environmental Protection Law. Moreover, for serious violations of environmental law inter alia those causing serious damage to the human life and property, criminal sanctions have been introduced in the Criminal Law. Taking account of the special role of the government in the ETS, particular attention will be placed on the administrative procedure, especially on the questions of whether and how the enterprises and public can have access to the court in pursuit of the judicial remedy regarding some governmental actions in the course the emissions trading.

\footnotetext{
${ }^{1}$ Ibid.

2 Marks, D. (2010), p.976.

${ }^{3}$ See the Notice of the General Office of the State Council on Issuing the Provisions on the Main Functions, Internal Bodies and Staffing of the National Development and Reform Commission, 15 July 2008. General Office of State Council, (in Chinese).

${ }^{4}$ See Qin, T. B. (2009), p.7.
} 
Similar to other environmental enforcement, a variety of administrative decisions will be taken by the government in designing and implementing the ETS, together with the application of several regulatory instruments and administrative sanctions ranging from warnings, fines, the confiscation of unlawful gains, pollution control within deadlines, permit revocation, and enterprise closure. ${ }^{1}$ In order to check the administrative enforcement decisions, three relevant review mechanisms are available, including the internal review and administrative review conducted within the administrative system as well as the judicial review. ${ }^{2}$

With regard to the judicial review of the administrative action, it can be initiated by the regulated entities in accordance with the Administrative Litigation Law. According to Article 2 of the Administrative Litigation Law of China, a citizen, a legal person or any other organisation shall have the right to bring a law suit against the government, if he or it considers that his or its lawful rights and interests have been infringed upon by a specific administrative act of an administrative organ or its personnel. ${ }^{3}$ The scope of such a 'specific administrative act' is listed in Article 11 of the same law, including, for instance, the administrative sanction and refusal to issue an administrative permit or licence. ${ }^{4}$ With the amendment to Administrative Litigation Law in November 2014, the word 'specific' is deleted and the scope of the administrative act concerned is also enlarged to a certain degree. However, some matters such as the administrative rules and regulations, regulations, or decisions and orders with general binding force adopted by administrative organs still cannot be brought to the court as stipulated in Article 12 of that law. ${ }^{5}$

However, the role of the judicial system remains quite limited in environmental governance. In theory, the court is expected to play an important role in the control of the administration through the process of judicial review. Nevertheless, the Chinese courts have tended to take a rather cautious approach in practice, in particular in cases when citizens take the government to court for non-performance or wrongful administration. ${ }^{6}$ If the regulated entities fail to comply with the administrative orders made by competent governments, the government without administrative execution power, however, could seek for the judicial compulsory execution of such administrative orders based on the Administrative Litigation Law and Administrative Enforcement Law, enhancing the government's enforcement powers. ${ }^{7}$

To a certain degree, the judicial system still often fails to function independently, mainly due to the strong relationship between the court and government and, inter alia, the fact that the courts are funded by the governments at the same level. ${ }^{8}$ Although the ongoing judicial reform is still struggling to address this problem slowly, one may nevertheless raise the question of whether relevant administrative suits relating to the ETS would emerge and would be dealt with correctly

\footnotetext{
${ }^{1}$ For more information and discussion concerning the specific regulatory instruments and administrative sanctions, please refer to: OECD (2006); see also Ma, X. \& Ortolano, L. (2000).

${ }^{2}$ Yang, T., \& Zhang, X. (2012), p.10-11.

3 Article 2, Administrative Litigation Law.

${ }^{4} \mathrm{Ibid}$, at Article 11.

5 Ibid, at Article 12.

${ }^{6}$ Du, Q. (2009), p.440-441.

${ }^{7}$ See Article 66 of Administrative Litigation Law of China, and Article 53 of Administrative Enforcement Law of China; See also Zhang, X.M., Ortolano, L. \& Lü, Z.M. (2010).

${ }^{8}$ Du, Q. (2009), p.441-442.
} 
in practice, given the powerful government but weak judicial system in China. The pilot projects may provide some first insights.

\subsection{Regulatory instruments for addressing climate change}

The regulatory framework constituted by the policies and legislations, generally speaking, relies on a mix of instruments which can be grouped into two main approaches, command-and-control instruments and market-based instruments.

\subsubsection{Command-and-control instruments}

As the traditional regulatory approach, command-and-control instruments have been employed in the field of Chinese climate policy and law. In addition to the political control system, like the target-based accountability system mentioned above, it may appear in the form of relevant standards, administrative measures, and emissions permits.

\section{Adopting standards concerning energy saving and emissions reduction}

The combination of environmental standards and energy standards can be easily identified in the features of the standards controlling GHG emissions, since the climate change issue is closely related to the exploration of atmospheric environment and energy. ${ }^{1}$

As provided in the Energy Conservation Law, a sound system of standards of energy efficiency should be established. According to a report submitted by a law enforcement inspection group of the NPCSC, until the end of 2010, China had adopted 27 mandatory national standards on the energy consumption limit of high energy consumption products, 41 mandatory national energy efficiency standards concerning some major terminal energy-using products and about 100 energy saving standards related to building. ${ }^{2}$ The manufacturer that consumes energy exceeding the energy efficiency standards shall be ordered to rectify within a time limit by the competent authorities, while outdated products, equipment and production techniques with excess energy consumption shall be eliminated. ${ }^{3}$

The mandatory standards mentioned in the field of climate change, inter alia energy saving and emissions reduction, are supposed to play import roles in the climate regime. Nevertheless, environmental standard is usually not considered by scholars as formal legal norm, in view of its name, structure, contents, and the promulgating procedure. ${ }^{4}$ In other words, environmental standards, as one environmental administrative instrument, will not have legal effect until they are recognised in the legislation and applied by the environmental administration. ${ }^{5}$

\footnotetext{
1 Liu, M. M. (2012), p.145.

2 The inspection report about the implementation of the Energy Conservation Law, Standing Committee of the National People's Congress inspection group, 20 December 2010 (in Chinese).

3 Article 16, Energy Conservation Law of China.

${ }^{4}$ See Song, H. L. (2008).

${ }^{5}$ Zhang, Y. \& Wang, J. (2012), p.191.
} 


\section{Closing small power plants}

Closing small coal-fired power plants and outdated capacity through administrative measures, in order to transform the industry structure and to improve the energy efficiency and the environmental quality, can be considered as an 'iron hand' with the strong characteristics of a command-and-control instrument frequently used by the Chinese government.

The application of this 'iron hand' can be traced back to the $9^{\text {th }}$ Five-Year Plan period (1996-2000), when the small coal-fired power plants started to be closed by governments. Except for a pause in 2003 to 2004, due to a power supply shortage, the policy of closing coal-fired power plants almost never stopped and continued through to $11^{\text {th }}$ Five-Year Planning period (2006-2010). Moreover, it ramped up quickly by the adoption of the Comprehensive Working Plan of Energy Conservation and Emission Reduction by the State Council in 2007, accelerating the closing of small plants and outdated capacity in 14 high energy-consumption industries. ${ }^{1}$ It is estimated that the replacement of inefficient facilities can save total net energy by 63 Mtce (million metric tonnes of coal equivalent) final energy and 150 Mtce primary energy. ${ }^{2}$ However, this 'iron hand' instrument has been criticised heavily, which will be discussed further in the last part of this section.

\subsubsection{Market-based instruments}

In the instrument mix of climate policy and legislation, market-based instruments are considered important policy tools that would help China achieve the climate targets in a more controlled and predictable way. ${ }^{3}$ In addition to the economic incentives applied in the legislation and policies, carbon taxation and carbon emissions trading schemes emerged as two important market-based options for China, which have caused heated debates among academic circles, policy makers and other stakeholders.

\section{Carbon taxation}

The introduction of a carbon tax, levying a tax on $\mathrm{CO}_{2}$ emissions, has been suggested for a few years to strengthen the climate policy and legislation in China. A few years ago, environmental taxation emerged as a hot topic in Chinese academic circles, inter alia in the field of economic and environmental law. Despite the fact that no specific carbon tax has been established in China yet, it is argued that a variety of existing taxes and fees concerning natural resources and environment protection, to a certain degree, have constituted an invisible carbon taxation by putting a price on $\mathrm{CO}_{2}$ emissions, with similar functions in addressing climate change and

\footnotetext{
${ }^{1}$ The industries are electric power, iron-making, steel-making, electrolytic aluminium, ferroalloy, calcium carbide, coking, cement, coal, plate glass, pulp and paper, alcohol, monosodium glutamate, and citric acid. See the Notice of State Council on Printing and Distributing the Comprehensive Working Plan of Energy Conservation and Emission Reduction, State Council, 23 May 2007 (in Chinese).

2 Price, L., et al. (2011), p.2172.

${ }^{3} \mathrm{Wu}, \mathrm{Q} .(2011), \mathrm{p} .22-25$.
} 
protecting environment. ${ }^{1}$ However, the difference between carbon taxation and other environmental taxation and energy taxation cannot be overlooked. ${ }^{2}$

Aiming to control and to reduce $\mathrm{CO}_{2}$ emissions, the carbon taxation was considered and studied in 2007 by a research group organised by the Ministry of Finance. ${ }^{3}$ Furthermore, a proposal concerning the environmental taxation policy, as reported, was submitted to the Ministry of Finance in January 2012 by its subordinated research institute, in which the environmental protection tax instead of the pollutant discharge fee and carbon tax might be introduced independently at the same time. ${ }^{4}$ A draft concerning the Environmental Protection Taxation, drawn up by the Ministry of Finance, Ministry of Environmental Protection and State Administration of Taxation, was submitted to the State Council for deliberation in March 2013 and may be finally submitted to the NPC for deliberation and approval. However, it is reported that the provisions concerning the carbon tax have been deleted in this draft. ${ }^{5}$

Although the introduction of carbon tax is still in the primary stage of legislation, controversy has been sparked in the academic literature. In terms of the impact and effect of the carbon tax, some concerns on its negative effect by increasing the cost of the industries, energy sector and the whole economy have been raised. On the contrary, the carbon tax has been supported by many scholars, arguing that a low-rate carbon tax is a feasible and effective option for China with a smaller influence on the economic development and it can stimulate $\mathrm{CO}_{2}$ emissions reduction. ${ }^{6}$ To be specific, it is argued that a carbon tax can help achieve the reduction target of $\mathrm{CO}_{2}$ emissions by two means: forcing the enterprises make greater effort in saving energy and improving energy efficiency, by increasing the price of fossil fuels in the form of a carbon tax on the one hand and ensuring environmental justice and transforming the social energy consumption model by recycling the revenue from the carbon tax back to the industries and the middle-and-low income groups on the other hand. ${ }^{7}$ In this sense, the carbon tax may be an attractive alternative to an ETS.

\section{Carbon emissions trading}

In addition to the carbon taxation, a carbon emissions trading scheme, a typical market-based instrument, is an important option for the climate regime of China, in spite of the immaturity of the Chinese market-oriented economy. In this respect, China has not only participated in the $\mathrm{CDM}$ as being a host at the international level for investment in order to compensate emissions from developed countries that have ratified the Kyoto Protocol ${ }^{8}$, but China has also been

\footnotetext{
${ }^{1}$ Wang, W. G. (2012), p.12.

2 Zhang, Z. T. (2010b), p.99.

${ }^{3}$ See Yu, G. \& Elsworth, R. (2012),p. 14

${ }^{4}$ Liang, J. \& Wang, H.(2012), China Planning Carbon Tax as Independent Tax Category, It May Be Levied Before 2015, 5 January 2012, Available from: http:/www.chinanews.com/cj/2012/01-05/3581265.shtml, last accessed 12 January 2014 (in Chinese).

${ }_{5}^{5}$ Ding, K. Y. \& Cao M. H. (2014), New draft of Environmental Protection Taxation without the carbo $\mathrm{n}$ tax has been submitted to the State Council for deliberation, 19 June 2014, available at: http://www.g w.com.cn/news/news/2014/0619/200000354689.shtml, last accessed 19 September 192014 (in Chinese).

${ }^{6}$ See Lu, C., Tong, Q., \& Liu, X. (2010); Wang, J. N., Yan, G. \& et al. (2009).

7 Chen, H. W. \& Zhang, L. (2009), p.39.

${ }^{8}$ By the end of August 2012, China had approved 4,540 CDM projects, 2,364 of which have been registered with the UN CDM Executive Board, accounting for $50.41 \%$ of the world's total registered programs. See China's
} 
establishing the voluntary project-based ${ }^{1}$ and mandatory allowance-based ETSs at the domestic level. In this thesis, the discussion will only focus on the mandatory allowance-based GHG ETS, the so-called carbon emissions trading in China. The provisions concerning the establishment of the pilot projects of a carbon emissions trading scheme have been mentioned in the $12^{\text {th }}$ Five-Year Planning (2011-2015) ${ }^{2}$ and other national policies. In particular, seven pilot projects of two provinces (Guangdong and Hubei) and five municipalities (Beijing, Tianjin, Shanghai, Chongqing, and Shenzhen) have been approved by NDRC on 29 October 2011 in order to explore the design and implementation of mandatory $\mathrm{CO}_{2}$ ETS in China. ${ }^{3}$

Moreover, the application of ETS in controlling pollution in China can be traced back to the pilot projects of $\mathrm{SO}_{2}$ ETS adopted more than two decades ago, the practice of which may still provide some lessons for the design and implementation of the $\mathrm{CO}_{2}$ ETS. Generally speaking, the evolutionary trajectory of $\mathrm{SO}_{2}$ ETS can be divided into two periods, including a starting period (1987-2000) and an experimental period (2001-present) ${ }^{4}$, in which different programmes have been introduced and implemented in pursuit of practical lessons. On the basis of the introduction of the licensing system for the discharge of water and air pollutants by the State Environmental Protection Agency (SEPA, the forerunner of the Ministry of Environmental Protection) since $1988^{5}$, the experiment of $\mathrm{SO}_{2}$ ETS was started slowly. ${ }^{6}$ With the Law on the Prevention and Control of Atmospheric Pollution amended in 2000, establishing the licensing system for $\mathrm{SO}_{2}$ in specific areas ${ }^{7}$, more and more pilot projects of $\mathrm{SO}_{2}$ ETS were implemented at the local levels. ${ }^{8}$ Moreover, on 6 August 2014, the General Office of the State Council promulgated a guiding opinion on the pilot projects of $\mathrm{SO}_{2}$ and other main pollutants emissions trading, in an attempt to move from the local experiments towards the regional and then the national schemes gradually. ${ }^{9}$

Policies and Actions for Addressing Climate Change (2012), NDRC, November 2012 (in Chinese).

${ }^{1}$ It covers the trading activities in the voluntary reduction of emissions of six kinds of GHG, which are carbon dioxide $\left(\mathrm{CO}_{2}\right)$, methane $\left(\mathrm{CH}_{4}\right)$, nitrous oxide $\left(\mathrm{N}_{2} \mathrm{O}\right)$, hydro fluorocarbons (HFCs), perfluorinated carbons (PFCs), and sulfur hexafluoride $\left(\mathrm{SF}_{6}\right)$. These GHG emission reductions generated by the projects shall be filed for the record and registered with the competent department, such as the Chinese Certified Emission Reduction (CCER), before they can be traded. See NDRC, Interim Measures for the Administration of Voluntary Greenhouse Gas Emission Reduction Trading, 13 June 2012 (in Chinese). It is noticeable that a limited proportion of CCER is accepted to cover the emissions in some pilot projects.

2 Chapter 21, $12^{\text {th }}$ Five-Year Planning (2011-2015).

3 The Notice on Initiating Pilot Programs of Emissions Trading, NDRC, 29 October 2011 (in Chinese).

${ }^{4}$ See Lin, F. \&. Buhi. J. (2009), p.143-145.

${ }^{5}$ For instance, SEPA promulgated the Interim Methods on Administration of Licences for Discharge of Water Pollutants in 1988 and introduced a licensing system for the discharge of air pollutants in sixteen cities in 1991.

${ }^{6}$ For instance, the air pollutant emissions trading programs were launched in six cities since 1994 and the pilot projects of $\mathrm{SO}_{2}$ ETS in two cities (Nantong of Jiangsu Province and Benxi of Liaoning Province) based on a study supported by the cooperation between the China's SEPA and the Environmental Defense Fund of US in 1999. See Wang, J.N., Yang, J.T., et al. (2004).

7 This specific area for the total amount of control of major air pollutants are delimited by the State Council and the provincial governments. See Article 15, Law of China on the Prevention and Control of Atmospheric Pollution.

${ }^{8}$ For instance, in 2002 SEPA launched the $\mathrm{SO}_{2}$ emissions trading in four provinces, three municipalities and one state-owned electricity-generating group, the so-called ' $4+3+1$ program'. The Ministry of Finance and SEPA tried to expand the $\mathrm{SO}_{2}$ emissions trading to the power sector at the national level in 2007, given the fact that the coal-fired power plants are the major source of the $\mathrm{SO}_{2}$ emissions in China. See Notice on promoting the demonstration pilot of 'the research project on the implementation of the total quantity control and emissions trading policy for $\mathrm{SO}_{2}$ in China', SEPA, 1 March 2002, (in Chinese).

9 See Guiding Opinions of the General Office of the State Council on Further Promoting the Pilot Scheme of Payable Use and Trading of Pollutant Emission Rights, the General Office of the State Council, 6 August 2014 (in Chinese). 
The following sections 3 and 4 of this chapter will focus on the description and analysis of the pilot projects of $\mathrm{CO}_{2}$ emissions trading in depth, in search of possible solutions to the legal problems by taking account of the lessons learnt from the $\mathrm{SO}_{2}$ ETS where possible.

\subsection{Concluding remarks and observations}

\subsubsection{The roles of and relationship between legislation and policy}

The present regulatory framework for climate change relies on a vast range of policies and legislation belonging to different fields as well as a mix of policy instruments. It is noticeable that policy and legislation play a different role in the regulatory framework for addressing climate change, which will be a similar case for the ETS. In particular, policy, inter alia the Five-Year Planning seems to play a more important role than the law in the regulatory framework. Most of the national goals and policy for addressing climate change, such as the carbon intensity reduction target, were set up in the $12^{\text {th }}$ Five-Year Planning (2011-2015), paving the way for the adoption and further improvement of a series of climate policies, legislation and governmental rules. A variety of measures, including the initiative of seven pilot projects of $\mathrm{CO}_{2}$ ETS, have been adopted in numerous governmental documents implementing the $12^{\text {th }}$ Five-Year Planning. However, it must be pointed out that the implementation and enforcement of the $12^{\text {th }}$ Five-Year Planning (2011-2015) and other governmental documents have relied greatly on the target-based accountability system, holding the leading cadres of the local governments responsible for the fulfilment of the carbon intensity reduction target allocated by the top-down approach. Nevertheless, neither specific legal liabilities for non-compliance nor corresponding judicial remedies have been established in the implementation of the $12^{\text {th }}$ Five-Year Planning and related governmental documents. The application of the cadre system hence signals a move towards a political rather than a legal approach. ${ }^{1}$

In order to achieve the carbon intensity reduction target set up in the $12^{\text {th }}$ Five-Year Planning (2011-2015), more and more climate-related legislation has been adjusted or enacted in China. Nevertheless, one has to admit that this preliminary legal framework still lacks specific and systemic climate legislation with higher legal rank, for which a call for the adoption of the Climate Law may be a helpful option. Meanwhile, observation of the existing climate-related legislation has also indicated that most provisions appear to be principles, guidelines and declarations rather than mandatory rules, resulting in weak performance and enforcement in practice. Although China's environmental protection law appears to be quite comprehensive, there is an indication that its enforcement still suffers greatly from several statutory deficiencies, such as too much reliance on local officials who are reluctant to and do not perform well, low penalties for noncompliance by private actors, a limited and weak judicial system ${ }^{2}$, and the enforcement tension between the central and local governments due to the decentralisation and growing local protectionism. ${ }^{3}$

\footnotetext{
${ }^{1}$ See Golding, W. F. (2011), p.399.

2 McCubbin, P. R. (2008), p.3-4, see also Wang, C. F. (2006).

3 See Marks, D. (2010), p.974-975; see also Beyer, S. (2006); Lo, C. W.-H., Fryxell, G. E., van Rooij, B., et al. (2012). The enforcement issues, inter alia the tension between the central and local governments, will be further examined and analysed in the following chapter concerning enforcement.
} 
Therefore a dilemma facing China can be identified. On the one hand, the policies inter alia the governmental documents relying on the cadre system and other political and administrative measures have usually been implemented quite strictly and well by the governments, due to the substantial and powerful influence of the policies rather than legal force. On the other hand, the content of the legislation still needs further improvement and the implementation remains a challenge since law-according-to-the-books is quite different from the law-in-action in China. By analogy, the establishment and implementation of the ETS appears to face similar challenges, which will be examined in the following sections.

In the special Chinese context, the policies and legislation, together comprising the climate regulatory framework, has to co-exist, co-function and interact in a well-designed regulatory framework. Given that the legislative competence has been allocated to limited authorities and the requirement and procedure of the legislation is not easy to meet in a short time, policies or governmental documents can be first adopted and implemented when no relevant legislation is yet in place. Moreover, the provisions of policies and legislation should be connected and should interact in a better way.

Taking the implementation and enforcement provisions as an example, the content and measures adopted in the policies can be confirmed, accepted and transformed in the legislation, aiming to obtain sufficient legal effect and to improve the legal system per se. As observed by Li Zhiping, the responsibilities for government to fulfil the binding targets established in the Five-Year Plans should be based on the premise of corresponding legal duties set up in the legislation and enforced by legal liability system. ${ }^{1}$ According to the Environmental Protection Law, local governments at all levels should be responsible for the environmental quality of areas under their jurisdiction $^{2}$; if a mistake in law-making and policy making as well as misconduct in environmental enforcement is found, disciplinary and administrative penalties will be imposed on the person of any state administrative organ found directly liable, according to the specific administrative procedure provided in the Law on Public Servant, the Law on Administrative Supervision and relevant laws. ${ }^{3}$ In addition, the target-based responsibility system has also found its way into the Energy Conservation Law and the amendment of the Environmental Protection Law in 2014. However, the relevant legal liabilities system for failing to meet the target and other noncompliance in addressing climate change, in particular the implementation of the emissions trading, still needs further improvement. ${ }^{4}$

\subsubsection{Multi-level governance structure: the Chinese context}

The discussion of the legal and political system in section 2.2 of this chapter has been provided in order to give insight into the governance structure in China, inter alia the special characteristic of centralisation with a certain degree of decentralisation, in which the climate law and policy are framed and implemented. In accordance with the multi-categories and multi-levels of legal ranks

\footnotetext{
1 Li, Z. P. (2008), p.40.

2 Article 6,28, Environmental Protection Law of China (revised).

${ }^{3}$ See Article 53,55,56 Public Servants Law of China; see also Article 4-9, Interim Provisions on Punishment of Acts Violating Laws and Disciplines on Environmental Protection.

${ }^{4}$ The enforcement and legal liability issues will be further discussed in the following enforcement section.
} 
of Chinese legislation, the legislative competences have been distributed to certain state organs at different levels. The formulation and implementation of the climate-related legislation within different rankings has revealed the centralisation feature of the Chinese legislation system. However, there is a possibility for a decentralised experimentaion before deciding on a central steering in terms of the establishment of a national legislation and regime. In view of the vast territory and varied local circumstances in China, the local experimentation in accordance with local circumstances [yin di zhi yi] under the strong guidance by the central authorities has been employed as a traditional approach in the legislative system, with the co-existence of centralisation and decentralisation. ${ }^{1}$ Moreover, it is this local experimentation approach that paves the way for the policy initiative of the ETS in the form of pilot projects in China.

In addition, a glance at the institutional framework for climate policy making suggests that governments at the central and local levels have played a significant role in the administrative structure for climate policy. In particular, the NDRC has played its steering role by ordering the decentralised experiments such as the pilot projects of $\mathrm{CO}_{2}$ ETS. In view of the significant steering role of the NDRC in Chinese economic and social development, the current administrative structure addressing climate change has indicated the increasing political awareness of the need to take action for addressing climate change at the national level. Moreover, with the NDRC leading the climate change policy making, the policy regarding climate change has tended to be more coherent and integrated at the central level, suggesting a positive path of future improvement from a fragmented approach to a more integrated system. ${ }^{2}$

Furthermore, in line with the traditional top-down approach that applied in the adoption of relevant climate policy and law, the implementation and enforcement of the Chinese climate regime still relies largely on the policy instruments, such as the target-based accountability system set up in the Five-Year Planning. In addition, the analysis above has also indicated the possible role the Chinese judicial system may play in enforcing climate policy and law. Although there may not be a lot of room for the court to settle the potential dispute relating to the climate regime, there is also a need to shed light on the potential role of and specific challenges facing the judicial system in the legal framework for the ETS.

\subsubsection{Potential leading role of market-based instrument}

The fulfilment of the climate target has relied greatly on the command-and-control instrument, while the market-based instrument starts to play an increasingly important role.

It cannot be denied that the application of most of the administrative tools, such as shutting down some installations with an 'iron hand', in view of the special Chinese context with an extensive and strong administration system, have indeed produced quick and effective results. ${ }^{3}$ However, most of the fast and effective results are attained at the price of sacrificing the interest of those installations by administrative order rather than through due process, endangering the Chinese immature market economy and the legal system to a certain degree. Moreover, the existing

${ }^{1}$ For a general discussion on the experimentation, refer to: Heilmann, S. (2011); Wang, S.G. (2011).

2 Zhang, H. (2012), p.10266.

${ }^{3}$ Ibid, p. 10267. 
mechanisms implemented in a top-down approach remain the traditional command-and-control instruments initiated and implemented mainly by the government. ${ }^{1}$ In this respect, a bottom-up approach based on market mechanisms has been brought into the Chinese climate regulatory framework, aiming to achieve the climate target in a more cost-effective way.

The preliminary observation of the recent policy development has suggested that market-based instruments, such as carbon taxation and carbon emissions trading, will be used to address climate change. Moreover, a heated debate on the instrument choice between carbon tax and carbon emissions trading has been sparked, comparing the advantages and disadvantages of the two approaches. ${ }^{2}$ Both are supported or opposed based on various reasons from different perspectives, but this thesis will only focus on carbon emissions trading.

All of the seven pilot projects of carbon emissions trading have came into operation respectively, but the regulatory framework for carbon emissions trading is still being constructed and improved, which still requires further in-depth observation.

\section{The emergence of $\mathrm{CO}_{2}$ ETS pilot projects in China}

\subsection{Overview of the development concerning the pilot projects}

This section presents the main features of the ETS pilot projects in China. In order to explore the design and implementation of the $\mathrm{CO}_{2}$ ETS in China, seven pilot projects have been selected and approved by the NDRC since 2011, which were expected to be started in 2013 and then expanded across the country in 2015 . $^{3}$ Implementing pilot projects in different regions would, provide a chance for China to test emissions trading models that suit various circumstances, taking into experience and lessons to be gathered at a local level before the implementation of such a national scheme. ${ }^{4}$ Due to the difficulties and challenges for the establishment of the legal framework for ETS in China, five pilot projects were started by the end of 2013 while the pilots of Hubei and Chongqing were started in April and May 2014 respectively, which is presented in the timeline below. The description (in this section) and analysis (in section 4) of the pilot projects in this chapter will focus on their development until the end of August 2014.

\footnotetext{
1 Zhang, Z. T. (2010a), p.40-41.

2 See Cao, M. D. (2010); Cao, M. D. (2011); Wang, H. \& Cao, M. D. (2011); Yang, X. S. (2010).

3 Shi, D. D. (2011), China will start pilot project for carbon emissions trading, Dong Fang Daily, 8 July 2011, available at: http://www.dfdaily.com/html/113/2011/7/18/632294.shtml. last accessed 22 July 2013.

${ }^{4}$ Yu, G. \& Elsworth, R. (2012), p.13.
} 
Figure 2 Timeline concerning the establishment of the pilot projects

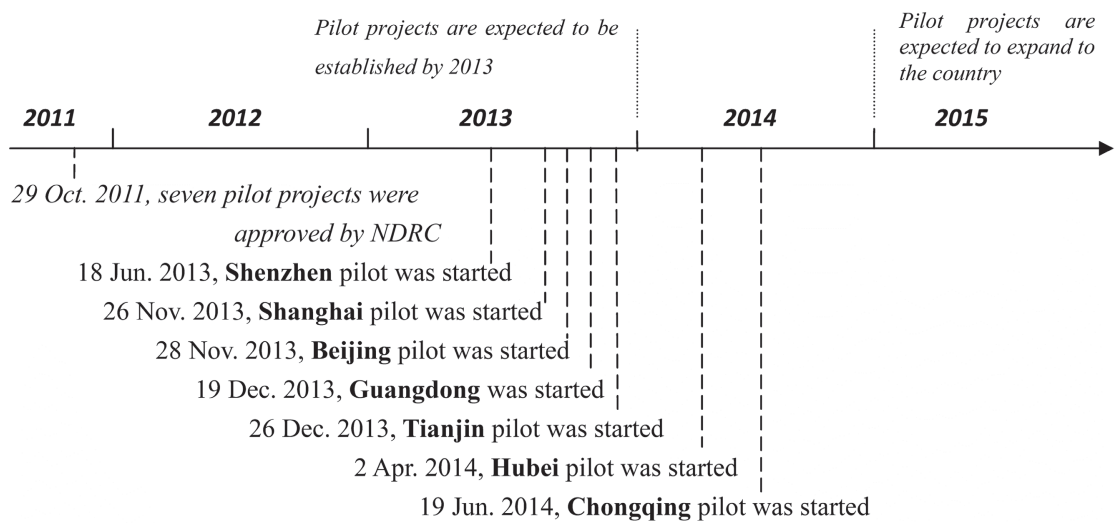

After the Chinese pilot projects of carbon emissions trading are started by the local governments, the allowances allocated can be traded in the local secondary market respectively. Despite the fact that the pilot projects have just kicked off for a short time, a report has suggested that the Chinese carbon market, with around 750 million tonnes of allowances issued in the initial allocation, has become the second largest carbon market in the world, after the European carbon market. ${ }^{1}$ However, the specific status of each local carbon market varies a lot, which is indicated by the table below. ${ }^{2}$

Table 4 status of some pilot projects (by the end of April 2014)

\begin{tabular}{|l|l|l|l|l|}
\hline \multirow{2}{*}{ Pilot project } & \multirow{2}{*}{ Transaction started } & \multicolumn{2}{|l|}{ Transaction volume } & \multirow{2}{*}{$\begin{array}{l}\text { Average price } \\
\text { (CNY/tonnes) }\end{array}$} \\
\cline { 3 - 4 } & & (tonnes) & $(\mathrm{CNY})$ & 70.29 \\
\hline Shenzhen & 18 June 2013 & 271600 & 19.09 million & 7. \\
\hline Shanghai & 26 November 2013 & 273900 & 10.37 million & 37.86 \\
\hline Beijing & 28 November 2013 & 103100 & 5.39 million & 52.28 \\
\hline Guangdong & 19 December 2013 & 126100 & 7.59 million & 60.19 \\
\hline Tianjin & 26 December 2013 & 144000 & 4.13 million & 28.68 \\
\hline Hubei & 2 April 2014 & 2198200 & 53.19 million & 24.20 \\
\hline
\end{tabular}

Furthermore, an overview of their regulatory framework shows that the pilot projects are mainly designed by the local authorities through local regulations, rules of local government, and other normative documents, which can be exemplified by the legislation table in the annex to this thesis. For instance, Shenzhen, as the front-runner among the pilot projects, promulgated the first formal local regulation concerning carbon emissions trading in China, which was adopted by Shenzhen People's Congress Standing Committee on 10 November $2011^{3}$, and it was praised as one of the highlights and representing progress in legislative activity on climate change in 2012

\footnotetext{
1 Annual report on the Chinese carbon market in 2013, Sino Carbon Innovation \& Investment Co., Ltd., January 2014, available at: http://www.sino-carbon.cn/upload/14/01/2014012700001.pdf, last accessed 2 March 2014 (in Chinese).

${ }^{2}$ For further information, refer to the website of the exchanges for the transaction in the pilot projects.

${ }^{3}$ Provisions of controlling carbon emissions for Shenzhen special economic zone, Shenzhen People's Congress Standing Committee, 10 November 2011, (in Chinese).
} 
by the GLOBE Climate Legislation Initiative ${ }^{1}$. In addition, a detailed rule of local government, the Interim Measures on Carbon Emissions Trading Management in Shenzhen, was adopted by the Shenzhen municipal government on 19 March 2014. ${ }^{2}$ Until the end of June 2014, except for the local regulations adopted by the Shenzhen and Beijing authorities, and three rules of local governments promulgated for the pilot projects of Shanghai, Guangdong, Shenzhen and Hubei, most of the regulatory documents relating to the pilot projects are issued in the form of 'other normative documents' adopted by local governments that do not constitute formal legislation in China. Furthermore, the development trajectory of the pilot projects has implied that some of the pilot projects have been started with primary or draft rules rather than detailed implementation rules, which can be exemplified by the Shenzhen pilot started based on the local regulation with only ten general provisions. Moreover, some governmental normative documents will have expired after a specific period, in line with the experimental character of the pilot projects. For instance, the Interim Measures on Management of Carbon Emissions Trading in Tianjin will be abolished by 31 May $2016 .^{3}$

In order to gain a deeper understanding of the status quo and trends in the development concerning the Chinese carbon emissions trading, the primary design features of these pilot projects in terms of target setting, allowance allocation, inspection and enforcement, in line with the three key elements of the theoretical framework, will be introduced in this section and examined in depth in section 4 of this chapter. Despite the fact that these carbon emissions trading pilot projects are still in the course of being designed and implemented, there is an indication that some important common design options have been shared among them. All of the pilot projects seem to have adopted the cap-and-trade model. Free allocation is widely applied in the initial stages of the pilot projects. Moreover, most pilot projects have established a monitoring, reporting and third-party verification system and have set up sanctions for some noncompliance in enforcement. However, given the attempt of the Chinese government to explore the suitable ETS in line with the local circumstances, such as the emissions profile, industry structure and economy development level, the specific design features of the similar design options in the seven pilot projects have appeared to be quite different at the same time.

In this sense, the description of the pilot projects in terms of the three key elements in this section will take the Shenzhen pilot project as the starting point ${ }^{4}$, supplemented by an explanation regarding the main differences with the other pilot projects. In view of the limited information about the reasons why the pilot projects are designed and implemented in that way, this section describes the pilot projects based on the available information, such as the published rules, literature and relevant news reports to the extent possible.

\footnotetext{
${ }^{1}$ More information can refer to the 3rd Climate Legislation Study released by the Global Legislators O rganisation (GLOBE International) on 14 January 2013, available at http://www.globeinternational.org/inde x.php/summits/summits-2012-2013/climate-legislation-summit-london-2013/62-policy-and-legislation/climate-le gislation-study, last accessed 4 June 2014.

${ }_{2}$ Interim Measures on Carbon Emissions Trading Management in Shenzhen, Shenzhen Municipal Government, 19 March 2014 (in Chinese).

3 Article 40, Notice of Distributing Interim Measures on Management of Carbon Emissions Trading in Tianjin, General Office of Tianjin Municipal Government, 20 December 2013 (in Chinese).

${ }^{4}$ The reason for choosing Shenzhen pilot as the starting point mainly relies on the fact that Shenzhen pilot is the first CO2 ETS pilot started, and, moreover, relatively detailed provisions regarding emissions trading have been provided in this pilot.
} 


\subsection{Target setting}

\subsubsection{China's carbon emissions reduction target}

The $\mathrm{CO}_{2}$ ETS is an instrument applied to achieve the carbon intensity reduction target in China. Thus the determination and distribution concerning the carbon intensity reduction target will be discussed below, since this has a significant impact on the design of the pilot projects, in particular the cap setting.

\section{National carbon emissions reduction target}

A national carbon emissions reduction target has been adopted in the $12^{\text {th }}$ Five-Year Planning (2011-2015) as a binding target, declaring that China will reduce its $\mathrm{CO}_{2}$ emissions by $17 \%$ per unit of GDP compared to the 2010 level by $2015 .^{1}$ There are two special characteristics of this carbon emissions reduction target set up in the $12^{\text {th }}$ Five-Year Planning (2011-2015).

Firstly, the Chinese national carbon emissions reduction target has been set up in the form of a carbon intensity reduction target, a typical relative target contrasted with an absolute target. In line with the definition of 'carbon intensity' by IPCC, the national $\mathrm{CO}_{2}$ emissions reduction target adopted in the $12^{\text {th }}$ Five-Year Planning (2011-2015) in China has been referred to as the carbon intensity reduction target. Different from absolute targets like the emissions reduction targets adopted in the Kyoto Protocol and in the EU, this so-called carbon intensity reduction target is directly connected with the GDP growth.

In view of the possibility that the carbon intensity can be calculated based on GDP and the total amount of $\mathrm{CO}_{2}$ emissions, however, it is also argued that the carbon intensity reduction target may be considered to be an emissions cap in essence and converted into an absolute cap regardless of its nature as a relative target. ${ }^{2}$ Based on different carbon intensity reduction targets and calculations of GDP based on statistics or anticipation, different caps on the emissions thus can be calculated in different scenarios. But if there is more or less economic growth than anticipated, such an emissions cap would have to be increased or decreased correspondingly.

Secondly, the national carbon emissions reduction target has been grouped into the category of 'binding targets' in the Five-Year Planning for the first time. Due to the approval by the NPC, the top level of the legislature in China, the Five-Year Planning is supposed to have legal force $($ fa $l v$ xiao $l i){ }^{3}$. Based on the analysis of the Five-Year Planning in section 2.1.1 of this chapter, it is clear that the national carbon intensity target that cannot be changed, even by the central government, as a so-called binding target is supposed to be allocated to and implemented by local governments, in pursuit of its achievement by all levels of governments.

\footnotetext{
${ }^{1}$ See the $12^{\text {th }}$ Five-Year Planning (2011-2015).

2 Wang, S. L, Wang J.N.: Carbon intensity is a kind of emissions cap in essence, $21^{\text {st }}$ Century Busines s Herald, 19 April 2011, available at: http://epaper.21 cbh.com/html/2010-04/19/content_119479.htm, last a ccessed 23 September 2014 (in Chinese).

${ }^{3}$ Chapter 16, the $12^{\text {th }}$ Five-Year Planning (2011-2015).
} 


\section{Distribution of carbon intensity reduction targets}

Similar to other binding targets set up in the $12^{\text {th }}$ Five-Year Planning (2011-2015), the national carbon intensity reduction target has been allocated from the central level to the local level through a top-down approach. Firstly the national carbon intensity reduction target has been allocated to provinces and municipalities by the State Council (more specially, by the NDRC) and then the provincial targets are furthered distributed to local cities by the provincial governments.

At the national level, the carbon intensity reduction target has been distributed among provinces and municipalities through the issuance of the Work Plan for Greenhouse Gas Emissions Control during the $12^{\text {th }}$ Five-Year Period by the State Council at the end of $2011 .{ }^{1}$ In the Work Plan mentioned above, each province or municipality has been allocated an individual carbon intensity reduction target, ranging from 19.5\% (Guangdong) to 10\% (Tibet and Qinghai), which can be distinguished in three groups (shown in table below). ${ }^{2}$ Group Two comprises nine provinces allocated a carbon intensity reduction target equal to the national average, reducing $17 \%$ carbon intensity by 2015 . However, the targets distributed to Group One, including the highest target for Guangdong, are higher than 17\%, while Group Three has been allocated lower targets. ${ }^{3}$ Within the groups, further differentiation has been made, resulting in nine categories of different provincial targets.

Table 5 Carbon Intensity Reduction Target during the 12 ${ }^{\text {th }}$ Five-Year Period (2011-2015)

\begin{tabular}{|c|c|c|c|}
\hline \multirow{2}{*}{ Group } & Category & Provinces & $\begin{array}{c}\text { Reduction of CO2 } \\
\text { emissions per Unit GDP } \\
\text { compared to 2010 }\end{array}$ \\
\hline \multirow{2}{*}{ I } & 1 & Guangdong & $19.5 \%$ \\
\cline { 2 - 4 } & 2 & Tianjin, Shanghai, Jiangsu and Zhejiang & $19 \%$ \\
\cline { 2 - 4 } & 3 & Beijing, Hebei, Liaoning and Shandong & $18 \%$ \\
\cline { 2 - 4 } & 4 & Fujian and Sichuan & $17.5 \%$ \\
\hline \multirow{2}{*}{ II } & 5 & $\begin{array}{c}\text { Shanxi, Jilin, Anhui, Jiangxi, Henan, } \\
\text { Hubei, Hunan, Chongqing, and Shaanxi }\end{array}$ & $17 \%$ \\
\cline { 2 - 5 } III & 6 & Yunnan & $16.5 \%$ \\
\cline { 2 - 5 } & 7 & $\begin{array}{c}\text { Inner Mongolia, Heilongiang, Guangxi, } \\
\text { Guizhou, Gansu and Ningxia }\end{array}$ & $16 \%$ \\
\cline { 2 - 4 } & 9 & Hainan and Xinjiang & $11 \%$ \\
\hline
\end{tabular}

\footnotetext{
${ }^{1}$ See the Notice on Issuing the Work Plan for Greenhouse Gas Emissions Control during the $12^{\text {th }}$ Five-Year Plan Period, State Council, 1 December 2011, (in Chinese).

${ }^{2}$ Ibid.

${ }^{3}$ Guerin, E. \& Wang, X.(2012), p.8.
} 
Compared to the distribution of energy intensity reduction targets in the $11^{\text {th }}$ Five-Year Planning (2006-2010), this top-down approach seems to be more in line with the local circumstances, taking account of the existing economic and environmental performance in different provinces. In the $11^{\text {th }}$ Five-Year Planning (2006-2010), the national energy intensity reduction target, reducing energy consumption per unit of GDP by $20 \%$ by $2010^{1}$, was assigned to provinces more or less based on an equal-numbers principle: most of them (20 provinces) were allocated an energy intensity reduction target equal to the national average $(20 \%)$ and only a few of them received a higher (4 provinces with $22 \%$ ) or lower (2 provinces with $17 \%, 2$ provinces with $16 \%$, 1 province with $15 \%$ and 2 with $12 \%$ ) target. ${ }^{2}$ Even the NDRC admitted that the target distribution in $11^{\text {th }}$ Five-Year Planning (2006-2010) was not reasonable enough, recognising the need to distribute the targets based on the local endowment of resources, development level and technical ability. ${ }^{3}$

Given the main objective of the carbon intensity reduction target, urging provinces to search for a suitable industry structure and energy consumption patterns in pursuit of their own green development, how the carbon intensity reduction targets are determined and distributed in an equitable and effective way is very important. ${ }^{4}$ However, the target distribution approach applied in the $12^{\text {th }}$ Five-Year Planning $(2011-2015)$ is still being criticised as the political negotiation between the central government and the local governments. ${ }^{5}$

\subsubsection{Cap setting in the pilot projects}

The Notice on Initiating Pilot Programmes of Emissions Trading issued by the NDRC, setting the stage of establishing $\mathrm{CO}_{2}$ ETS in China, has approved the establishment of pilot projects in seven provinces/municipalities and required those provincial/municipal governments to determine the GHG emissions cap for the pilot project respectively. ${ }^{6}$ All of these pilot projects seem to follow the cap-and-trade model. However, the carbon intensity reduction targets allocated by the State Council have a significant impact on the cap setting among the pilot projects.

In the Shenzhen pilot project, Development and Reform Commission (DRC) in Shenzhen should set up an overall $\mathrm{CO}_{2}$ emissions cap for all the emitters (covered by or outside the pilot) and should determine the annual cap for the pilot project in accordance with the carbon intensity reduction targets allocated by the State Council and Guangdong Province, local economic and social development trend, industrial development policies, the sectoral development stage and abatement potential, historical emissions and abatement effects, and other relevant factors. ${ }^{7}$

\footnotetext{
${ }^{1}$ See $11^{\text {th }}$ Five-Year Planning.

2 See Teng, F. (2012).

3 Yang, Y. Y. (2010), NDRC admitted the problems in allocating the energy saving and emissions redu ction targets during $11^{\text {th }}$ Five-Year period. Beijing News, 30 September 2010, available at: http://news.xin huanet.com/fortune/2010-09/30/c 12622103.htm, last accessed 12 July 2013 (in Chinese).

${ }^{4}$ Lin, B. Q. (2010), The allocation of carbon intensity binding target in the $12^{\text {th }}$ Five-Year Plan, China Business News, 29 March 2010, A08. (in Chinese).

${ }^{5}$ See Teng, F. (2012), p.11; see also Yu, G. \& Elsworth, R.(2012), p.11.

6 The Notice on Initiating Pilot Programs of Emissions Trading, NDRC, 29 October 2011(in Chinese).

7 Article 10 and 14, Interim Measures on Carbon Emissions Trading Management in Shenzhen, Shenzhen Municipal Government, 19 March 2014 (in Chinese).
} 
However, it is not easy to access the information regarding its specific cap. It is only reported that the cap for the period from 2013 to 2015 reaches about 100 million tonnes of $\mathrm{CO}_{2}$ equivalent. ${ }^{1}$ Moreover, it is emphasised that the so-called cap is an 'intensity-based' and 'regulable cap" ${ }^{2}$ with relative and dynamic features, which is determined and regulated by Shenzhen DRC. To be specific, the allowances in the Shenzhen pilot project have been allocated to the emitters as the 'pre-allocated' allowances every three years based on the projection, which can be increased or reduced ex post each year in accordance with the actual emissions and output of specific product of the emitters concerned in the previous year, aiming to ensure the achievement of the emitter's carbon intensity target determined ex ante. In other words, the total amount of the allowances can be adjusted regularly to accommodate the dynamic economic development, since the cap on emissions is eventually determined by the carbon intensity targets and actual output. ${ }^{3}$ In practice, the allowances which were pre-allocated to the emitters covered by Shenzhen pilot for 2013 were finally adjusted by Shenzhen DRC on 29 May 2014, reducing the pre-allocated allowances by around three million allowances (about $9 \%$ of the pre-allocated allowances) in accordance with the actual production and the carbon intensity reduction target determined ex ante. ${ }^{4}$

By analogy, the caps for the other pilot projects are mainly determined by the provincial/municipal DRC, taking account of similar factors as those in Shenzhen, with the aim to ensure the achievement of the carbon intensity reduction target allocated by the government at a higher level. Although not all the specific caps for the pilot projects have been determined and published explicitly before the trading period, the pilot projects of Guangdong, Hubei and Chongqing have determined and published their specific caps in the allowances allocation plans. ${ }^{5}$ However, it has been provided explicitly or otherwise there are indications that some of the caps for the pilot projects may be determined and adjusted in line with the dynamic economic development, similar to the case in Shenzhen. For instance, the cap for the Beijing pilot project also appears to be a dynamic cap that will be adjusted in the case of significant changes in the level of emissions, due to the reorganisation, merging, closure, or other special circumstances of the emitters, which will be examined later in the sections addressing allowance allocations. ${ }^{6}$ Nevertheless, the Hubei pilot project seems to refuse the dynamic cap. According to Qi Shaozhou, who has played an important part in designing the Hubei pilot project, the cap for Hubei pilot project — the total amount of allowances — cannot be changed, although the cap has been determined based on a prediction of the model with medium economic growth and a low carbon scenario chosen from the nine models. ${ }^{7}$

\footnotetext{
${ }^{1}$ See the press conference on the launch of the carbon emissions trading pilot in Shenzhen, Shenzhen Government Online, 21 May 2013, available at: http://www.sz.gov.cn/cn/xxgk/xwfyr/wqhg/20130521/, last accessed 2 July 2014 (in Chinese).

2 Jiang, J.J., et al. (2014), p.2-3; see also Shenzhen Carbon Trading Task Group (2013).

3 Jiang, J.J., et al. (2014), p.2-3.

4 Detailed information is available on the website of Shenzhen DRC, http://www.sz.gov.cn/cn/xxgk/bmdt/ 201405/t20140529_2455203.htm, last accessed 23 December 2014 (in Chinese).

5 For instance, the cap for Guangdong pilot project in 2013, about 388 million allowances, was revealed in the notice concerning the first work plan for the allowance allocation issued by Guangdong DRC. See the first allocation and work plan for the carbon emissions allowance in Guangdong Province (trial), Guangdong DRC, 25 November 2013 (in Chinese).

${ }^{6}$ Notice concerning the implementation of Beijing carbon emissions trading pilot project, Beijing DRC, 22 November 2011 (in Chinese)

${ }^{7}$ See Qi, S. Z. \& Wang, B.B.(2014).
} 
In addition to the cap for the ETS sectors, other pilot projects, such as Guangdong, Beijing, Tianjin, and Shanghai, have also attempted to set up a local cap on the $\mathrm{CO}_{2}$ emissions from all emitters within their territories, in line with their respective carbon intensity reduction target. In particular, a cap of 660 million tonnes of $\mathrm{CO}_{2}$ emissions was established in 2015 in line with Guangdong's allocated carbon intensity reduction target (19.5\%). It was the first quantified emissions cap among the seven pilot projects and was confirmed when the Guangdong's work plan carrying out the low-carbon pilot province was approved by the NDRC in 2012. ${ }^{1}$ Compared to the overall GHG emissions of 508 million tonnes of $\mathrm{CO}_{2}$ equivalent in $2007^{2}$, however, Guangdong's overall emissions cap in 2015 is still supposed to allow for a considerable increase in the GHG emissions in order to accommodate the rapid economic growth demand in Guangdong.

The specific design features concerning the cap setting among the pilot projects are summarized in the table below.

\footnotetext{
${ }^{1} \mathrm{Li}, \mathrm{M} . \mathrm{Y}$. Guangdong sets a cap on carbon emissions for the first time and distributes the carbon inte nsity reduction target to 21 cities, The 21 st Century Business Herald, 13 March 2012, available at: http: //www.21 cbh.com/HTML/2012-3-13/zMMDcyXzQwODgzMw.html, last accessed 12 August 2013 (in Chin ese).

${ }^{2}$ Guangdong's working plan carrying out the low carbon pilot province was approved first. Nan Fang Daily, 11 January 2012 (in Chinese).
} 
Table 6 Summary of cap setting among the pilot projects

\begin{tabular}{|c|c|c|c|c|}
\hline $\begin{array}{l}\text { Pilot } \\
\text { projects }\end{array}$ & $\begin{array}{l}\text { Decision } \\
\text { making }\end{array}$ & Consideration in cap setting & $\begin{array}{l}\text { Specific } \\
\text { caps }\end{array}$ & $\begin{array}{l}\text { Ex post } \\
\text { adjustment }\end{array}$ \\
\hline Shenzhen & $\begin{array}{l}\text { Shenzhen } \\
\text { DRC }\end{array}$ & $\begin{array}{l}\text { carbon intensity reduction target, } \\
\text { local development trend, industrial } \\
\text { development policies, sectoral } \\
\text { development stage, abatement } \\
\text { potential and effect, historic } \\
\text { emissions, etc. }\end{array}$ & $\begin{array}{l}\text { About } 100 \\
\text { million for } \\
2013-2015 \\
\text { (reported) }\end{array}$ & Allowed \\
\hline Shanghai & $\begin{array}{l}\text { Shanghai } \\
\text { DRC }\end{array}$ & $\begin{array}{l}\text { allocated binding targets controlling } \\
\text { GHG emissions, municipal goal of } \\
\text { economic growth, cap for energy } \\
\text { consumption }{ }^{2} \text {, proportion of } \\
\text { emissions covered by the pilot } \\
\text { project }^{3}\end{array}$ & $\begin{array}{l}\text { Not } \\
\text { known }\end{array}$ & Not known \\
\hline Beijing & $\begin{array}{l}\text { Beijing } \\
\text { DRC }\end{array}$ & $\begin{array}{l}\text { municipal economy and social } \\
\text { development plan }\end{array}$ & $\begin{array}{l}\text { Not } \\
\text { known }\end{array}$ & Allowed \\
\hline Guangdong & $\begin{array}{l}\text { Guangdong } \\
\text { DRC }\end{array}$ & $\begin{array}{l}\text { carbon intensity reduction target, the } \\
\text { development plan for key sectors, } \\
\text { target controlling energy total } \\
\text { consumption }\end{array}$ & $\begin{array}{l}388 \\
\text { million for } \\
2013\end{array}$ & Not known \\
\hline Tianjin & $\begin{array}{l}\text { Tianjin } \\
\text { DRC }\end{array}$ & $\begin{array}{l}\text { municipal } \mathrm{CO}_{2} \text { emissions cap, } \\
\text { historical emissions, industries' } \\
\text { technical features, abatement } \\
\text { potential, development plan, etc. }^{6}\end{array}$ & $\begin{array}{l}\text { Not } \\
\text { known }\end{array}$ & Not known \\
\hline Hubei & Hubei DRC & $\begin{array}{l}\text { provincial economic growth, } \\
\text { industrial structural optimisation, etc }\end{array}$ & $\begin{array}{l}324 \\
\text { million for } \\
2014^{8}\end{array}$ & Prohibited \\
\hline Chongqing & $\begin{array}{l}\text { Chongqing } \\
\text { DRC }\end{array}$ & $\begin{array}{l}\text { carbon intensity reduction target, the } \\
\text { historical emissions level, industrial } \\
\text { abatement potential, etc. }\end{array}$ & $\begin{array}{l}125 \\
\text { million for } \\
2013^{10}\end{array}$ & Not known \\
\hline
\end{tabular}

\footnotetext{
${ }^{1}$ Article 10, 14, Interim Measures on Carbon Emissions Trading Management in Shenzhen, Shenzhen Municipal Government, 19 March 2014 (in Chinese).

${ }^{2}$ Article 6, Trial Management Measures for Carbon Emissions in Shanghai, Shanghai Municipal Government, 18 November 2013 (in Chinese).

3 The allocation and management plan for the carbon emissions allowance in Shanghai municipality (2013-2015), Shanghai DRC, 22 November 2013 (in Chinese).

${ }^{4}$ Decision on the Implementation of Carbon Emissions Trading Pilot on Premise of Strict Total Control of Carbon Emissions, Standing Committee of Beijing People's Congress, 27 December 2013 (in Chinese).

5 Article 11, Trial Measures of Guangdong Province on the Management of the Carbon Emissions, Guangdong Provincial Government, 15 January 2014; see also Article 3(2), Implementation program of carbon emissions trading pilot in Guangdong Province, Guangdong Provincial Government, 7 September 2012 (in Chinese).

${ }^{6}$ Article 6, Notice of Distributing Interim Measures on Management of Carbon Emissions Trading in Tianjin, General Office of Tianjin Municipal Government, 20 December 2013 (in Chinese).

7 Article 11, Interim Measures of Hubei Province on the Management and Trading of the Carbon Emission Right, Hubei Provincial government, 4 April 2014 (in Chinese).

${ }^{8}$ The allocation plan for the carbon emissions allowance in Hubei Province, Hubei DRC, 26 March 2014 (in Chinese).

9 Article 7, The Notice of distributing the Interim Management Measures of Chongqing Municipality on Carbon Emissions Trading, Chongqing Municipal Government, 26 April 2014 (in Chinese).

${ }_{10}$ The notice of issuing the carbon emissions allowances for 2013 in Chongqing municipality, Chongqing DRC, 28 May 2014 (in Chinese).
} 


\subsection{Allowance allocation}

How to allocate the allowances to the emitters covered by the pilot projects has been recognised as one of the most crucial and controversial elements of the legal framework for the ETS in China. According to the emerging regulatory frameworks for the pilot projects, the allowances have been allocated through a mix of methods, within which free allocation seems to be the dominant choice while auctioning is supposed to be phased in gradually. Moreover, various special allocation rules have also been adopted in the pilot projects respectively, aiming to accommodate the dynamic economy development and some local circumstances.

Taking the Shenzhen pilot project as an example, before the official start of trading in the secondary market on 18 June 2013, it is reported that about 100 million units of allowances were allocated to 635 emitters covered by the Shenzhen pilot project free of charge for the period from 2013 to 2015 on a one-off basis. ${ }^{1}$ At that time, however, there were no specific rules published, but general principles were provided in the local regulation, stipulating that the specific quantity of allowances to be allocated to the emitters shall be determined in line with the open, fair, scientific and rational principles combined with other factors, including industrial policy and the installation-level emissions. ${ }^{2}$ Most of the information concerning the allowance allocation rules was only revealed by the government during the press conference at the start of the Shenzhen pilot project. It was not until 19 March 2014 that the detailed rules about allowance allocation were provided by the Interim Measures on Carbon Emissions Trading Management adopted by the Shenzhen municipal government, nine months after the official start.

In the Shenzhen pilot project, the allowances have been divided into five categories and a mix of allocation methods have been applied for the allocation to different emitters covered. To be specific, the allowances are divided into five categories, including the pre-allocating allowances ${ }^{3}$, allowances for allocation adjustment, an allowances reserve for new entrants, allowances for auctioning, and an allowances reserve for price stabilisation. ${ }^{4}$ Moreover, a mix of allocation methods including free allocation and auctioning has been applied. In particular, the preceding three categories of allowances mentioned above will be allocated free, while the rest will be allocated by auctioning or selling at a fixed price. ${ }^{5}$

Similarly, the allowances in other pilot projects, such as Beijing, Guangdong and Hubei, have also been divided into various categories, mainly including the allowances for the existing emitters, allowances reserved for the new entrants, and allowances reserved for adjustment/ market regulation. ${ }^{6}$ Meanwhile, most of the allowances in other pilot projects, such as

\footnotetext{
${ }^{1}$ Including 33.2 million units for 2013, 33.78 million for 2014, 34.78 million for 2015. See Li, S. Y.(2 013), The carbon emissions trading in Shenzhen will contain three parts, Shenzhen Special Zone Daily, 15 June 2013, A3, available at: http://sztqb.sznews.com/html/2013-06/15/content_2516453.htm (in Chines e).

2 Article 4, Provisions of controlling carbon emissions for Shenzhen special economic zone, Shenzhen People's Congress Standing Committee, 10 November 2012 (in Chinese).

3 It means that the allocation is not the final result and may be adjusted later.

${ }^{4}$ Article 15, Interim Measures on Carbon Emissions Trading Management in Shenzhen, Shenzhen Municipal Government, 19 March 2014 (in Chinese).

5 Ibid, at Article 16.

${ }^{6}$ See Trial Methods for the allowances allocation in the Beijing pilot project, Beijing DRC, 22 November 2013; Article 11, Trial Measures of Guangdong Province on the Management of the Carbon Emissions, Guangdong
} 
Guangdong, Shanghai, Tianjin and Hubei, have also been allocated free of charge and the auctioning will be considered and phased in as a complementary method.

\subsubsection{Free allocation based on various allocation criteria}

In the Shenzhen pilot project, the free allowances have been allocated to the emitters in line with the sector-based approach. Benchmarking is applied in the free allocation to the enterprises in the electricity, water-supply and gas industries, while the building sector receives the allowances based on the respective standards of energy consumption limit and the area of construction. ${ }^{1}$ In particular, free allocation to the manufacturing sectors is implemented by a special so-called 'competitive game method', taking account the emitter's historical emissions, the sector's benchmark and other factors. ${ }^{2}$ This game method is a special free allocation procedure which will be explained below.

In order to implement free allocation to the manufacturing sectors, the government in Shenzhen needs to set up a specific sectoral cap, to provide for allocation rules and organise the procedures. ${ }^{3}$ To be specific, the government firstly divides the manufacturing sectors into 22 sub-sectors or groups and then determines the respective carbon intensity target and total amount of allowances for each sub-sector or group in the period from 2013 to 2015, based on the historical emissions data and the added value of the enterprises from 2009 to 2011 , as well as Shenzhen's carbon intensity reduction target in the $12^{\text {th }}$ Five-Year Period (2011-2015). ${ }^{4}$ Under a determined sectoral cap, emitters covered by the same sector have to compete with each other for the free allowances in the finite repeated 'game' held through an electronic allocation platform designed and operated by the government. ${ }^{5}$ Based on the historical and targeted intensity benchmarks of the sectors and other relevant information, the emitters submit the emissions demanded and projected output for the period from 2013 to 2015, and then an allocation result for each emitter in that round will be decided automatically by the platform. ${ }^{6}$ The emitter that is satisfied with and accepts the allocation result can exit the 'game', while those dissatisfied with the result can continue to compete for remaining allowances in the next round until all the allowances are allocated. ${ }^{7}$ In this sense, this special allocation procedure has been designed to shift the allowance allocation from a 'game' between government and emitters to one between emitters and emitters, in view of the information asymmetry between the government and emitters for the rapid but uncertain future development of manufacturing sectors. ${ }^{8}$ Moreover, it is stated that the allowances allocation has been conducted on a case-by-case basis, resulting in differential treatment among the emitters: the emitters with higher carbon intensity will receive

Provincial Government, 15 January 2014; Article 11, Interim Measures of Hubei Province on the Management and trading of the Carbon Emission Right, Hubei Provincial Government, 4 April 2014 (in Chinese).

${ }^{1}$ Article 17, Interim Measures on Carbon Emissions Trading Management in Shenzhen, Shenzhen Municipal Government, 19 March 2014 (in Chinese).

${ }^{2}$ Ibid.

3 Jiang, J. J. (2014), p.3-4.

4 The press conference on the launch of the carbon emissions trading pilot in Shenzhen, Shenzhen Gov ernment Online, 21 May 2013, available at: http:/www.sz.gov.cn/cn/xxgk/xwfyr/wqhg/20130521/ last acce ssed 2 July 2014 (in Chinese).

${ }_{5}^{5}$ Ibid, see also Jiang, J. J. (2014), p.3-4.

${ }^{6}$ Ibid.

7 Ibid.

${ }^{8}$ Ibid. 
less allowances and vice versa ${ }^{1}$, attempting to stimulate clean production. But it is also stressed that preferential allocation will be considered for those emitters deemed to be the strategic and emerging industries, regardless of their high carbon intensity. ${ }^{2}$

Different from the Shenzhen pilot project, other pilot projects have generally chosen grandfathering as the main allocation method for free allocation. But the pilot projects have chosen different base years of the historical emissions for free allocation (see discussion below). Although grandfathering has been deemed to be the principal rule for free allocation, benchmarking has also been taken into consideration for specific sectors in other pilot projects. For instance, the new entrants in the pilot projects of Tianjin and Beijing will receive the allowances mainly based on benchmarks. ${ }^{3}$ In addition, special design features can also be identified in the free allocation used in the Chongqing pilot projects, in which the free allowances allocation is mainly based on the application/requisition by the emitters covered. ${ }^{4}$

With regard to grandfathering, it is mainly based on the historical emissions of the period from 2010 to 2012 in Guangdong's pilot project. Nevertheless, the allowances of Shanghai pilot project will be distributed mainly based on the historical emissions in the period from 2009 to 2011. The free allocation for 2013 in Beijing will also be based on the emissions average between 2009 and 2011, while free allocation for 2014 and 2015 will be based on the verified emissions of the previous year. The diversity of the choices in relation to the base year for grandfathering has reflected the discretion enjoyed by local governments when the verified emissions data is not available at the beginning stage of the ETS. Nevertheless, when the monitoring and verification mechanism is in place, the verified emissions of the previous year or period is foreseen to be chosen as the base year for grandfathering in general.

\subsubsection{Auctioning with different functions}

In addition to free allocation, auctioning has been considered and even applied in some pilot projects. In the Shenzhen pilot project, it is stipulated that the proportion of the allowances to be auctioned should not be less than $3 \%$ of the annual total amount of allowances, which may be increased gradually in a move to full auctioning. ${ }^{5}$ However, the auction has been held in practice

\footnotetext{
1 The press conference on the launch of the carbon emissions trading pilot in Shenzhen, Shenzhen Gov ernment Online, 21 May 2013, available at: http:/www.sz.gov.cn/cn/xxgk/xwfyr/wqhg/20130521/ last acce ssed 2 July 2014 (in Chinese).

2 Article 17, Interim Measures on Carbon Emissions Trading Management in Shenzhen, Shenzhen Municipal Government, 19 March 2014 (in Chinese); see also The news conference on the launch of the carbon emissions trading pilot in Shenzhen, Shenzhen Government Online, 21 May 2013, available at: http://www.sz.gov.cn/cn/xxgk/xwfyr/wqhg/20130521/ last accessed 2 July 2014 (in Chinese).

${ }^{3}$ In this respect, 23 sectoral benchmarks (with 41 subdivided benchmarks) have been determined and published by Beijing DRC on 29 April 2014. See the notice on issuing the sectoral benchmarks of the carbon emissions intensity, Beijing DRC, 29 April 2014 (in Chinese).

${ }^{4}$ To be specific, in view of the possible difference between the sum of the amount applied by the emitter and the annual cap of allowances for the pilot project, if the former is smaller than the latter, the emitters will receive the amount of allowances that they have applied for; but when the former is larger than the latter, the allocation has to follow a specific but complicated method provided by the rules of managing the allowance adopted by Chongqing DRC. See Article 10, The notice of distributing the rules of managing the carbon emissions allowance in Chongqing Municipality, Chongqing DRC, 28 May 2014 (in Chinese).

5 Article 20, Interim Measures on Carbon Emissions Trading Management in Shenzhen, Shenzhen Municipal Government, 19 March 2014 (in Chinese); see also Cui, X.(2013), The carbon emissions trading in Shenzhen
} 
only as an additional mechanism with the aim to facilitate the compliance with the scheme, when the compliance deadline for 2013 is approaching. According to the Auction Notice issued by the China Emissions Exchange (Shenzhen) on 27 May 2014, 200,000 allowances were to be auctioned with a price floor of $35.43 \mathrm{CNY}$ on 6 June 2014, half of the average of the market prices of the allowances in Shenzhen pilot until 27 May 2014. ${ }^{1}$ However, the bidders are limited to the emitters whose actual emissions still exceed the allowances confirmed after the annual ex post adjustment by Shenzhen DRC on 29 May $2014 .^{2}$ Moreover, the allowances to be bought by the qualified bidders should not be more than $15 \%$ of the difference between the actual emissions and allowances they hold, all of which must be used for compliance rather than transactions in the market. ${ }^{3}$ Nevertheless, only about 70,000 allowances have been auctioned at the price floor. 4

Additional auctions have also been held in the pilot projects of Shanghai and Guangdong with a similar aim, but the design feature and outcome of those auctions varies a lot, which can be demonstrated by the Shanghai pilot below. Moreover, it is noticeable that regular auctioning has been implemented as an important method with special design features in the initial allocation of allowances in Guangdong pilot project, but the elaboration below shows that this front runner is still exploring and testing a suitable design for auctioning. In addition, the auctioning will also be applied as a price discovery mechanism in Hubei pilot project. ${ }^{5}$

Regarding the additional auctioning, according to Shanghai's announcement concerning auctioning for governmental adjustment, 580,000 tonnes of allowances were to be auctioned on 30 June 2014, the deadline for surrendering the allowances for compliance, with a price floor equal to 1.2 times of the weighted average market price of the previous 30 trading days, which should not be more than $46 \mathrm{CNY}$ at the same time. ${ }^{6}$ Meanwhile, the auction is also only open to the emitters with excess emissions and the allowances auctioned can only used for compliance rather than transactions. ${ }^{7}$ Only 7,220 tonnes of allowances were auctioned by two enterprises at the price of $48 \mathrm{CNY} /$ tonne on that day, since most enterprises had bought the allowance at the market price lower than $46 \mathrm{CNY} /$ tonne before the auction was held. In this sense, the additional auctioning in the pilot projects of Guangdong, Shenzhen and Shanghai could be considered as a kind of governmental

will be launched in June, Shenzhen Economic Daily, 4 April 2013, A01, available

at: http://szsb.sznews.com/html/2013-04/04/content_2431510.htm (in Chinese).

${ }^{1}$ Public notice of auction of China Emissions Exchange (Shenzhen), available at: http://www.cerx.cn/Port al/home.seam, last accessed 22 September 2014 (in Chinese).

${ }^{2} \mathrm{Ibid}$. This ex post adjustment will be explained in the following section 3.3 .3 of this chapter.

3 Ibid.

${ }^{4}$ Information is available at the website of China Emissions Exchange (Shenzhen): http://www.cerx.cn/P ortal/home.seam (in Chinese).

${ }^{5}$ Instead of the price determined by government, auctioning is supposed to discover the real market price of the allowance through the market mechanism in Hubei. To be specific, in line with the specific allocation methods determined by Hubei DRC, 8\% of the annual total amount of allowances in 2014 (324 million allowances) will be set aside for the governmental reserve, less than $30 \%$ of which will be categorised as the allowance reserve for price discovery and will be allocated by government via auctioning. See the allocation plan for the carbon emissions allowance in Hubei Province, Hubei DRC, 26 March 2014 (in Chinese); see also Article 15, Interim Measures of Hubei Province on the Management and Trading of the Carbon Emission Right, Hubei Provincial Government, 4 April 2014 (in Chinese).

${ }^{6}$ Announcement of auctioning the allowances for the governmental adjustment in the compliance period, Shanghai DRC, 13 June 2014 (in Chinese).

${ }^{7}$ Ibid. 
adjustment of allowances allocation, facilitating compliance by buying allowances from the auction, implying the link between the auctioning and compliance.

The regular auctioning has been designed and implemented with a unique feature in Guangdong. The free allowances allocated to the emitters in the Guangdong pilot project could not be 'activated' - traded or surrendered for compliance - until the emitters concerned had bought a specific amount of allowances required by the government, through the quarterly auctioning with a price floor determined by Guangdong DRC together with the price department. ${ }^{1}$ To be specific, the proportion of the allowances bought from the auctioning platform for the industrial emitters in the Guangdong pilot project is not higher than $3 \%$, while the proportion for the power sector will be increased gradually to over $50 \%$ in $2020 .^{2}$ In practice, about 9.76 million allowances have been auctioned at the price floor of $60 \mathrm{CNY}$ in four auctions held for the annual allowance allocation in 2013. ${ }^{3}$ However, it is reported that some emitters, which may not receive the free allowances, have been reluctant to participate in the auctioning, not buying any allowances from the auctioning. ${ }^{4}$ In this light, an additional auction in Guangdong pilot project, as mentioned above, was held on 25 June 2014, with an attempt to provide the last chance for the emitters to buy the allowances they need. According to the amendment in the allocation plan for 2014, nevertheless, buying the allowances from auctioning will no longer be a mandatory condition for receiving free allowances. Meanwhile, the reserve prices for the regular four auctions will be $25,30,35$, and $40 \mathrm{CNY}$ respectively, increasing gradually. ${ }^{5}$

\subsubsection{Special rules}

In the design and implementation of the allocation of allowances, various special rules adopted among the pilot projects are worthy of attention. In particular, some special rules including $e x$ post adjustment, price regulations, allocation for new entrants, and settlement of relevant disputes have been adopted in most of the pilot projects.

\section{Ex post adjustment}

Notably, the ex post adjustment of the allowances allocation has been applied in some pilot projects including Shenzhen, Shanghai, Beijing, Guangdong, Hubei, and Chongqing. Different from the ex post adjustment for the normal situations of closure and new entrants in the EU ETS, inter alia in Germany, the ex post adjustment applied in the Chinese pilot projects mainly aims to accommodate new circumstances, in particular the different performances of economic growth in

\footnotetext{
${ }^{1}$ Article 21, Trial Measures of Guangdong Province on the Management of the Carbon Emissions, Guangdong Provincial Government, 15 January 2014; see also Article 9, Implementation Rules of Guangdong Province for the management of carbon emissions allowances (Trial), Guangdong DRC, 20 March 2014 (in Chinese).

${ }^{2}$ Article 9, Implementation Rules of Guangdong Province for the management of carbon emissions allowances (Trial), Guangdong DRC, 20 March 2014 (in Chinese).

3 Data from the website of China Emissions Exchange (Guangzhou), the designated auctioning platform in Guangdong pilot project, http://www.cnemission.com.

${ }^{4}$ It is reported that about 60 enterprises, around a quarter of the total enterprises covered by the pilot projects did not buy the allowances as required until 13 May 2014. Data from the website of China Emissions Exchange (Guangzhou) mentioned above.

5 Implementation plan for the carbon emissions allowances allocation in 2014 for Guangdong province, Guangdong DRC, 18 August 2014 (in Chinese).
} 
light of the impact of the carbon intensity reduction target on the allowances allocation and other specific situations related to the price regulation to be discussed later.

In the Shenzhen pilot project, the allowances pre-allocated to the emitters every three years will be adjusted by Shenzhen DRC before 20 May every year, in accordance with the respective sectoral carbon intensity target, determined by the Shenzhen DRC, and the actual data of the emissions and other statistical index of the previous year. ${ }^{1}$ To be specific, the actual amount of allowances that the emitter should get is equal to its total production quantity (actual industrial added value) multiplied by the specific sectoral carbon intensity target of the previous year. ${ }^{2}$ In the case of a difference between the projected production output and actual output, Shenzhen DRC could increase or reduce the allowances allocated to the emitters ex post, in order to adjust the allowances allocation in line with the carbon intensity reduction target. ${ }^{3}$ In other words, both the increase and decrease adjustment of the allowances are allowed, but the total amount of allowances to be added cannot exceed the amount of allowances to be deducted, except for the case of new investment projects of fixed assets meeting specific requirements. ${ }^{4}$ In practice, three million allowances allocated to the emitters in 2013 have been deducted ex post by Shenzhen DRC on 29 May $2014 .^{5}$

Similarly, the allowances allocated to emitters in the rest of the pilot projects, except for the Tianjin pilot project, will also be subjected to the annual adjustment ex post. However, the specific requirement and threshold for the ex post adjustment has been established differently among other pilot projects as elaborated below. Moreover, the government in other pilot projects may also implement the ex post adjustment by increasing and/ or reducing the allowances allocated to the emitters. It is explicitly provided that Shanghai DRC can adjust the allowances allocation by means of withdrawing or complementing the difference ${ }^{6}$, while the Guangdong pilot project just stipulates that the emitter facing significant changes in the production and operation situation can apply for a modification of the allowances allocation. ${ }^{7}$ Since the provisions above do not confine this ex post adjustment to a decrease adjustment, the increase adjustment may not be prohibited in Guangdong. In other words, if the emissions of one emitter are far beyond the allowances received from the initial allocation because of bad performance and outdated technology, there is still a possibility for the government to allocate more allowances to that emitter ex post. However, this kind of increase adjustment ex post, which will result in an increase of the cap, the total amount of the allowances, may not be compatible with the environmental goal of the ETS. Meanwhile, the uncertainty for emitters caused by the ex post adjustment should not be overlooked, which will be discussed later in section 4.2 of this chapter.

\footnotetext{
${ }^{1}$ Article 17 and 19, Interim Measures on Carbon Emissions Trading Management in Shenzhen, Shenzhen Municipal Government, 19 March 2014 (in Chinese).

${ }^{2}$ Ibid, at Article 19.

${ }^{3}$ Ibid.

${ }^{4}$ Ibid, at Article 18, 19.

${ }^{5}$ Information is available at the website of Shenzhen DRC, http://www.sz.gov.cn/cn/xxgk/bmdt/201405/t2 0140529 2455203.htm, 29 May 2014 (in Chinese).

6 The allocation and management plan for the carbon emissions allowance in Shanghai municipality (2013-2015), Shanghai DRC, 22 November 2013 (in Chinese).

Article 16, Trial Measures of Guangdong Province on the Management of the Carbon Emissions, Guangdong Provincial Government, 15 January 2014 (in Chinese).
} 
The threshold for ex post adjustment varies among the pilot projects. For instance, the allowances for the period from 2013 to 2015 in the pilot projects of Shanghai and Beijing have been allocated in one time. Shanghai DRC will adjust the allowances allocated to the emitters annually based on its business volume in the current year, before the deadline for surrendering the allowances in the annual compliance cycle. ${ }^{1}$ Nevertheless, the trigger for ex post adjustment in Beijing pilot is different. If the amount of $\mathrm{CO}_{2}$ emissions increases or decreases by 5,000 tonnes or by $20 \%$ compared to the previous year, due to an extension, the increase of production, mergers and acquisitions, and other factors, the emitters concerned have to apply for a modification of the allowances allocation by letter, which will be checked and adjusted ex post by Beijing DRC based on a relevant examination including a verification by the third-party verifiers when necessary. ${ }^{2}$ A similar design to the Beijing pilot project, concerning the ex post adjustment of allocation for the difference between the allowances allocated and the actual emissions, has also been adopted in the Hubei pilot project. However, Hubei's threshold for the ex post adjustment will be a little different from that in Beijing, requiring that the difference between the actual emissions and allowances allocation ex ante should be 20,000 tonnes or $20 \%$ compared to the previous year. ${ }^{3}$ But in the Chongqing pilot project, if the amount of allowances applied by the emitters is larger or smaller than the emissions amount verified and authorised by Chongqing DRC by more than $8 \%$, the difference of allowances will be reduced or re-allocated correspondingly. ${ }^{4}$

\section{Price regulation mechanism}

The price regulation mechanism has been incorporated into the design of allowances allocation for the Shenzhen pilot project. On the one hand, aiming to deal with the serious market fluctuations by increasing the supply of the allowances, the allowances reserve for market price stabilisation has to be sold by the government to the emitters at a fixed price. ${ }^{5}$ But it is emphasised that these allowances can only be surrendered by emitters for compliance rather than transactions. ${ }^{6}$ On the other hand, it is also possible for Shenzhen DRC to buy back the allowances from the market in line with the specific requirements and scale (no more than $10 \%$ of the annual total amount of allowances) determined ex ante, in order to reduce the supply of allowances and thus stabilise the market price. $^{7}$ However, there is not much information about the threshold for the price regulations nor the determination and specific level of the fixed price mentioned in the Shenzhen pilot project yet.

Similar mechanisms for price regulation can also be found in the pilot projects of Guangdong, Tianjin and Beijing. By analogy, some allowances, in particular the specific allowances reserve

\footnotetext{
${ }^{1}$ The allocation and management plan for the carbon emissions allowance in Shanghai municipality (2013-2015), Shanghai DRC, 22 November 2013 (in Chinese).

${ }^{2}$ Notice concerning the implementation of Beijing carbon emissions trading pilot project, Beijing DRC, 22 November 2013 (in Chinese).

3 Article 17, Interim Measures of Hubei Province on the Management and Trading of the Carbon Emission Right, Hubei Provincial Government, 4 April 2014 (in Chinese).

${ }^{4}$ Article 12-14, The Notice of distributing the rules of managing the carbon emissions allowance in Chongqing Municipality, Chongqing DRC, 28 May 2014 (in Chinese).

5 Article 21, Interim Measures on Carbon Emissions Trading Management in Shenzhen, Shenzhen Municipal Government, 19 March 2014 (in Chinese)

${ }^{6}$ Ibid.

${ }^{7}$ Ibid, at Article 22.
} 
for adjustment/ market regulation/ price regulation established in these pilot projects mentioned above could also be auctioned or sold by the government in order to stabilise the market price by putting more allowances into the market. ${ }^{1}$ For instance, according to the "price warning mechanism' implied in a notice issued by Beijing DRC, a certain amount of allowances will be put on the market through auctioning by Beijing DRC when the market price is too high due to the short supply of allowances. ${ }^{2}$ Meanwhile, the municipal DRC in the pilot projects of Beijing and Tianjin may also buy back some allowances from the market when the price is too low because of the surplus of allowances. ${ }^{3}$ Moreover, detailed and clear rules providing for the specific threshold and guidance for the price regulation have been adopted in the Beijing pilot project $^{4}$, which will be analysed in section 4.2 of this chapter.

\section{Allocation to new entrants}

Some pilot projects have established specific allowances reserved for new entrants, the allocation of which usually follows the free allocation approach. In Shenzhen, 2\% of the annual total amount of allowances should be reserved for the new entrants. ${ }^{5}$ However, the new fixed asset investment project, with anticipated annual carbon emissions exceeding 3,000 tonnes of $\mathrm{CO}_{2}$ equivalent, shall submit a carbon emission assessment report to the Shenzhen DRC. ${ }^{6}$ Based on the sectoral average emissions, industry policy and relevant factors, Shenzhen DRC pre-allocates the allowances to these new projects in the year when they are put into operation, and then adjusts the allowances allocation when the authorised actual statistical data of operation is available. $^{7}$

Different from Shenzhen and other pilot projects, the treatment of new entrants in the Guangdong pilot project has been designed with unique features. Similar to that in the Shenzhen pilot project, for a new fixed asset investment project with a comprehensive energy consumption exceeding 10,000 tonnes of standard coal equivalent in the energy saving investigation, a carbon emission assessment needs to be conducted by Guangdong DRC, on the basis of which, together with the total emissions cap of Guangdong, the allowance for that new entrant will be determined. $^{8}$ The same as the existing emitters in Guangdong, the new entrants could not

\footnotetext{
${ }^{1}$ Ibid, at Article 21; see also Article 21, 42(3), Trial Measures of Guangdong Province on the Management of the Carbon Emissions, Guangdong Provincial Government, 15 January 2014; see also Article 7, Notice of Distributing Interim Measures on Management of Carbon Emissions Trading in Tianjin, General Office of Tianjin Municipal Government, 20 December 2013 (in Chinese).

2 Notice concerning the implementation of Beijing carbon emissions trading pilot project, Beijing DRC, 22 November 2013; see also Huang, H.(2012), Beijing launched the carbon emissions trading pilot with the introduction of third-party verification, China High-tech Industry Herald, 9 April 2012, A1, available at: http://paper.chinahightech.com.cn/html/2012-04/09/content_28056.htm (in Chinese).

3 Notice concerning the implementation of Beijing carbon emissions trading pilot project, Beijing DRC, 22 November 2013, see also Article 27, Notice of Distributing Interim Measures on Management of Carbon Emissions Trading in Tianjin, General Office of Tianjin Municipal Government, 20 December 2013.

${ }^{4}$ Management measures on the open-market operation relating to the carbon emissions trading, Beijing DRC, Beijing Bureau of Finance, 10 June 2014 (in Chinese).

5 Article 18, Interim Measures on Carbon Emissions Trading Management in Shenzhen, Shenzhen Municipal

Government, 19 March 2014 (in Chinese).

${ }^{6}$ Ibid.

${ }^{7}$ Ibid.

8 Article 5(3), Implementation program of carbon emissions trading pilot in Guangdong Province, Guangdong Provincial Government, 7 September 2012; see also Article 20, Trial Measures of Guangdong Province on the Management of the Carbon Emissions, Guangdong Provincial Government, 15 January 2014 (in Chinese).
} 
receive the free allowances until they bought enough allowances through auctioning as was required before 2014. ${ }^{1}$ Furthermore, the success of such new projects in getting the same amount of allowances as the assessment result will be an important basis for the approval procedures by the competent department in charge of investment at all levels. ${ }^{2}$ In other words, whether or not such a special new investment can be approved and a new enterprise can be established, in some cases, relies on the allowances allocation result to a large degree. Moreover, the allowances allocated to such new investment projects cannot be traded until they are approved as tradable allowances when the project is completed and put into operation. ${ }^{3}$ In this respect, the allowances to be allocated to the new entrants ex ante are deemed to be non-tradable allowances, which cannot be traded by the operator of the new entrants until the completion of construction and start of operation. It is argued that this special treatment of the allowance is supposed to help the government regulate the increase of emissions and thus control the cap to a certain degree. $^{4}$

\section{Settlement of the dispute on the allocation result}

In view of the possible dispute that may emerge in the allocation of allowances, relevant settlement mechanisms have been provided in some pilot projects. Given the special approach adopted in Shenzhen explained above, the possible dispute on allowances allocation would mainly concentrate on the determination of the actual emissions data verified by a third party, which will be discussed in section 3.4 below.

But in other pilot projects, like Guangdong, the implementation plan for allowance allocation formulated by Guangdong DRC, stipulating the principle, method, and procedures of allocation, shall be submitted to Guangdong provincial government for approval every year, after the review by the committee composed of relevant leading departments, experts, industry associations, and enterprises in which the experts should be more than two-thirds of total members. ${ }^{5}$ Moreover, if the emitter concerned objects to the allocation result, that emitter can request a review and the Guangdong DRC should check and provide a written reply within 20 days. $^{6}$ Similarly, the emitter that raises an objection to the allocation, offset or cancellation of the allowances in the Hubei pilot project can also apply for it to be double checked, to which Hubei DRC should reply within 20 days. $^{7}$ However, it is not clear whether the emitters covered by these pilot projects can

\footnotetext{
${ }^{1}$ Article 20, Trial Measures of Guangdong Province on the Management of the Carbon Emissions, Guangdong Provincial Government, 15 January 2014 (in Chinese).

2 Article 5(3), Implementation program of carbon emissions trading pilot in Guangdong Province Guangdong Provincial Government, 7 September 2012 (in Chinese). With regard to the competent authority, there are different authorities in charge of the decision for different investment projects. For instance, the local DRC is responsible for the capital construction investment projects, while the local Departments of Economic and Trade are in charge of the technical transformation investment projects in the field of industries, transportation and commerce. See Article 5 of The notice on printing and distributing the interim measures of Guangdong province about approval of the enterprise's investment projects, 6 December 2005 (in Chinese).

3 Article 5(4), Implementation program of carbon emissions trading pilot in Guangdong Province, Guangdong Provincial Government, 7 September 2012.

${ }^{4}$ Guangdong set up a good example for the establishment of the national carbon market, Nan Fang Daily, 11 September 2012 (in Chinese).

5 Article 12, Trial Measures of Guangdong Province on the Management of the Carbon Emissions, Guangdong Provincial Government, 15 January 2014 (in Chinese).

${ }^{6}$ Ibid, at Article 31.

7 Article 22, Interim Measures of Hubei Province on the Management and Trading of the Carbon Emission Right, Hubei Provincial Government, 4 April 2014 (in Chinese).
} 
and will have access to the court, challenging the governmental decisions relating to the allowances allocation, which will be observed later in the section 4.2 of this chapter.

\subsubsection{Summary}

The description of relevant rules concerning the allocation of allowances in the pilot projects has indicated that the allowances have been allocated through a mix of several allocation methods, which is shown in the following table. Moreover, most of the regulatory frameworks for the pilot projects have demonstrated that free allocation has been chosen as the main allocation method for the $\mathrm{CO}_{2}$ ETS in the piloting phase, in pursuit of a smooth establishment of the ETS to the extent possible, which is similar to the approach adopted in the EU ETS. To be specific, most of the allowances in the pilot projects have been allocated to the emitters free of charge mainly based on the historical emissions, while benchmarking has also been applied to some sectors and to the new entrants. In addition to the bold step of Guangdong requiring all the emitters to buy a certain amount of allowances through auctioning, auctioning has also been considered as a complementary method to phase in gradually, yet no definite timetable of the auctioning has been provided in the rest of the pilot projects.

Aiming to accommodate the economic growth and different circumstances of the pilot projects, a variety of factors besides the historical emissions has been taken into account in the free allocation. For instance, Shanghai will allocate the allowances based on the historical emissions together with the development stage of the sectors, considering the reasonable growth and the early action in emissions reduction. ${ }^{1}$ Furthermore, the allowances allocation, inter alia the allocation for new entrants, may be integrated into other economic policy instruments by the government to a certain extent, in pursuit of the transition into the low-carbon economy. Particular provisions concerning the treatment of new entrants in Guangdong has exemplified that the result of allowance allocation may constitute one of the conditions for specific investment projects to be undertaken. In this respect, given its close connection with market access, how to allocate the allowances is no longer just a distributional issue.

Particular attention should also be paid to the unique role of the government in the allocation of allowances, in light of the possibility of ex post adjustment and price regulation. In view of the uncertain projection of the economic growth and emissions in the free allocation, the ex post adjustment of the allowances allocation, in accordance with the economic development and actual emissions of previous year, has been employed in most of the pilot projects with various thresholds and requirements. Moreover, several pilot projects such as Beijing, Tianjin, Shenzhen, Guangdong, and Hubei, have reserved a specific amount of allowances for governmental regulation in pursuit of price stabilisation of the carbon market. Furthermore, the description above has also suggested that specific additional auctioning, as a governmental adjustment instrument facilitating compliance, has been implemented by the Shanghai, Shenzhen and Guangdong pilot projects. However, these special mechanisms, such as the ex post adjustment, may also limit the role of the market. Hence, the cost-effectiveness of the specific pilot projects containing ex post adjustment deserves economic research.

\footnotetext{
${ }^{1}$ Implementing Opinions of the Shanghai Municipal Government on Pilot Carbon Emissions Trading in Shanghai Municipality, Shanghai Municipal Government, 31 July 2011 (in Chinese).
} 
Table 7 Major allocation methods applied in the pilot projects

\begin{tabular}{|c|c|c|c|c|}
\hline \multirow{2}{*}{$\begin{array}{l}\text { Pilot } \\
\text { projects }\end{array}$} & \multicolumn{2}{|l|}{ Free allocation } & \multirow[t]{2}{*}{ Auctioning } & \multirow[t]{2}{*}{ Special rules } \\
\hline & $\begin{array}{l}\text { Based on historical } \\
\text { emissions/intensity }\end{array}$ & benchmarking & & \\
\hline Shenzhen & $\begin{array}{l}\text { manufacturing sectors, based } \\
\text { on the 'competitive game } \\
\text { method'; } \\
\text { for building sectors, based } \\
\text { on respective standards of } \\
\text { energy consumption limit } \\
\text { and the area of construction }\end{array}$ & $\begin{array}{l}\text { enterprises in } \\
\text { electricity, } \\
\text { water-supply } \\
\text { and gas sector }\end{array}$ & $\begin{array}{l}\text { one auction to } \\
\text { facilitate } \\
\text { compliance }\end{array}$ & $\begin{array}{l}\text { ex post adjustment; } \\
\text { price regulation } \\
\text { mechanism }\end{array}$ \\
\hline Shanghai & $\begin{array}{l}\text { industrial sectors (except the } \\
\text { power sectors), the buildings } \\
\text { including shopping mall, } \\
\text { hotels and business offices }\end{array}$ & $\begin{array}{l}\text { power } \\
\text { sectors; } \\
\text { non-industrial } \\
\text { sectors }\end{array}$ & $\begin{array}{l}\text { one auction to } \\
\text { facilitate } \\
\text { compliance }\end{array}$ & ex post adjustment; \\
\hline Beijing & $\begin{array}{l}\text { industrial emitters and } \\
\text { service sectors, based on the } \\
\text { total amount of the historical } \\
\text { emissions; } \\
\text { for existing heat-supply } \\
\text { enterprises and thermal } \\
\text { power plants (operating } \\
\text { before 2013), based on } \\
\text { intensity of historical } \\
\text { emissions (average between } \\
\text { 2009-2012) }\end{array}$ & $\begin{array}{l}\text { new entrants } \\
\text { ( } 23 \text { sectoral } \\
\text { benchmarks } \\
\text { have been } \\
\text { determined) }\end{array}$ & & $\begin{array}{l}\text { ex post adjustment; } \\
\text { price regulation } \\
\text { mechanism }\end{array}$ \\
\hline $\begin{array}{l}\text { Guangdon } \\
\mathrm{g}\end{array}$ & $\begin{array}{l}\text { based on historical } \\
\text { emissions, sectoral baseline } \\
\text { and abatement potential; } \\
\text { free allowance was } \\
\text { 'activated' by buying } \\
\text { sufficient allowances } \\
\text { through auctioning in 2013 } \\
\text { (not required since 2014) }\end{array}$ & & $\begin{array}{l}\text { auctioning } \\
\text { quarterly with } \\
\text { a price floor; } \\
\text { one additional } \\
\text { auction to } \\
\text { facilitate } \\
\text { compliance }\end{array}$ & $\begin{array}{l}\text { ex post adjustment; } \\
\text { price regulation } \\
\text { mechanism; } \\
\text { connection between } \\
\text { allowance allocation } \\
\text { and approval for } \\
\text { new fixed asset } \\
\text { investment projects }\end{array}$ \\
\hline Tianjin & existing emitters & new entrants & $\begin{array}{l}\text { may be } \\
\text { considered for } \\
\text { only frice } \\
\text { market price } \\
\text { stabilisation }\end{array}$ & $\begin{array}{l}\text { price regulation } \\
\text { mechanism }\end{array}$ \\
\hline Hubei & $\begin{array}{l}\text { existing emitters, mainly } \\
\text { based on historical emissions } \\
\text { together with specific } \\
\text { adjustment indictors }\end{array}$ & & $\begin{array}{l}\text { will be used } \\
\text { for price } \\
\text { discovery }\end{array}$ & $\begin{array}{l}\text { ex post adjustment; } \\
\text { allowances not } \\
\text { traded/surrendered } \\
\text { will be cancelled at } \\
\text { the end of June } \\
\text { annually }\end{array}$ \\
\hline Chongqing & $\begin{array}{l}\text { mainly based on the } \\
\text { application/requisition by the } \\
\text { emitters }\end{array}$ & & & $\begin{array}{l}\text { ex post adjustment; } \\
\text { no more than half of } \\
\text { the annual } \\
\text { allowances allocated } \\
\text { can be sold }\end{array}$ \\
\hline
\end{tabular}




\subsection{Inspection and enforcement}

Given the importance of timely and accurate emissions data for emissions trading, specific guidelines or requirements relating to the inspection system as well as the enforcement mechanism have been adopted in the pilot projects.

In the pilot project of Shenzhen, the local regulation provides for the basic requirement for MRV and the penalties for excess emissions. The Interim Measures of Shenzhen Municipality on Carbon Emissions Trading Management sets forth detailed requirements and procedures for MRV systems. In addition, the Market Supervision Administration of Shenzhen Municipality has formulated and released two guidance documents. The first contains guidance on quantifying and reporting GHG emissions; the second contains guidance for verification. These became effective on 1 December 2012, ${ }^{1}$ intended to support the establishment of a comprehensive MRV system.

Among other pilot projects, as shown in the annex of relevant legislations and policies, the basic requirements for inspection and enforcement have also been stipulated by the local regulations and the rules of local government. For instance, the local regulation adopted by the Beijing People's Congress Standing Committee has provided for legal liability for excess emissions and the failure to submit an emissions report or verification report. Most of the detailed rules of and specific requirements for the enforcement package among other pilot projects (see the annex of legislation and policy), similar to that in Shenzhen, have been stipulated by relevant guidelines or implementation rules, the other normative documents with relatively weak legally binding force. The detailed design of the enforcement package among the pilot projects, in particular the MRV system and the sanctions provisions, will be presented below.

\subsubsection{MRV system}

The collection of emissions data in the pilot projects follows an annual compliance cycle respectively, containing the requirement for and procedure of monitoring, reporting and verification of the emissions data. For instance, the emitters in the Shenzhen pilot project are required to submit the annual emissions report ${ }^{2}$ verified by a third party verifier before April 30 annually. ${ }^{3}$ The technical process of the monitoring, reporting and verification of the $\mathrm{CO}_{2}$ emissions in the pilot projects, in particular for those applying the monitoring plan, such as Shanghai, mainly contains several steps illustrated by the following chart. ${ }^{4}$

\footnotetext{
${ }^{1}$ Notice of Issuance of Specification with Guidance for Quantification and Reporting of Organisation's Greenhouse Gas Emissions, Shenzhen Municipal Market Supervision Administration, 6 November 2012; Notice of Issuance of Specification With Guidance for Verification of Organisation's Greenhouse Gas Emissions, Shenzhen Municipal Market Supervision Administration, 7 November 2012 (in Chinese).

${ }^{2}$ If the emitters are industrial enterprises, annual statistical index data is also needed. See Article 28, Interim Measures on Carbon Emissions Trading Management in Shenzhen, Shenzhen Municipal Government, 19 March 2014 (in Chinese).

3 Ibid, at Article 29.

${ }^{4}$ Notice of Printing and Distributing Interim Guideline for Verification and Reporting of Greenhouse Gas Emissions, Shanghai DRC, 11 December 2012 (in Chinese). In particular, the guidelines for the monitoring and reporting of GHG emissions in the EU ETS (Commission Decision 2007/589/EC) has been applied as one of the references when adopting the interim guideline in Shanghai pilot project.
} 
Figure 3 MRV process in the Shanghai pilot project

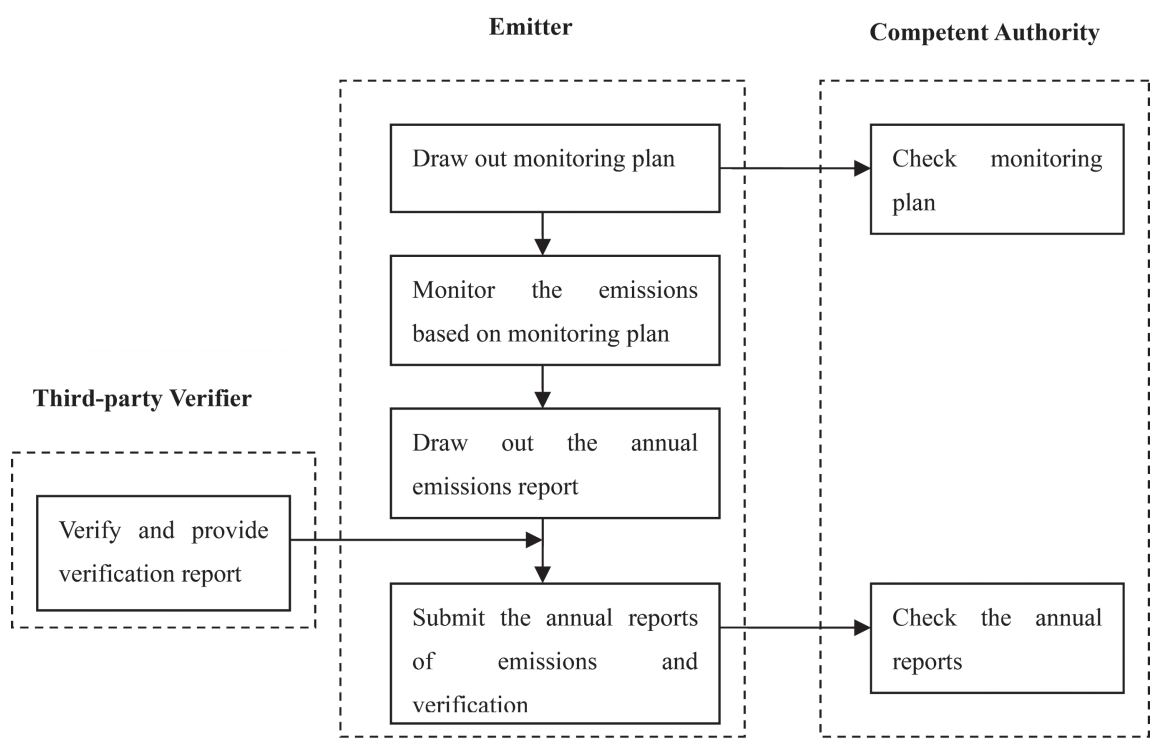

(Source: Interim guideline for MRV of GHG-emissions in Shanghai (SH/MRV-001-2012))

\section{Monitoring and Reporting}

According to Shenzhen's local regulation, the emitters covered are required to submit an annual emissions report, verified by a third party, to Shenzhen DRC. ${ }^{1}$ The emitters covered by the Shenzhen pilot project are responsible for the truthfulness, accuracy and standardisation of the emissions report, and they shall not provide false data or collude with the verifiers in providing false data. ${ }^{2}$ Based on the guidance on quantifying and reporting GHG emissions mentioned above, the emitter collects the emissions data. Within ten workdays after each quarter, the emitter shall submit the emissions report of previous quarter to the Shenzhen DRC, while the annual report should be submitted by the end of March.

Other pilot projects such as Shanghai, Guangdong, Tianjin, and Hubei have applied the instrument of a monitoring plan with similar requirements and procedures as elaborated below, based on which the emitter will monitor the $\mathrm{CO}_{2}$ emissions and submit the annual emissions report for verification by the third-party verifier. ${ }^{3}$ In addition to the requirement for emitters covered by the pilot projects to submit the annual emissions reports of the preceding year within a specified time period, a carbon emissions reporting system for specific emitters not yet covered

\footnotetext{
${ }^{1}$ Article 7, Provisions of Controlling Carbon Emissions for Special Economic Zone, Shenzhen People's Congress Standing Committee, 10 November 2012 (in Chinese).

2 Ibid, at Article 30.

${ }^{3}$ See for instance, Article13, Notice of Distributing Interim Measures on Management of Carbon Emissions Trading, General Office of Tianjin Municipal Government, 20 December 2013; Article 32, Interim Measures of Hubei Province on the Management and Trading of the Carbon Emission Right, Hubei Provincial Government, 4 April 2014; Article 12, Trial Management Measures for Carbon Emissions in Shanghai, Shanghai Municipal Government, 18 November 2013 (in Chinese).
} 
by the pilot projects has also been established in the pilot projects of Shanghai and Guangdong, preparing for the expansion of the scope concerning the pilot projects in the future. ${ }^{1}$

With regard to the application of the monitoring plan, uncertainty and challenges exist among the pilot projects. For instance, the emitter covered by Shanghai pilot project is required to draw out a monitoring plan, which has to be submitted to the competent authority by the end of each year, and the emitter has to report to the authority if there is a substantial change in the monitoring plan. ${ }^{2}$ It is not clear whether the monitoring plan should be approved by Shanghai DRC. The draft of this provision, released for public consultation by Shanghai municipality on 12 July 2013, may provide some clues for us. According to Article 7 of this draft, the monitoring plan shall be submitted to the competent authority to register for the record (bei an) in the fourth quarter of each year. In this light, there appears to be no need for the authority to approve the monitoring plan, since it will not be considered and granted as one kind of administrative permission. Similar uncertainty concerning the monitoring plan also exists in other pilot projects.

\section{Verification and supervision}

In order to ensure the quality of the emissions data reported by the emitters, the emissions data reported has to be verified by a third-party verifier in all the pilot projects. With regard to the accreditation of the verifier and verification process, basic requirements and specific guidelines have been provided by most pilot projects (see the annex of legislation and policy).

In the Shenzhen pilot project, the third-party verification must be conducted in an objective, fair and impartial manner. ${ }^{3}$ In order to guarantee the credibility of the verifiers, the qualified verifiers that have registered in the Market Regulation Department of Shenzhen government need to be disclosed to the public, together with their relevant compliance information included in the Enterprise Credit System. ${ }^{4}$ Meanwhile, the emitters shall employ the qualified verifier but the emitters are prohibited from choosing the same verification organisation and verifiers for three consecutive years. ${ }^{5}$ When the verification is completed, Shenzhen DRC has to conduct a spot check on the emissions report and verification report of the emitters, the percentage of which should be no less than $10 \%$ of the total number of emitters covered by the pilot projects; moreover, the key inspection will be placed on the emitters graded as being a high-level risk in

\footnotetext{
${ }^{1}$ See Article 3(1), Implementing Opinions on Pilot Carbon Emissions Trading, Shanghai Municipal Government, 3 July 2012 (in Chinese); see also Article 3(1), Implementation Program of Carbon Emissions Trading Pilot, Guangdong Provincial Government, 7 September 2012 (in Chinese).

2 Article 11, Trial Management Measures for Carbon Emissions in Shanghai, Shanghai Municipal Government, 18 November 2013 (in Chinese).

3 Article 7, Provisions of Controlling Carbon Emissions for Special Economic Zone, Shenzhen People's Congress Standing Committee, 10 November 2012 (in Chinese).

4 Article 31, 63, Interim Measures on Carbon Emissions Trading Management in Shenzhen, Shenzhen Municipal Government, 19 March 2014 (in Chinese). The credit record of an enterprise contains its basic registration information, commercial credit information, and other relevant information that may affect the enterprise's credit, such as the illegal behavior record that has been punished by the government. See Article 43 of Administrative Measures of Shenzhen Municipality on Credit Information Collecting and Credit Rank Evaluating of Enterprises , 19 November 2002 (in Chinese)

${ }^{5}$ See ibid, at Article 30. The same prohibition also exists in Tianjin pilot, see Article15, Notice of Distributing Interim Measures on Management of Carbon Emissions Trading, General Office of Tianjin Municipal Government, 20 December 2013 (in Chinese).
} 
the risk assessment result of the emissions report. ${ }^{1}$ In view of the significance of the verification report on the determination of the specific amount of allowances to be surrendered for compliance, the emitter with an objection to the verification result is also allowed to apply for a review by Shenzhen DRC, which should provide up a review decision within ten working days. ${ }^{2}$ In order to implement the spot check or review the verification result, Shenzhen DRC may entrust another specialised institution. ${ }^{3}$ Moreover, in the case of the objection to the review decision and inspection result, the emitters concerned in Shenzhen can apply for an administrative reconsideration or institute an administrative lawsuit before the court. ${ }^{4}$

Different from the Shenzhen pilot project, there seems to be the possibility that the third-party verifiers can be employed by the competent authorities or the emitters in other pilot projects; moreover, the pilot projects have made different choices exemplified below. Meanwhile, similar to the Shenzhen pilot, a review or spot check on the verification report may also be used by the government under special circumstances in other pilot projects, while the governmental review or spot check of the verification report is conducted based on different conditions among the pilot projects. Moreover, the procedures for and consequences of the review of the verification report also differ in other pilot projects. Furthermore, special measures have been applied by other pilot projects, like Beijing, aiming to ensure the effectiveness of the verification.

Concerning the employment of the verifier, the third-party verifier can be contracted by the emitters or the Shanghai $\mathrm{DRC}^{5}$, while some pilot projects, such as Tianjin, Hubei and Chongqing, have required the third-party verifiers to be engaged by the provincial DRC rather than the emitters themselves. ${ }^{6}$ In particular, Beijing DRC has drawn up a list distributing the task of verifying all the emitters covered by the Beijing pilot project among the third-party verifiers, which are selected and engaged by the government through the procedure of open selection and peer review. Despite the fact that this list enclosed in this notice is proposed by the government, it is emphasised that it will not be adjusted until the emitters submit such an application. In other words, the third-party verifiers are chosen, employed and paid by the government rather than the emitters themselves, at least in the initial stage of the pilot project in Beijing.

As far as the oversight of the verification report is concerned, the requirements and procedures differ in the pilot projects. For instance, the verification report will be reviewed

\footnotetext{
${ }^{1}$ Interim Measures on Carbon Emissions Trading Management in Shenzhen, Shenzhen Municipal Government, 19 March 2014 (in Chinese).

2 Ibid, at Article 33.

$3 \mathrm{Ibid}$, at Article 33 and 34. A similar provision also exists in the Chongqing pilot project, see Article 18, The Notice of distributing the Interim Management Measures of Chongqing Municipality on Carbon Emissions Trading, Chongqing Municipal Government, 26 April 2014 (in Chinese).

4 Article 33, 35, Interim Measures on Carbon Emissions Trading Management in Shenzhen, Shenzhen Municipal Government, 19 March 2014 (in Chinese).

5 See Article 13, Trial Management Measures for Carbon Emissions in Shanghai, Shanghai Municipal Government, 18 November 2013 (in Chinese).

${ }^{6}$ See Article 34, Interim Measures of Hubei Province on the Management and Trading of the Carbon Emission Right, Hubei Provincial Government, 4 April 2014; see also Article 16, The Notice of distributing the Interim Management Measures of Chongqing Municipality on Carbon Emissions Trading, Chongqing Municipal Government, 26 April 2014; see also the Notice carrying out the verification of the carbon emissions of the enterprises covered by the Tianjin carbon emissions trading pilot project in 2013, Tianjin DRC, 21 May 2014 (in Chinese).
} 
by the competent authority through a spot check in the Hubei pilot project. ${ }^{1}$ The emitters in the Chongqing pilot project can request a review based on the condition that the difference in the annual emissions amount between the emissions report and verification report is not less than $10 \%$ or 100,000 tonnes. $^{2}$ In addition to the conditions mentioned in the Shenzhen and Chongqing pilot projects, the municipal DRC in the Shanghai and Tianjin pilot projects should conduct the review under other circumstances, including when the annual emissions amount is higher or lower than that of the previous year by $20 \%$ and other necessary cases. ${ }^{3}$ When the review is finished, if the emitters covered by Hubei pilot disagree with the review result, they can request a double check with the relevant evidentiary material within five workdays after the receipt of the review result, and then the competent authority shall check the request and make a conclusion within 20 workdays. ${ }^{4}$ Similarly, the emitter making the objection to the annual carbon emissions amount determined by Guangdong DRC can still apply for a review within 15 workdays. ${ }^{5}$ It is however not clear whether the emitter concerned in these pilot projects can also have access to the court, as is the case in the Shenzhen pilot project, in order to challenge the government's decisions on its annual emissions amount or relevant inspection decisions.

In addition to the payment, the third-party verifiers in the Beijing pilot project will get different financial support from Beijing DRC in the form of monetary rewards, based on the review results of the verification reports, which will be classified into four categories including Excellent, Fine, Qualified and Failed. ${ }^{6}$ To be specific, if a verification report is reviewed as 'Excellent', the verifier can get a 120,000 CNY (about 15,000 EUR) reward; the verifier can get 100,000 CNY for each 'Fine' report and can get 80,000 CNY for the 'Qualified' report. Even if the verification report 'Failed', in the review for the first time, the verifier can still get 80,000 CNY if it is reviewed as Qualified the second time.

\subsubsection{Sanctions}

\section{Penalties for excess emissions}

For excess emissions in the Shenzhen pilot project, Shenzhen DRC can order the emitter to surrender the number of allowances required to cover the extra emissions within a specific time period or will deduct the allowances directly from the holding account, including, if necessary, from allowances for the subsequent year's holdings. ${ }^{7}$ In addition, a financial penalty in an

\footnotetext{
${ }^{1}$ Article 38, Interim Measures of Hubei Province on the Management and Trading of the Carbon Emission Right, Hubei Provincial Government, 4 April 2014 (in Chinese).

2 Article 18, The Notice of distributing the Interim Management Measures of Chongqing Municipality on Carbon Emissions Trading, Chongqing Municipal Government, 26 April 2014 (in Chinese).

3 Article 15, Trial Management Measures for Carbon Emissions in Shanghai, Shanghai Municipal Government, 18 November 2013; See also Article17, Notice of Distributing Interim Measures on Management of Carbon Emissions Trading, General Office of Tianjin Municipal Government, 20 December 2013 (in Chinese).

${ }^{4}$ Article 39, Interim Measures of Hubei Province on the Management and Trading of the Carbon Emission Right, Hubei Provincial Government, 4 April 2014 (in Chinese).

5 Article 20, Implementation Rules of Guangdong Province for the report and verification of enterprises' carbon emissions information (Trial), Guangdong DRC, 18 March 2014 (in Chinese).

${ }^{6}$ Notice of Guangdong Development and Reform Commission on carrying out the reporting and third-party verification of carbon dioxide emissions, Beijing DRC, 2 August 2013 (in Chinese).

7 Article 75, Interim Measures on Carbon Emissions Trading Management in Shenzhen, Shenzhen Municipal Government, 19 March 2014 (in Chinese).
} 
amount equal to three times the market average price of last six continuous months will be imposed on the emitter with excess emissions in the Shenzhen pilot project. ${ }^{1}$ Moreover, the sanction for the excess emissions also relies on other penalties. To be specific, the emitter concerned will be punished by 'naming and shaming', by means of putting the noncompliance into its credit record and disclosing it to the public through the government and the media; the emitter will also be punished by disqualification in applying for relevant governmental financial funds within five years; in particular for the State-Owned Enterprise (SOE), the noncompliance record will be reported to competent state-owned assets supervision and administration commission and will be included in the performance evaluation system for the SOE (including its leading cadres) at the same time. ${ }^{2}$

Similar sanctions for excess emissions have also been established by other pilot projects with different specific designs and intensity as shown below. Nevertheless, no fines have been established for excess emissions in the pilot projects of Tianjin and Chongqing, mainly due to the lack of legislation providing for the provisions concerning financial penalties in these two pilot projects. In particular, the punishment for an emitter with excess emissions in Tianjin is mainly relying on the disqualification from enjoying preferential and supporting policies provided by the government within three years. ${ }^{3}$ In this respect, a draft decision, released for public consultation on 23 April 2014 by the Legal Affair Office of Chongqing Municipal Government, attempts to impose financial penalties on noncompliance relating to the ETS. With regard to the excess emissions, emitters may be punished by three times of the average market price of the previous month before the compliance deadline. ${ }^{4}$

Different from the penalties established in Shenzhen, twice the allowance of the shortfall will be deducted from the allowances of next year's holding by provincial DRC in the pilot projects of Guangdong and Hubei. ${ }^{5}$ The fine for the excess emissions in Beijing ranges from three to five times the average market price ${ }^{6}$, similar to that in Shenzhen. However, the failure to surrender enough allowances to cover the actual emissions will result in a fine of $50,000 \mathrm{CNY}$ in Guangdong ${ }^{7}$ and the fines range from 50,000 to 100,000 CNY in Shanghai ${ }^{8}$. But for the emitters covered by Hubei pilot project, the fine will range from one to three times the market price for the excess emissions, with a maximum of $150,000 \mathrm{CNY} .{ }^{9}$

\footnotetext{
${ }^{1}$ Article 8, Provisions of Controlling Carbon Emissions for Special Economic Zone, Shenzhen People's Congress Standing Committee, 10 November 2012; See also Article 75, Interim Measures on Carbon Emissions Trading Management in Shenzhen, Shenzhen Municipal Government, 19 March 2014 (in Chinese).

2 See Article 65, Interim Measures on Carbon Emissions Trading Management in Shenzhen.

3 Article 32, Notice of Distributing Interim Measures on Management of Carbon Emissions Trading, General Office of Tianjin Municipal Government, 20 December 2013 (in Chinese).

${ }^{4}$ Decision on the management of the carbon emissions (draft for public consultation), Legal Affair Office of Chongqing Municipal Government, 23 April 2014 (in Chinese).

5 Article 37, Trial Measures on Carbon Emissions Management, Guangdong Provincial Government, 15 January 2013; see also Interim Measures of Hubei Province on the Management and Trading of the Carbon Emission Right, at Article 46 (in Chinese).

6 Decision on Implementation of Carbon Emissions Trading Pilot on Premise of Strict Total Control of Carbon Emissions, Beijing People's Congress Standing Committee, 27 December 2013 (in Chinese).

7 Article 37, Trial Measures on Carbon Emissions Management, Guangdong Provincial Government, 15 January 2013 (in Chinese)

${ }^{8}$ Article 39, Trial Management Measures for Carbon Emissions in Shanghai, Shanghai Municipal Government, 18 November 2013 (in Chinese).

9 Article 46, Interim Measures of Hubei Province on the Management and Trading of the Carbon Emission Right, Hubei Provincial Government, 4 April 2014 (in Chinese).
} 


\section{Penalties for the non-compliance relating to MRV}

With regard to the non-compliance that occurred in the MRV process, penalties on emitters or verifiers will be imposed by the government in Shenzhen. In the case of the lack of an emissions report due to the noncompliance of the emitter or the falsification of emissions data, Shenzhen DRC will determine its annual emissions strictly. ${ }^{1}$ Similar to the noncompliance by way of excess emissions, if the emitter fails in submitting the emissions report, Shenzhen DRC can also disclose its credit information to the public, cancel its relevant financial fund provided by the government and include it in the performance evaluation system for the SOEs. ${ }^{2}$ With regard to other noncompliance in the form of falsification of the carbon emissions data by the emitters or collusion between the emitter and verifier, and the issuance of a false verification report or misrepresentation by the verifier, a correction within a limited time period will be ordered and a fine for the difference between the actual emissions and the false data in an amount equal to three times of the average market price will be imposed by the Shenzhen DRC. ${ }^{3}$ Moreover, the verifier releasing the information or data of the emitter may also be subjected to a fine ranging from 50,000 to $100,000 \mathrm{CNY}$, together with the civil liability for the damage it caused to the emitter. In addition to the fine, the offending verification organisation will be struck off the verifier register, meaning that the verifier concerned can no longer carry out verification in Shenzhen pilot project. ${ }^{4}$

In other pilot projects, the non-compliance relating to the MRV is also subjected to various kinds of sanctions with different intensity. With regard to the emitter's non-compliance, administrative penalties, in particular the fine, have been frequently used. Moreover, negative treatment in allowances allocation has also been applied to punish the emitter refusing or hindering the verification in Hubei. Moreover, the sanctions, including administrative, civil and criminal liabilities for the noncompliance in terms of verification, have also been established or considered in other pilot projects, implying the local government's attempt to regulate the verifiers strictly. In particular, a ban on verification within specific time together with the fine has also been established in Guangdong pilot project.

Different from 'naming and shaming' and other types of penalties in Shenzhen, an emitter's failure to comply with emissions reporting rules in the pilot projects of Shanghai and Hubei may result in financial penalties ranging from 10,000 to $30,000 \mathrm{CNY}^{5}$. In particular, if the emitter covered by the Hubei pilot project does not provide the verifiers with relevant information and material as required, resulting in the impossibility of an effective verification, the competent authority shall warn and order the emitter concerned to accept

\footnotetext{
${ }^{1}$ Article 67, Interim Measures on Carbon Emissions Trading Management in Shenzhen, Shenzhen Municipal Government, 19 March 2014 (in Chinese).

2 Ibid, at Article 65.

3 Ibid, at Article 70-72.

4 Ibid, at Article 63 .

5 Article 37-38, Trial Management Measures for Carbon Emissions in Shanghai, Shanghai Municipal Government, 18 November 2013; See also Article 36, Trial Measures on Carbon Emissions Management, Guangdong Provincial Government, 15 January 2013 (in Chinese); Article 47, Interim Measures of Hubei Province on the Management and Trading of the Carbon Emission Right, Hubei Provincial Government, 4 April 2014 (in Chinese).
} 
the verification within a definite time. ${ }^{1}$ Otherwise, the allowances to be allocated to the emitter in next year will be reduced to only half of the previous year's allowance, if the emitter does not accept the verification in the due time. ${ }^{2}$

In view of the significance of verification in the ETS, violations by a third-party verifier, such as issuing a false verification report, a verification report with a gross error or unauthorised use, or the publication of commercial secrets or carbon emissions information of the emitters, may result in fines ranging from 30,000 to 50,000 CNY in Guangdong ${ }^{3}$ and Chongqing ${ }^{4}$, while they may range from 30,000 to $100,000 \mathrm{CNY}$ in Shanghai. ${ }^{5}$ Similar to the Shenzhen pilot project, the noncompliance mentioned above, as well as others such as providing a double service resulting in a conflict of interest, an error in the data of the verification report due to negligence, or a failure to surrender the verification report in due time without justified reasons, will also result in a ban on verification in Guangdong within three years. ${ }^{6}$ As for the third-party verifying organisation that cannot fulfil its obligation to provide the competent authority with a verification report in an independent, objective and fair way before the last workday in April each year in the Hubei pilot projects, a warning will be given by the competent authority. ${ }^{7}$ Moreover, if there is illegal income, such as from corruption, the illegal income will be confiscated and a fine of one to three times of the illegal income will be imposed, with a maximum of 150,000 CNY; if no illegal income occurs, the enterprise will be fined from 10,000 to $50,000 \mathrm{CNY}^{8}$ In addition to the administrative penalties, civil liabilities and criminal sanctions may also be imposed on the third-party verifier that issues a false verification report or uses or releases commercial secrets of the emitters whose emissions they verify in Tianjin ${ }^{9}$ and Chongqing ${ }^{10}$. For instance, the verifiers that cannot perform as required in Chongqing will not only face the punishment of 'naming and shaming' but also should compensate the emitters concerned if they are liable for the damage caused by the inadequate verification report. ${ }^{11}$

\section{Enforcement measures in practice}

In Shenzhen pilot project, when the deadline of the first compliance cycle in 2013 was approaching, Shenzhen DRC made some effort to facilitate and ensure the compliance of the

\footnotetext{
${ }^{1}$ Article 48, Interim Measures of Hubei Province on the Management and Trading of the Carbon Emission Right, Hubei Provincial Government, 4 April 2014 (in Chinese).

${ }_{2}$ Ibid.

3 Article 39, Trial Measures on Carbon Emissions Management, Guangdong Provincial Government, 15 January 2013 (in Chinese; author's translation).

${ }^{4}$ Decision on the management of the carbon emissions (draft for public consultation), Legal Affair Office of Chongqing Municipal Government, 23 April 2014 (in Chinese).

5 Article 41, Trial Management Measures for Carbon Emissions in Shanghai, Shanghai Municipal Government, 18 November 2013 (in Chinese).

${ }^{6}$ Article 22, Implementation Rules of Guangdong Province for the report and verification of enterprises' carbon emissions information (Trial), Guangdong DRC, 18 March 2014 (in Chinese).

${ }^{7}$ Article 50, Interim Measures of Hubei Province on the Management and Trading of the Carbon Emission Right, Hubei Provincial Government, 4 April 2014 (in Chinese).

${ }^{8}$ Ibid.

9 Article 34, Notice of Distributing Interim Measures on Management of Carbon Emissions Trading, General Office of Tianjin Municipal Government, 20 December 2013 (in Chinese).

${ }^{10}$ Article 37, The Notice of distributing the Interim Management Measures of Chongqing Municipality on Carbon Emissions Trading, Chongqing Municipal Government, 26 April 2014 (in Chinese).

${ }^{11}$ Ibid.
} 
emitters. As mentioned in section 3.3.2 of this chapter, the additional auctioning of a specific amount of allowances has been held in Shenzhen, with an attempt to facilitate the emitter to purchase enough allowances to cover its emissions. In addition, Shenzhen DRC has issued a specific notice emphasising the possible penalties to be imposed on the violators in line with the local legislation and have established a specific team for the enforcement. Moreover, Shenzhen DRC has required the Chinese Emissions Exchange (Shenzhen) to publish and update the list of the emitter having complied with the scheme on its website, and it has tried to remind and urge the emitter to surrender the allowance in due time through the media, emails and phones. Finally, 613 emitters in the Shenzhen pilot project have surrendered sufficient allowances to cover their emissions while four emitters failed (two respective lists of emitters have been published by Shenzhen DRC on 3 July 2014). ${ }^{1}$

In the implementation of other pilot projects, different enforcement measures have been employed to ensure the high level of compliance, some of which can be shown as below. In particular, detailed standards determining the administration discretion has been established in the implementation of the administrative penalties in the Beijing pilot project. For five pilot projects, except for the pilot projects of Hubei and Chongqing that started in 2014, compliance results are known. All the emitters covered by the Shanghai pilot project, 191 emitters, have complied with the scheme before the deadline. ${ }^{2}$ However, noncompliance still exists in other pilot projects including in Shenzhen mentioned above. According to the Guangdong DRC, 182 emitters succeeded in complying with the scheme while only two emitters failed. ${ }^{3} 413$ emitters covered by the Beijing pilot project complied with the scheme but 12 emitters still failed. ${ }^{4}$ The noncompliance is supposed to be punished in line with the sanctions provisions described above. Given the limited information provided by the pilot projects, however, it remains unclear whether all the noncompliance has been punished strictly in practice or not.

Similar to the Shenzhen pilot project, additional auctioning at different prices has also been held in the pilot projects of Guangdong and Shanghai; the Beijing DRC also issued a notice on 19 June 2014, three days after the deadline for compliance, publishing a list comprising with 257 emitters that had not surrendered the allowances by then and ordering them to comply with the scheme within ten workdays to avoid sanctions. ${ }^{5}$ The Tianjin pilot project has postponed twice the deadline for surrendering the allowances to cover the emissions ${ }^{6}$,

\footnotetext{
1 The information is available at the website of Shenzhen DRC, available at: http://www.szpb.gov.cn/, la st accessed 28 September 2014 (in Chinese).

${ }_{2}^{2}$ Relevant information is available at the website of Shanghai DRC, http://www.shdrc.gov.cn/main?main colid=357\& top_id=316\&main_artid=24609.

${ }^{3}$ Meanwhile, 18 emitters were relieved from the obligation to surrender the allowances, since it turned out that they did not meet the threshold for complying. Information is available at the website of Guangdong DRC, http://www.gddpc.gov.cn/xxgk/gzdt1/gzdt/201407/t20140715_250335.htm, last accessed 28 September 2014 (in Chinese).

${ }^{4}$ Relevant information is available at the website of Beijing DRC, 25 September 2014, available at: htt p://www.bjpc.gov.cn/gzdt/201409/t8284787.htm, last accessed 28 September 2014 (in Chinese).

5 Relevant information is available at the website of Beijing DRC, http://www.bjpc.gov.cn/tztg/201406/t7 863548.htm, last accessed 28 September 2014 (in Chinese).

6 According to the notice issued by Tianjin DRC on 21 May 2014, since all the verifications for 2013, contracted by the government, were supposed to be finished before 20 June 2014, the deadline for compliance was postponed to 10 July 2014 by Tianjin DRC, 40 days later than determined in the Interim Measures before. Furthermore, the deadline was postponed to 25 July 2015 again, by a notice issued by Tianjin Climate Exchange on 8 July 2014. The detailed information concerning these notices can be referred to the websites of Tianjin DRC and of Tianjin Climate Exchange, available at: http://www.tjdpc.gov.cn/zwgk/zcfg/wnwj/ny/201406/t20140605
} 
partly due to the emitter's reluctance to surrender sufficient allowances, to which the lenient punishment for excessive emissions mentioned above seems to have contributed to a large extent.

On 6 May 2014, Beijing DRC adopted a decision on the regulation of the discretion in implementing the administrative penalties in the $\mathrm{CO}_{2}$ ETS, together with a set of trial executive standards in the form of a detailed table. ${ }^{1}$ On the basis of the fact, plot and relevant factors of the illegal act, the noncompliance is categorised into one of four groups subjected to impunity, lighter punishment, normal punishment and heavier punishment. Moreover, the specific legal basis for the types and ranges of the penalties for major noncompliance emerging from the Beijing pilot project have been stipulated to be the executive standard mentioned above. For instance, with regard to the financial penalties for excess emissions, the lighter punishment will be three times the average market price, while the normal punishment will be four times and the heavier punishment will be five times. ${ }^{2}$ Due to the specific and detailed requirement for the implementation of the administrative penalties, this decision together with the executive standard is supposed to control and regulate the exertion of administrative discretion in line with the law, aiming to ensure its legality and reasonability. ${ }^{3}$

In summary, similar enforcement packages, including the choice of self-monitoring, self-reporting and third-party verification as well as basic penalties for excess emissions and major noncompliance in MRV, have been established for the pilot projects. However, the differences in terms of the specific design concerning the MRV systems and sanctions are also evident. The main differences can be found in the application of a monitoring plan, the employment of the verifier, the regulation of the verification process, and the different types of penalties with various intensities for the non-compliance among the pilot projects. In particular, quite some detailed difference regarding the basic penalties can be demonstrated by the summary table below.

51471.shtml; http://chinatcx.cn/tcxweb/pages/news/news_info.jsp?article_id=2583, last accessed 28 September 2014 (in Chinese).

${ }^{1}$ Decision on the regulation of the discretion in implementing the administrative penalties in the carbon emissions trading, Beijing DRC, 6 May 2014 (in Chinese).

${ }^{2}$ Ibid.

${ }^{3}$ Ibid, at Article 1, 4. 
Table 8 Basic penalties for major noncompliance among the pilot projects

\begin{tabular}{|c|c|c|c|c|c|}
\hline \multirow{2}{*}{$\begin{array}{l}\text { noncompl } \\
\text {-jance } \\
\text { sanctions }\end{array}$} & \multirow[b]{2}{*}{ Excess emissions } & \multicolumn{4}{|c|}{ Noncompliance in monitoring and reporting } \\
\hline & & $\begin{array}{l}\text { Failure to submit } \\
\text { emissions report } \\
\text { /verification } \\
\text { report }\end{array}$ & $\begin{array}{l}\text { falsificatio } \\
\mathrm{n} \text { of } \\
\text { emissions } \\
\text { data }\end{array}$ & $\begin{array}{l}\text { Issuance of } \\
\text { false } \\
\text { verification } \\
\text { report }\end{array}$ & $\begin{array}{l}\text { unauthorised } \\
\text { use/publication } \\
\text { of commercial } \\
\text { secrets/emission } \\
\text { s information }\end{array}$ \\
\hline \multirow[t]{2}{*}{ Shenzhen } & $\begin{array}{l}\text { deducting allowances in short } \\
\text { directly from the holding } \\
\text { account; a fine equal to three } \\
\text { times the market average price } \\
\text { of last six continuous months }\end{array}$ & & \multicolumn{2}{|c|}{$\begin{array}{l}\text { a fine for the difference } \\
\text { between actual emissions } \\
\text { and false data, equal to } \\
\text { three times the average } \\
\text { market price }\end{array}$} & $\begin{array}{l}\text { A fine from } \\
50,000 \text { to } \\
100,000 \mathrm{CNY}\end{array}$ \\
\hline & \multicolumn{2}{|c|}{$\begin{array}{l}\text { naming and shaming; cancelling the governmental } \\
\text { financial fund within five years; including the } \\
\text { noncompliance in the performance evaluation system } \\
\text { for the SOEs }\end{array}$} & \multicolumn{3}{|c|}{$\begin{array}{l}\text { a ban on verification for verification } \\
\text { organisation in Shenzhen }\end{array}$} \\
\hline Beijing & $\begin{array}{l}\text { ordered to surrender the } \\
\text { allowances; a fine ranging from } \\
\text { three to five times the average } \\
\text { market price }\end{array}$ & $\begin{array}{l}\text { A fine below } \\
50,000 \mathrm{CNY}\end{array}$ & & & \\
\hline \multirow[t]{2}{*}{ Shanghai } & $\begin{array}{l}\text { A fine ranging from } 50,000 \text { to } \\
100,000 \mathrm{CNY} \text {; }\end{array}$ & $\begin{array}{l}\text { A fine ranging } \\
\text { from } 10,000 \text { to } \\
30,000 \mathrm{CNY}\end{array}$ & & \multirow{2}{*}{\multicolumn{2}{|c|}{$\begin{array}{l}\text { A fine ranging from } 30,000 \text { to } \\
100,000 \mathrm{CNY}\end{array}$}} \\
\hline & \multicolumn{3}{|c|}{$\begin{array}{l}\text { Naming and shaming; disqualification of receiving municipal } \\
\text { financial support and rating for energy saving and emissions } \\
\text { reduction; notification to corresponding department in charge of the } \\
\text { approval of new fixed assets investment }\end{array}$} & & \\
\hline Tianjin & $\begin{array}{l}\text { ordered to make the correction } \\
\text { within a limited period; } \\
\text { disqualified from enjoying } \\
\text { governmental preferential and } \\
\text { supporting policies for three } \\
\text { years }\end{array}$ & & & \multicolumn{2}{|c|}{$\begin{array}{l}\text { subjected to administrative, civil } \\
\text { and criminal liabilities }\end{array}$} \\
\hline $\begin{array}{l}\text { Guangdo } \\
\text { ng }^{1}\end{array}$ & $\begin{array}{l}\text { twice the allowance of the } \\
\text { shortfall will be deducted from } \\
\text { the allowances of next year's } \\
\text { holding; a fine of } 50,000 \mathrm{CNY}\end{array}$ & \multicolumn{2}{|c|}{$\begin{array}{l}\text { a fine ranging from } 10,000 \text { to } \\
30,000 \mathrm{CNY}\end{array}$} & \multicolumn{2}{|c|}{$\begin{array}{l}\text { a fine from } 30,000 \text { to } 50,000 \\
\text { CNY; a ban on verification in } \\
\text { Guangdong within three years }\end{array}$} \\
\hline Hubei $^{2}$ & $\begin{array}{l}\text { twice the allowance of the } \\
\text { shortfall will be deducted from } \\
\text { the allowances of next year's } \\
\text { holding; a fine ranging from } \\
\text { one to three times of the market } \\
\text { price (maximum: } 150,000 \\
\text { CNY); naming and shaming; } \\
\text { included in the performance } \\
\text { evaluation system for SOEs }\end{array}$ & $\begin{array}{l}\text { a fine from } 10,000 \\
\text { to } 30,000 \mathrm{CNY} \text {; } \\
\text { in case of the } \\
\text { refusal of } \\
\text { verification, the } \\
\text { allowance for next } \\
\text { year will be } \\
\text { reduced to only } \\
\text { half of the } \\
\text { allowance in the } \\
\text { previous year }\end{array}$ & & & \\
\hline \multirow[t]{2}{*}{$\begin{array}{l}\text { Chongqin } \\
\mathrm{g}^{3}\end{array}$} & \multicolumn{2}{|c|}{$\begin{array}{l}\text { naming and shaming; disqualification in applying for } \\
\text { the relevant governmental financial fund and } \\
\text { appraising within } 3 \text { years; including the } \\
\text { noncompliance in the performance evaluation system } \\
\text { for the SOEs }\end{array}$} & & & \\
\hline & $\begin{array}{l}\text { May be punished by three times } \\
\text { the average market price of the } \\
\text { previous month before the } \\
\text { compliance deadline }\end{array}$ & $\begin{array}{l}\text { may be fined } \\
\text { ranging from } \\
20,000 \text { to } 50,000 \\
\text { CNY }\end{array}$ & & $\begin{array}{l}\text { May be fined } \\
\text { ranging from } \\
30,0000 \text { to } \\
50,000 \mathrm{CNY}\end{array}$ & \\
\hline
\end{tabular}

1 For a double service provided with conflict of interest by verifier, there will be a fine ranging from 30,000 to $50,000 \mathrm{CNY}$, a ban of verification in Guangdong within three years.

2 For bad performance in verification: a fine from 10,000 to 50,000 CNY; or a fine of one to three times of the illegal income (maximum: 150,000 CNY) and the illegal income will be confiscated.

3 For bad performance in verification: naming and shaming. 


\section{Analysis of the key elements of China's ETS}

\subsection{Target setting}

\subsubsection{Legal effect of the carbon emissions reduction targets}

As indicated above, the binding carbon intensity reduction target at the national level set up in the $12^{\text {th }}$ Five-Year Planning (2011-2015) has paved the way for the new era of GHG emissions reduction and the establishment of an ETS in China. However, the legal effect of the carbon emissions reduction target, inter alia the so-called binding carbon intensity reduction target and the 'cap' set up for the pilot projects, needs to be examined from a legal perspective. To be specific, the legal effect of the emissions reduction target mainly depends on the legal source in which it is stipulated and the legal liability for non-compliance.

\section{The national carbon intensity reduction target}

At the national level, China's carbon intensity reduction target is established by the $12^{\text {th }}$ Five-Year Planning (2011-2015), thus the legal effect of the target is firstly determined by the legal status of the $12^{\text {th }}$ Five-Year Planning (2011-2015). However, there is already a debate over the legal status of the Five-Year Planning. ${ }^{1}$ Since it is approved by the NPC, the top legislator in China, the $12^{\text {th }}$ Five-Year Planning (2011-2015) can be seen as a kind of legal document, as it is stated therein that it has 'legal force", giving the impression that it is legislation. However, strictly speaking, the $12^{\text {th }}$ Five-Year Planning is not the same as formal legislation with full legal force, such as the law and administrative regulation. Instead, the $12^{\text {th }}$ Five-Year Planning functions as a national policy binding the government to a large extent. ${ }^{3}$ The exploration in this section will focus on the specific characteristic of the $12^{\text {th }}$ Five-Year Planning (2011-2015) in terms of its contents and enforcement measures.

Firstly, the content of the $12^{\text {th }}$ Five-Year Planning (2011-2015) appears to be policy direction rather than a concrete legal right and obligation. Exactly as the stated in the beginning of the $12^{\text {th }}$ Five-Year Planning (2011-2015), it is formulated 'with the main aim to state the strategic intention of the nation, specify the working emphasis of the government, and lead the acts of the market players', which is 'a grand blueprint for the economic and social development of China ... and an important basis for government to perform the duties of economy regulation, market supervision, social administration, and public service'. ${ }^{4}$ With respect to the carbon intensity reduction target, it is determined as one of the main objectives guiding the government and market players to make notable achievements in resource conservation and environmental protection in China. Nevertheless, the individual right and obligation is not specified under the carbon intensity reduction target in the planning. On the contrary, the targets and burden sharing

${ }^{1}$ See Hao, T.C. (2007); Li, Z. P. (2007a); Xue, K. P. (2007); Cao, W. (2011).

2 Part 16, $12^{\text {th }}$ Five-Year Planning (2011-2015).

3 Similar points can be seen in Li, Z. P. (2007a); Xue, K. P. (2007); Cao, W. (2011), p.14-15.

${ }^{4}$ See the $12^{\text {th }}$ Five-Year Planning (2011-2015). 
among local governments and individual enterprises have been distributed through a top-down approach mainly by other normative documents adopted by government rather than specific legislation.

Secondly, the implementation and enforcement of the $12^{\text {th }}$ Five-Year Planning (2011-2015) critically depends on the governmental actions and, political and administrative systems rather than the legal liability system. Taking the binding targets, including the carbon intensity reduction target, as an example, they are still just the 'the government's commitment to the people'. ${ }^{1}$ As a result, it is the governments that are bound by the binding targets set up in the $12^{\text {th }}$ Five-Year Planning (2011-2015) directly. In other words, the binding effect of the planning is limited to the government per se rather than individuals. In this sense, the governments should implement the plan and achieve the targets by governmental actions. ${ }^{2}$ However, the $12^{\text {th }}$ Five-Year Planning still lacks the legal mechanisms for the implementation and enforcement of these binding targets.

Despite its declaration of 'legal force', the $12^{\text {th }}$ Five-Year Planning (2011-2015) is not a real legislation; however, it is very powerful given the specific political and administrative systems in China. ${ }^{3}$ For instance, the results of the performance evaluation concerning the binding targets, established in the $12^{\text {th }}$ Five-Year Planning (2011-2015), will be deemed as an important basis for the election, promotion, punishment of, and awards for the leading cadres. ${ }^{4}$ In this respect, it can be exemplified by the target-based accountability system mentioned in section 2.1 of this chapter. In other words, the local governments, in particular the leading cadres, are accountable for the fulfilment of the carbon intensity reduction target, and failure to achieve the carbon intensity reduction targets allocated by the higher level of authorities will be punished in the administrative accountability system. Nevertheless, there seems to be no accountability mechanism for holding the central government accountable. Furthermore, neither specific legal liabilities for non-compliance nor corresponding judicial remedies have been established in the implementation of the $12^{\text {th }}$ Five-Year Planning (2011-2015). Despite Article 82 of the Law on Public Servants, which stipulates that a leading cadre shall admit his mistake and resign from the leading post in certain serious cases, ${ }^{5}$ the administrative accountability system in China is still very young and relies on relevant policies of the ruling party and governmental documents.

\section{The local carbon emissions reduction targets}

At the local level, the legal effect concerning the provincial carbon intensity reduction target and converted 'emissions cap' faces similar challenges as those that emerged at the national level. As indicated above, the national carbon intensity reduction target was distributed to 31 provinces and municipalities by the governmental document, the Work Plan issued by the State Council. From the perspective of the legal hierarchy system, strictly speaking, the Work Plan, as the 'other normative document' adopted by the State Council, falls outside the range of the formal

\footnotetext{
${ }^{1}$ Section 1, Chapter 61 of the $12^{\text {th }}$ Five-Year Planning (2011-2015).

2 Chapter 61, the $12^{\text {th }}$ Five-Year Planning (2011-2015).

3 See Li, Z. P. (2007a), p.30-33; Xue, K. P. (2007).

4 Section 3, Chapter 61 of the $12^{\text {th }}$ Five-Year Planning (2011-2015).

5 Article 82, Public Servants Law of China.
} 
legal sources of the Chinese legal system. ${ }^{1}$ According to the allocation result of the Work Plan, the provincial carbon intensity reduction targets have been adopted in the provincial governmental documents, relevant rules or policies. However, none of the provincial targets had been set up in the formal local regulations or rules of local governments until the time of writing.

The same is true for the establishment of the 'cap' for the pilot projects, which refers to the total amount of allowances to be allocated. The description in section 3.2 of this chapter revealed that the caps for the pilot projects have mainly been determined by the provincial DRC in the governmental documents. For instance, the caps for the pilot projects of Guangdong, Hubei and Chongqing have been set up in the allowances allocation plans formulated by their provincial DRC respectively. In view of the legal ranks of these allocation plans, the legal effect of the cap is also very weak. If the governments want to allocate more/less allowances in special circumstances by changing the cap, there seems to be no legal rules precluding them from doing so, which may be exemplified by the ex post adjustment applied to the allowances allocation later.

Therefore, the legal effect of the emissions reduction targets, including the national and provincial carbon intensity reduction targets, as well as the caps set up for the pilot projects, appears to be relatively weak and deficient from a legal perspective, due to the legal status of the $12^{\text {th }}$ Five-Year Planning (2011-2015) and relevant governmental documents. However, the de facto binding effect of these targets, in particular the carbon intensity reduction target, can still be identified and reflected in its distribution and implementation system with a strong interaction between the central government and local governments.

\subsubsection{Competence distribution for cap setting}

Despite the deficient legal effect of the carbon emissions reduction targets set up in China, the competence distribution for cap setting in the ETS remains a significant element that cannot be overlooked from the legal perspective. In China, the relationship between central and local governments is a traditional and tough topic, which has been hotly debated in the abundant literature from the perspective of constitutional law and administration law. ${ }^{2}$ In the arena of climate change policy and law, the complicated central-local nexus has also been revealed in the elaboration of target setting and distribution approach, where the binding carbon emissions reduction target has been set up by the central government and then allocated to the local governments by a top-down approach with a strong centralised characteristic on the one hand, whereas the local target is implemented by various tools including the establishment of the ETS through the experimentation approach with an obvious decentralised trend on the other hand.

Given the particular system of target setting and allocating in China, the analysis of the centralisation and decentralisation model for competence distribution in this section, aiming to explore the interaction between central and local governments, will not only shed light on the broader legal context in which the target setting is distributed between central and local

\footnotetext{
${ }^{1}$ See the introduction in section 2 of this chapter, see also the Legislation Law of China.

2 Further discussion can refer to abundant literature including but not limited to: Zhang, Q. F. (2011), Xu, Q.F. (2012).
} 
governments, but it will also focus on the specific arrangement for the pilot projects. This section is not going to give an answer as to the perfect model of competence distribution in cap setting for the pilot projects in China. On the contrary, the analysis conducted here mainly intents to provide a deeper understanding of the complicated central-local nexus in China's ETS, which should be taken into consideration when distributing the competence of target setting.

\section{The coexistence of centralisation and decentralisation}

In the streamlining of controlling and reducing GHG emissions, the target setting and allocation process, in which the central government usually plays a role in policy formulation while the local government is responsible for implementing policy at the local level, has revealed the particular coexistence of centralisation and decentralisation in the competence distribution.

On the one hand, the description of target setting and allocation in section 3.2 of this chapter has witnessed the centralisation model applied in the pilot projects to a large extent, distributing the carbon intensity reduction targets from the central level to lower levels usually by governmental documents or administrative orders. Instead of the equal-numbers allocation methodology applied in the $11^{\text {th }}$ Five-Year Planning (2006-2010), the allocation of carbon intensity reduction target in the $12^{\text {th }}$ Five-Year Planning (2011-2015) has adopted a more tailored approach, aiming to reflect the inter-province disparity and to provide more flexible and diverse incentive policies at the local level. ${ }^{1}$ Due to the traditional top-down approach relying on strong administrative tools, however, inadequate interaction between the central and local governments within the legal system still exists. In order to maximise the local interest, the local government may try to lobby for a laxer target and negotiate with the higher levels of governments. But once the targets are allocated by the higher levels of governments, the lower levels of governments bound by these targets have to accept and achieve them; otherwise they will be subjected to the administrative responsibility.

On the other hand, attention should also be paid to the decentralised feature embodied in the allocation and implementation of the carbon intensity reduction targets, in view of the local disparities between the developed and developing provinces. After the allocation of carbon intensity reduction targets to the provincial level, the central government's focus is shifted to supervising target achievement by ensuring the overall national target is accomplished by all the local governments, thus less attention is paid to the policy implementation at various localities and how the allocated target has been achieved. Moreover, the discussion on the experimental approach at the local level within the multi-level structure in section 2.4 of this chapter suggested its significance in leading to the formation and reform of policy and law with a wider geographical coverage, even at the national level. ${ }^{2}$

\footnotetext{
1 Teng, F. (2012), p.11-12.

2 The experimental approach is not new to the Chinese political system, based on which a variety of successful cases and failures are worth attention. For instance, the establishment of a special economic zone, such as Shenzhen, which is deemed to be the first step in China's reform and opening-up policy, has played a key role of driving force in reforming Chinese legal system. With respect to the failing experiments in the past, few of them went through public scrutiny and ex post evaluation but were just phased out silently. See Chung, J. H. (2000), p.58; Heilmann, S. (2011), p.85.
} 
At present, the establishment of $\mathrm{CO}_{2}$ ETS pilot projects in seven provinces/municipalities has followed the same approach. In line with the bottom-up approach, the description above has indicated that all the caps for the pilot projects have been set up by the local governments, in particular the provincial DRC. On the basis of the decentralised competence distribution between the central and local governments, more flexibility can be given to the local governments in determining the caps for the pilot projects, in pursuit of a suitable design and implementation of the ETS adapted to the local circumstances. The decentralisation in competence distribution can be exemplified by the various types and specific procedures for cap setting among the pilot projects, such as the 'intensity-based' cap set up in Shenzhen and the seemingly absolute cap established in Hubei. Nevertheless, most of the emissions reduction targets, in particular the caps for pilot projects, have been determined in line with the carbon intensity reduction targets allocated by the central governments and the higher level of governments.

\section{The potential tension and consideration in the central-local nexus}

As indicated by practice, the national carbon intensity target has been distributed by a top-down approach on the one hand, and the cap for the emissions trading pilot projects are being established through a bottom-up approach by local governments on the other hand. The potential tension between the central and local authorities emerging from this central-local nexus needs to be considered and addressed in line with the Chinese legal system.

In line with the legislative competence distribution in China, provincial authorities, in the course of designing and establishing the emissions trading pilots, indeed can adopt their own emissions reduction targets as well as other related regulatory rules for emissions trading in its local regulations, given no relevant national laws or administrative regulations had been promulgated yet. ${ }^{1}$ However, special attention should be paid to the tendency that local governments, under the existing performance evaluation system, may focus on local economic development, inter alia the GDP growth, and try to increase local financial revenue on the one hand, while the central government may focus on the overall environmental target and market integrity in pursuit of the maximum social welfare on the other hand. ${ }^{2}$ As a result, potential tension in the target setting may emerge, in which the central government attempts to set up a stringent emissions reduction target and allocates it to the provinces, while the local governments may prefer a generous target to be implemented within its competence. Therefore in the context of the coexistence of centralisation and decentralisation, two important issues should be taken into consideration in the course of distributing competence of target setting between central government and local governments in China.

Firstly, despite the fact that the caps for the pilot projects are set up under the influence of the carbon intensity reduction target, the centralisation approach for the determination and distribution of the carbon intensity reduction targets is not free from challenge. The local carbon intensity reduction target, with which the local governments must comply, has been distributed by governmental documents or administrative orders. The existing mechanisms applied by the

\footnotetext{
${ }^{1}$ See Article 3 of the Constitution and Article 64 of Legislation Law; see also the discussion in section 2 of this chapter.

${ }^{2}$ Liu, X. Y. (2011), p.28.
} 
central government in the implementation are still mainly relying on the strong political regime, such as the target-based accountability system. The interaction between the central government and local governments is still limited to the political or administrative structure rather than the specific legal framework. In this respect, how to define the specific boundary between the local and central governments in terms of the cap setting within a legal framework remains a huge challenge facing the ETS in China.

Secondly, in view of the decentralised implementation approach, one may raise the question of how the central government guides the local initiatives such as the ETS pilots and controls the target setting conducted by local governments, in order to ensure the fulfilment of the national carbon intensity reduction targets and consistency of the local emissions reduction targets. Despite the fact that all the provinces are bound by their own carbon intensity reduction targets allocated by the central government via the top-down approach, there is still considerable local discretion in cap setting, which can be exemplified by the practice that the caps for the pilot projects have been set up by the local governments without the approval of the central government. Despite that some key issues have been determined by the NDRC through the issuance of the Notice on Initiating Pilot Programmes of Emissions Trading, hierarchical guidance from the central government still appears to be rather weak, lacking the mechanism enabling a more consistent and convergent approach for the development of local experiments. ${ }^{1}$ It cannot be denied that the decentralised approach can provide the necessary flexibility for provincial governments in choosing and designing the suitable instrument at the local levels in order to reduce GHG emissions. However, as discussed above, if the existing performance evaluation system making the GDP the most important index is not changed fundamentally, the provincial government may still pay more attention to economic growth than to environmental protection, in particular the GHG emissions reduction. In particular, when the economic competition and carbon leakage issues are taken into consideration, one may raise the questions whether and to what extent the provinces want to set up the stringent caps for the pilot projects. Meanwhile, the problem of the race-to-bottom may take place again, which will be a challenge for the central government to ensure consistency of the provincial targets in order to ensure a level playing field for the national market.

\subsubsection{Dynamic and relative features stemming from the cap setting}

Stemming from the relative intensity-based targets such as the carbon intensity reduction targets and the dynamic caps for several pilot projects, the dynamic nature of the cap setting in pursuit of the green growth by balancing the economic development and emissions reduction has been demonstrated in the pilot projects.

\section{Intensity target}

Chinese carbon emissions reduction targets have been set up in the form of intensity targets. With regard to the concept of intensity target per se, it is so controversial that it has been

${ }^{1}$ See Zhang, H. (2013), p.264. 
criticised for its uncertainty on the one hand and it is supported for its flexibility on the other hand. $^{1}$

Instead of the determination of an absolute amount of emissions to be produced or reduced, the intensity target can allow the amount of emissions to increase in order to accommodate economic development. In other words, the amount of emissions to be produced is not certain when it is determined, since it depends on the economic growth rate. Moreover, a variety of concerns about uncertainty stemming from the calculation method of the carbon intensity reduction target may be raised in the course of implementing the carbon intensity reduction target. In view of the uncertainty of the economic growth rate, the overall emissions cap, converted from the carbon intensity reduction target, might need to be adjusted in line with the actual GDP, in order to ensure the achievement of the fixed carbon intensity reduction targets.

However, the adjustment of the overall emissions cap may have a significant impact on the ETS sectors and non-ETS sectors. Especially for the pilot projects established based on cap-and-trade model, the possibility of the 'over-allocation' or inadequate allocation of allowances because of unexpected economic growth should be considered carefully. In this respect, two possible options may be available: maintain or adjust the cap for ETS sectors. If the first option is chosen, some problems may emerge under different economic circumstances. When there is higher economic growth, more emissions should have been allowed to be produced than were determined for the pilot projects, while less allowances are available to accommodate this due to the constant cap, resulting in an 'extra' burden for the ETS sectors to reduce more emissions than needed. Particularly in the case of the lower economic growth than expected, more emissions will need to be reduced than were determined for the pilot projects. Given the fixed cap for the ETS sector, the additional emissions reduction burden has to be shifted to the non-ETS sectors, which might cause new controversy over the burden sharing between the ETS sector and non-ETS sectors. If the second option is adopted, then the legal design and implementation of the ex post adjustment needs to be considered and dealt with carefully.

\section{Dynamic cap}

The description in section 3.3 of this chapter has revealed that the second option mentioned above has been chosen by some pilot projects. To be specific, the so-called caps set up for the pilot projects have been determined in line with the carbon intensity reduction targets and may be adjusted ex post, usually after the emissions verification but before the compliance deadline, in accordance with the actual emissions and economic output.

According to the preliminary regulatory framework established for the pilot projects, the caps for the pilot projects are mainly determined on the basis of the projection of the economic growth, the development plan, the abatement costs, and other factors, thus in pursuit of the fulfilment of the carbon intensity reduction targets allocated by the higher level of governments. In view of the difficulty in the precise prediction of the economic growth, it is impossible to ensure that the caps determined by the governments in advance will be the same as the final amount of

\footnotetext{
${ }^{1}$ Further information may refer to Dudek D. \& Golub A. (2003); Ellerman D \& Wing, I. S. (2003).
} 
emissions to be allowed in line with the carbon intensity reduction target. In this respect, despite the fact that all the pilot projects have been designed based on the theoretical cap-and-trade model, particular attention has been paid to the special characteristics and consequences in terms of the relationship between economic development and cap adjustment with respect to the design and implementation of the ETS in practice.

Based on the description in section 3 of this chapter, some pilot projects, such as Shenzhen, Beijing, Shanghai, and Hubei, have employed the ex post adjustment of the allowances allocation $^{1}$, in order to accommodate the economic development and to achieve the green growth in line with the carbon intensity reduction target. However, regarding the questions of whether the caps will be adjusted finally or not due to the ex post adjustment of the allowance allocation, the pilot projects seem to provide different answers. In this respect, the cap for the Hubei pilot is not allowed to be changed, while the cap for Shenzhen pilot is a regulable cap that can be adjusted in line with the carbon intensity reduction target, which has been demonstrated by the deduction of about three million of allowances from the cap for 2013.

In this light, cap setting in Chinese emissions trading has clearly dynamic features, exemplified by the design of the Shenzhen pilot. It is argued that, the regulable cap based on the fixed intensity in Shenzhen pilot projects, dynamically dealing with the relationship among the GHG emissions reduction, economic development and structural adjustment, should be considered to be a promising option for the establishment of the Chinese ETS in the initial stage. ${ }^{2}$ The so-called pre-allocation and the ex post adjustment of allowances allocation, a special design of the Chinese pilot projects, has indicated to the local government's innovative attempts to design its own unique scheme accommodating the Chinese circumstance, in particular the rapid and uncertain economic growth. ${ }^{3}$

Nevertheless, it may be a great challenge for an ETS with an intensity-based cap to deliver a clear signal to the market participants, given the final cap will be adjusted according to the actual output and the fixed intensity. ${ }^{4}$ There are two situations that can arise in the ex post adjustment, increasing or decreasing the cap. Since the rights and obligations of the enterprises concerned will be influenced substantially due to the governmental ex post adjustment of the allowances and then the cap, it will be very crucial to design and implement these special instruments within the legal framework, providing clear legal rules and thus allowing for expectations and certainty for the market players.

If there are specific rules relating to the ex post adjustment, it is crucial to ensure that these rules are adopted with sufficient legal force and can be enforced effectively within the legal system, in order to provide the necessary legal certainty for market players. Especially in the context that the preliminary regulatory framework for the pilot projects are mainly being established based on the relevant rules of local governments with other normative documents and policies that are

\footnotetext{
${ }^{1}$ The details concerning the ex post adjustment to allowances allocation will be discussed in the following section 4.2 of this chapter.

${ }^{2}$ Shenzhen Carbon Trading Task Group (2013), p.11-12.

${ }^{3}$ Further discussion on ex post adjustment in allowances allocation will be presented in section 4.2 of this chapter.

${ }^{4}$ Jiang, J.J., et al. (2014), p.4.
} 
adopted by the local governments themselves, one may raise the question whether the local governments themselves are bound by and enforced to comply with the local regimes or not. Otherwise, the rights of the market participants might be endangered by the arbitrary or illegal governmental actions in terms of the cap adjustment that could not be controlled effectively within a sound legal framework. Meanwhile, it is not clear whether the enterprises concerned may go to court to challenge the ex post adjustment in the current regulatory framework. As far as relevant governmental documents are turned into legislation, it remains questionable whether such legal rules will be enforced by the court. If China wants to adhere to the rule of law, the legislation needs to be clearer. Moreover, in the case that the enterprises are allowed to have access to the court, further observation is required on how it functions in the legal system, aiming to evaluate whether and how the legal system for ETS works in China.

Without the clear rules, in addition to the legal uncertainty stemming from the ex post adjustment, there may be a negative impact on the emitter's trading motivation and behaviour. If the cap is decreased, there will be fewer allowances available for the emitters covered by the pilot project to comply with the scheme. But when the cap is increased, the emitters covered may expect more allowances. In particular for the emitters with excess emissions, they may expect the allowances allocated in the ex post adjustment to cover the emissions rather than buying the allowances from the market. In this sense, the motivation to trade, which is the essence of emissions trading, may be taken away by the ex post adjustment. ${ }^{1}$

\subsubsection{Concluding observation}

Based on the analysis of carbon emissions reduction targets and caps for the pilot projects in China, several preliminary conclusions can be drawn in terms of the observation on the legal effect concerning the emissions reduction target adopted, the competence distribution for target setting and the special design with dynamic features in the Chinese context.

Firstly, neither the carbon intensity reduction targets determined and distributed at the national and local levels nor the caps set up for the pilot projects have full legal effect, which should be addressed in the legal framework for the ETS. Despite the fact that the $12^{\text {th }}$ Five-Year Planning (2011-2015) was adopted by the top legislator and the governments are bound by its binding target by means of the performance evaluation system, the $12^{\text {th }}$ Five-Year Planning (2011-2015) cannot be considered to be real legislation due to the characteristics of its contents and its enforcement system. Consequently, the national carbon intensity reduction target cannot be deemed to be a fully legally binding target for the government and emitters and neither are the provincial targets allocated by the governmental documents. However, it is these carbon emissions reduction targets that must be implemented and achieved by the governments by means of a variety of instruments including emissions trading. Given that the total amount of emissions to be produced by the emitters covered by the pilot projects is equal to the cap, the rights and obligations of the emitters covered will be influenced by the cap setting significantly. However, the analysis above has indicated that the caps for pilot projects are still mainly set up in the governmental documents rather than in legislation, resulting in the relative weakness of its

${ }^{1}$ This thesis will not discuss it in depth, but it deserves further analysis from an economic perspective. 
legal effect. Since the target setting is the first key element of the legal framework for emissions trading, one may raise the questions of how to determine the emissions reduction targets in particular the cap within the existing Chinese legal system, which should be the law rather than policies.

Secondly, the competence concerning target setting has been distributed in the special context of the coexistence of centralisation and decentralisation in China. In view of China's strong characteristic of centralisation, while the local situations differ greatly in terms of economic development and emissions reduction, the national carbon intensity reduction target has been distributed by a top-down approach, on the one hand, and the ETS pilot projects are being established by a bottom-up approach through local experimentation, on the other hand. The caps for the pilot projects have been determined by the local governments characterised by decentralisation, on the one hand, while the caps are set up under the significant influence of the carbon intensity reduction targets distributed by the higher levels of governments via a centralisation approach, on the other hand. In this respect, particular attention has to be paid to the potential challenges facing centralisation and the decentralisation at the same time. Regarding the decentralisation approach to cap setting, it may be necessary for the central government to control the cap setting by local governments in diverging way, in order to ensure the consistency of the local targets with the integrity of the overall environmental goal. With respect to the centralised model applied to the distribution of the carbon intensity reduction targets, it remains a huge challenge for the central government to ensure that the local circumstances will be taken into due consideration. As a result, the potential tension between the central government and local government in target setting may be easily identified in the Chinese central-local nexus. Given the particular legal context in China, a number of questions concerning this complicated nexus of central-local government, in terms of competence distribution in target setting, defining the respective role of central and local governments and their relationship, still need to be addressed within the legal system of China.

Thirdly, special attention should be paid to the attempt by the pilot projects to set up a dynamic cap in accordance with the economic development and carbon intensity reduction targets. China adopted the carbon intensity reduction target in the $12^{\text {th }}$ Five-Year Planning (2011-2015) at the national level, a typical relative target different from the absolute target adopted in the EU ETS, demonstrating that China has chosen a type of GHG emissions reduction target based on its own circumstances in pursuit of the green growth. Aiming to achieve their allocated carbon intensity reduction targets, however, the local governments are setting up the caps for the pilot projects established based on the cap-and-trade model. Even though the carbon intensity reduction target can be converted into the so-called emissions cap based on the calculation and the prediction of the GDP growth under different scenarios, the uncertainty issues stemming from the economic projection may arise inevitably. In this respect, some of the caps, such as the cap for the Shenzhen pilot project, have been determined in the form of an intensity-based cap rather than a fixed and absolute cap. Moreover, several pilot projects have employed an ex post adjustment of the cap, in view of the dynamic economic development and the political obligation to achieve the binding carbon intensity reduction targets. To a certain extent, this special design of the ex post adjustment of the cap, determined based on the projection of the dynamic economic development, 
may provide the local governments with flexibility to fulfil the carbon intensity reduction targets. Nevertheless, given the insufficient legal effect of the emissions reduction targets, as well as the regulatory framework for the pilot projects, it remains a huge challenge to design and to implement the ex post adjustment of cap within a sound legal framework providing for clear legal rules to which the governmental adjustment could be bound and controlled effectively in order to provide legal certainty and expectations for the market players. ${ }^{1}$

\subsection{Allowance allocation}

The description of the allocation rules for the pilot projects in section 3.3 of this chapter indicated to some common design features shared among the pilot projects, such as the mix of allocation methods and the dominant role of free allocation in the initial stage. Moreover, the elaboration of some special rules concerning the allocation of allowances in the pilot projects have implied 'innovative' attempts of the local governments to accommodate the dynamic economy growth and local circumstances in the experimental approach. In view of the divergent and similar design features among the pilot projects, the competence distribution in the allocation of allowances with decentralised characteristics will be deliberated firstly, and then the special design or consideration for the allocation rules aiming to accommodate the dynamic economy will be discussed later.

\subsubsection{Competence distribution for allowance allocation}

In line with the competence distribution in target setting, the allocation of allowances in the pilot projects has been determined and implemented by the local governments, thereby using their discretion, which can be demonstrated by the diversity of the allocation rules stipulated in the relevant legislation and governmental normative documents adopted in the pilot projects. In other words, despite the 'informal' guidance of the NDRC, the rules for allowance allocation are being designed with a bottom-up approach in which the competence of allocating allowances has been distributed to the local governments. As analysed in the section concerning the multi-level governance structure in the Chinese legal system, this decentralised model for the allocation of allowances can be rationalised in accordance with the experimental approach to the establishment of the ETS in China gradually. However, this decentralisation approach for the allocation of allowances is not free of challenges.

\section{The lack of legal rules for allocation}

The decentralised competence for allowance allocation, in line with the experimental approach, can accommodate local circumstances to a large degree but, at the same time, sufficient legislative competence for adopting legal rules for allowance allocation lacks among the pilot projects. According to the legislative competence distribution in the Chinese legal system, as discussed in section 2 of this chapter, the provincial congress and its standing committee can still

\footnotetext{
${ }^{1}$ Further discussion on the ex post adjustment will be provided in section 4.2 of this chapter, in the analysis on the allowances allocation.
} 
adopt local regulations while the provincial governments can adopt the rules of local government. However, the legal basis has not been used in order to adopt allocation rules in the initial stage of some pilot projects, resulting in a lack of legal rules for allowance allocation. For instance, the Shenzhen government has been authorised by the local regulation to determine and to adopt relevant rules concerning emissions trading. ${ }^{1}$ Despite the fact that the Shenzhen government the front-runner among the pilot projects - has allocated nearly 100 million allowances to 635 emitters $^{2}$, except for a general principle provided in the local regulation mentioned above ${ }^{3}$, no definite and specific rules for the allocation of allowances had been adopted or published until about nine months after the allocation ${ }^{4}$.

Even though more and more relevant rules concerning the allocation of allowances are being adopted among the pilot projects, the legal effect of these rules per se still needs to be examined. Due to the decentralised approach to competence distribution in the allocation of allowances, no laws or administrative regulations can be adopted for allowance allocation by the pilot projects. Based on the overview of the regulatory framework for the pilot projects listed in the annex, some of the pilot projects have provided the general principle and basic rules for the allocation of allowances in the rules of local government, while some of them are still relying on the other normative documents adopted by local governments. For instance, most of the allocation plans and specific rules concerning the allocation methods are adopted by the local DRC. In line with the legislative structure and legal ranks in the Chinese legal system described in section 2 above, except for the rules of local government adopted in Guangdong, Hubei, Shanghai, and Shenzhen, most of the allocation rules have fallen outside the range of formal legislation. Because of the low legal rank regarding the allocation rules, one may raise the question whether the local governments will change these rules easily when they want to do so, resulting in uncertainty for the market participants. In other words, the allocation of allowances has a substantial impact on the enterprises covered by or relating to the ETS and they should be provided with sufficient legal certainty.

\section{The diversity of the design features}

Most of the pilot projects have chosen a mix of allocation methods in which free allocation plays a dominant role. Moreover, several pilot projects have taken similar initiatives in applying the $e x$ post adjustment of the allowances allocation and reserving a specific amount of allowances for price stabilisation and new entrants. Nevertheless, due to the regional disparity in terms of the economic structure with different abatement potential and abatement costs among the pilot projects, the difference in terms of the allocation rules designed by the local governments is clearly visible.

\footnotetext{
${ }^{1}$ Provisions on controlling carbon emissions for Shenzhen special economic zone, Shenzhen People's Congress Standing Committee, 10 November 2012.

2 The press conference on the launch of the carbon emissions trading pilot in Shenzhen, Shenzhen Gov ernment Online, 21 May 2013, available at: http://www.sz.gov.cn/cn/xxgk/xwfyr/wqhg/20130521/, last acc essed 2 July 2014 (in Chinese).

3 Article 4, Provisions on controlling carbon emissions for Shenzhen special economic zone, Shenzhen People's Congress Standing Committee, 10 November 2012.

4 See Interim Measures on Carbon Emissions Trading Management in Shenzhen, Shenzhen Municipal Government, 19 March 2014
} 
For instance, in spite of the trend that most of the pilot projects have chosen free allocation as the main allocation method in order to reduce resistance against the ETS to the greatest extent possible, the description of the general rules in the pilot projects has shown the diversity in terms of allocation criteria and other detailed provisions of the free allocation rules. Aiming to accommodate various local circumstances, such as the fact that emitters covered by Shenzhen pilot project mainly belong to the service sector while those based in Hubei are in the industrial sector and have with high levels of emissions, the allowance allocation with different design features at the local level may be necessary for the setup and operation of the pilot projects of emissions trading to a certain extent.

Meanwhile, the diversity of the allowances allocation can also be demonstrated by the design and implementation of the auctioning among the pilot projects. During the initial stage of the piloting phase, auctioning has been employed in the pilot projects of Guangdong, Hubei, Shanghai and Shenzhen, in which the auctioning rules have been designed and implemented with various functions. To be specific, auctioning has been applied as an important method in the initial allocation of the allowances in 2013 for all the emitters covered by the Guangdong pilot project, which couldn't receive the free allowances until they bought a specific amount of allowances through auctioning as required. The mandatory auctioning in the Guangdong pilot project was probably supposed to promote the development of this market-based mechanism by putting a price on the allowances, but it was cancelled in 2014 partly because of the emitters' opposition to the heavy burden caused by the auctioning. ${ }^{1}$ The auctioning employed in the pilot project of Shenzhen and Shanghai, however, has only been implemented to facilitate the emitters to buy sufficient allowances for compliance with the scheme. One may raise the question whether the scheme is still cost-effective since this additional auction may take away the reason for trading, which needs to be determined by economic research. Moreover, the special auctioning facilitating the compliance in Shenzhen, Shanghai and Guangdong also vary greatly in terms of the specific designs, such as the determination of the reserve price and procedures.

\section{The potential local protectionism under the risk of carbon leakage}

Designing and testing different allocation rules by the local authorities is supposed to be one of the goals of establishing the pilot projects, providing lessons to determine the allocation rules for the possible national scheme. If the allocation rules are determined by the local governments without national guidelines or principles, nevertheless, several special problems, including potential local protectionism under the risk of carbon leakage, need to be considered and addressed within the legal framework.

With regard to the issues of carbon leakage, as observed by Bellevrat, China may possibly face competitiveness and carbon leakage issues at two different levels when implementing the carbon markets. The one could occur between covered and non-covered provinces/sectors in the piloting phase regarding emissions trading; and the other could possibly happen at the international level

\footnotetext{
${ }^{1}$ Zhang, Q. \& Wei, Y. P., The compliance is finished and the auctioning rule will be changed in Gu angdong carbon ETS, 21 st Century Business Herald, 22 July 2014, available at:http://epaper.21 cbh.com/ht ml/2014-07/22/content_105783.htm?div=-1, last accessed 1 August 2014 (in Chinese).
} 
in the future as far as a nation-wide ETS is concerned. ${ }^{1}$ Moreover, due to the diversity of the allocation rules among the pilot projects, similar emitters based in different piloting provinces/municipalities will be treated differently, despite the fact that they are competing with each other in the national market and international market. In this context, some of the emitters covered by the pilot projects will be exposed to the risk of carbon leakage to different extents, meaning that their products will be more expensive and the cheaper products may be bought from other regions. ${ }^{2}$ In view of the decentralised characteristics of the competence distribution in relation to allowances allocation during the pilot phase, particular attention must be paid to the risk of carbon leakage at the provincial level.

As far as the issues of carbon leakage are concerned, which is usually accompanied by the industries' modernisation and transfer, the local governments may have complicated attitudes to carbon leakage. The discussion on target setting in the former section of this chapter has revealed the fact that all the local governments are bound by the carbon intensity reduction target set up in the $12^{\text {th }}$ Five-Year Planning (2011-2015). However, one must also bear in mind that the most important factor in the evaluation of the local governments and its leading officials still relies heavily on economic growth and in particular GDP growth. In this respect, in addition to the competition among the enterprises running similar businesses, the local governments have also been placed in a de facto 'tournament'. ${ }^{3}$ Given the fact that only seven pilot projects are exploring the establishment of the $\mathrm{CO}_{2} \mathrm{ETS}$, the economic impact on the emitters participating in the pilot projects and the risk of carbon leakage has to be considered carefully by the local governments when designing these pilot projects.

Moreover, the financial situation of the local governments still relies heavily on the fiscal revenue collected from the enterprises by taxes and fees, in particular the big enterprise that participate in national and international competition. Especially with regard to the industries/emitters covered by the pilot projects that can make a contribution to local economic development and revenue growth, the local governments may do their best to persuade the industries to stay. In this respect, the choice of free allocation as the main allocation method among the pilot projects has demonstrated the attempt of the local government to reduce the negative impacts on the emitters covered by the pilot projects. ${ }^{4}$ Furthermore, aiming to maintain the competitive advantage and the fast growth of local GDP, local governments are usually motivated to support and to protect the local industries, easily resulting in the local protectionism in China.

\subsubsection{Allowance allocation in the dynamic economy}

In view of the dynamic economic development in China, especially in the process of transitioning into a low-carbon economy, the allocation rules for allowances have been designed and implemented with the aim to accommodate the dynamic economic development and in

1 Bellevrat, E. (2011), p.13.

2 But with regard to the questions of whether the price is indeed already high enough to causing the leakage, economic analysis is still required.

${ }^{3}$ More discussion on the 'Promotion Tournament' in China may refer to economic and political literature, such as Zhou, L. A. (2007).

${ }^{4}$ Kossoy, A. et al.(2013), p.69. 
particular rapid economic growth. It is noticeable that, in addition to the carbon intensity reduction target, relevant factors, such as the abatement cost, abatement potential and the economic development plan, have been taken into consideration in the determination of the total amount of allowances, as well as the specific amount of allowances to be allocated to the emitters. Moreover, a number of the special designs concerning the allowance allocation among the pilot projects have suggested the attempts of the local government to allocate the allowances in line with the dynamic economic development to the extent possible. Below, the most important provisions will be discussed.

\section{Governmental adjustment of the allocation of allowances}

Aiming to achieve the carbon intensity reduction targets allocated to the local governments at all levels, the carbon intensity of specific sectors and emitters has been considered as an important criterion for allowance allocation, which can be exemplified by the allocation methods applied in the Shenzhen pilot project. In view of the potential gap between the projection of the economic development and the reality of the emissions, particular attention has been paid to the policy options of amending the allocation plans or adjusting the allowances allocation ex post, taking account of the actual economic development as well as the carbon intensity reduction target to be achieved.

Firstly, the allocation plan determined ex ante could be amended annually before the allocation, in line with the economic development of the previous year in some pilot projects. As described in the former section, some pilot projects such as Tianjin, Guangdong, Shanghai, and Shenzhen will allocate all the allowances for the period from 2013 to 2015 at one time based on respective criteria and allocation rules. In this respect, the government chooses to adjust the allocation plan annually, in accordance with the local economic development and the emitters' actual emissions of previous year. For instance, the emissions cap and allocation plan for the coming year in Tianjin can be amended in accordance with the actual economic and social development as well as compliance by emitters. ${ }^{1}$ In other words, the allocation plan for the next year can be amended by the competent authority before the annual allowance is allocated, aiming to accommodate the latest economic developments.

Secondly, the description of the pilot projects has also revealed the trend that the allowances allocated to the emitters based on the historical emissions or other criteria ex ante will be adjusted ex post by the local governments. Among the pilot projects of Beijing, Guangdong, Hubei, Shanghai, and Shenzhen, there are explicit provisions providing for the governmental ex post adjustment of the allowance allocation. For instance, in line with the emitters' specific carbon intensity reduction target determined by the Shenzhen government, the allowances allocated to the emitters covered, based on the projected increase of its industrial value added, should be increased or decreased on the basis of the actual value added in the last year. ${ }^{2}$ In other words, additional allowances will be distributed to the emitters if its actual value added grows

\footnotetext{
1 Article 2(3), Implementing Program of the Tianjin Municipal Government on Pilot Carbon Emissions Trading, General office of Tianjin Municipal Government, 2 February 2013 (in Chinese).

${ }^{2}$ Article 17,19, Interim Measures on Carbon Emissions Trading Management in Shenzhen, Shenzhen Municipal Government, 19 March 2014 (in Chinese).
} 
beyond expectations, and vice versa. As a result, the so-called 'over-allocated' allowances may be taken back from the emitters by the government if their projected development goal cannot be reached, which is exemplified by the deduction of three million allowances in the ex post adjustment of the allowances by Shenzhen DRC on 29 May 2014 . $^{1}$

As analysed in the section concerning the target setting of this chapter, the choice of the intensity-based target has demonstrated China's attempt to balance the fast economic growth and the GHG emissions reduction. Especially given the uncertain projection of the economic development in the allowance allocation, the governmental ex post adjustment of the allocation result based on the actual economic development seems to be logical in the Chinese context to a certain degree, in which the ETS are established to achieve the carbon intensity reduction target finally. In this respect, the possible use of the ex post adjustment aiming to correct any unintended negative result of the ex ante allocation, in particular providing an incentive for the emitters to ask for more allowances by projecting a high amount of production ${ }^{2}$, appears to have been accepted and applied in several pilot projects. To the extent possible, the governmental ex post adjustment is supposed to provide some possibility for the ETS to adapt to the dynamic economic development in China, bringing the allocation of allowances in line with the real production $^{3}$. In line with the green growth, there will still be a mitigation of emissions in a relative way. Meanwhile, the ex post adjustment of the allocation of allowances by means of increasing or decreasing the allowances based on the real production or verified emissions in the previous years, modulating the supply and demand balance, can be employed as an important price stabilisation mechanism in case of unexpected market development.

Due to the ex post adjustment of the allocation of allowances, however, the questions arise as to whether the cap for these pilot projects will be adjusted accordingly or not, which have been discussed in the cap setting in section 4.1 of this chapter. It is noticeable that the cap for the Shenzhen pilot project is a flexible and dynamic one in line with the ex post adjustment on the basis of the carbon intensity reduction target. Moreover, the total amount of allowances to be added during the ex post adjustment phase in the Shenzhen pilot project cannot exceed the amount of allowances to be deducted, except for the additional allowances for the new investment projects of fixed assets coming from the allowances reserved for the new entrants. ${ }^{4}$

Nevertheless, the ex post adjustment implemented within the predetermined and fixed cap still exists in other pilot projects. For instance, the cap for Hubei pilot cannot be changed, while the allowances reserve can be allocated to the new entrants or the emitters with production increase. ${ }^{5}$ But one may still raise the question of where the additional allowances come from, if the increase in the ex post adjustment requires more allowances than are available in the allowances

\footnotetext{
${ }^{1}$ Information is available at the website of Shenzhen DRC, http://www.sz.gov.cn/cn/xxgk/bmdt/201405/t2 0140529 2455203.htm, last accessed 24 July 2014 (in Chinese).

${ }^{2}$ Backes, C., Deketelaere, K., Peeters, M., \& Schurmans, M. (2008), p.206.

3 Ibid, p. 179.

4 Article 19, Interim Measures on Carbon Emissions Trading Management in Shenzhen, Shenzhen Municipal Government, 19 March 2014.

5 According to the explanation of the scholar leading the research group participating in the design of the Hubei pilot for the government, see Qi, S.Z. \& Wang, B.B. (2014).
} 
reserve. Meanwhile, it remains questionable how the allowances taken back from the emitters should be dealt with in the case of the decrease ex post adjustment.

\section{Price stabilisation mechanism in the allocation of allowances}

In addition to the ex post adjustment of the allocation results, some pilot projects provide governmental price stabilisation mechanisms connected with the allocation of allowances. According to the description in section 3 of this chapter, several pilot projects, such as Beijing, Tianjin, Shenzhen, Guangdong, and Hubei, have reserved a specific amount of allowances for governmental regulation in the form of selling and buying allowances in specific circumstances, such as the severe price fluctuation, in pursuit of price stabilisation of the carbon market. In other words, if the price is too high because of scarcity in the case of economic growth, it is possible for the local governments or their specific agency to put some allowances on the market via auctioning or other allocation methods. On the contrary, when the price is too low due to a surplus of allowances, the local governments concerned are allowed to buy back the allowances from the market, in order to raise the price to a reasonable level.

With regard to the price stabilisation mechanism mentioned above, the governmental adjustment to the allocation of allowances seems to be a logical design feature in the ETS established in the context of China's regulated economy ${ }^{1}$, in which the government is still playing a very substantial role. Moreover, one of the direct reasons for the governmental adjustment of the allowance allocation in the pilot projects may also be found in the dilemma that the EU cannot 'rescue' the EU ETS suffering from the depressed price of the EUA, mainly due to the structural surplus of allowances in supply. ${ }^{2}$

However, there is a challenge facing the design and implementation of the price stabilisation mechanism in the allocation of allowances. For instance, it is still not clear about the threshold of price fluctuation triggering the governmental adjustment of the allocation of allowances for most pilot projects. Except for the governmental normative document in the Beijing pilot project, providing the specific circumstances, basic measures and procedures for the governmental price regulation $^{3}$, no specific legislation or document has been adopted in the other pilot projects. Instead of an explicit definition and requirements, the vague provisions in the pilot projects mentioning an 'abnormal price' or 'unusual fluctuation', still cannot provide the market participants with clear expectations about the circumstance in which the government may become involved in the market price development. Moreover, one may raise the question as to how the government will adjust the allocation of allowances by buying and selling the allowances on the market. Given the difference between the government and market players, it is important to see whether the governments themselves or a specific agency engaged by the government, such as a carbon central bank, will implement the price stabilisation mechanism. In light of the vague provisions mentioned among the pilot projects, it is important to set up a clear

\footnotetext{
${ }^{1}$ Kossoy, A. et al.(2013), p.69.

2 See COM/2012/652 final.

3 Management measures on the open-market operation relating to carbon emissions trading in Beijing (trial), Beijing DRC, Beijing Bureau of Finance, 10 June 2014 (in Chinese).
} 
legal framework regulating the governmental action in terms of the allocation of allowances for the purpose of a stabilised price.

\section{Special allocation rules for new entrants}

Following the step-by-step approach, the scope of the pilot projects or the national scheme is expected to be extended gradually in the future. Especially in view of the rapid economic growth, the increase of emissions will be foreseen in the near future, and new entrants to be covered by the pilot projects or the future national scheme may not be marginal volumes as they are in the EU ETS. ${ }^{1}$ On the contrary, the new entrants may quickly play a substantial role in the proper functioning of the ETS, which are worthy of due consideration in the pilot projects as well as the future national scheme. ${ }^{2}$ In this context, the design of the allowances allocation rules has included treatment of new entrants. In addition to the options of reserving specific allowances for new entrants and allocating the allowances to new entrants by auctioning, forcing the operators to internalize the cost of carbon emissions in their production decisions ${ }^{3}$, other special allocation rules have also been adopted by the local governments, such as Guangdong.

There is an indication that some special allocation rules for the new entrants covered by the pilot projects have been employed as important policy instruments by the government, aiming to strike a balance between the rapid economic growth and GHG emissions reduction. Taking the Guangdong pilot project as an example, specific new fixed asset investment projects have to go through a separate 'carbon emissions assessment'. ${ }^{4}$ On the basis of the result of that carbon emissions assessment, the allocation of allowances to the new entrants then will have a great impact on the governmental decision of whether the new investment project as a whole can be approved or not. If the competent authorities reject the investment project due to the negative result of the allowance allocation, the emitters concerned have the right to request a review and the Guangdong DRC should check and make a written reply within 20 days. ${ }^{5}$ However, one may still raise the question whether the investor can seek judicial remedies for the decision on the allocation of allowances within the legal framework for the ETS or not.

Guangdong's effort in combining the allowance allocation with other important economic policy instruments in pursuit of the achievement of the emissions reduction target and the transition into a low-carbon economy has demonstrated the value of the pilot projects again, providing important lessons for the design of the national ETS in the future. Nevertheless, this kind of special treatment for new entrants in the allocation process, which may have a significant influence on the protection of the investment rights and market access, needs to be designed carefully in accordance with the laws. Otherwise, similar kinds of special allocation rules determined by local governments without unified rules or principles at the national level might result in another new form of local protectionism and excessive administrative intervention. In

\footnotetext{
${ }^{1}$ Bellevrat, E. (2011), p.11.

2 Ibid..

3 Ibid.

4 Article 5(3), Implementation program of carbon emissions trading pilot in Guangdong Province, Guangdong Provincial Government, 7 September 2012 (in Chinese).

5 Article 31, Trial Measures of Guangdong Province on the Management of the Carbon Emissions, Guangdong Provincial Government, 15 January 2014 (in Chinese).
} 
view of the connection between the investment approval and allowances allocation decisions in Guangdong, which is already a more developed 'market economy' than other provinces; it is quite a complicated and controversial issue worthy of careful consideration by the local governments and the central government.

\subsubsection{Concluding observation}

In view of the core role that allowances have in the ETS, particular attention should be paid to the process and result of the allocation of allowances. On the one hand, it is the allocation process that divides up the cap into the specific amount of allowances for all the emitters covered by the pilot projects, in which there may be interaction and tension between the government and emitters. On the other hand, the results of each specific allocation will have a substantial impact on the legal right and competition position of the relevant enterprises and regions. In this respect, there is a need to analyse the legal relationship among various actors involved in the allocation of allowances in two dimensions.

\section{Horizontal dimension: equal treatment among the emitters and regions}

On the horizontal dimension, the equal treatment among the emitters and regions remains a complicated challenge facing the allocation of allowances. As far as the equal treatment in the allocation of allowances is concerned, many factors should be taken into consideration, including the competence distribution for allocation, the different choices of allocation methods and the specific design of the allocation method and procedures. With regard to the choices and special design of the allocation methods, a number of publications have examined the distribution effect of the major allocation methods from the perspectives of economics and law ${ }^{1}$. From the legal perspective, however, the emphasis of this section has been placed on the competence distribution between the central and local governments, in light of the significant role of the government and the multi-level governance structure in China.

In this respect, the analysis above has suggested the potential problems emerging in the existing decentralised approach, in which the allocation rules are designed and implemented by the local governments. In addition to the insufficiency of legal rules for allowance allocation, the diversity of the design features concerning the allocation rules adopted in the pilot projects as well as the potential local protectionism under the risk of carbon leakage may be caused by this decentralised approach. Given that the allocation rules are determined respectively by different local governments rather than the central government, in particular taking account of the strong indications of local protectionism under the existing GDP-oriented performance evaluation system of the cadre, one has to raise the question as to how to ensure equal treatment and fair competition among the emitters running similar businesses but covered by different pilot projects.

However, the centralisation approach is not free of challenges either. If the allowances are allocated by the central government, it is also very questionable whether the regional disparity

${ }^{1}$ See for instance, Qi, S. Z. \& Wang, B.B. (2013); Ding, D. \& Feng, J.R. (2013); Weishaar, S. (2009). 
among the provinces in terms of economic development and environmental protection will be taken into due consideration, which will be discussed later in section 5 concerning the national scheme.

\section{Vertical dimension: governmental adjustment in the allocation of allowances}

From the vertical dimension, there is a special need to deal with the relationship between government and the market in light of the unique role of the Chinese government in the allocation of allowances. As a market established artificially by the government, there is no doubt about the significant role of the government throughout the design and implementation of the ETS, including in target setting, allowance allocation and enforcement. In the allocation of allowances, each specific allocation decision made by the government will have a substantial and direct impact on the emitters concerned. Especially in light of the special design of the governmental ex post adjustment, including inter alia potential price stabilisation mechanisms and the compliance promotion measures adopted in some pilot projects, one has to raise the question as to how to regulate and control the governmental actions in line with the Chinese legal system, in pursuit achieving the delicate balance between the flexibility and stability of emissions trading. In view of the special design of the allocation of allowances among the pilot projects in China, the governmental adjustment to the allowances allocation, not only the regular adjustment in the routine of allowances allocation but also the special adjustment like the price stabilisation mechanisms should be regulated within the legal framework, in order to ensure legal certainty for market participants. If there is great uncertainty about governmental control of the emission trading market, the market may not perform well, although the impact of uncertainty about governmental control on market behaviour deserves further economic analysis.

\section{Regular adjustment}

With regard to the routine procedure of the allocation of allowances, it is important for the government to make the decision on the allocation of allowances by taking account of the opinions of the stakeholders and making sure the enterprises are informed of the governmental decision, in light of the impact of the allocation decisions on the enterprises involved. For instance, the review committee for allowances allocation, composed of experts, enterprises, industry associations, and relevant leading departments, is supposed to enhance public participation $^{1}$ in the allocation of allowances in Guangdong ${ }^{2}$ and thus increase the reasonability and fairness of the allocation.

In addition, it is crucial to provide necessary remedies for emitters who are not satisfied with the allowances allocation conducted by the government. ${ }^{3}$ In this respect, several pilot projects have set up some remedy measures. For instance, the emitters covered by Guangdong pilot project can apply for a review of the allocation result and the Guangdong DRC should carry out a review

\footnotetext{
1 The implementation of public participation in China still needs to be observed, but it exceeds the scope of this $\mathrm{PhD}$ research, and it will thus be left untouched in this thesis.

2 Article 12, Trial Measures of Guangdong Province on the Management of the Carbon Emissions, Guangdong Provincial Government, 15 January 2014 (in Chinese).

3 Ding, D. \& Pan, F. F. (2012), p.109.
} 
and reply in writing within 20 days. ${ }^{1}$ It is a good idea to provide a resolution to the dispute over the allowances allocation within the administrative system in the pilot projects, but it is questionable whether the application for a review of the allowance allocation is equal to the administrative reconsideration provided in the Chinese administrative law.

Therefore, one may raise the question whether it is possible for the emitters that are still dissatisfied with the governmental review to institute an appropriate administrative reconsideration and administrative litigation. According to Chinese administrative law, only a specific type of administrative act can be brought to the administrative reconsideration or litigation. ${ }^{2}$ However, the rules provided in the pilot projects are not clear enough, and they require further clarification on whether the emitters concerned have the right to have access to the court in this case. Since the specific allocation decision made by the government has a substantial impact on the rights and obligations of the individual emitters, it can be deemed to be a specific administrative act in line with the administrative law. Especially for the regular governmental ex post adjustment of the allocation result, such as the practice in Shenzhen, the specific emitters would be influenced by the governmental actions. If China indeed would like to follow the 'rule of law', the emitter, who is not satisfied with the allocation decisions, should be eligible to seek a judicial remedy for the regular governmental adjustment in addition to the routine allocation decision.

\section{Special adjustment}

In particular for the governmental adjustment of the market supply and demand of allowances through the allowances reserve and other mechanisms in the case of price fluctuation or other specific circumstances, which will have a direct impact on the market participants, the governmental action needs to be regulated in line with the legal framework for the ETS in China. As far as the government regulation or intervention is concerned, especially in the Chinese context, the question emerges of how to define a clear boundary between the government and market, which is also the key to the reform of the economic system in China. According to the Decision of the Central Committee of the CPC on Several Major Issues on Comprehensively Deepening Reforms, the blueprint guiding development and reform in China, the market should play a decisive role in the allocation of resources while the government should play a better role in market regulation. ${ }^{3}$ Given the existing serious problems relating to government intervention in the Chinese market, it may also a big challenge for the pilot projects to deal with the relationship between the government and market.

Nevertheless, the description above has suggested that the local governments usually have the final say on the allocation process as well as the decisions in the pilot projects, even though the emitters and other stakeholders are encouraged to participate in the decision-making procedures gradually. Especially in the case of an ex post adjustment and price stabilisation mechanism,

\footnotetext{
${ }^{1}$ Article 31, Trial Measures of Guangdong Province on the Management of the Carbon Emissions, Guangdong Provincial Government, 15 January 2014 (in Chinese).

2 Article 2, Administrative Litigation Law of China.

3 Decision of the Central Committee of the Communist Party of China on Several Major Issues on Comprehensively Deepening Reforms, adopted by the $3^{\text {rd }}$ Plenary Session of the $18^{\text {th }}$ CPC Central Committee, 12 November 2013 (in Chinese).
} 
considerable discretion enjoyed by the government has been indicated to be in place in some pilot projects. Given the highly administrative and technical nature and complexity of the governmental ex post adjustment, it may be a great challenge to design a clear and suitable legislative framework for it. ${ }^{1}$ Moreover, special attention should be paid to the legal regulation of the governmental behaviour per se relating to the allocation of allowances, in order to prevent an illegal governmental intervention in the allocation process and to provide necessary remedies for the emitters concerned. However, given the fact that the regulatory framework for the pilot projects are being established by the local government, it is questionable whether the local government could set up a framework binding and controlling the local government effectively or not. Moreover, as discussed in the former part of this section, such an effective legislative framework cannot be established by the local governments due to their lack of legislative competence. On the contrary, the legal framework for the allocation of allowances and the necessary governmental adjustment needs to be designed and implemented at the national level, taking account of the lessons from the pilot projects.

\subsection{Inspection and enforcement}

Although the pilot project designs vary, they share a number of features, including favouring self-monitoring, self-reporting and third-party verification. Policy makers have established a programme for monitoring and the verification of GHG emissions, and there are indications that the programme includes the authority to impose major financial penalties for noncompliance with Chinese $\mathrm{CO}_{2}$ ETS requirements. Establishing an enforcement system is not free of challenges, particularly considering the issues of the legality of rules adopted in the pilot projects and the authority of the central and local governmental entities in China that will be enforcing these requirements. A multi-level enforcement system implemented by central and local authorities that is consistent with the Chinese legal system and a gradual harmonisation or centralisation of authority may hold some promise for developing an effective system.

\subsubsection{Analysis of the MRV system}

The collection of emissions data is essential for an effective ETS and presents crucial challenges for the pilot projects, including the need for clear legal requirements and enforceable rules. Although detailed MRV rules are still being developed, certain preliminary design features are common in the relevant rules.

\section{Diversity and convergence in the content of the MRV rules}

MRV rules for the pilot projects are being developed by local governments, taking into account local circumstances and, in particular, the available capacity of the emitters, verifiers and governments for the performance of the MRV. As a result there will be some variation among the pilot projects. For instance, Shanghai and Guangdong have established different thresholds for emitters to report and verify their emissions, although both of them are designed to allow for

${ }^{1}$ Backes, C., Deketelaere, K., Peeters, M., \& Schurmans, M. (2008), p.205. 
the gradual enlargement of the scope of the projects. Only the Shanghai, Tianjin, Guangdong, and Hubei pilot projects require the development of monitoring plans by emitters. Moreover, the contents of the annual emissions reports submitted by the emitters differ depending on specific pilot projects.

On the other hand, it is expected that there will be similarity in the pilot projects based on the requirement for third-party verification and the specific data required to be reported. In light of the technical nature of the MRV rules, the convergence of the design features was presented in the description of the pilot projects. Nevertheless, relevant guidelines and rules for MRV systems are still being developed in some pilot projects and concerns about the quality and comparability of emissions data collected in the pilot projects have been shared by the participants and stakeholders. ${ }^{1}$

\section{Choice of self-monitoring, self-reporting and third-party verification}

All the pilot projects have adopted the approach of self-monitoring, self-reporting and third-party verification of the emissions data. However, the choice of self-monitoring and self-reporting creates a challenge for the regulators to ensure and to promote the reliability and accuracy of data collected through self-monitoring and self-reporting. Similar challenges have already emerged in the experience of the $\mathrm{SO}_{2}$ ETS, in which the data collection relies on the reports submitted by the emitters together with the spot check via on-site inspections by local Environmental Protection Bureaus. ${ }^{2}$ Nevertheless, these $\mathrm{SO}_{2}$ emissions data reported by the emitters themselves have been criticised in terms of reliability, accuracy and consistency, since most of the data is calculated based on coal consumption and the sulphur content of the coal, and only some of the data is based on periodic monitoring instead of continuous monitoring. ${ }^{3}$ In addition to technical improvement, like the application of CEMs, a possible solution, such as incorporating the obligation of self-monitoring and self-reporting into the $\mathrm{SO}_{2}$ emissions permit, publishing the emissions reports on the governmental website, and providing an incentive for the correction of noncompliance by the emitters themselves, has been proposed by scholars. ${ }^{4}$

Moreover, a balance will be required between relying on emitters and governmental agencies to ensure that the environmental objectives will be attained. ${ }^{5}$ The imposition of administrative and criminal sanctions for false reporting may be an option for the government, but there are difficulties in the adoption of criminal penalties in the legal framework at the local level, which will be discussed in section 4.3.2 below. In this sense, an important aspect of maintaining that balance will be to subject the emissions data to verification, which could be conducted by the governmental/regulatory body or private third-party organisations. ${ }^{6}$ Governmental agencies in China may face challenges in carrying out the verification task, such as a lack of resources and

\footnotetext{
${ }^{1}$ See relevant news reports such as Li, X.C. Carbon Emissions Trading in China Has Been Launched Substantially, China Sec. J., 18 June, 2013 (in Chinese).

2 Article 12, 21 Law of China on the Prevention and Control of Atmospheric Pollution.

${ }^{3}$ See Chang, Y.C. \& Wang, N.(2010). p.3363, see also Wang, J.N., Yang, J.T., et al. (2004), p.4

${ }^{4}$ See for instance, Li, Z. P. (2007b), p. 473.

5 Peeters, M. (2006a), p.193.

${ }^{6}$ Rohleder, J. (2006), p.26.
} 
expertise. In light of this, reliance on private third-party verification might be a feasible alternative to governmental inspection for China.

The third-party verifiers may play a significant role as gatekeepers in the enforcement of the law. ${ }^{1}$ Except for a few circumstances in which third-party verifiers are employed by the government in the early piloting stages of an ETS, such as the pilot projects of Beijing, Tianjin, Chongqing, and Hubei, the third-party verifiers are usually expected to be contracted by and paid by the emitters, which would seem to be compatible with the 'polluter pays' principle. However, considerable concerns exist as to the independence, professionalism, competence, and accountability of the third-party verifiers. In particular, the severe penalties for excess emissions to be applied in some pilot projects may put pressure on the relationship between emitter and verifier, leading to fraud, showing less emissions in the verification report than is true in reality. Therefore, the governmental regulation of the third-party verification through accreditation and supervision of the verification process will be crucial for the legal framework for enforcement. In this respect, some pilot projects, such as Shenzhen, Shanghai, Beijing, and Tianjin, have introduced or stated the intention to apply the mechanisms of spot checking or double-checking the verifications by government authorities or another third-party verification body entrusted by the government.

Nevertheless, both the relationship between the emitter and verifier and the relationship between the verifier and government will have to be well-defined in the applicable regulations. In the case that the verifiers are employed by the emitters, the rights and obligations of both sides would be provided in the MRV rules as well as the contract signed between them. As was described in the previous section, the basic obligations of the emitter and the third-party verifier of compliance and provisions on penalties for noncompliance have been stipulated in the relevant rules or guidelines adopted in the pilot projects. For instance, if the emitter objects to the verification report, there is a possibility for the emitters in some pilot projects to apply for a review by the government on some conditions. Moreover, the verifiers will not only be punished by the government for a specific illegal act, such as issuing a false verification report or failure to provide the verification report in due time, but the verifiers may also be responsible for the damage to the emitters caused by the verifier's fault.

However, the relationship among the emitter, verifier and the government may become complicated when the government is involved in the verification process. When the verifiers are entrusted by the government in some pilot projects, in the form of government procurement of service (zheng fu gou mai fu wu), there is a special legal relationship between the government and verifiers. On the one hand, both the government and the verifier, as equal parties to the government procurement agreement on the verification service, should comply with the contract providing for the rights and obligations of both sides, which is similar to other ordinary contracts. On the other hand, the government, as the regulator and gatekeeper of the whole scheme, is competent and responsible for ensuring that the verifiers operate in line with the law, for the sake of the public interest. In this sense, attention should be paid to the mix of public law and private law embedded in the relationship between the government and verifiers. In addition, the emitters

${ }^{1}$ Kraakman, R. H. (1986), p.12. 
have to accept the verification carried out by the third-party verifiers employed by the government; otherwise, the government will punish the emitters concerned. In this case, it seems that the verifiers are executing a governmental function to some extent, asking for the verifiers to be covered by the public law. Moreover, given that the verifiers are contracted by the government to verify the emissions report on behalf of the government, one may raise the question whether the government would also bear the liability for the damage caused by the verifiers or not.

\section{Legal effect of the MRV rules adopted in the pilot projects}

Although the legal framework for the MRV system in China is still evolving, it is primarily based on rules of local government as well as on other normative documents like the detailed rules provided by the relevant guidelines. According to the Chinese legislative system, the local regulations adopted in Shenzhen and Beijing and the rules of local government adopted by Shenzhen, Shanghai, Guangdong, and Hubei would have a relatively high ranking, while the MRV guidelines would have a relatively weak legally binding effect.

In this respect, the guidelines for MRV adopted in Shenzhen and Shanghai have revealed some challenges facing the pilot projects. In the first step of establishing the framework for the MRV system, the MRV guidelines in Shanghai and Shenzhen were adopted by the local governments in the form of 'technical documents' and 'standardisation guiding technical documents'. According to the Administrative Regulation on the National Standardisation Technical Guidance Document adopted in 1998, the standardisation guiding technical document (biao zhun hua zhi dao xing ji shu wen jian) is classified as a 'standard document', serving as a reference document and providing guidance or information for specific standardisation operations during the technical development of the project. ${ }^{1}$ It may be inappropriate to make the standardisation guiding technical document mandatory or binding as a result of citing it in the standard. ${ }^{2}$ In other words, the guidelines adopted in Shenzhen and Shanghai should only be considered to be recommendations or a reference for the emitters, which thus cannot be enforced as they are not binding. With regard to the guidelines in the governmental normative document adopted by the provincial DRC in the pilot projects of Guangdong and Chongqing, strictly speaking, they cannot be considered to be formal legislation either, due to the weak legally binding effect of these governmental normative documents per se.

Because of the highly technical nature of the measurement and collection of emissions data, it cannot be expected that the pilot projects will develop these programmes quickly. Beginning with the standardisation of guiding technical documents and governmental documents before the adoption of specific standards or legislation seems to be an acceptable and reasonable approach for the pilot programmes. Voluntary standards and standardisation guiding technical documents can play a positive role in regulation, guidance and evaluation. ${ }^{3}$ Nevertheless, one may question whether a framework built on such provisions with weak legally binding effect can provide the

\footnotetext{
${ }^{1}$ Article 2, Provisions on the Administration of National Standardisation Technical Guidance Document, State Bureau of Quality \& Tech. Supervision, 24 December 1998 (in Chinese).

2 Ibid. at Article 4.

3 See Huang, M. Q. (2011); see also Song, G. D. (2006), p.200.
} 
necessary and effective enforcement of emissions trading, especially given the weak environmental enforcement in China.

Two options may be considered in the establishment of a legal framework for the Chinese MRV system to ensure robust compliance. One alternative is for the specific MRV rules to be included in formal legislation (for example, laws and administrative regulations) at the national or local level. In this respect, detailed MRV rules are increasingly being incorporated into the local legislation for the pilot projects, which can be exemplified by the rules of the local government adopted in the Shenzhen pilot project. Another alternative is for detailed MRV rules to be included in compulsory standards instead of the standardisation guiding technical documents. The legal basis for the latter option can be found in Article 2 of the Standardisation Law, stipulating that standards should be formulated for the technical requirements and testing methods related to environmental protection, which need to be unified. ${ }^{1}$ As interpreted by the State Bureau of Quality and Technical Supervision, technical requirements and testing methods related to environmental protection under Article 2 include index and testing methods for safety and sanitary protection as well as the environmental quality and emissions of the pollutants. ${ }^{2}$ Although not certain, GHG emissions may fall within the scope of the regulation of the emissions of pollutants. In addition, the National Technical Committee 548 on Carbon Management of Standardisation Administration of China was established on 15 July 2014 by the approval of the Standardisation Administration of China, at the request of the NDRC. ${ }^{3}$ This specific technical committee will be in charge of the amendment of the relevant national standards concerning the management of the carbon emissions, including the recording and reporting of the $\mathrm{CO}_{2}$ emissions by the emitters, which may pave the way for the establishment of a national MRV system for carbon emissions trading to some extent.

\section{Possible option: Greenhouse gas emissions permit}

Parallel to the MRV system initiated by local governments, the central government is also making an effort to establish a national ETS. A permit system for $\mathrm{CO}_{2}$ emissions might be considered to be an important instrument for regulating the self-monitoring and self-reporting of emitters by the country. ${ }^{4}$ Emitters will not be permitted to emit GHGs unless they have permits and meet all the necessary requirements stipulated in the permits. In this respect, there may be a possibility for the requirements of a monitoring plan to be incorporated into the GHG emissions permit system, enhancing the effectiveness of emissions mitigation and adding an important building block to the legal framework for emissions trading. However, it is still not clear whether this permit system will be designed and implemented as a traditional command-and-control system or not.

\footnotetext{
${ }^{1}$ Article 2 (3), Standardisation Law of China.

2 Interpretation of Standardisation Law of People's Republic of China, State Bureau of Quality \& Tech. Supervision, 23 July 1990 (in Chinese).

3 Relevant information can refer to the website of NDRC, available at: http://qhs.ndrc.gov.cn/gzdt/201407 /t20140717_619058.html.

${ }^{4}$ Wang, E. D. (2013), The Cap and Intensity Target for the Carbon Emissions May Be Implemented at the Same Time in the 13th Five-Year Period, 21 st Cent. Bus. Herald, 21 May 21 2013, at 21 (in Chinese).
} 
A GHG emissions permit will create an administrative permission in China. In the past, administrative permissions were abused arbitrarily by the governments in controlling and intervening in the markets. Aiming to reduce the number of issues requiring administrative permission and to standardise the procedures for doing so, the Administrative Permission Law of China was adopted in 2003. ${ }^{1}$ After a decade of implementation of the Administrative Permission Law, however, the reformation of the administrative permissions to reduce the number of activities requiring administrative permission remains a huge challenge facing China in pursuit of the transformation of government functions and the improvement of the market economy.

The institution of a new type of administrative permission, such as the GHG emissions permits, must be considered very carefully. According to Article 12 of the Administrative Permission Law, the specific scope of the administrative permission that may be instituted includes, for instance:

(1) matters relating to the special activities that directly involve... protection of the ecological environment..., which are subject to approval in accordance with the statutory requirements; (2) matters relating to the development and utilisation of limited natural resources, the allocation of public resources as well as access to the market of the special trades that have a direct bearing on public interests, to which special rights need to be granted;...(4) matters relating to important equipment, facilities, products..., which need to be verified by means of inspection, tests, and quarantine, and in accordance with technical standards and specifications;...(6) other matters for which the procedure for administrative permission may be instituted, as provided for by laws and administrative regulations. ${ }^{2}$

Whether GHG emissions fall within the scope of the specific categories stipulated in Article 12 or the general category of 'other matters' provided by other laws and administrative regulations depends primarily on the perception and understanding of the impact of GHG emissions, a controversial topic per se. Nevertheless, the creation of a GHG emissions permit is possible if it is required by specific laws and administrative regulations, such as the climate law or other climate-related laws or administrative regulations. In addition, the procedure for administrative permission regulating the matters provided in Article 12 above may also be instituted by local regulations where relevant laws or administrative regulations are not formulated. ${ }^{3}$ Furthermore, if it is really necessary for administrative permission to be granted directly, the provincial governments may institute provisional procedures for administrative permission by adopting rule of local government. ${ }^{4}$

Furthermore, attention may also be paid to the system of registration for the record, another alternative to the permitting system which was described briefly in the MRV rules of the Shanghai pilot project. With regard to the registration system, there may be no need for the authority to approve the monitoring plan, since it will not be considered as one kind of administrative permission, which is necessary before the enterprises can carry out certain activities. On the contrary, this system of registration for the record belongs to another regulatory

${ }^{1}$ See Administrative Permission Law of China.

2 Ibid. at Article 12.

3 Ibid. at Article 15 .

${ }^{4}$ Ibid.. 
instrument applied by the government for supervision afterwards, in which the administrative permission or approval is not required ex ante. In other words, the emitter can emit specific GHGs after submitting sufficient and qualified materials including the monitoring plan for registration, without approval by the government. The choice of the registration system seems to be a practical approach, in light of the controversy about the impact of GHG emissions and the sensitivity around administrative permissions in China. In this sense, the emitters can operate and emit the GHG emissions without applying for a GHG emissions permit, but the government can still oversee the monitoring activities and may punish the emitter by prohibiting it from emitting GHGs in line with the Law on Administrative Penalty, if the emitter's failure to meet the basic requirement provided by the MRV rules is detected in the inspection by the verifiers or the government. In this case, according to the rule of law, there should be a possibility for the emitters to go to the court to challenge the punishment decision, for instance, by arguing an alternative method to monitor in good faith.

\subsubsection{Sanctions}

\section{Types of penalties applied in the pilot projects}

Various types of noncompliance by the participants may occur. In addition to the requirement of an MRV system, a rigorous sanctions regime is an essential element of an effective ETS. Taking into account the special nature of a market-based system as well as its ultimate environmental goal, several major penalties (including financial, administrative and criminal) may be options in designing sanctions appropriate for emissions trading. Each pilot project has suggested that several types of the penalties will be employed in the enforcement package for the Chinese ETS.

First, imposing a financial penalty seems to be a standard option. The imposition of financial penalties on an offender who does not surrender sufficient allowances to cover its actual emissions has been widely considered to be a necessary and effective approach in order to reduce or to remove the incentive for noncompliance. Moreover, not only the excess emissions but financial penalties will also be imposed for the failure to fulfil obligations in relation to the MRV system to a different extent in the pilot projects of Shenzhen, Shanghai, Beijing, Guangdong, and Hubei. Yet, no financial penalties had been established in the pilot projects of Tianjin and Chongqing by July 2014 .

Second, requiring compensation for excess emissions is necessary to provide incentives for the achievement of the environmental goal. The emissions cap set for the ETS is equal to the overall quantity of allowances; thus, the amount of emissions emitted by emitters should not exceed the quantity of allowances held by them. The enforcement rules in the Shenzhen pilot project may provide a good model for the Chinese pilot projects, explicitly providing that the governmental authorities can order the emitter to surrender the number of allowances required to cover the extra emissions within a specific time period or the governmental authorities will deduct the allowances directly from the holding account, including, if necessary, from allowances for the next year's holdings. ${ }^{1}$ Moreover, if the emitters covered by Guangdong and Hubei pilot projects

\footnotetext{
${ }^{1}$ Article 75, Interim Measures on Carbon Emissions Trading Management in Shenzhen, Shenzhen Municipal
} 
still refuse to perform the obligation to surrender the allowances as ordered by the provincial DRC, twice the allowances will be deducted from the allowances for the next year's holding. ${ }^{1}$ In contrast, other pilot projects, such as Shanghai and Tianjin, only provide that the governmental authorities would order the emitters to make the correction, without any specificity as to how.

Third, other types of penalties, such as administrative and criminal penalties, should also be considered in designing the enforcement mechanisms. According to the Law on Administrative Penalty, types of administrative penalties include:

(1) disciplinary warnings; (2) fines; (3) confiscation of illegal gains or confiscation of unlawful property or things of value; (4) ordering the suspension of production or business; (5) temporary suspension or rescission of permits or licences; (6) administrative detention ${ }^{2}$; and (7) other penalties as prescribed by laws and administrative regulations. ${ }^{3}$

In this respect, emitters in the Shanghai pilot project that violate the MRV rules may face, administrative penalties in addition to financial penalties, including 'naming and shaming' by publishing the noncompliance and possible disqualification from receiving governmental funding and other types of support. ${ }^{4}$ Meanwhile, 'naming and shaming' has been employed by the pilot projects of Shenzhen, Beijing and Shanghai in order to urge the emitters to comply with the schemes. Moreover, the warning and a ban on verification has also been applied in some pilot projects. Furthermore, criminal penalties may also be applied to third-party verifiers that issue false verification reports in Tianjin. ${ }^{5}$

\section{Legal basis for penalties in the pilot projects}

In order to ensure compliance and instil confidence in the ETS, it is necessary to establish a binding and stringent sanctions regime. The legal basis and specific implementation procedures for penalties to be applied by local governments in the pilot projects should be consistent with the Chinese legal system. Because most of the penalties that would be imposed by the pilot projects will be administrative penalties, the establishment and implementation of sanctions for noncompliance ought to be designed in accordance with the Law on Administrative Penalties to ensure that the sanctions will be enforceable. ${ }^{6}$ Administrative penalties may only be created through laws, administrative regulations, local regulations and specific rules of ministries and local governments. ${ }^{7}$ In light of the fact that GHG emissions are still not considered as pollutants to be regulated in China, the sanctions provisions established in the Environmental Protection

Government, 19 March 2014.

${ }^{1}$ Article 37, Trial Measures of Guangdong Province on the Management of the Carbon Emissions, Guangdong Provincial Government; see also Interim Measures of Hubei Province on the Management and Trading of the Carbon Emission Right, at Article 46.

2 The administrative detention is usually not more than 15 days, see for instance Law on Public Security Administration Punishments of China, Standing Committee of the of the National People's Congress, 26 October 2012. Although the administrative detention is not a criminal sanction like imprisonment, it allows a specific governmental department, in particular the public security department, to restrict the freedom of the individual for some time. There is already debate and criticism over the establishment and implementation of administrative detention in China.

3 Article 8, Administrative Penalty Law of China.

4 Article 40, Trial Management Measures for Carbon Emissions in Shanghai, Shanghai Municipal Government.

5 Article 34, Notice of Distributing Interim Measures on Management of Carbon Emissions Trading in Tianjin, General Office of Tianjin Municipal Government.

6 Article 3, Administrative Penalty Law of China.

${ }^{7}$ Ibid. at Article 14. 
Law cannot be applied directly in the case of $\mathrm{CO}_{2}$ pilot projects. Until the end of November 2014, except for the local regulations adopted by the Shenzhen and Beijing authorities, and three four rules of local governments promulgated for the pilot projects of Shanghai, Guangdong, Shenzhen and Hubei, other regulatory documents relating to the pilot projects are mainly issued in the form of 'other normative documents' adopted by local governments that are not the formal legislation in China. Hence, one may raise questions as to whether local regulations, rules of local governments and other governmental documents adopted in the pilot projects have sufficient legal status to impose penalties.

The Law on Administrative Penalty as well as the Legislative Law in China permits the imposition of administrative penalties through local regulations, except for the restriction of freedom of individuals and the rescission of a business licence of an enterprise. ${ }^{1}$ However, there are limitations as to the type of administrative penalties that may be imposed under the rules of certain local governments; for example, the administrative penalty of a disciplinary warning or a certain level of fine may be all that is permitted under specific circumstances prescribed in the law. ${ }^{2}$ Therefore, some of the extra administrative penalties mentioned above could be implemented through local regulations and rules of local government adopted in the pilot projects; however, the rescission of a business licence of an enterprise or criminal liability for noncompliance can only be established at the national level.

Fines can be established by law, administrative regulation or local regulation. ${ }^{3}$ In addition, a certain level of fine could be imposed based on the rules of ministries and provincial governments. ${ }^{4}$ In this respect, the Standing Committees of the People's Congress of Shenzhen and Beijing as well as municipal / provincial governments of Shanghai, Shenzhen, Guangdong and Hubei have the authority to establish a financial penalty for noncompliance through local regulations and rules. At the same time, it is also the main reason for the lack of financial penalties in the pilot projects of Tianjin and Chongqing, which have only adopted the governmental normative documents rather than relevant local regulations or rules of local governments yet. In line with the Chinese legislative system, hence there is no legal barrier for provincial (and certain municipal) governments, such as the local governments implementing the pilot projects, to impose the financial penalty through the local regulation and rule of local government.

\section{Effectiveness of financial penalties in the pilot projects}

Financial penalties are expected to be an important sanction for noncompliance. In the pilot projects of Shenzhen and Beijing, financial penalties for excess emissions are indexed to the prevailing market price. For example, the financial penalty adopted in Shenzhen is equal to three times the market average price of last six continuous months. ${ }^{5}$ Because the amount is prescribed,

\footnotetext{
1 Ibid. at Article 11.

2 Ibid. at Article 13.

3 Ibid. at arts. 9-11.

${ }^{4}$ Ibid. at arts. 12-13.

5 Article 8, Provisions of controlling carbon emissions for Shenzhen special economic zone, Shenzhen People's Congress Standing Committee. See also Article75, Interim Measures on Carbon Emissions Trading Management in Shenzhen, Shenzhen Municipal Government.
} 
there is no need for the local authority to determine the specific amount of fine. In contrast, the Shanghai and Guangdong pilot projects permit the competent authorities, usually the provincial DRC, to determine the fine within a certain range stipulated in the rules of local government. As for Hubei pilot project, the fine is connected to the market price but limited to a cap of 150, 000 CNY.

In a market-based system, the financial penalty can play a key role in ensuring the compliance of the participants in pursuit of the profits to the detriment of the environment. ${ }^{1}$ Nevertheless, the effectiveness of the financial penalty depends largely on the level of the penalty. Although exorbitant penalties may not always prove to be effective, ${ }^{2}$ if the penalty is too low, the low cost of breaking the law may jeopardise the programme. The financial penalty established in Shenzhen, imposing a fine equal to three times the market price on the violator demonstrates the government's attempt to raise the cost of breaking the law in order to better ensure the effectiveness of the sanction. Moreover, a financial penalty can also act as a deterrent for potential violators because the emitters, as rational economic players, might be expected to choose to buy allowances to cover excess emissions from the market at market prices rather than paying three (or five) times as much in fines.

However, it is still an open question whether the penalties applied in other pilot projects, such as a cap on the penalty of $150,000 \mathrm{CNY}$ in Hubei, will serve as an effective deterrent. In this respect, it is criticised that the financial penalties for the noncompliance in the $\mathrm{SO}_{2}$ ETS pilot projects, such as the maximum fine of 30,000 CNY in Taiyuan and 100,000 CNY in Jiangsu, have been too small to ensure the compliance with the schemes. ${ }^{3}$ Compared to the high cost in emissions reduction, literature suggests that the emitters may simply choose to pay the maximum fine and continue to emit $\mathrm{SO}_{2}$ without any regulatory constraint, leading to insufficient motivation to participate in the trading and comply with the scheme. ${ }^{4}$ However, due to the limited legislative competence of the local governments, it is difficult for the local government to establish the stringent financial penalties in the rules of local government, the specific maximum amount of which shall be stipulated by the standing committees of the provincial people's congresses. ${ }^{5}$ In this respect, for instance, the maximum for the fine that can be established by Hubei provincial government has already been raised largely from 30,000 to 150,000 CNY by the standing committee of the people's congresses of Hubei province ${ }^{6}$, although it may remain relative low for some big industries.

Although the revised Environmental Protection Law cannot provide a solid and direct legal basis for the pilot projects as mentioned above, the strict sanctions for the illegal discharge of pollutants established in the amendment to the Environmental Protection Law in 2014 may pave the way for a stringent financial penalty punishing the excess emissions covered by the ETS, if

\footnotetext{
${ }^{1}$ Cheng, Y. Y. (2013), p.32.

2 See Shavell, S. (1985).

3 See Morgenstern, R. D., et al (2004), p.26; see also Chang, Y. C. \& Wang, N. (2010), p.3363.

${ }^{4}$ See Chang, Y. C. \& Wang, N. (2010), p.3363.

5 See Article 13, Administrative Penalty Law of China

${ }^{6}$ See The regulation of the standing committee of the people's congresses of Hubei province on the maximum amount of the administrative fine established by governmental rule, adopted on 21 September 1996, revised on 23 May 2013 (in Chinese).
} 
specific GHGs are deemed to be pollutants in the future. According to the Environmental Protection Law revised in 2014, if an emitter is fined and ordered to make a correction due to the illegal discharge of pollutants but they refuse to make the correction, the competent authority that makes the punishment decision may impose the fine consecutively on a daily basis according to the original amount of the fine commencing from the date immediately following the date when the emitter was ordered to make correction. ${ }^{1}$ Moreover, it is stipulated that local regulations may increase the types of illegal acts subject to the fine consecutively on a daily basis as prescribed above in light of the actual needs of environmental protection. ${ }^{2}$ In this sense, there seems to be a possibility for the local ETS pilot projects to impose this strict fine on the excess emissions in relevant local regulations, depending on three conditions: specific GHGs are regulated as pollutants in China; actual needs of environmental protection are demonstrated; and local authorities adopt specific local regulations in line with the Chinese legislative system. Since these are new legal provisions, it needs to be observed whether any legal problems may occur in practice.

\section{Implementation of the sanction regimes}

Since most of the sanctions established for the non-compliances in the pilot projects are administrative penalties, the decision to impose a penalty on the offender should be made in accordance with the legal procedures stipulated in the Law on Administrative Penalties, which requires the administrative body to conduct a comprehensive, objective and fair investigation and to collect relevant evidence. ${ }^{3}$ However, the detailed provisions related to these procedures are still missing in some of the local regulations or other relevant rules in the pilot projects to date.

Although some special enforcement measures have been employed to implement the sanctions regime, the pilot projects face several challenges. It can be exemplified by the attempts of the Beijing DRC to regulate the discretion in the implementation of the administrative penalties by adopting detailed standards for decision. ${ }^{4}$ With regard to this widely spreading application of the standards for administrative discretion (cai liang ji zun), a growing body of literature is beginning to focus on the legal effect, implementation and other legal issues relating to it. ${ }^{5}$ Because of its legal status (it concerns 'other normative documents' adopted by the Beijing DRC), this decision and the standard can only be considered to be a kind of policy provision in the Chinese system, still having a substantial impact on the governmental department as well as the emitters concerned. On the one hand, this kind of policy provision appears to be a self-regulatory document binding the Beijing DRC per se, aiming to reduce and to avoid its abuse of the discretion in the course of punishing the violators to the extent possible. On the other hand, the rights and obligations of the emitters concerned, in particular the violators and the potential offenders, will be influenced by the implementation of this categorised and detailed

\footnotetext{
${ }^{1}$ Article 59, Environmental Protection Law.

2 Ibid.

3 Article 36, Administrative Penalty Law of China.

${ }^{4}$ Decision on the regulation of the discretion in implementing the administrative penalties in the carbon emissions trading, Beijing DRC, 6 May 2014 (in Chinese)

${ }_{5}^{5}$ More discussion on this topic can refer to some Chinese literature, such as Yu, L. Y. (2008); Zhou, Y. Y. (2007).
} 
punishment standard in the enforcement process, despite the legal nature of this decision and standard.

Furthermore, under the Law on Administrative Penalties, administrative counterparts, including the citizens, legal persons and organisations, have the right to refuse to accept an administrative penalty and may apply for administrative reconsideration or bring an administrative lawsuit appealing that penalty. ${ }^{1}$ Emitters participating in emissions trading have the same right to appeal the administrative decision in court, although it remains questionable whether such case law will emerge in China in order to provide a source with further information on how the sanction regime can be applied in practice and what legal protection ETS participants may get. Especially in view of the powerful government but weak judicial system in China, in particular the fact that the courts are funded by the governments at the same level, the limited role of judicial system and independent court decision has to be a concern. ${ }^{2}$

\subsubsection{Concluding observation}

Achieving a high level of compliance with the ETS relies on a stringent enforcement package including a robust MRV system and rigorous sanctions for noncompliance. As described in section 3.4 of this chapter, some pilot projects have provided extra auctioning to avoid noncompliance, implying the link between allocation and enforcement. However, considering the common problem of weak enforcement of environmental regulations in China generally, the design and implementation of an effective enforcement package for emissions trading, consistent with other aspects of the Chinese legal system, presents a challenge to the pilot projects and the possible development of a national scheme in China.

As discussed above, a system of self-monitoring, self-reporting and third-party verification has been applied in the pilot projects. Because of the potential for corruption and collusion between verifiers and emitters, special attention must be paid to the independence of the third-party verification body in the legal framework for the Chinese $\mathrm{CO}_{2}$ ETS. In this regard, it will be necessary for China to establish and to strengthen the legal framework for accreditation and verification. Providing for spot-checking or a full review of the verification report by the government or experts working for the government may also be helpful in improving and ensuring the quality of the verification report. Furthermore, use of GHG emissions permit system and monitoring plan to be approved by or registered for the record to the government may improve the integrity and certainty of the programme for covered emitters.

In order to develop a stringent legal responsibility system for noncompliance, it is important for China to make sure that the primary types of noncompliance are subjected to just sanctioning in conformity with the Chinese legal system. In other words, not only excessive emissions should be punished but also noncompliance with regard to the MRV should result in appropriate penalties. Appropriate penalties should include not only the surrender of an equal amount of allowances for excess emissions until the next trading period, but it should also include an

1 Article 6, Administrative Penalty Law of China.

2 Du, Q. (2009), p.441-442 
effective and proportionate financial punishment. In this respect, both the options of a fixed amount of penalty and a penalty linked to the market price of the allowances have been reflected in the pilot projects. Additional penalties, such as administrative penalties for other types of noncompliance have been applied or considered by the pilot projects. In any case, all sanctions should be designed and enforced in accordance with the Chinese legal system, in particular the Administrative Penalty Law. Given the currently quite limited role of courts in China, it would be important to ensure the private actors can challenge the government's sanction decision before courts, if China indeed wants to follow the rule of law. However, it remains to be seen, and has to be evaluated, whether, on the one hand, the practice of imposing penalties will be effective enough, and, on the other hand, how the imposition of penalties will be done in view of the Chinese rule of law and how, in this respect, operators may have access to independent courts.

Based on this analysis of the existing pilot projects, including consideration of the design concerning the MRV system and sanctions for noncompliance, at least two important challenges remain. First, the legal nature and effect of the enforcement rules and their relationship to China's legal regime is an important challenge. A successful ETS requires a strong enforcement arm. This will require a sound legal basis with clear authority for the issuance of the GHG emissions permit, requirements for MRV and sanctions for noncompliance. As noted above, there is some uncertainty as to the legal foundation of the pilot projects. This is particularly the case with regard to enforcement, due to the legal source of requirements and the hierarchy of law in China, especially where guidelines and standards are involved. It is understandable that the legal framework of the pilot projects may require further attention given the complexity of the subject matter and the complication in legislative procedures. Moreover, the effectiveness of enforcement will largely depend on the legislative competence of the local authorities in designing specific enforcement rules.

Secondly, it remains quite questionable to what extent the enforcement package provided and implemented at the local levels can ensure the compliance and thus the environmental effectiveness achieved by the pilot projects. The pilot projects are encouraged to explore any feasible approaches to the establishment of an effective enforcement package. Most of the measures being implemented - including the requirement for an MRV system and the establishment of penalties - have been adopted in the form of local regulations, provincial governmental rules or recommended standards at the local level, which is consistent with the authority granted under existing Chinese laws. Although there are common features in the pilot programmes regarding self-monitoring, self-reporting and third-party verification, it is inevitable that the diversity of specific enforcement rules developed by local authorities and seeking to accommodate different local circumstances will develop.

The effectiveness of enforcement that relies on self-monitoring and self-reporting will depend upon the integrity of the data and the technological tools available to the regulated entities and the regulators. The development of effective programmes and tools will require human and financial resources. Due to the GDP-oriented performance evaluation system of the local cadre, in making decisions about the level of enforcement and the strictness of the requirements, local 
governments will be mindful of the benefits of having these industries in their local economy; accordingly, there is still a risk that a 'race-to-bottom' may result when designing and implementing enforcement rules in China. In this respect, the active and crucial roles of the local authorities in designing and implementing the enforcement package will have an important influence on the environmental effectiveness of the programmes as well as the development of a level playing field for the industries concerned. ${ }^{1}$

As a result, particular attention must be paid to the appropriate allocation of competences between the central authority and the local authorities with regard to the design and implementation of the enforcement programme. These questions will have particular relevance as China's central government moves to establish a national scheme based on the lessons learnt from the pilot projects, which will be discussed in the following section concerning the national scheme.

\section{The potential for a national ETS in China}

At the very beginning of the experimentation with the $\mathrm{CO}_{2} \mathrm{ETS}$ in China, the establishment of a national scheme based on the experience of pilot projects in 2015 has been put on the agenda of the Chinese government in particular the NDRC. The description and analysis of the pilot projects that are in the process of being designed and implemented has indicated some potential legal barriers and political circumstances that local governments have to deal with when developing a sub-national ETS. In this sense, the potential for a national ETS in China can serve as an alternative policy option. This section will firstly shed light on the rationality for a national ETS through comparing the option of sub-national ETS with a national scheme and then move to the discussion on the possible design of the national ETS in the Chinese context.

\subsection{Rationality for a national ETS}

Admittedly, by all indications, the period from 2011 to 2015 will be an intensive period of experimentation with the $\mathrm{CO}_{2}$ ETS in China. The economic impacts that the ETS pilot projects may have on the Chinese economy by the end of the $12^{\text {th }}$ Five-Year Planning (2011-2015) may determine whether or not a national ETS will be established. ${ }^{2}$ At the time of writing, it is still hard to assess and analyse what economic impact the ETS pilots have on the Chinese economy, but the questions of whether a sub-national ETS or a national ETS would be a suitable choice for China have been raised. Some have argued that the scope of the pilot projects should be expanded while others propose the linkage among the pilot projects based on the assessment and a summary of them, in order to move to a national ETS. ${ }^{3}$ Practically speaking, the pilot projects, as expected, have indeed provided for thought-provoking lessons by means of identifying substantial legal barriers and political circumstances that the local governments have to, or even

\footnotetext{
${ }^{1}$ Peeters, M. (2006b), p.185.

2 Han, G., Olsson, M., Hallding, K., \& Lunsford, D. (2012), p.52-53.

${ }^{3}$ Wu, H.L., Sun, X., \& Wu, H.(2013). What challenges are facing China's carbon emissions trading into the real world? Economic Information Daily, 5 August 2013 (in Chinese).
} 
may fail to, deal with when they establish and implement the ETS at the local level. To a certain degree, it is these challenges facing the pilot projects that have driven the policy makers to consider the option of a national scheme.

Stemming from the special legal system and political system in China, most of the challenges facing the local governments discussed in section 4 of this chapter, including the inadequate competence, the concerns on the fragmentation and inconsistency of the local carbon markets and the risk of local protectionism driven by the GDP-oriented evaluation system, cannot be solved in a short time. The option of the national ETS may offer alternative solutions to these dilemmas emerging from the pilot projects.

\subsubsection{Requirement for sufficient legislative competence}

From a legal perspective, a well-designed and effective legal framework, stipulating the definite rights and obligations of the parties involved and setting up the rules for the functioning of the scheme, plays a crucial role in the establishment and implementation of the ETS. The practice of the pilot projects has indicated that such legal frameworks for the sub-national ETS are mainly provided by local authorities in the form of local regulations (thus far only in Shenzhen and Beijing), rules of local governments (in Shanghai, Shenzhen, Guangdong, and Hubei) and other governmental normative documents. Due to the strict and complicated legislative procedure, the adoption of other normative documents instead of local legislation seems to be a practical choice for the local governments who want to set up the ETS quickly according to the ambitious schedule set up by the central government.

However, the discussion in section 2 and 4 of this chapter has pointed out the potential weakness of the local regulatory framework, which maybe even cannot be qualified as an adequate legal framework because of the insufficient legal effect and the low legal ranks of its components, the local legislation and the governmental policies. For instance, as analysed in section 4 , the administrative penalties relating to emissions trading provided in the rules of local government must meet certain requirements and the specific amount of the fine should be determined by the local people's congress. ${ }^{1}$ Moreover, some important rules concerning emissions trading, such as the legal nature of the allowances, should be determined by the $\mathrm{law}^{2}$, which exceeds the legislative competence distributed to the local authorities. In this light, the local regulatory framework, without the support of the superior legislation, cannot provide an effective legal framework for the ETS because of the insufficient legislative competence of the local authorities.

On the contrary, if a national ETS is to be established, the required legislative framework providing a sufficient legal basis for the ETS can be established based on the legislation adopted at the national level. As a unitary state, it is feasible for China to establish a unified and nation-wide legal framework for the ETS. ${ }^{3}$ In line with the legislative competence distribution in the Chinese legal system, the national authorities, including the NPC and the State Council, have sufficient competence to adopt legislation addressing the administrative permit, and

\footnotetext{
${ }^{1}$ See Article 13, Administrative Penalty Law of China.

2 For instance, see Article 5, Property Law of China.

3 Feng, J. R. (2013), p.161.
} 
administrative and, if necessary, criminal penalties relating to the ETS. As a result, comprised of the national legislation clearly stipulating the legal rights and obligations of the participants as well as the potential penalties for the offenders, the legal framework will certainly have a binding legal effect on all the parties involved, not only the market participants but also the government per se. However, taking the government to court may still be a limited option, even in the national legal framework, in view of the strong government but weak judicial system in China.

\subsubsection{Concerns on the fragmentation and inconsistency of the local carbon markets}

The description in section 3 of this chapter has, to a large degree, revealed the diversity of the design features of the pilot projects in terms of the target setting, allowance allocation methods, MRV rules, and sanctions which are determined by the local governments in the bottom-up experimental approach. In addition to the local disparities in, for example, the economic development, industrial structure and the emissions profile among the pilot projects, other factors have also contributed to such diversity to a large extent, including a lack of principles or measures guiding the design of the pilot projects, different political wills and capacities of the local governments. Different from the relatively integrated collaboration among the governmental agencies at the national level, the climate governance regimes at the local level appears to be rather fragmented and divergent. ${ }^{1}$ Since the $\mathrm{CO}_{2}$ ETS is currently designed and implemented respectively in each pilot project, an inevitable outcome may be foreseen that there will be at least seven local carbon emissions trading markets established, based on seven independent regulatory frameworks, at the same time in China. Given the parallel existence of the local carbon emissions trading with diversified features and isolated geographic coverage, fragmentation of the local carbon markets exists.

Especially for emitters and sectors covered by different pilot projects, the concerns on and potential negative influence of the fragmentation and inconsistency of the local carbon market needs to be evaluated when discerning the lessons to be learnt. Due to the diversified design of the pilot projects, emitters from the same sector but located in different regions may be treated differently, which can be exemplified by the description of the design features in terms of the allocation of allowances among the pilot projects. Although most pilot projects have opted for free allocation, it is argued that the different levels of the allowance price in the pilot projects may have a substantial impact on the competitiveness of the enterprises. ${ }^{2}$ Different costs and burdens may be imposed on similar enterprises competing with each other when they participate in the ETS, simply because of their location. In regard to the economic reform of the last three decades, China has endeavoured to build up a single market with unified rules promulgated by legislator, attempting to free individual from excessive intervention by local governments and ensure their autonomous and equal status when participating in the market competition ${ }^{3}$. In this sense, this kind of differential treatment among enterprises based on different administrative

\footnotetext{
${ }^{1}$ Zhang, H. (2012), p.10272.

2 Zheng, S., Wei, X. H., \& Zhang, M.S. (2013), p.66.

${ }^{3}$ Liang, B. (2008), p.78.
} 
regions may hamper the establishment of a single market with fair competition. This topic needs to be part of the evaluation of the pilot projects.

In addition, if the difference concerning the provisions and price is very great among the pilot projects, the fragmentation and inconsistency of the local carbon market may also aggravate the carbon leakage issues, driving the emitters at issue to relocate to the sub-national schemes with loose requirements or to escape from them to other non-ETS regions. Furthermore, unfortunately, in the case of carbon leakage, together with the transfer of carbon emissions, some additional environmental problems such as other types of pollution may also be transferred to poorer regions when the emitters move there. In this sense, the poorer regions often suffer from the extra negative environmental impact caused by carbon leakage.

Meanwhile, the impact of the path dependence also needs to be considered in the application of the experimental approach. The experiments may create the possibility of exploring the promising design of a national ETS in China, but one may also raise the question whether the fragmentation of established local carbon markets would impede the establishment of a national scheme. For instance, due to the inconsistency of the rules concerning the measurement and reporting of the $\mathrm{CO}_{2}$ emissions adopted in the pilot projects, the lack of homogeneity and comparability may constitute one of the biggest barriers to linking pilot projects or establishing a national scheme. ${ }^{1}$ In this respect, a transitional period to converge the projects might be a way out.

Moreover, the fragmentation and inconsistency of the pilot projects have also given rise to the questions of whether the local carbon markets can function and develop in a vital way facilitating cost-effective emission reductions. In this respect, there is an indication that the isolation and limited market size of the $\mathrm{SO}_{2}$ ETS in several cities have made a contribution to their failure in China. $^{2}$ In view of the limited scope, coverage and number of participants of each pilot project, it remains a question whether these local markets can be developed in a positive way with sufficient trading among market participants.

\subsubsection{Risk of local protectionism driven by the GDP-oriented evaluation system}

Given the political context in China, the risk of local protectionism driven by the GDP-oriented evaluation system of the cadres is worthy of attention when designing and implementing the ETS at the local level.

As discussed in section 4.2 of this chapter, the potential of local protectionism with the risk of carbon leakage has indicated that local governments may be motivated to give preferential treatment when allocating allowances to emitters located in their territories, aiming to maintain the fast growing rate of the local GDP. The analysis of the legal effect concerning the carbon intensity reduction target set up in the $12^{\text {th }}$ Five-Year Planning (2011-2015) has suggested that

${ }^{1}$ Zheng, S., Wei, X. H., \& Zhang, M.S. (2013), p.65.

${ }^{2}$ Detailed discussions can be found in the literature, for instance, Wang, Y.G. \& Ge, X.A. etc (2011), p.271. 
the fulfilment of these targets is backed up by the promotion system of the local cadres as well as the administrative accountability system. However, not only the promotion but also the punishment of cadres still relies heavily on the GDP-oriented evaluation system.

In this respect, a research report analysing the incentives and outcomes of the Chinese local environmental policies in 283 cities between 2000 and 2009 has suggested that municipal spending on environmental improvements is at best uncorrelated to the cadres' odds of promotion as well as local GDP growth. ${ }^{1}$ To be specific, one standard deviation increase in the average GDP growth rate compared to the previous level raises the probability of promotion for mayors by $10.0 \%$, but one standard deviation increase in the average GDP scaled environmental improvement investment lowers the probability of promotion for mayors by $6.3 \%{ }^{2}$ This finding may, to a certain degree, explain why local governments are reluctant to implement or even resist environmental policies which would hinder sustaining high levels of local GDP growth. Moreover, it can also be exemplified again by the failed attempt during 2005 and 2006 to change the GDP-oriented system, by incorporating a certain environmental index in the performance evaluation of the local officials on the basis of how much they have protected or damaged the environment, due to the technical difficulties and widespread opposition from local officials. ${ }^{3}$ Despite the positive indication that the system is being changed slowly, exemplified by the National $12^{\text {th }}$ Five-Year Planning for Environmental Protection that incorporates environmental protection into the so-called 'one-vote veto' index of the performance evaluation system of the local government for the first time ${ }^{4}$, there is most likely still a long way to go.

The risk of local protectionism stemming from the existing GDP-oriented evaluation system in China may influence the design and implementation of the pilot projects. Taking target setting as example, an emissions cap is usually considered as a potential constraint on the local economic growth, in light of the connection between carbon emissions and economic development. A structural administrative resistance, in which the desire for fast economic growth has discouraged the attempts to establish legally binding and stringent emission targets, has been suggested by Lo in his discussion of target setting in the pilot projects. ${ }^{5}$

Moreover, the existing legislative competence distribution in China might also facilitate the occurrence of local protectionism. According to China's current legislative system, the local authorities, in particular those in charge of the design and implementation of the pilot projects are competent to adopt relevant local regulations and local governmental rules. Nevertheless, owing to the low transparency, lack of public participation, the lagging and weak legislative oversight from higher-level authorities in the local legislative process, the local interest, inter alia some unreasonable motivation may have had a negative impact on the local legislation, turning the legislation into the tool supporting rather than fighting against local protectionism. ${ }^{6}$ Regarding the design and implementation of carbon emissions trading, it is also possible for

\footnotetext{
${ }^{1}$ See Wu, J., et al. (2013).

2 Ibid, p.22-23.

3 Economy, E., \& Lieberthal, K. (2007), p. 92.

${ }^{4}$ Notice of Printing and Distributing the National $12^{\text {th }}$ Five-Year Planning for Environmental Protection, State Council, 15 December 2011 (in Chinese).

${ }^{5}$ Lo, A. Y. (2012), p.765-766.

${ }^{6}$ See Ma, H. D. (2003), p.158; see also Hu, Y. H. (1999).
} 
local authorities to adopt relevant rules protecting the local industries by means of setting a loose emissions reduction target, allocating excess free allowances to the emitters and applying a weak enforcement package.

Given local authorities' deep-seated political unwillingness to disrupt local economic growth under China's political circumstances in which the GDP-oriented evaluation system still plays a dominant role, the propensity and possibility of local protectionism would still exist in the national scheme designed by the central government. Although it would be difficult for the local authorities to protect the local emitters by means of adopting relevant legislation designing the ETS, it may be still possible for the local governments to do that in the implementation of the national scheme, such as in the form of lax enforcement or even other types of collusion and corruption. In this light, an effective environmental governance structure supported by centralised administrative control over the local authorities has been argued to play a crucial role in achieving effective enforcement. ${ }^{1}$ Therefore, in the course of designing and implementing the ETS, it still remains important for the central authority in China to strike a balance between respecting the discretion enjoyed by the local authorities on the one hand and controlling the risk of local protectionism on the other hand. In this respect, the establishment of the national scheme in which the basic elements of the ETS will be determined and supervised at the central level may help to reduce the risk of local protectionism and to control the local protectionism to the extent possible.

\subsection{Further consideration on the possible design of the national}

\section{ETS}

In line with the experimental approach, the pilot projects are supposed to pave the way for the establishment and operation of a national scheme. On the one hand, the challenges facing the pilot projects analysed above have demonstrated the rationality of the need for a national ETS to a certain extent. On the other hand, the experience gathered in the pilot projects may provide some useful lessons for dealing with some basic issues relating to the ETS in the Chinese context, for example the design of allocation methods and of an enforcement framework, which will be discussed below. In addition, the competence distribution between the central and local authorities still deserves due consideration for the design of the national scheme by the policy makers at the national level.

\subsubsection{Consideration on competence distribution for target setting}

\section{Significance of competence distribution in a national scheme}

As far as the national scheme is concerned, one has to pay attention to the need for a legal framework providing clear competence distribution between the central and local authorities when designing and implementing the national ETS. Contrary to the informal and blurred

${ }^{1}$ Sitaraman, S. (2007), p.335. 
interaction between the central authority (in particular the NDRC) and the local authorities (including the local governments and the local people congress) in the pilot projects, the relationship between the central and local level must be defined clearly in a national ETS in accordance with the Chinese legal framework.

However, the competence distribution between the central and local authorities, including but not limited to the legislative competence distribution discussed in section 2 of this chapter, has been demonstrated as an important but difficult issue throughout the reformation and development of Chinese political, economic and legal systems. The principle of 'giving full scope to the initiative and enthusiasm of the local authorities under the unified leadership of the central authorities' ${ }^{1}$ stipulated in the Constitution has provided general guidance on the competence distribution between the central and local authorities, with the characteristic of centralisation together with a certain degree of decentralisation. Meanwhile, this general principle was further clarified in the important policy and blueprint of the reform and development adopted by the ruling party, in which the economic and social affairs were classified into three categories including national and inter-regional affairs, local affairs and affairs managed jointly by the central and local authorities for the first time, providing conditions for competence distribution between the central and local authorities. ${ }^{2}$ However, it is still hard to distinguish the national and regional affairs in practice, in particular in the case of $\mathrm{CO}_{2}$ emissions, produced locally but affecting the environment nationally and globally. In this respect, the coordination between the central and local authorities constitutes a necessary element of the legal framework for the Chinese ETS.

Furthermore, similar to other environmental governance structures, the co-existence and co-function of centralisation and decentralisation will still be found in the national scheme. Given the vast scale of the potential national scheme, with large number of participants, the national ETS cannot be designed and implemented by the central authority without the involvement of the local authorities, especially in terms of the allocation of allowances and enforcement ${ }^{3}$. As analysed in section 2 of this chapter, the legal framework for the national ETS has to be established in line with the multi-level governance structure in China. However, one can raise the question of what other tasks still need to be accomplished by the local authorities in the case of a national scheme. Following the existing approach of environmental governance, in the national ETS, the central authority may focus on the policy making and the construction of the basic legal framework for the ETS at the national level, while the local governments are responsible for the enforcement at the local level. Moreover, scholars argue that fundamental and common issues should be stipulated in laws and administrative regulations adopted at the national level, but operational rules for the specific implementation of emissions trading are allowed to be adopted at the local level aiming to accommodate the local circumstances. ${ }^{4}$

\footnotetext{
1 Article 3, Constitution of China.

2 Decision of the Central Committee of the Communist Party of China on Some Issues concerning the Improvement of the Socialist Market Economy, adopted by the $3^{\text {rd }}$ Plenary Session of the 16th CPC Central Committee, 14 October 2003 (in Chinese).

3 Xiong, L., \& Qi, S. Z. (2012), p.64.

${ }^{4}$ See Zhang, Z. T. (2010c), p.48; See also Feng, J. R. (2013), p.161; Zheng, S., Wei, X.H. \& Zhang, M. S. (2013), p.66.
} 
With regard to the emissions reduction target of the national scheme, in particular the cap, if the cap-and-trade model is really going to be chosen, it can still be set through two approaches analysed in section 4.1 of this chapter. The first approach is the decentralised approach and the second approach would be the centralised model. If the decentralised approach is the case, the emissions reduction target for the national scheme may be the sum of the local targets determined at the local level via the bottom-up approach. If the centralised model will be applied, the target or the cap for the national scheme will be firstly decided at the central level and then distributed to the local governments based on certain criteria. These two models will be elaborated upon below.

\section{Concerns on the inconsistency of the local caps under the decentralised model}

When the decentralised model is applied, one has to raise similar questions as to how the central government can guide and control the target setting at the local levels, aiming to ensure the fulfilment of the national carbon emissions reduction target and the environmental integrity of the national scheme. There may be two possible outcomes in the decentralised approach. On the one hand, substantial competences may be distributed to the local authorities to determine their local targets, which need not be approved and will not be adjusted by the central government. On the other hand, the local targets set up by the local authorities cannot be determined without the formal approval of the central authority.

Given the unique social and political structure in China, the second possible outcome may be more likely to occur. In view of the evidence and the lessons learnt from the economic reform since 1978, there is an indication that the attention of central government has been gradually shifted towards the macro-level control, trying to leave the micro-level regulation in the hands of local governments and market players. ${ }^{1}$ However, due to the significance of the emissions reduction target as an important instrument influencing economic development and environmental integrity, it would be better if the target setting for the national ETS would fall within the scope of the macro-level control by the central government. Hence, with the approval from the central authorities, it is possible for the local authorities to set up the local targets summing up the final target for the national scheme.

In this sense, specific attention must be paid to the further challenges facing the legal framework, in particular the legal procedures for the approval by the central government and the remedies for the potential tension between the central and local authorities. For instance, when the provincial targets proposed/determined by the local authorities are refused or revised by the central government, probably represented by the NDRC, one may raise the question as to what the local governments can do if they are not content with the results of this disapproval. The process of legalisation in terms of competence distribution may be considered as a new and effective method to adjust the new central-local relationship in the ETS. ${ }^{2}$ Nevertheless, except for the legislative review stipulated in the Legislative Law, few legal mechanisms exist to deal with the conflict between the central and local governments in China. Especially taking account of the

\footnotetext{
${ }^{1}$ See Liang, B. (2008), p.74; see also World Bank (1988).

${ }^{2}$ Liang, B. (2008), p.75; see also Li, L. C. (2000).
} 
strong administration organisation relying on the administrative commands and the weak judicial system, there seems to be little opportunity for the court to step in to resolve the potential tension between the local and central governments. As a result, it appears impossible for the current Chinese legal system to provide specific judicial review or remedies addressing potential disputes over target setting emerging from the decentralisation model to be applied in the national scheme.

\section{Potential challenges relating to the centralised model}

If the centralisation model is adopted, two possible outcomes may also emerge. The first possibility is that the target will be determined by the central government and the emitters covered by the scheme will receive the allowances based on unified allocation principles or rules, while the second possibility is that the central government will decide on a nation-wide target and allocate the target to the local governments, similar to the case of the carbon intensity reduction target. Moreover, according to Sun Cuihua, the vice president of Department of Climate Change of the NDRC, there is an indication that the cap for the national scheme would probably be set up following a top-down approach similar to that of the second option mentioned above. $^{1}$

In the first possible scenario that the target will be established at the central level, the potential waterbed effect needs to be taken into account. Although a nation-wide cap for the ETS is adopted by the central authority, there is still a possibility for local governments to adopt more stringent targets or measures within its jurisdiction. However, taking account of the legal experiences from the EU ETS, in particular the so-called 'waterbed effect' under the EU-wide cap, the attraction for the local authorities to adopt a more stringent policy on the trading sectors may be affected. Hence, the question as to how to balance environmental integrity on the one hand and the attraction for the local authorities to adopt a more stringent policy on the trading sectors on the other hand remains a challenge for China's ETS.

In the case of the second scenario, the challenges facing the central government may concentrate on the application of the differential treatment of the different regions with various circumstances, in particular in the course of the division of the target and the allocation of allowances. In addition to the competence distribution between the central and local governments from a vertical perspective, the equal treatment among the local regions from a horizontal perspective also needs to be dealt with delicately.

\subsubsection{Challenges relating to the allocation of allowances}

Closely connected to target setting, the allocation of allowances in the national scheme may also be designed in line with the models of centralisation and decentralisation discussed above. Meanwhile, according to a Market Readiness Proposal submitted by the NDRC to World Bank's Partnership for Market Readiness (PMR), three options for allowance allocation may be taken

\footnotetext{
1 The allowance of carbon emissions trading will be allocated by the State in the future, Beijing Business Today, 4 April 2014 (in Chinese).
} 
into consideration for a national ETS: (1) the national authority determines a uniform allocation method and directly allocates the allowances to emitters covered by the scheme; (2) the central government firstly allocates allowances to local governments, then the local governments allocate the allowances to the emitters in accordance with the allocation methods determined by local governments; (3) the allocation process is similar to that in option two, but the allocation methods will be determined by the central government rather than the local governments, leaving some flexibilities to the local governments. ${ }^{1}$ Moreover, the central government, as mentioned above, has intended to allocate the allowances of the national scheme with a top-down approach in two steps in which the allowances will be firstly allocated to the provincial governments by the central government and then the provincial governments are responsible for the allocation to the emitters. ${ }^{2}$ In this sense, due to the remarkable regional disparity in terms of economic development in China, how to apply an objectively justified differential treatment to the strong and weak regions will still be a critical issue. Furthermore, with regard to the allocation of allowances to the emitters in the second step, one must raise the question of whether the provincial government has to allocate the allowances according to unified or diversified rules.

As far as the allocation of allowances among the provincial governments is concerned, the remarkable regional disparity and unbalanced development, in particular the ongoing inter-regional emissions transfer or carbon leakage, needs to be taken into account. For instance, the last decade has witnessed a gradual inter-regional $\mathrm{CO}_{2}$ emissions transfer embodied in the power transmissions in China, from the eastern area to the central and western regions that are the major base for power generation, partly due to the different resource endowment and regional disparity influenced by the energy prices. ${ }^{3}$ From the environmental perspective, the transfer of industries together with emissions is not bad if the national carbon emissions reduction target will still be reached. Nevertheless, the re-location of the emitters, due to the attempts by some local governments to restructure the industries and the different intensity of the local environmental protection policies, still needs to be dealt with by the differentiated regional policies determined at the national level. ${ }^{4}$ As a result, it has been argued that the developed regions like the eastern provinces should be allocated more responsibility, while the poor regions such as the provinces in the central and western areas shall shoulder less of a burden but get more supporting policies, aiming to establish a national scheme with flexibility in balancing the local interest among the regions. ${ }^{5}$

Aiming to deal with the regional disparities in a more equal way under a centralised model, the allocation of allowances for the national ETS in China can be implemented through the following approaches. On the one hand, the coordination between local and central governments should be enhanced to respect and reflect local disparities and priorities. ${ }^{6}$ For instance, based on the unified principles or methodologies determined by the central government, the competence

\footnotetext{
${ }^{1}$ NDRC (2013), Market Readiness Proposal (MRP): Establishing a National Emissions Trading Scheme in China, p.87.

2 The allowance of carbon emissions trading will be allocated by the State in the future, Beijing Business Today, 4 April 2014 (in Chinese).

3 More disucussion can be found in Meng, L., Guo, J. e., Chai, J., \& Zhang, Z. (2011).

${ }^{4}$ See Xiao, Y. et al (2014).

${ }^{5}$ See Feng, J. R. (2013), p.161; see also Meng, L., Guo, J. e., Chai, J., \& Zhang, Z. (2011); Wang, K. et al. (2013); Yi, W.J., Zou, L.L., et al. (2011).

6 Teng, F. (2012), p.18.
} 
of allocating allowances to the emitters could be distributed to the local governments, allowing flexibility at the local level to the extent possible. On the other hand, mechanisms balancing different interest groups of localities need to be further considered and designed. In this sense, the preferential treatment of the weak regions may be taken into account in the initial allocation of allowances ${ }^{1}$, such as reserving a certain amount of allowances in order to support the emitters located in the weak regions. Meanwhile, given the emissions transfer that occurred with the carbon leakage, attention should also be paid to the establishment of other regional rebalance mechanisms in the legal framework for the national scheme, such as financial supporting measures for the weak regions funded by the revenue collected from the allowances auctioning in the strong regions. ${ }^{2}$

In addition to the differential treatment among the provinces in the first step of the allocation of allowances in the national scheme, the subsequent allocation to the emitters by provincial governments also has significant relevance. Both of options two and three proposed in the MRP mentioned above seem to be viable choices. In this sense, the practice of the allocation of allowances in the current pilot projects merits attention. In a report assessing the allocation of allowances in the pilot projects, an interview with industries disclosed concerns on the equal treatment among emitters covered by different pilot projects. ${ }^{3}$ From the perspective of the industries concerned, not only the diversity of the allocation methods for the same sectors located in different pilot projects, but also the various criteria and measures applied in the ex post adjustment of the allocation by the local governments, may make a contribution to the differential treatment and unequal competition. ${ }^{4}$ Moreover, the potential local protectionism is also worthy of attention. In this respect, option three, mentioned above, seems to be a promising choice for the national scheme. On the one hand, it requires the local government to allocate the allowances in line with the basic principles and unified rules determined by the central government. On the other hand, it also offers the local governments with the necessary flexibility by choosing different allocation adjustment factors provided by the central government and adopting specific implementation rules in order to accommodate the local circumstances.

\subsubsection{Evolving progress towards a harmonised enforcement system}

In parallel to the local efforts and innovation in the design and implementation of the enforcement package among the pilot projects, the ongoing attempts by the national governments to establish a national MRV system has also been witnessed in the pilot phases. In addition to the establishment of National Technical Committee 548 on Carbon Management of Standardisation Administration of China as well as the proposal of establishing a GHG emissions permitting system at the national level, ten trial guidelines concerning the MRV of GHG emissions produced by the emitters of ten sectors have been issued in a notice released by the NDRC on 15 October 2013. ${ }^{5}$ According to this notice, these specific trial guidelines are supposed to be used

\footnotetext{
${ }^{1}$ See Xiong, L. \& Qi, S. Z. (2012), p.64.

2 Meng, L., Guo, J. e., Chai, J., \& Zhang, Z. (2011), p.6143.

${ }^{3}$ See Wu, Q., Neelis, M. \& Casanova, C. (2014).

${ }^{4} \mathrm{Wu}$, Q., Neelis, M. \& Casanova, C. (2014), p.15.

5 The ten sectors include the sectors of power generation, power grid, steel, magnesium smelting, cement, civil aviation, ceramics, glass, aluminum electrolysis, and chemicals. See the Notice on printing and distributing the guidelines of the accounting methods and report of the enterprises' GHG emissions of ten sectors (Trial), General
} 
only as reference. ${ }^{1}$ However, the NDRC took a further step towards the establishment of the national MRV system in the beginning of 2014, requiring the key emitters emitting more than 13,000 tonnes of $\mathrm{CO}_{2}$ equivalent in 2010 to report their emissions of six GHGs (including $\mathrm{CO}_{2}$, $\mathrm{CH}_{4}, \mathrm{~N}_{2} \mathrm{O}, \mathrm{HFCs}, \mathrm{PFCs}, \mathrm{SF}_{6}$ ) in line with the unified guidelines adopted at the national level including the ten mentioned above and others to be issued in the future. ${ }^{2}$ Despite the fact that the scope and coverage of these MRV guidelines may not be the same as those of the future national ETS, the design and implementation of these expanding national MRV guidelines, together with the experience of the pilot projects, can pave the way for the establishment of the MRV system for the national scheme. Furthermore, the existing MRV system under the UNFCCC may also make a contribution to the establishment and smooth functioning of the MRV system for the national ETS by means of the integration of the fundamental requirements for data collection related to the current research and projects on GHG inventories. ${ }^{3}$

However, particular attention still needs to be paid to the competence distribution between the central authority and local authorities with regard to the design and implementation of the enforcement package for the national scheme. The discussion in section 4 of this chapter has pointed out the potential challenges emerging from the pilot projects, including the risk of local protectionism and a 'race-to-bottom' due to the predominant GDP-oriented performance evaluation system. Meanwhile, the limitation in terms of the legal basis for and legal effectiveness of the penalties imposed by the local authorities has also highlighted the significance of an inspection and enforcement system established at the national level.

A multi-level enforcement package with division and coordination between the central and local authorities ${ }^{4}$ may help to ease the pressure on local authorities to reduce requirements in order to attract new businesses to their area and will contribute to a harmonised enforcement system for emissions trading throughout China. In this respect, similar attempts by national governments to manage the MRV system based on the coordination between the central and local governments can be found in the notice regarding MRV guidelines mentioned above, indicating that the national government will design and provide relevant provisions while the local governments are responsible for the implementation. ${ }^{5}$

On the one hand, the central authorities are competent and responsible for the design and establishment of the basic legal framework for the enforcement packages. The harmonisation or unification of the enforcement rules at the national level, in the form of national legislation or compulsory standards, is an important option worth careful consideration. This would contribute to uniformity in standards and enforcement. Based on the national enforcement system established by the central authorities in the form of the basic legislation concerning the emissions trading or specific MRV regulations/standards, the implementation of the MRV system as well

office of NDRC, 15 October 2013 (in Chinese).

${ }^{1}$ Ibid.

${ }^{2}$ Notice on the arrangement for the reporting of greenhouse gas emissions by the key enterprises or institutions,

NDRC, 13 January 2014 (in Chinese).

3 Wang, X. (2011), p.11.

${ }^{4}$ Liao, B. \& Cui, J. X. (2012), p.117-118; see also Cao, M. D. \& Cui, J. X. (2012), p.141-149.

5 Notice on the arrangement for the reporting of greenhouse gas emissions by the key enterprises or institution, NDRC, 13 January 2014 (in Chinese). 
as the sanctions for noncompliance by the local governments can be regulated to the extent possible.

On the other hand, local authorities, responsible for the implementation of the enforcement packages, would be able to adopt detailed implementing rules on the basis of the relevant national legislation that take into account their own local circumstances, such as the industrial structure and the emitters' capacity for data collection. Taking the imposition of penalties for noncompliance as an example, local governments may adopt detailed operational 'discretional standards' as those in Beijing mentioned above in section 3.4 of this chapter, in line with the basic types and ranges of the penalties provided in the national legislation. Moreover, within the framework of minimum punitive rules set up at the national level, the local governments should be allowed to implement additional and more stringent measures in accordance with the law, in pursuit of better environmental quality. In the meantime, some flexibility could also be offered to the local governments, such as the application of economic incentives and complementary measures employed in the current pilot projects, aiming to stimulate and to facilitate the emitters' compliance with the national scheme.

\subsection{Concluding remarks}

In view of the challenges facing the pilot projects, the establishment of a national ETS has become a rational choice for China. Due to the legislative structure of the Chinese legal system, the local authorities cannot provide a sufficiently effective legal framework for the pilot ETS. In addition, the diversified design features of the pilot projects may lead to the fragmentation and inconsistency in the local carbon markets, creating problems such as differentiated treatment among the pilot projects. Moreover, driven by the existing GDP-oriented performance assessment system of the cadres, there is a risk of local protectionism in which the local governments may try to favour the local emitters in developing the local pilot projects, causing a negative impact on the level playing field. In this sense, the national ETS is considered to be a rational option to avoid these problems embedded in the local pilot projects.

However, some specific issues still need to be addressed in the design and implementation of the national scheme. In addition to the specific problems concerning the design and implementation of the three key elements, the competence distribution will be a significant issue throughout the national scheme. In particular for cap setting for the national ETS, the competence distribution between the central and local authorities remains a critical challenge. Both of the centralised and decentralised models have to deal with their own legal conflicts under different scenarios in line with the Chinese legal and political context respectively, similar to that emerging from the pilot projects. With regard to the allocation of allowances in the national ETS, several design options in line with the competence distribution are available. But it is more likely for the central government to allocate the allowances to the provinces and to set up the basic principles and unifier rules, based on which the local governments can allocate the allowances to the emitters by adopting specific implementation rules accommodating local circumstances. In view of the obvious regional disparity among the provinces, an objectively justified differential treatment is 
worth consideration in the allocation of allowances to the provinces. As far as the inspection and enforcement for a national ETS is concerned, a multi-level enforcement package with division and coordination between the central and local authorities may be a practical choice. Further consideration on the national ETS has to be conducted in which legal experiences from the EU ETS through a comparative analysis can be taken into account.

\section{Comparative analysis between the EU ETS and the Chinese}

\section{ETS}

In the course of the design and implementation of the ETS in China, policy makers and academics have paid much attention to the EU ETS, aiming to search for a better understanding of and to draw possible lessons from this existing scheme. While the Chinese ETS is still in its initial development with the regulatory framework being formed and improved at the local level and national level gradually, it is possible to sketch the basic characteristics and direction of the Chinese ETS. The comparative analysis to be conducted in this section will mainly focus on the design and implementation of the EU ETS and the Chinese pilot projects, thereby reflecting on the possible design concerning the Chinese national scheme where possible. However, the comparative analysis here is not intended to provide a comprehensive and detailed comparison of all the similarities and differences between the EU ETS and the Chinese ETS. On the contrary, the emphasis will be placed on their fundamental features as well as the specific designs in terms of their three key elements, namely target setting, allowances allocation, inspection and enforcement. In order to provide an in-depth understanding of the major differences and similarities analysed and the extent to which the legal experience of the EU ETS may be relevant for and "translated" for the Chinese ETS, an exploration of the reasons behind the differences will follow.

\subsection{Comparison of the design features: similarities and differences}

The comparative analysis in this part will focus on the overall legal framework for and the three key elements of emissions trading in the EU and China. Based on the description and analysis of the EU ETS and the Chinese pilot projects in this chapter and chapter 3, it is not difficult to identify some similarities and differences between them, which will be addressed below.

\subsubsection{General characteristics of the legal framework for the ETS}

Both the EU ETS and the Chinese ETS have followed an experimental approach to a large extent. However, when comparing the EU ETS and Chinese ETS from a legal perspective, it is noticeable that both the ETSs were established based on different legal frameworks in the EU and China, in line with their legal and political systems respectively. The description above has revealed the unique approach adopted by China experimenting with mainly a non-legislative framework and struggling towards a legal framework by adopting relevant legislation gradually, 
while the EU ETS was established by a binding legal framework from the very beginning that had to be changed in order to improve its functioning. In this sense, there is more flexibility in the Chinese ETS while there is more legal certainty in the EU ETS.

\section{EU ETS: harmonised binding legal framework}

In retrospect, there is an indication that the turning point of the establishment of the EU ETS came with the Kyoto Protocol. Aiming to implement the Kyoto Protocol, a series of policies, such as the Green Paper on EU ETS (March 2000), the first ECCP (June 2000) and other supporting documents, were adopted in preparation for the establishment of the EU ETS.

Nevertheless, the EU quickly adopted legislation — which was binding by nature - instead of policies, with the aim to provide an effective legal framework for the EU ETS. The establishment and implementation of the EU ETS is based on a legal framework constructed by the binding legislative instruments including directives, regulations and decisions as well as other additional tools such as the MRV guidelines before 2012 at the EU level, meanwhile, supplemented by the national legislation promulgated by the Member States. In particular, the adoption of Directive 2003/87/EC in 2003, amended in 2004, 2008 and 2009, has formed the foundation of the legal framework for the EU ETS to a large extent. Moreover, many other necessary steps have also been taken at both the European and national levels, such as the adoption and amendment of the Auctioning Regulations, Registry Regulations, the MRV guidelines and then the MRR and AVR, aiming to ensure that the EU ETS can be implemented and can function within a comprehensive legal framework.

Furthermore, not only the market participants but also the governments at both EU level and national level are bound by the legal framework for the EU ETS. According to the EU legal system, the secondary legislation relating to the EU ETS has been adopted with different legally binding effect depending on its specific nature. For instance, as analysed in Chapter 3, regulations, such as the Auctioning Regulation, are binding in their entirety and can be applied directly in all Member States, while the EU ETS Directive is binding as to the result to be achieved and still leaves the Member States some flexibility to choose the form and methods for its implementation. ${ }^{1}$ Based on this binding legislation adopted at the EU level and, in the course of implementation, by Member States, market players make their trading choices. Furthermore, the cases brought by different parties before the courts have revealed the importance of judicial remedies in the legal framework for the EU ETS, in which the disputes relating to the implementation of the EU ETS can be settled in the judicial system. Especially the case law concerning the NAPs in the first and second trading periods demonstrated that both the EU (represented by the Commission) and Member States must respect and obey the legal framework for the EU ETS, ensuring that Member States implement the EU ETS legislation properly, on the one hand, and the that Commission will not cross the line, on the other hand.

Meanwhile, it is also noticeable that the legal framework for the EU ETS is moving towards harmonisation and is still in the process of evolution. To a certain extent, the legal framework for

${ }^{1}$ Article 288, TFEU. 
the EU ETS is amended following the 'learning by doing' approach as claimed by the Commission. In addition to the amendment of the EU ETS Directives, in particular the significant change in 2009, a structural reform of the EU ETS was proposed again at the start of the third period, aiming to address a growing structural surplus of allowances since 2009 . Nevertheless, the legal framework for the EU ETS can only be changed in accordance with the EU legal system. Even facing a serious depressed EUA price due to the surplus of allowances, the Commission and Member States are bound to change or reform the legal framework per se in accordance with the specific legislative procedure. For instance, new legislation is required for the establishment of a price stability mechanism.

\section{Chinese ETS: experiment with a non-legislative approach towards a legal framework}

On the contrary to the establishment of a binding regulatory framework for the EU ETS, the establishment and exploration of the ETS in China, in particular with the ongoing pilot projects, seems to be established and implemented within a regulatory framework mainly composed of policies and legislation of a relatively low legal rank which was adopted at the central and local levels. The $\mathrm{CO}_{2}$ ETS is applied to achieve the so-called 'binding' carbon intensity reduction target adopted in the $12^{\text {th }}$ Five-Year Planning (2011-2015), the fulfilment of which is backed up by the cadre responsibility system that has been supported by a variety of governmental documents. In view of the existing Chinese regulatory framework for addressing climate change, with a heavy reliance on policies rather than legislation, the context in which the Chinese ETS will be designed and implemented, therefore leaves questions as to what kind of legal framework for emissions trading can be established in China.

In addition to this broader policy context, notably, the experimentation with the carbon emissions trading was also initiated by a policy document issued by the NDRC and then implemented by various policies and governmental rules at the local level. As revealed in the description of the pilot projects, except for the local regulations with only several articles which were adopted in the Shenzhen and Beijing pilot projects and four rules of local governments promulgated by Shanghai, Shenzhen, Guangdong and Hubei by June 2014, little legislation has been adopted for the purpose of the establishment of the legal framework for carbon emissions trading in China. This phenomenon can be partly explained by the legislative structure, in which only limited legislative competence has been distributed to the local authorities. Furthermore, it is not easy for the pilot projects to set up a regulatory framework, given the short time in which they had to start.

The analysis in section 4 of this chapter has pointed out the insufficient legal basis for the pilot projects, indicating that some of the pilot projects are still mainly established and implemented based on the governmental documents rather than the legislation. Without legal certainty provided by clear legal rules, one may wonder whether this will reduce the incentive to trade. In this respect, particular attention may be paid to the practice and experience of the Shenzhen pilot project. Although the local regulation adopted on 10 November 2011 is noted to be the first legislation in China to restrict GHG, it only has ten simple and abstract provisions. The detailed and operational rules were not available until the adoption of a rule of local government on 19 
March 2014. ${ }^{1}$ During the nine months after its official start, the target setting, allowances allocation and the measurement of the emissions in Shenzhen have been implemented mainly in accordance with the local policies and governmental normative documents, instead of the definite and binding legislation. Nevertheless, during this period about 1.59 million tonnes of allowances have been traded in Shenzhen based on such a relatively weak legal framework. This was the largest transaction volume of allowances traded among the pilot projects by the end of June $2014 .^{2}$ It is necessary to have more information to understand how trading works in a weak legal framework and what has motivated the sellers and buyers. In addition, the potential disadvantage of this weak regulatory framework can also be exemplified by the implementation of the additional auctioning facilitating compliance in Shenzhen and Shanghai. Without clear legal rules determined ex ante, arbitrary governmental action may occur, potentially resulting in less trading activities due to legal uncertainty.

Despite the fact that the pilot projects are established to explore and to test the possible design of the ETS in China, the experience of the pilot projects, inter alia the growing trade without a sufficient legal basis in Shenzhen, has suggested one of the most important differences between the EU ETS and the Chinese ETS. To a large degree, the difference concerning the regulatory framework for emissions trading has a significant impact on the design and implementation of emissions trading in regard to the three key elements of both of the schemes in the EU and China. Moreover, the establishment of an effective legal framework for the national ETS still remains a huge challenge for China, posing a significant barrier to the success of the ETS, not to mention the gap in the legal regime and the weak enforcement, inter alia the judicial remedies, in practice.

\subsubsection{Target setting}

\section{Type of target: absolute vs. relative}

\section{EU:}

Aiming to achieve the absolute target mandated for the EU-15 as a whole in the Kyoto Protocol from 2008 to 2012 (at least 8\% reduction of the 1990 level), the EU ETS was established based on the cap-and-trade model in which the GHG emissions reduction target was determined in the form of a cap, the total amount of the allowances to be allocated. Before 2013, the cap for the EU ETS was equal to the sum of the national caps set up by Member States. Due to the significant change to the EU ETS Directive in 2009, an EU-wide cap is determined for the EU ETS. The Commission adopted Decision 2010/634/EU on 9 July 2010, which determined and adjusted the absolute EU-wide cap, the quantity of allowances to be issued under the EU ETS for 2013, amounting to $2,084,301,856 .^{3}$ In other words, the GHG emissions reduction target for the EU ETS is fixed in advance before the trading period and will only be adjusted in accordance with the law.

\footnotetext{
${ }^{1}$ Interim Measures on Carbon Emissions Trading Management in Shenzhen, Shenzhen Municipal Government, 19 March 2014 (in Chinese).

2 The information of transaction provided on the website of Shenzhen emissions trading exchange, available at: http://www.szets.com/Portal/home.seam, see also the Wang, X. Q. Uneven development of the carbon emissions trading experts a tripping point, Shenzhen Special Zone Daily, 7 July 2014 (in Chinese).

${ }^{3}$ See Commission Decision 2010/634/EU
} 


\section{China:}

China has set up a national carbon intensity reduction target, a typical relative target, in pursuit of green growth. Instead of a fixed amount of emissions reduction target, the carbon intensity reduction target will allow emissions growth in line with the economic development. Aiming to ensure the fulfilment of the carbon intensity reduction targets, great expectations have been placed on the application of the ETS. With regard to the Chinese ETS, there is an indication that not only the current pilot projects but also the future national scheme is also to be established based on the cap-and-trade model which has to be designed under the broader umbrella of a carbon intensity target.

Hence, attention must be paid to the remarkable difference between the so-called caps applied in the pilot projects and those in the EU ETS. Although many local governments have claimed their attempts to control the total amount of their $\mathrm{CO}_{2}$ emissions in relevant policies or legislation, there is not much information available as to whether these overall emissions caps exist and what they are. Even though the carbon intensity reduction target can be 'converted' into an emissions cap based on the calculation and the prediction of the GDP growth under different scenarios, the so-called 'cap' in China may still allow an emissions growth instead of an absolute emissions reduction.

With regard to the cap for the pilot projects, some pilot projects such as Guangdong, Hubei and Chongqing, have determined and published their annual caps for 2013 or 2014 in their allowances allocation plans ${ }^{1}$, while the caps for other pilot projects remain unknown to the public. The caps for the pilot projects appear to be determined mainly in accordance with their carbon intensity reduction targets allocated by the higher level authorities, in order to accommodate more emissions than before. Furthermore, the analysis in section 4 has suggested that the cap for some pilot projects may be adjusted by the local governments in a dynamic way, which has been exemplified by the intensity-based cap setting in Shenzhen pilot project. According to the official interpretation of Shenzhen pilot project, their so-called cap for each year in the period from 2013 to 2015 is a flexible and dynamic cap in line with its carbon intensity reduction target, allowing the cap to be adjusted — increased or decreased - in accordance with the real production. ${ }^{2}$

\section{Legal effect of the target: legally binding vs. politically binding}

\section{EU:}

The legal effect of the overall GHG emissions reduction targets and the cap for the EU ETS can be analysed separately for the first two trading periods and the third period.

In the first two trading periods, there was no legally binding target set for the EU or its Member States in Directive 2003/87/EC, which did not set a cap for the number of total emissions ${ }^{3}$. On

\footnotetext{
${ }^{1}$ Detailed information can be referred to section 3.2 of this chapter.

2 The news conference on the launch of the carbon emissions trading pilot in Shenzhen, Shenzhen Gov ernment Online, 21 May 2013, available at: http:/www.sz.gov.cn/cn/xxgk/xwfyr/wqhg/20130521/, last acc essed 2 July 2014 (in Chinese).

3 De Sépibus, J. (2007), p.3.
} 
the contrary, the overall cap of the EU ETS is equal to the sum of national caps established by the Member States themselves in the NAPs. Given that the Kyoto commitment period (2008-2012) was not yet applicable during the first trading period of the EU ETS, Member States were not yet bound to an emission reduction obligation ${ }^{1}$. Even though the 'over-allocation' by the Member States has been criticised a lot, it still cannot be considered to be a real problem resulting in the breach of a legal obligation, particularly for the first trading period.

However, in the second trading period, overlapping with the Kyoto commitment period, all the Member States and the EU per se were obliged to achieve the Kyoto target. The EU ETS is just one of the instruments applied to achieve the Kyoto target, requiring the national caps of the Member States to be set up in line with their Kyoto targets, but there were still no specific legally binding targets for the EU ETS or the Member States. In this sense, although the Commission rejected or even reduced the national caps based on the assessment of the NAPs, focusing on the consistency with the Member State's Kyoto target, Member States, such as Poland, still won cases challenging decisions of the Commission, who wanted the Member States to reduce the national ETS cap. The competence distribution between the EU and the Member States may be the main reason for this, which was already analysed in chapter 3. However, at the same time it has to be demonstrated that Member States were not bound by any specific targets under the EU ETS but only under the overall Kyoto target.

In the third trading period, an EU-wide cap was adopted with legally binding effect in the EU ETS Directive revised by Directive 2009/29/29/EC in line with the '20-20-20' targets, despite the fact that the legally binding target concerning the GHG emissions reduction at the international level after 2012 had not been set up yet. Within the dual regulatory framework to reduce $20 \%$ GHG emissions of 1990 level before 2020, the EU ETS sectors should reduce the level of emissions by $21 \%$ compared to 2005 level. ${ }^{2}$ Therefore, according to the EU ETS Directive, the EU-wide cap determined by the Commission shall decrease by a linear factor of $1.74 \%$ compared to the average annual total amount of allowances in the second phase. ${ }^{3}$ Moreover, the EU-wide cap for the EU ETS each year shall be determined by the specific decision adopted by the Commission. Due to the legal effect of the EU ETS Directive and the specific decision, the allowances to be allocated should stay within this cap.

\section{China:}

In addition to the specific type of emissions reduction target established in China, the legal effect of the carbon intensity reduction target adopted in China also represents another significant difference between the EU ETS and Chinese ETS.

The analysis in section 4.1 of this chapter pointed out the weaknesses and deficiencies of the legal effect with regard to the carbon intensity reduction target because of the legal sources in which it is stipulated and the liability for non-compliance is established. Due to the characteristics of its contents and enforcement system, the legal status of the $12^{\text {th }}$ Five-Year

\footnotetext{
${ }^{1}$ Peeters, M. (2008), p.16.

2 See COM(2008)30 final, p.6.

3 Article 9, EU ETS Directive.
} 
Planning (2011-2015) is more likely to be considered to be a policy document rather than legislation, despite its declaration of 'legal force'. As a result, the legal effect of the national carbon intensity reduction target, set up as a so-called binding target in the Planning as well as the provincial targets, allocated by the governmental documents through a top-down approach, is deemed to be quite weak.

However, the de facto binding effect of these governmental carbon emissions reduction targets at all levels in China is rather strong, backed up by the cadre responsibility system and other political and administrative measures. Relying on a unique implementation and enforcement system in China, the achievement of these binding targets has been integrated into the cadre responsibility system. ${ }^{1}$ In light of the target-based accountability system, the local officials, inter alia the leading officials have to comply with their local carbon intensity reduction targets by means of applying a variety of instruments including the ETS. In this respect, the government and the officials are bound by the carbon intensity reduction target administratively and politically. Moreover, the practice in China has suggested that the implementation of the carbon intensity reduction targets with the politically binding effects seems to be more effective than other abstract provisions stipulated in the legislation in China.

\section{Competence distribution: centralisation vs. decentralisation}

\section{EU:}

With regard to the cap setting for the EU ETS, the significance and controversy relating to the competence distribution between the EU and Member States has been demonstrated by the emergence of a variety of law suits concerning the NAPs in the first two periods to a large extent. According to the EU legal system, the competence to regulate the mitigation of climate change, including emissions trading, is generally shared between the EU and the Member States. Nevertheless, the evolution of the EU ETS has witnessed two main models applied to the competence distribution, including the decentralised model from 2005 to 2012 and then the centralised model from 2013 beyond.

In the first decentralised model, the target for the EU ETS was equal to the sum of the national targets set up in the NAPs determined by the Member States. However, the analysis of the case law concerning the NAPs has exemplified the tension between the Commission's power to reject and the Member States' competence in elaborating the NAPs. Although the competence distribution between the EU and Member States, in particular the boundary of the Commissions' competence in the cap setting, has been further clarified and confirmed by the judgment of the courts, the problems due to the decentralised decision-making approach still need to be solved in the revision of the legal framework per se.

Especially given the risk of so-called 'over-allocation'² due to the generosity of Member States in determining their own national caps, the competence distribution model was changed to a

\footnotetext{
${ }^{1}$ Lin, J. (2012), p.11.

${ }^{2}$ Member States had to achieve the national targets in 2008-2012 under the Kyoto Protocol and have complied with them, but the room for allowances is still generous.
} 
centralised model in the revision of the EU ETS Directive in 2009 with a significant shift of decision making for cap setting from the national level to the EU level. As a result, an EU-wide cap for the EU ETS is determined and adjusted in pursuit of one EU market by integration. Of course, the justification and the level of this centralisation should be further considered in line with the principle of subsidiarity and the proportionality principle in the EU legal system; moreover, some potential problems caused by the centralised model, such as the waterbed effect, also need to be taken into consideration.

\section{China:}

In terms of competence distribution, China also faces similar challenges concerning the choice of a decentralised or centralised model, as in the EU ETS. As indicated by the practice, the national carbon intensity reduction target has been distributed by a top-down approach on the one hand and the emissions trading pilot projects are being established through a bottom-up approach by local governments, on the wish of the central government, on the other hand.

This particular central-local nexus in the competence distribution has been revealed in the determination and allocation of the national carbon intensity reduction target. Following the traditional centralised approach, the carbon intensity reduction target in the $12^{\text {th }}$ Five-Year Planning (2011-2015) was set up at the national level and distributed to local levels via a top-down approach. With regard to the target setting for the ETS, the pilot projects are allowed to set up their own caps in their own jurisdiction. ${ }^{1}$ Meanwhile, the caps with different sizes (the total amount of allowances to be allocated) have been adopted by the local governments in line with their carbon intensity reduction targets and other relevant local circumstances respectively. In the case of the possible national scheme, it remains questionable whether there will be a national cap or other types of emissions reduction targets set up by the central government or not. However, as discussed in section 5.1 of this chapter, both possible outcomes of the decentralised and centralised approach adopted for target setting in the national scheme seem unable to be free of challenges.

If the decentralised approach is chosen, given the unique social and political structure in China, it is likely that the local targets will probably be determined by the local authorities with a formal approval from the central authority. In this respect, potential tension between the central and local authorities in terms of the rejection or approval of the local targets may emerge, similar to the conflict between the EU and the Member States in the first two trading periods. Nonetheless, the possible solution to this potential tension in China may be very different to that in the EU. Due to the strong administrative system but weak judicial system in China, there appears to be little room for judicial review for the settlement of a dispute over the competence distribution between the central and local governments. On the contrary, the political negotiation may be employed to prevent and to solve the possible dispute.

If the centralised approach is adopted, the question however remains as to whether it will follow the example of the distribution of the carbon intensity reduction target at different levels or turn to other options like the full harmonisation approach adopted in the third trading period of the

${ }^{1}$ NDRC Notice on Initiating Pilot Programs of Emissions Trading, NDRC, 29 October 2011 (in Chinese). 
EU ETS, in which there will be no local targets but a nation-wide target. Especially for the latter, if the local governments still have competence to aim for an ambitious target, a potential waterbed effect under the nation-wide cap still needs to be taken into account. With the former, the problem of carbon leakage and equal treatment may appear.

\subsubsection{Allowances allocation}

\section{Competence distribution for the allocation of allowances}

EU:

Given the close connection between cap setting and the allocation of allowances in the EU ETS, in which the total amount of the allowances to be allocated is equal to the cap, the competence for the allocation of allowances has been distributed in line with the decentralised and centralised models adopted in cap setting. In other words, allowances were allocated in the NAPs through a decentralised approach in the first and second trading period, but then the allocation procedures were centralised under the EU-wide cap in the third trading period.

In the decentralised model, on the basis of the general rules and criteria stipulated in the EU ETS Directive, Member States have extensive competence to decide on and implement free allocation or auctioning in their NAPs, in which they allocate the allowances to each covered installation. In this respect, the different intensity of the auctioning among the Member States was an obvious illustration. Moreover, the special rules stipulated and applied by Member States in the first and second period, such as the allocation to new entrants and ex post adjustment rules discussed in section 3.2 of chapter 3, have also demonstrated the character of decentralisation in the EU ETS before 2013 .

However, the allocation methods implemented by Member States, not only auctioning but also free allocation, were harmonised to a large extent in the centralised model after 2013. Except for some special cases, the allowances are distributed according to fully-harmonised and EU-wide rules stipulated explicitly in Directive 2009/29/EC, meaning that the same rules are applied across all the EU Member States. Moreover, the Auctioning Regulation and the specific EU-wide rules for transitional free allocation (Benchmarking Decision) have been adopted at the EU level, aiming to centralise the allocation procedures.

\section{China:}

In the pilot phase, in line with the competence distribution in target setting, the allowances have been or are being allocated by the local governments, mainly by the local DRC. Aiming to accommodate the local circumstances, including the industry structure and the emissions profile of the emitters, the local governments have determined their own specific allocation methods and have allocated the allowances to the individual emitters covered by the pilot projects, which have been exemplified by the diverse choices of the free allocation criteria and various designs for auctioning among the pilot projects. Moreover, some special allocation methods applied in the pilot projects, such as the special treatment provision for the new entrants in Guangdong pilot, 
have also to a certain degree demonstrated the decentralised approach applied to the allocation of allowances.

Regarding the potential national scheme, one may still be able to ask the questions as to which level of the authorities should be given the competence of allocating allowances. Given the risk of local protectionism discussed above, if the decentralised approach is applied, the allowances can be allocated by the local governments following some basic principles set up by the central authorities. If the allowance is going to be allocated through a centralised model, then the central authority may follow the example of the EU ETS in the third trading period, allocating the allowances to individual emitters directly based on the EU-wide allocation rules. Meanwhile, the centralised model may also be implemented, following the tradition of distributing the carbon intensity reduction target via the top-down approach, in which the allowances may be allocated from the central government to the local governments and then finally to the emitters. In this respect, an objectively justified differential treatment among the provinces may be worth attention when the central government deals with the regional disparity in the allocation of allowances. With regard to allocation to the emitters at the local level, the need to ensure the basic consistency of the allocation methods remains obvious.

In this sense, the combination of centralisation and decentralisation to the extent possible appears to be a promising and practical option for the allocation of allowances in the national scheme, although potential challenges stemming from both systems should be considered carefully.

\section{Allocation methods}

The description of the EU ETS and the Chinese pilot projects has indicated that both have chosen a mix of allocation methods, including free allocation and auctioning, but the role and design of the specific allocation method may differ in different stages.

\section{EU:}

In the EU ETS, free allocation, and in particular the grandfathering implemented by the Member States, has played a dominant role in the first and second trading periods. In the first and second trading periods, a majority of Member States chose to allocate the allowances based on grandfathering, but the baselines of the historical emissions used by the Member States were not uniform until the second trading period. Meanwhile, benchmarking, another free allocation method, has usually been applied to the new entrants and the power sectors. Contrary to the first two trading periods, the application of the free allocation method is limited to specific circumstances in the third trading period. For instance, the electricity sectors located in certain Eastern European Member States can still receive free allowances through grandfathering according to Article 10c of the EU ETS Directive. Moreover, transitional free allocations to certain sectors exposed to carbon leakage will take the form of Community-wide ex ante benchmarks from 2013 beyond.

With regard to auctioning, it was only implemented in a narrow scope during the first two trading periods but it was to be phased in gradually after 2013. Before 2013, the proportion of 
the allowances to be auctioned in the Member States was rather small. However, the revision of the EU ETS Directive in 2009 made auctioning the default rule rather than exception in the allocation of allowances, especially for the power sectors applying full auctioning.

However, the analysis in section 4.2 of chapter 3 also pointed out the concerns on the equal treatment of the installations due to the competence distribution and the choices of allocation methods. Particularly in the centralised model with the application of mixed allocation methods, the sectors covered by the EU ETS are differentiated into three categories subjected to different treatment from 2013 beyond. In this respect, the objective justification for the differential treatment still needs to be considered and examined.

\section{China:}

There is an indication that most of the pilot projects have allocated the allowances through a mix of several allocation methods. Except for the auctioning employed regularly in Guangdong and other pilot projects in special circumstances, free allocation has been chosen as the main allocation method at least in the initial stage of the pilot projects, aiming to get the ETS established and operational as soon as possible. In this respect, free allocation indeed seems to be a practical choice favoured by the EU as well as China. In addition to grandfathering, benchmarking has also been taken into consideration by local governments in the mix of allocation methods for specific sectors, in accordance with local circumstances and the actual development of the schemes. Due to the various designs and implementation concerning the mix of the allocation methods in the decentralised approach, however, there has already been a need to pay attention to the differential treatment of the similar industries covered by different pilot projects, in order to avoid the competition problem. Meanwhile, the equal treatment issue, as an expression of or in relation to the polluter pays principle, also deserves attention.

The choice of a mix of allocation methods remains a feasible option to be applied in the national scheme. It will also be very important to take account of the differential treatment issues due to the mix of allocation methods in the national scheme. Especially in the case that the mixed allocation methods are designed and implemented by the local governments, which was discussed in the decentralisation model for competence distribution above, the concerns on the different treatment may become more prominent.

\section{Governmental adjustment}

Another obvious difference between the EU ETS and Chinese ETS can be found in their attitude and approach to the governmental adjustment of the allowance allocation in the legal framework.

\section{EU:}

Based on the EU ETS Directive and relevant legislation adopted at the EU level, there was no specific provision concerning the governmental adjustment of the allocation of allowances, indicating that little attention has been paid to the element of ex post adjustments when the EU ETS was designed. ${ }^{1}$ However, the attempts of some Member States to introduce the ex post

${ }^{1}$ Backes, C., Deketelaere, K., Peeters, M., \& Schurmans, M. (2008), p.206. 
adjustment mechanism in the allocation of allowances have given rise to attention and discussion on this issue in the EU ETS. In this respect, the Germany vs. Commission case, in which the Commission refused the original NAP submitted by Germany proposing ex post adjustments to the quantity of allowances allocated to installations, ${ }^{1}$ has provided an example. According to the Commission, 'the non-acceptance of ex post adjustments is essential for the allowance market development ${ }^{2}$, which can be traced back to the theory argued by Dales that the government should take a firm stand against increasing its authorised issue of allowances no matter what happens ${ }^{3}$. However, the Commission failed to convince the court. On the basis of the court's analysis of the nature and effects of the ex post adjustment mechanisms in the ruling, Germany won the case in the end. ${ }^{4}$ Moreover, academic attention has also been paid to the possibility and special design of using ex post intervention in order to correct any adverse consequences of ex ante allocation. ${ }^{5}$

Furthermore, it appears that a subtle change was undertaken when the EU ETS suffered depressed EUA prices due to the structural surplus of allowances since 2009. In order to deal with the growing surplus of allowances, the Commission proposed not only short-term measures but also a structural reform of the EU ETS, in which the governmental adjustment of the allowances allocation seems to have been considered. For instance, by means of an amendment to the EU ETS Directive and the Auctioning Regulation, the auctioning of 900 million allowances will be postponed by the Commission until 2019-2020. ${ }^{6}$ In addition to the 'back-loading' of some allowances, a market stability reserve has also been proposed by the Commission for the beginning of the next trading period in 2021, which may allow the governments to adjust the supply of allowances to be auctioned in line with the pre-defined rules. ${ }^{7}$ Although the market price stabilisation mechanisms proposed above are not the same as what was drafted by Germany in the NAP in the first trading period, the ex post adjustment of the allowances allocation seems to be more accepted in the EU ETS to a certain extent. However, the potential ex post adjustment measures can only be designed and implemented within the legal framework for the EU ETS that is in the process of reform.

\section{China:}

Different from the experience in the EU ETS, governmental adjustment of the allowance allocation already found its way into the design of the Chinese ETS from the very beginning. In this respect, particular attention should be paid to the special attempts to accommodate the dynamic economy in the design of the allocation methods for the Chinese ETS, not only in the pilot projects but also for the future national scheme, which may differ from the EU ETS to a large extent.

As described in section 3 of this chapter, several pilot projects have established the annual adjustment mechanisms concerning the allocation of allowances in accordance with the emitter's

\footnotetext{
${ }^{1}$ Case T-374/04: Germany v. Commission, [2007] ECR II-04431.

2 COM (2005) 703 final, p.16.

3 Dales, J. H. (1968), p.95.

${ }^{4}$ Case T-374/04: Germany v. Commission, [2007] ECR II-04431.

5 Backes, C., Deketelaere, K., Peeters, M., \& Schurmans, M. (2008), p.206.

6 See Decision No 1359/2013/EU; see also Commission Regulation EU No 176/2014.

${ }^{7}$ See $\operatorname{COM}(2014)$ 20/1.
} 
real production and other relevant elements, which can be exemplified by the Shenzhen pilot project. Moreover, some pilot projects have also employed the governmental adjustment of allowances allocation as one of the important mechanisms for price stabilisation and compliance promotion in some special circumstances. However, the legal basis for and specific design of the possibilities for governmental adjustment relating to the allocation of allowances differs among the pilot projects. In contrast to the very vague and simple provisions mentioned in the regulatory framework for several pilot projects, some detailed rules or specific governmental documents have been adopted in some pilot projects, such as in Beijing and Shenzhen. It nevertheless remains questionable whether the governmental adjustment can be regulated effectively by the regulatory framework established mainly by these governmental documents with low legal ranks. Moreover, it needs to be explored how such adjustments negatively influence the cost-effectiveness of the ETS. If China wants to follow the rule of law, it is important for the competence in relation to and procedures for governmental adjustment to be clearly defined and controlled within the legal system in order to avoid the uncertainty and arbitrariness of governmental action in China. As a result, how to design a suitable and effective legal framework for these special allocation rules remains a unique challenge facing the Chinese ETS.

\subsubsection{Inspection and enforcement}

\section{MRV rules}

The harmonised approach in terms of the MRV has been identified in the EU ETS, requiring the emissions to be self-monitored, self-reported by the operators and verified by third-party verifiers in the EU ETS Directive and related legislation. As a special inspection tool, the GHG emissions permit has been set up in the EU ETS Directive as the precondition for all the stationary installations covered by the EU ETS to emit specific GHGs, requiring and regulating the compliance, inter alia the self-monitoring and self-reporting of the operators. In addition to the basic principles for the monitoring and reporting of emissions and criteria for the verification of emissions set out in Annex IV and Annex V to the EU ETS Directive, further specific rules were provided in the guidelines adopted by the Commission in the first and second trading periods. Moreover, two respective regulations addressing MRV were adopted in the third trading period, indicating to further harmonisation for the MRV in the EU ETS.

It is interesting that some similar design features of the MRV rules in the EU ETS have been accepted by the pilot projects, paving the way for the future national scheme in China. The description of the MRV rules provided among the pilot projects has suggested that self-monitoring, self-reporting and third-party verification is likely to be applied in the emissions trading in China at the local level and the national level. In this respect, the role of and requirement for the third-party verifiers is crucial, in view of the need to ensure proper monitoring and reporting for emissions trading. However, the relationships among the third-party verifiers, the emitters and local governments are not the same among the pilot projects, giving rise to the question of how to ensure the independence and objectiveness of the verification in China. Despite the fact that the MRV rules are being designed separately by the local governments, because of their technical nature, the convergence of the basic rules can still be 
identified. Moreover, due to the weakness of the legal effect of the local MRV rules and the concerns about the quality and comparability of emissions data collected by the pilot projects, the need to harmonise or unify the MRV rules at the national level has already been recognised, for which the central government is making effort by means of adopting more national guidelines and considering other options like the national standards with a stronger legal force.

\section{Sanctions}

With regard to the sanctions for non-compliance emerging in the ETS, there is an indication that the EU and the present pilot projects in China have made some common choices concerning the types of penalties, but they have designed them with different degrees of stringency, implying that some experiences from the EU ETS may have already been taken on by the pilot projects.

According to the EU ETS Directive, a fixed-amount financial penalty would be imposed on excessive emissions, together with compensation by re-surrendering the excess allowances. Meanwhile, the 'naming and shaming', the prohibition from transferring allowances and administrative measures against accreditation certificates are also included in the enforcement package. Although this thesis has not paid specific attention to the implementation in the Member States, the question remains however as to whether Member States may enjoy the discretion to establish a national enforcement package with stricter sanctions for any infringements of the EU ETS rules, especially in regard to the imposition of financial penalties ${ }^{1}$. In this respect, the opinions on the case law differ between the court and the Advocate General, providing an interesting illustration.

However, in China, where the national scheme is still under discussion and construction, the sanctions are being designed and implemented respectively by pilot projects at the local level. The description in section 3 of this chapter has implied that most of the pilot projects are establishing sanctions including fines, compensation for the excess emissions, naming and shaming, which are quite similar to the sanctions provided in the EU ETS. For instance, the financial penalty for excess emissions compared to the amount of allowances surrendered by the operators or emitters covered by the ETS seems to be a basic common choice of both the EU and China. Nevertheless, the form and level of the financial penalties applied in the EU and the pilot projects, and even among the pilot projects, have been designed quite differently. Meanwhile, the amount of allowances to be re-surrendered for excessive emissions also differs to a large degree, which can be exemplified by the pilot projects of Guangdong and Hubei that require the offenders to re-surrender twice the number of allowances that represent the excessive emissions.

In addition, a greater difference can be identified in terms of the specific design of the additional sanctions and extra enforcement measures. It is noticeable that the violators in the pilot projects of Shanghai, Tianjin, Shenzhen, Chongqing, and Hubei may be disqualified from appraising and receiving financial support related to climate policy from the governments for several years. In particular for the SOEs covered by some pilot projects, noncompliance will be incorporated into the performance evaluation system of the leading cadres. Moreover, most pilot projects have also

1 Jans, J. H. \& Vedder, H. H. B. (2011), p.118. 
established some necessary legal liabilities for various parties involved, including the emitters, verifiers, exchanges, the governments, and their staff. In particular, there is an indication that the sanctions for the violation of the MRV rules have been taken into account in view of the Chinese context where there are serious problems of fraud and corruption that may endanger the sound operation of the ETS. Questions however remain as to whether and how these enforcement measures will be implemented effectively in practice, the answer to which requires further observation in the future.

\section{Economic incentive?}

Furthermore, special attention should also be paid to the tendency to apply economic incentive measures in the pilot projects, serving as important supplements to the sanctions in the Chinese ETS. Especially in the initial stage of the experimentation in pilot projects, economic incentive mechanisms are necessary and important to attract the emitters to participate in emissions trading to the extent possible. In addition to some general financial support, such as loans on favourable terms and governmental special funds, further financial support measures have been proposed in some pilot projects in China.

In this respect, Beijing DRC has established attractive economic incentive measures for the verifiers, ranging from 120,000 CNY (about 15,000 EUR) to 80,000 CNY (about 10,000 EUR) in line with the four grades for the results of the review of the verification report, aiming to ensure the quality of the verification report of the emissions data. ${ }^{1}$ In this sense, the economic incentive measure may play the role of an important tool in getting support from the participants in the initial stage and ensuring compliance with the ETS in the special Chinese context. The essence of verification is to ensure that the data is correct. But based on the information provided by the Beijing DRC, it is not clear what the difference between the four grades (Excellent, Fine, Qualified, Failed) concerning the verification report is and how it is implemented in practice, which needs to be considered and observed carefully.

\subsection{Reasons behind the differences}

The comparative analysis above has pointed out some main similarities and differences between the EU ETS and the Chinese ETS. Although the EU ETS has been considered to be an important model for the establishment of the Chinese ETS, the design features in terms of those three key elements have turned out quite differently in the Chinese context. In order to gain further insight into the reasons for the differences concerning the design features and to gain a mutual understanding of each other, certain important aspects, including the legal, political and economic systems between the EU and China, are worthy of comparative analysis in this section.

\footnotetext{
${ }^{1}$ The notice concerning the report and verification of the carbon dioxide emissions, Beijing DRC, 5 August 2013.
} 


\subsubsection{Legal tradition and legal system}

The remarkable differences in terms of the regulatory framework and the three key elements between the EU ETS and the Chinese ETS may be firstly explained by their legal traditions, in particular the role of law and policy in their respective legal systems.

\section{The adherence to the rule of law in the $\mathrm{EU}$}

The EU ETS is established and implemented in line with the classical western legal system symbolised by the rule of law, which is an important foundation of EU law.

As far as the theory of the rule of law is concerned, vast literature can be found. As a western concept, the notion of the rule of law can be traced back to ancient Greece. For instance, Plato insisted that the government should be bound by the law as its 'slave' concluded that the laws, when good, should be supreme. ${ }^{2}$ With regard to the criteria that constitute the rule of law, Fuller argued that eight criteria that must be satisfied for law to exist: generality, publicity, prospectivity, clarity, non-contradictoriness, capability of being obeyed, stability, and conformity between norms as stated and norms as applied. ${ }^{3}$ Moreover, according to some scholars, there may be at least five basic elements that constitute the rule of law, including the capacity of legal rules to guide people, the efficacy of the law in guiding people, stability, the supremacy of legal authority, and instrumentalities of impartial justice. ${ }^{4}$ In particular for the supremacy of legal authority, all the officials, including the judges, should be ruled by the law and obey it. ${ }^{5}$ Moreover, derived from the concerns about limits on governmental power in Western democratic system, the heart of the rule of law in the Western world thus lies on the idea that the government itself is bound by law. ${ }^{6}$ In other words, legislation passed by the legislature, in line with its competence prescribed by the constitution, should bind the governments at all levels, preventing governmental abuse of power and official arbitrariness. $^{7}$

Furthermore, it has been argued that the transformation of the European legal system, inter alia the preliminary ruling system and the competence of the Commission to take Member State to court in case of infringements, has made the possible emergence of an international rule of law in Europe, and the political process is influenced by law and court decisions. ${ }^{8}$ In this respect, the complex legal framework comprised of relevant legislation relating to the ETS and the case law in the first and second trading period of the EU ETS have provided a vivid illustration of the rule of law in the European context.

\footnotetext{
${ }^{1}$ Cooper, J. et al (1997), p.1402.

2 See Aristotle. Politics. Translated by Benjamin Jowett, Digireads.com Publishing, 2005, p.47.

3 See Fuller, L. L. (1964), p. 33-39.

4 Fallon, R. H. Jr. (1997), p.8-9.

${ }^{5}$ Raz, J. (1979), p.212-220.

6 See, Kairys, D. (2003), p.307-329.

${ }^{7}$ See Hager, B. M. (1999), p.21-23; the classic discussion can be traced back to book of Dicey, A.V., the Introduction to the Study of the Law of the Constitution.

8 Alter, K. J. (2003), p.229.
} 


\section{The legal system with Chinese characteristics}

However, the legal context in which the ETS is being established in China is very different from the Western style. Despite the attempt and effort made by China to build a legal system premised on the rule of law in the last three decades, in accordance with economic and political reform, the concept and practice of the rule of law has emerged in line with the socialist legal system with Chinese characteristics.

\section{The role of law in China}

At the initial stage, the understanding of the role of law in China basically rests on the rule by law, an instrument applied by government rather than the normative and political theory in Western jurisprudence. ${ }^{1}$ Admittedly, as argued by scholars, it has taken more than 20 years for China to accept the idea of the rule of law instead of the rule by law. ${ }^{2}$ Moreover, in a long march towards the rule of law in China, the legal concept of the rule of law did not begin to appear in governmental policy until 1996 and then lead to the constitutional mandate in $1999 .^{3}$

With the desire to build a consistent legal system binding the government in China, a vast number of legislative acts have been adopted in recent decades. To a certain degree, the gap between the rule by law and the rule of law is closing but it still exists. In this field, the literature has placed a considerable emphasis on the questions of whether the Chinese legal reform is sufficient and effective compared to the Western model of the rule of law. ${ }^{4}$ In particular, the two basic requirements of the rule of law emphasised by Aristotle, the rightly constituted laws and the supremacy of laws, remain huge challenges for China at present. Admittedly, the establishment of a sound functioning legal system does not mean that China should embrace and copy the western notion of the rule of law. Moreover, the development of the rule of law in China may be different from that rooted in Western democracy, in view of the historical and present situation. ${ }^{5}$ However, it does require that 'there must be law to rely on' [you fa ke yi] providing the legal infrastructure to foster the rule of law in China. Moreover, with respect to the role of law in the ongoing reform in China, a subtle but positive change is slowly being witnessed in the past few years. As discussed in section 2.2 of this chapter, the reform through bottom-up experimentation usually relies on policy rather than legislation in light of the Chinese special circumstances; relevant legislation will then be adopted or amended based on the experiences gathered from the experimental reform. However, as signalled by the decision of the ruling party on the rule of law in 2014, the policy makers in China start to emphasise the important links between the legislation and reform decisions, requiring that a significant reform should be conducted based on law by means of adopting or amending relevant legislation in advance. ${ }^{6}$

\footnotetext{
1 The differences among rule by man, rule by law, rule of law in China have been discussed in the literature, see, for instance, Li, B. Y. \& Chen, G. M. (1998); Li, B. Y. \& Li, Q. (1999), p.2-5; see also Orts, E. W. (2001).

${ }^{2}$ Li, B. Y. \& Li, Q. (1999), p.2-5.

3 See Wang, C. G. (2010), p.6-8; see also Peerenboom, R. (2002); Orts, E. W. (2001).

${ }^{4}$ See, for instance, Keith, R. C. (1991); Turner-Gottschang, K., Feinerman, J. V., \& Guy, R. K. (2000); Vermeer, E. B., \& Hooghe, I. (2002).

5 Zhang, M. (2010), p.7.

${ }^{6}$ Decision of the Central Committee of Communist Party of China on the comprehensive promotion of several
} 
With regard to the establishment and implementation of the Chinese ETS, there is still a long way to go. Remarkably, a well designed and effective legal framework is still missing, not to mention the concerns on the potential weak enforcement in the future. Particularly in the course of the establishment of the legal framework, the strong roles of policies and governmental normative documents have been revealed by the description above. In contrast to the EU ETS, the Chinese ETS is established mainly by policies and governmental documents adopted in the pilot projects through the experimental approach, which can be demonstrated by the practice of the Shenzhen pilot. The description and analysis of the climate policies relating to the ETS in China has suggested the special and substantial role of policies in China, which may be very effective in achieving the climate targets when they are implemented through and backed up by the cadre responsibility system. Nevertheless, the reliance on strong political steering instead of steering through the legal system may give rise to concerns about predictability, certainty, transparency, and enforcement relating to the ETS in China. Recognising the significance of the legal framework for the ETS, some local authorities have indeed tried to establish a binding legal framework through the adoption of relevant local regulations and rules of local governments. Given the relatively low legal ranks of the local legislation adopted by the local authorities, due to their limited legislative competence, there is still a need for a legal framework established at the national level.

\section{The supreme role of government}

In addition to the roles of and relationship between the policy and legislation analysed in section 2.4 of this chapter, the role of the government in the broader context of the legal reform in China, where the Chinese ETS is now being established, may also provide a better understanding of the difference between the EU ETS and the Chinese ETS.

Rooted in the Confucian tradition relying on a great leader, who is virtuous and acts for the good of the country, there is still a strong desire to rely on good government rather than on law in China ${ }^{1}$, which may be exemplified by 'the renaissance of Confucianism' suggesting that the law should assist the cultivation of virtue in governing a state ${ }^{2}$. Moreover, the Chinese government and the ruling party have often claimed to know what is best and try to do what is good for the people $^{3}$. As a result, the governments at both the central and local levels have still taken the lead in many areas, usually in a very powerful but seldom accountable way. ${ }^{4}$ In terms of political modernisation and market modernisation, as argued by scholars, the government can become involved in economic development via the models of state-driven and market-driven development. ${ }^{5}$ In a state-driven development, the state plays a leading role in law reform, attempting to adopt comprehensive laws ${ }^{6}$, while the market-driven model does not require state efforts to establish a comprehensive legal framework at the beginning of the reform process and

major issues of the rule of law, adopted by the $4^{\text {th }}$ Plenary Session of the $18^{\text {th }}$ CPC Central Committee, 23 October 2014 (in Chinese).

1 Hager, B. M. (1999), p.18, 25.

2 Fan, R. P. (2011), p.68.

3 Peerenboom, R. (2002), p.516.

${ }^{4}$ Wang, C. G. (2010), p.29.

${ }_{6}$ See Cooter, R. D. (1997); see also Clarke, D. C. (2007).

${ }^{6}$ Clarke, D. C. (2007), p.568. 
emphasises gradual approval of privately created norms by courts and legislatures ${ }^{1}$. To a certain degree, the model of state-driven development has been argued to be almost an exclusive path of legal reform in China. ${ }^{2}$

However, there is still a considerable gap between the limited laws adopted and the practice in China. In the literature it has been argued that the main reason for this may lie in the party-state's limited willingness to 'permit law to function as a framework to facilitate private transactions', rather than for other social or economic reasons. ${ }^{3}$ Moreover, to a certain degree, the function of the judicial system has also usually been limited to providing services to satisfy the need of the political and state policies within a specified period, in particular the demand of economic growth ${ }^{4}$. As a consequence, compared to the role of the government, the judicial system has a rather weak and awkward status in the Chinese political system, like 'a bird in a cage'. In view of its weak role and the independence being questioned, there seems to be very limited room for the Chinese judicial system to play a similar role in the enforcement of the Chinese ETS as that of the courts in the EU ETS.

In this sense, the establishment and enforcement of the Chinese ETS may still be influenced greatly by the political will of the central and local governments as well as the ruling party, to obey the law and to respect market discipline themselves. ${ }^{6}$ However, the good news is that the need for establishing a well-designed legal framework for the ETS is one of the insights gained from the EU ETS and has been recognised by the policy makers at the national and local level, which can be exemplified by the efforts made by the pilot projects to adopt relevant local legislation and the repeated statements made by the officials of the NDRC emphasising the importance of the law for the establishment of a national ETS, even though it will not come easily. ${ }^{7}$

\subsubsection{Governance structure and competence distribution}

The commonalities and differences in terms of competence distribution within the multi-level governance structure forms another important aspect of the comparison between the EU ETS and the Chinese ETS. There is already an implication that the competence distribution between different levels of authorities involved in the ETS may have a substantial impact on the specific design and implementation of the three key elements.

\footnotetext{
1 Kovacic, W. E. (2001), p.265.

2 Clarke, D. C. (2007), p.568.

3 Lubman, S. B. (1999), p.300-309; see also Zhang, X. C. (2007), p.586.

4 See for instance, Potter, P. B. (1999).

${ }^{5}$ Lubman, S. B. (1999), p.300-309.

${ }^{6}$ Zhang, X. C. (2007), p.587.

7 See, for instance, Sun, H. L. \& Mao, Z. H. China will establish a national carbon market by legislati on in order to improve the emissions management system, Xinhua Net, 15 September 15 2013, availabl e at: http://news.xinhuanet.com/2013-09/15/c_117375846.htm, last accessed 22 December 2014 (in Chines e).
} 


\section{Common challenges}

The application of the EU ETS and the Chinese ETS has suggested the involvement of different levels of authorities: the EU Member States in the EU ETS and the central-local governments in China. Moreover, the analysis of the design features in terms of the key elements has indicated that how the competences are distributed between different levels of authorities in the form of power division within their legal frameworks respectively seems to be a common challenge facing the EU ETS and the Chinese ETS. In particular, practice in relation to the EU ETS has witnessed a transition from the decentralisation model to the centralisation model in terms of target setting and allowances allocation, illustrating the importance and complexity of the competence distribution between the EU and the Member States. It is interesting that the competence distribution between the central and local authorities also remains a huge challenge to be addressed in the establishment of the pilot projects as well as in the possible design of the national scheme in China.

As for both the EU and China, there may be a considerable gap in terms of the concerns and priorities on the agendas between different levels of authorities. Especially in the case of GHG emissions reduction with little local effect, the local action, usually at the cost of economic development to a certain extent, is only part of the contribution to the national, regional or global reduction. Based on the cost-benefit analysis, the lower-level authorities (like the Member States in the EU and the local governments in China) may prefer the direct benefit from the local economic development to the indirect improvement of the environmental quality. However, the higher-level authorities (such as the Commission in the EU and the central government represented by the NDRC in China) may focus on the overall economic development and environmental integrity. In this respect, the potential conflict between different levels of authorities in the course of deciding and implementing the ETS may emerge in both the EU and China, which can be exemplified by the respective discussions on competence distribution relating to the target setting in the EU ETS and Chinese ETS.

\section{Diverse governance structure}

In view of the close connection between the competence distribution and the political and legal systems, there is a special need to examine the governance structure and in particular the administrative structure between the EU and China that has resulted in some differences between their ETS. As far as the legal and political structure is concerned, the obvious difference between the EU and China would be noticed easily. In particular, stemming from the different forms of the state structure, the relationship between different levels of authorities from the vertical perspective can be differentiated in the EU and China.

Differing from a traditional international organisation and an association of states, the EU is an autonomous entity, a so-called supranational organisation, created based on international treaties but still in the process of evolution. As provided in Article $47 \mathrm{TEU}$, the EU 'shall have legal personality'. ${ }^{1}$ In this light, practice has also indicated that the EU has been considered as an

${ }^{1}$ Article 47, TEU. 
independent union with its own sovereign rights and responsibilities to a certain degree, due to the partial surrender of sovereign rights from the Member States. ${ }^{1}$ Moreover, the competence distribution between the EU and Member States has been clarified in the Treaty of Lisbon. The exercise of EU competences is subject to three fundamental principles that are provided in Article 5 TEU, in particular the principle of conferral. Furthermore, it is emphasised that the legal personality of the EU does not authorise the EU to legislate or to act beyond its competences conferred upon by the Member States in the Treaties. ${ }^{2}$

Concerning the establishment and implementation of the EU ETS, it is a competence shared by the EU and Member States. Based on the principles of subsidiarity and proportionality, the EU ETS is established at the EU level but it leaves a substantial level of competence to the Member States in the first and second trading periods with the decentralised approach. However, this decentralised model was changed based on the negotiation and consent among the Member States, by means of the revision of the EU ETS Directive in 2009 in line with the ordinary legislative procedure applying qualified majority voting. ${ }^{3}$ In this respect, the transition from the decentralised model to the centralised model has demonstrated the evolution of the competence distribution between the EU and Member States. Despite the complicated reasons for the current trend towards harmonisation in the EU ETS, it is noticeable that the adjustment to the competence distribution between the EU and its Member States cannot take place without the consent of the Member States, through unanimous voting or qualified majority voting, in accordance with the EU legal system.

By contrast, China is a unitary state with full sovereignty. As for the relationship between the central and local governments, it has been evolving in line with the political and legal reform in Chinese history. However, there is an indication that the tradition of authoritarianism or even totalitarianism still has a considerable impact on the Chinese governance structure, in particular the administrative structure. Because of the single party controlled system after the founding of the People's Republic of China in 1949, the so-called 'democratic centralisation of authority' (min zhu ji zhong zhi) still shares many common features with the traditional top-down authoritarian system, in which the lower authorities, inter alia the local leaders, are nominated and empowered by the higher level in the top-down approach, aiming to secure the central authority and control. ${ }^{4}$

As an instrument applied in this context, the Chinese ETS is destined to be established with similar essential characteristics in terms of the competence distribution between the central and local governments. The development of the pilot projects has suggested that the decentralised model will be applied in the piloting phase, in which the competence of designing and implementing the ETS seems to have been exercised mainly by the local governments. However, particular attention must also be paid to the fact that the pilot projects were initiated on the wish of the central government in the form of a simple notice ordering the decentralised experiments

\footnotetext{
${ }^{1}$ Borchardt, K.D. (2010), p.32-33.

2 Declarations annexed to the Final Act of the Intergovernmental Conference which adopted the Treaty of Lisbon, signed on 13 December 2007, OJ C 83, 30.3.2010, p.346.

3 Article 192(1), TFEU.

${ }^{4}$ Zhang, M. (2010), p.41-42, see also Peerenboom, R. (2002), p.188.
} 
to be implemented by seven municipalities and provinces. Moreover, as the experiment was established to search for the best practice for a future national scheme, the pilot projects are designed and implemented under the substantial influence of the central government in various forms, formal or informal, aiming to win in the competition against other pilots. In other words, the Chinese ETS is being established in line with a de facto centralised model, in which the central government is always playing a steering role by initiating the pilot projects with a decentralised approach and influencing the design and destiny of the pilot projects, although the central government did not officially get involved in the decision-making process of the pilot projects. Even in the future national scheme, the competence distribution may still follow the centralised model, while leaving certain competences in terms of the specific design and implementation to the local authorities.

In view of the highly centralised character and tradition of the competence distribution in a unitary state, it appears to be more likely and easier for China to establish and implement the ETS based on a centralised model than for the EU. Meanwhile, the sufficient legislative competence distributed to the central authority can also provide the necessary conditions for the establishment of an effective legal framework for the ETS in China.

\section{Different approaches}

Based on the different political and legal contexts in the EU and China, different approaches have been applied in dealing with the relationships between the higher and lower levels of authorities involved in the ETS in accordance with both of the multi-level governance structures.

In the EU ETS, the relationship between the EU (represented by the Commission) and Member States is subjected to the specific rules stipulated in the EU ETS Directive as well as other general principles of EU law, in particular the principle of subsidiarity. Meanwhile, the competence distribution between the Commission and Member States has been adjusted gradually in line with the EU legal system, in pursuit of a delicate balance between the competences at each level that may facilitate the proper functioning of the EU ETS. Furthermore, the court has played an important role in dealing with the conflicts between the Commission and Member States, which has been demonstrated to a large degree by the case law concerning the NAP in the EU ETS before 2013.

On the contrary, the relationship between the central and local governments in the Chinese ETS is still likely to be dealt with in a political approach, following the traditional authoritarian regime. In this respect, the allocation of the national carbon intensity reduction target has indicated the special role of the Chinese cadre responsibility system in addressing the pressing problems facing China. Especially in the context of a large authoritarian bureaucracy, which is hesitant or reluctant to embrace the development of the independent institutional supervision over the local officials, the cadre responsibility system however remains quite a simple core mechanism allowing the central authority to control their local agents to the extent possible, aiming to solve the principal-agent problem within the Chinese administration system. ${ }^{1}$

${ }^{1}$ Minzner, C. F. (2009), p.90. 
Meanwhile, little room has been left for the court in dealing with the relationship between the central and local governments. The heavy reliance on the top-down cadre responsibility system in controlling the local governments has caused numerous negative problems, such as the classic risk of 'over control', selective policy implementation, and 'mistranslation' of central norms, many of which have been recognised by the Chinese authorities. ${ }^{1}$ However, it is very difficult to fix these problems in the near future. As a result, it may be not surprising to see the significant impact of the political accountability system on the design and implementation of the Chinese ETS, in particular the competence distribution between the central and local governments. Furthermore, it remains a complicated question of whether and how to define an appropriate relationship between the central and local governments in the legal framework for the Chinese ETS.

\subsubsection{Economic system and economic governance}

As a market-based instrument, the design and operation of the ETS will be affected greatly by the level of economic development, the type of economic system and the structure of the corresponding economic governance, where remarkable differences can be identified between the EU and China.

\section{Different levels of economic development}

Because of their different levels of economic development, the EU and China, with different commitments to reduce GHG emissions under the Kyoto Protocol, have chosen different types of GHG emissions reduction targets. Notably, the largest share of historical and current global GHG emissions coming from the developed countries, such as the Member States of the EU, while the emissions from developing countries like China will increase to satisfy their social and development demands. ${ }^{2}$

In line with the principle of CBDR, the EU as a whole has committed to reduce GHG emissions below 1990 levels by $8 \%$ in the period $2008-2012^{3}$ and by $20 \%$ in the period $2012-2020^{4}$ collectively, thereby setting up the cap to be reduced linearly for the EU ETS. However, with regard to China, a developing country with a fast growing GDP and with levels of GHG emissions that have not peaked yet, the priority of economic growth still dominates the agenda of the state. The choice of the carbon intensity reduction target has indicated to China's attempt to balance the fast economic growth and the GHG emissions reduction. Moreover, the need to address the dynamic economic development also results in various special design features among the pilot projects, which can be exemplified by the intensity-based cap and ex post adjustment of the allowances allocation in the Shenzhen pilot project. By analogy, similar attention will also be paid to the impact of the dynamic economic development on the establishment of the legal framework for the national scheme in China.

${ }^{1}$ See Minzner, C. F. (2009), p.98-106; see also O'Brien, K., \& Li, L. (1999), p.176-181.

2 Recital of UNFCCC.

3 Annex B, Kyoto Protocol.

${ }^{4}$ Article 1, Doha amendment to the Kyoto Protocol. 


\section{Economic governance in different economic systems}

Given the fact that the EU ETS has been established based on the free market economy, but the Chinese ETS will be built upon the so-called Chinese socialist market economy, the role of government in the design and implementation of the respective ETSs have been quite different.

On the basis of the matured market economy relying on the market mechanisms, in which the market players make their own choices based on the price signal, the possibility of governmental adjustment or intervention in the EU ETS has been very limited. However, special attention needs to be paid to the debate on the solutions to the growing surplus of allowances, largely because of the economic crisis that has depressed emissions more than anticipated, such as postponing the auctioning of 900 million allowances from the years 2013-2015 until 2019-2020. ${ }^{1}$ In addition, five other options have been proposed by the Commission at the same time as the structural reform measures for the EU ETS. ${ }^{2}$ However, according to the EU legal system, any possible measures to be taken by governments with the aim to address the imbalance between the supply and demand of allowances and hence the proper functioning of the EU ETS requires a necessary modification of the legislation relating to the EU ETS. By the time of writing, most of the structural reform measures proposed by the Commission are still going through or moving towards the relevant legislative process.

It is not clear whether these proposals can 'rescue' the EU ETS, as expected by the Commission, but the Chinese pilot projects seem to be rather alert to prevent this experience of the EU ETS. In order to deal with the possible market failure that may emerge in the ETS, in particular the abnormal price fluctuation, relevant governmental price regulation mechanism has been applied or considered by several pilot projects. Furthermore, particular attention should be paid to the fact that the price regulation measures to be applied in the pilot projects such as Shenzhen and Beijing are quite similar to those that could be adopted by the government in the emissions trading market proposed by Dales, acting as an active broker.

However, the attempt to regulate the carbon price in the form of governmental intervention in the Chinese ETS pilot projects is not just based on the experience from the EU ETS or the theory designed by Dales. On the contrary, it seems to be an inevitable outcome in line with the Chinese socialist market economy system to a large degree. Within an emerging market economy with a socialist political tradition, the Chinese government sometimes is still used to managing the economy by exercising a 'visible hand' in the form of governmental administrative measures, following the tradition in the old planned economy. For instance, the prices of key commodities, including electricity, are still regulated by the NDRC through its Department of Price in China. Given that the regulated electricity companies would still be unable to pass the costs on to the electricity users, observers have indicated that, when the power industry is covered by the Chinese ETS, the Department of Price would play a central role in deciding how to manage the cost of carbon and its fluctuations in the context of a regulated power market. ${ }^{3}$

\footnotetext{
1 See Decision No 1359/2013/EU, see also Commission Regulation EU No 176/2014.

2 See COM(2012) 652 final.

${ }^{3}$ Kossoy, A. \& Guigon, P. (2012), p.94-100.
} 
Moreover, as far as the economic system and governance is concerned, particular attention should also be paid to the special role of the SOE in the Chinese ETS. In view of the significance of the SOE in the Chinese GHG emissions profile as well as the emissions reduction, the SOE has been considered to be an important economic and political actor with a substantial impact on the design and implementation of the Chinese ETS. ${ }^{1}$ For instance, the description of the pilot projects has indicated the performance evaluation system of the SOE and in particular of its leaders has been employed as one instrument of the enforcement package, similar to the approach to the fulfilment of the carbon intensity reduction targets. Furthermore, in the Market Readiness Proposal provided by the NDRC, the analysis of the participation of Central Government Managed SOE in the Chinese ETS has been proposed as one of the building blocks for the establishment of a national scheme. ${ }^{2}$ In this respect, the traditional governmental management, at least for the SOE covered by the ETS, may not cease to exist in the Chinese ETS.

Coupled with other critical issues, such as the widespread corruption, the tendency of excessive governmental intervention and price control in specific sectors has given rise to the question of whether the Chinese ETS could be established and function well without a mature free-market economy. ${ }^{3}$ In this light, the regulatory experience of the $\mathrm{SO}_{2}$ ETS at the local level since the 1990s, in which the excessive governmental intervention in the emissions market has been criticised heavily, has already cast doubt on the prospect that the emissions market could operate free from arbitrary manipulation by the government. ${ }^{4}$ For instance, the literature has criticised the fact that a great proportion of $\mathrm{SO}_{2}$ emissions trading has been done mainly based on the administrative order or instruction from the local government, in particular the local environmental protection bureaus, following the traditional planned economy approach rather than the price-based market mechanism. ${ }^{5}$ This trading, which is not the real transaction that is based on the real price reflecting the demand and supply in the market, cannot provide a clear price signal and expectation for the market players. As a result, most of the emitters intend to keep the allowances to cover their own emissions or to prepare for their own future development, rather than participating in emissions trading, thereby impeding the prospective and continued development of the emissions trading market. In this sense, excessive governmental intervention will have a negative impact on the trading behaviour of the market players and thus the proper functioning of the ETS.

In addition to the governmental price regulation measures, the economic incentive measures supporting the establishment and operation of the ETS, which have been incorporated into the regulatory framework in some pilot projects like the Beijing pilot, have at the same time exemplified the special active role of the government in the governance structure of the Chinese ETS. Moreover, the initiative in the Beijing pilot project also indicates that the relationship

${ }^{1}$ Bergsager, H. \& Korppoo, A. (2013), p.57-59; see also NDRC(2013), Market Readiness Proposal: Establishing a National Emissions Trading Scheme in China, p.175-180.

2 NDRC(2013), Market Readiness Proposal: Establishing a National Emissions Trading Scheme in China, p.175-194.

${ }^{3}$ Han, G., Olsson, M., Hallding, K., \& Lunsford, D. (2012); see also Lo, A. Y. (2013), p.73.

${ }_{5}^{4}$ See Tao, J., \& Mah, D. N.-y. (2009).

5 See Zhao, H. Y. \& Zhao, J. J. (2009), p.32-33; see also Qin, T. B. \& Wang, Y. (2009), p.5; Wang, J. N., Dong, Z. F. \& et al(2009), p.19. 
among the government, emitters and verifiers seems to be much more complicated than that in the EU ETS, but it will be interesting to observe whether this special design can ensure the quality of the emissions data in the special Chinese context as expected or not.

The description of the pilot projects has represented a tailoring of a market-based instrument to a socialist market economy, but the problems regarding its design and implementation remain evident. ${ }^{1}$ There is no doubt that it is possible for the Chinese government to regulate the ETS in line with its particular economic governance structure, but it requires the governmental action per se to be regulated effectively within the legal framework for the ETS. As argued by scholars, the reform of the Chinese socialist market economy calls for a dual-dimensional governance: on the one hand, China should deepen the market-oriented reforms and reduce the administrative intervention in pursuit of the establishment of a market economy; on the other hand, the macro-control should be strengthened, as the 'invisible hand' needs to be supported by 'a visible hand' and the market failure needs to be corrected by state intervention. ${ }^{2}$ By analogy, aiming to establish and operate the Chinese ETS in a political-economic context where free market and democratic regime is still under construction ${ }^{3}$, the governmental intervention should be limited to specific circumstances stipulated ex ante in the legal framework and should be implemented strictly in accordance with the legal procedure. However, the detailed rules regulating the governmental adjustment or intervention are still missing in most of the pilot projects. Moreover, the liability system for misconduct relating to the governmental adjustment or intervention, including the cadre responsibility system, still deservers further observation and exploration in depth.

\section{Concluding observation}

The current establishment of an ETS in China has followed an experimental approach, which needs to be evaluated to find out whether, how and why it works or fails in practice. As argued by Qian, the reform of transition and developing countries, such as China, is mainly confronted with the challenge of finding a feasible way towards the goal rather than setting that goal. ${ }^{4}$ With the experimental approach in developing the Chinese ETS, similar to that in the EU ETS, many problems are emerging in the pilot projects and various lessons can be learnt for the potential national Chinese scheme. But before the development of a national scheme is possible, there is a need to observe and evaluate the problems that have emerged from the pilot projects, in order to learn lessons from the pilot projects and to make recommendations for the further development of the national scheme. For instance, it would be important to evaluate the effect of the pilot projects on GHG emissions reduction based on empirical information and analysis. Such evaluation may provide further insights into the functioning of the pilot projects as occurrence of carbon leakage. However, in view of the short experimentation period in the ambitious agenda of the government, it is questionable whether there will be enough time for a thorough evaluation. Meanwhile, whether and how the government will conduct the evaluation also remains unclear.

${ }^{1}$ Munnings, C., et al (2014), p.43.

2 Zhu, J. W. (2011), p.37.

${ }^{3}$ Lo, A. Y. (2013), p.73.

${ }^{4}$ Qian, Y. Y. (2002). p.49. 
Moreover, in light of the limited and unclear information about the pilot projects, it is rather difficult for scholars to evaluate the pilot projects either, since it is not clear what was the aim of the government with the existing choice and it is difficult to assess other possible options. In this respect, improvements in terms of information disclosure in the Chinese context are needed, aiming to facilitate the evaluation of the Chinese ETS.

Furthermore, the comparative analysis presented in section 6.1 has shown not only similarities but also important differences regarding regulatory design and implementation in terms of the three key elements between the Chinese pilot projects and the EU ETS. Although the EU ETS has been considered as an important model for the establishment of the Chinese ETS, the design features have turned out quite differently in the Chinese context. As argued in the research methodology of this thesis, legal borrowing is evident in the ETS. First the Kyoto Protocol borrowed from the US acid rain programme and then the EU ETS borrowed from the Kyoto Protocol ${ }^{1}$; however, differences between the schemes regarding the design features do exist in legal borrowing and "translation" because of the different situations at play.

In this sense, the efforts in searching for the solutions to problems in the EU ETS may provide China with profound insights, but the potential improvements of the Chinese ETS need to be carried out within the Chinese context with its unique character in mind. Based on the analysis in the previous chapters, further recommendations for potential improvements of the regulatory design and implementation of the Chinese ETS will be provided in the following concluding chapter.

\footnotetext{
${ }^{1}$ See Wiener, J. B. (2001).
} 


\section{CHAPTER 5 \\ CONCLUSION AND RECOMMENDATIONS}

This chapter reviews which improvements may be recommended regarding the regulatory design and implementation of the ETS in China, particularly seen from the perspective of aiming to strengthen the rule of law. As was explained in section 6.2.1 of chapter 4, the rule of law is recognised in the Chinese constitution, and the gap between the rule by law and the rule of law is closing but it still exists. The pursuit of a sound legal system does not necessarily mean that China should embrace and copy the western notion of the rule of law. Moreover, the specific development of the rule of law in China may be different from that rooted in Western democracy, in view of China's own situation. However, it does require that 'there must be law to rely on' [you fa ke yi], providing the legal infrastructure to foster the rule of law in China. From this perspective, striving to strengthen the rule of law, which means that there must be law to rely on, recommendations will be made for improving the legal framework for the Chinese ETS, in particular the specific design regarding the three key elements. With this, sub-question 4 of this thesis will be answered.

In section 1, first a summary of the main findings of each chapter of this thesis will be given. Then section 2 will deal with the need for a legal framework for the Chinese ETS, while section 3 will provide conclusions regarding the potential improvements of the regulatory design and implementation regarding the selected three key elements. Lastly, some future research challenges will be pointed out in section 4 .

\section{Summary of the findings thus far}

In chapter 2 of this thesis, a theoretical legal framework for examining the ETS was explored and proposed, in order to provide an understanding of the key elements of the legal framework for an ETS. Based on the original concept of emissions trading firstly proposed by Dales, together with two basic emissions trading models, three key elements of the ETS, namely (1) target setting, (2) allowances allocation, and (3) inspection and enforcement, were selected and elaborated on in this chapter. With regard to the first key element, setting a stringent target for emissions trading within a multi-level governance structure is a critical challenge, requiring competences to be distributed between different levels of authorities in line with the specific legal system. In this respect, the merits of and concerns on two basic models for competence distribution, centralisation and decentralisation, were analysed. Regarding the second element, the allowance allocation, the process and result concerning the initial allocation of allowances is of significance, since it determines the specific positions of the covered industries within the ETS. Especially in the case of the combination of different initial allocation methods, including free allocation and auctioning, which is a feasible choice for the government to accommodate different 
circumstances, the equal treatment of emitters has emerged as an important issue to be addressed in the design and implementation of the allocation of allowances. As the last cornerstone underpinning the proper functioning of the ETS, provisions for inspection and enforcement should be established. This implies a robust MRV system collecting the emissions data and a rigorous sanction system for non-compliance.

Chapter 3 of this thesis focused on the legal experiences with the EU ETS regarding the three key elements in terms of their regulatory design and case law. The review of the development concerning the EU ETS has indicated that two basic models can be differentiated in terms of target setting and the allocation of allowances, while the basic design of the enforcement system has been implemented and evolved comparatively stably through all three trading periods. In the domain of cap setting for the EU ETS, the cap was set up mainly by Member States in a decentralised model in the first two trading periods, moving to a harmonised model with a shift of competence to the Commission since 2013. The case law relating to the NAP in the first model was analysed to offer further insight into the competence distribution, but also possible concerns under the centralised model were considered. With regard to the allocation of allowances, free allocation has played the dominant role in the first and second trading periods, while auctioning is phased in gradually in the third trading period. Embedded in the application of the mix of allocation methods through those two models, however, the potential differential treatment has been questioned even before the court. Different from cap setting and allowance allocation, the enforcement package for the EU ETS has not changed a lot. It has moved gradually towards harmonisation across the EU. Meanwhile, the design features concerning self-monitoring, self-reporting and third-party verification adopted in the EU ETS, suggesting the need for the independence of and supervision of the third-party verifier, has provided an example for other countries who want to establish an ETS, like China. Furthermore, in terms of the establishment of the sanctions system, the question of whether the automatic and fixed financial penalty is necessary and proportionate has been examined in the case law, which provides us with meaningful inspiration in the choice and design of penalties.

After presenting and examining the design and implementation of the Chinese pilot projects, chapter 4 of this thesis detected and explained the similarities and differences between the Chinese ETS and the EU ETS. On the basis of the brief introduction to the Chinese legal system, it was pointed out that the Chinese $\mathrm{CO}_{2}$ ETS will be established within a multi-level governance structure, in which policy rather than law plays a significant role. Given the experimental approach adopted, the legal framework for the Chinese ETS is still in the course of development and evolution. Nevertheless, based on the description and analysis of the pilot projects being established at the local level, some challenges in terms of target setting, allowances allocation, inspection and enforcement facing the Chinese ETS have been identified and examined in this thesis. Meanwhile, the rationality for a potential national ETS has been explored and some further possible options concerning the design and implementation of a national scheme have been posed. Furthermore, a comparison of the design features, presented in section 6.1 of chapter 4, has showed similarities and differences between the EU ETS and the Chinese ETS in terms of the general characteristic of the legal framework and their specific design regarding the three key elements selected. In an attempt to gain a mutual understanding of both systems, the reasons for 
the differences between the EU ETS and the Chinese ETS have been discussed in section 6.2 from the perspectives of the legal, political and economic systems.

Putting the above findings into a broader context, a number of observations appear to be in order. Although the ETS seems to be quite simple and effective in economic theory, it is a very complicated market-based regulatory instrument, the legal framework for which has to be designed in accordance with the specific political and legal systems, which has been demonstrated by the EU ETS and the Chinese ETS respectively. In order to answer the fourth sub-question, which is how can China, particularly seen from the perspective of its aim to strengthen the rule of law and its aim to establish a national ETS, improve the regulatory design and implementation of its own ETS, in particular regarding the selected key elements, recommendations for the Chinese ETS, on the basis of the comparative analysis between the EU ETS and the Chinese ETS, will be put forward below.

\section{The need for a legal framework for the Chinese ETS}

\subsection{The significance of a legal framework regulating governmental}

\section{action}

If China indeed wants to strengthen the rule of law, the improvement for the Chinese ETS will firstly require the establishment of an effective legal framework. Different from the EU ETS, China has been experimenting with the ETS in a non-legislative framework while struggling towards establishing a legal framework. As far as the Chinese legal system is concerned, core problems exist, such as the legal force of relevant rules and legal enforcement. Due to the strict and complicated legislative procedure, the adoption of other normative documents instead of formal legislation, or the adoption of legislation of a low legal rank rather than higher level legislation, seems to be a practical choice for the Chinese local governments who want to set up the ETS quickly according to the ambitious schedule set up by the central government. However, from the perspective of the rule of law, a sound legal framework is vital for the proper functioning of an ETS. In this respect, the significance of the legal framework has been exemplified by the experience of the EU ETS, in which most of the key elements of the ETS have been stipulated in legislation mainly adopted at the EU level, and supplemented and implemented by national laws promulgated by the Member States. If China also wants to move to the rule of law, it is important for China to establish a legal framework providing clear legal rules for the ETS.

Moreover, in view of the special role of the government in the ETS, a legal framework regulating governmental action effectively is much needed. From a theoretical point of view, the success of an ETS relies on a fully-developed and mature free-market economy as well as on effective governmental regulation in line with the law. In other words, the ideal effective legal framework for such market-based instruments should be designed with a clear and proper relationship between the government and the market, in which the government plays the steering role on the 
basis of the market mechanism. For instance, in the course of setting up the cap for emissions trading, where the government plays a dominant role, how the competences can be distributed between the different levels of authorities needs to be addressed in the legal framework. In the allocation of allowances, which has a substantial and direct impact on the interests and legal positions of the emitters covered, the role of the government should be defined on both the horizontal and vertical dimensions, requiring the government to justify differential treatment of emitters and of developed and developing regions, and to adjust the allowance allocation strictly in accordance with clear rules stipulated in the legal framework.

In particular taking account of the significant and supreme role played by the government in the Chinese ETS, it will be of significance to establish a legal framework providing for the effective regulation of governmental action in order to achieve the rule of law and to ensure confidence in the market in China. However, the practice in the pilot projects has suggested that the establishment and implementation of the Chinese ETS still relies greatly on the willingness of the government. Most of the key elements have been designed and implemented by the local governments concerned, often in the form of governmental documents, without a sufficient legal basis provided by the regulatory framework in order to make them legally binding. Especially in the case of abnormal price fluctuations in the future, one may wonder whether and how the government will act. Law is needed to avoid governmental arbitrariness and abuse of governmental power.

In contrast to the Chinese ETS, the EU ETS is established through law from the very beginning, with amendments to the legislation over time. Following the legal tradition concerning the rule of law, the legal rights and obligations of the parties involved in the EU ETS constitute the core of this legal framework. Meanwhile, established mainly on the basis of the EU ETS Directive, the competence distributed to the governments at various levels in the EU has been determined in the legislation or clarified by the court in case law. As a result, this legal framework legally binds not only the market participants but, importantly, also the governments themselves. The experience in the EU ETS has demonstrated the significance of the legal system in dealing with the relationship between the government and the market, but it has also implied some shortcomings embedded in its legal framework, in particular the lack of some necessary legal mechanisms allowing the government to take proper action to address emergencies having a substantial impact on the whole system, such as the surplus of allowances induced by the economic crisis. However, this issue can't be addressed until a legislative amendment is adopted.

Taking account of the legal experiences with the EU ETS, if China indeed wants to follow the rule of law, it is crucial to provide a well-designed and enforceable legal framework for emissions trading, in which the roles of the government and the market will be differentiated clearly and properly.

\subsection{The choice between policy and legislation}

In pursuit of an effective legal framework in line with the particular political and legal context in China, the choice between policy and legislation will be further discussed below. 
From the perspective of the rule of law, the proper functioning of the ETS requires a legal framework providing for precise, well-designed and legally binding rules guiding and regulating the relevant activities of all the parties involved in the ETS, in particular the government per se. China's legal reform in the last three decades has demonstrated, to a large extent, its attempt to establish and to promote the market economy through the adoption of lots of relevant legislation. ${ }^{1}$ Especially for a market created artificially by the government, the key elements of the ETS, in particular those relating to the rights and obligations of the market participants and the government, such as the governmental competence, the allocation rules and enforcement measures, need to be determined explicitly and promulgated before trade takes place. Otherwise, market players are not sure how to act, which may impede trading. ${ }^{2}$ Taking account of the insufficient legally binding effect of the regulatory framework for the pilot projects, it remains necessary for the central and local authorities to adopt relevant legislation replacing some existing policies and governmental documents, aiming to move towards a legal framework in accordance with the concept of the rule of law in the Chinese context and hence to provide more predictability and certainty for the market participants. In light of the limits of the local legislation in terms of the content and the legally binding effect, the legislation should be adopted mainly by the national authorities supplemented by the local authorities in implementation in accordance with their respective legislative competences..

In addition to the formal legislation, policy may still play a role in the regulatory framework for the Chinese ETS, which may be quite different from the EU ETS. As revealed by the analysis of chapter 4, the Chinese climate governance framework has a heavy reliance on policy. From a functional perspective, policy provisions such as various normative documents adopted by local governments, which have provided important rules for the establishment of the pilot projects, seem to be considered as complementary components forming the regulatory framework for the Chinese ETS. It is worthy of further study how the policy provisions fit and facilitate the Chinese economic and political reality, but China's experience and even some "success" with policy instruments should not constitute an argument against fostering the rule of law. ${ }^{3}$ However, due to its flexibility and de facto effectiveness stemming from the political and administration system, the governmental policy and specific policy instrument may still be an attractive and flexible option for the policy makers establishing the regulatory framework for the Chinese ETS. In view of these special contexts, practically speaking, the policy will not be excluded from the regulatory framework for the Chinese ETS in the near future; however, if China wants to strengthen the rule of law, the use of policy has to be limited to specific circumstances in accordance with the law. The policy provisions might be a suitable choice for some supporting measures for the establishment and implementation of the Chinese ETS, such as the accountability system binding the government and the economic incentives facilitating compliance by the market participants. Nevertheless, the application of such policies should not contravene the rule of law, in particular, by infringing the right of market players.

\footnotetext{
${ }^{1}$ Clarke, D. C. (2007), p.577-578. In this respect, Weber has argued that the right legal institutions can promote growth, see Weber, M. (1978); Weber, M., Rheinstein, M., \& Shils, E. A. (1954).

${ }_{2}^{2}$ Further research examining the behaviour of market players would be necessary in another study.

3 Qian, Y. Y. (2002), p.49.
} 
Therefore, in order to improve the regulatory design and implementation of the Chinese ETS in line with the rule of law, it is possible for China to establish a legal framework mainly based on formal legislation, while allowing some policy provisions to provide for some supporting measures. Some scholars have proposed a mixed legal structure, in which the formal legislation, supplemented and assisted by the policy provisions, should play the leading role in addressing the needs of public governance, in pursuit of the ultimate goal of good governance in line with the rule of law. ${ }^{1}$ With regard to the legal framework for the Chinese ETS, there is also a possibility for the combination of the legislation adopted by the central and local authorities in accordance with their legislative competences, and some policy provisions, for instance, in the form of governmental documents relating to the ETS. However, a major breakthrough is still needed to distinguish the functions of legislation from the functions of policy provisions in China. $^{2}$ Meanwhile, in view of the different nature and effect of policy and legislation, particular attention should be paid to the need to strike a delicate balance between certainty and flexibility when establishing the legal framework for the Chinese ETS.

\section{The potential improvement of the three selected elements}

When investigating how the ETS is currently "translated" in the Chinese context, there are similarities and differences between the Chinese ETS and the EU ETS in terms of the specific design of the selected key elements, which were explained in the comparative analysis in section 6 of chapter 4. Some of the different approaches adopted by the Chinese ETS can be justified in view of the Chinese context, while some of them don't fit into China's aim to strengthen the rule of law. If China indeed wants to move to the rule of law, these approaches need to be improved, which will be discussed below in view of the legal experiences with the EU ETS.

\subsection{Target setting}

As a specific instrument aiming to ensure the environmental goal of the climate policy, the GHG emissions reduction target should be legally binding and strict. In order to improve the regulatory design and implementation of target setting for the Chinese ETS, attention needs to be paid to the types and legal effect of the emissions reduction target for the ETS on the one hand and the competence distribution for target setting on the other hand.

\section{Type of the target for the Chinese ETS}

The choice of the type of emissions reduction target is closely connected to the choice of the emissions trading model. As argued in this thesis, although the EU has followed the Kyoto Protocol by choosing an absolute cap and hence has built up the EU ETS on the basis of the cap-and-trade model, China can still opt for the relative target (the carbon intensity reduction target) in pursuit of green growth. Nevertheless, the practice of the Chinese pilot projects shows that they have been established based on the cap-and-trade model, possibly because of its

\footnotetext{
${ }^{1}$ See Luo, H. C. \& Bi, H. H. (2006); Cheng, X. H. (2007).

2 Wang, X. (2001), p. 150.
} 
theoretical advantages including the secured environmental goal, its simple design and relatively easy operation. However, the caps for the Chinese pilot projects have been set up in a different way compared to the EU ETS, which can be exemplified by the dynamic intensity-based cap for the Shenzhen pilot project, together with the governmental ex post adjustment of the allocation of allowances in line with the actual economic development. This different approach may be justified in view of the strongly political binding effect of the carbon intensity reduction target and the need to accommodate the fast economic growth. But the special design may make the cap setting even more complicated. In particular regarding the ex post adjustment, it is necessary to strike a balance between legal certainty for the covered emitters who want to use allocated allowances, on the one hand, and flexibility by means of an ex post adjustment in the cap setting, on the other hand. Although there is already some attempt to reduce the negative impact of an $e x$ post adjustment on trading behaviour, such as setting the trigger and conditions for the ex post adjustment, the application of ex post adjustment in cap setting makes the design of the Chinese cap-and-trade scheme rather burdensome and complicated, creating a risk of legal uncertainty and governmental arbitrariness. In this respect, the credit-and-trade model (as discussed in section 2.2 of chapter 2) that can accommodate dynamic economic growth seems to be another suitable and feasible alternative for the Chinese ETS, which needs further consideration. In this sense, the special approaches and experiences of the Chinese ETS may also provide further insight into how to set the target in a rapidly growing economy for other countries.

\section{The legal effect of the target for the Chinese ETS}

Within the framework of the overall carbon intensity reduction targets binding the governments at all levels, the cap for the Chinese ETS should be a specific target with legally binding force, instead of an abstract and vague policy goal. Due to the special approaches mentioned above, the cap setting for the Chinese ETS remains so complicated that only a few rules relating to cap setting have been adopted in a vague and abstract way for the pilot projects. Moreover, different from the EU ETS, none of the caps for the Chinese pilot projects have been set up in formal legislation. Some pilot projects, such as Guangdong, Hubei and Chongqing, are making progress by means of the determination and publication of the absolute cap ex ante. However, it may still be difficult to imagine how other pilot projects can be established and operated as expected without a cap determined and published ex ante before the trade. The reasons for these choices may lie in a large number of factors, including but not limited to some reservations of the Chinese government in international political negotiations and the technical difficulties in converting the carbon intensity reduction target into an appropriate cap. But from the perspective of the rule of law, the lack of a legally binding cap determined ex ante implies a lack of sufficient legal effect and thus legal certainty.

Taking account of the legal experiences with the EU ETS, it remains necessary for the Chinese legal framework to provide for clear legal rules concerning the cap setting. On this basis, if China opts for an absolute cap for the ETS, the cap needs to be determined and published ex ante in the legal documents with sufficient legally binding force, in order to ensure legal certainty for effective GHG emission reduction and for the market players. Moreover, critical issues, such as 
the procedure to set up the cap, and whether and under what circumstances the cap may be adjusted ex post should also be addressed in this legal framework.

\section{Competence distribution for cap setting}

In order to improve the regulatory design and implementation of the Chinese ETS, the competence distribution for cap setting between different levels of governments within a multi-level structure needs to be determined and designed in line with the Chinese specific legal system.

Due to the considerable gaps in terms of the concerns and priorities on the agendas of different levels of authorities involved in the ETS, especially as far as the high cost of reducing GHG emissions with little local beneficial effect is concerned, the lower levels of authorities would tend to use a lax cap by allocating more allowances to the local emitters for various reasons. In order to ensure the effective reduction of GHG emissions by 'controlling' the cap setting at the lower level, the potential conflict between different levels of authorities may also occur in China, in particular taking account of the risk of local protectionism under the GDP-oriented assessment system. In China, however, the practice of the pilot projects and the experience of the determination and allocation of the carbon intensity reduction target has implied that the conflict may be still addressed through a political approach, including the political negotiation and heavy reliance on the top-down cadre responsibility system. It is not easy to change the Chinese traditional authoritarian regime in the short term, but if China wants to follow the rule of law, it would be important for the Chinese ETS to distribute the competence for cap setting in a legal framework. Regarding the EU ETS, the competence distribution and possible solution to the potential conflict has been determined in the legal framework for the EU ETS, allowing interaction between different levels of authorities checked by judicial approaches in accordance with the EU legal system. In view of the Chinese specific political system, there may be little room left for the court to deal with such conflict in the domain of competence distribution. Nevertheless, taking account of the legal experiences with the EU ETS, China may consider setting up clear legal rules in the legal framework for the ETS, providing the necessary interaction and coordination between the central government and local governments, in order to prevent and to deal with similar potential conflicts.

In addition, it is possible for China to distribute the competence for cap setting based on a combination of decentralisation and centralisation in line with its own specific legal system. As discussed in chapter 4 , four approaches for establishing the cap featuring a different degree of centralisation or decentralisation can be considered for the Chinese ETS in view of the establishment of the national scheme. Whatever approach is to be adopted, the policy makers will have to deal with different challenges built into each approach, because of China's unique national conditions and political structures. In this respect, the analysis in chapter 3 on the evolution of cap setting for the EU ETS, moving from the decentralisation to the centralisation model, may provide meaningful inspiration for China. Given the fact that the ETS is an instrument employed to achieve an environmental goal, the competence distribution needs to be determined in an approach ensuring the stringency of the cap, requiring the higher level 
authorities to control the cap setting at the local level in the decentralisation model, on the one hand, while allowing and encouraging the local authorities to adopt additional measures to reduce the emissions, on the other hand. Especially in the Chinese context where the central government usually plays the steering role, with regard to the ETS, which relies on the implementation by the local governments, the compromised or balanced approach, such as the combination of centralisation and decentralisation may be a pragmatic choice. For instance, in view of the legal experience with the EU ETS, it is also possible for the cap to be set up based on the centralisation model while giving a certain degree of flexibility to the local governments in implementation regarding the allocation of allowances to be discussed below.

\subsection{Allowances allocation}

Since in the Chinese ETS allowances confer a public law right with economic value on the entitled emitters, the allowance allocation has a substantial impact on the legal position of the individual emitter and thus on the competitive position of the regional economic development. In pursuit of improvement of the Chinese ETS, two categories of relationships throughout the allocation of allowances need to be addressed in the legal framework. One is the competitive relationship among the emitters and among the regional economies on the horizontal level and the other is the relationship between the government and the emitter on the vertical level. In this light, attention needs to be placed on the equal treatment among the emitters and regions from a horizontal perspective, on the one hand, and the governmental adjustment of the allocation result from a vertical perspective, on the other hand.

\section{Allocating allowances in view of equal treatment}

In pursuit of the equal treatment among the emitters and the various regions, it is important to ensure that the allowances are allocated based on unified or consistent rules, for which the competence distribution for allocation is relevant. In particular, the practice of the pilot projects has already implied a potential risk rooted in the decentralised model for the allocation of allowances. In the absence of unified national principles, standards or guidelines, this decentralised model may cause serious problems endangering the level playing field among the emitters covered by different pilot projects. Moreover, the lack of legally binding allocation rules at the local levels might even turn the decentralised allocation into a tool of local protectionism to a certain degree. In view of the legal experience with the EU ETS, especially the harmonisation of the allocation of allowances in the third trading period, China can also consider the application of such a centralised model. From a practical perspective, however, the combination of the centralisation and decentralisation approach, in which the basic allocation principles and rules should be determined in the national legislation, while the lower levels of authorities are allowed to implement the allocation rules in line with the specific local situation, would be a feasible approach for the Chinese ETS that would correspond to the basic idea of the Constitution.

In addition, different allocation methods may be chosen based on an objective justification. At the regional level, especially in a possible national scheme, it is important for the central 
government to treat the developed and developing regions differently in the course of allowances allocation as well as burden sharing in an objectively justified way, in order to strike a balance between market integrity and regional disparity. The legal experiences with the EU ETS, such as the special allocation of the allowances to be auctioned for the purpose of solidarity and growth within the Community as provided in Article 10.2(b) of the EU ETS Directive, may be a useful approach for China. At the emitter level, within the mix of allocation methods chosen by the Chinese ETS, some special allocation rules have been designed for specific sectors or emitters in view of the risk of carbon leakage, possibly resulting in problems relating to the differential treatment, which needs to be objectively justified on the basis of sufficient consultation and due procedure. Considering the legal experience with the EU ETS, in pursuit of an objective justification for the differential treatment, an explicit legal basis and detailed rules concerning the differential allocation, needs to be in place within the legal framework in order to avoid governmental arbitrariness and potential collusion. Moreover, adequate and effective communication and consultation with the stakeholders, in particular the sectors concerned, should be taken into account seriously in the decision-making process if China wants to move towards the rule of law.

\section{Designing the governmental adjustment in the legal framework}

As an obvious difference between the EU ETS and the Chinese ETS, some Chinese pilot projects have applied the ex post governmental adjustment of the allocation result, while such governmental adjustment is generally not allowed in the EU. The different approach adopted by the Chinese ETS may be justified by the context of the Chinese market economy with socialist characteristics, in which the governmental adjustment usually has been considered as a flexible instrument applied to accommodate the dynamic economic development. Particularly in consideration of the EU experience in dealing with the so-called 'surplus' of allowances mainly due to the economic crisis and then the structural reform of the EU ETS, the necessity of the governmental adjustment of the allowances allocation seems to be more and more evident in the eyes of the policy makers in China.

However, as discussed in the ex post adjustment of the cap, the regulatory design and implementation of such governmental adjustment is rather complicated and problematic. Especially without a specific legal basis, it may risk improper governmental action endangering market expectations and legal certainty to a certain extent. This also explains that, even in the face of the current so-called 'depressed' EUA price, governmental adjustment will not be accepted by the EU unless it would be included as a possibility, after intense debate, in the amendment of the EU ETS Directive and relevant legislation. Nevertheless, these kinds of governmental action, based on the meticulous design within the legal framework, may be helpful to facilitate the establishment of the ETS in the developing market economy at the initial stage, in particular, to stabilise the market to a certain degree in the face of severe fluctuations.

In view of building the rule of law, for China, there is a need to design and control the governmental adjustment by specific clear rules provided in the legal framework ex ante, aiming to strike a balance between legal certainty and flexibility. The legal framework should provide 
clear rules stipulating in which circumstances the government is allowed to adjust the allocation of allowances, facilitating the government to give a timely response to the rapid changes emerging in the economic situation using the allocation of allowances.

\subsection{Inspection and enforcement}

An enforcement package comprised of a robust MRV system and rigorous sanctions for non-compliance is the final cornerstone underpinning the establishment and operation of the ETS.

\section{MRV rules}

The evident significance of the real and accurate emissions data has been well recognised by policy makers in the Chinese ETS. Moreover, the Chinese pilot projects have applied the approach of self-monitoring, self-reporting and third-party verification, with quite a similar design as that of the EU ETS. The use of such MRV approach will not only bring opportunities in improving quality and efficiency concerning emissions data collection, but it may also create challenges for the establishment and operation of the Chinese ETS, asking for further improvement in line with the rule of law.

Different from the EU ETS, the current MRV rules for the pilot projects are still mainly provided for at the local level, leading to the weakness of the legal effect and the possible diversity of the quality of inspection. In this respect, the harmonisation approach of the MRV rules for the EU ETS, moving from the guidelines to the regulations, may still provide inspiration for China to establish a more unified MRV system with a stronger legal force in the legal framework for the ETS. Moreover, the specific design of the MRV rules also requires further improvement. For instance, considering the legal experience with the EU ETS, the instruments of the GHG emissions permit system and the monitoring plan are important to strengthen the legal obligations and requirements concerning monitoring and reporting for the emitters. But the legal basis for the establishment of such instruments should be firstly provided in line with the Chinese legal system. In view of the complicated relationship among the emitter, verifier and the government, the independence of the third-party verification remains a fundamental challenge for the Chinese ETS. Taking account of the experience with the EU ETS, such as the adoption of the Accreditation and Verification Regulation, it will also be important for China to strengthen the legal framework for accreditation and verification, stipulating clearly the legal rights and obligations of the verifiers as well as the responsibility for possible non-compliance. In addition, it is noticeable that the Chinese government has tried to improve and to ensure the quality of the verification report with some special mechanisms, including a double check for the verification report and extra economic incentives for the verifier. But if China wants to strengthen the rule of law, these positive attempts by the government need to be designed and implemented within the legal framework. For instance, necessary judicial remedies should be available for the emitters and verifiers to address possible disputes over the reviewing result concerning the verification report. 


\section{Sanctions}

Aiming to establish a stringent legal liability system for non-compliance that may occur in the Chinese ETS, it is important for China to make sure that the main types of non-compliance of the participants involved are subjected to appropriate punishment. Most of the Chinese pilot projects have established various types of penalties for excessive emissions and other non-compliance regarding the MRV. But when a national scheme is established, it is necessary to set up a unified sanction system, at least for the basic non-compliance such as excess emissions, in order to ensure the market integrity and equal treatment among the emitters located in different areas. In this respect, the legal experience from the EU ETS, establishing a harmonised penalty for excess emissions at the EU level, provides a useful example.

In addition, the specific design and implementation of each penalty in line with the rule of law remains critical for the Chinese ETS. Taking the penalties for the excess emissions as examples, not only a specific amount of allowances (equal or more than one times of the excessive emissions) should be compensated in the next trading period, but also an effective and proportionate financial punishment should be imposed on the violators. In this respect, it is a positive attempt of some pilot projects to establish stringent sanctions by requiring the violator to compensate with allowances amounting to more than one times of the excess emissions. Meanwhile, both the options of the fixed amount and the indexed penalty linked with the market price of the allowances have been applied by different pilot projects. However, in light of the doubt cast on the effectiveness of the fixed but small amount of the fines applied in some pilot projects, it will be important and necessary to establish a more severe fine that would outweigh the economic value of the shortage of allowances at the national level in line with the Chinese legal system. Based on the minimum punitive rules set up at the national level, the local governments should also be allowed to implement additional and more stringent measures. Moreover, considering the legal experience with the EU ETS, in particular considering the case law dealing with the question of whether and how the excess emissions penalties should be implemented in line with the principle of proportionality, China may need to have a further consideration before choosing an automatic approach for the Chinese ETS in accordance with the Administrative Penalty Law.

Furthermore, it is possible for China to consider some special complementary instruments for the enforcement package in line with the Chinese political and legal systems, on the condition that the rule of law is respected. In particular, the cadre responsibility system may remain an important approach, controlling the local governments and SOEs in view of ensuring well-functioning ETS pilot projects. For instance, in view of the fact that ETS pilot projects are meant to contribute to compliance with the carbon intensity reduction target, the cadre responsibility system may urge and stimulate the leaders of the local government to strengthen the legal framework with additional and stringent sanctions on violations that may endanger the achievement of the carbon intensity reduction target. 


\section{Future research challenges}

The design and implementation of the ETS in a legal system is very complicated. Because of the experimental approach taken for the establishment of the Chinese ETS, the evaluation and gradual improvement will be necessary in this process, creating a need for further observation and the future research suggested below.

In particular, the Chinese $\mathrm{CO}_{2}$ ETS is still very young and is in the process of development, which needs to be evaluated and, subsequently, improved. Since the analysis of the Chinese pilot projects is limited to their development before September 2014, the first possible direction for future research is the further observation on and evaluation of the pilot projects that are still developing and changing. As observed in the analysis above, there is a need to evaluate the pilot projects based on more updated information concerning their application in practice, in order to gain more insight into the questions as to whether, how and why the ETS really works in the Chinese context. In view of the difference between policy and law, it remains questionable whether and to what extent some experiences from the existing experimentation mainly based on policy can be used for the solution to the problems that may emerge in the scheme established based on binding laws. The further analysis of the practice in the Chinese ETS may provide us with more clues.

Secondly, more specific attention can be placed on the role of government in the design and implementation of the ETS within China's special legal system. As a market-based instrument that has to be applied based on a well-designed and complicated legal framework, the design and implementation of the ETS involves a lot of governmental administration. In view of the unique role of the Chinese government, it will be important to further observe and reflect on what is the role of the government and how should the government act in the Chinese legal system when applying a market-based instrument. Taking the governmental ex post adjustment as example, it will be worth shedding light on the interesting interaction between the governmental power and individual rights under the Chinese legal system. Especially in view of the recent amendment to the Administrative Litigation Law in November 2014, which is intended to facilitate the individual to take the government to the court since May 2015, it will be interesting to observe the opportunity for and possible role of the court in dealing with the potential legal conflicts between governmental authorities and ETS operators.

Thirdly, the analysis of this thesis has demonstrated the legal complexity embedded in the design and implementation of an ETS. It necessitates a re-consideration of the application of the ETS, as well as other market-based instruments, in environmental governance, in particular for developing countries that are still struggling to move towards the rule of law. Meanwhile, there is substantial interaction between the ETS and other instruments, such as China's target-based accountability system mentioned above, but most of the attention of this thesis has been placed on the design and implementation of the ETS per se. In this respect, it will be worth exploring how other instruments inter alia, the command-and-control instruments, influence the design and 
implementation of the ETS and how they can interact and coordinate with each other in the Chinese legal system. 


\section{SUMMARY}

\section{TOWARDS A MARKET-BASED CLIMATE REGIME IN CHINA?}

\section{A Legal PERSPECTIVE ON THE DESIGN AND IMPLEMENTATION OF GREENHOUSE GAS EMISSIONS TRADING}

In order to reduce GHG emissions and thereby to address climate change effectively, the ETS has been introduced and applied at different levels with various designs. The ETS, as a market-based instrument, seems to be rather simple theory, but the design and implementation of an ETS demands substantial governmental regulation and presents significant challenges for the establishment and enforcement of a sound legal framework for the ETS in a specific legal system. China is applying an experimental approach to establishing an ETS to reduce $\mathrm{CO}_{2}$ emissions cost-effectively. This experimental approach is intended to allow China to explore and to improve the regulatory design and implementation of the ETS gradually within its special economic, political and legal context, while taking account of the legal experiences with the existing ETSs, in particular the EU ETS. This doctoral research aims to answer the question: How can China, seen from the perspective of its specific legal system, and considering the legal experiences with the EU ETS, improve the regulatory design and implementation of its own ETS? This research shows that both the establishment of the EU ETS and the Chinese ETS follow the experimental approach, but the Chinese ETS is quite different from the EU ETS. In addition to the specific design concerning the three key elements, the relationship between the government and the market needs to be defined and clarified by a sound legal framework.

This research contains three parts: the theoretical legal framework for examining an ETS, the legal experience with the EU ETS, and the analysis of and consideration on the emerging Chinese ETS. In pursuit of a better understanding of the ETS from a theoretical perspective, the original concept of the ETS proposed by economists and two basic emissions trading models with distinct features are analysed first. Based on the review of the economic and legal literature addressing the ETS, this research establishes a theoretical legal framework for examining the ETS comprising three key elements, namely (1) target setting, (2) allowances allocation, and (3) inspection and enforcement. In particular, the basic feature of and specific requirement for these three key elements are sketched, laying a foundation for the understanding and analysis of the ETS applied in the EU and China.

The EU ETS is established based on a very complicated legal framework, which is still subject to improvement and reformation. In general, two models addressing target setting and allowances allocation can be differentiated in the EU ETS due to the significant amendments to the EU ETS Directive in 2009, but the enforcement package has been developed with a rather stable and harmonised approach throughout the three trading periods. Aiming to gain legal insights for China, the description and analysis of the EU ETS in this thesis sheds light on the legal problems that emerged in the legal framework for the EU ETS. In particular, special attention is paid to the legal conflicts between the Commission and Member States regarding cap setting, the equal treatment issues accompanied by the allocation of allowances and specific challenges facing the enforcement package, also exemplified by case law. 
The Chinese $\mathrm{CO}_{2}$ ETS is being developed in line with the experimental approach. Due to the special nature of the Chinese legal system, the pilot projects are being designed with various features by seven local governments, while the central government is still playing a steering role through the traditional political and administrative mechanisms, such as the target-based accountability system. With regard to the design and implementation of the pilot projects, some challenges and legal barriers are evident, such as the relatively weak legal force of the regulatory framework, the risk of local protectionism and governmental arbitrariness, the complexity and uncertainty of relevant rules like the ex post adjustment. In this respect, the rationality of a national ETS is examined and the possible design of a national scheme is further considered, taking account of the lessons from the pilot projects.

Meanwhile, the examination of the pilot projects in this research suggests that there are some similarities between the EU and China in terms of the basic design of the ETS, such as choosing the cap-and-trade model, applying a mix of allocation methods, establishing a self-monitoring, self-reporting and third-party verification system, and imposing financial penalties for excess emissions. However, the analysis of the specific design and implementation of the key elements shows that some elements of the pilot projects are quite different from and even more complicated than those of the EU ETS, which can be exemplified by the establishment of an intensity-based dynamic cap together with the ex post adjustment in allowances allocation. In this respect, the characteristics, in terms of the legal tradition and legal system, the governance structure and competence distribution, the economic system and economic governance make a big contribution to the differences between the EU ETS and Chinese ETS. In particular, the difference in the roles of government in the establishment and implementation of the ETS in line with the specific legal system is one key to the understanding of and making a comparison between the EU and China. Particularly a clear determination of the respective role of the government and the market under the legal framework for the ETS remains the core issue that has to be addressed in China while moving towards a market-based climate regime based on the rule of law.

Based on the analysis above, several recommendations can be made to provide further insight into the potential improvement of the regulatory design and implementation of the Chinese ETS, in view of China's aim to strengthen the rule of law. Firstly, there is a special need to establish a legal framework for the ETS, which is mainly based on the formal legislation supplemented by some policy provisions, in order to provide clear legal rules defining and distributing competences to governments in applying the ETS. Secondly, if China chooses to establish the ETS based on a cap-and-trade model, not only the potential challenges facing the centralised and decentralised models, but also the problems embedded in the ex post adjustment in view of its potential effect on the market, need to be taken into account when setting up a cap with legally binding force ex ante. Thirdly, the national allocation principles or rules, in which any differential treatment should be based on an objective justification, is important to ensure equal treatment in the allocation of allowances, and the governmental adjustment of the allocation should also be conducted and regulated within a clear legal system. Last but not least, the enforcement package for the Chinese ETS could be strengthened by establishing a harmonised MRV system and imposing sufficiently severe sanctions for noncompliance, both of which however require an adequate legal design and effective governmental regulation. 


\section{Relevant treaties, legislation, policy documents and case law in the EU}

\section{Treaties}

TEU, Consolidated version of the Treaty on European Union, OJ C 326, 26.10.2012, p. 13-390

TFEU, Consolidated version of the Treaty on the Functioning of the European Union, OJ C 326, 26.10.2012, p. 47-390

\section{Legislation}

Council Directive 96/62/EC of 27 September 1996 on ambient air quality assessment and management, OJ L 296, 21.11.1996, p. 55-63

Directive 2003/87/EC of the European Parliament and of the Council of 13 October 2003 establishing a scheme for greenhouse gas emission allowance trading within the Community and amending Council Directive 96/61/EC, OJ L 275, 25.10.2003, p. 32-46

Directive 2004/101/EC of the European Parliament and of the Council of 27 October 2004 amending Directive 2003/87/EC establishing a scheme for greenhouse gas emission allowance trading within the Community, in respect of the Kyoto Protocol's project mechanisms, OJ L 338, 13.11.2004, pp. 18-23

Directive 2008/101/EC of the European Parliament and of the Council of 19 November 2008 amending Directive 2003/87/EC so as to include aviation activities in the scheme for greenhouse gas emission allowance trading within the Community, OJ L 8, 13.1.2009, p.3-21

Directive 2008/1/EC of the European Parliament and Council concerning integrated pollution prevention and control, OJ L 24, 29.1.2008, p. 8-29

Directive 2009/28/EC of the European Parliament and of the Council of 23 April 2009 on the promotion of the use of energy from renewable sources and amending and subsequently repealing Directives 2001/77/EC and 2003/30/EC. OJ L 140, 5.6.2009, p. 16-62

Directive 2009/29/EC of the European Parliament and of the Council of 23 April 2009 amending Directive 2003/87/EC so as to improve and extend the greenhouse gas emission allowance trading scheme of the Community. OJ L 140, 5.6.2009, p. 63-87.

Directive 2009/31/EC of the European Parliament and of the Council of 23 April 2009 on the geological storage of carbon dioxide and amending Council Directive 85/337/EEC, European Parliament and Council Directives 2000/60/EC, 2001/80/EC, 2004/35/EC, 2006/12/EC, 2008/1/EC and Regulation (EC) No 1013/2006. OJ L 140, 5.6.2009, p. 114-135.

Directive 2010/75/EU of the European Parliament and of the Council of 24 November 2010 on industrial emissions (integrated pollution prevention and control) OJ L 334, 17.12.2010, p. $17-119$ 
Regulation (EC) No 765/2008 of the European Parliament and of the Council of 9 July 2008 setting out the requirements for accreditation and market surveillance relating to the marketing of products and repealing Regulation (EEC) No 339/93, , OJ L 218, 13.8.2008, p.30-47

Commission Regulation (EU) No 1031/2010 of 12 November 2010 on the timing, administration and other aspects of auctioning of greenhouse gas emission allowances pursuant to Directive 2003/87/EC of the European Parliament and of the Council establishing a scheme for greenhouse gas emission allowances trading within the Community, OJ L 302, 18.11.2010, p.1-41.

Commission Regulation (EU) No 600/2012 of 21 June 2012 on the verification of greenhouse gas emission reports and tonne-kilometre reports and the accreditation of verifiers pursuant to Directive 2003/87/EC of the European Parliament and of the Council, OJ L 181, 12.7.2012, p. $1-29$

Commission Regulation (EU) No 601/2012 of 21 June 2012 on the monitoring and reporting of greenhouse gas emissions pursuant to Directive 2003/87/EC of the European Parliament and of the Council, OJ L 181, 12.7.2012, p. 30-104

Commission Regulation (EU) No 784/2012 of 30 August 2012 amending Regulation (EU) No 1031/2010 to list an auction platform to be appointed by Germany and correcting Article 59(7) thereof, OJ L 234, 31.8.2012, p. 4-6

Commission Regulation (EU) No 1042/2012 of 7 November 2012 amending Regulation (EU) No $1031 / 2010$ to list an auction platform to be appointed by the United Kingdom, OJ L 310, 9.11.2012, p. 19-23

Commission Regulation (EU) No 176/2014 of 25 February 2014 amending Regulation (EU) No $1031 / 2010$ in particular to determine the volumes of greenhouse gas emission allowances to be auctioned in 2013-20, OJ L 56, 26.2.2014

Regulation (EU) No 421/2014 of the European Parliament and of the Council of 16 April 2014 amending Directive 2003/87/EC establishing a scheme for greenhouse gas emission allowance trading within the Community, in view of the implementation by 2020 of an international agreement applying a single global market-based measure to international aviation emissions, OJ L 129, 30.4.2014, p. 1-4

Council Decision 2002/358/EC of 25 April 2002 concerning the approval, on behalf of the European Community, of the Kyoto Protocol to the United Nations Framework Convention on Climate Change and the joint fulfilment of commitments thereunder. O J L 130, 15.5.2002, p. $1-3$.

Decision No 406/2009/EC of the European Parliament and of the Council of 23 April 2009 on the effort of Member States to reduce their greenhouse gas emissions to meet the Community's greenhouse gas emission reduction commitments up to 2020 , OJ L 140, 5.6.2009, p. 136-148 
Decision No 1359/2013/EU of the European Parliament and of the Council of 17 December 2013 amending Directive 2003/87/EC clarifying provisions on the timing of auctions of greenhouse gas allowances, O J L 343/1, 19.12.2013

Commission Decision 2004/156/EC of 29 January 2004 establishing guidelines for the monitoring and reporting of greenhouse gas emissions pursuant to Directive 2003/87/EC of the European Parliament and of the Council, OJ L 59, 26.2.2004, p. 1.

Commission Decision 2011/278/EU of 27 April 2011 determining transitional Union-wide rules for harmonised free allocation of emission allowances pursuant to Article 10a of Directive 2003/87/EC of the European Parliament and of the Council (notified under document C(2011) 2772), O J L 130, 17.5.2011

Commission Decision 2007/589/EC of 18 July 2007 establishing guidelines for the monitoring and reporting of greenhouse gas emissions pursuant to Directive 2003/87/EC of the European Parliament and of the Council, OJ L 229, 31.8.2007, p. 1-85

Commission Decision 2010/2/EU of 24 December 2009 determining, pursuant to Directive 2003/87/EC of the European Parliament and of the Council, a list of sectors and subsectors which are deemed to be exposed to a significant risk of carbon leakage, OJ L 1, 5.1.2010, p. $10-18$

Commission Decision 2010/384/EU of 9 July 2010 on the Community-wide quantity of allowances to be issued under the EU Emission Trading Scheme for 2013, OJ L 175/36, 10.7.2010

Commission Decision 2010/634/EU of 22 October 2010 adjusting the Union-wide quantity of allowances to be issued under the Union Scheme for 2013 and repealing Decision 2010/384/EU, O J L 279/34, 23.10.2010.

Commission Decision 2011/278/EU of 27 April 2011determining transitional Union-wide rules for harmonised free allocation of emission allowances pursuant to Article 10a of Directive 2003/87/EC of the European Parliament and of the Council, O J L 130/1, 17.5.2011,

Commission Decision 2011/745/EU of 11 November 2011 amending Decisions 2010/2/EU and 2011/278/EU as regards the sectors and subsectors which are deemed to be exposed to a significant risk of carbon leakage (notified under document C(2011) 8017), OJ L 299, 17.11.2011, p. 9-12

Commission Decision 2012/498/EU of 17 August 2012 amending Decisions 2010/2/EU and 2011/278/EU as regards the sectors and subsectors which are deemed to be exposed to a significant risk of carbon leakage (notified under document C(2012) 5715), OJ L 241, 7.9.2012, p. $52-54$ 
Commission Decision 2013/448/EU: Commission Decision of 5 September 2013 concerning national implementation measures for the transitional free allocation of greenhouse gas emission allowances in accordance with Article 11(3) of Directive 2003/87/EC of the European Parliament and of the Council (notified under document C(2013) 5666), OJ L 240, 7.9.2013, p. $27-35$,

Commission Decision 2014/9/EU of 18 December 2013 amending Decisions 2010/2/EU and 2011/278/EU as regards the sectors and subsectors which are deemed to be exposed to a significant risk of carbon leakage (notified under document C(2013) 9186), OJ L 9, 14.1.2014, p. $9-12$

\section{Other documents adopted by the Commission}

${ }^{1} \mathrm{C}(2004)$ 2515/2 final

Commission Decision of 7 July 2004 concerning the national allocation plan for the allocation of greenhouse gas emission allowances notified by Germany in accordance with Directive 2003/87/EC of the European Parliament and of the Council, Brussels, C(2004) 2515/2 final, 07.07.2004

C (2011) 1983 final

Commission Decision of 29.3.2011 on guidance on the methodology to transitionally allocate free emission allowances to installations in respect of electricity production pursuant to Article 10c(3) of Directive 2003/87/EC, C(2011) 1983 final, Brussels, 29.3.2011

C (2012) 3230 final

Communication from the Commission Guidelines on certain state aid measures in the context of the greenhouse gas emission allowance trading scheme post 2012, C (2012) 3230 final, Strasbourg, 22.5.2012

${ }^{2} \mathrm{COM}(92) 226$ final

Proposal for a Council Directive introducing a tax on carbon dioxide emissions and energy. COM (92) 226 final, OJ C 196, 3.8.1992, p.1-8

COM (2000) 87 final

European Commission, Green Paper on trading of greenhouse gas emissions within the European Union, COM (2000) 87 final, 8.2.2000

\footnotetext{
${ }^{1}$ According to the Commission, 'C' refers to the documents relating to official instruments for which $t$ he Commission has sole responsibility. Some are transmitted to the Council or Parliament for informatio $\mathrm{n}$ see the explanation on the website of the Commission, available at: http://ec.europa.eu/transparency/reg doc/? fuseaction=search.

2 According to the Commission, ' $\mathrm{COM}$ ' refers to the proposed legislation and other Commission communications to the Council and/or the other institutions, and their preparatory papers. Commission documents for the other institutions (legislative proposals, communications, reports, etc.).
} 
COM (2001) 581 final

Proposal for a Directive of the European Parliament and of the Council Establishing a Framework for Greenhouse Gas Emissions Trading within the European Community and Amending Council Directive 96/61/EC, COM (2001) 581 final, Brussels, 23.10.2001

COM (2003)0830 final

Communication from the Commission on guidance to assist Member States in the implementation of the criteria listed in Annex III to Directive 2003/87/EC establishing a scheme for greenhouse gas emission allowance trading within the Community and amending Council Directive 96/61/EC, and on the circumstances under which force majeure is demonstrated, COM(2003)0830 final, Brussels, 7.1.2004

COM (2005) 703 final

Communication from the Commission: 'Further guidance on allocation plans for the 2008 to 2012 trading period of the EU Emission Trading Scheme', COM (2005) 703 final, Brussels, 22.12.2005

COM (2006) 725

Communication from the Commission to the Council and to the European Parliament on the assessment of national allocation plans for the allocation of greenhouse gas emission allowances in the second period of the EU Emissions Trading Scheme accompanying Commission Decisions of 29 November 2006 on the national allocation plans of Germany, Greece, Ireland, Latvia, Lithuania, Luxembourg, Malta, Slovakia, Sweden and the United Kingdom in accordance with Directive 2003/87/EC, COM (2006) 725, Brussels, 29.11.2006

COM (2008) 16

Proposal for a directive of the European Parliament and of the Council amending Directive $2003 / 87 / \mathrm{EC}$ so as to improve and extend the greenhouse gas emission allowance trading system of the Community, COM (2008) 16, Brussels, 23.1.2008

COM (2008)30 final

Communication from the Commission to the European Parliament, the Council, the European Economic and Social Committee and the Committee of the Regions - 2020 by 2020 - Europe's Climate Change Opportunity, COM (2008)30 final, 23.1.2008,

COM (2010) 265 final

the Communication from the Commission to the European Parliament, the Council, The European Economic and Social Committee and the Committee of the Regions --Analysis of options to move beyond $20 \%$ greenhouse gas emission reductions and assessing the risk of carbon leakage $\{\operatorname{SEC}(2010) 650\}, \operatorname{COM}(2010) 265$ final, 26.5.2010 
COM (2011) 112 final

Communication from the Commission to the European Parliament, the Council, the European Economic and Social Committee and the Committee of the Regions A Roadmap for moving to a competitive low carbon economy in 2050, COM(2011) 112 final, Brussels, 8.3.2011

COM (2012) 416 final

Proposal for a Decision of the European Parliament and of the Council amending Directive 2003/87/EC clarifying provisions on the timing of auctions of greenhouse gas allowances, $\operatorname{COM}(2012) 416$ final, Brussels, 25.7.2012

COM (2012) 652 final

Report from the Commission to the European Parliament and the Council on the state of the European carbon market in 2012, COM (2012) 652 final, Brussels, 14.11 .2012

COM(2014) 20/1 - Proposal for a Decision of the European Parliament and of the Council concerning the establishment and operation of a market stability reserve for the Union greenhouse gas emission trading scheme and amending Directive 2003/87/EU, COM(2014) 20/1, 22.01 .2014

${ }^{1} \mathrm{SEC}(2008) 52$

Commissions Staff Working Document Accompanying document to the Proposal for a Directive of the European Parliament and of the Council amending Directive 2003/87/EC so as to improve and extend the EU greenhouse gas emission allowance trading system Impact Assessment,

Brussels, 23.1.2008

\section{Major case law relating to the EU ETS}

\section{CJEU:}

Case C-6/08 P US Steel Košice v Commission (Order of the Court) [2008] ECR I-96.

Case C-127/07 Société Arcelor Atlantique et Lorraine and Others [2008] ECR I-9895

Case C-279/08 P Netherlands v Commission [2011] ECR I-7671

Case C-366/10 Air Transport Association of America [2011] (not yet reported).

Case C-504/09 P Poland v Commission [2012] (not yet reported).

Case C-505/09 P Estonia v Commission [2012] (not yet reported).

Case C-203/12 Billerud Karlsborg AB and Billerud Skärblacka AB v Naturvårdsverket [2013] (not yet reported).

General Court:

Case T-178/05 UK v Commission [2005] ECR II-4807

Case T-374/04 Germany v Commission [2007] ECR II-4431

Case T-233/04 Netherlands v Commission [2008] ECR II-591

Case T-183/07 Poland v Commission [2009] ECR II-3395

Case T-263/07 Estonia v Commission [2009] ECR II-3463

\footnotetext{
${ }^{1}$ According to the Commission, 'SEC' refers to the documents which cannot be classified in any of the other series. 
Case T-16/04 Arcelor SA v Parliament and Council [2010] ECR II-211

Case T-27/07 US Steel Košice v. Commission, CFI 1 October 2007, [2007] ECR II-128.

Case T-387/04 EnBW Energie Baden-Württemberg AG v Commission [2007] ECR II-1195

Case T-369/07 Latvia v Commission [2011] ECR II-1039

Case T-370/11 Poland v Commission [2013] (not yet reported). 


\section{Relevant legislation, policies and governmental documents in China}

\section{Legislation:}

Constitution of China, promulgated by National People's Congress, 4 December 1982, revised 14 March 2004

Legislation Law of China, promulgated by National People's Congress, 15 March 2000

Environmental Protection Law of China, promulgated by Standing Committee of the National People's Congress, 26 December 1989, revised 24 April, 2014, to be effective as of 01 January 2015

Law of China on the Prevention and Control of Atmospheric Pollution, promulgated by Standing Committee of the National People's Congress, 29 April 2000

Energy Conservation Law of China, promulgated by Standing Committee of the National People's Congress, 28 October 2007

Renewable Energy Law of China, promulgated by Standing Committee of the National People's Congress, 26 December 2009

Public Servants Law of China, promulgated by Standing Committee of the National People's Congress, 27 April 20050

Standardisation Law of China, promulgated by Standing Committee of the National People's Congress, 29 December 1988

Administrative Permission Law of China, promulgated by Standing Committee of the National People's Congress, 27 August 2003

Administrative Penalty Law of China, promulgated by National People's Congress, 17 March 1996

Administrative Litigation Law of China, promulgated by promulgated by National People's Congress, 4 April 1989, revised 1 November 2014, to be effective as of 1 May 2015

Administrative Enforcement Law of China, promulgated by Standing Committee of the National People's Congress, 30 June 2011

Administrative Supervision Law of China, promulgated by Standing Committee of the National People's Congress, 25 June 2010

Property Law of China, promulgated by National People's Congress, 16 March 2007,

Resolutions of Standing Committee of the National People's Congress on Actively Addressing Climate Change, adopted by Standing Committee of the National People's Congress, 27 August 2009 
The Provisions on the Administration of the National Standardisation Technical Guidance Document, the State Bureau of Quality and Technical Supervision, 24 December 1998.

Interim Provisions on Punishment of Acts Violating Laws and Disciplines on Environmental Protection, adopted by the Ministry of Supervision and the State Environmental Protection Administration, 20 February 2006

Measures for the Management of China Clean Development Mechanism Fund, adopted by Ministry of Finance, Ministry of Agriculture, NDRC, Ministry of Foreign Affairs, Ministry of Science and Technology, Ministry of Environmental Protection, China Meteorological Bureau, 14 September 2010

Administrative Measures for the Operation of Clean Development Mechanism Projects, adopted by NDRC, Ministry of Science and Technology, Ministry of Foreign Affairs; Ministry of Finance, 3 August 2011

Notice of the NDRC on Printing and Distributing the Interim Measures for the Administration of Voluntary Greenhouse Gas Emission Reduction Trading, NDRC, 13 June 2012

\section{Policies and other governmental normative documents:}

$11^{\text {th }}$ Five-Year Planning(2006-2010)

Guidelines of the Eleventh Five-Year Planning for National Economic and Social Development, National People's Congress, 16 March 2006

$12^{\text {th }}$ Five-Year Planning(2011-2015)

Guidelines of the Twelfth Five-Year Planning for National Economic and Social Development, National People's Congress, 16 March 2011

Decision of the Central Committee of the Communist Party of China on Some Issues concerning the Improvement of the Socialist Market Economy, adopted by the $3^{\text {rd }}$ Plenary Session of the $16^{\text {th }}$ CPC Central Committee, 14 October 2003

Decision of the Central Committee of the Communist Party of China on Several Major Issues on Comprehensively Deepening Reforms, adopted by the $3^{\text {rd }}$ Plenary Session of the $18^{\text {th }} \mathrm{CPC}$ Central Committee, 12 November 2013

Decision of the Central Committee on the comprehensive promotion of several major issues of the rule of law, adopted by the $4^{\text {th }}$ Plenary Session of $18^{\text {th }}$ CPC Central Committee, 23 October 2014

The interpretation of Standardisation Law of China, the State Bureau of Quality and Technical Supervision, 23 July 1990 
Notice on promoting the demonstration pilot of 'the research project on the implementation of the total quantity control and emissions trading policy for $\mathrm{SO}_{2}$ in China', State Environmental Protection Administration, 1 March 2002

The Notice of the State Council on Printing and Distributing the Comprehensive Working Plan of Energy Conservation and Emission Reduction, State Council, 23 May 2007.

Notice of NDRC Regarding Carrying Out of Pilot Projects in Low Carbon Provinces and Low Carbon Cities, NDRC, 19 July 2010

Notice of the State Council on Printing and Distributing the Comprehensive Work Plan for Energy Conservation and Emission Reduction in the 12th Five-Year Planning Period, State Council, 31 August 2011

The Notice on Initiating Pilot Programmes of Emissions Trading, NDRC, 29 October 2011.

Notice of Printing and Distributing the National $12^{\text {th }}$ Five-Year Planning for Environmental Protection, State Council, 15 December 2011

The Notice on Issuing the Work Plan for Greenhouse Gas Emissions Control during the Twelfth Five-Year Plan Period, State Council, 1 December 2011.

The Notice on printing and distributing the guidelines of the accounting methods and report of the enterprises' GHG emissions of ten sectors (Trial), General office of NDRC, 15 October 2013

Notice on the arrangement for the reporting of greenhouse gas emissions by the key enterprises or institution, NDRC, 13 January 2014

Guiding Opinions of the General Office of the State Council on Further Promoting the Pilot Scheme of Payable Use and Trading of Pollutant Emission Rights, the General Office of the State Council, 6 August 2014 
Table 9 Specific legislation and policy adopted in the pilot projects (by the end of June 2014)

\begin{tabular}{|c|c|c|c|c|}
\hline Pilots & Time & Legislation or policy (in Chinese) & Authority & Legal rank \\
\hline \multirow[t]{4}{*}{ Shenzhen } & $\begin{array}{l}10 \text { Nov. } \\
2012\end{array}$ & $\begin{array}{l}\text { Provisions of Controlling Carbon Emissions for } \\
\text { Special Economic Zone }\end{array}$ & $\begin{array}{l}\text { Standing } \\
\text { Committee of } \\
\text { Shenzhen } \\
\text { People's Congress }\end{array}$ & $\begin{array}{l}\text { Local } \\
\text { regulation }\end{array}$ \\
\hline & $\begin{array}{l}6 \text { Nov. } \\
2012\end{array}$ & $\begin{array}{l}\text { Notice of Issuance of Specification With } \\
\text { Guidance for Quantification and Reporting of } \\
\text { Organisation's Greenhouse Gas Emissions }\end{array}$ & $\begin{array}{l}\text { Shenzhen Mun. } \\
\text { Market } \\
\text { Supervision } \\
\text { Administration }\end{array}$ & $\begin{array}{l}\text { other } \\
\text { normative } \\
\text { document }\end{array}$ \\
\hline & $\begin{array}{l}7 \text { Nov. } \\
2012\end{array}$ & $\begin{array}{l}\text { Notice of Issuance of Specification With } \\
\text { Guidance for Verification of Organisation's } \\
\text { Greenhouse Gas Emissions }\end{array}$ & $\begin{array}{l}\text { Shenzhen Mun. } \\
\text { Market } \\
\text { Supervision } \\
\text { Administration }\end{array}$ & $\begin{array}{l}\text { other } \\
\text { normative } \\
\text { document }\end{array}$ \\
\hline & $\begin{array}{l}19 \text { Mar. } \\
2014\end{array}$ & $\begin{array}{l}\text { Interim Measures on Carbon Emissions Trading } \\
\text { Management in Shenzhen }\end{array}$ & $\begin{array}{l}\text { Shenzhen } \\
\text { Municipal } \\
\text { Government }\end{array}$ & $\begin{array}{l}\text { Rule of local } \\
\text { government }\end{array}$ \\
\hline \multirow[t]{4}{*}{ Shanghai } & $\begin{array}{l}3 \text { Jul. } \\
2012\end{array}$ & $\begin{array}{l}\text { Implementing Opinions of the Shanghai } \\
\text { Municipal Government on Pilot Carbon } \\
\text { Emissions Trading in Shanghai Municipality }\end{array}$ & $\begin{array}{l}\text { Shanghai } \\
\text { Municipal } \\
\text { Government }\end{array}$ & $\begin{array}{l}\text { other } \\
\text { normative } \\
\text { document }\end{array}$ \\
\hline & $\begin{array}{l}11 \text { Dec. } \\
2012\end{array}$ & $\begin{array}{l}\text { Notice of Printing and Distributing Provisional } \\
\text { Guideline for Verification and Reporting of } \\
\text { Greenhouse Gas Emissions, together with nine } \\
\text { trial sector-based guidelines }\end{array}$ & Shanghai DRC & $\begin{array}{l}\text { other } \\
\text { normative } \\
\text { document }\end{array}$ \\
\hline & $\begin{array}{l}18 \text { Nov. } \\
2013\end{array}$ & $\begin{array}{l}\text { Interim Administrative Measures of Shanghai } \\
\text { Municipality on carbon emissions }\end{array}$ & $\begin{array}{l}\text { Shanghai } \\
\text { Municipal } \\
\text { Government }\end{array}$ & $\begin{array}{l}\text { Rule of local } \\
\text { government }\end{array}$ \\
\hline & $\begin{array}{l}22 \text { Nov. } \\
2013\end{array}$ & $\begin{array}{l}\text { The allocation and management plan for the } \\
\text { carbon emissions allowance in Shanghai } \\
\text { municipality }\end{array}$ & Shanghai DRC & $\begin{array}{l}\text { other } \\
\text { normative } \\
\text { document }\end{array}$ \\
\hline \multirow[t]{5}{*}{ Beijing } & $\begin{array}{l}22 \text { Nov. } \\
2013\end{array}$ & $\begin{array}{l}\text { Notice concerning the implementation of Beijing } \\
\text { carbon emissions trading pilot project, together } \\
\text { with five attachment including the Trial Methods } \\
\text { for the allowances allocation in Beijing pilot } \\
\text { project, guidelines for accounting and reporting } \\
\text { of CO2 emissions(2013), Trial administrative } \\
\text { measures on the verification organisation, and so } \\
\text { on }\end{array}$ & Beijing DRC & $\begin{array}{l}\text { other } \\
\text { normative } \\
\text { document }\end{array}$ \\
\hline & $\begin{array}{l}27 \text { Dec. } \\
2013\end{array}$ & $\begin{array}{l}\text { Decision on Implementation of Carbon Emissions } \\
\text { Trading Pilot on Premise of Strict Total Control } \\
\text { of Carbon Emissions }\end{array}$ & $\begin{array}{l}\text { Standing } \\
\text { Committee of } \\
\text { Beijing People's } \\
\text { Congress }\end{array}$ & $\begin{array}{l}\text { Local } \\
\text { regulation }\end{array}$ \\
\hline & $\begin{array}{l}\text { 6 May } \\
2014\end{array}$ & $\begin{array}{l}\text { Decision on the regulation of the discretion in } \\
\text { implementing the administrative penalties in the } \\
\text { carbon emissions trading }\end{array}$ & Beijing DRC & $\begin{array}{l}\text { other } \\
\text { normative } \\
\text { document }\end{array}$ \\
\hline & $\begin{array}{l}28 \text { May } \\
2014\end{array}$ & $\begin{array}{l}\text { Notice of Distributing Interim Measures on } \\
\text { Management of Carbon Emissions Trading in } \\
\text { Beijing }\end{array}$ & $\begin{array}{l}\text { Beijing Municipal } \\
\text { Government }\end{array}$ & $\begin{array}{l}\text { other } \\
\text { normative } \\
\text { document }\end{array}$ \\
\hline & $\begin{array}{l}10 \text { Jun. } \\
2014\end{array}$ & $\begin{array}{l}\text { Management measures on the open-market } \\
\text { operation relating to the carbon emissions trading } \\
\text { in Beijing (trial) }\end{array}$ & $\begin{array}{l}\text { Beijing DRC, } \\
\text { Beijing Bureau of } \\
\text { Finance }\end{array}$ & $\begin{array}{l}\text { other } \\
\text { normative } \\
\text { document }\end{array}$ \\
\hline \multirow[t]{4}{*}{ Guangdong } & $\begin{array}{l}7 \text { Sep. } \\
2012\end{array}$ & $\begin{array}{l}\text { Implementation programme of carbon emissions } \\
\text { trading pilot in Guangdong Province }\end{array}$ & $\begin{array}{l}\text { Guangdong } \\
\text { Provincial } \\
\text { Government }\end{array}$ & $\begin{array}{l}\text { other } \\
\text { normative } \\
\text { document }\end{array}$ \\
\hline & $\begin{array}{l}25 \text { Nov. } \\
2013\end{array}$ & $\begin{array}{l}\text { The first allocation and work plan for the carbon } \\
\text { emissions allowance in Guangdong Province } \\
\text { (trial) }\end{array}$ & Guangdong DRC & $\begin{array}{l}\text { other } \\
\text { normative } \\
\text { document }\end{array}$ \\
\hline & $\begin{array}{l}\text { 15 Jan. } \\
2014\end{array}$ & $\begin{array}{l}\text { Trial Measures of Guangdong Province on the } \\
\text { Management of the Carbon Emissions }\end{array}$ & $\begin{array}{l}\text { Guangdong } \\
\text { Provincial } \\
\text { Government }\end{array}$ & $\begin{array}{l}\text { Rule of local } \\
\text { government }\end{array}$ \\
\hline & $\begin{array}{l}18 \text { Mar. } \\
2014\end{array}$ & $\begin{array}{l}\text { Implementation Rules of Guangdong Province } \\
\text { for the report and verification of enterprises' } \\
\text { carbon emissions information(Trial) }\end{array}$ & Guangdong DRC & $\begin{array}{l}\text { other } \\
\text { normative } \\
\text { document }\end{array}$ \\
\hline
\end{tabular}




\begin{tabular}{|c|c|c|c|c|}
\hline & $\begin{array}{l}20 \text { Mar. } \\
2014\end{array}$ & $\begin{array}{l}\text { Implementation Rules of Guangdong Province } \\
\text { for the management of carbon emissions } \\
\text { allowances (Trial) }\end{array}$ & Guangdong DRC & $\begin{array}{l}\text { other } \\
\text { normative } \\
\text { document }\end{array}$ \\
\hline & $\begin{array}{l}18 \text { Aug. } \\
2014\end{array}$ & $\begin{array}{l}\text { Implementation plan for the carbon emissions } \\
\text { allowances allocation in } 2014 \text { for Guangdong } \\
\text { province }\end{array}$ & Guangdong DRC & $\begin{array}{l}\text { other } \\
\text { normative } \\
\text { document }\end{array}$ \\
\hline \multirow[t]{4}{*}{ Tianjin } & $\begin{array}{l}7 \text { Aug. } \\
2011\end{array}$ & $\begin{array}{l}\text { General plan of the development of the emissions } \\
\text { trading market in Tianjin }\end{array}$ & Tianjin DRC & $\begin{array}{l}\text { other } \\
\text { normative } \\
\text { document }\end{array}$ \\
\hline & $\begin{array}{l}2 \text { Feb. } \\
2013\end{array}$ & $\begin{array}{l}\text { Implementing Programme of the Tianjin } \\
\text { Municipal Government on Pilot Carbon } \\
\text { Emissions Trading }\end{array}$ & $\begin{array}{l}\text { General office of } \\
\text { Tianjin Municipal } \\
\text { Government }\end{array}$ & $\begin{array}{l}\text { other } \\
\text { normative } \\
\text { document }\end{array}$ \\
\hline & $\begin{array}{l}27 \text { Feb. } \\
2013\end{array}$ & $\begin{array}{l}\text { The Notice of distributing the implementation } \\
\text { programme of carbon emissions trading pilot in } \\
\text { Tianjin }\end{array}$ & $\begin{array}{l}\text { General office of } \\
\text { Tianjin Municipal } \\
\text { Government }\end{array}$ & $\begin{array}{l}\text { other } \\
\text { normative } \\
\text { document }\end{array}$ \\
\hline & $\begin{array}{l}20 \text { Dec. } \\
2013\end{array}$ & $\begin{array}{l}\text { Notice of Distributing Interim Measures on } \\
\text { Management of Carbon Emissions Trading in } \\
\text { Tianjin }\end{array}$ & $\begin{array}{l}\text { General office of } \\
\text { Tianjin Municipal } \\
\text { Government }\end{array}$ & $\begin{array}{l}\text { other } \\
\text { normative } \\
\text { document }\end{array}$ \\
\hline \multirow[t]{3}{*}{ Hubei } & $\begin{array}{l}18 \text { Feb. } \\
2013\end{array}$ & $\begin{array}{l}\text { The notice of printing and distributing the } \\
\text { implementation programme of carbon emissions } \\
\text { trading pilot in Hubei Province }\end{array}$ & $\begin{array}{l}\text { General Office of } \\
\text { Hubei Provincial } \\
\text { Government }\end{array}$ & $\begin{array}{l}\text { other } \\
\text { normative } \\
\text { document }\end{array}$ \\
\hline & $\begin{array}{l}26 \text { Mar. } \\
2014\end{array}$ & $\begin{array}{l}\text { The allocation plan for the carbon emissions } \\
\text { allowance in Hubei Province }\end{array}$ & Hubei DRC & $\begin{array}{l}\text { other } \\
\text { normative } \\
\text { document }\end{array}$ \\
\hline & $\begin{array}{l}4 \text { Apr. } \\
2014\end{array}$ & $\begin{array}{l}\text { Interim Measures of Hubei Province on the } \\
\text { Management and Trading of the Carbon Emission } \\
\text { Right }\end{array}$ & $\begin{array}{l}\text { Hubei Provincial } \\
\text { Government }\end{array}$ & $\begin{array}{l}\text { Rule of local } \\
\text { government }\end{array}$ \\
\hline \multirow[t]{6}{*}{ Chongqing } & $\begin{array}{l}26 \text { Apr. } \\
2014\end{array}$ & $\begin{array}{l}\text { The Notice of distributing the Interim } \\
\text { Management Measures of Chongqing } \\
\text { Municipality on Carbon Emissions Trading }\end{array}$ & $\begin{array}{l}\text { Chongqing } \\
\text { Municipal } \\
\text { Government }\end{array}$ & $\begin{array}{l}\text { other } \\
\text { normative } \\
\text { document }\end{array}$ \\
\hline & $\begin{array}{l}28 \text { May } \\
2014\end{array}$ & $\begin{array}{l}\text { The Notice of distributing the rules of the } \\
\text { reporting and verification of carbon emissions } \\
\text { from the industrial enterprises in Chongqing }\end{array}$ & Chongqing DRC & $\begin{array}{l}\text { other } \\
\text { normative } \\
\text { document }\end{array}$ \\
\hline & $\begin{array}{l}28 \text { May } \\
2014\end{array}$ & $\begin{array}{l}\text { The work rules of the verification of the carbon } \\
\text { emissions from the industrial enterprises in } \\
\text { Chongqing (trial) }\end{array}$ & Chongqing DRC & $\begin{array}{l}\text { other } \\
\text { normative } \\
\text { document }\end{array}$ \\
\hline & $\begin{array}{l}28 \text { May } \\
2014\end{array}$ & $\begin{array}{l}\text { The guideline on the accounting and reporting of } \\
\text { the carbon emissions from the industrial } \\
\text { enterprises in Chongqing (trial) }\end{array}$ & Chongqing DRC & $\begin{array}{l}\text { other } \\
\text { normative } \\
\text { document }\end{array}$ \\
\hline & $\begin{array}{l}28 \text { May } \\
2014\end{array}$ & $\begin{array}{l}\text { The notice of issuing the carbon emissions } \\
\text { allowances for } 2013 \text { in Chongqing municipality }\end{array}$ & Chongqing DRC & $\begin{array}{l}\text { other } \\
\text { normative } \\
\text { document }\end{array}$ \\
\hline & $\begin{array}{l}28 \text { May } \\
2014\end{array}$ & $\begin{array}{l}\text { The Notice of distributing the rules of managing } \\
\text { the carbon emissions allowance in Chongqing } \\
\text { Municipality }\end{array}$ & Chongqing DRC & $\begin{array}{l}\text { governmental } \\
\text { normative } \\
\text { document }\end{array}$ \\
\hline
\end{tabular}




\section{BIBLIOGRAPHY}

Ackerman, B. A., \& Stewart, R. B. (1987). Reforming environmental law: the democratic case for market incentives. Colum. J. Envtl. L., 13, 171

Ahman,M., Burtraw, D., Kruger, J. \& Zetterberg, L. (2006). A ten year rule to guide the allocation of EU emission allowances. Energy Policy, 35, 1718-1730

Alford, W. P., \& Shen, Y. (1997). Limits of the Law in Addressing China's Environmental Dilemma. Stan. Envtl. LJ, 16, 125.

Alter, K. J. (2003). Establishing the supremacy of European law: The making of an international rule of law in Europe: Oxford University Press

Backes, C., Deketelaere, K., Peeters, M., \& Schurmans, M. (2008). The Underestimated Possibility of Ex Post Adjustments: Some Lessons from the Initial Greenhouse Gas Emissions Trading Scheme. in M. Faure \& M. Peeters (Eds.), Climate change and European emissions trading: lessons for theory and practice: Edward Elgar,178-207

Balme, R. (2011). China's Climate Change Policy: Governing at the Core of Globalization. The Carbon \& Climate Law Review, 5(1), 44-56.

Baumol, W. J., \& Oates, W. E. (1988). The theory of environmental policy: Cambridge Univ Press

Bausch, C., \& Cavalieri, S. (2007). Allocation of Greenhouse Gas Allowances in the United States A Northeastern Example. The Carbon \& Climate Law Review, 1(2), 129-138.

Becker G., S. (1968). Crime and punishment: An economic approach. Journal of Political Economy, 76(2), 169-217.

Bellevrat, E. (2011). What are the key issues to be addressed by China in its move to establish Emissions Trading Systems? working paper of Institut du développement durable et des relations internationales $n^{\circ} 17 / 11$ December 2011

Bergsager, H. \& Korppoo, A. (2013). China's State-Owned Enterprises as Climate Policy Actors:The Power and Steel Sectors, available at: http://dx.doi.org/10.6027/TN2013-527, last accessed 19 April 2014

Betz, R., Rogge, K., \& Schleich, J. (2006). EU emissions trading: an early analysis of national allocation plans for 2008-2012. Climate Policy, 6(4), 361-394.

Betz, R., \& Sato, M. (2006). Emissions trading: lessons learnt from the 1st phase of the EU ETS and prospects for the 2nd phase. Climate Policy, 6,351-359.

Beyer, S. (2006). Environmental law and policy in the People's Republic of China. Chinese Journal of International Law, 5(1), 185-211. 
Bogojević, S. (2009). Ending the Honeymoon: Deconstructing Emissions Trading Discourses. Journal of Environmental law, 21(3), 443-468

Bogojević, S. (2013). Emissions Trading Schemes: Markets, States and Law: Hart Publishing

Borchardt, K.D. (2010). The ABC of European Union law: Publications Office of the European Union

Bothe, M.(2001). Tradable Emission Certificates as a Mechanism for National Compliance under the UNFCCC, in Tao Zhenghua and Wolfrum Rfidiger eds.( 2001). Implementing International Environmental Law in Germany and China, Den Haag u.a.

Brauch, J. (2005). The Margin of Appreciation and the Jurisprudence of the European Court of Human Rights: Threat to the Rule of Law, Columbia Journal of European Law, v.11, $113-150$

Buchner, B., Carraro,C. \& Ellerman, A. D.(2006). The Allocation of European Union Allowances: Lessons, Unifying Themes and General Principles, FEEM (Fondazione Eni Enrico Mattei) FEEM Working Paper No. 116.06, available at: http://ssrn.com/abstract=929109, last accessed 25 April 2013

Cai, S. Q.(2012). On China's Energy Saving and Emission Reduction System. Journal of Jiangsu University (Social Science Edition), v.14, No.7103, 8-16. (in Chinese )

Calabresi, G., \& Melamed, A. D. (1972). Property rules, liability rules, and inalienability: one view of the cathedral. Harvard Law Review, Vol. 85, No. 6, 1089-1128

Cao, M. D. (2010). On Emission Trading System. Available at: http://ssrn.com/abstract=1803901, last accessed 3 July 2013

Cao, M. D. (2011). China's Law Development in the Climate Change Era. Available at SSRN: http://ssrn.com/abstract=1832006, last accessed 3 July 2013

Cao, M. D.\& Cui, J. X.(2012). The monitoring and reporting of greenhouse gas emissions in Germany: legislative lessons and policy recommendation. Journal of Wuhan University of Technology (Social Sciences Edition), Vol.02, 141-149 (in Chinese)

Cao, W. (2011). A study on the legal problems of target responsibility system for energy-saving and emission-reduction, Master dissertation of East China University of Political Science and Law (in Chinese)

Chang, Y. C. \& Wang, N. (2010). Environmental regulations and emissions trading in China. Energy Policy, 38(7), 3356-3364

Charles de Secondat, Baron de Montesquieu (1748). The Spirit of Laws ,republished by University of California Press in 1977. 
Chen, B. (2014). Design Philosophy of Carbon Market and Its Empirical Studies: China Economic Publishing House (in Chinese)

Chen, H.W. \& Zhang, L. (2009). Thoughts about the feasibility of using carbon tax to reduce greenhouse gases emissions. Finance Forum, 1, 35-40 (in Chinese)

Chen, H.Z. (2013). Target setting: lessons from the EU ETS and preliminary learning points for China. Journal of Jiangsu University (Social Science Edition), 04, 14-23 (in Chinese)

Chen, H.Z. (2014a). On the Legal Approaches to the Regulation of the Carbon Price in China_Lessons From the EU ETS, Jinan Journal (Philosophy \& Social Science Edition), No.5, 34-43 (in Chinese)

Chen, H.Z.(2014b). Inspection and Enforcement in Chinese Carbon Emissions Trading: Progress, Problems and Prospect, Environmental Law Reporter, 44, 10596-10606

Chen, L.(2012). Contextualizing legal transplant: China and Hong Kong, in Monateri, P. G. (eds.). Methods of comparative law: Edward Elgar Publishing, 192-209

Chen, P. (2014). A Comparative Legal Study of Emissions Trading Systems in the EU and in China, PhD dissertation, Ghent University

Chen, T. (2001). Policy legitimation and legalisation. Administration and Law, 01,53-55 (in Chinese)

Cheng, X. H. (2007). Hard Law, Soft Law, and Economic Law, Gansu Social Sci,4, 219-226 (in Chinese).

Cheng, X. H \& Chen, H. Z. (2014). On the Two Dimensions of the Legal System concerning the Allowances Allocation in Carbon Emissions Trading: the Case of Guangdong. Journal of South China Normal University (Social Science Edition), Vol.02, 103-108 (in Chinese)

Cheng, Y. Y. (2013). Study on the legal liabilities in addressing climate change. Journal of China University of Geosciences (Social Sciences Edition). Vol.02, 27-32 (in Chinese)

Choi, I. (2005). Global Climate Change and the Use of Economic Approaches: The Ideal Design Features of Domestic Greenhouse Gas Emissions Trading with an Analysis of the European Union's CO2 Emissions Trading Directive and the Climate Stewardship Act. Nat. Resources J., 45, 865 .

Chung, J. H. (2011). Central Control and Local Discretion in China: Leadership and Implementation during Post-Mao Decollectivization: Oxford University Press

Carlarne, C. P. (2010). Climate Change Law and Policy: EU and USA approaches: Oxford University Press. 
Clarke, D. C. (2007). Legislating for a market economy in China. The China Quarterly, 191, 567-585.

Clò, S. (2011). European Emissions Trading in Practice: An Economic Analysis: Edward Elgar Publishing,

Coase, R.( 1960). The problem of Social Cost, Journal of Law and Economics, 3(October), 1-44.

Convery, F .J. (2009). Origins and Development of the EU ETS, Environmental and Resource Economics, Vol.43, No. 3, 391-412

Convery, F. J. \& Redmond, L. (2007). Market and price developments in the European Union emissions trading scheme. Review of Environmental Economics and Policy, 1(1), 88-111

Cooper, J. et al (1997). Complete Works By Plato: Hackett Publishing

Cooper, R. (2010). Europe's Emissions Trading System, Discussion Paper 2010-40, Harvard Project on International Climate Agreements. Cambridge: Harvard Kennedy School.

Cooter, R. D. (1997). Market modernization of law: Economic development through decentralized law. In Jagdeep S. Bhandari \& A. O. Sykes (Eds.), Economic Dimensions in International Law: Comparative and Empirical Perspectives. Cambridge: Cambridge University Press. 275-316.

Craig, P., \& De Búrca, G. (2011). EU law: text, cases, and materials(fifth edition): Oxford University Press, USA

Dales, J. H. (1968). Pollution, Property and Prices: an essay in policy-making and economics: University of Toronto Press, republished by Edward Elgar Publishing Limited in 2002.

Davis, K. E., \& Trebilcock, M. J. (2001). Legal reforms and development. Third World Quarterly, 22(1), 21-36.

de Bruyn,S., Nelissen, D. \& Koopman, M. (2013). Carbon leakage and the future of the EU ETS market: Impact of recent developments in the EU ETS on the list of sectors deemed to be exposed to carbon leakage, Delft, CE Delft, April 2013, available at: http://www.cedelft.eu/art/uploads/CE_Delft_7917_Carbon_leakage_future_EU_ETS_mark et_Final.pdf., last accessed 2 July $201 \overline{3}$

de Cendra de Larragán, J. (2008). Too Much Harmonization? An Analysis of the Commission's Proposal to Amend the EU ETS from the Perspective of Legal Principles. In Faure Michael \& P. Marjan (Eds.), Climate Change And European Emissions Trading: Lessons for Theory and Practice: Edward Elgar. 53-87

de Cendra de Larragán, J. (2010a). Distributional choices in EU climate change law and policy: towards a principled approach? Doctorate Thesis, Maastricht University

de Cendra de Larragán, J.(2010b). Distributional choices in EU climate change law and policy: towards a principled approach? : Kluwer Law International

de Cendra de Larragán, J. \& Peeters, M. (2010). Distributional choices in EU climate change policy seen through the lens of legal principles. In W. J. M. Martens \& C. T. Chang (Eds.), The Social and Behavioural Aspects of Climate Change: Linking Vulnerability, Adaptation and Mitigation: Greenleaf Publishing, page 
de Sépibus, J. (2007). Scarcity and Allocation of Allowances in the EU Emissions Trading Scheme - A Legal Analysis. NCCR Trade Working Paper (No 2007/32 )

de Sépibus, J. (2009). The European emission trading scheme put to the test of state aid rules. Environmental Liability, 4, 125-128

Delbeke, J. et al (2006). The EU greenhouse gas emissions trading scheme: Claeys \& Casteels

Deng, H. F. (2011). Legal interactive mechanism on climate change: a comparative study of China and US experiences. US-China Law Review, 8, 431

Deng, K. Z.(2011). On the Achievement of Good Governance Environment Through Executive Responsibility. Public Administration \& Law, No,04, 25-28(in Chinese)

Depledge, J., (2000). Tracing the Origins of the Kyoto Protocol: An Article-by-article Textual History, UNFCCC

Dhondt, N. (2003). Integration of environmental protection into other EC policies: Legal theory and practice (Vol. 2): Europa Law Publishing.

Ding, D. \& Feng, J. R. (2013). On China's Allocation Method of Carbon Trading Quota. International Business, 83-92. (in Chinese)

Ding, D. \& Pan, F. F. (2012). Analysis of the Legal Attribute of Carbon Emission Right. Law Science Magazine, No.9, 103-109 (in Chinese)

Driesen, D. M. (2010). Capping carbon. Environmental Law, 40:1, 1-52

Du, Q. (2009). The People's Repblic of China, in Kotzé, L. J. and A. R. Paterson (eds.). The role of the judiciary in environmental governance: comparative perspectives: Kluwer Law International, 412-449

Dudek D \& Golub A.(2003). Intensity Targets: Pathway or Roadblock to Preventing Climate Change While Enhancing Growth. Climate Policy, 3(S2), S21-S28

Economy, E., \& Lieberthal, K. (2007). Scorched earth: Will environmental risks in China overwhelm its opportunities? Harvard Business Review, 85(6), 88-96

Ecorys (2013). Carbon Leakage Evidence Project, September 2013, available at: http://ec.europa.eu/clima/policies/ets/cap/leakage/docs/cl_evidence_factsheets_en.pdf, last accessed 3 April 2014

Egenhofer, C. , et al. (2010). The EU ETS and climate change policy towards 2050. Centre for European Policy Studies Report

ELI (1997). Implementing an emissions cap and allowance trading system for greenhouse gases: lessons from the acid rain program. Environmental Law Institute (ELI), Washington, DC 
Ellerman, A. D.(2008). New Entrant and Closure Provisions: How do they Distort? The Energy Journal, vol.29, 63-76

Ellerman, A. D., \& Buchner, B. K. (2007). The European Union emissions trading scheme: origins, allocation, and early results. Review of Environmental Economics and Policy, 1(1), 66-87.

Ellerman, A. D., Buchner, B. K. \& Carraro, C. (2007). Unifying themes, in: Ellerman, A. D., Buchner, B. K. \& Carraro, C (eds.), Allocation in the European Emissions Trading Scheme: Rights, Rents and Fairness: Cambridge University Press, 339

Ellerman, A. D. \& Joskow, P.L. (2008). The European Union's Emissions Trading System in Perspective, available http://www.c2es.org/publications/european-union-emissions-trading-system, last accessed 9 May 2013

Ellerman D \& Wing, I. S.(2003). Absolute versus Intensity-Based Emission Caps. Climate Policy, 3(S2), S7-S20

Enzmann, J. \& Marr, S. (2008). Moving Towards Phase III-Key Elements of the review of the EU ETS. Journal for European Environmental \& Planning Law, 5(2), 159-181

Epiney, A. (2012). Climate Protection Law in the European Union- Emergence of a New Regulatory System. Journal of European Environmental \& Planning Law, 9(1), 5-33

Eritja, M. C.(2006). Reviewing the Challenging Task Faced by Member States in Implementing the Emissions Trading Directive: Issues of Member State Liability, In M. Peeters \& K. Deketelaere (Eds.), EU climate change policy: the challenge of new regulatory initiatives, Edward Elgar Publishing, 69-82

European Environmental Agency (2008). Application of the Emissions Trading Directive by EU Member States-reporting year 2007, Technical report No 3/2008, available at: http://www.eea.europa.eu/publications/technical_report_2008_3, last accessed 2 August 2014

European Environmental Agency (2009). Application of the Emissions Trading Directive by EU Member States-reporting year 2008, Technical report No 13/2008, available at http://www.eea.europa.eu/publications/technical_report_2008_13, last accessed 2 August 2014

Fairhurst, J. (2010). Law of the European Union (7 ed.): Longman Pub Group

Fallon, R. H. Jr. (1997). 'The Rule of Law' as a Concept in Constitutional Discourse. Columbia Law Review, Vol. 97, No. 1, 1-56 
Fan, R. P. (2011). Jiang Qing on Equity, in Fan, R. P. (ed), The Renaissance of Confucianism in Contemporary China: Springer, 55-73

Fang, Y., \& Zeng, Y. (2007). Balancing energy and environment: The effect and perspective of management instruments in China. Energy, 32(12), 2247-2261.

Faure, M.(2004). European Environmental Criminal Law: Do we really need it?. European Environmental Law Review, 18-29

Faure, M. (2010). Effective, proportional and dissuasive penalties in the implementation of the Environmental Crime and Shipsource Pollution Directives: Questions and Challenges. European Energy and Environmental Law Review, 256-278.

Faure, M. \& Johnston, J. S. (2009). Law and Economics of the Environmental Federalism: Europe and the United States Compared. The. Va. Envtl. LJ, 27, 205.

Faure, M., Peeters, M., \& Wibisana, A. G. (2006). Economic instruments: suited to developing countries? In M. Faure \& N. Niessen (Eds.), Environmental law in development: lessons from the Indonesian experience: Edward Elgar, 218-262

Feng, J. R. (2013). On Legislative Approaches of Carbon Trading in the EU and US: Their Inspirations to China. Hebei Law Science, vol.31.No.05,151-162 (in Chinese)

Frame, D. J. (2011). The problems of markets: Science, norms and the commodification of carbon. The Geographical Journal, 177(2), 138-148.

Frankenberg, G. (1985). Critical comparisons: Re-thinking comparative law. Harv. Int'l. LJ, 26, 411

Fuller, L. L. (1964). The Morality of Law (Revised Edition):Yale University Press

Gao, H. J. (2009). Rethinking the study of comparative law: contemporary challenges and paradigm shifts. Social Sciences in China, vol.06, 161-170 (in Chinese)

Ghaleigh, N. (2009). Emissions Trading Before the European Court of Justice: Market Making in Luxembourg. In Freestone,D. \& Streck, C. (eds.),Legal Aspects of Carbon Trading: Kyoto, Copenhagen and Beyond: Oxford University Press, U. of Edinburgh School of Law Working Paper No. 2009/12.

Golding, W. F. (2011). Incentives for Change: China's Cadre System Applied to Water Quality. Pac. Rim L. \& Pol'y J., 20, 399-428

Gordley, J,(2012). The functional method in Monateri, P. G. (eds). Methods of comparative law: Edward Elgar Publishing. 107-119

Görlach, B. et al (2008). Carbon leakage: the relocation of production and emissions as a challenge for emissions trading? Available at: http://www.dehst.de/EN/Home,/ last accessed 3 June 2013 
Guerin, E. \& Wang, X. (2012). Mitigation targets and actions in China up to 2020. IDDRI working papers $\mathrm{N}^{\circ} 01 / 2012$ available at: http://www.iddri.org/Publications/Mitigation-targets-and-actions-in-China-up-to-2020, last accessed 22 July 2013

Gunningham, N. A. (1997). Towards Effective and Efficient Enforcement of Occupational Health and Safety Regulation: Two Paths to Enlightenment. Comp. Lab. L. \& Pol'y J., 19, 547.

Groussot, X., (2006). General Principles of Community Law: Europa Law Publishing, Groningen

Grubb, M., Azar, C., \& Persson, U. M. (2005). Allowance allocation in the European emissions trading system: a commentary. Climate Policy, 5(1), 127-136.

Grubb, M. \& Neuhoff, K., (2006). Allocation and competitiveness in the EU emissions trading scheme: policy overview. Climate Policy, 6(1), 7-30

Hager, B. M. (1999). The Rule of Law: A Lexicon for Policy Makers: Mansfield Center for Pacific Affairs. available at: http://www.mansfieldfdn.org/backup/programs/program_pdfs/lexicon.pdf, last accessed 12 March 2013

Han, G., Olsson, M., Hallding, K., \& Lunsford, D. (2012). China's Carbon Emission Trading: An Overview of Current Development, available at: http://www.sei-international.org/mediamanager/documents/Publications/china-cluster/SEI-F ORES-2012-China-Carbon-Emissions.pdf, last accessed 13 March 2013

Handke, A. (2012). The Accreditation \& Verification Regulation (AVR): from the perspective of the German CA, presented at the Compliance Forum Event, October 1-2, 2012, Brussels, available at: http://ec.europa.eu/clima/events/docs/0059/handke_en.pdf, last access date: September 82014.

Hansjürgens, B. (2005). Emissions Trading for Climate Policy: US and European Perspectives: Cambridge University Press

Hao, T. C. (2007). Does the Chinese National Economic and Social Development Planning has Legal Binding Force?. Study \& Exploration, No.2, 99-102

Hartridge, O. (2006). An introduction to the monitoring and reporting guidelines (Commission Decision 2004/156/EC) and registries regulation (Commission Regulation (EC) No 2216/2004) In Delbeke, J. (eds), The EU Greenhouse Gas Emissions Trading Scheme, Claeys \& Casteels, pages

Heilmann, S. (2011). Policy-making through Experimentation: The Formation of a Distinctive Policy Process in Heilmann, S., \& Perry, E. J. (eds), Mao's invisible hand: the political foundations of adaptive governance in China: Harvard University Asia Center, Cambridge, MA. , 62 
Hu, Y. H. (1999). The theoretical analysis on the cause for the local protectionism. Jiangxi Social Sciences, vol. 9, 30-32 (in Chinese)

Huang, M. Q. (2011). On the Soft Law Measure in the Economic Field-Analysis based on empirical and normative research methods. Economic Law Review, vol.02, 1-32 (in Chinese)

IPCC (2007). Climate Change 2007: Mitigation. Contribution of Working Group III to the Fourth Assessment Report of the Intergovernmental Panel on Climate Change, B. Metz, O.R. Davidson, P.R. Bosch, R. Dave, L.A. Meyer (eds), Cambridge University Press, Cambridge, also available at: http://www.ipcc.ch/publications_and_data/ar4/wg3/en/annex1-ensglossary-a-d.html, last accessed 3 August 2013

IPCC (2014). Climate Change 2014 Synthesis Report, available at: http://www.ipcc.ch/report/ar5/syr/, last accessed 6 December 2014

IEA (2012). Key World Energy Statistics 2012, available at: http://www.iea.org/publications/freepublications/publication/kwes.pdf, last accessed 20 July 2014

Jacquemont, F. (2005). The Kyoto compliance regime, the European bubble: some legal consequences. In Bothe, M. \& Rehbinder, E. (eds.), Climate Change Policy: Eleven International Pub

Jans, J.H., de Lange, R., Prechal, S., Widdershoven, R. J. G. M., (2007). Europeanisation of Public Law: Europa Law Publishing, Groningen

Jans, J. H. \& Vedder, H. H. B. (2011). European Environmental Law: After Lisbon (Fourth Edition) : Europa Law Publishing

Jiang, J.J., et al.(2014). The construction of Shenzhen's carbon emission trading scheme. Energy Policy, http://dx.doi.org/10.1016/j.enpol.2014.02.030i

Jin, Z. N. (2010). Second discussion on the legal source status of 'other normative document'. Public Law Research, 115-131 (in Chinese)

Kahn-Freund, O. (1974). On Uses and Misuses of Comparative Law. The Modern Law Review, $37(1), 1-27$

Kairys, D.(2003). Searching for the Rule of Law. Suffolk University Law Review, Vol. 36, 307-329, Available at SSRN: http://ssrn.com/abstract=724341, last accessed 2 March 2014

Keith, R. C. (1991). Chinese Politics and the New Theory of 'Rule of law'. The China Quarterly, $125,109-118$

Kossoy, A. \& Guigon, P. (2012). The State and Trends of the Carbon Market 2012. The World
Bank,
Washington,
DC.
Available
at: 
http://siteresources.worldbank.org/INTCARBONFINANCE/Resources/State_and_Trends_2 012_Web_Optimized_19035_Cvr\&Txt_LR.pdf, last accessed 20 March 2014

Kossoy, A. et al.(2013). Mapping Carbon Pricing Initiatives: Developments and Prospects 2013, the World Bank Report prepared by the Ecofys, Washington DC, May 2013, available at: http://www-wds.worldbank.org/external/default/WDSContentServer/WDSP/IB/2013/05/23/ 000350881_20130523172114/Rendered/PDF/779550WP0Mappi0til050290130morning0.p df, last accessed 20 March 2014

Kovacic, W. E. (2001). Institutional foundations for economic legal reform in transition economies: the case of competition policy and antitrust enforcement. Chicago-Kent Law Review, Vol. 77, No. 1, 265-315

Kraakman, R. H. (1986). Gatekeepers: the anatomy of a third-party enforcement strategy. $J L$ Econ.\& Org., 2, 53

Krämer, L. (2006). Some Reflections on the EU Mix of Instruments on Climate Change. in Peeters, M. \& Deketelaere, K. (Eds.), EU climate change policy: the challenge of new regulatory initiatives: Edward Elgar, 279-296

Krämer, L. (2007). EC Environmental Law, London: Sweet \& Maxwell

Kruger, J., \& Egenhofer, C. (2006). Confidence through compliance in emissions trading markets. Sustainable Development Law \& Policy, 6(2), 3.

Kruger, J., Oates, W. E., \& Pizer, W. A. (2007). Decentralization in the EU emissions trading scheme and lessons for global policy. Review of Environmental Economics and Policy, 1(1), $112-133$

Kuik, O., \& Oosterhuis, F. (2008). Economic impacts of the EU ETS: preliminary evidence. In M. Faure \& M. Peeters (Eds.), Climate Change and European Emissions Trading: Edward Elgard, 208-222

Kurkowski, S. J. (2005). Distributing the Right to Pollute in the European Union: Efficiency, Equity, and the Environment. NYU Envtl. LJ, 14, 698.

Lee, M.(2005). EU Environmental Law: Challenges, Changes and Decision-Making: Oxford

Lefevere, J. (2005). Greenhouse gas emissions trading: a background. In M. Bothe \& E. Rehbinder (Eds.), Climate change policy, Utrecht: Eleven International Publishing

Legrand, P. (1997). Impossibility of Legal Transplants, The. Maastricht J. Eur. \& Comp. L., 4, 111. 
Li, B. Y. \& Chen, G. M. (1998). The difference between the 'rule of law' and 'rule by law'. The People's Congress of China, No. 8, 16-19 (in Chinese)

Li, B. Y. \& Li, Q. (1999). From 'rule by law' to 'rule of law': it takes twenty years to change one word. Law Science, No.7, 2-5 (in Chinese)

Li, L. C. (2000). The 'rule of law' policy in Guangdong: Continuity or departure? Meaning, significance and processes. The China Quarterly, 161, 199-220.

Li, Z. P. (2007a). Analysis on the legal effect of the energy saving and emissions reduction target. Environmental Protection, 12, 30-33 (in Chinese)

Li, Z. P. (2007b). Study on the legislation of the pollutant discharge permit system in China: concurrent discussion on the coordination between the basic environmental protection systems, Conference Proceedings of China Law Society Association of Environment and Resources Law in 2007, 466-473 (in Chinese)

Li, Z. P. (2008). On the Government s Environmental Responsibility and Liability-Based on the Government Responsibility for the Environmental Quality. Journal of China University of Geosciences (Social Sciences Edition), Vol.8 No.2, 37-41 (in Chinese)

Li, Z.P. (2012). A Study on the Supervision Mechanism of Carbon Emissions Trading Market. Journal of Jiangsu University (Social Science Edition), Vol.14 No 1, 56-62 (in Chinese)

Liang, B. (2008). The changing Chinese legal system, 1978-present: Centralization of power and rationalization of the legal system: Routledge

Liao, B. \& Cui, J. X.(2012). The experience and lessons of the management system and legislation of the measurement for the greenhouse gas emissions in the EU ETS. Contemporary Law Review, Vol. 04, 111-118 (in Chinese)

Lin, F. \&. Buhi. J. (2009). Emissions Trading Across China: Incorporating Hong Kong and Macau into an Urgently Needed Air Pollution Control Regime Under 'One Country, Two Systems'. Journal of Transnational Law \& Policy, Vol.19.1, 123-178

Lin, J. (2012). Climate Governance in China: Using the 'Iron Hand'. In Benjamin J. Richardson (Eds.), Local Climate Change Law: Environmental Regulation in Cities and Other Localities: Edward Elgar Publishing. available at: http://hdl.handle.net/10722/144482

Liu, M. M. (2012). Study on the regime framework for climate legislation in China. Jiangxi Social Science, v.09,144-150 (in Chinese) 
Liu, X. Y. (2011). A Study on Local Government Behaviour under Gross Control on Low-carbon Economy--Based on Game Theory, Master dissertation of Anhui University. (in Chinese)

Lo, A. Y. (2012). Carbon emissions trading in China. Nature Climate Change, 2(11), 765-766

Lo, A. Y. (2013). Carbon trading in a socialist market economy: Can China make a difference? Ecological Economics, 87, 72-74.

Lo, C. W.-H., Fryxell, G. E., van Rooij, B., et al. (2012). Explaining the enforcement gap in China: Local government support and internal agency obstacles as predictors of enforcement actions in Guangzhou. Journal of Environmental Management, 111, 227-235.

Lu, C., Tong, Q., \& Liu, X. (2010). The impacts of carbon tax and complementary policies on Chinese economy. Energy Policy, 38(11), 7278-7285

Lubman, S. B. (1999). Bird in a cage: Legal reform in China after Mao: Stanford University Press.

Luo, H. C. \& Bi, H. H. (2006). Governance Through Soft Law. Jurists Rev. 1 (in Chinese)

Ma, H. D. (2003).Causes of the Formation and Measures of the Resolution of Localism. Tribune of Political Science and Law(Journal of China University of Political Science and law), Vol.21,No.6, 157-162 (in Chinese)

Ma, X. \& Ortolano, L. (2000). Environmental regulation in China: institutions, enforcement, and compliance: Rowman \& Littlefield.

Mace, M. I. (2005). The Legal Nature of Emission Reductions and EU Allowances: Issues Addressed in an International Workshop. Journal for European Environmental \& Planning Law, 2(2), 123-134

Manea, S. (2012).Defining Emissions Entitlements in the Constitution of the EU Emissions Trading System. Transnational Environmental Law, 1:2, 303-323

Marks, D. (2010). China's climate change policy process: improved but still weak and fragmented. Journal of Contemporary China, 19(67), 971-986.

Massai, L.(2011). European Climate and Clean Energy Law and Policy: Routledge

Matthes, F. et al (2005). The environmental effectiveness and economic efficiency of the European Union Emissions Trading Scheme: Structural aspects of allocation, Oko-Institut report to the World Wildlife Federation (WWF), available at: 
http://assets.wwf.es/downloads/ets_estructura_oeko_completo.pdf, last accessed 14 July 2014

McAllister, L. K. (2009). The overallocation problem in cap-and-trade: Moving toward stringency. Columbia Journal of Environmental Law, 34(2), 395-445

McAllister, L. K. (2010a). The Enforcement Challenge of Cap-and-Trade Regulation. Environmental Law(Portland), 40(4): 1195-1230.

McAllister, L. K. (2010b). Enforcing Cap and Trade: A Tale of Two Programs. San Diego J. Climate \& Energy L, 2(1), 1-28.

McAllister, L. K. (2011). Regulation by Third-Party Verification. Boston College Law Review 53(1), 1-64.

McCubbin, P. R. (2008). China and climate change: Domestic environmental needs, differentiated international responsibilities, and rule of law weaknesses. Environmental \& Energy Law \& Policy Journal. Available at SSRN: http://ssrn.com/abstract=1212562, last accessed 20 November 2013

Meadows, D. (2006). The emissions allowances trading Directive 2003/87EC explained, in Delbeke, J. et al (eds), The EU Greenhouse Gas Emissions Trading Scheme, Claeys \& Casteels, 63-115

Mendes de Leon, P. (2012). Enforcement of the EU ETS: The EU's convulsive efforts to export its environmental values, Air and Space Law 37(4), 287-306.

Meng, L., Guo, J. e., Chai, J., \& Zhang, Z. (2011). China's regional CO2 emissions: Characteristics, inter-regional transfer and emission reduction policies. Energy Policy, $39(10), 6136-6144$.

Mertens de Wilmars, D. (2011). Recent Case Law on the European Scheme for Greenhouse Gas Emissions Allowance Trading, in Tristan Baumé et al (eds.), Today's Multi-layered Legal Order: Current Issues and Perspectives: Paris Legal Publishers, 211-218

Michaelowa, A., \& Betz, R. (2001). Implications of EU Enlargement on the EU Greenhouse Gas 'Bubble' and Internal Burden Sharing, International Environmental Agreements: Politics, Law and Economics, 1(2), 267-279.

Michaels, R. (2006). The functional method of comparative law. In M. R. R. Zimmermann (Ed.), The Oxford Handbook of Comparative Law: Oxford University Press, 339-382

Minzner, C. F. (2009). Riots and Cover-Ups: Counterproductive Control of Local Agents in China. U. Pa. J. Int'l L., 31, 53. 
Mol, A. P., \& Carter, N. T. (2006). China's environmental governance in transition. Environmental Politics, 15(02), 149-170.

More, G. (1999). The principle of equal treatment: From market unifier to fundamental right? In P. Craig \& G. de Búrca (Eds.), The evolution of EU law: Oxford University Press,517-773

Morgenstern, R. D., et al (2004). Emissions Trading to Improve Air Quality in an Industrial City in the People's Republic of China, Resources for the Future, Discussion Paper 04-16

Mossoux, Y. (2010). Causation in the polluter pays principle. European Energy and Environmental Law Review, 19(6), 279-295

Mulkey, M. E. (2004). Judges and Other Lawmakers: Critical Contributions to Environmental Law Enforcement. Sustainable Dev. L. \& Pol'y, 4, 2.

Munnings, C., et al (2014). Assessing the Design of Three Pilot Programs for Carbon Trading in China, Resources for the Future discussion paper, available at: https://webmail.maastrichtuniversity.nl/owa/redir.aspx?C=87313f78941e4b90a6458831d36 dcd77\&URL=http $\% 3 \mathrm{a} \% 2 \mathrm{f} \% 2$ fwww.rff.org $\% 2$ fPublications $\% 2 \mathrm{fPages} \% 2 \mathrm{fPublicationDetail}$ s.aspx\%3fPublicationID\%3d22458, last accessed November 22014

Netherlands Environmental Assessment Agency (2008). Consequences of the European Policy Package on Climate and Energy, available at: www.mnp.nl

Oates, W.E. (2002). A Reconsideration of Environmental Federalism. In List, J. and A de Zeeuw (Eds.) Recent Advances in Environmental Economics (1-32). Cheltenham, UK.: Edward Elgar, 1-32

O’Brien, K., \& Li, L. (1999). Selective policy implementation in rural China. Comparative Politics, 31(2), 167-186.

OECD (1989). Environmental Policy Benefits: Monetary Valuation, Paris: OECD.

OECD (1997). Evaluating Economic Instruments for Environmental Policy, Paris: OECD.

OECD (2004). Tradeable Permits: Policy Evaluation, Design and Reform, Paris: OECD.

OECD (2006). Environmental Compliance and Enforcement in China: an Assessment of Current Practice and Ways forward, available at: http://www.oecd.org/dataoecd/33/5/37867511.pdf, last accessed 17 August 2013

Olsen, B. E. (2006). The IPPC Permit and the Greenhouse Gas Permit, in Peeters, M. \& Deketelaere, K. (Eds.), EU climate change policy: the challenge of new regulatory initiatives: Edward Elgar, 153-168

Orts, E. W. (2001). Rule of Law in China, The. Vand. J. Transnatl. L., 34, 43. 
Orts, E. W. (2003). Environmental Law with Chinese Characteristics, Wm. \& Mary Bill of Rts. J., 11,545

Pan, H. D. (1990). Comparative law in China: retrospect and prospect. Journal of Comparative Law, vol. 2, 1-13(in Chinese)

Peerenboom, R. (2002). China's long march toward rule of law: Cambridge University Press.

Peeters, M. (1992). Towards a European System of Tradable Pollution Permits. Tilburg Foreign L. Rev. 2: 117 .

Peeters, M. (2003). Emissions trading as a new dimension to European environmental law: the political agreement of the European Council on greenhouse gas allowance trading. European Environmental Law Review, 12(3), 82-92

Peeters, M. (2006a). Inspection and Market-Based Regulation Through Emissions Trading: The Striking Reliance on Self-Monitoring, Self-Reporting and Verification. Utrecht Law Review, 2(1), 177-95.

Peeters, M. (2006b). Enforcement of the EU greenhouse gas emissions trading scheme. In M. Peeters \& K. Deketelaere (Eds.), EU climate change policy: the challenge of new regulatory initiatives: Edward Elgar Publishing, 169-187

Peeters, M. (2006c). Elaborating on Integration of Environmental Legislation: the Case of Indonesia. In M. Faure \& N. Niessen (Eds.), Environmental law in development: lessons from the Indonesian experience. Northampton, UK: Edward Elgar, 92-127

Peeters, M. (2008). Legislative choices and legal values: considerations on the further design of the European greenhouse gas Emissions Trading Scheme from a viewpoint of democratic accountability. In M. Faure \& M. Peeters (Eds.), Climate change and European emissions trading: lessons for theory and practice: Edward Elgar, 17-52

Peeters, M. (2011a). The EU ETS and the role of the courts: Emerging contours in the case of Arcelor. Climate law, 2(1), 19-36.

Peeters, M. (2011b). Climate Law in The Netherlands: an overview of current mitigation measures, in: Erkki J. Hollo (ed.) Ympäristöjuridiikka (Finnish Environmental Law Review), $3 / 11,125-134$

Peeters, M. (2011c). The enforcement of greenhouse gas emissions trading in Europe: reliability ensured? In Kotze, L.etc (eds) (2011). Compliance and enforcement in environmental law: towards more effective implementation (The IUCN Academy of Environmental Law Series): Edward Elgar Pub, 407-430

Peeters, M. (2013). Climate Change, Targets, and Trade: An EU perspective on the differential treatment of international competing industries, in M. van Asselt, M. Everson \&E. Vos (eds), 
Trade, Health and the Environment: The European Union Put to the Test: Earthscan Ltd, 133-156

Peeters, M. (2014). Instrument mix or instrument mess? The administrative complexity of the EU legislative package for climate change. In M. Peeters \& R. Uylenburg (Eds.), EU Environmental Legislation: Legal Perspectives on Regulatory Strategies: Edward Elgar Publishing, 173-192

Peeters, M. \& Stallworthy, M. (2012). Legal Consequences of the Effort Sharing Decision for Member State Action. In M. Peeters, M. Stallworthy \& J. De cendra de (Eds.), Climate Law in Eu Member States: Towards National Legislation for Climate Protection: Edward Elgar publishing, 15-38

Peeters, M., Weishaar, S., \& de Cendra de Larragán, J. (2007). A Governance Perspective on the Choice between 'Cap and Trade' and 'Credit and Trade' for an Emissions Trading Regime. European Environmental Law Review, 16(7), 191-202,

Peeters, M., \& Weishaar, S. (2009). Exploring Uncertainties in the EU ETS: 'Learning by Doing' Continues Beyond 2012. The Carbon \&Climate Law Review, 3(1), 88-101.

Peterson, S. (2004). Monitoring Accounting and Enforcement in Emissions Trading Regimes, in OECD, Greenhouse Gas Emissions Trading and Project-based Mechanisms: OECD Publishing. doi: 10.1787/9789264105775-en

Pigou, A. C. (1932). The economics of welfare (1920), London: McMillan\&Co.,

Pizer, W. A. (2005). The case for intensity targets. Climate Policy, 5(4), 455-462

Polinsky, A.M. \& Shavell, S., (1979). The optimal trade-off between the probability and magnitude of fines. American Economic Review, 69, 880-891

Potter, P. B. (1999). The Chinese legal system: continuing commitment to the primacy of state power. The China Quarterly, 159(1), 673-683

Price, L., et al. (2011). Assessment of China's energy-saving and emission-reduction accomplishments and opportunities during the 11th Five Year Plan. Energy Policy, 39(4), 2165-2178

Qi, S. Z. \& Wang, B. B. (2013). Initial allowances allocation in carbon trading: comparison of modes and methods, Wuhan University Journal (Philosophy \& Social Science), No.5, 19-28 (in Chinese)

Qi, S. Z. \& Wang, B. B. (2014). Design features of the Hubei carbon emissions trading: solid cap and flexible structure, $21^{\text {st }}$ Century Business Herald, April 142014 (in Chinese) 
Qian, Y. Y. (2002). How Reform Worked in China. William Davidson Institute Working Paper Number 473. Available at SSRN: http://ssrn.com/abstract=317460, last accessed 22 May 2013

Qin, T. B. (2009). From Stander-By to Stakeholder: China's Perspective on Climate Change. Available at SSRN: http://ssrn.com/abstract=1325152, last accessed 18 June 2013

Qin, T. B. \& Fu, L. (2012). EU ETS Legislation Process and its Implications for China. Journal of Jiangsu University (Social Science Edition), Vol.14 No.3, 17-21(in Chinese)

Qin, T.B. \& Wang, Y. (2009). A Study on Governmental Intervention of Emission Trading System, Western Law Review, 1-6 (in Chinese)

Raz, J. (1979). The Rule of Law and Its Virtue, in The Authority of Law: Essays on Law and Morality: Oxford University Press

Reinaud, J. (2008). Climate Policy and Carbon Leakage: Impacts of the European Emissions Trading Scheme on Aluminium, IEA, available at: http://www.iea. org/publications/freepublications/publication/Aluminium_EU_ETS.pdf, last accessed 2 May 2013

Reitze, A. W. Jr., \& Schell, S. D. (1999). Self-Monitoring and Self-Reporting of Routine Air Pollution Releases. Colum. J. Envtl. L., 24, 63.

Risbey, S.J. (2006). Some Dangers of 'Dangerous' Climate Change. Climate Policy, 6(5), $527-536$

Rohleder, J. (2006). The role of third-party verification in emissions trading systems: developing best practices. Sustainable Development Law \& Policy, 6(2), 7.

Rommeney, D. (2008). Climate \& Energy Policy in the People's Republic of China: An Overview concerning Chinese Domestic Laws, and the Instruments and Measures of Climate Change Mitigation. Beijing: Heinrich Böll Foundation China.

Rose, C.M. (1999). Expanding the Choices for the Global Commons: Comparing Newfangled Tradable Allowance Schemes to Old-Fashioned Common Property Regimes, Duke Environmental Law \& Policy Forum, 10 (45), 45-72

Schleich, J, Betz, R. \& Rogge. K. (2007). EU emission trading: better job second time around? Fraunhofer Institute for Systems and Innovation Research (ISI), S2/2007, available at: http://ideas.repec.org/p/zbw/fisisi/s22007.html, last accessed 2 September 2013

Schmitt-Rady, B. (2006). A Level Playing Field? Initial Allocation of Allowances in Member States In M. Peeters \& K. Deketelaere (Eds.), EU climate change policy: the challenge of new regulatory initiatives: Edward Elgar, 83-97

Scott, J. (2011). The Multi-Level Governance of Climate Change. Carbon \& Climate Law Review, 5(1), 25 
Shavell, S. (1985). Criminal law and the optimal use of nonmonetary sanctions as a deterrent. Columbia Law Review, 85(6), 1232-1262

Shen, Z. L. eds. (2009). Jurisprudence ( $3^{\text {rd }}$ edition), Beijing University Press (in Chinese)

Shenzhen Carbon Trading Task Group (2013). On a Trading System for Carbon Emission by Macro and Structural Regulating. China Opening Journal, No. 3, 7-17 (in Chinese)

Sitaraman, S. (2007). Regulating the Belching Dragon: Rule of Law, Politics of Enforcement, and Pollution Prevention in Post-Mao Industrial China. Colo. J. Int'l Envtl. L. \& Pol'y, 18, 267.

Skjærseth, J. B. (2010) EU Emissions Trading: Legitimacy and Stringency. Environmental Policy and Governance, 20, 295-308

Skjærseth, J. B.\& Wettestad, J. (2009). The origin, evolution and consequences of the EU emissions trading system. Global Environmental Politics, 9(2), 101-122

Song, G. D. (2006). The main source of the soft law in Public Sphere, in Luo, H. C. et al (eds.), Soft Law and Public Governance: Peking University Press (in Chinese).

Song, H. L. (2008). Study on the legal nature of technical standard: orientation from the perspective of administrative legal system. Research on Administrative Law, v.03:42 (in Chinese)

Sorrell, S., \& Sijm, J. (2013). Carbon Trading in the Policy Mix. Oxford Review of Economic Policy, 19(3), 420-437.

Spassov, Y. (2012). EU ETS: Upholding the Carbon Price Without Incidence of Carbon Leakage. Journal of Environmental Law, 24:2, 311-344

Squintani, L., Holwerda, M. \& de Graaf, K. (2012). Regulating Greenhouse Emissions from EU-ETS Installations: What Room is Left for the Member States?, in: M. Peeters, M. Stallworthy \& J. De cendra de (Eds.), Climate Law in Eu Member States: Towards National Legislation for Climate: Edward Elgar publishing, 67-88

Stavins, R. N. (1989). Harnessing market forces to protect the environment. Environment: Science and Policy for Sustainable Development, 31(1), 5-35.

Stranlund, J. K., Chavez, C. A., \& Field, B. C. (2002). Enforcing Emissions Trading Programs: Theory, Practice, and Performance. Policy Studies Journal, 30(3), 343-361.

Swift, B. (2005). US Emissions Trading: Myths, Realities, and Opportunities. Nat. Resources \& Env't, 20, 3.

Tao, J., \& Mah, D. N.-y. (2009). Between market and state: dilemmas of environmental governance in China's sulphur dioxide emission trading system. Environment and planning. C, Government \& policy, 27(1), 175.

Teng, F. (2012). China: Improving the local-central climate governance nexus. working papers $\mathrm{N}^{\circ} 08 / 2012$,

IDDRI, available at: 
http://www.iddri.org/Publications/China-Improving-the-local-central-climate-governance-n exus, last accessed 2 June 2013

Tiebout, C. M. (1956). A pure theory of local expenditures. The journal of political economy, 64(5), 416-424.

Tietenberg, T. H. (2006). Emissions trading: principles and practice: Resources for the Future.

Tietenberg, T., \& Johnstone, N. (2004). Ex post evaluation of tradeable permits: methodological issues and literature review. In OECD (2004). Tradeable Permits: Policy Evaluation, Design and Reform, OECD, Paris.

Tridimas, T. (2006). The General principles of Community law, Oxford: Oxford University Press

Turner-Gottschang, K., Feinerman, J. V., \& Guy, R. K. (2000). The limits of the rule of law in China: Univ of Washington Press.

Van Aken, N., \& Paques, M. (2008). The 'Emissions Trading Scheme' Case-Law: Some New Paths for a Better European Environmental Protection. In M. Faure \& M. Peeters (Eds.), Climate change and European emissions trading: lessons for theory and practice: Edward Elgar, 88-127

Van Asselt, H. (2009). The EU ETS in the European Climate Policy Mix: Past, Present and Future. ADAM Project, No. 018476-GOCE, available at: http://ssrn.com/abstract=1596892

van Asselt, H. \& Biermann, F.(2007). European Emissions Trading and the International Competitiveness of Energy-Intensive Industries: A Legal and Political Evaluation of Possible Supporting Measures. Energy Policy, Vol. 35, No. 1, 497-506

Van den Bergh, R. (2000). Economic criteria for applying the subsidiarity principle in European environmental law. In R. Revesz, P. Sands \& R. Steward (Eds.), Environmental Law, the Economy, and Sustainable Development. Cambridge: Cambridge University Press.

van Zeben, J. A. W. (2009a). (De) Centralized law-making in the revised EU ETS, Carbon \&Climate Law Review 3(3), 340-356

Van Zeben, J. A. W. (2009b). The European emissions trading scheme case law. Review of European Community \& International Environmental Law, 18(2), 119-128.

van Zeben, J. A. W. (2012) . Competence Allocation and Regulatory Functioning: A Study of the European Union Emissions Trading Scheme, $\mathrm{PhD}$ thesis of Universiteit van Amsterdam.

Vermeer, E. B., \& Hooghe, I. (2002). China's Legal Reforms and Their Political Limits: Routledge.

Verschuuren, J. \& Fleurke, F. (2014). Report on the legal implementation of the EU ETS at Member State level, ENTRACTE REPORT, available at: http://entracte-project.eu/research/report-legal-studies/, last accessed 1 November 2014 
Vis, P. (2006). Basic design options for emissions trading, in Delbeke, J. (eds), The EU Greenhouse Gas Emissions Trading Scheme: Claeys \& Casteels. pages

Wagner, W. E. (2003). Commons ignorance: The failure of environmental law to produce needed information on health and the environment. Duke LJ, 53, 1619.

Wang, C. F. (2006). Chinese Environmental Law Enforcement: Current Deficiencies and Suggested Reforms. Vt. J. Envtl. L., 8, 159.

Wang, C. G. (2010). From the Rule of Man to the Rule of Law, In Cai D. J. \& Wang, C. G ed. China's Journey Toward the Rule of law: Legal Reform 1978-2008: Brill Academic Pub, $1-50$

Wang, H. \&Cao, M. D. (2011). The Reaction to Climate Change: Tradable Pollution Permit or Carbon Tax. Legal Forum, Vol.26, No.1, 10-115 (in Chinese)

Wang, J. N. (2008). The latest practice of emissions trading system and its future. ENVTL. ECON., 10, 31-45

Wang, J.N., Yang, J.T., et al. (2004). Sulfure dioxide emission trading in China: piloting programs and its perspective, available at: http://www.researchgate.net/profile/Jeremy_Schreifels/publication/237010478_Sulfur_Diox ide_Emission_Trading_in_China_Piloting_Programs_and_Its_Perspective/file/60b7d529f3 88556b12.pdf, last accessed 22 July 2013

Wang, J. N., Yan, G. \& et al. (2009). The study on China's carbon tax policy to mitigate climate change. Chinese Environmental Science, 29 (1), 101-105 (in Chinese)

Wang, J. N., Dong, Z. F. \& et al. (2009). The Practice and Prospect of the Emissions Trading in China. Environmental Protection, vol. 420, No. 5B, 17-22 (in Chinese)

Wang, K. et al (2013). Regional allocation of CO2 emissions allowance over provinces in China by 2020. Energy Policy, vol. 54, 214-229

Wang, Q.T. (2011). Invisible 'Laws': Abnormity of Other Normative Documents in Judicial Review. Modern Law Science, Vol. 33 No.2, $82-89$ (in Chinese)

Wang, S. G. (2011). Learning through Practice and Experimentation: The Financing of Rurual Health Care in Heilmann, S., \& Perry, E. J. (eds), Mao's Invisable Hand: The Political Foundations of Adapative Governance in China, Harvard University Asian Centre, Cambridge, MA., 102

Wang, X. (2001). Law and Policy of the European Union on Greenhouse Gas Emissions Reduction and their Methodological Significance to China, In Nazrul Islam, Isabel Martínez, Ikechi Mgbeoji, and Wang Xi (eds). Environmental Law in Developing Countries: Selected 
Issues. IUCN, Gland, Switzerland and Cambridge, UK, CDG, Berlin, Germany and ZAV, Bonn, Germany. xiv $+140-153$

Wang, X. (2011). Building MRV for a successful emissions trading system in China. working paper of Institut du développement durable et des relations internationales $n^{\circ} 16 / 11$ December 2011

Wang, W. G. (2012). On some key issues of carbon tax in China. Journal of Jiangsu University (Social Science Edition), v.06:12-15 (in Chinese)

Wang, Y. G. \& Ge, X. A. et al (2011). China's Pathway towards Carbon Emissions Trading Scheme: International Experience \& China's Practices: Economy\& Management Press (in Chinese)

Watson, A. (1993). Legal transplants: an approach to comparative law (2 ed.): University of Georgia Press

Weber, M. (1978). Economy and society: An outline of interpretative sociology,Vol. 1, University of California Press.

Weber, M., Rheinstein, M., \& Shils, E. A. (1954). Max Weber on law in economy and society (Vol. 84): Harvard University Press Cambridge, MA.

Weishaar, S. (2008a). EU greenhouse gas emissions trading and competition law. In Faure, M. \& Peeters, M. (Eds.), Climate change and European emissions trading: lessons for theory and practice: Edward Elgar. 151-177

Weishaar, S. (2008b): Germany v Commission: The ECJ on Ex Post Adjustment under the EU ETS, Review of European Community \& International Environmental Law, 126-129

Weishaar, S. (2009). Towards auctioning: the transformation of the European greenhouse gas emissions trading system: present and future challenges to competition law (Vol.2): Kluwer Law International.

Weishaar, S. (2014). Emissions Trading Design: A Critical Overview, Cheltenham: Edward Elgar

Weishaar, S. \& Fitsum G. Tiche (2013) , Hybrid emissions trading systems: what about efficiency? In Faure, M. \& Xu,G. (eds.), Economics and Regulation in China: Routledge, 221-239

Whitman, J.Q.(1998). What is wrong with Inflicting Shame Sanctions?, The Yale Law Journal, vol.107, 1055-1092.

Wiener, J. B. (2001). Something Borrowed for Something Blue: Legal Transplants and the Evolution of Global Environmental Law. Ecology LQ, 27, 1295-1372 
Wiener, J. B. (2003). Whose Precaution After All? A Comment on the Comparison and Evolution of Risk Regulatory Systems, 13 Duke Journal of International \& Comparative Law, 207-262

Wiener, J. B. (2011). The Real Pattern of Precaution, in Wiener, J. B. et al(eds), The reality of precaution: Comparing risk regulation in the United States and Europe, Washington DC: RFF Press, 519-565

Winter, G. (2010). The climate is no commodity: taking stock of the emissions trading system. Journal of Environmental Law, 22(1), 1-25.

Woerdman, E., Arcuri, A. and Clò, S.,(2007). Emissions Trading and the Polluter-Pays Principle: Do Polluters Pay under Grandfathering?, in Working Paper Series of University of Groningen. Available at SSRN: http://ssrn.com/abstract=1271843 or http://dx.doi.org/10.2139/ssrn.1271843

Woerdman, E., Clò, S. \& Arcuri, A. (2008). Emissions Trading and the Polluter-Pays Principle: Assessing Grandfathering and Over-allocation, in Faure, M. \& Peeters, M. (Eds.), Climate change and European emissions trading: lessons for theory and practice: Edward Elgar. $128-150$

World Bank (1988). China: finance and investment, The World Bank, Washington DC;

Wu, J., et al (2013). Incentives and Outcomes: China's Environmental Policy, National Bureau of Economic Research, Working Paper No. 18754, February 2013, available at: http://www.nber.org/papers/w18754, last accessed 10 April 2014

Wu, P. (2006). On the legal source status of 'other normative document' in Administrative Law. Journal of Capital Normal University(Social Sciences Edition), No.03, 30-35 (in Chinese)

Wu, Q. (2011). Policy and Politics of a Carbon Market in China. In J. Peetermans, ed. Greenhouse Gas Market Report 2011: Asia and Beyond: the Roadmap to Global Carbon \& Energy Markets. Geneva, Switzerland: International Emissions Trading Association. 22-25.

Wu, Q., Neelis, M. \& Casanova, C. (2014). Chinese Emissions Trading Schemes - Initial Assessment on Allocation (Ecofys report), available at http://www.ecofys.com/files/files/ecofys-2014-industry-views-chinese-ets-allocations-chine se.pdf, last accessed 10 July 2014 (in Chinese)

Xiao, Y. et al (2014). An Empirical Study of Carbon Emission Transfer and Carbon Leakage in Regional Industrial Transfer in China: Analysis Based on Inter-regional Input-output Model in 2002 and 2007. Journal of Finance and Economics, vol. 40, No. 2, $75-84$ (in Chinese) 
Xin, C. Y. (2007). The theory and practice of legal transplant. Northern Legal Science, vol.03, 5-13 (in Chinese)

Xiong, L., \& Qi, S. Z. (2012). The Structural Defects, Institutional Changes and Implications of the EU ETS. Chinese Journal of European Studies, No.01, 51-64 (in Chinese)

$\mathrm{Xu}$, Q.F. (2012). The Theories of the Allocation of Central authority and Local Authority in our Country: Beginning from the Property of Power. Law and Social Development 03,148-160 (in Chinese)

Xue, K. P. (2007). Analysis of the '11th Five-Year Plan' from an Economic Law Perspective. Law Science Magazine, 01,61-64 (in Chinese)

Yandle, B. (1999). Grasping for the Heavens: 3-D Property Rights and the Global Commons, Duke Environmental Law \& Policy Forum, 10 (13), 13-44

Yang, T., \& Percival, R. V. (2009). The Emergence of Global Environmental Law. Ecology Law Quarterly, 36, 615-664

Yang, T.,\& Zhang, X. (2012). Public Participation in Environmental Enforcement with Chinese Characteristics: A Comparative Assessment of China's Environmental Complaint Mechanism. Geo. Int'l Envtl. L. Rev., 24, 325.

Yang, X. S. (2010). Addressing climate change: comparative analysis between carbon tax and carbon emissions trading. Qinghai Social Science, No.06, 36-39 (in Chinese)

Yao, R., Li, B., \& Steemers, K. (2005). Energy policy and standard for built environment in China. Renewable Energy, 30(13), 1973-1988.

Yi, W.J., Zou, L.L., et al. (2011). How can China reach its CO2 intensity reduction targets by 2020? A regional allocation based on equity and development. Energy Policy, 39(5), 2407-2415.

Yu, G. \& Elsworth, R. (2012). Turning the Tanker: China's Changing Economic Imperatives and its Tentative Look to Emissions Trading.(Sandbag Report). available at: http://www.sandbag.org.uk/site_media/pdfs/reports/Sandbag_Turning_the_Tanker_Final.pd f, last accessed 12 July 2014

Yu, L. Y. (2008). Between Normativeness and Rigidity-Searching Administrative Discretion Criteria in Jinhua City. Tsinghua Law Review, vol. 2, No. 3, 54-80 (in Chinese)

Zang, D. S. (2009). From environment to energy: China's reconceptualization of climate change. Wis. Int'l LJ, 27, 543. 
Zapfel, P. (2007). A brief but lively chapter in EU climate policy: the Commission's perspective, in Ellerman, A. D., Buchner, B. K. \& Carraro, C (eds.), Allocation in the European Emissions Trading Scheme: Rights, Rents and Fairness: Cambridge University Press, 13-38

Zhan, Z.L. (1992). On other normative documents except the administrative regulation and administrative rule. China Legal Science, No.02, 108-113 (in Chinese)

Zhang, H. (2012). China's Energy Conservation and Carbon Emissions Reduction System: Development and Status Quo of the Regulatory and Institutional Framework. Environmental Law Reporter: News \& Analysis, 42(3) 10260-10279

Zhang, H. (2013). Designing and Implementing an Emissions Trading Market in China: The case of Tianjin, In Faure, M. \& Xu,G.D. (eds.), Economics and Regulation in China: Routledge, 240-268

Zhang, M. (2010). Socialist Legal System with Chinese Characteristics: China's Discourse for the Rule of Law and a Bitter Experience, The. Temp. Int'l \& Comp. LJ, 24, 1.

Zhang, Q. F. (2011). Right to Equity and Local Diversity: China Democracy and Law Press (in Chinese)

Zhang, X. M., Ortolano, L. \& Lü, Z.M. (2010). Agency Empowerment through the Administrative Litigation Law: Court Enforcement of Pollution Levies in Hubei Province. The China Quarterly, 202, 307-326. doi:10.1017/S0305741010000251.

Zhang, X. C. (2007). Commentary on 'Legislating for a Market Economy in China'. The China Quarterly, 191, 586-589

Zhang, Y. \& Wang, J. (2012). Problems of Chinas system of environmental standards and the countermeasures. China Environmental Science, 32(1), 187-192,

Zhang, Z. T. (2007). New ideas on the amendment of the Energy Conservation Law: origins and development from the perspective of notion and institution. Legal Science, v.02,116-121 (in Chinese)

Zhang, Z. T. (2010a). Study on the framework for China's legislation law. Journal of Nanjing University (Philosophy, Humanities and Social Sciences), No.5, 37-43 (in Chinese)

Zhang, Z. T. (2010b). Ideas on carbon taxation legislation in China. Law Science Magazine, v.31.No.02, 98-100 (in Chinese)

Zhang, Z. T. (2010c). Preliminary Study on China's Low-Carbon City Legislation in the Context of Climate Change. Journal of Poyang Lake, vol. 04, 43-48 (in Chinese )

Zhang, Z. X. (1999). Should the rules of allocating emissions permits be harmonised? Ecological Economics, 31(1), 11-18. 
Zhao, H. Y. \& Zhao, J. J. (2009). On the Legal Evolution of Total Quantity Control of Pollutant Discharge and Its Trend. Journal of SJTU(Philosophy and Social Sciences), 28-34 (in Chinese)

Zheng, S., Wei, X. H., \& Zhang, M.S. (2013). Investigation on the regional carbon exchanges. China Investment, No. 02, 64-67 (in Chinese)

Zhou, L. A. (2007). Governing China's Local Officials: An Analysis of Promotion Tournament Model. Economic Research Journal, 7, 36-50 (in Chinese)

Zhou, Y. Y. (2007). On the legitimacy of discretion Standard. China Legal Science, No. 6, 22-32 (in Chinese)

Zhu, J. W. (2006). On the legal transplant in the legislation of the contemporary China. Journal of Henan Administrative Institute of Politics and Law, vol. 04, 87-96 (in Chinese)

Zhu, J. W. (2011). The Socialist Legal System with Chinese Characteristics: Its Structure, Features and Trends. Social Sciences in China. Vol. XXXII, No. 3, 87-103 (in Chinese)

Zhu, S. L. (1996). The Rule of Law and its Native Resource, Beijing: Chinese University of Political Science and Law Press (in Chinese)

Zweigert, K., \& Kötz, H. (1998). An Introduction to Comparative Law, translated by Tony Weir: Oxford University Press (3 Revised edition) 


\section{VALORISATION ADDENDUM}

\section{Societal relevance}

This research deals with a prominent element of the current political debate and policy development in China surrounding the climate regime. The carbon emissions trading scheme is considered by Chinese policy makers to be an important instrument for reducing GHG emissions, therefore helping China's transition into a low-carbon economy. This can be exemplified in recent years through many policies and legislation for establishing emissions trading at the national and local levels. In particular, experiments with carbon emissions trading have been initiated in seven local pilot projects since 2011, in view of the establishment of a national scheme. While China is experimenting with pilot projects, it still faces the challenge of how to design and implement this market-based instrument within its own legal system, particularly in view of its aim to strengthen the rule of law as stipulated in the Constitution since 1999.

This research deals with the question of how China can improve the regulatory design and implementation of its ETS. It contains an in-depth examination of the specific design and implementation of these pilot projects, and gives insight into potential improvements of the ETS in China in order to ensure the reduction of GHG emissions in a cost-effective manner. As a result this research is relevant for (1) effectively combatting the global problem of climate change, and, in particular, how China could contribute to that; (2) the search for cost-effective ways to deal with this immense task; and (3) understanding how the reduction of GHG emissions can occur in view of the rule of law as specifically understood in China. The Chinese ETS is still in mid-development, and the evaluation of its design and implementation is necessary to see whether and how the current regulatory framework for the Chinese ETS can work in practice. The detailed description and analysis of the legal problems emerging from the pilot projects provides an up-to-date understanding of carbon emissions trading in China. Based on this detailed analysis, this research puts forward a number of recommendations for the potential improvement of the regulatory design and implementation of the Chinese ETS, thereby taking account of legal experiences with the EU ETS. To be specific, chapter 5 of this thesis provides recommendations from a legal perspective for the establishment of the legal framework for the Chinese ETS and specific improvements concerning its three selected key elements. The policy recommendations can be relevant for the practical development of the Chinese ETS and provide input on the future regulatory design and implementation of the ETS in China.

To explore how to improve the regulatory design and implementation of the Chinese ETS, this research takes account of the legal experience with the EU ETS in terms of its regulatory design and related case law. Established by Directive 2003/87/EC, the EU ETS is the first and largest domestic GHG emissions trading system in the world. With the comparative methodology applied in this research, the EU ETS has been elaborated on and analysed in order to obtain legal insights for potential improvements of the Chinese ETS. In this sense, the analysis of the EU ETS is also relevant for the understanding and review of the EU ETS, particularly in terms of those three key elements. Furthermore, the comparative analysis between the EU ETS and the 
Chinese ETS provides insights that help to gain a mutual understanding of the respective systems, which is helpful for policy makers in the EU and China to explore whether it is possible, and to what extent it is possible to learn from each other before considering the possible linkage between the two systems in the future.

\section{Target groups}

First of all, the research results developed in the concluding chapter (chapter 5) are addressed to Chinese policy makers who have the power to establish the ETS at the local and national level. Along with Chinese policy makers, the research results can also be of immense interest for the industries currently covered by or influenced by the Chinese ETS. As the ETS aims to reduce their GHG emissions, the instrument is of direct importance to their economic activities. However, the ETS is relatively new for industries: they need to learn more about the legal aspects of the ETS. This research provides industries with a more specific understanding of the ETS. Moreover, the research findings may to some extent be helpful for them to develop strategies to deal with this new regulatory instrument, particularly including how to exercise their own rights and to perform their obligations correctly. Also, since the Chinese ETS will be gradually expanded to become a national scheme, industries - which are not yet covered by the current pilot projects but which may be included in a national scheme later - can prepare themselves for the ETS through a more in-depth understanding as provided by the outcome of this thesis. Potential China-based market players, such as banks that can participate in the allowances trading market or the low-carbon investment may also be interested in this research. Last but not least, other stakeholders, such as environmental NGOs may also use this research result to obtain a further understanding of this kind of market-based instrument, in order to play a better role in the Chinese governance structure addressing climate change.

Moreover, the results of this research can also be of interest to policy makers and industries outside China, including the EU, in view of the emergence of global environmental law, and more particularly, the potential linkage between the Chinese ETS and the EU ETS in the future. The specific analysis of the EU ETS in terms of the regulatory design and related case law, (see chapter 3 of this thesis), provides insight into the EU ETS, particularly by reflecting on the success and problems of the legal framework for the EU ETS. In light of the possible linkage between the EU ETS and the Chinese ETS, similar to that between the EU and Australia, these results can provide the policy makers and stakeholders from the EU with the necessary understanding of and insight into the complex Chinese climate regime, and more particularly the way in which and why the Chinese ETS is being established and implemented in a special context. In this respect, the thorough comparative analysis of the similarities and differences between the EU ETS and the Chinese ETS, together with the reasons behind the differences, will be of importance. In particular, the analysis of the Chinese ETS and, connected to that, the Chinese legal system will be useful for the EU-based industries or investors when determining whether and how to carry out business covered by or related to the Chinese ETS. In addition, this research will also be of interest to policy makers in other jurisdictions. For instance, some special design of the Chinese ETS aiming to accommodate the rapid economic development, which can be exemplified by the intensity-based cap together with the ex post adjustment in the allocation 
of allowances, may provide some inspiration for other emerging economies that also want to establish its own ETS to reduce GHG emissions.

\section{Activities and services}

Given that the Chinese ETS is still in its infant stage, much legislation and policy has yet to be adopted or is being adopted at the local and national levels. The results of this thesis can be transformed into relevant policy proposals for policy makers in the debate on what legislation and policy is to be adopted and adapted, and how, particularly in terms of the regulatory design and implementation of the three key elements as discussed.

The analysis and recommendations provided by this research can also be used for developing relevant legal-technical reports for market players, especially industries covered by the ETS. This supports them to develop proper strategies when participating in the ETS, as it will be based on a better understanding of the legal framework for the Chinese ETS. In addition, these results can be published in journals or presented in relevant workshops so that ideas can be shared with the stakeholders, thereby facilitating discussion on improvements to the Chinese ETS.

\section{Innovation}

These results can be described as innovative because they seek to move forward the proper establishment of the ETS - a market-based instrument - in China, a country that still heavily depends on governmental (top-down) regulation. With a view of a possible national scheme to be established after 2015, the design of the Chinese pilot projects has been discussed mainly from the economic perspective in the extant research and literature. But the question of how to improve the regulatory design and implementation of the Chinese ETS from a legal perspective has still not been addressed sufficiently in the academic literature or in practice, and faces the challenge that the rule of law is still far from mature in China. This research, more specifically, the legal analysis of the Chinese pilot projects, can provide a large amount of primary information and insights into how and why the Chinese ETS is designed and implemented in view of its special context, thereby leading to the recommendations to inspire potential improvements of the Chinese ETS with the aim to strengthen the rule of law.

\section{Plans and implementation}

Firstly, this research can be made available to policy makers at the local level and the national level. To be specific, it can be submitted to the national and local DRC of China, providing insights that may be taken into account by governmental bodies when making decisions on the design and implementation of the Chinese ETS. It can also be used and translated into legal-technical reports or policy proposals for the future process to pass legislation related to the ETS in China, such as procedures seeking public opinion.

Secondly, this research result can be used to formulate articles published in journals and more popular public media, which can give wider stakeholders and audiences a better understanding of 
the ETS from a legal perspective. In that way, more attention can also be drawn to the discussion on the improvement of the Chinese ETS in light of the need to strengthen the rule of law.

Finally, the research result can also be offered to relevant research institutes or think tanks working on the design and implementation of the Chinese ETS. Through cooperation with these organisations, the results can be developed and transformed into more specific legal-technical reports, which can then be delivered to relevant industries covered by or influenced by the Chinese ETS, along with other potential stakeholders. 


\section{Curriculum Vitae}

Huizhen Chen (born in Guangzhou, China in 1985), studied Law at Sun Yat-sen University in China from September 2004 to June 2008 and obtained a bachelor' degree in Law. Since September 2008, she has taken part in the 'M.Sc. leading to D.Sc.' graduate program for a Ph.D Degree in Jurisprudence at the School of Law of Sun Yat-sen University. In September 2011, she joined the Institute for Transnational Legal Research (METRO) in Maastricht University to conduct her doctoral research. 
